PNNL-15042

WTP-RPT-008, Rev. 1

\title{
Organic Analysis of C-104 Tank Waste
}
J. C. Evans
G. M. Mong
J. A. Campbell
A. K. Sharma
F. V. Hoopes
M. J. Steele
E. W. Hoppe
R. T. Steele
G. S. Klinger
M. W. Urie

February 2001

Prepared for CH2M Hill Hanford Group, Inc.

under Project Number 41503 


\title{
DISCLAIMER
}

This report was prepared as an account of work sponsored by an agency of the United States Government. Neither the United States Government nor any agency thereof, nor Battelle Memorial Institute, nor any of their employees, makes any warranty, express or implied, or assumes any legal liability or responsibility for the accuracy, completeness, or usefulness of any information, apparatus, product, or process disclosed, or represents that its use would not infringe privately owned rights. Reference herein to any specific commercial product, process, or service by trade name, trademark, manufacturer, or otherwise does not necessarily constitute or imply its endorsement, recommendation, or favoring by the United States Government or any agency thereof, or Battelle Memorial Institute. The views and opinions of authors expressed herein do not necessarily state or reflect those of the United States Government or any agency thereof.

\author{
PACIFIC NORTHWEST NATIONAL LABORATORY \\ operated by \\ BATTELLE \\ for the \\ UNITED STATES DEPARTMENT OF ENERGY \\ under Contract DE-AC05-76RL01830
}

Printed in the United States of America

Available to DOE and DOE contractors from the

Office of Scientific and Technical Information,

P.O. Box 62, Oak Ridge, TN 37831-0062;

ph: (865) 576-8401

fax: $(865) 576-5728$

email: reports@adonis.osti.gov

\footnotetext{
Available to the public from the National Technical Information Service, U.S. Department of Commerce, 5285 Port Royal Rd., Springfield, VA 22161 ph: (800) 553-6847 fax: $(703) 605-6900$

email: orders@ntis.fedworld.gov

online ordering: http://www.ntis.gov/ordering.htm
}

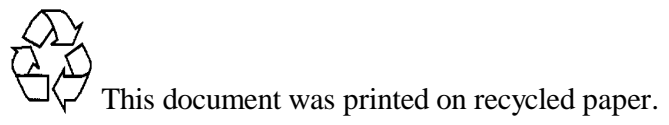


PNNL-15042

WTP-RPT-008, Rev. 1

\title{
Organic Analysis of C-104 Tank Waste
}

\author{
J. C. Evans \\ G. M. Mong \\ J. A. Campbell \\ A. K. Sharma \\ F. V. Hoopes \\ M. J. Steele \\ E. W. Hoppe \\ R. T. Steele \\ G. S. Klinger \\ M. W. Urie
}

February 2001

Prepared for

CH2M Hill Hanford Group

under Project Number 41503

Pacific Northwest National Laboratory

Richland, Washington, 99352 


\section{Summary}

Fourteen jars of waste material from Tank C-104 were received by PNNL. The contents of all jars were mixed to provide a single composite. Each composite was homogenized and representative sub-samples extracted for organic, radiochemical, and inorganic regulatory analyses.

The representative sub-samples were analyzed for inorganic, radiochemical, and organic analyses for analytes of interest as defined in Test Plan BNFL-29953-30, Rev. 1. This report presents the organic results. The inorganic and radiochemical results are reported in report WTP-RPT-007, PNNL-13364 (formerly BNFL-RPT-043).

The organic characterization of analyses of the as received material for C-104 includes the following:

(1) Volatile Organic Analysis

(2) Semi-volatile Organic Analysis

(3) Polychlorinated biphenyls and pesticides

(4) Polychlorinated dibenzo-p-dioxins and polychlorinated dibenzofurans

(5) Oxalate, formate, acetate, and acrylate by ion chromatography

(6) Ethanol, methanol, 2-propanol, 1-propanol, n-butanol, triethylamine, 2-methyl-2-propanol, and 2-butanol by headspace analysis

Except for a very few cases, the characterization results met or exceeded the quality control requirements established by the governing quality assurance plan, and met or exceeded the minimum reportable quantity requirements specified by BNFL. Whenever possible the analyses were performed to SW-846 protocols so that the results can be used to support permit application, as well as provide feed envelope characterization data.

Table S.1 summarizes the results for target analytes, which produced quantifiable results. All other target analytes were either non-detects or below the quantitation limit. Numerous tentatively identified compounds with estimated quantities measured were also detected by the VOA and SVOA methods. Those data are reported in the respective sections for those two methods. 
Table S.1. C-104 Summary Results - Target Analytes Detected

\begin{tabular}{|c|c|c|c|c|c|c|c|}
\hline \multirow{3}{*}{ CAS \# } & \multirow{3}{*}{ Target Analyte } & \multicolumn{3}{|c|}{ C-104 Supernatant } & \multicolumn{3}{|c|}{ C-104 Wet Centrifuged Solids } \\
\hline & & Blank & Sample & Duplicate & Blank & Sample & Duplicate \\
\hline & & $\mu \mathrm{g} / \mathrm{L}$ & $\mu \mathrm{g} / \mathrm{L}$ & $\mu \mathrm{g} / \mathrm{L}$ & $\mu \mathrm{g} / \mathrm{Kg}$ & $\mu \mathrm{g} / \mathrm{Kg}$ & $\mu \mathrm{g} / \mathrm{Kg}$ \\
\hline \multicolumn{8}{|c|}{ VOA Compounds } \\
\hline 106-35-4 & 3-Heptanone & U & $74 \mathrm{~J}$ & $\mathrm{U}$ & $\mathrm{U}$ & 420 & 800 \\
\hline $106-97-8$ & Butane & $\mathrm{U}$ & $\mathrm{U}$ & $\overline{\mathrm{U}}$ & $\overline{\mathrm{U}}$ & 2,100 & 3,000 \\
\hline $107-13-1$ & Acrylonitrile & $\mathrm{U}$ & $\mathrm{U}$ & $\mathrm{U}$ & $\mathrm{U}$ & $\mathrm{U}$ & 990 \\
\hline $109-66-0$ & Pentane & $\mathrm{U}$ & $\mathrm{U}$ & $\mathrm{U}$ & $\bar{U}$ & 5,600 & 7,400 \\
\hline $110-43-0$ & 2-Heptanone & $\mathrm{U}$ & $97 \mathrm{~J}$ & $\mathrm{U}$ & $\mathrm{U}$ & $400 \mathrm{~J}$ & 810 \\
\hline $110-54-3$ & Hexane & 11 & 5,000 & $\mathrm{U}$ & $\overline{\mathrm{U}}$ & 7,000 & 9,200 \\
\hline $111-65-9$ & Octane & $\mathrm{U}$ & 3,800 & $\mathrm{U}$ & $\overline{\mathrm{U}}$ & 3,400 & 4,600 \\
\hline $111-84-2$ & Nonane & $\mathrm{U}$ & 6,200 & $\mathrm{U}$ & $\mathrm{U}$ & 2,900 & 4,500 \\
\hline $123-38-6$ & Propionaldehyde & $\mathrm{U}$ & $\mathrm{U}$ & $\mathrm{U}$ & $\mathrm{U}$ & 880 & 1,100 \\
\hline $142-82-5$ & Heptane & $\mathrm{U}$ & 1,900 & $\mathrm{U}$ & $\mathrm{U}$ & 5,200 & 6,300 \\
\hline $67-64-1$ & Acetone & $1.8 \mathrm{~J}$ & 1,000 & $\mathrm{U}$ & $5.5 \mathrm{~J}$ & $190 \mathrm{JB}$ & $430 \mathrm{JB}$ \\
\hline $75-09-2$ & Methylene Chloride & 19 & 8,000 & $\mathrm{U}$ & $4.3 \mathrm{~J}$ & 880 & 1,900 \\
\hline \multicolumn{8}{|c|}{ SVOA Compounds } \\
\hline 126-73-8 & Tributyl phosphate & 2,500 & $2,100 \mathrm{~B}$ & $2,000 \mathrm{~B}$ & 5,500 & $57,000 \mathrm{~B}$ & $50,000 \mathrm{~B}$ \\
\hline $62-75-9$ & N-Nitrosodimethylamine & $\mathrm{U}$ & 1,300 & 1,900 & $\mathrm{U}$ & $\mathrm{U}$ & $\mathrm{U}$ \\
\hline $88-85-7$ & Dinoseb & $250 \mathrm{~J}$ & $2,200 \mathrm{~B}$ & $2,500 \mathrm{~B}$ & 6,500 & $6,400 \mathrm{~B}$ & $3,400 \mathrm{~B}$ \\
\hline $92-52-4$ & Biphenyl & 2,600 & $2,000 \mathrm{~B}$ & $2,000 \mathrm{~B}$ & 6,200 & $2,100 \mathrm{~B}$ & $1,700 \mathrm{~B}$ \\
\hline $95-48-7$ & 2-Methylphenol & 1,700 & $\mathrm{U}$ & $\mathrm{U}$ & 3,100 & $\mathrm{U}$ & $\mathrm{U}$ \\
\hline $98-86-2$ & Acetophenone & 3,000 & $2,300 \mathrm{~B}$ & $2,200 \mathrm{~B}$ & 8,800 & $6,300 \mathrm{~B}$ & $6,200 \mathrm{~B}$ \\
\hline $100-02-7$ & 4-Nitrophenol & $\mathrm{U}$ & $290 \mathrm{~J}$ & $\mathrm{U}$ & $\mathrm{U}$ & $\mathrm{U}$ & $\mathrm{U}$ \\
\hline $109-06-8$ & 2-Methylpyridine & $\mathrm{U}$ & $350 \mathrm{~J}$ & $510 \mathrm{~J}$ & $\mathrm{U}$ & $\mathrm{U}$ & $\mathrm{U}$ \\
\hline $534-52-1$ & 4,6-Dinitro-2-methylphenol & $\bar{U}$ & $140 \mathrm{~J}$ & $\mathrm{U}$ & $\mathrm{U}$ & $\mathrm{U}$ & $\mathrm{U}$ \\
\hline \multicolumn{8}{|l|}{ Pesticides } \\
\hline $319-84-6$ & Alpha-BHC & $\mathrm{U}$ & $\mathrm{U}$ & 1.4 & $\mathrm{U}$ & $\mathrm{U}$ & 5.5 \\
\hline $319-85-7$ & Beta-BHC & $\mathrm{U}$ & 3.4 & $\mathrm{U}$ & $\overline{\mathrm{U}}$ & $\mathrm{U}$ & $\mathrm{U}$ \\
\hline $58-89-9$ & Gamma-BHC & $\mathrm{U}$ & $\mathrm{U}$ & $\mathrm{U}$ & $\mathrm{U}$ & 8.2 & 17.6 \\
\hline $1024-57-3$ & Heptachlor Epoxide & $\bar{U}$ & $\bar{U}$ & 1.6 & $\overline{\mathrm{U}}$ & 2.7 & $\mathrm{U}$ \\
\hline $319-86-8$ & delta-BHC & $\mathrm{U}$ & $\mathrm{U}$ & $\mathrm{U}$ & $\mathrm{U}$ & 6.4 & 7.2 \\
\hline 5103-71-9 & alpha-Chlordane & $\mathrm{U}$ & $\mathrm{U}$ & $\mathrm{U}$ & $\bar{U}$ & $\mathrm{U}$ & 2.2 \\
\hline $72-55-9$ & 4,4'-DDE & $\bar{U}$ & $\mathrm{U}$ & $\mathrm{U}$ & $\overline{\mathrm{U}}$ & 5.6 & $\mathrm{U}$ \\
\hline 7421-93-4 & Endrin Aldehyde & $\mathrm{U}$ & $\mathrm{U}$ & $\mathrm{U}$ & $\mathrm{U}$ & 4.3 & $\mathrm{U}$ \\
\hline \multicolumn{8}{|l|}{ PCBs } \\
\hline $\begin{array}{l}12674-11-2 \\
53469-21-9\end{array}$ & Aroclor 1016/1242 & $\mathrm{U}$ & 3.8 & 4.9 & $\mathrm{U}$ & 121 & 154 \\
\hline 12672-29-6 & Aroclor 1248 & $\mathrm{U}$ & 4.3 & 5.3 & $\mathrm{U}$ & 278 & 202 \\
\hline 11097-69-1 & Aroclor 1254 & $\mathrm{U}$ & 1.8 & 2.3 & $\mathrm{U}$ & 72.8 & 80.2 \\
\hline \multirow{2}{*}{$\begin{array}{l}11096-82-5 \\
37324-23-5\end{array}$} & Aroclor 1260/1262 & $\mathrm{U}$ & $\mathrm{U}$ & $\mathrm{U}$ & $\mathrm{U}$ & 37.8 & 40.3 \\
\hline & Total PCB & $\mathrm{U}$ & 17.9 & 20.6 & $\mathrm{U}$ & 522 & 488 \\
\hline \multicolumn{8}{|c|}{ Dioxins/Furans } \\
\hline & None Detected & & & & & & \\
\hline
\end{tabular}




\begin{tabular}{|c|c|c|c|c|c|c|c|}
\hline \multirow[b]{3}{*}{ CAS \# } & \multirow[b]{3}{*}{ Target Analyte } & \multicolumn{3}{|c|}{ C-104 Supernatant } & \multicolumn{3}{|c|}{ C-104 Wet Centrifuged Solids } \\
\hline & & Blank & Sample & Duplicate & Blank & Sample & Duplicate \\
\hline & & $\mu \mathrm{g} / \mathrm{L}$ & $\mu \mathrm{g} / \mathbf{L}$ & $\mu \mathrm{g} / \mathrm{L}$ & $\mu g / K g$ & $\mu \mathrm{g} / \mathrm{Kg}$ & $\mu \mathrm{g} / \mathrm{Kg}$ \\
\hline \multicolumn{8}{|c|}{ Organic Anions } \\
\hline \begin{tabular}{|c|}
$144-62-7$ \\
\end{tabular} & Oxalate & $\mathrm{U}$ & $1,090,000$ & 980,000 & $\mathrm{U}$ & $1,230,000$ & $3,300,000$ \\
\hline $64-18-6$ & Formate & $\bar{U}$ & $2,670,000$ & $2,120,000$ & $\mathrm{U}$ & 750,000 & $2,200,000$ \\
\hline \multicolumn{8}{|c|}{ Headspace Analysis } \\
\hline 67-56-1 & Methanol & $\mathrm{U}$ & 16,000 & $\mathrm{U}$ & & & \\
\hline $64-17-5$ & Ethanol & 2,200 & $8,000 \mathrm{~B}$ & $2,900 \mathrm{~B}$ & & & \\
\hline 71-23-8 & 1-Propanol & $\mathrm{U}$ & 2,700 & $\mathrm{U}$ & & & \\
\hline $71-36-3$ & n-Butanol & $\mathrm{U}$ & 28,000 & $\mathrm{U}$ & & & \\
\hline $121-44-8$ & Triethylamine & $\mathrm{U}$ & $15 \mathrm{~J}$ & $\mathrm{U}$ & & & \\
\hline
\end{tabular}

U flag = Compound not detected; Compound concentration less than the MDL

$\mathrm{J}$ flag = Compound detected, but concentration is less than the MDL

$\mathrm{B}$ flag = Compound was present in the method blank 


\section{Terms and Abbreviations}

$\begin{array}{ll}\text { ASR } & \text { analytical service request } \\ \text { BNFL } & \text { BNFL, Inc; subsidiary of British Nuclear Fuels, Ltd. } \\ \text { CAS\# } & \text { Chemical Abstracts Service Registry Number } \\ \text { CCC } & \text { Calibration check compound } \\ \text { CLP } & \text { Contract Laboratory Program } \\ \text { CoC } & \text { chain of custody } \\ \text { K-D } & \text { Kuderna-Danish } \\ \text { ECD } & \text { electron capture detector } \\ \text { GC/ECD } & \text { gas chromatography/electron capture detection } \\ \text { GC/MS } & \text { gas chromatography/mass spectrometry } \\ \text { HLRF } & \text { High Level Radiation Facility } \\ \text { IC } & \text { ion chromatography } \\ \text { LCS } & \text { Laboratory Control Standard } \\ \text { MDL } & \text { method detection limit } \\ \text { MRQ } & \text { minimum reportable quantity } \\ \text { MS } & \text { matrix spike } \\ \text { MSD } & \text { matrix spike duplicate } \\ \text { M\&TE } & \text { measuring and test equipment } \\ \text { NPH } & \text { normal paraffin hydrocarbons } \\ \text { \%D } & \text { percent difference } \\ \text { PCB } & \text { polychlorinated biphenyl } \\ \text { QC } & \text { quality control } \\ \text { RSD } & \text { relative standard deviation } \\ \text { SAL } & \text { Shielded Analytical Laboratory } \\ \text { SPCC } & \text { system performance check compound } \\ \text { SVOA } & \text { semi-volatile organic analysis } \\ \text { TCLP } & \text { Toxicity characteristic leaching procedure } \\ \text { TIC } & \text { tentatively identified compound } \\ \text { USEPA } & \text { United States Environmental Protection Agency } \\ \text { VOA } & \text { volatile organic analysis } \\ & \end{array}$




\section{Units}

$\begin{array}{ll}{ }^{\circ} \mathrm{C} & \text { degree Centigrade } \\ { }^{\circ} \mathrm{F} & \text { degree Fahrenheit } \\ \mathrm{g} & \text { gram } \\ \mathrm{Kg} & \text { kilogram } \\ \mathrm{L} & \text { liter } \\ \mu \mathrm{g} & \text { microgram } \\ \mathrm{mL} & \text { milliliter } \\ \mathrm{mM} & \text { millimolar } \\ \mathrm{min} & \text { minute } \\ \mathrm{ng} & \text { nanogram } \\ \text { Vol\% } & \text { volume percent } \\ \text { Wt\% } & \text { weight percent }\end{array}$




\section{Contents}

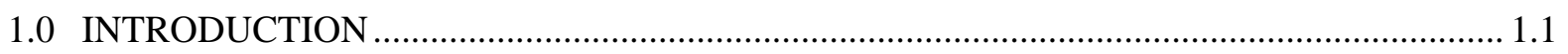

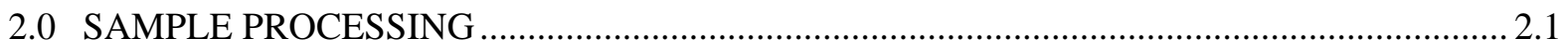

2.1 Total Dissolved Solids and Weight Percent Solids .............................................2.1

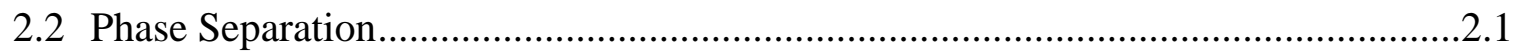

2.3 Supernatant Density Measurements ..............................................................2.2

2.4 Organic Extractions and Sub-sampling ............................................................2.2

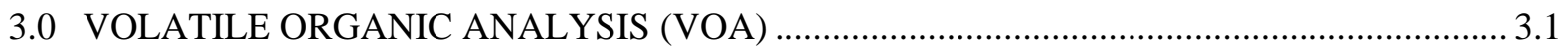

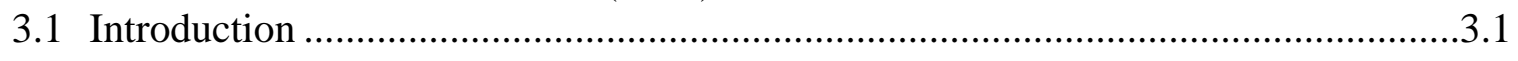

3.2 Sample Preparation.....................................................................................

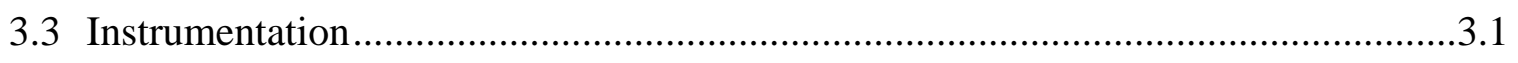

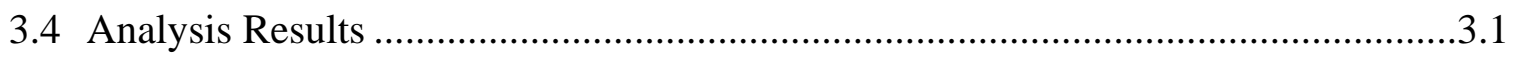

3.4.1 Results for Calibrated/Regulatory Analytes of Interest........................................... 3.2

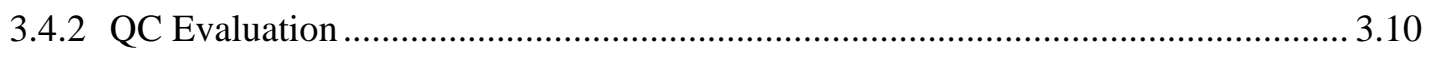

4.0 SEMI-VOLATILE ORGANIC ANALYSIS (SVOA) …..................................................... 4.1

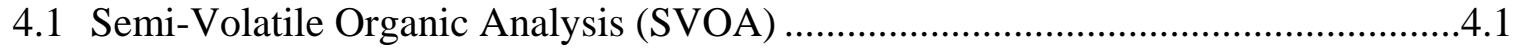

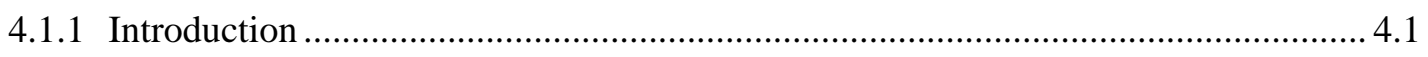

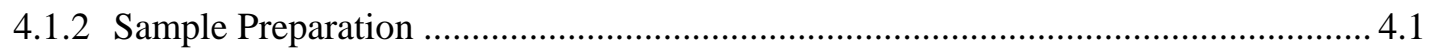

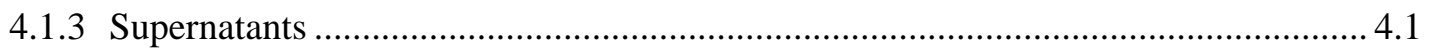

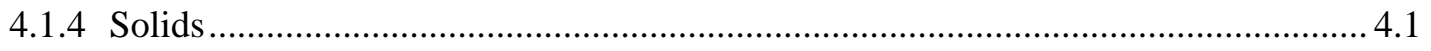

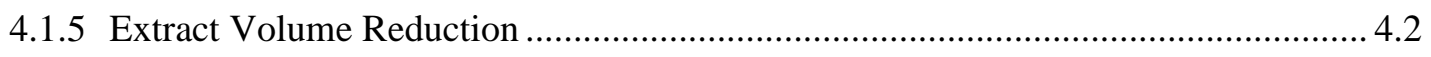

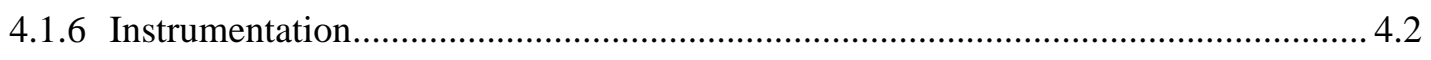

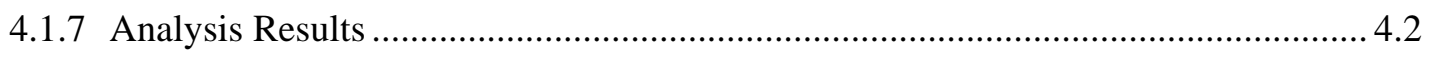

4.1.8 Results for Calibrated/Regulatory Analytes of Interest............................................ 4.2

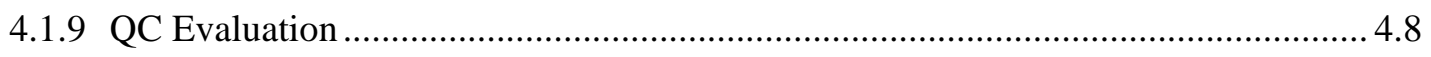

4.1.10 Other Observations (or Deviations/Concerns/Issues) .......................................... 4.10

5.0 POLYCHLORINATED BIPHENYLS/PESTICIDES ANALYSIS ….................................. 5.1

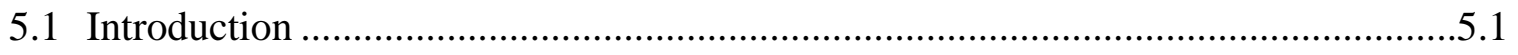

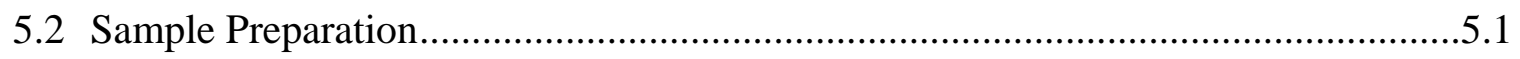

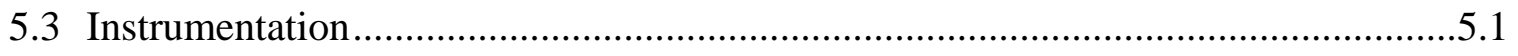

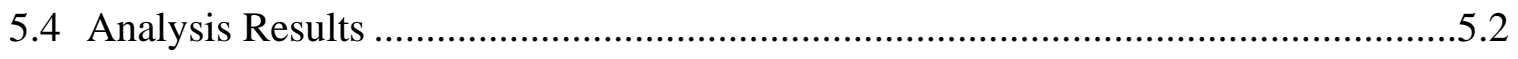

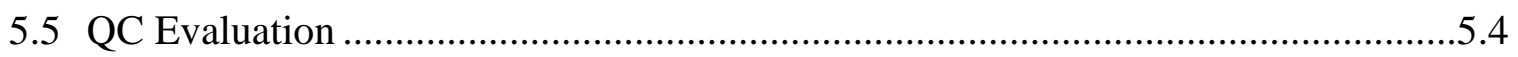

6.0 POLYCHLORINATED DIBENZO-P-DIOXINS AND DIBENZOFURANS

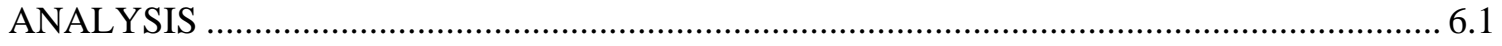

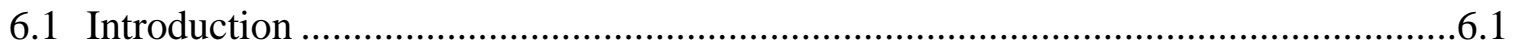




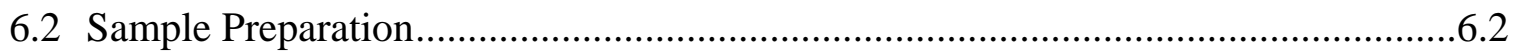

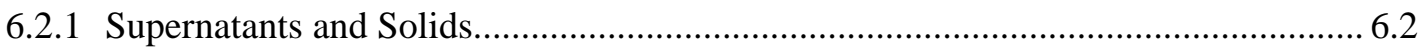

6.2.2 Laboratory Control Standard, Glassware Blank, and Silica Gel Cleanup.................. 6.2

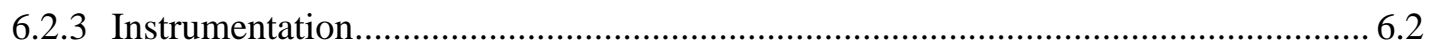

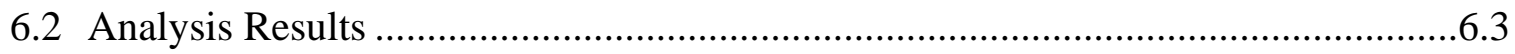

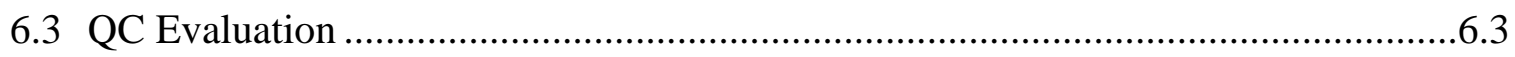

6.3.1 Ion Abundance Ratios and Response Factors --- Standards....................................... 6.3

6.3.2 Ion Abundance Ratios - Samples, Duplicates, and Matrix Spikes ............................. 6.4

6.3.3 Dioxins and Furans Matrix Spike Recoveries ........................................................... 6.5

6.4 Other Observations (Deviations/Concerns/Issues) .......................................................6.6

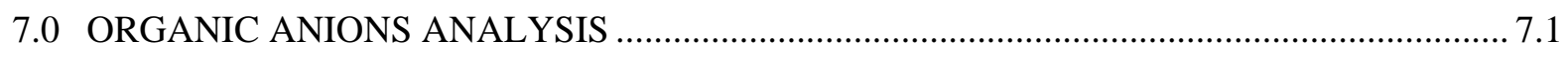

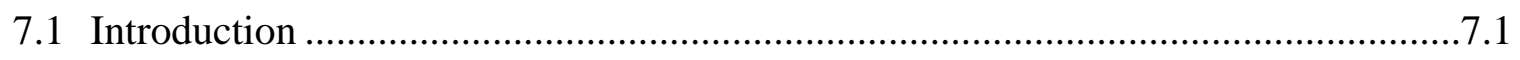

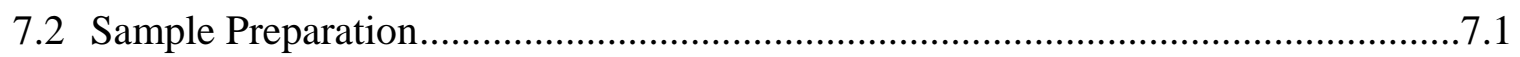

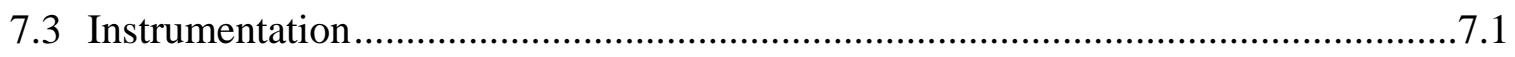

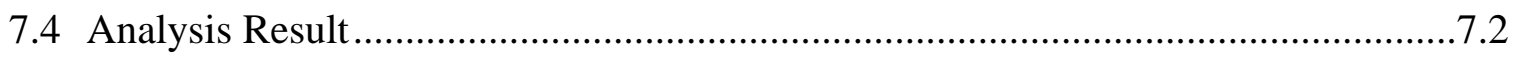

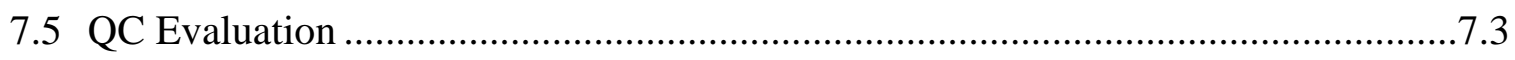

7.6 Other Observations (or Deviations/Concerns/Issues) ................................................7.3

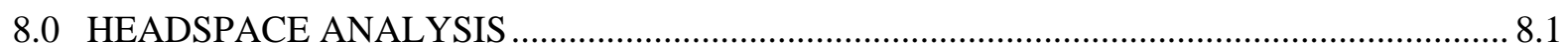

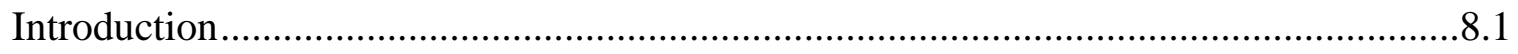

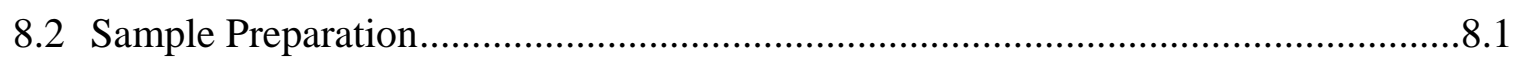

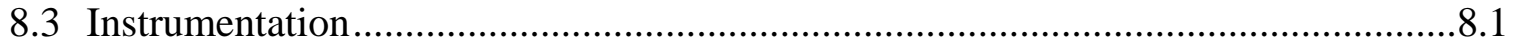

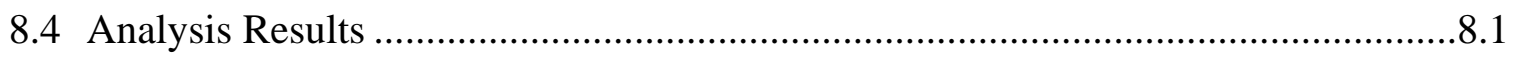

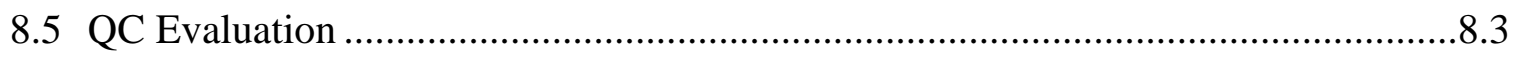

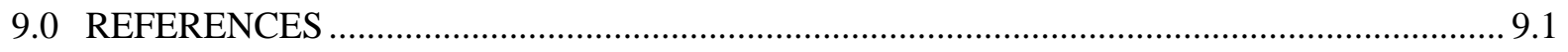

APPENDIX A: PNNL TEST PLAN FOR C-104 SAMPLE COMPOSITING, BNFL29953-31, REV. 0 ………………………………………………………………….... A.1

APPENDIX B: PNNL TEST PLAN FOR INORGANIC, ORGANIC, AND RADIOCHEMICAL CHARACTERIZATION OF C-104 HLW SAMPLE - BNFL29953-30, REV. 1

APPENDIX C: PNNL TEST PLAN FOR ORGANIC EXTRACTION OF C-104 SAMPLES AND SUB-SAMPLING FOR VOA, HEADSPACE, AND ANIONS, BNFL-29953-080, REV. NO. 1

APPENDIX D: VOLATILE ORGANIC ANALYSIS RESULT FORMS ……………………........ D.1

APPENDIX E: SEMI-VOLATILE ORGANIC ANALYSIS RESULT FORMS ...................................1

APPENDIX F: DIOXINS AND FURANS ION ABUNDANCE RATIOS AND RESPONSE FACTORS 


\section{Figures}

Figure 1.1. Flow Diagram for C-104 As Received Analytical Samples

Figure 7.1. IC Chromatogram of Standard Solution. Peak 2-acetate; 3-acrylate; 4-formate; 5-carbonate; 6-sulfate; 7-oxalate.

Figure 7.2. IC Chromatogram of C-104 Solids MS Sample. Peak 2-possibly F; Peak 3-formate; 4-chloride; 5-nitrate; 6-unknown; 7-carbonate; 8-sulfate; 9-oxalate.

Figure 7.3. IC Chromatogram of C-104 Supernatant MS Sample. Peak 3-possibly F-; 4-formate; 5-chloride; 6-nitrate; 7-unknown; 9-carbonate; 10-sulfate; 11-oxalate

Figure 7.4. IC Chromatogram of C-104 Supernatant MSD. Peak 2-possibly F-; 3-formate; 4chloride; 6-nitrate; 6-unknown; 7-unknown; 8-carbonate; 9-sulfate; and 10-oxalate....... 7.6

Figure B.1. Analytical Sub-Sampling Flowchart ............................................................................

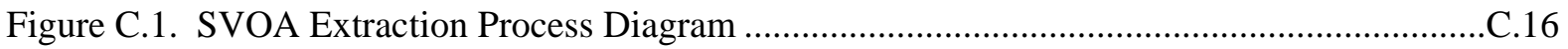

Figure C.2. Pesticide/PCB Extraction Process Diagram ................................................................17

Figure C.3. Dioxin/Furan Extraction Process Diagram..................................................................18 


\section{Tables}

Table S.1. C-104 Summary Results - Target Analytes Detected ....................................................... iv

Table 2.1. Slurry Vol\% and Wt\% Solids, TDS, and Centrifuged Solids Wt\% Solids ...................... 2.1

Table 2.2. Density Results for C-104 Supernatant Composite....................................................... 2.2

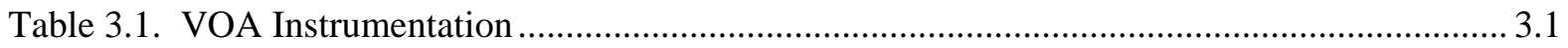

Table 3.2. C-104 VOA Results - BNFL \& SW846 8260B Target Analyte List................................. 3.4

Table 3.3. C-104 VOA Tentatively Identified Compounds .............................................................. 3.7

Table 3.4. Target VOA Minimum Reportable Quantities ................................................................ 3.8

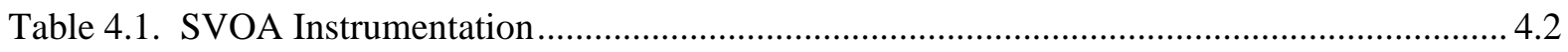

Table 4.2. C-104 SVOA Results - Project \& SW846 8270C Target Analyte List ............................ 4.4

Table 4.3. C-104 Supernatant SVOA Tentatively Identified Compounds ....................................... 4.7

Table 4.4. C-104 Wet Centrifuged Solids SVOA Tentatively Identified Compounds........................ 4.8

Table 4.5. Target SVOA Minimum Reportable Quantities ............................................................. 4.11

Table 5.1. PCB/Pesticides Analysis Instrumentation .................................................................. 5.2

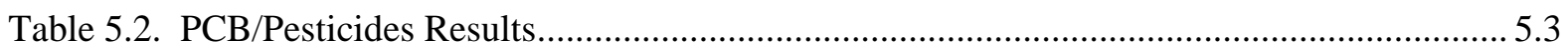

Table 5.3. Target PCB/Pesticides Minimum Reportable Quantities ................................................. 5.4

Table 5.4. C104 - Pesticide Spike Recoveries ................................................................................. 5.5

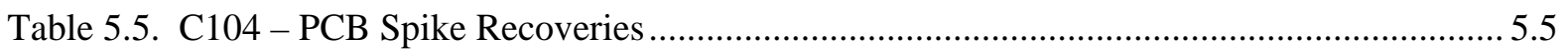

Table 6.1. Standard Compounds Measured Using HRGC/LRMS ................................................ 6.1

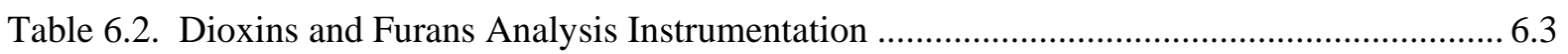

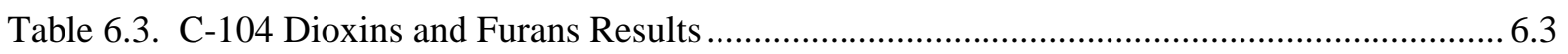

Table 6.4. Theoretical Ion Abundance Ratios and Control Limits..................................................... 6.4

Table 6.5. Acceptance Criteria Summary of Ion Abundance Ratios.................................................. 6.5

Table 6.6. C-104 - Dioxins and Furans Spike Recoveries .............................................................. 6.6

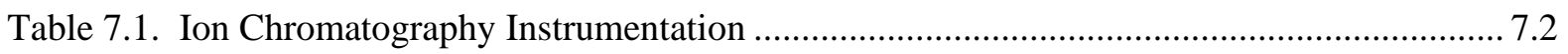

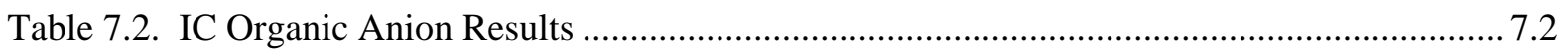

Table 7.3. IC Organic Anions Matrix Spike Recoveries .............................................................. 7.3

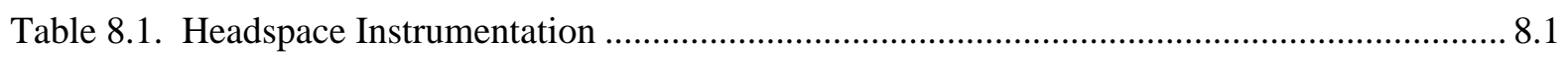

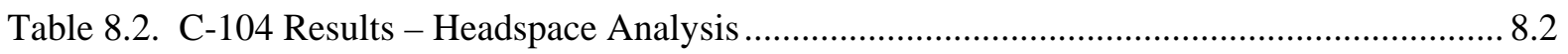

Table 8.3. Target Headspace Minimum Reportable Quantities ......................................................... 8.2

Table 8.4. C-104 Headspace Matrix Spike Recoveries ................................................................. 8.3

Table B.1. “As Received” Sub-Samples for Characterization ............................................................6.

Table B.2. Organic Analytical Sub-Sampling Quantities Required ${ }^{(1)}$...............................................7

Table B.3. Inorganic/Radiochemistry Analytical Sub-Sampling Quantities Required ${ }^{(1)}$..................8.8

Table B.4. Organic Analytes of Interest List and MRQs .................................................................

Table B.5. Inorganic and Radiochemistry Analytes of Interest List ................................................11

Table C.1. Liquid portion HLW organic analysis MDLs ...................................................................

Table C.2. Solid Portion HLW Organic Analysis MDLs ..............................................................6

Table C.3. Surrogate Spike Compounds and Levels Added to Samples .............................................6.6

Table C.4. Laboratory Control Sample Spiking Level................................................................9 
Table F.1. Ion Abundance Ratios and Response Factors for Standards ............................................2

Table F.2. Ion Abundance Ratios for Supernatant Matrix Spikes ...................................................F.5

Table F.3. Ion Abundance Ratios for Solids Matrix Spikes ...........................................................5.5

Table F.4. Ion Abundance Ratios for Supernatant Samples, Duplicates, and Process Blanks...........F.6

Table F.5. Ion Abundance Ratios for Solids Samples, Duplicates, and Process Blanks....................F.6 


\subsection{Introduction}

This report presents the organic analytical results for "as received" C-104 tank waste materials. The organic analyses were conducted in support of BNFL Proposal No. 29274/30406 Task 5.0. The organic analysis results obtained from the "as received" tank waste materials may be used to support permitting activities, as well as to provide limited characterization information for subsequent process testing (Tasks 2 through 4). Based on the sampling and storage history of the samples, preservation or refrigeration of the "as received" samples was not performed. Also, hold times specified by SW-846 protocols had expired prior to receiving the samples. The method detection limits (MDL) for the analytes of interest were significantly impacted by the limited quantity of sample available for analysis. However, wherever possible the analytical protocols followed SW-846 guidelines. The concentrations of spiking solutions and choice of extraction solvents were based on SW-846 methods. Because of the unusual and highly hazardous nature of these samples, no attempt was made to sample or store the materials in a headspace free manner prior to analysis. Substantial loss of volatiles was thus inevitable during the storage phase. Additional losses may also have occurred during field sampling, compositing, and subsampling prior to laboratory study. Chemical transformations, which can be induced by radiolytic processes during storage of highly radioactive materials, may also be responsible for in situ formation of volatile compounds.

The organic analytes of interest (target compounds) and recommended methods are defined in the BNFL Proposal No. 29274/30406 and Test Plan BNFL-29953-30 Revision 1. Except where noted in this report, all organic target compounds defined by these documents are reported, with estimated MDLs provided where target compounds were not detected. Where detected, non-target compounds are identified, reported and quantified to the extent possible.

The composite of the C-104 as received material was prepared per Test Plan BNFL-29953-31. Appendix A contains the full text of that Test Plan. The C-104 composite (from 14 shipping jars) was prepared in a three-liter stainless steel vessel with a bottom drain spigot. A bladed stainless steel impeller was used to homogenize the material. While the composite was being stirred, it was drained into three 125-mL glass jars to evaluate representative sub-sampling. These sub-samples were allowed to settle for a minimum of 16 hours. After this settling period, the volume percent of settled solids in each of the 125 -mL glass jars were similar (i.e., $88.9 \%$ to $89.9 \%$ compared to the overall average of $87 \%$ found for all 14 jars), providing indication that the sub-samples are representative of the composite. Following confirmation of representative sub-sampling, three additional $500-\mathrm{mL}$ glass bottles were used to sub-sample the remainder of the C-104 composite.

Figure 1.1 provides the sample flow diagram for the preparation of the $\mathrm{C}-104$ as received analytical characterization sub-samples. Two containers of C-104 composite slurry (C-104 Comp A and C-104 Comp B) and one container of composite supernatant (C-104 SUP A) were allocated for organic, inorganic, and radiochemical characterization. The compositing and sub-sampling operations were conducted in the High Level Radiation Facility (HLRF). The sub-samples were transferred under chain-of-custody (CoC) to the Shielded Analytical Laboratory (SAL) for characterization analysis preparation and distribution.

The organic results for the analytes of interest for the C-104 as received materials are typically reported in " $\mu \mathrm{g} / \mathrm{L}$ supernatant" or " $\mu \mathrm{g} / \mathrm{Kg}$ centrifuged wet solids". However, in some cases where the analyte concentrations are high or the method sensitivity is low, the results are reported in $\mu \mathrm{g} / \mathrm{mL}$ or $\mu \mathrm{g} / \mathrm{g}$. Although the supernatants were processed by weight, the density of the supernatants has been used to provide the results in $\mu \mathrm{g} / \mathrm{L}$ or $\mu \mathrm{g} / \mathrm{mL}$, as appropriate. 
To evaluate the concentration of analytes of interest in the as received slurry material, estimates of the slurry concentration have been calculated from the analyte concentrations measured in the supernatant and in the wet centrifuged solids. To provide a conservative total slurry concentration, the highest measured concentration from either the sample or the duplicate for each phase is used in the calculation. Where no analyte concentration is measured (i.e., results less than MDL), the lowest MDL is used in the calculation. The "maximum" slurry concentration is calculated by Equation (1):

$$
\mathrm{C}_{\mathrm{m}}=\left(\left(\mathrm{C}_{\mathrm{l}} / \mathrm{D}_{\mathrm{l}}\right) * \mathrm{~W}_{\mathrm{l}}\right)+\left(\mathrm{C}_{\mathrm{s}} * \mathrm{~W}_{\mathrm{s}}\right)
$$

Where: $\quad \mathrm{C}_{\mathrm{m}}=$ Maximum slurry concentration in $\mu \mathrm{g} / \mathrm{Kg}$

$\mathrm{C}_{\mathrm{l}}=$ Concentration of supernatant in $\mu \mathrm{g} / \mathrm{L}$

$\mathrm{D}_{\mathrm{l}}=$ Density of supernatant in $\mathrm{g} / \mathrm{mL}$ (i.e. 1.161)

$\mathrm{W}_{\mathrm{l}}=$ Weight fraction of supernatant (i.e., 0.18)

$\mathrm{C}_{\mathrm{s}}=$ Concentration of solids in $\mu \mathrm{g} / \mathrm{Kg}$

$\mathrm{W}_{\mathrm{s}}=$ Weight fraction of solids (i.e. 0.82 )

Throughout this report the term method detection limit (MDL) is used. This 'estimated' MDL is the 'estimated' analytical instrument detection limit (IDL) times all processing factors, such as sample quantities used and dilutions resulting from digestion processing. For most of the methods the estimated IDLs are defined as the lowest calibration standard; however, in some cases the estimated IDL is defined as half to 2-times the lowest calibration standard. The MDLs stated in this report are nominal for each of the analysis methods and are not based on performance of the methods on LAW glass matrices. These MDLs are the best available estimate of the ability to detect and quantify the analytes of interest. No effort has been made to establish matrix-specific MDLs for any of the analyses. 


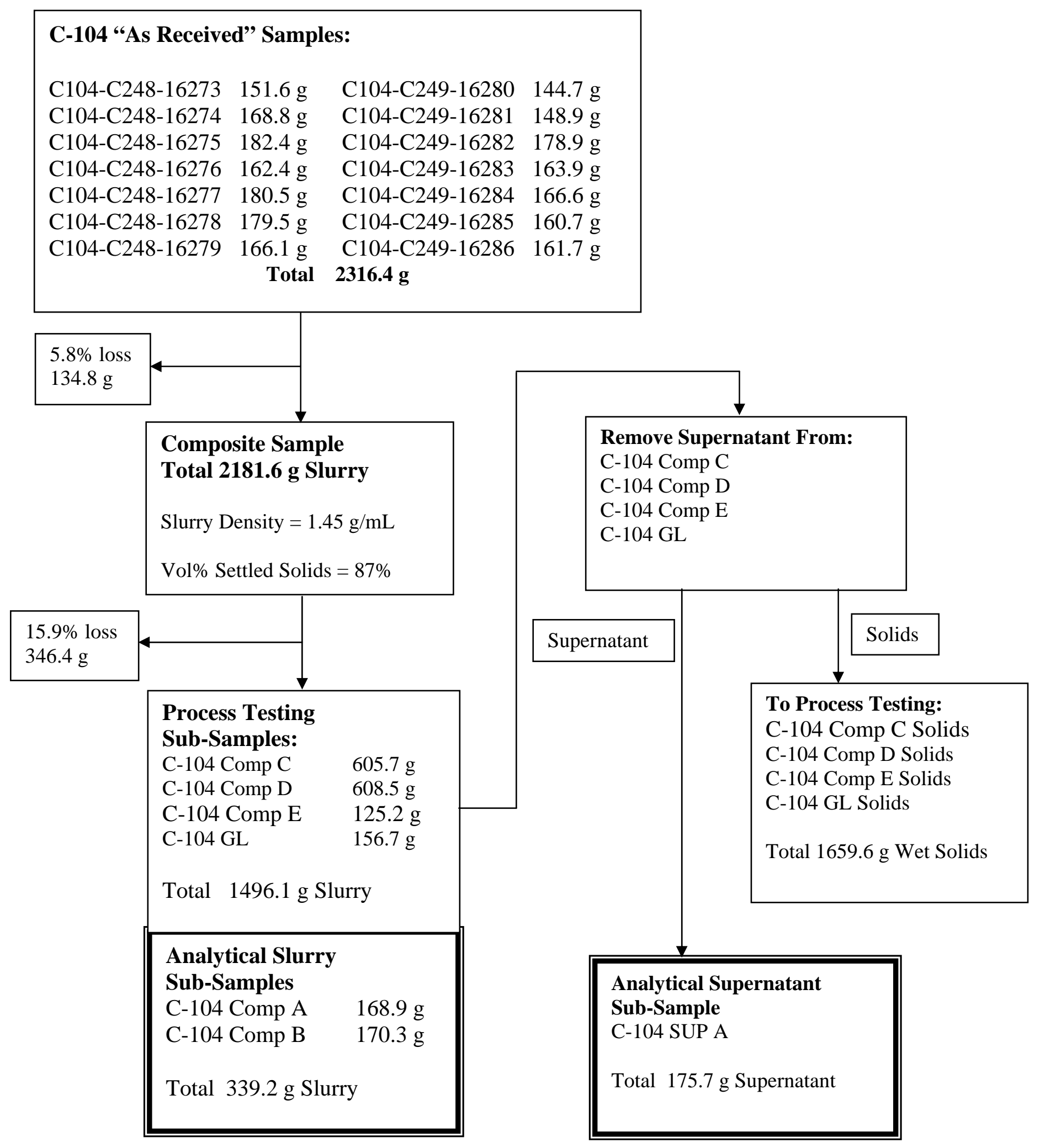

Figure 1.1. Flow Diagram for C-104 As Received Analytical Samples 


\subsection{Sample Processing}

Sample processing instructions were provided to the SAL via special instructions included with Analytical Service Request (ASR) Number 5729 while the total dissolved solids (TDS), weight percent solids, and phase separation instructions were provided via Test Plan BNFL-TP-29953-080, Rev. 1 (Appendix B). For all organic analyses, the sample, sample duplicate, matrix spikes (MS), and matrix spike duplicates (MSD) for the supernatants and wet centrifuged solids sub-sampling was performed prior to inorganic and radiochemical sub-sampling as a precaution -to minimize loss of volatile organic compounds.

\subsection{Total Dissolved Solids and Weight Percent Solids}

Duplicate aliquots (approximately 3 g each) were withdrawn from C-104 Comp A for determination of centrifuged weight percent solids (wt\% solids) of the composite slurry, TDS of the supernatant, and wt\% solids (dry) of the centrifuged solids phase. The aliquots were withdrawn from the C-104 Comp A jar while the contents were mechanically stirred providing homogeneous sub-samples. The aliquots were placed in volume-graduated centrifuge tubes and centrifuged at $1100 \mathrm{rpm}$ for about one hour. Following centrifuging, the volume percent solids and wt\% solids (wet) were determined on the slurry. Following phase separation by decanting, the wt\% solids (dry) of the centrifuged solids fraction and the TDS of the supernatant fraction were determined. Table 2.1 provides the results for the TDS and percent solids.

Table 2.1. Slurry Vol\% and Wt\% Solids, TDS, and Centrifuged Solids Wt\% Solids

\begin{tabular}{||l|l|l|l|l||}
\hline \multirow{2}{*}{\multicolumn{1}{|c|}{ Sample ID }} & \multicolumn{2}{|c|}{ Slurry } & Supernatant & Centrifuged Solids \\
\cline { 2 - 6 } & $\begin{array}{c}\text { Volume \% } \\
\text { Centrifuged } \\
\text { Solids (Wet) }\end{array}$ & $\begin{array}{c}\text { Weight \% } \\
\text { Centrifuged } \\
\text { Solids (Wet) }\end{array}$ & TDS (\%) & $\begin{array}{c}\text { Weight \% } \\
\text { Solids (Dry) }\end{array}$ \\
\hline \hline C-104 Comp A & 63 & 81.0 & 16.7 & 58.8 \\
\hline $\begin{array}{l}\text { C-104 Comp A } \\
\text { Dup }\end{array}$ & 60 & 83.0 & 16.8 & 59.4 \\
\hline
\end{tabular}

Based on the Slurry wt\% wet centrifuged solids and the Centrifuged Solids wt\% dry solids, the Slurry wt\% solids (dry) averages 51.5\%.

\subsection{Phase Separation}

The contents of C-104 Comp A and C-104 Comp B were separated into solids and supernatant phases so that organic analyses could be performed on each phase (i.e., supernatant and wet solids). The phase separation was performed by centrifuging and decanting the supernatant. Each sample was centrifuged in its original jar at $1100 \mathrm{rpm}$ for one hour, and the supernatant decanted and combined with C-104 SUP A. Following phase separation, the RPL Number 00-01360 was used to identify the supernatant sample and 00-01361 was used to identify the centrifuged solids sample. 


\subsection{Supernatant Density Measurements}

Due to the viscous nature of the as received supernatant, most supernatant samples were processed by weight (i.e., most analytical sub-samples were aliquotted by weight instead of by volume). The density of the supernatant was determined by weighing 5-mL aliquots delivered from a calibrated 5 -mL pipette. The delivery volume of the pipette was determined by five replicate measurement of water corrected for the SAL ambient temperature. The resulting average density was used to convert supernatant results from a per mass to a per volume basis, when necessary. Table 2.2 provides the density results obtained on the C-104 supernatant following phase separation.

Table 2.2. Density Results for C-104 Supernatant Composite

\begin{tabular}{||l|l|c|c|}
\hline \multirow{2}{*}{ RPL Number } & \multicolumn{1}{|c|}{ Sample ID } & $\begin{array}{c}\text { Density } \\
(\mathbf{g} / \mathbf{m L})\end{array}$ & $\begin{array}{c}\text { Average Density } \\
\mathbf{( g / m L )}\end{array}$ \\
\hline \hline $00-01360$ & Supernatant & 1.163 & \multirow{2}{*}{1.161} \\
\cline { 2 - 3 } & Supernatant Duplicate & 1.160 & \multirow{2}{*}{1.160} \\
\cline { 2 - 3 } & Supernatant Triplicate & 1.160 \\
\hline
\end{tabular}

\subsection{Organic Extractions and Sub-sampling}

Complete details of organic extractions and sub-sampling for organic analysis may be found in Test Plan BNFL-29953-080, Rev. 1 (Appendix B). 


\subsection{Volatile Organic Analysis (VOA)}

\subsection{Introduction}

Volatile organic analyses were performed on both the supernatant and wet centrifuged solids from samples of C-104 following phase separation. The VOA samples were aliquotted, prepared for analysis and removed from the SAL hot cells prior to introducing any organic solvents (e.g., methylene chloride) into the area.

The samples, both supernatants and wet centrifuged solids, were diluted with organic-free water to a final volume of approximately $5 \mathrm{~mL}$ in disposable dual septa-sealed purge vessels. The volatiles were purged from the samples with helium onto a multi-bed absorbent trap using a commercial purge and trap sample concentrator and auto-sampler. The trapped volatiles were then thermally desorbed onto a 75 -meter by 0.45 -millimeter DB-624 column (2.55-micron film) that was directly interfaced to the mass spectrometer. The samples were analyzed using VOA method PNL-ALO-335 (per SW-846 8260B protocols).

\subsection{Sample Preparation}

Supernatant and solids from C-104 were prepared in the SAL by accurately weighing an aliquot of sample into pre-cleaned, 40 -mL purge vessels and adding sufficient blank water diluent to achieve a final volume of $5 \mathrm{~mL}$. Sample, duplicate, MS, MSD, and blank samples were prepared in this manner in the SAL. Following transfer under CoC from the SAL to the analytical laboratories, all samples were refrigerated to ensure that sample integrity was maintained. Internal standards and surrogate compounds were added to each sample (including the MS and MSD) and target spike compounds are added to the MS and MSD. Once the spikes and standards were added, the samples were loaded into the VOA auto-sampler for purging.

\subsection{Instrumentation}

The analytical instrumentation used for VOA assays consisted of an auto-sampler, purge and trap system, and gas chromatograph mass spectrometer system. Detailed description of the VOA system is provided in Table 3.1 .

Table 3.1. VOA Instrumentation

\begin{tabular}{||l|l|l|l||}
\hline \hline System/Instrument & \multicolumn{1}{|c|}{ Manufacturer } & \multicolumn{1}{|c||}{ Model Number } & \multicolumn{1}{|c|}{ M\&TE $^{(\mathbf{1})}$ Number } \\
\hline \hline Auto-sampler & Dynatech & PTA-30 & WD25729 \\
\hline Purge \& Trap & OI & 4560 & WD25728 \\
\hline GC/MS & Hewlett Packard & 5890II/5989A & WC22547/WC28119 \\
\hline
\end{tabular}

(1) Measuring and Test Equipment

\subsection{Analysis Results}


The VOA target (calibrated analytes) results for C-104 supernatant and solids phases are given in Table 3.2. Additionally, the results for any VOA tentatively identified compounds (TIC) that were detected for both supernatant and solids phases are given in Table 3.3. For both target compounds and TICs, the results are given in units of $\mu \mathrm{g} / \mathrm{L}$ for the supernatant and $\mu \mathrm{g} / \mathrm{Kg}$ for the wet solid phase.

The MDLs provided are based upon instrument detection limits and the weight or volume of the sample used for the analysis. The MDLs are nominal, and are not based upon performance of the method on these specific sample matrices. In nearly all cases the MDLs for the wet centrifuged solids and the supernatants (after adjusting for density) meet the BNFL VOA minimum reportable quantity (MRQ) requirements as detailed in Table 3.4.

\subsubsection{Results for Calibrated/Regulatory Analytes of Interest}

Supernatant:

As seen in Table 3.2, target compounds detected in the C-104 supernatant were primarily limited to alkanes ranging from hexane to nonane. In addition, butanone and the ketone counterparts to hexane and heptane were also detected but at levels below the quantitation limit. Acetone and methylene chloride were found above the quantitation limits. Hexane, acetone, and methylene chloride were detected in the hot cell storage blank, but at least two orders of magnitude lower than was found in the sample. A septa on the vial containing the duplicate supernatant sample was found to be leaking. The analytical results for the supernatant duplicate sample did not detect any analytes, an outcome reflecting the compromised sample containment. Comparison of the supernatant sample data and its duplicate is thus meaningless. An attempt to reanalyze new sample aliquots is discussed later in this section.

A number of tentatively identified compounds were also detected as seen in Table 3.3. These were the heavier alkanes through tridecane and the corresponding alkenes that were not target compounds. The primary components of normal paraffin hydrocarbons (NPH), undecane, dodecane, and tridecane, commonly used at the Hanford site, were the most abundant compounds. The quantity of $\mathrm{NPH}$ was greater in the supernatant sample than in the solids. This indicates that the slurry was saturated with these organics otherwise their solubilities would dictate their precipitation onto the surfaces of the solid phase. There may have been an undetected separable organic layer, or micelles containing these organics, which may explain the difference between the supernatant and solid results, however, if present, it was not visible during inspection of the sample in the hot cell.

Solids:

The C-104 solid samples contained a greater variety and generally larger amount of target analytes compared to the supernatant samples. A greater range of alkanes was also detected in the solids, ranging from butane through nonane. Since the samples were obtained and stored at ambient temperatures, the presence of butane in these samples indicated that volatile compounds were likely to have been continuously generated. Acrylonitrile, propionaldehyde, and methylene chloride were found above the quantitation limits. Acrylonitrile was found above the quantitation limit in the sample duplicate, but was not detected in the sample.

Like in the supernatant samples, ketone counterparts to each of the alkanes were detected, but were found at levels below the quantitation limits. Other compounds that were detected but that were below the quantitation limit include benzene and ethyl benzene, propyl nitrate, and acetone.

A greater variety of tentatively identified compounds were found in the solid samples than in the supernatant. This result further supports the premise that continuous generation of volatile constituents was occurring in the solid material. By virtue of partitioning, these constituents would 
otherwise be located preferentially where the greater quantity of organic material was present, which was determined to be in the supernatant. That may also indicate that some of the volatile constituents had been lost from the supernatant material during handling, although the relatively low volatility of NPH should be expected to act as a chemical trap or "keeper solvent."

The absence or lower concentration level of the more volatile compounds in the supernatant could also be an artifact. This could occur because of the static nature of containment and continuous production of volatile constituents in the solid samples.

Sample aliquots were obtained one week later to provide sample duplicate and spike duplicate information lost in the first analysis set. When compared to the first data set, the results indicated that major losses of volatile constituents had occurred. Therefore, the second data set is not provided in this report. However, the dissimilarity in the results indicated that the majority of difference between the supernatant and solid phases is likely due to losses rather than artificial elevation. 
Table 3.2. C-104 VOA Results - BNFL \& SW846 8260B Target Analyte List

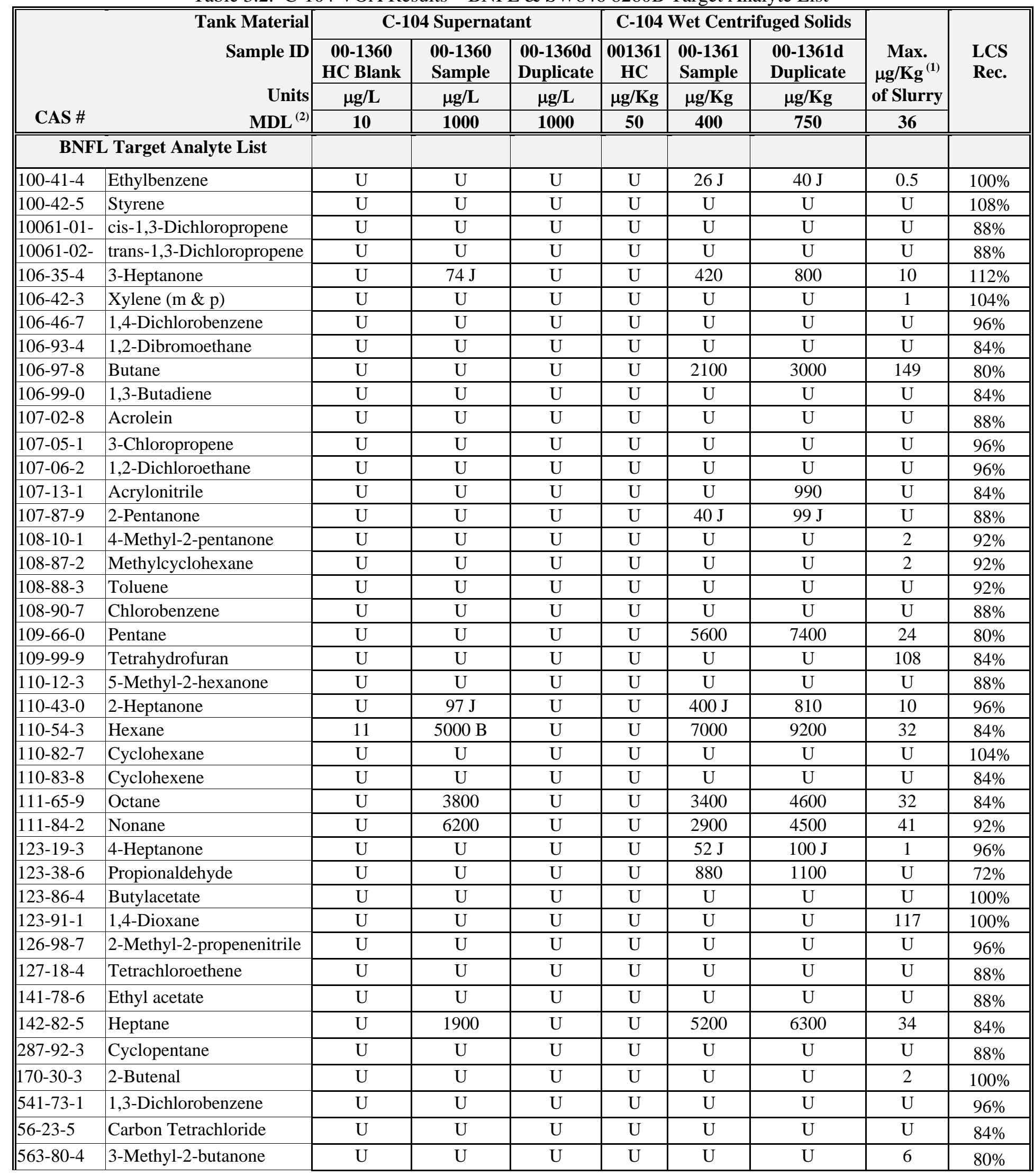




\begin{tabular}{|c|c|c|c|c|c|c|c|c|c|}
\hline \multirow[b]{4}{*}{ CAS \# } & \multirow{4}{*}{$\begin{array}{r}\text { Tank Material } \\
\text { Sample ID } \\
\text { Units } \\
\text { MDL }^{(2)} \\
\end{array}$} & \multicolumn{3}{|c|}{ C-104 Supernatant } & \multicolumn{3}{|c|}{ C-104 Wet Centrifuged Solids } & \multirow{3}{*}{$\begin{array}{c}\text { Max. } \\
\mu \mathrm{g} / \mathrm{Kg}^{(1)} \\
\text { of Slurry }\end{array}$} & \multirow{4}{*}{$\begin{array}{l}\text { LCS } \\
\text { Rec. }\end{array}$} \\
\hline & & \multirow{2}{*}{\begin{tabular}{|c|}
$\begin{array}{c}00-1360 \\
\text { HC Blank }\end{array}$ \\
$\mu \mathrm{g} / \mathrm{L}$ \\
\end{tabular}} & \multirow{2}{*}{$\begin{array}{c}00-1360 \\
\text { Sample } \\
\mu g / L\end{array}$} & \multirow{2}{*}{$\begin{array}{c}\text { o0-1360d } \\
\text { Duplicate }\end{array}$} & \multirow{2}{*}{ 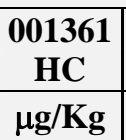 } & \multirow{2}{*}{$\begin{array}{c}00-1361 \\
\text { Sample } \\
\mu \mathrm{g} / \mathrm{Kg}\end{array}$} & \multirow{2}{*}{$\begin{array}{c}\text { 00-1361d } \\
\text { Duplicate } \\
\mu \mathrm{g} / \mathrm{Kg} \\
\end{array}$} & & \\
\hline & & & & & & & & & \\
\hline & & 10 & 1000 & 1000 & 50 & 400 & 750 & 36 & \\
\hline 591-78-6 & 2-Hexanone & $\overline{\mathrm{U}}$ & $24 \mathrm{~J}$ & $\mathrm{U}$ & $\overline{\mathrm{U}}$ & $130 \mathrm{~J}$ & $270 \mathrm{~J}$ & 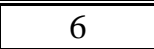 & 92\% \\
\hline $627-13-4$ & Propyl nitrate & $\mathrm{U}$ & $\mathrm{U}$ & $\mathrm{U}$ & $\mathrm{U}$ & $30 \mathrm{~J}$ & $40 \mathrm{~J}$ & $\mathrm{U}$ & $96 \%$ \\
\hline 67-64-1 & Acetone & $1.8 \mathrm{~J}$ & $1000 \mathrm{~B}$ & $\mathrm{U}$ & $5.5 \mathrm{~J}$ & $190 \mathrm{JB}$ & $430 \mathrm{JB}$ & 304 & $76 \%$ \\
\hline 67-66-3 & Chloroform & $\mathrm{U}$ & $\mathrm{U}$ & $\mathrm{U}$ & $\mathrm{U}$ & $\mathrm{U}$ & $\mathrm{U}$ & $\mathrm{U}$ & $88 \%$ \\
\hline 71-43-2 & Benzene & $\mathrm{U}$ & $\mathrm{U}$ & $\mathrm{U}$ & $\mathrm{U}$ & $25 \mathrm{~J}$ & $60 \mathrm{~J}$ & 2 & $88 \%$ \\
\hline 71-55-6 & 1,1,1-Trichloroethane & $\mathrm{U}$ & $\mathrm{U}$ & $\mathrm{U}$ & $\mathrm{U}$ & $\mathrm{U}$ & $\mathrm{U}$ & $\mathrm{U}$ & $84 \%$ \\
\hline 74-83-9 & Bromomethane & $\mathrm{U}$ & $\mathrm{U}$ & $\mathrm{U}$ & $\mathrm{U}$ & $\mathrm{U}$ & $\mathrm{U}$ & $\mathrm{U}$ & $96 \%$ \\
\hline $74-87-3$ & Chloromethane & $\mathrm{U}$ & $\mathrm{U}$ & $\mathrm{U}$ & $\bar{U}$ & $\mathrm{U}$ & $\mathrm{U}$ & $\mathrm{U}$ & $84 \%$ \\
\hline $75-00-3$ & Chloroethane & $\mathrm{U}$ & $\mathrm{U}$ & $\mathrm{U}$ & $\mathrm{U}$ & $\mathrm{U}$ & $\mathrm{U}$ & $\mathrm{U}$ & $92 \%$ \\
\hline 75-01-4 & Vinyl Chloride & $\mathrm{U}$ & $\mathrm{U}$ & $\mathrm{U}$ & $\mathrm{U}$ & $\mathrm{U}$ & $\mathrm{U}$ & $\mathrm{U}$ & $80 \%$ \\
\hline 75-05-8 & Acetonitrile & $\mathrm{U}$ & $\mathrm{U}$ & $\mathrm{U}$ & $\mathrm{U}$ & $\mathrm{U}$ & $\mathrm{U}$ & 7 & $88 \%$ \\
\hline 75-09-2 & Methylene Chloride & 19 & $8000 \mathrm{~B}$ & $\mathrm{U}$ & $4.3 \mathrm{~J}$ & $880 \mathrm{~B}$ & $1900 \mathrm{~B}$ & $\mathrm{U}$ & $84 \%$ \\
\hline $75-15-0$ & Carbon Disulfide & $\mathrm{U}$ & $\mathrm{U}$ & $\mathrm{U}$ & $\mathrm{U}$ & $\mathrm{U}$ & $\mathrm{U}$ & $\mathrm{U}$ & $84 \%$ \\
\hline $75-34-3$ & 1,1-Dichloroethane & $\mathrm{U}$ & $\mathrm{U}$ & $\mathrm{U}$ & $\mathrm{U}$ & $\mathrm{U}$ & $\mathrm{U}$ & $\mathrm{U}$ & $88 \%$ \\
\hline $75-35-4$ & 1,1-Dichloroethene & $\mathrm{U}$ & $\mathrm{U}$ & $\mathrm{U}$ & $\mathrm{U}$ & $\mathrm{U}$ & $\mathrm{U}$ & $\mathrm{U}$ & $88 \%$ \\
\hline $75-43-4$ & Dichlorofluoromethane & $\mathrm{U}$ & $\mathrm{U}$ & $\mathrm{U}$ & $\mathrm{U}$ & $\mathrm{U}$ & $\mathrm{U}$ & $\mathrm{U}$ & $104 \%$ \\
\hline $75-45-6$ & Chlorodifluoromethane & $\mathrm{U}$ & $\mathrm{U}$ & $\mathrm{U}$ & $\mathrm{U}$ & $\mathrm{U}$ & $\mathrm{U}$ & 4 & $76 \%$ \\
\hline 75-69-4 & Trichlorofluoromethane & $\mathrm{U}$ & $\mathrm{U}$ & $\mathrm{U}$ & $\mathrm{U}$ & $\mathrm{U}$ & $\mathrm{U}$ & $\mathrm{U}$ & $76 \%$ \\
\hline 75-71-8 & Dichlorodifluoromethane & $\mathrm{U}$ & $\mathrm{U}$ & $\mathrm{U}$ & $\mathrm{U}$ & $\mathrm{U}$ & $\mathrm{U}$ & $\mathrm{U}$ & $76 \%$ \\
\hline 76-13-1 & 1,2,2-Trichloro-1,1,2- & $\mathrm{U}$ & $\mathrm{U}$ & $\mathrm{U}$ & $\mathrm{U}$ & $\mathrm{U}$ & $\mathrm{U}$ & $\mathrm{U}$ & $88 \%$ \\
\hline $76-14-2$ & 1,2-Dichloro-1,1,2,2- & $\mathrm{U}$ & $\mathrm{U}$ & $\mathrm{U}$ & $\mathrm{U}$ & $\mathrm{U}$ & $\mathrm{U}$ & $\mathrm{U}$ & $80 \%$ \\
\hline $78-87-5$ & 1,2-Dichloropropane & $\mathrm{U}$ & $\mathrm{U}$ & $\mathrm{U}$ & $\mathrm{U}$ & $\mathrm{U}$ & $\mathrm{U}$ & $\mathrm{U}$ & $100 \%$ \\
\hline 78-93-3 & 2-Butanone & $\mathrm{U}$ & $290 \mathrm{~J}$ & $\mathrm{U}$ & $\mathrm{U}$ & $52 \mathrm{~J}$ & $320 \mathrm{~J}$ & 57 & $88 \%$ \\
\hline $79-00-5$ & 1,1,2-Trichloroethane & $\mathrm{U}$ & $\mathrm{U}$ & $\mathrm{U}$ & $\mathrm{U}$ & $\mathrm{U}$ & $\mathrm{U}$ & $\mathrm{U}$ & $88 \%$ \\
\hline 79-01-6 & Trichloroethene & $\mathrm{U}$ & $\mathrm{U}$ & $\mathrm{U}$ & $\mathrm{U}$ & $\mathrm{U}$ & $\mathrm{U}$ & $\mathrm{U}$ & $88 \%$ \\
\hline $79-34-5$ & 1,1,2,2-Tetrachloroethane & $\mathrm{U}$ & $\mathrm{U}$ & $\mathrm{U}$ & $\mathrm{U}$ & $\mathrm{U}$ & $\mathrm{U}$ & $\mathrm{U}$ & $92 \%$ \\
\hline $95-47-6$ & Xylene (o) & $\mathrm{U}$ & $\mathrm{U}$ & $\mathrm{U}$ & $\mathrm{U}$ & $\mathrm{U}$ & $\mathrm{U}$ & 0.3 & $104 \%$ \\
\hline $95-50-1$ & 1,2-Dichlorobenzene & $\mathrm{U}$ & $\mathrm{U}$ & $\mathrm{U}$ & $\mathrm{U}$ & $\mathrm{U}$ & $\mathrm{U}$ & $\mathrm{U}$ & $92 \%$ \\
\hline $96-22-0$ & 3-Pentanone & $\mathrm{U}$ & $\mathrm{U}$ & $\mathrm{U}$ & $\mathrm{U}$ & $\mathrm{U}$ & $\mathrm{U}$ & $\mathrm{U}$ & $92 \%$ \\
\hline \multicolumn{10}{|c|}{ SW-846 8260B Target Analyte List } \\
\hline $103-65-1$ & Propylbenzene & $\mathrm{U}$ & $\mathrm{U}$ & $\mathrm{U}$ & $\mathrm{U}$ & $\mathrm{U}$ & $\mathrm{U}$ & $\mathrm{U}$ & $96 \%$ \\
\hline 104-51-8 & Butylbenzene & $\mathrm{U}$ & $\mathrm{U}$ & $\mathrm{U}$ & $\mathrm{U}$ & $\mathrm{U}$ & $\mathrm{U}$ & $\mathrm{U}$ & $84 \%$ \\
\hline $106-43-4$ & 4-Chlorotoluene & $\mathrm{U}$ & $\mathrm{U}$ & $\mathrm{U}$ & $\mathrm{U}$ & $\mathrm{U}$ & $\mathrm{U}$ & $\mathrm{U}$ & $108 \%$ \\
\hline 108-67-8 & 1,2,3-Trimethylbenzene & $\mathrm{U}$ & $\mathrm{U}$ & $\mathrm{U}$ & $\mathrm{U}$ & $\mathrm{U}$ & $\mathrm{U}$ & $\mathrm{U}$ & $84 \%$ \\
\hline 108-86-1 & Bromobenzene & $\mathrm{U}$ & $\mathrm{U}$ & $\mathrm{U}$ & $\mathrm{U}$ & $\mathrm{U}$ & $\mathrm{U}$ & $\mathrm{U}$ & $92 \%$ \\
\hline $110-57-6$ & $\begin{array}{l}\text { trans-1,4-Dichloro-2- } \\
\text { butene }\end{array}$ & $\mathrm{U}$ & $\mathrm{U}$ & $\mathrm{U}$ & $\mathrm{U}$ & $\mathrm{U}$ & $\mathrm{U}$ & $\mathrm{U}$ & $96 \%$ \\
\hline $120-82-1$ & 1,2,4-Trichlorobenzene & $\mathrm{U}$ & $\mathrm{U}$ & $\mathrm{U}$ & $\mathrm{U}$ & $\mathrm{U}$ & $\mathrm{U}$ & $\mathrm{U}$ & $92 \%$ \\
\hline $124-48-1$ & Dibromochloromethane & $\mathrm{U}$ & $\mathrm{U}$ & $\mathrm{U}$ & $\mathrm{U}$ & $\mathrm{U}$ & $\mathrm{U}$ & $\mathrm{U}$ & $88 \%$ \\
\hline $135-98-8$ & sec-Butylbenzene & $\mathrm{U}$ & $\mathrm{U}$ & $\mathrm{U}$ & $\mathrm{U}$ & $\mathrm{U}$ & $\mathrm{U}$ & $\mathrm{U}$ & $92 \%$ \\
\hline $142-28-9$ & 1,3-Dichloropropane & $\mathrm{U}$ & $\mathrm{U}$ & $\mathrm{U}$ & $\mathrm{U}$ & $\mathrm{U}$ & $\mathrm{U}$ & $\mathrm{U}$ & $88 \%$ \\
\hline 156-59-2 & cis-1,2-Dichloroethene & $\mathrm{U}$ & $\mathrm{U}$ & $\mathrm{U}$ & $\mathrm{U}$ & $\mathrm{U}$ & $\mathrm{U}$ & $\mathrm{U}$ & $88 \%$ \\
\hline
\end{tabular}




\begin{tabular}{|c|c|c|c|c|c|c|c|c|c|}
\hline \multirow[b]{4}{*}{ CAS \# } & \multirow{2}{*}{$\begin{array}{r}\text { Tank Material } \\
\text { Sample ID }\end{array}$} & \multicolumn{3}{|c|}{ C-104 Supernatant } & \multicolumn{3}{|c|}{ C-104 Wet Centrifuged Solids } & \multirow{3}{*}{$\begin{array}{c}\text { Max. } \\
\mu \mathrm{g} / \mathrm{Kg}^{(1)} \\
\text { of Slurry }\end{array}$} & \multirow{4}{*}{$\begin{array}{l}\text { LCS } \\
\text { Rec. }\end{array}$} \\
\hline & & $\begin{array}{c}00-1360 \\
\text { HC Blank } \\
\end{array}$ & $\begin{array}{l}00-1360 \\
\text { Sample } \\
\end{array}$ & $\begin{array}{l}\text { 00-1360d } \\
\text { Duplicate } \\
\end{array}$ & \begin{tabular}{|c|}
001361 \\
HC \\
\end{tabular} & $\begin{array}{l}00-1361 \\
\text { Sample } \\
\end{array}$ & $\begin{array}{l}\text { 00-1361d } \\
\text { Duplicate }\end{array}$ & & \\
\hline & \multirow{2}{*}{$\begin{array}{r}\text { Units } \\
\mathrm{MDL}^{(2)} \\
\end{array}$} & $\mu \mathrm{g} / \mathrm{L}$ & $\mu \mathrm{g} / \mathrm{L}$ & $\mu \mathrm{g} / \mathrm{L}$ & $\mu \mathrm{g} / \mathrm{Kg}$ & $\mu \mathrm{g} / \mathrm{Kg}$ & $\mu \mathrm{g} / \mathrm{Kg}$ & & \\
\hline & & 10 & 1000 & 1000 & 50 & 400 & 750 & 36 & \\
\hline $156-60-5$ & trans-1,2-Dichloroethene & $\overline{\mathrm{U}}$ & $\overline{\mathrm{U}}$ & $\mathrm{U}$ & $\overline{\mathrm{U}}$ & $\overline{\mathrm{U}}$ & $\overline{\mathrm{U}}$ & 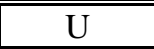 & $88 \%$ \\
\hline $563-58-6$ & 1,1-Dichloropropene & $\mathrm{U}$ & $\mathrm{U}$ & $\mathrm{U}$ & $\mathrm{U}$ & $\mathrm{U}$ & $\mathrm{U}$ & $\mathrm{U}$ & $84 \%$ \\
\hline $594-20-7$ & 2,2-Dichloropropane & $\mathrm{U}$ & $\mathrm{U}$ & $\mathrm{U}$ & $\mathrm{U}$ & $\mathrm{U}$ & $\mathrm{U}$ & $\mathrm{U}$ & $88 \%$ \\
\hline 74-95-3 & Dibromomethane & $\mathrm{U}$ & $\mathrm{U}$ & $\mathrm{U}$ & $\mathrm{U}$ & $\mathrm{U}$ & $\mathrm{U}$ & $\mathrm{U}$ & $88 \%$ \\
\hline 74-97-5 & Bromochloromethane & $\mathrm{U}$ & $\mathrm{U}$ & $\mathrm{U}$ & $\mathrm{U}$ & $\mathrm{U}$ & $\mathrm{U}$ & $\mathrm{U}$ & $84 \%$ \\
\hline $75-25-2$ & Bromoform & $\mathrm{U}$ & $\mathrm{U}$ & $\mathrm{U}$ & $\mathrm{U}$ & $\mathrm{U}$ & $\mathrm{U}$ & $\mathrm{U}$ & $88 \%$ \\
\hline $75-27-4$ & Bromodichloromethane & $\mathrm{U}$ & $\bar{U}$ & $\mathrm{U}$ & $\bar{U}$ & $\mathrm{U}$ & $\mathrm{U}$ & $\mathrm{U}$ & $88 \%$ \\
\hline 87-61-6 & 1,2,3-Trichlorobenzene & $\mathrm{U}$ & $\mathrm{U}$ & $\mathrm{U}$ & $\mathrm{U}$ & $\mathrm{U}$ & $\mathrm{U}$ & $\mathrm{U}$ & $96 \%$ \\
\hline $87-68-3$ & Hexachloro-1,3-butadiene & $\mathrm{U}$ & $\mathrm{U}$ & $\mathrm{U}$ & $\mathrm{U}$ & $\mathrm{U}$ & $\mathrm{U}$ & $\mathrm{U}$ & $96 \%$ \\
\hline $91-20-3$ & Naphthalene & $\mathrm{U}$ & $\mathrm{U}$ & $\mathrm{U}$ & $\mathrm{U}$ & $\mathrm{U}$ & $\mathrm{U}$ & $\mathrm{U}$ & $96 \%$ \\
\hline $95-49-8$ & 2-Chlorotoluene & $\mathrm{U}$ & $\mathrm{U}$ & $\mathrm{U}$ & $\mathrm{U}$ & $\mathrm{U}$ & $\mathrm{U}$ & $\mathrm{U}$ & $100 \%$ \\
\hline $95-63-6$ & 1,2,4-Trimethylbenzene & $\mathrm{U}$ & $\mathrm{U}$ & $\mathrm{U}$ & $\mathrm{U}$ & $\mathrm{U}$ & $\mathrm{U}$ & $\mathrm{U}$ & $88 \%$ \\
\hline $96-12-8$ & $\begin{array}{l}\text { 1,2-Dibromo-3- } \\
\text { chloropropane }\end{array}$ & $\mathrm{U}$ & $\mathrm{U}$ & $\mathrm{U}$ & $\mathrm{U}$ & $\mathrm{U}$ & $\mathrm{U}$ & $\mathrm{U}$ & $84 \%$ \\
\hline $96-18-4$ & 1,2,3-Trichloropropane & $\mathrm{U}$ & $\mathrm{U}$ & $\mathrm{U}$ & $\mathrm{U}$ & $\mathrm{U}$ & $\mathrm{U}$ & $\mathrm{U}$ & $104 \%$ \\
\hline $98-06-6$ & tert-Butylbenzene & $\mathrm{U}$ & $\mathrm{U}$ & $\mathrm{U}$ & $\mathrm{U}$ & $\mathrm{U}$ & $\mathrm{U}$ & $\mathrm{U}$ & $100 \%$ \\
\hline $98-82-8$ & Isopropylbenzene & $\mathrm{U}$ & $\mathrm{U}$ & $\mathrm{U}$ & $\mathrm{U}$ & $\mathrm{U}$ & $\mathrm{U}$ & $\mathrm{U}$ & $92 \%$ \\
\hline $99-87-6$ & 4-Isopropyltoluene & $\mathrm{U}$ & $\mathrm{U}$ & $\mathrm{U}$ & $\mathrm{U}$ & $\mathrm{U}$ & $\mathrm{U}$ & $\mathrm{U}$ & $88 \%$ \\
\hline
\end{tabular}

${ }^{(1)}$ Maximum slurry $\mu \mathrm{g} / \mathrm{Kg}$ calculated using results of Tables 2.1 (weight fractions) and 2.2 (supernatant density)—See Section 1.0

(2) MDL = Method detection limit based on instrument detection limit and sample quantity

$\mathrm{U}$ flag = Compound not detected; Compound concentration less than the MDL

$\mathrm{J}$ flag = Compound detected, but concentration is less than the MDL

$\mathrm{B}$ flag = Compound was present in the method blank 
Table 3.3. C-104 VOA Tentatively Identified Compounds

\begin{tabular}{|c|c|c|c|c|c|}
\hline \multicolumn{3}{|c|}{ C-104 Supernatant 00-1360 } & \multirow{2}{*}{$\begin{array}{c}\text { Sample } \\
\mu \mathrm{g} / \mathrm{L}\end{array}$} & \multirow{2}{*}{$\begin{array}{c}\text { Duplicate } \\
\mu \mathrm{g} / \mathrm{L}\end{array}$} & \multirow{2}{*}{$\begin{array}{c}\text { Blank } \\
\mu \mathrm{g} / \mathrm{L}\end{array}$} \\
\hline CAS \# & TIC & Ret. Time (Min.) & & & \\
\hline $124-38-9$ & Carbon dioxide & 3.08 & -- & -- & $78 \mathrm{~J}$ \\
\hline $19689-18-0$ & 4-Decene & 19.51 & $5300 \mathrm{~J}$ & -- & -- \\
\hline $124-18-5$ & Decane & 19.63 & $42000 \mathrm{~J}$ & -- & -- \\
\hline \multirow[t]{2}{*}{$1120-21-4$} & Undecane & 21.90 & $93000 \mathrm{~J}$ & -- & -- \\
\hline & Unknown Siloxane & 22.58 & -- & -- & $23 \mathrm{~J}$ \\
\hline 7206-17-9 & 6-Dodecene, (E)- & 23.75 & $8300 \mathrm{~J}$ & -- & -- \\
\hline $112-40-3$ & Dodecane & 23.88 & $49000 \mathrm{~J}$ & -- & -- \\
\hline $820-29-1$ & 5-Decanone & 24.20 & $12000 \mathrm{~J}$ & -- & -- \\
\hline $928-80-3$ & 3-Decanone & 24.50 & $4800 \mathrm{~J}$ & -- & -- \\
\hline $693-54-9$ & 2-Decanone & 24.68 & $5100 \mathrm{~J}$ & -- & -- \\
\hline \multirow[t]{2}{*}{$629-50-5$} & Tridecane & 25.73 & $3800 \mathrm{~J}$ & -- & -- \\
\hline & Unknown Siloxane & 25.96 & -- & -- & $3.1 \mathrm{~J}$ \\
\hline $50639-02-6$ & 5-Undecanone, 2-methyl- & 26.11 & $9200 \mathrm{~J}$ & $-{ }_{--}$ & -- \\
\hline \multicolumn{3}{|c|}{\begin{tabular}{|c|} 
C-104 Wet Centrifuged Solids 00-1361 \\
\end{tabular}} & Sample & Duplicate & Blank \\
\hline CAS \# & TIC & Ret. Time (Min.) & $\mu \mathrm{g} / \mathrm{Kg}$ & $\mu \mathrm{g} / \mathrm{Kg}$ & $\mu \mathrm{g} / \mathrm{Kg}$ \\
\hline $592-76-7$ & 1-Heptene & 11.53 & $3200 \mathrm{~J}$ & $5400 \mathrm{~J}$ & -- \\
\hline $111-66-0$ & 1-Octene & 14.50 & $3300 \mathrm{~J}$ & $4600 \mathrm{~J}$ & -- \\
\hline \multirow[t]{2}{*}{$124-11-8$} & 1-Nonene & 17.17 & $2100 \mathrm{~J}$ & $2900 \mathrm{~J}$ & -- \\
\hline & Unknown Siloxane & 19.16 & -- & -- & $61 \mathrm{~J}$ \\
\hline $19689-18-0$ & 4-Decene & 19.61 & $1800 \mathrm{~J}$ & $3100 \mathrm{~J}$ & -- \\
\hline $124-18-5$ & Decane & 19.71 & $13000 \mathrm{~J}$ & $26000 \mathrm{~J}$ & -- \\
\hline 111-13-7 & 2-Octanone & 20.54 & $1200 \mathrm{~J}$ & -- & -- \\
\hline $764-96-5$ & 5-Undecene, (Z)- & 21.82 & $2800 \mathrm{~J}$ & $6200 \mathrm{~J}$ & -- \\
\hline $1120-21-4$ & Undecane & 21.97 & $24000 \mathrm{~J}$ & $50000 \mathrm{~J}$ & -- \\
\hline $764-97-6$ & 5-Undecene, (E)- & 22.06 & $1600 \mathrm{~J}$ & -- & -- \\
\hline \multirow[t]{2}{*}{ 19549-83-8 } & 3-Heptanone, 2,6-dimethyl- & 22.27 & $1900 \mathrm{~J}$ & -- & -- \\
\hline & Unknown Siloxane & 22.58 & -- & $3000 \mathrm{~J}$ & $34 \mathrm{~J}$ \\
\hline $821-55-6$ & 2-Nonanone & 22.75 & $2600 \mathrm{~J}$ & $3800 \mathrm{~J}$ & -- \\
\hline $124-12-9$ & Octanenitrile & 23.09 & $1500 \mathrm{~J}$ & $2200 \mathrm{~J}$ & -- \\
\hline $2030-84-4$ & 4-Dodecene & 23.86 & $2900 \mathrm{~J}$ & $6700 \mathrm{~J}$ & -- \\
\hline $112-40-3$ & Dodecane & 24.00 & $21000 \mathrm{~J}$ & $43000 \mathrm{~J}$ & -- \\
\hline $624-16-8$ & 4-Decanone & 24.31 & $6300 \mathrm{~J}$ & $10000 \mathrm{~J}$ & -- \\
\hline $928-80-3$ & 3-Decanone & 24.61 & $2700 \mathrm{~J}$ & $4400 \mathrm{~J}$ & -- \\
\hline 693-54-9 & 2-Decanone & 24.79 & $3000 \mathrm{~J}$ & $5000 \mathrm{~J}$ & -- \\
\hline $2243-27-8$ & Nonanenitrile & 25.17 & $1400 \mathrm{~J}$ & $2100 \mathrm{~J}$ & -- \\
\hline 629-50-5 & Tridecane & 25.86 & $1900 \mathrm{~J}$ & $4500 \mathrm{~J}$ & -- \\
\hline 33083-83-9 & 5-Undecanone & 26.24 & $4400 \mathrm{~J}$ & $9300 \mathrm{~J}$ & -- \\
\hline
\end{tabular}

"-----" = Compound not detected

$\mathrm{J}$ Flag = Estimated quantity. TIC compounds estimated using the response factor from the closest eluting internal standard. 
Table 3.4. Target VOA Minimum Reportable Quantities

\begin{tabular}{|c|c|c|c|}
\hline CAS \# & VOA Compounds & $\begin{array}{c}\text { Solids Target } \\
\text { MRQ }^{(1)} \\
\mu \mathrm{g} / \mathrm{Kg}\end{array}$ & $\begin{array}{c}\text { Supernatant Target MRQ } \\
\text { (Density }=1.161 \text { ) } \\
\mu \mathrm{g} / \mathrm{L}\end{array}$ \\
\hline 141-78-6 & Acetic acid ethyl ester & 11000 & 12800 \\
\hline $75-05-8$ & Acetonitrile & 12700 & 14700 \\
\hline $107-02-8$ & Acrolein & ----- & ----- \\
\hline $107-13-1$ & Acrylonitrile & 28000 & 32500 \\
\hline 3825-26-1 & Ammonium perfluorooctanoate & ----- & ----- \\
\hline $71-43-2$ & Benzene & 3300 & 3800 \\
\hline 74-83-9 & Bromomethane & 5000 & 5800 \\
\hline $106-99-0$ & 1,3-Butadiene & ----- & ----- \\
\hline 106-97-8 & Butane & ----- & ----- \\
\hline 78-93-3 & 2-Butanone & 12000 & 13900 \\
\hline $4170-30-3$ & 2-Butenaldehyde (2-Butenal) & ----- & ----- \\
\hline $71-36-3$ & n-Butyl alcohol & 900 & 1050 \\
\hline $123-86-4$ & Acetic acid n-butyl ester & $\begin{array}{ll}---- \\
\end{array}$ & ----- \\
\hline $75-15-0$ & Carbon disulfide & ----- & ----- \\
\hline $56-23-5$ & Carbon tetrachloride & 2000 & 2320 \\
\hline $108-90-7$ & Chlorobenzene & 2000 & 2320 \\
\hline $75-45-6$ & Chlorodifluoromethane & ----- & ----- \\
\hline $75-00-3$ & Chloroethane & ----- & ----- \\
\hline 75-01-4 & 1-Chloroethene & 2000 & 2320 \\
\hline 67-66-3 & Chloroform & 2000 & 2320 \\
\hline $74-87-3$ & Chloromethane & 10000 & 11600 \\
\hline $107-05-1$ & 3-Chloropropene & 10000 & 11600 \\
\hline $110-82-7$ & Cyclohexane & ----- & ----- \\
\hline $108-94-1$ & Cyclohexanone & ----- & ----- \\
\hline $110-83-8$ & Cyclohexene & $\begin{array}{ll}---- \\
\end{array}$ & $\begin{array}{ll}---- \\
\end{array}$ \\
\hline $287-92-3$ & Cyclopentane & $\begin{array}{ll}---- \\
--9\end{array}$ & ----- \\
\hline 76-14-2 & 1,2-Dichloro-1,1,2,2-tetrafluoroethane & $\begin{array}{ll}---- \\
\end{array}$ & ----- \\
\hline 75-71-8 & Dichlorodifluoromethane & 2400 & 2790 \\
\hline $75-34-3$ & 1,1-Dichloroethane & 2000 & 2320 \\
\hline $107-06-2$ & 1,2-Dichloroethane & 2000 & 2320 \\
\hline $75-35-4$ & 1,1-Dichloroethene & 2000 & 2320 \\
\hline $75-43-4$ & Dichlorofluoromethane & ----- & ----- \\
\hline 75-09-2 & Dichloromethane (methylene chloride) & 10000 & 11600 \\
\hline 78-87-5 & 1,2-Dichloropropane & ----- & ----- \\
\hline $10061-01-5$ & Cis-1,3-Dichloropropene & 6000 & 6970 \\
\hline $10061-02-6$ & trans-1,3-Dichloropropene & 6000 & 6970 \\
\hline $57-14-7$ & 1,1-Dimethylhydrazine & ----- & ----- \\
\hline 123-91-1 & 1,4-Dioxane & $\begin{array}{ll}----- \\
\end{array}$ & $\begin{array}{ll}---- \\
\end{array}$ \\
\hline $64-17-5$ & Ethyl alcohol & $\begin{array}{ll}---- \\
\end{array}$ & ----- \\
\hline $100-41-4$ & Ethyl benzene & 3300 & 3830 \\
\hline $106-93-4$ & Ethylene dibromide & 5000 & 5810 \\
\hline $142-82-5$ & n-Heptane & $\begin{array}{ll}---- \\
\end{array}$ & ----- \\
\hline $110-43-0$ & 2-Heptanone & $\begin{array}{l}---- \\
\end{array}$ & $\begin{array}{l}---- \\
\end{array}$ \\
\hline
\end{tabular}




\begin{tabular}{|c|c|c|c|}
\hline CAS \# & VOA Compounds & $\begin{array}{c}\text { Solids Target } \\
\text { MRQ }^{(1)} \\
\mu \mathrm{g} / \mathrm{Kg}\end{array}$ & $\begin{array}{c}\text { Supernatant Target MRQ } \\
\text { (Density }=1.161 \text { ) } \\
\mu \mathrm{g} / \mathrm{L}\end{array}$ \\
\hline $106-35-4$ & 3-Heptanone & ----- & ----- \\
\hline $123-19-3$ & 4-Heptanone & ----- & $\begin{array}{ll}---- \\
--1\end{array}$ \\
\hline $684-16-2$ & Hexafluoroacetone & ----- & ----- \\
\hline $110-54-3$ & n-Hexane & ----- & ----- \\
\hline $591-78-6$ & 2-Hexanone & $\begin{array}{c}---- \\
--1\end{array}$ & $\begin{array}{cl}---- \\
\end{array}$ \\
\hline $67-56-1$ & Methyl alcohol (Methanol) & ----- & ----- \\
\hline $624-83-9$ & Methyl isocyanate & $\begin{array}{ll}---- \\
\end{array}$ & $\begin{array}{cl}---- \\
--1\end{array}$ \\
\hline $563-80-4$ & 3-Methyl-2-butanone & ----- & ----- \\
\hline $110-12-3$ & 5-Methyl-2-hexanone & $\begin{array}{ll}---- \\
--1\end{array}$ & $\begin{array}{ll}---- \\
\end{array}$ \\
\hline 108-10-1 & 4-Methyl-2-pentanone & 11000 & 12800 \\
\hline 75-65-0 & 2-Methyl-2-propanol & ----- & ----- \\
\hline $126-98-7$ & 2-Methyl-2-propenenitrile & 28000 & 32500 \\
\hline $108-87-2$ & Methylcyclohexane & ----- & ----- \\
\hline $60-34-4$ & Methylhydrazine & ----- & ----- \\
\hline $78-92-2$ & 1-Methylpropyl alcohol(2-butanol) & $\begin{array}{ll}---- \\
--1\end{array}$ & $\begin{array}{ll}---- \\
--1\end{array}$ \\
\hline $627-13-4$ & Nitric acid, propyl ester & ----- & ----- \\
\hline $111-84-2$ & n-Nonane & $\begin{array}{ll}---- \\
-9\end{array}$ & $\begin{array}{ll}---- \\
-\end{array}$ \\
\hline $111-65-9$ & n-Octane & ----- & ----- \\
\hline $75-21-8$ & Oxirane & ----- & ----- \\
\hline 109-66-0 & n-Pentane & ----- & ----- \\
\hline 107-87-9 & 2-Pentanone & $\begin{array}{ll}---- \\
\end{array}$ & $\begin{array}{ll}---- \\
\end{array}$ \\
\hline $96-22-0$ & 3-Pentanone & ----- & ----- \\
\hline $67-64-1$ & 2-Propanone (Acetone) & 53300 & 61900 \\
\hline $123-38-6$ & n-Propionaldehyde & ----- & ----- \\
\hline $107-12-0$ & Propionitrile & 120000 & 139300 \\
\hline $71-23-8$ & n-Propyl alcohol (1-propanol) & ----- & ----- \\
\hline $67-63-0$ & 2-Propyl alcohol (Isopropanol; Propan-2-ol) & $\begin{array}{ll}---- \\
\end{array}$ & $\begin{array}{ll}---- \\
\end{array}$ \\
\hline $100-42-5$ & Styrene & ----- & ----- \\
\hline $79-34-5$ & 1,1,2,2-Tetrachloroethane & 2000 & 2320 \\
\hline $127-18-4$ & 1,1,2,2-Tetrachloroethene & 2000 & 2320 \\
\hline 109-99-9 & Tetrahydrofuran & ----- & ----- \\
\hline 108-88-3 & Toluene & 3300 & 3830 \\
\hline 76-13-1 & 1,2,2-Trichloro-1,1,2-trifluoroethane & 10000 & 11600 \\
\hline $71-55-6$ & 1,1,1-Trichloroethane & 2000 & 2900 \\
\hline $79-00-5$ & 1,1,2-Trichloroethane & 2000 & 2320 \\
\hline $79-01-6$ & 1,1,2-Trichloroethylene & 2000 & 2320 \\
\hline 75-69-4 & Trichlorofluoromethane & 10000 & 11600 \\
\hline $108-38-3$ & m-Xylene & 3300 & 3830 \\
\hline $95-47-6$ & o-Xylene & 3300 & 3830 \\
\hline $106-42-3$ & p-Xylene & 3300 & 3830 \\
\hline
\end{tabular}

(1) MRQ = Minimum Reportable Quantity. Values provided by BNFL.

“-----” = No MRQ target provided. 


\subsubsection{QC Evaluation}

Instrument tuning check criteria and 12-hour calibration clock window criteria were met for all initial calibration and sample analysis sequences as seen in the " $5 \mathrm{~A}$ " Forms in the Appendix C. The initial calibration met the criteria of USEPA SW-846 method 8260B, as seen in the "6A" Form in the Appendix C. All five-system performance check compounds (SPCC) met the criteria for minimum response factor, and all six calibration check compounds (CCC) met the maximum relative standard deviation (RSD) criteria.

The continuing calibration check standard met the criteria of USEPA SW-846 method 8260B, as seen in the "7A" Forms in the Appendix C. All calibration check standards met the SPCC and CCC criteria. Only Acrolein at $16.7 \%$ exceeded the recommended percent difference (\%D) of $15 \%$.

The internal standards used in this study were 1,4-difluorobenzene, pentafluorbenzene, chorobenzene$\mathrm{d}_{5}$, and 1,4-dichorobenzene- $\mathrm{d}_{4}$. The surrogate compounds used were toluene- $\mathrm{d}_{8}$, bromofluorobenzene, dibromofluoromethane, and 1,2-dichloroethane- $\mathrm{d}_{4}$. These eight compounds were added to each sample, duplicate, MS, MSD, and blank sample analyzed.

To evaluate surrogate recoveries, Contract Laboratory Program (CLP) limits for low-level soil samples were used only as a guide and are included on the "2A \& 2B" Forms in Appendix C. Only the supernatant duplicate sample failed to meet the limits due to a leaking vial. Attempts to reanalyze sample aliquots obtained one week later found noticeably lower concentrations of most analytes. Therefore, reanalysis data is not presented.

The CLP criterion for internal standard response was used ( $\pm 50 \%$ of the calibration check standard response). Internal standard response met the criteria for all but two of the samples, which was due to leaking vials. Both the supernatant duplicate and the supernatant matrix spike duplicate failed. The internal standard data are summarized on the each of the CLP-type "8A" Forms in the Appendix C.

Matrix spiking was performed by adding the methanolic calibration solution to the samples at a level of $250 \mathrm{ng}$ per compound. As described previously, no spike duplicate data is available for the supernatant due to a leaking sample container. In general, when compounds were found in the unspiked supernatant or solid, their recoveries in the spiked samples were erratic. This is likely caused by the small sample size used which was $\sim 0.055-0.139$ grams. The small sample sizes were necessary because of the relatively high levels of NPH present. Sample aliquots of one gram or less often exhibit poor reproducibility.

Ethyl acetate and butyl acetate appear to be reacting with both matrices types. Except for the solid duplicate, 2-butenal exhibited no recovery also. The difference in recovery between the solid sample and its duplicate for 2-butenal is not understood.

Propionitrile coeluted with Cyclohexene on the DB-624 column used for this analysis and was not calibrated because the only abundant mass, $\mathrm{m} / \mathrm{z}=54$ ) was common to Cyclohexene. Likewise, Cyclohexanone coeluted with methylcyclohexane and no abundant and unique masses permitted calibration of Cyclohexane using the DB-624 column. 


\subsection{Semi-Volatile Organic Analysis (SVOA)}

\subsection{Semi-Volatile Organic Analysis (SVOA)}

\subsubsection{Introduction}

Semi-volatile organic analyses were performed on both the supernatant and wet centrifuged solids from tank C-104 samples following phase separation. Supernatants and wet centrifuged solids were extracted with methylene chloride as per Test Plan BNFL-29953-80, Revision 1. The extracted samples were reduced in volume using a Kuderna-Danish concentrator. Following volume reduction, an aliquot was prepared and analyzed for semi-volatiles by method PNL-ALO-345.

The SVOA samples were extracted at the initial starting $\mathrm{pH}$ of the samples and then adjusted and reextracted for those compounds (e.g. phenols) that are not extracted at high $\mathrm{pH}$. This extraction approach is fully detailed in TP BNFL-29953-80 Revision 1. The approach calls for dissolving the solids, if possible, and extracting the solution by the conventional liquid-liquid extraction procedure. However, during processing of the solids phases it was determined that a high fraction of the solids were insoluble following dilution with $0.01 \mathrm{~N} \mathrm{NaOH}$ solution. Therefore, the aqueous dissolution step detailed in the Test Plan was eliminated and the solids were subjected directly to an ultrasonication extraction using a methylene chloride combined with a desiccant.

\subsubsection{Sample Preparation}

Prior to performing the extraction process for the SVOA, the aliquots of the supernatants and the wet centrifuged solids (mixed with deionized water) were titrated with phosphoric acid. The resulting titration curves were used to establish the quantity of phosphoric acid required to adjust the extracting $\mathrm{pH}$ to level defined by the procedure (approximately 6.5).

\subsubsection{Supernatants}

For each supernatant sample of C-104 extracted, a known quantity (10 to 20 g) of sample was transferred into a Teflon separatory funnel. Appropriate spikes, internal standards, and surrogates were added to the samples prior to subjecting the samples to the extraction process. Each supernatant sample was extracted with three $25-\mathrm{mL}$ portions of methylene chloride by subjecting the separatory funnel to mechanical shaking. Following this initial extraction, the supernatant was chilled in ice and stirred while the $\mathrm{pH}$ was adjusted with a predetermined quantity of phosphoric acid. Samples of C104 formed significant precipitates that were separated from the supernatant by centrifuging and decanting. The extraction process was repeated on the $\mathrm{pH}$-adjusted supernatant. The precipitates formed following acid addition were extracted (by ultrasonication) using three 25 -mL portions of methylene chloride. All extracts from the supernatant sample were combined and passed through a column containing an anhydrous sodium sulfate desiccant to complete the supernatant extraction process.

\subsubsection{Solids}

For each of the wet centrifuged solids samples extracted, a known quantity (2.5 to $5 \mathrm{~g}$ ) of sample was transferred to a small Teflon bottle and anhydrous sodium sulfate (pre-dried in a muffle furnace) desiccant was added. Appropriate spikes, internal standards, and surrogates were added to the samples prior to subjecting the samples to the ultra-sonication extraction process. Each sample was 
ultra-sonicated with three 25 -mL portions of methylene chloride. Following this initial extraction, the $\mathrm{pH}$ of the solids was adjusted with a predetermined quantity of phosphoric acid and the ultrasonication extraction process repeated. All extracts from the solids sample were combined and passed through a column containing an anhydrous sodium sulfate desiccant to complete the solids extraction process.

\subsubsection{Extract Volume Reduction}

Once the extraction processes were completed in the SAL, the supernatant extracts and the wet centrifuged solids extracts were transferred under $\mathrm{CoC}$ from the SAL to the analytical laboratories and refrigerated prior to subsequent volume reduction processing. During the volume reduction processing, each extract was reduced in volume to $1 \mathrm{~mL}$ for each of the supernatant samples and 10 mLs for each of the solids. The solid extracts had exhibited foaming during the concentration step and were not concentrated further for that reason. The SVOA concentrated extracts were refrigerated until analysis was performed.

\subsubsection{Instrumentation}

The analytical instrumentation used for SVOA consists of an autosampler-injector and gas chromatograph mass spectrometer system. Detailed description of the SVOA system is provided in Table 4.1.

Table 4.1. SVOA Instrumentation

\begin{tabular}{||l|l|l|l||}
\hline \hline System/Instrument & Manufacturer & Model Number & M\&TE $^{(\mathbf{1})}$ Number \\
\hline \hline Autosampler & Hewlett Packard & $7673 \mathrm{~A}$ & N/A \\
\hline GC/MS & Hewlett Packard & $5890 \mathrm{II} / 5972$ & WB47238/WD25623 \\
\hline
\end{tabular}

${ }^{(1)}$ Measuring and Test Equipment

\subsubsection{Analysis Results}

The SVOA target (calibrated analytes) results for C-104 supernatant and solids phases are given in Table 4.2. Additionally, the results for any SVOA TICs that were detected for both C-104 supernatant and solids phases are given in Tables 4.3 and 4.4. For both target compounds and TICs, the results are given in units of $\mu \mathrm{g} / \mathrm{L}$ for the supernatant and $\mu \mathrm{g} / \mathrm{Kg}$ for the wet solid phase.

The MDLs provided are based upon instrument detection limits that are achievable in reagent water and the weight or volume of the sample used for the analysis. The MDLs are nominal, and are not based upon performance of the method on these specific sample matrices. Minimum reported quantities specified by BNFL for a limited number of SVOA compounds are listed in Table 4.5.

\subsubsection{Results for Calibrated/Regulatory Analytes of Interest}

\section{C-104 Supernatant Results}

As detailed in the QC section, relatively few unspiked target compounds were detected in the C-104 supernatant. Only N-nitrosodimethylamine was found at levels greater than the MDL. Bis(2ethylhexyl)phthalate, 2-methylpyridine, 4-nitrophenol and 4,6-dinitrophenol were detected at levels below the quantitation limit. 
The TIC results contained two siloxane compounds, hexamethyl-cyclotetrasiloxane and decamethylcyclotetrasiloxane were found in the samples and blank, and were likely leached from the Teflonlined, silcone rubber septum used in the I-Chem bottles that held the sample extracts prior to removal from the SAL.

Several straight chain alkanes were detected that include decane, undecane, dodecane, tridecane, tetradecane and pentadecane (components of NPH, a diluent used in the PUREX and B-Plant solvent extraction processes). A number of organic acids such as pentanoic acid, hexanoic acid, heptanoic acid, 2-ethyl hexanoic acid, octanoic acid, valproic acid, nonanoic acid, decanoic acid, undecanoic acid and dodecanoic acid were found in the C-104 supernatant. These organic acids are likely oxidation products of the alkanes in the tank waste and were generally found in higher concentrations than the alkanes in the supernatant, likely due to their greater solubility. Hexanenitrile and methylene propanedinitrile were detected. The compound 2-methoxy-2methyl butane was found in the blank and samples at similar levels. It is possible that it is an oxidation product of a free-radical scavenger, amylene, used in the residue-analysis grade methylene chloride or a reaction product of the acetone used in the spiking solution. Several alcohols, ketones, and esters such as 2,2-dimethyl-3-pentanone, 2-decanone and butyl nonanoate were identified in the samples. These compounds are likely oxidation products of the alkanes in the tank waste.

Nitric acid, propyl ester was identified in supernatant, and is likely to be the result of a reaction of the nitrous acid formed from the nitrite in the tank waste after the $\mathrm{pH}$ adjustment. Several nitrated phenolic compounds such as 2-fluoro-6-nitrophenol, 4-methyl-2-nitrophenol, 3-fluoro-4-nitrophenol, 3-methyl-4-nitrophenol, and 2-methyl-3,5-dinitrophenol were detected in the supernatant. These compounds are likely reaction products of the spiked phenolic compounds.

\section{C-104 Solids Results}

As detailed in the QC section, only one unspiked target compound was detected in the C-104 wet centrifuged solids, bis(2-ethylhexyl)phthalate, a common plasticizer, was detected at levels below the method quantitation limit. Tributyl phosphate was detected in the C-104 solids at levels well above the quantitation limit.

The compound 1,1,2-trichloroethane is reported in the TIC results for the blank, and is likely to be a reaction product or trace contaminant of the methylene chloride extraction solvent. The TIC results contained two siloxane compounds, octamethyl-cyclotetrasiloxane (samples) and decamethylcyclotetrasiloxane (blank), and were likely leached from the Teflon lined, silcone rubber septum used in the I-Chem bottles that held the sample extracts prior to removal from the SAL.

Several straight chain alkanes were detected that included decane, undecane, dodecane, tridecane, and tetradecane (components of NPH, a diluent used in the PUREX and B-Plant solvent extraction processes). These alkanes were detected in the C-104 solids at concentrations several hundred times higher than those found in the C-104 supernatant samples. A series of ketone compounds such as various undecanone, dodecanone and tridecanone compounds were detected in the C-104 solid samples. These compounds are presumed to be oxidation products of the straight chain alkanes.

A number of potentially artifact compounds such as alcohols, enols and aldol condensation products were reported in the data for the blank; these are likely to be aldol condensation products of the acetone used in the spiking solutions. 
Table 4.2. C-104 SVOA Results - Project \& SW846 8270C Target Analyte List

\begin{tabular}{|c|c|c|c|c|c|c|c|c|c|}
\hline & \multirow{3}{*}{$\begin{array}{l}\text { Tank ID: } \\
\text { RPL ID: }\end{array}$} & \multicolumn{3}{|c|}{ C-104 Supernatant } & \multicolumn{3}{|c|}{ C-104 Wet Centrifuged Solids } & \multirow[b]{2}{*}{$\begin{array}{l}\text { LCS } \\
\text { Rec. }\end{array}$} & \multirow{2}{*}{$\begin{array}{c}\text { Max } \\
\text { Slurry } \\
\text { Conc. }^{(1)} \\
\mu \mathrm{g} / \mathrm{Kg} \\
\end{array}$} \\
\hline & & $\begin{array}{c}\text { 00-1360bl } \\
\text { Proc Blk } \\
\mu \mathrm{g} / \mathrm{L} \\
\end{array}$ & \begin{tabular}{|c|}
$\begin{array}{c}00-1360 \\
\text { Sample } \\
\mu \mathrm{g} / \mathrm{L}\end{array}$ \\
\end{tabular} & \begin{tabular}{|c|}
$\begin{array}{c}\text { 99-1360d } \\
\text { Duplicate } \\
\mu \mathrm{g} / \mathrm{L}\end{array}$ \\
\end{tabular} & $\begin{array}{c}\text { 00-1361bl } \\
\text { Proc Blk } \\
\mu \mathrm{g} / \mathrm{Kg} \\
\end{array}$ & $\begin{array}{c}\text { 00-1361 } \\
\text { Sample } \\
\mu \mathrm{g} / \mathrm{Kg}\end{array}$ & $\begin{array}{c}\text { 00-1361d } \\
\text { Duplicate } \\
\mu \mathrm{g} / \mathrm{Kg}\end{array}$ & & \\
\hline & & 560 & 560 & 560 & 2000 & 19000 & 20000 & & 15700 \\
\hline \multicolumn{10}{|c|}{ Project Target Analyte List } \\
\hline $100-00-5$ & 1-Chloro-4-nitrobenzene ${ }^{(3)}$ & 2600 & $2100 \mathrm{~B}$ & $1900 \mathrm{~B}$ & 6300 & $2800 \mathrm{BJ}$ & $2900 \mathrm{BJ}$ & $130 \%$ & 15700 \\
\hline $100-25-4$ & 1,4-Dinitrobenzene ${ }^{(3)}$ & 1600 & $1500 \mathrm{~B}$ & $1500 \mathrm{~B}$ & 4400 & $2300 \mathrm{BJ}$ & $1500 \mathrm{BJ}$ & $110 \%$ & 15700 \\
\hline $100-51-6$ & Benzyl alcohol & $\mathrm{U}$ & $\mathrm{U}$ & $\mathrm{U}$ & $\mathrm{U}$ & $\mathrm{U}$ & $\mathrm{U}$ & -- & 15700 \\
\hline $106-44-5$ & 4-Methylphenol ${ }^{(3)}$ & 2900 & $\mathrm{U}$ & $\mathrm{U}$ & 6800 & $\mathrm{U}$ & $6100 \mathrm{BJ}$ & $85 \%$ & 15700 \\
\hline 106-46-7 & 1,4-Dichlorobenzene & $\mathrm{U}$ & $\mathrm{U}$ & $\mathrm{U}$ & $\mathrm{U}$ & $\mathrm{U}$ & $\mathrm{U}$ & $61 \%$ & 15700 \\
\hline $108-95-2$ & \begin{tabular}{|l|} 
Phenol \\
\end{tabular} & $\mathrm{U}$ & $\mathrm{U}$ & $\mathrm{U}$ & $\mathrm{U}$ & $\mathrm{U}$ & $\mathrm{U}$ & $25 \%$ & 15700 \\
\hline $110-86-1$ & Pyridine $^{(3)}$ & 2400 & $2300 \mathrm{~B}$ & $3100 \mathrm{~B}$ & 8200 & $6500 \mathrm{BJ}$ & $\mathrm{U}$ & $110 \%$ & 15700 \\
\hline $117-81-7$ & Bis(2-Ethylhexyl)phthalate & $\mathrm{U}$ & $480 \mathrm{~J}$ & $96 \mathrm{~J}$ & $\mathrm{U}$ & $5900 \mathrm{~J}$ & $\mathrm{U}$ & -- & 15700 \\
\hline $117-84-0$ & Di-n-octylphthalate & $\mathrm{U}$ & $\mathrm{U}$ & $\mathrm{U}$ & $\mathrm{U}$ & $\mathrm{U}$ & $\mathrm{U}$ & -- & 15700 \\
\hline 118-74-1 & Hexachlorobenzene & $\mathrm{U}$ & $\mathrm{U}$ & $\mathrm{U}$ & $\mathrm{U}$ & $\mathrm{U}$ & $\mathrm{U}$ & -- & 15700 \\
\hline $120-82-1$ & 1,2,4-Trichlorobenzene & $\mathrm{U}$ & $\mathrm{U}$ & $\mathrm{U}$ & $\mathrm{U}$ & $\mathrm{U}$ & $\mathrm{U}$ & $66 \%$ & 15700 \\
\hline $122-39-4$ & N,N-Diphenylamine & $\mathrm{U}$ & $\mathrm{U}$ & $\mathrm{U}$ & $\mathrm{U}$ & $\mathrm{U}$ & $\mathrm{U}$ & $0 \%$ & 15700 \\
\hline 126-73-8 & Tributyl phosphate ${ }^{(3)}$ & 2500 & $2100 \mathrm{~B}$ & $2000 \mathrm{~B}$ & 5500 & $57000 \mathrm{~B}$ & $50000 \mathrm{~B}$ & $110 \%$ & 15700 \\
\hline $128-37-0$ & Butylated Hydroxytoluene ${ }^{(3)}$ & 1500 & $130 \mathrm{BJ}$ & $92 \mathrm{BJ}$ & $170 \mathrm{~J}$ & $670 \mathrm{BJ}$ & $790 \mathrm{BJ}$ & -- & 15700 \\
\hline $2234-13-1$ & Octachloronaphthalene $^{(3,4)}$ & 45000 & $38000 \mathrm{~B}$ & $36000 \mathrm{~B}$ & 250000 & $65000 \mathrm{~B}$ & $51000 \mathrm{~B}$ & $5500 \%$ & 15700 \\
\hline $309-00-2$ & Aldrin & $\mathrm{U}$ & $\mathrm{U}$ & $\mathrm{U}$ & $\mathrm{U}$ & $\mathrm{U}$ & $\mathrm{U}$ & -- & 15700 \\
\hline 319-84-6 & alpha-BHC & $\mathrm{U}$ & $\mathrm{U}$ & $\mathrm{U}$ & $\mathrm{U}$ & $\mathrm{U}$ & $\mathrm{U}$ & -- & 15700 \\
\hline 319-85-7 & beta-BHC & $\mathrm{U}$ & $\mathrm{U}$ & $\mathrm{U}$ & $\mathrm{U}$ & $\mathrm{U}$ & $\mathrm{U}$ & -- & 15700 \\
\hline $465-73-6$ & Isodrin & $\mathrm{U}$ & $\mathrm{U}$ & $\mathrm{U}$ & $\mathrm{U}$ & $\mathrm{U}$ & $\mathrm{U}$ & -- & 15700 \\
\hline $50-29-3$ & 4,4'-DDT & $\mathrm{U}$ & $\mathrm{U}$ & $\mathrm{U}$ & $\mathrm{U}$ & $\mathrm{U}$ & $\mathrm{U}$ & -- & 15700 \\
\hline $50-32-8$ & Benzo(a)pyrene & $\mathrm{U}$ & $\mathrm{U}$ & $\mathrm{U}$ & $\mathrm{U}$ & $\mathrm{U}$ & $\mathrm{U}$ & -- & 15700 \\
\hline $53-70-3$ & Dibenz(a,h)anthracene & $\mathrm{U}$ & $\mathrm{U}$ & $\mathrm{U}$ & $\mathrm{U}$ & $\mathrm{U}$ & $\mathrm{U}$ & -- & 15700 \\
\hline 541-73-1 & 1,3-Dichlorobenzene & $\mathrm{U}$ & $\mathrm{U}$ & $\mathrm{U}$ & $\mathrm{U}$ & $\mathrm{U}$ & $\mathrm{U}$ & -- & 15700 \\
\hline 58-89-9 & gamma-BHC (Lindane) & $\mathrm{U}$ & $\mathrm{U}$ & $\mathrm{U}$ & $\mathrm{U}$ & $\mathrm{U}$ & $\mathrm{U}$ & -- & 15700 \\
\hline $60-57-1$ & Dieldrin & $\mathrm{U}$ & $\mathrm{U}$ & $\mathrm{U}$ & $\mathrm{U}$ & $\mathrm{U}$ & $\mathrm{U}$ & -- & 15700 \\
\hline $62-75-9$ & N-Nitrosodimethylamine & $\mathrm{U}$ & 1300 & 1900 & $\mathrm{U}$ & $\mathrm{U}$ & $\mathrm{U}$ & -- & 15900 \\
\hline $67-72-1$ & Hexachloroethane & $\mathrm{U}$ & $\mathrm{U}$ & $\mathrm{U}$ & $\mathrm{U}$ & $\mathrm{U}$ & $\mathrm{U}$ & -- & 15700 \\
\hline $72-20-8$ & Endrin & $\mathrm{U}$ & $\mathrm{U}$ & $\mathrm{U}$ & $\mathrm{U}$ & $\mathrm{U}$ & $\mathrm{U}$ & -- & 15700 \\
\hline $72-54-8$ & 4,4'-DDD & $\mathrm{U}$ & $\mathrm{U}$ & $\mathrm{U}$ & $\mathrm{U}$ & $\mathrm{U}$ & $\mathrm{U}$ & -- & 15700 \\
\hline $76-44-8$ & Heptachlor & $\mathrm{U}$ & $\mathrm{U}$ & $\mathrm{U}$ & $\mathrm{U}$ & $\mathrm{U}$ & $\mathrm{U}$ & -- & 15700 \\
\hline $82-68-8$ & Pentachloronitrobenzene & $\mathrm{U}$ & $\mathrm{U}$ & $\mathrm{U}$ & $\mathrm{U}$ & $\mathrm{U}$ & $\mathrm{U}$ & $0 \%$ & 15700 \\
\hline $87-68-3$ & Hexachlorobutadiene & $\mathrm{U}$ & $\mathrm{U}$ & $\mathrm{U}$ & $\mathrm{U}$ & $\mathrm{U}$ & $\mathrm{U}$ & -- & 15700 \\
\hline $87-86-5$ & Pentachlorophenol & $\mathrm{U}$ & $\mathrm{U}$ & $\mathrm{U}$ & $\mathrm{U}$ & $\mathrm{U}$ & $\mathrm{U}$ & $0 \%$ & 15700 \\
\hline $88-85-7$ & Dinoseb $^{(4)}$ & $250 \mathrm{~J}$ & $2200 \mathrm{~B}$ & $2500 \mathrm{~B}$ & 6500 & $6400 \mathrm{BJ}$ & $3400 \mathrm{BJ}$ & $160 \%$ & 15900 \\
\hline $91-20-3$ & \begin{tabular}{|l|} 
Naphthalene \\
\end{tabular} & $\mathrm{U}$ & $\mathrm{U}$ & $\mathrm{U}$ & $\mathrm{U}$ & $\mathrm{U}$ & $\mathrm{U}$ & -- & 15700 \\
\hline $92-52-4$ & Biphenyl $^{(3)}$ & 2600 & $2000 \mathrm{~B}$ & $2000 \mathrm{~B}$ & 6200 & $2100 \mathrm{BJ}$ & $1700 \mathrm{BJ}$ & $100 \%$ & 15700 \\
\hline $95-48-7$ & 2-Methylphenol ${ }^{(3)}$ & 1700 & $\mathrm{U}$ & $\mathrm{U}$ & 3100 & $\mathrm{U}$ & $\mathrm{U}$ & $76 \%$ & 15700 \\
\hline $95-50-1$ & \begin{tabular}{|l|} 
1,2-Dichlorobenzene \\
\end{tabular} & $\mathrm{U}$ & $\mathrm{U}$ & $\mathrm{U}$ & $\mathrm{U}$ & $\mathrm{U}$ & $\mathrm{U}$ & -- & 15700 \\
\hline $98-86-2$ & Acetophenone $^{(3)}$ & 3000 & $2300 \mathrm{~B}$ & $2200 \mathrm{~B}$ & 8800 & $6300 \mathrm{BJ}$ & $6200 \mathrm{BJ}$ & $190 \%$ & 15700 \\
\hline $98-95-3$ & Nitrobenzene & $\mathrm{U}$ & $\mathrm{U}$ & $\mathrm{U}$ & $\mathrm{U}$ & $\mathrm{U}$ & $\mathrm{U}$ & -- & 15700 \\
\hline \multicolumn{10}{|c|}{ SW-846 8270C Target Analyte List } \\
\hline $100-01-6$ & 4-Nitroaniline & $\mathrm{U}$ & $\mathrm{U}$ & $\mathrm{U}$ & $\mathrm{U}$ & $\mathrm{U}$ & $\mathrm{U}$ & -- & 15700 \\
\hline $100-02-7$ & 4-Nitrophenol & $\mathrm{U}$ & $290 \mathrm{~J}$ & $\mathrm{U}$ & $\mathrm{U}$ & $\mathrm{U}$ & $\mathrm{U}$ & $14 \%$ & 15700 \\
\hline $100-75-4$ & N-Nitrosopiperidine & $\mathrm{U}$ & $\mathrm{U}$ & $\mathrm{U}$ & $\mathrm{U}$ & $\mathrm{U}$ & $\mathrm{U}$ & -- & 15700 \\
\hline $101-55-3$ & 4-Bromophenyl-phenylether & $\mathrm{U}$ & $\mathrm{U}$ & $\mathrm{U}$ & $\mathrm{U}$ & $\mathrm{U}$ & $\mathrm{U}$ & -- & 15700 \\
\hline $1024-57-3$ & Heptachlor Epoxide & $\mathrm{U}$ & $\mathrm{U}$ & $\mathrm{U}$ & $\mathrm{U}$ & $\mathrm{U}$ & $\mathrm{U}$ & -- & 15700 \\
\hline 1031-07-8 & Endosulfan Sulfate & $\mathrm{U}$ & $\mathrm{U}$ & $\mathrm{U}$ & $\mathrm{U}$ & $\mathrm{U}$ & $\mathrm{U}$ & -- & 15700 \\
\hline 103-33-3 & Azeobenzene & $\mathrm{U}$ & $\mathrm{U}$ & $\mathrm{U}$ & $\mathrm{U}$ & $\mathrm{U}$ & $\mathrm{U}$ & -- & 15700 \\
\hline $105-67-9$ & 2,4-Dimethylphenol & $\mathrm{U}$ & $\mathrm{U}$ & $\mathrm{U}$ & $\mathrm{U}$ & $\mathrm{U}$ & $\mathrm{U}$ & -- & 15700 \\
\hline
\end{tabular}




\begin{tabular}{|c|c|c|c|c|c|c|c|c|c|}
\hline \multirow{3}{*}{$\mid$} & \multirow{3}{*}{$\begin{array}{r}\text { Tank ID: } \\
\text { RPL ID: }\end{array}$} & \multicolumn{3}{|c|}{ C-104 Supernatant } & \multicolumn{3}{|c|}{ C-104 Wet Centrifuged Solids } & \multirow[b]{2}{*}{$\begin{array}{l}\text { LCS } \\
\text { Rec. }\end{array}$} & \multirow{2}{*}{$\begin{array}{c}\text { Max } \\
\text { Slurry } \\
\text { Conc. }^{(1)} \\
\mu \mathrm{g} / \mathrm{Kg}\end{array}$} \\
\hline & & $\begin{array}{c}00-1360 b l \\
\text { Proc Blk } \\
\mu \mathrm{g} / \mathrm{L}\end{array}$ & \begin{tabular}{|c|}
$00-1360$ \\
Sample \\
$\mu \mathrm{g} / \mathrm{L}$
\end{tabular} & \begin{tabular}{|c|}
$\begin{array}{c}\text { 99-1360d } \\
\text { Duplicate } \\
\mu \mathrm{g} / \mathrm{L}\end{array}$ \\
\end{tabular} & $\begin{array}{c}00-1361 b l \\
\text { Proc Blk } \\
\mu \mathrm{g} / \mathrm{Kg}\end{array}$ & $\begin{array}{c}00-1361 \\
\text { Sample } \\
\mu \mathrm{g} / \mathrm{Kg}\end{array}$ & \begin{tabular}{|c}
$\begin{array}{c}00-1361 d \\
\text { Duplicate } \\
\mu \mathrm{g} / \mathrm{Kg}\end{array}$ \\
\end{tabular} & & \\
\hline & & 560 & 560 & 560 & 2000 & 19000 & 20000 & & 15700 \\
\hline $10595-95-6$ & N-Nitrosomethylethylamine & $\mathrm{U}$ & $\mathrm{U}$ & $\mathrm{U}$ & $\mathrm{U}$ & $\mathrm{U}$ & $\mathrm{U}$ & -- & 15700 \\
\hline $106-47-8$ & 4-Chloroaniline & $\mathrm{U}$ & $\mathrm{U}$ & $\mathrm{U}$ & $\mathrm{U}$ & $\mathrm{U}$ & $\mathrm{U}$ & -- & 15700 \\
\hline $108-60-1$ & 2,2'-oxybis(1-Chloropropane) & $\mathrm{U}$ & $\mathrm{U}$ & $\mathrm{U}$ & $\mathrm{U}$ & $\mathrm{U}$ & $\mathrm{U}$ & -- & 15700 \\
\hline 109-06-8 & 2-Methylpyridine & $\mathrm{U}$ & $350 \mathrm{~J}$ & $510 \mathrm{~J}$ & $\mathrm{U}$ & $\mathrm{U}$ & $\mathrm{U}$ & -- & 15700 \\
\hline $111-44-4$ & bis(2-Chloroethyl)ether & $\mathrm{U}$ & $\mathrm{U}$ & $\mathrm{U}$ & $\mathrm{U}$ & $\mathrm{U}$ & $\mathrm{U}$ & -- & 15700 \\
\hline $111-91-1$ & bis(2-Chloroethoxy)methane & $\mathrm{U}$ & $\mathrm{U}$ & $\mathrm{U}$ & $\mathrm{U}$ & $\mathrm{U}$ & $\mathrm{U}$ & -- & 15700 \\
\hline $119-93-7$ & 3,3'-Dimethylbenzidine & $\mathrm{U}$ & $\mathrm{U}$ & $\mathrm{U}$ & $\mathrm{U}$ & $\mathrm{U}$ & $\mathrm{U}$ & -- & 15700 \\
\hline $120-12-7$ & Anthracene & $\mathrm{U}$ & $\mathrm{U}$ & $\mathrm{U}$ & $\mathrm{U}$ & $\mathrm{U}$ & $\mathrm{U}$ & -- & 15700 \\
\hline $120-58-1$ & Isosafrole & $\mathrm{U}$ & $\mathrm{U}$ & $\mathrm{U}$ & $\mathrm{U}$ & $\mathrm{U}$ & $\mathrm{U}$ & -- & 15700 \\
\hline $120-83-2$ & 2,4-Dichlorophenol & $\mathrm{U}$ & $\mathrm{U}$ & $\mathrm{U}$ & $\mathrm{U}$ & $\mathrm{U}$ & $\mathrm{U}$ & -- & 15700 \\
\hline $121-14-2$ & 2,4-Dinitrotoluene & $\mathrm{U}$ & $\mathrm{U}$ & $\mathrm{U}$ & $\mathrm{U}$ & $\mathrm{U}$ & $\mathrm{U}$ & $77 \%$ & 15700 \\
\hline $129-00-0$ & Pyrene & $\mathrm{U}$ & $\mathrm{U}$ & $\mathrm{U}$ & $\mathrm{U}$ & $\mathrm{U}$ & $\mathrm{U}$ & $89 \%$ & 15700 \\
\hline $130-15-4$ & 1,4-Naphthoquinone & $\mathrm{U}$ & $\mathrm{U}$ & $\mathrm{U}$ & $\mathrm{U}$ & $\mathrm{U}$ & $\mathrm{U}$ & -- & 15700 \\
\hline $131-11-3$ & Dimethylphthalate & $\mathrm{U}$ & $\mathrm{U}$ & $\mathrm{U}$ & $\mathrm{U}$ & $\mathrm{U}$ & $\mathrm{U}$ & -- & 15700 \\
\hline $132-64-9$ & Dibenzofuran & $\mathrm{U}$ & $\mathrm{U}$ & $\mathrm{U}$ & $\mathrm{U}$ & $\mathrm{U}$ & $\mathrm{U}$ & -- & 15700 \\
\hline $134-32-7$ & 1-Naphthylamine & $\mathrm{U}$ & $\mathrm{U}$ & $\mathrm{U}$ & $\mathrm{U}$ & $\mathrm{U}$ & $\mathrm{U}$ & -- & 15700 \\
\hline $143-50-0$ & Kepone & $\mathrm{U}$ & $\mathrm{U}$ & $\mathrm{U}$ & $\mathrm{U}$ & $\mathrm{U}$ & $\mathrm{U}$ & -- & 15700 \\
\hline 1888-71-7 & Hexachloropropene & $\mathrm{U}$ & $\mathrm{U}$ & $\mathrm{U}$ & $\mathrm{U}$ & $\mathrm{U}$ & $\mathrm{U}$ & -- & 15700 \\
\hline $191-24-2$ & Benzo(g,h,i)perylene & $\mathrm{U}$ & $\mathrm{U}$ & $\mathrm{U}$ & $\mathrm{U}$ & $\mathrm{U}$ & $\mathrm{U}$ & -- & 15700 \\
\hline $193-39-5$ & Indeno(1,2,3-cd)pyrene & $\mathrm{U}$ & $\mathrm{U}$ & $\mathrm{U}$ & $\mathrm{U}$ & $\mathrm{U}$ & $\mathrm{U}$ & -- & 15700 \\
\hline $205-99-2$ & Benzo(b)fluoranthene & $\mathrm{U}$ & $\mathrm{U}$ & $\mathrm{U}$ & $\mathrm{U}$ & $\mathrm{U}$ & $\mathrm{U}$ & -- & 15700 \\
\hline $206-44-0$ & Fluoranthene & $\mathrm{U}$ & $\mathrm{U}$ & $\mathrm{U}$ & $\mathrm{U}$ & $\mathrm{U}$ & $\mathrm{U}$ & -- & 15700 \\
\hline $207-08-9$ & Benzo(k)fluoranthene & $\mathrm{U}$ & $\mathrm{U}$ & $\mathrm{U}$ & $\mathrm{U}$ & $\mathrm{U}$ & $\mathrm{U}$ & -- & 15700 \\
\hline $208-96-8$ & Acenaphthylene & $\mathrm{U}$ & $\mathrm{U}$ & $\mathrm{U}$ & $\mathrm{U}$ & $\mathrm{U}$ & $\mathrm{U}$ & -- & 15700 \\
\hline 218-01-9 & Chrysene & $\mathrm{U}$ & $\mathrm{U}$ & $\mathrm{U}$ & $\mathrm{U}$ & $\mathrm{U}$ & $\mathrm{U}$ & -- & 15700 \\
\hline 2303-16-4 & Diallate (cis) & $\mathrm{U}$ & $\mathrm{U}$ & $\mathrm{U}$ & $\mathrm{U}$ & $\mathrm{U}$ & $\mathrm{U}$ & -- & 15700 \\
\hline $2303-16-4$ & Diallate (trans) & $\mathrm{U}$ & $\mathrm{U}$ & $\mathrm{U}$ & $\mathrm{U}$ & $\mathrm{U}$ & $\mathrm{U}$ & -- & 15700 \\
\hline $23950-58-5$ & Pronamine & $\mathrm{U}$ & $\mathrm{U}$ & $\mathrm{U}$ & $\mathrm{U}$ & $\mathrm{U}$ & $\mathrm{U}$ & -- & 15700 \\
\hline $319-86-8$ & delta-BHC & $\mathrm{U}$ & $\mathrm{U}$ & $\mathrm{U}$ & $\mathrm{U}$ & $\mathrm{U}$ & $\mathrm{U}$ & -- & 15700 \\
\hline 33213-65-9 & Endosulfan II & $\mathrm{U}$ & $\mathrm{U}$ & $\mathrm{U}$ & $\mathrm{U}$ & $\mathrm{U}$ & $\mathrm{U}$ & -- & 15700 \\
\hline $510-15-6$ & Chlorobenzilate & $\mathrm{U}$ & $\mathrm{U}$ & $\mathrm{U}$ & $\mathrm{U}$ & $\mathrm{U}$ & $\mathrm{U}$ & -- & 15700 \\
\hline $51-28-5$ & 2,4-Dinitrophenol & $\mathrm{U}$ & $\mathrm{U}$ & $\mathrm{U}$ & $\mathrm{U}$ & $\mathrm{U}$ & $\mathrm{U}$ & -- & 15700 \\
\hline $534-52-1$ & 4,6-Dinitro-2-methylphenol & $\mathrm{U}$ & $140 \mathrm{~J}$ & $\mathrm{U}$ & $\mathrm{U}$ & $\mathrm{U}$ & $\mathrm{U}$ & -- & 15700 \\
\hline 53494-70-5 & Endrin Ketone & $\mathrm{U}$ & $\mathrm{U}$ & $\mathrm{U}$ & $\mathrm{U}$ & $\mathrm{U}$ & $\mathrm{U}$ & -- & 15700 \\
\hline $53-96-3$ & 2-Acetylaminofluorene & $\mathrm{U}$ & $\mathrm{U}$ & $\mathrm{U}$ & $\mathrm{U}$ & $\mathrm{U}$ & $\mathrm{U}$ & -- & 15700 \\
\hline $55-18-5$ & N-Nitrosodiethylamine & $\mathrm{U}$ & $\mathrm{U}$ & $\mathrm{U}$ & $\mathrm{U}$ & $\mathrm{U}$ & $\mathrm{U}$ & -- & 15700 \\
\hline $56-49-5$ & 3-Methylcholanthrene & $\mathrm{U}$ & $\mathrm{U}$ & $\mathrm{U}$ & $\mathrm{U}$ & $\mathrm{U}$ & $\mathrm{U}$ & -- & 15700 \\
\hline $56-55-3$ & Benzo(a)anthracene & $\mathrm{U}$ & $\mathrm{U}$ & $\mathrm{U}$ & $\mathrm{U}$ & $\mathrm{U}$ & $\mathrm{U}$ & -- & 15700 \\
\hline $57-74-9$ & Chlordane (alpha) & $\mathrm{U}$ & $\mathrm{U}$ & $\mathrm{U}$ & $\mathrm{U}$ & $\mathrm{U}$ & $\mathrm{U}$ & -- & 15700 \\
\hline $57-74-9$ & Chlordane (gamma) & $\mathrm{U}$ & $\mathrm{U}$ & $\mathrm{U}$ & $\mathrm{U}$ & $\mathrm{U}$ & $\mathrm{U}$ & -- & 15700 \\
\hline $58-90-2$ & 2,3,4,6-Tetrachlorophenol & $\mathrm{U}$ & $\mathrm{U}$ & $\mathrm{U}$ & $\mathrm{U}$ & $\mathrm{U}$ & $\mathrm{U}$ & -- & 15700 \\
\hline $59-50-7$ & 4-Chloro-3-methylphenol & $\mathrm{U}$ & $\mathrm{U}$ & $\mathrm{U}$ & $\mathrm{U}$ & $\mathrm{U}$ & $\mathrm{U}$ & $44 \%$ & 15700 \\
\hline $60-11-7$ & p-Dimethylaminoazobenzene & $\mathrm{U}$ & $\mathrm{U}$ & $\mathrm{U}$ & $\mathrm{U}$ & $\mathrm{U}$ & $\mathrm{U}$ & -- & 15700 \\
\hline $606-20-2$ & 2,6-Dinitrotoluene & $\mathrm{U}$ & $\mathrm{U}$ & $\mathrm{U}$ & $\mathrm{U}$ & $\mathrm{U}$ & $\mathrm{U}$ & -- & 15700 \\
\hline $608-93-5$ & Pentachlorobenzene & $\mathrm{U}$ & $\mathrm{U}$ & $\mathrm{U}$ & $\mathrm{U}$ & $\mathrm{U}$ & $\mathrm{U}$ & -- & 15700 \\
\hline 621-64-7 & N-Nitroso-di-n-propylamine & $\mathrm{U}$ & $\mathrm{U}$ & $\mathrm{U}$ & $\mathrm{U}$ & $\mathrm{U}$ & $\mathrm{U}$ & $79 \%$ & 15700 \\
\hline $62-44-2$ & Phenacetin & $\mathrm{U}$ & $\mathrm{U}$ & $\mathrm{U}$ & $\mathrm{U}$ & $\mathrm{U}$ & $\mathrm{U}$ & -- & 15700 \\
\hline $62-50-0$ & Ethyl methane sulfonate & $\mathrm{U}$ & $\mathrm{U}$ & $\mathrm{U}$ & $\mathrm{U}$ & $\mathrm{U}$ & $\mathrm{U}$ & -- & 15700 \\
\hline $62-53-3$ & Analine & $\mathrm{U}$ & $\mathrm{U}$ & $\mathrm{U}$ & $\mathrm{U}$ & $\mathrm{U}$ & $\mathrm{U}$ & -- & 15700 \\
\hline $66-27-3$ & Methyl methane sulfonate & $\mathrm{U}$ & $\mathrm{U}$ & $\mathrm{U}$ & $\mathrm{U}$ & $\mathrm{U}$ & $\mathrm{U}$ & -- & 15700 \\
\hline 7005-72-3 & 4-Chlorophenyl-phenylether & $\mathrm{U}$ & $\mathrm{U}$ & $\mathrm{U}$ & $\mathrm{U}$ & $\mathrm{U}$ & $\mathrm{U}$ & -- & 15700 \\
\hline 70-30-4 & Hexachlorophene & $\mathrm{U}$ & $\mathrm{U}$ & $\mathrm{U}$ & $\mathrm{U}$ & $\mathrm{U}$ & $\mathrm{U}$ & -- & 15700 \\
\hline $72-43-5$ & Methoxychlor & $\mathrm{U}$ & $\mathrm{U}$ & $\mathrm{U}$ & $\mathrm{U}$ & $\mathrm{U}$ & $\mathrm{U}$ & -- & 15700 \\
\hline
\end{tabular}




\begin{tabular}{|c|c|c|c|c|c|c|c|c|c|}
\hline & \multirow{3}{*}{$\begin{array}{l}\text { Tank ID: } \\
\text { RPL ID: }\end{array}$} & \multicolumn{3}{|c|}{ C-104 Supernatant } & \multicolumn{3}{|c|}{ C-104 Wet Centrifuged Solids } & \multirow[b]{2}{*}{$\begin{array}{l}\text { LCS } \\
\text { Rec. }\end{array}$} & \multirow{2}{*}{\begin{tabular}{|c|} 
Max \\
Slurry \\
Conc. ${ }^{(1)}$ \\
$\mu \mathrm{g} / \mathrm{Kg}$
\end{tabular}} \\
\hline & & $\begin{array}{c}00-1360 b l \\
\text { Proc Blk } \\
\mu \mathrm{g} / \mathrm{L}\end{array}$ & $\begin{array}{c}\text { 00-1360 } \\
\text { Sample } \\
\mu \mathrm{g} / \mathrm{L}\end{array}$ & \begin{tabular}{|c} 
99-1360d \\
Duplicate \\
$\mu \mathrm{g} / \mathrm{L}$
\end{tabular} & $\begin{array}{c}00-1361 b l \\
\text { Proc Blk } \\
\mu \mathrm{g} / \mathrm{Kg}\end{array}$ & $\begin{array}{c}\text { 00-1361 } \\
\text { Sample } \\
\mu \mathrm{g} / \mathrm{Kg}\end{array}$ & $\begin{array}{c}\text { 00-1361d } \\
\text { Duplicate } \\
\mu \mathrm{g} / \mathrm{Kg}\end{array}$ & & \\
\hline & & 560 & 560 & 560 & 2000 & 19000 & 20000 & & 15700 \\
\hline $72-55-9$ & 4,4'-DDE & $\mathrm{U}$ & $\mathrm{U}$ & $\mathrm{U}$ & $\mathrm{U}$ & $\mathrm{U}$ & $\mathrm{U}$ & -- & 15700 \\
\hline 76-01-7 & Pentachloroethane & $\mathrm{U}$ & $\mathrm{U}$ & $\mathrm{U}$ & $\mathrm{U}$ & $\mathrm{U}$ & $\mathrm{U}$ & -- & 15700 \\
\hline \begin{tabular}{|l|}
$77-47-4$ \\
\end{tabular} & Hexachlorocyclopentadiene & $\mathrm{U}$ & $\mathrm{U}$ & $\mathrm{U}$ & $\mathrm{U}$ & $\mathrm{U}$ & $\mathrm{U}$ & -- & 15700 \\
\hline $78-59-1$ & Isophorone & $\mathrm{U}$ & $\mathrm{U}$ & $\mathrm{U}$ & $\mathrm{U}$ & $\mathrm{U}$ & $\mathrm{U}$ & -- & 15700 \\
\hline $83-32-9$ & Acenaphthene & $\mathrm{U}$ & $\mathrm{U}$ & $\mathrm{U}$ & $\mathrm{U}$ & $\mathrm{U}$ & $\mathrm{U}$ & $74 \%$ & 15700 \\
\hline $84-66-2$ & Diethylphthalate & $\mathrm{U}$ & $\mathrm{U}$ & $\mathrm{U}$ & $\mathrm{U}$ & $\mathrm{U}$ & $\mathrm{U}$ & -- & 15700 \\
\hline $84-74-2$ & Di-n-butylphthalate & $\mathrm{U}$ & $\mathrm{U}$ & $\mathrm{U}$ & $\mathrm{U}$ & $\mathrm{U}$ & $\mathrm{U}$ & -- & 15700 \\
\hline $85-01-8$ & Phenanthrene & $\mathrm{U}$ & $\mathrm{U}$ & $\mathrm{U}$ & $\mathrm{U}$ & $\mathrm{U}$ & $\mathrm{U}$ & -- & 15700 \\
\hline $85-68-7$ & Butylbenzylphthalate & $\mathrm{U}$ & $\mathrm{U}$ & $\mathrm{U}$ & $\mathrm{U}$ & $\mathrm{U}$ & $\mathrm{U}$ & -- & 15700 \\
\hline $86-73-7$ & Fluorene & $\mathrm{U}$ & $\mathrm{U}$ & $\mathrm{U}$ & $\mathrm{U}$ & $\mathrm{U}$ & $\mathrm{U}$ & -- & 15700 \\
\hline $86-74-8$ & Carbazole & $\mathrm{U}$ & $\mathrm{U}$ & $\mathrm{U}$ & $\mathrm{U}$ & $\mathrm{U}$ & $\mathrm{U}$ & -- & 15700 \\
\hline $87-65-0$ & 2,6-Dichlorophenol & $\mathrm{U}$ & $\mathrm{U}$ & $\mathrm{U}$ & $\mathrm{U}$ & $\mathrm{U}$ & $\mathrm{U}$ & -- & 15700 \\
\hline $88-06-2$ & 2,4,6-Trichlorophenol & $\mathrm{U}$ & $\mathrm{U}$ & $\mathrm{U}$ & $\mathrm{U}$ & $\mathrm{U}$ & $\mathrm{U}$ & -- & 15700 \\
\hline $88-74-4$ & 2-Nitroaniline & $\mathrm{U}$ & $\mathrm{U}$ & $\mathrm{U}$ & $\mathrm{U}$ & $\mathrm{U}$ & $\mathrm{U}$ & -- & 15700 \\
\hline $88-75-5$ & 2-Nitrophenol & $\mathrm{U}$ & $\mathrm{U}$ & $\mathrm{U}$ & $\mathrm{U}$ & $\mathrm{U}$ & $\mathrm{U}$ & -- & 15700 \\
\hline $91-57-6$ & 2-Methylnaphthalene & $\mathrm{U}$ & $\mathrm{U}$ & $\mathrm{U}$ & $\mathrm{U}$ & $\mathrm{U}$ & $\mathrm{U}$ & -- & 15700 \\
\hline $91-58-7$ & 2-Chloronaphthalene & $\mathrm{U}$ & $\mathrm{U}$ & $\mathrm{U}$ & $\mathrm{U}$ & $\mathrm{U}$ & $\mathrm{U}$ & -- & 15700 \\
\hline $91-59-8$ & 2-Naphthylamine & $\mathrm{U}$ & $\mathrm{U}$ & $\mathrm{U}$ & $\mathrm{U}$ & $\mathrm{U}$ & $\mathrm{U}$ & -- & 15700 \\
\hline 91-94-1 & 3,3'-Dichlorobenzidine & $\mathrm{U}$ & $\mathrm{U}$ & $\mathrm{U}$ & $\mathrm{U}$ & $\mathrm{U}$ & $\mathrm{U}$ & -- & 15700 \\
\hline $924-16-3$ & N-Nitrosodi-n-butylamine & $\mathrm{U}$ & $\mathrm{U}$ & $\mathrm{U}$ & $\mathrm{U}$ & $\mathrm{U}$ & $\mathrm{U}$ & -- & 15700 \\
\hline $92-67-1$ & 4-Aminobiphenyl & $\mathrm{U}$ & $\mathrm{U}$ & $\mathrm{U}$ & $\mathrm{U}$ & $\mathrm{U}$ & $\mathrm{U}$ & -- & 15700 \\
\hline $92-87-5$ & Benzidine & $\mathrm{U}$ & $\mathrm{U}$ & $\mathrm{U}$ & $\mathrm{U}$ & $\mathrm{U}$ & $\mathrm{U}$ & -- & 15700 \\
\hline $930-55-2$ & N-Nitrosopyrolidine & $\mathrm{U}$ & $\mathrm{U}$ & $\mathrm{U}$ & $\mathrm{U}$ & $\mathrm{U}$ & $\mathrm{U}$ & -- & 15700 \\
\hline $94-59-7$ & Safrole & $\mathrm{U}$ & $\mathrm{U}$ & $\mathrm{U}$ & $\mathrm{U}$ & $\mathrm{U}$ & $\mathrm{U}$ & -- & 15700 \\
\hline $95-57-8$ & 2-Chlorophenol & $\mathrm{U}$ & $\mathrm{U}$ & $\mathrm{U}$ & $\mathrm{U}$ & $\mathrm{U}$ & $\mathrm{U}$ & $42 \%$ & 15700 \\
\hline $95-94-3$ & 1,2,4,5-Tetrachlorobenzene & $\mathrm{U}$ & $\mathrm{U}$ & $\mathrm{U}$ & $\mathrm{U}$ & $\mathrm{U}$ & $\mathrm{U}$ & -- & 15700 \\
\hline $95-95-4$ & 2,4,5-Trichlorophenol & $\mathrm{U}$ & $\mathrm{U}$ & $\mathrm{U}$ & $\mathrm{U}$ & $\mathrm{U}$ & $\mathrm{U}$ & -- & 15700 \\
\hline $959-98-8$ & Endosulfan I & $\mathrm{U}$ & $\mathrm{U}$ & $\mathrm{U}$ & $\mathrm{U}$ & $\mathrm{U}$ & $\mathrm{U}$ & -- & 15700 \\
\hline $99-09-2$ & 3-Nitroaniline & $\mathrm{U}$ & $\mathrm{U}$ & $\mathrm{U}$ & $\mathrm{U}$ & $\mathrm{U}$ & $\mathrm{U}$ & -- & 15700 \\
\hline $99-35-4$ & 1,3,5-Trinitrobenzene & $\mathrm{U}$ & $\mathrm{U}$ & $\mathrm{U}$ & $\mathrm{U}$ & $\mathrm{U}$ & $\mathrm{U}$ & -- & 15700 \\
\hline $99-55-8$ & 5-Nitro-o-toluidine & $\mathrm{U}$ & $\mathrm{U}$ & $\mathrm{U}$ & $\mathrm{U}$ & $\mathrm{U}$ & $\mathrm{U}$ & -- & 15700 \\
\hline 99-65-0 & 1,3-Dinitrobenzene & $\mathrm{U}$ & $\mathrm{U}$ & $\mathrm{U}$ & $\mathrm{U}$ & $\mathrm{U}$ & $\mathrm{U}$ & -- & 15700 \\
\hline \multicolumn{10}{|c|}{$\begin{array}{l}\text { (1) Maximum slurry } \mu \mathrm{g} / \mathrm{Kg} \text { calculated using results of Tables } 2.1 \text { (weight fractions) and } 2.2 \text { (supernatant density)- } \\
\text { See Section } 1.0 \\
\text { (2) MDL = Method detection limit based on instrument detection limit and sample quantity } \\
\text { (3) Compound added to surrogate spiking mixture (see QC Evaluation section). } \\
\text { (4) Response in calibration standard low due to suspected crystallization from solution, quantitation value should be } \\
\text { regarded as erroneously high } \\
\text { U flag = Compound not detected; Compound concentration less than the MDL } \\
\text { J flag = Compound detected, but concentration is less than the MDL } \\
\text { B flag = Compound was present in the method blank }\end{array}$} \\
\hline
\end{tabular}


Table 4.3. C-104 Supernatant SVOA Tentatively Identified Compounds

\begin{tabular}{|c|c|c|c|c|c|}
\hline \multirow[b]{3}{*}{ CAS \# } & \multirow[b]{3}{*}{ TIC } & \multirow[b]{3}{*}{$\begin{array}{c}\text { Ret. Time } \\
\text { (Min.) }\end{array}$} & \multicolumn{3}{|c|}{ C-104 Supernatant $00-1360$} \\
\hline & & & \multirow{2}{*}{$\begin{array}{c}\text { Sample } \\
\mu \mathrm{g} / \mathrm{L}\end{array}$} & \multirow{2}{*}{$\begin{array}{c}\text { Duplicate } \\
\mu \mathrm{g} / \mathrm{L}\end{array}$} & \multirow{2}{*}{$\begin{array}{c}\text { Blank } \\
\mu \mathrm{g} / \mathrm{L}\end{array}$} \\
\hline & & & & & \\
\hline $627-13-4$ & Nitric acid, propyl ester & 3.74-3.75 & $230 \mathrm{~J}$ & $370 \mathrm{~J}$ & 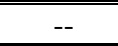 \\
\hline $2110-78-3$ & Methyl 2-hydroxy-2-isobutyrate & 4.06 & -- & -- & $200 \mathrm{NJ}$ \\
\hline $541-05-9$ & Cyclotrisiloxane, hexamethyl- & $6.43-6.44$ & $8200 \mathrm{~J}$ & $9000 \mathrm{~J}$ & -- \\
\hline $994-05-8$ & Butane, 2-methoxy-2-methyl- & $7.12-7.16$ & $3800 \mathrm{~J}$ & $5700 \mathrm{~J}$ & $6200 \mathrm{NJ}$ \\
\hline $1120-64-5$ & Oxazole, 4,5-dihydro-2-methyl- & $7.52-7.53$ & $7000 \mathrm{~J}$ & $8800 \mathrm{~J}$ & -- \\
\hline $628-73-9$ & Hexanenitrile & 8.29 & $140 \mathrm{~J}$ & -- & -- \\
\hline $109-52-4$ & Pentanoic acid & 9.50 & $680 \mathrm{~J}$ & -- & -- \\
\hline $3970-62-5$ & 3-Pentanol, 2,2-dimethyl- & 9.73 & $510 \mathrm{~J}$ & -- & -- \\
\hline $556-67-2$ & Cyclotetrasiloxane, octamethyl- & 10.85 & $3900 \mathrm{~J}$ & -- & -- \\
\hline $124-18-5$ & Decane & $11.31-11.32$ & $230 \mathrm{~J}$ & $400 \mathrm{~J}$ & -- \\
\hline $553-97-9$ & p-Benzoquinone, 2-methyl- & 11.75 & $400 \mathrm{~J}$ & -- & -- \\
\hline $142-62-1$ & Hexanoic acid & $11.91-12.11$ & $2200 \mathrm{~J}$ & $6300 \mathrm{~J}$ & -- \\
\hline $1120-21-4$ & Undecane & $13.52-13.54$ & $920 \mathrm{~J}$ & $1700 \mathrm{~J}$ & -- \\
\hline $541-02-6$ & Cyclopentasiloxane, decamethyl- & 14.13 & -- & -- & $300 \mathrm{~J}$ \\
\hline \multirow[t]{2}{*}{$111-14-8$} & Heptanoic acid & $14.07-14.22$ & $7000 \mathrm{~J}$ & $2700 \mathrm{~J}$ & -- \\
\hline & Unknown & 14.20 & $500 \mathrm{~J}$ & -- & -- \\
\hline $922-64-5$ & Propanedinitrile, methylene- & 14.22 & -- & $12000 \mathrm{~J}$ & -- \\
\hline $149-57-5$ & Hexanoic acid, 2-ethyl- & 14.43 & $160 \mathrm{~J}$ & -- & -- \\
\hline $1526-17-6$ & 2-Fluoro-6-nitrophenol & $14.58-14.60$ & $380 \mathrm{~J}$ & $750 \mathrm{~J}$ & -- \\
\hline 695-06-7 & 2(3H)-Furanone, 5-ethyldihydro- & 15.15 & $170 \mathrm{~J}$ & -- & -- \\
\hline $616-45-5$ & 2-Pyrrolidinone & 15.17 & -- & $160 \mathrm{~J}$ & -- \\
\hline $112-40-3$ & Dodecane & $15.50-15.52$ & $2000 \mathrm{~J}$ & $3300 \mathrm{~J}$ & -- \\
\hline $124-07-2$ & Octanoic Acid & $15.92-16.04$ & $9900 \mathrm{~J}$ & $14000 \mathrm{~J}$ & -- \\
\hline $99-66-1$ & Valproic Acid & 16.19 & -- & $170 \mathrm{~J}$ & -- \\
\hline $119-33-5$ & Phenol, 4-methyl-2-nitro- & $16.22-16.24$ & $380 \mathrm{~J}$ & $410 \mathrm{~J}$ & -- \\
\hline $700-38-9$ & 5-Methyl-2-nitrophenol & $16.71-16.73$ & $170 \mathrm{~J}$ & $180 \mathrm{~J}$ & -- \\
\hline $112-05-0$ & Nonanoic acid & $17.25-17.52$ & $3600 \mathrm{~J}$ & $5900 \mathrm{~J}$ & -- \\
\hline $629-50-5$ & Tridecane & $17.34-17.35$ & $2900 \mathrm{~J}$ & $3600 \mathrm{~J}$ & -- \\
\hline 101-83-7 & Cyclohexanamine, N-cyclohexyl- & 17.58 & -- & $95 \mathrm{~J}$ & -- \\
\hline $394-41-2$ & Phenol, 3-fluoro-4-nitro- & $18.29-18.30$ & $300 \mathrm{~J}$ & $250 \mathrm{~J}$ & -- \\
\hline $334-48-5$ & Decanoic acid & $18.74-18.81$ & $3100 \mathrm{~J}$ & $1000 \mathrm{~J}$ & -- \\
\hline 6175-49-1 & 2-Dodecanone & 18.96 & -- & $250 \mathrm{~J}$ & -- \\
\hline $629-59-4$ & Tetradecane & 19.01-19.03 & $820 \mathrm{~J}$ & $1200 \mathrm{~J}$ & -- \\
\hline $79-77-6$ & $\begin{array}{l}\text { 4-(2,6,6-trimethyl-1-cyclohexen-1-yl)- 3- } \\
\text { Buten-2-one }\end{array}$ & 20.12 & $270 \mathrm{~J}$ & -- & -- \\
\hline $112-37-8$ & Undecanoic acid & $20.17-20.20$ & $920 \mathrm{~J}$ & $1100 \mathrm{~J}$ & -- \\
\hline $0-00-0$ & Butyl nonanoate & 20.41 & -- & $130 \mathrm{~J}$ & -- \\
\hline $593-08-8$ & 2-Tridecanone & 20.57 & -- & $120 \mathrm{~J}$ & -- \\
\hline $629-62-9$ & Pentadecane & 20.61 & -- & $120 \mathrm{~J}$ & -- \\
\hline $143-07-7$ & Dodecanoic acid & 21.60 & $100 \mathrm{~J}$ & -- & -- \\
\hline $2581-34-2$ & Phenol, 3-methyl-4-nitro- & 22.17 & $89 \mathrm{~J}$ & -- & -- \\
\hline $497-56-3$ & Phenol, 2-methyl-3,5-dinitro- & 22.39 & -- & $230 \mathrm{~J}$ & -- \\
\hline \multicolumn{6}{|c|}{$\begin{array}{l}\text { Footnotes: } \\
\text { J flag = Estimated quantity. TIC compounds estimated using the response factor from the closest eluting } \\
\quad \text { internal standard. } \\
\text { N flag = Indicates presumptive evidence of compound based on mass spectral library search. } \\
\text { B flag = Compound was present in the method blank } \\
\text { “-----” = Compound not detected }\end{array}$} \\
\hline
\end{tabular}


Table 4.4. C-104 Wet Centrifuged Solids SVOA Tentatively Identified Compounds

\begin{tabular}{|c|c|c|c|c|c|}
\hline \multirow[b]{3}{*}{ CAS \# } & \multirow[b]{3}{*}{ TIC } & \multirow[b]{3}{*}{$\begin{array}{c}\text { Ret. Time } \\
\text { (Min.) }\end{array}$} & \multicolumn{3}{|c|}{ C-104 Wet Centrifuged Solids $00-1361$} \\
\hline & & & \multirow{2}{*}{$\begin{array}{c}\text { Sample } \\
\mu \mathrm{g} / \mathrm{Kg}\end{array}$} & \multirow{2}{*}{$\begin{array}{c}\text { Duplicate } \\
\mu \mathrm{g} / \mathrm{Kg}\end{array}$} & \multirow{2}{*}{$\begin{array}{l}\text { Blank } \\
\mu \mathrm{g} / \mathrm{Kg}\end{array}$} \\
\hline & & & & & \\
\hline $79-00-5$ & Ethane, 1,1,2-trichloro- & 5.33 & -- & -- & $5100 \mathrm{~J}$ \\
\hline $2110-78-3$ & Methyl 2-hydroxy-2-isobutyrate - & 6.201 & $38000 \mathrm{~J}$ & -- & -- \\
\hline 75-65-0 & 2-Propanol, 2-methyl- & 6.23 & -- & -- & $10000 \mathrm{~J}$ \\
\hline $625-31-0$ & 4-Penten-2-ol & $6.29-6.33$ & $58000 \mathrm{~J}$ & -- & $18000 \mathrm{~J}$ \\
\hline $507-45-9$ & Butane, 2,3-dichloro-2-methyl- & 6.674 & -- & -- & $2100 \mathrm{~J}$ \\
\hline $77-74-7$ & 3-Pentanol, 3-methyl- & 7.095 & -- & -- & $7900 \mathrm{~J}$ \\
\hline $556-67-2$ & Cyclotetrasiloxane, octamethyl- & 10.855 & -- & -- & $18000 \mathrm{~J}$ \\
\hline $124-18-5$ & Decane & 11.32-11.34 & $170000 \mathrm{~J}$ & $150000 \mathrm{~J}$ & -- \\
\hline $1120-21-4$ & Undecane & $13.58-13.62$ & $580000 \mathrm{~J}$ & $480000 \mathrm{~J}$ & -- \\
\hline 541-02-6 & Cyclopentasiloxane, decamethyl- & 14.113 & -- & -- & $1400 \mathrm{~J}$ \\
\hline $112-40-3$ & Dodecane & $15.59-15.62$ & $820000 \mathrm{~J}$ & $690000 \mathrm{~J}$ & -- \\
\hline 33083-83-9 & 5-Undecanone & $16.82-16.84$ & $52000 \mathrm{~J}$ & $44000 \mathrm{~J}$ & -- \\
\hline $2216-87-7$ & 3-Undecanone & $17.10-17.13$ & $34000 \mathrm{~J}$ & $25000 \mathrm{~J}$ & -- \\
\hline $112-12-9$ & 2-Undecanone & $17.19-17.22$ & $37000 \mathrm{~J}$ & $28000 \mathrm{~J}$ & -- \\
\hline $629-50-5$ & Tridecane & $17.42-17.46$ & $980000 \mathrm{~J}$ & $830000 \mathrm{~J}$ & -- \\
\hline $19780-10-0$ & 5-Dodecanone & $18.58-18.60$ & $67000 \mathrm{~J}$ & $64000 \mathrm{~J}$ & -- \\
\hline $1534-27-6$ & 3-Dodecanone & $18.83-18.85$ & $23000 \mathrm{~J}$ & $22000 \mathrm{~J}$ & -- \\
\hline $6175-49-1$ & 2-Dodecanone & $18.93-18.94$ & $14000 \mathrm{~J}$ & $10000 \mathrm{~J}$ & -- \\
\hline $629-59-4$ & Tetradecane & $19.05-19.07$ & $200000 \mathrm{~J}$ & $190000 \mathrm{~J}$ & -- \\
\hline $26215-90-7$ & 4-Tridecanone & 20.22-20.24 & $47000 \mathrm{~J}$ & $41000 \mathrm{~J}$ & -- \\
\hline $593-08-8$ & 2-Tridecanone & $20.54-20.56$ & $18000 \mathrm{~J}$ & $16000 \mathrm{~J}$ & -- \\
\hline 26496-20-8 & 4-Tetradecanone & 21.75-21.76 & $10000 \mathrm{~J}$ & $9500 \mathrm{~J}$ & -- \\
\hline \multicolumn{6}{|c|}{$\begin{array}{l}\text { Footnotes: } \\
\text { J flag = Estimated quantity. TIC compounds estimated using the response factor from the close } \\
\quad \text { standard } \\
\text { N flag = Indicates presumptive evidence of compound based on mass spectral library search. } \\
\text { “-----” = Compound not detected }\end{array}$} \\
\hline
\end{tabular}

\subsubsection{QC Evaluation}

Instrument tuning check criteria and 12-hour calibration clock window criteria were met (USEPA CLP 3/90 SOW) for all initial calibration and sample analysis sequences as seen in the " $5 \mathrm{~B}$ " Forms in Appendix D. The initial calibration met the criteria of USEPA SW-846 method 8270C, as seen in the “6B \& 6C" Form in the Appendix D. All four system performance compounds (SPCC) met the criteria for minimum response factor, and all 13 calibration check compounds (CCC) met the maximum relative standard deviation (RSD) criteria. Hexachlorophene had a very low response and was not used in the calibration. This compound was measured only because it was included in the commercial 8270C calibration mixture. Octachloronaphthalene was only detected in the lowest concentration standard, and had a very low response. Octachloronaphthalene is nearly insoluble in methylene chloride and requires addition of other solvents to maintain solubility. It is presumed that it precipitated out of the multi-component solution. 
The continuing calibration check standard met the criteria of USEPA SW-846 method 8270C, as seen in the "7A \& 7B" Forms in the Appendix D. All calibration check standards met the SPCC and CCC criteria. However, in comparison of the results for the continuing calibration standards to the initial calibration all compounds but with the exception of hexachlorophene, 1,3,5-nitrobenzene and octachloronaphthalene had relative percent differences below $30 \%$.

The internal standards used in this study were 1,4-dichorobenzene- $\mathrm{d}_{4}$, naphthalene- $\mathrm{d}_{8}$, acenaphthene$\mathrm{d}_{10}$, phenanthrene- $\mathrm{d}_{10}$, chrysene- $\mathrm{d}_{12}$, and perylene- $\mathrm{d}_{12}$. Each target compound was quantified using the relative response calculated from the most closely eluting internal standard. Acetophenone, nitrobenzene and nitrobenzene- $\mathrm{d}_{5}$ where quantified using the first internal standard. An additional internal standard, pyridine- $\mathrm{d}_{5}$, added to each sample, spike, blank and calibration standard to quantify the earliest eluting peaks. The internal standard area criteria of $-50 \%$ and $+100 \%$ were met for all C104 supernatant samples, matrix spikes, and process blanks. The C-104 solids samples, matrix spike, process blank and LCS met the internal standard area criteria. Internal standard area data are found on the "8B \& 8C" Forms in Appendix D.

The surrogate compounds used were 2-fluorophenol, phenol- $\mathrm{d}_{5}$, nitrobenzene- $\mathrm{d}_{5}$, 2-fluorobiphenyl, 2,4,6-tribromophenol, and terphenyl- $\mathrm{d}_{14}$. A mixture of project specific analytes containing 2-methyl phenol, 3-methyl phenol (co-elutes with 4-methyl phenol and is reported as 4-methyl phenol in summary tables and forms), acetophenone, tributyl phosphate, pyridine, 1,1'-biphenyl, 1,4dinitrobenzene, 2,6-bis(tert-butyl)-4-metyl phenol (butylated hydroxytoluene or BHT), octachloronaphthalene, pentachloronitrobenzene, 2-sec-butyl-4,6-dinitrotoluene (Dinoseb), 1-chloro4-nitrobenzene, and N,N-diphenylamine was inadvertently added to the surrogate spiking solution. Since there was insufficient C-104 material available in the laboratory to perform another extraction, the decision was made to report the data set.

Evaluation of surrogate recoveries are somewhat difficult in that performance based recovery limits have not been established for this type of sample matrix. Contract Laboratory Program (CLP) limits for low-level soil samples were used as a guide and are included on the " $2 \mathrm{C} \& 2 \mathrm{D}$ " Forms in Appendix D.

All phenolic surrogates were poorly recovered from all of the C-104 supernatant samples. It is believed this is due to the reaction of these compounds with the sample matrix. One possible reaction of these compounds is the reaction nitrous acid to form nitration products. Nitrous acid is a relatively weak acid, and some was likely formed when the $\mathrm{pH}$ of the samples was adjusted to 6.4 with the addition of phosphoric acid. Nitration products of 2-fluorophenol and 2-chlorophenol- $\mathrm{d}_{4}$ were identified in the C-104 supernatant samples TIC data (Table 4.4). The base neutral surrogate compounds all have acceptable recoveries. The C-104 solids samples were not concentrated to a final volume of $1 \mathrm{~mL}$ due to foaming problems with the extract during the concentration step. The extracts were concentrated to $10 \mathrm{~mL}$, making measurement of the surrogates difficult. However, the recoveries of the phenolic surrogates from the C-104 solids were much greater than for the supernatant. The tribromophenol recoveries were consistently low for the samples and matrix spikes. It is believed this is due to the presence of nitrite in the solids. The surrogate which were outside the QC limits are flagged with the "D" flag (for dilution) and not counted in the "total out" column in the "2C \& 2D” Forms in Appendix D.

Matrix spike recovery data are found on a summary page in Appendix D. The CLP “3C \& 3D" Forms could not successfully be produced using the Thru-Put system software. Each attempt resulted in program termination with an "Illegal Operation" error. In lieu of the CLP “3C \& 3D" Forms, the individual matrix recovery sheets for the MS and MSD are included in Appendix D. The sheets show 
the total amount of spike compounds added to the matrix spike and duplicate and include the contribution from those compounds added to the surrogate spiking solution.

The phenolic matrix spike compounds exhibited low, but acceptable, recovery in both the C-104 supernatant matrix spikes samples. In order to conserve sample and provide the lowest possible detection limit in the sample results, the matrix spike sample used approximately half the quantity of C-104 tank material as was used for the sample and sample duplicate. N,N-diphenylamine and pentachlorobenzene were not recovered in either the matrix spike or matrix spike duplicate.

Octachloronathlene values are measured very high relative to the calibration standard where most of it had precipitated from solution. Its actual response was low when compared with the total peak size for the other spike compounds. The C-104 solids matrix spike data exhibit a greater number of spike failures, but since these sample are ten-fold more dilute with respect to their associated process blank, this is not unexpected. However, performance based recovery limits for these spike compounds need to be established to access these spike recoveries.

$\mathrm{N}$-nitrosodimethylamine is reported in the C-104 supernatant data. The C-104 supernatant and solids samples contain large quantities of nitrite, $\sim 3 \%$ and $\sim 1 \%$, respectively. Adjustment of the sample $\mathrm{pH}$ to 6.4 with phosphoric acid in the second part of the extraction procedure was performed in order to protonate phenolic compounds so they were extractable in the solvent. As discussed above, this $\mathrm{pH}$ adjustment can produce some nitrous acid. Secondary amines, both aliphatic and aromatic, react with nitrous acid to produce $\mathrm{N}$-nitrosoamines:

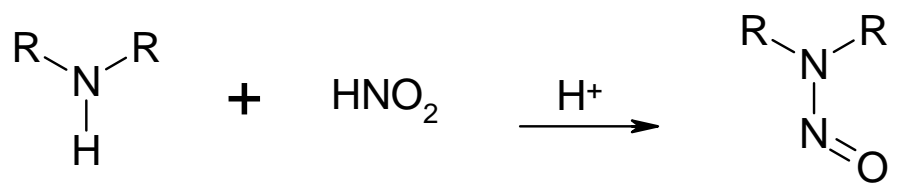

Primary amines react with $\mathrm{HNO}_{2}$ to form diazonium salts, however these tend to be unstable and produce alkenes, alcohols and nitrogen gas. It is not entirely clear as how to interpret the presence of $\mathrm{N}$-nitroso- compounds in the samples; it is conceivable they could be present in the native tank material. Further investigation into N-nitroso- compounds in tank samples that have lesser quantities of solubilized aluminum may be useful to answer the question of artifact formation.

There is evidence that nitrosation reactions can occur in slightly alkaline buffered systems (Challis, 1994). Alkaline $\mathrm{N}_{2} \mathrm{O}_{4}$ can also nitrosate secondary amines (Camaioni, 1997), and in situations where the formed nitrosoamines can be protected by partitioning into an organic solvent phase, it is conceivable that nitrosoamines can be formed and stabilized.

\subsubsection{Other Observations (or Deviations/Concerns/Issues)}

Test Plan BNFL-TP-29953-80 specified a 32-component SVOA matrix spike. Several of these compounds were not included in the matrix spiking solution for various reasons. A commercial source of the various isomers of pentachloronaphthalene, hexachloronaphthalene, and heptachloronaphthalene could not be found, however octachloronaphthalene was included in the spiking solution. Equal amounts of 2-, 3-, and 4-methylphenol were used to represent cresol [CAS 1319-77-3]. Some difficulties were encountered in preparing the multi-component spiking solution. The solvent initially used to prepare the spiking solution was methanol, which is completely miscible with the aqueous sample matrix. Unfortunately, several of the spike compounds have limited solubility or are insoluble in methanol. Other solvents were added, and solvent "cocktail” consisting of methanol, methylene chloride, diethyl ether, and acetone was used to dissolve the various 
compounds. After the addition of octachloronaphthalene, pentachloronitrobenzene and dinoseb, crystallization occurred. The relative amounts of the various solvents used were adjusted in order to get the crystals back into solution. It appears that the calibration solution had very low or no response for these compounds due to precipitation or recrystallization from the solution. A decision was made to limit the number of components in this spiking solution in order to avoid further problems with recrystallization from the solution. The samples were spiked with 16 of the analytes specified in the test plan, plus an additional seven that were part of the commercially available acid and base/neutral matrix spiking solutions.

Due to the inadvertent addition of one of the calibration mixtures to the surrogate spiking solution, the sample results for compounds 2-methyl phenol, 3-methyl phenol (co-elutes with 4-methyl phenol and is reported as 4-methyl phenol in summary tables and forms), acetophenone, tributyl phosphate, pyridine, 1,1'-biphenyl, 1,4-dinitrobenzene, 2,6-bis(tert-butyl)-4-metyl phenol (butylated hydroxytoluene or BHT), octachloronaphthalene, pentachloronitrobenzene, 2-sec-butyl-4,6dinitrotoluene (Dinoseb), 1-chloro-4-nitrobenzene, and N,N-diphenylamine should be treated as having a higher quantitation limit, equal to the spiking amount.

SVOA results for tributyl phosphate in the C-104 solids were not corrected for the small relative quantity of tributyl phosphate added to the surrogate spiking solution. The C-104 solids sample extracts were ten-fold more dilute than the associated processing blank, resulting in a final spike added concentration below the minimum quantitation limit.

Table 4.5. Target SVOA Minimum Reportable Quantities

\begin{tabular}{||l|l|c|c||}
\hline CAS \# & SVOA Compounds & $\begin{array}{c}\text { Solids Target } \\
\mathbf{M R Q}^{(\mathbf{1})} \\
\mathbf{\mu g} / \mathbf{K g}\end{array}$ & $\begin{array}{c}\text { Supernatant Target MRQ } \\
\text { (Density = 1.161 g/mL) } \\
\boldsymbol{\mu g} / \mathbf{L}\end{array}$ \\
\hline \hline $100-25-4$ & $1,4-D i n i t r o b e n z e n e$ & 800 & 930 \\
\hline $108-95-2$ & Phenol & 2100 & 2440 \\
\hline $110-86-1$ & Pyridine & 5300 & 6150 \\
\hline $118-74-1$ & Hexachlorobenzene & 3300 & 3830 \\
\hline $122-39-4$ & N,N-Diphenylamine & 4300 & 4990 \\
\hline $50-32-8$ & Benzo(a)pyrene & 1100 & 1280 \\
\hline $53-70-3$ & Dibenz[a,h]anthracene & 2700 & 3130 \\
\hline $62-75-9$ & N-nitrosodimethylamine & 800 & 930 \\
\hline $82-68-8$ & Pentachloronitrobenzene (PCNB) & 1600 & 1860 \\
\hline $87-68-3$ & Hexachlorobutadiene & 1900 & 2210 \\
\hline $95-50-1$ & 1,2-Dichlorobenzene & 2000 & 2320 \\
\hline $98-86-2$ & Acetophenone & 3200 & 3720 \\
\hline $98-95-3$ & Nitrobenzene & 4700 & 5460 \\
\hline \hline
\end{tabular}

(1) MRQ = Minimum Reportable Quantity. Values provided through BNFL private communication from L. Bostic (BNFL) to G. Klinger (Battelle). No MRQ target provided in communication for other target compounds. 


\subsection{Polychlorinated Biphenyls/Pesticides Analysis}

\subsection{Introduction}

For the PCB and pesticide analysis, the supernatants and solids samples were prepared and extracted in the SAL by the procedure outlined in Test Plan BNFL-29953-080, Rev. 1: Organic Extraction of C-104 Samples and Sub-sampling for VOA, Headspace, and Anions (see Appendix B). Following extraction, the resulting methylene chloride or methylene chloride/acetone residues were transferred from the SAL under CoC to the 329 laboratory. The residues were then exchanged into hexane and concentrated to $2 \mathrm{~mL}$. Following residue cleanup, analysis was performed for the PCB/pesticides by gas chromatography/electron capture detection (GC/ECD). Mass spectrometry was used for confirmation of PCBs.

\subsection{Sample Preparation}

Cleanup of the 2-mL extract residue was performed prior to GC/ECD analysis. For the pesticide analysis, additional cleanup was performed using cartridge columns. These were typically columns employing silica gel, alumina, or Florisil. In this case, Florisil (SW-846 Method 3620) cleanups were used.

Florisil cleanup was selected because of the ease of use and removal of potential interferences. Batch to batch variation in the composition of the Florisil or overloading the column may cause a change in the distribution patterns of the organochlorine pesticides. The lot number of cartridges used for this cleanup was evaluated for recovery of pesticides and PCBs and removal of unwanted polar materials before processing samples. The resulting Florisil cleaned residues were again concentrated to $2 \mathrm{~mL}$ using a micro-Snyder, Kuderna-Danish (K-D) apparatus.

After analysis for pesticides, the remaining residues were treated with concentrated sulfuric acid in an effort to improve the detection of PCBs by removing additional interfering contaminants. The remaining hexane residues were once again analyzed, however, only for PCBs.

Laboratory Control Samples (LCS) were prepared in a manner identical to the samples. They were prepared in fume hoods rather than the hot cells. Both solid and liquid LCS samples were essentially blank spikes. The solid matrix consisted of granular sodium sulfate, which was used as a drying agent in the sample preparation. The liquid matrix was blank water.

\subsection{Instrumentation}

The instrumentation used for the analysis of pesticides and PCBs consisted of a gas chromatograph equipped with two electron capture detectors (ECD). The analytical instrumentation is identified in Table 5.1. Both of the detectors were operated at $320^{\circ} \mathrm{C}$. Injections were made on-column onto a 10 -m fused silica retention gap, which was split between two analytical columns: a) $0.32 \mathrm{~mm}$ x $30 \mathrm{~m}$ CLP I (0.50 $\mu \mathrm{m}$ phase, Restek Corp.) and b) $0.32 \mathrm{~mm}$ x $30 \mathrm{~m}$ CLP II (0.25 $\mu \mathrm{m}$ film thickness, Restek Corp.). 
Table 5.1. PCB/Pesticides Analysis Instrumentation

\begin{tabular}{||c|c|c|c||}
\hline System/Instrument & Manufacturer & Model Number & M\&TE $^{\text {(1) }}$ Number \\
\hline \hline Gas Chromatograph & Hewlett-Packard & 5890 & WD 11127 \\
\hline
\end{tabular}

(1) Measuring and Test Equipment

The instrumentation used for confirmation was the same gas chromatograph/high-resolution mass spectrometer (GC/HRMS) used for the dioxins analysis (see Section 6). The mass spectrometer data was obtained at a resolution of 1000 .

\subsection{Analysis Results}

Pesticide and PCB results are presented in Table 5.2. GC/ECD analysis of the residue from the solid samples resulted in quite complex chromatograms. Although the presence of Aroclors was evident, substantial degradation of the expected response pattern was observed. The presence and approximate quantity of PCBs in the solid sample was confirmed using mass spectrometry. The concentration of PCB in the supernatant was not adequate for confirmation by mass spectrometry.

The GC/ECD chromatograms exhibited elution of compounds beyond the retention time of DCB in a pattern, which suggests the presence of polychlorinated terphenyls. 
Table 5.2. PCB/Pesticides Results

\begin{tabular}{|c|c|c|c|c|c|c|c|c|c|}
\hline \multirow[b]{3}{*}{ CAS \# } & \multirow{3}{*}{$\begin{array}{r}\text { Tank Material } \\
\text { Sample ID } \\
\text { Units }\end{array}$} & \multicolumn{4}{|c|}{ C104 Supernatant } & \multicolumn{4}{|c|}{ C104 Wet Centrifuged Solids } \\
\hline & & \multirow{2}{*}{\begin{tabular}{|l|}
$\mathrm{MDL}$ \\
$\mu \mathrm{g} / \mathrm{L}$
\end{tabular}} & $\begin{array}{c}00-1360 \\
\text { Proc. Blk } \\
\end{array}$ & $\begin{array}{c}00-1360 \\
\text { Sample } \\
\end{array}$ & $\begin{array}{c}00-1360 \\
\text { Duplicate }\end{array}$ & \multirow{2}{*}{$\begin{array}{l}\text { MDL } \\
\mu \mathrm{g} / \mathrm{Kg}\end{array}$} & \begin{tabular}{|c|}
$00-1361$ \\
Proc. Blk
\end{tabular} & \begin{tabular}{|c|}
$00-1361$ \\
Sample \\
\end{tabular} & \begin{tabular}{|c|c|}
$00-1361$ \\
Duplicate
\end{tabular} \\
\hline & & & $\mu \mathrm{g} / \mathrm{L}$ & $\mu \mathrm{g} / \mathrm{L}$ & $\mu \mathrm{g} / \mathrm{L}$ & & $\mu \mathrm{g} / \mathrm{Kg}$ & $\mu \mathrm{g} / \mathrm{Kg}$ & $\mu \mathrm{g} / \mathrm{Kg}$ \\
\hline \multicolumn{10}{|c|}{ BNFL Pesticide Analyte List } \\
\hline $309-00-2$ & Aldrin & 1.0 & $\mathrm{U}$ & $\mathrm{U}$ & $\mathrm{U}$ & 2.0 & $\mathrm{U}$ & $\mathrm{U}$ & $\mathrm{U}$ \\
\hline $319-84-6$ & Alpha-BHC & 1.0 & $\bar{U}$ & $\mathrm{U}$ & 1.4 & 2.0 & $\mathrm{U}$ & $\bar{U}$ & 5.5 \\
\hline $319-85-7$ & Beta-BHC & 1.0 & $\bar{U}$ & 3.4 & $\mathrm{U}$ & 2.0 & $\mathrm{U}$ & $\bar{U}$ & $\mathrm{U}$ \\
\hline $465-73-6$ & Isodrin & 2.0 & $\mathrm{U}$ & $\mathrm{U}$ & U & 4.0 & $\mathrm{U}$ & U & U \\
\hline $50-29-3$ & 4,4'-DDT & 2.0 & $\mathrm{U}$ & $\mathrm{U}$ & $\mathrm{U}$ & 4.0 & $\mathrm{U}$ & $\mathrm{U}$ & $\mathrm{U}$ \\
\hline 58-89-9 & Gamma-BHC & 1.0 & $\mathrm{U}$ & $\mathrm{U}$ & $\mathrm{U}$ & 2.0 & $\mathrm{U}$ & 8.2 & 17.6 \\
\hline $60-57-1$ & Dieldrin & 2.0 & $\mathrm{U}$ & $\mathrm{U}$ & $\mathrm{U}$ & 4.0 & $\mathrm{U}$ & $\mathrm{U}$ & $\mathrm{U}$ \\
\hline $72-20-8$ & Endrin & 2.0 & $\mathrm{U}$ & $\mathrm{U}$ & $\mathrm{U}$ & 4.0 & $\bar{U}$ & $\bar{U}$ & $\mathrm{U}$ \\
\hline 72-54-8 & 4,4 '-DDD & 2.0 & $\mathrm{U}$ & $\bar{U}$ & $\mathrm{U}$ & 4.0 & $\bar{U}$ & $\bar{U}$ & $\mathrm{U}$ \\
\hline $76-44-8$ & Heptachlor & 1.0 & $\bar{U}$ & $\bar{U}$ & $\mathrm{U}$ & 2.0 & $\mathrm{U}$ & $\bar{U}$ & $\mathrm{U}$ \\
\hline $8001-35-2$ & Toxaphene & 10 & $\mathrm{U}$ & $\mathrm{U}$ & $\mathrm{U}$ & 20 & $\mathrm{U}$ & $\mathrm{U}$ & $\mathrm{U}$ \\
\hline \multicolumn{10}{|c|}{ SW-846 8081A Pesticide Analyte List } \\
\hline $1024-57-3$ & Heptachlor Epoxide & 1.0 & $\mathrm{U}$ & $\mathrm{U}$ & 1.6 & 2.0 & $\mathrm{U}$ & 2.7 & $\mathrm{U}$ \\
\hline 1031-07-8 & Endosulfan Sulfate & 2.0 & $\bar{U}$ & $\bar{U}$ & $\mathrm{U}$ & 4.0 & $\mathrm{U}$ & $\mathrm{U}$ & $\mathrm{U}$ \\
\hline $319-86-8$ & delta-BHC & 1.0 & $\bar{U}$ & $\bar{U}$ & $\mathrm{U}$ & 2.0 & $\mathrm{U}$ & 6.4 & 7.2 \\
\hline 33213-65-9 & Endosulfan II & 2.0 & $\bar{U}$ & $\bar{U}$ & $\bar{U}$ & 4.0 & $\bar{U}$ & $\mathrm{U}$ & $\bar{U}$ \\
\hline 5103-74-2 & gamma-Chlordane & 1.0 & $\mathrm{U}$ & $\mathrm{U}$ & $\mathrm{U}$ & 2.0 & $\mathrm{U}$ & $\mathrm{U}$ & $\mathrm{U}$ \\
\hline 5103-71-9 & alpha-Chlordane & 1.0 & $\mathrm{U}$ & $\mathrm{U}$ & $\mathrm{U}$ & 2.0 & $\mathrm{U}$ & $\mathrm{U}$ & 2.2 \\
\hline 53494-70-5 & Endrin Ketone & 2.0 & $\mathrm{U}$ & $\mathrm{U}$ & $\mathrm{U}$ & 4.0 & $\mathrm{U}$ & $\mathrm{U}$ & $\mathrm{U}$ \\
\hline $72-43-5$ & Methoxychlor & 10 & $\mathrm{U}$ & $\mathrm{U}$ & $\mathrm{U}$ & 20 & $\mathrm{U}$ & $\mathrm{U}$ & $\mathrm{U}$ \\
\hline $72-55-9$ & 4,4'-DDE & 2.0 & $\mathrm{U}$ & $\mathrm{U}$ & $\mathrm{U}$ & 4.0 & $\mathrm{U}$ & 5.6 & $\mathrm{U}$ \\
\hline 7421-93-4 & Endrin Aldehyde & 2.0 & $\mathrm{U}$ & $\mathrm{U}$ & $\mathrm{U}$ & 4.0 & $\mathrm{U}$ & 4.3 & $\mathrm{U}$ \\
\hline 959-98-8 & Endosulfan I & 1.0 & $\mathrm{U}$ & $\mathrm{U}$ & $\mathrm{U}$ & 2.0 & $\mathrm{U}$ & $\mathrm{U}$ & $\mathrm{U}$ \\
\hline \multicolumn{10}{|c|}{ BNFL Polychlorinated Biphenyl Analyte List } \\
\hline \begin{tabular}{|l|}
$12674-11-2$ \\
$53469-21-9$
\end{tabular} & Aroclor 1016/1242 & 2.0 & $\mathrm{U}$ & 3.8 & 4.9 & 4.0 & $\mathrm{U}$ & 121 & 154 \\
\hline $11104-28-2$ & Aroclor 1221 & 2.0 & $\mathrm{U}$ & $\mathrm{U}$ & $\mathrm{U}$ & 4.0 & $\mathrm{U}$ & $\mathrm{U}$ & $\mathrm{U}$ \\
\hline 11141-16-5 & Aroclor 1232 & 2.0 & $\mathrm{U}$ & $\mathrm{U}$ & $\mathrm{U}$ & 4.0 & $\mathrm{U}$ & $\mathrm{U}$ & $\mathrm{U}$ \\
\hline 12672-29-6 & Aroclor 1248 & 2.0 & $\mathrm{U}$ & 4.3 & 5.3 & 4.0 & $\mathrm{U}$ & 278 & 202 \\
\hline 11097-69-1 & Aroclor 1254 & 2.0 & $\mathrm{U}$ & 1.8 & 2.3 & 4.0 & $\mathrm{U}$ & 72.8 & 80.2 \\
\hline \begin{tabular}{|l|}
$11096-82-5$ \\
$37324-23-5$
\end{tabular} & Aroclor 1260/1262 & 2.0 & $\mathrm{U}$ & $\mathrm{U}$ & $\mathrm{U}$ & 4.0 & $\mathrm{U}$ & 37.8 & 40.3 \\
\hline \multirow[t]{5}{*}{$11100-14-4$} & Aroclor 1268 & 2.0 & $\mathrm{U}$ & $\mathrm{U}$ & $\mathrm{U}$ & 4.0 & $\mathrm{U}$ & $\mathrm{U}$ & $\mathrm{U}$ \\
\hline & Total PCB & 14 & $\mathrm{U}$ & 17.9 & 20.6 & 24 & $\mathrm{U}$ & $522^{*}$ & $488^{*}$ \\
\hline & & & \% Recov. & \% Recov. & \% Recov. & & \% Recov. & $\%$ Recov. & \% Recov. \\
\hline & TCX (surrogate) & & 34.3 & 74.8 & 78.5 & & 5.3 & \begin{tabular}{|l|}
32.7 \\
\end{tabular} & 41.1 \\
\hline & DCB (surrogate) & & 74.4 & 71.9 & 72.7 & & 57.3 & 50.8 & 63.8 \\
\hline
\end{tabular}

$\mathrm{U}=$ Not detected; results less than MDL

* confirmed by mass spectrometry 
The pesticide results were obtained from residues that had undergone only the Florisil cleanup. The PCB results were obtained after an additional cleanup was performed using concentrated sulfuric acid.

As seen in Table 5.3, the BNFL target MRQs were met for both the wet centrifuged solids and supernatant (after adjusting for density).

Table 5.3. Target PCB/Pesticides Minimum Reportable Quantities

\begin{tabular}{||l|l|c|c||}
\hline CAS \# & Compound & $\begin{array}{c}\text { Solids Target } \\
\mathbf{M R Q}^{\mathbf{( 1 )}} \\
\mathbf{\mu g} / \mathbf{K g}\end{array}$ & $\begin{array}{c}\text { Supernatant Target } \\
\mathbf{M R Q}^{(\mathbf{2})} \\
\mathbf{\mu g} / \mathbf{L}\end{array}$ \\
\hline \hline All & $\begin{array}{l}\text { Polychlorinated } \\
\text { Biphenyls }\end{array}$ & 3300 & 3830 \\
\hline $309-00-2$ & Aldrin & 22 & 26 \\
\hline $319-84-6$ & Alpha-BHC & 22 & 26 \\
\hline $319-85-7$ & Beta-BHC & 22 & 26 \\
\hline $465-73-6$ & Isodrin & 22 & 26 \\
\hline $50-29-3$ & $4,4^{\prime}-$ DDT & ---- & --- \\
\hline $58-89-9$ & Gamma-BHC & ---- & 50 \\
\hline $60-57-1$ & Dieldrin & 43 & 50 \\
\hline $72-20-8$ & Endrin & 43 & ---- \\
\hline $72-54-8$ & $4,4^{\prime}-$ DDD & ---- & 26 \\
\hline $76-44-8$ & Heptachlor & 22 & 1050 \\
\hline $8001-35-2$ & Toxaphene & 900 & \\
\hline
\end{tabular}

(1) MRQ = Minimum Reportable Quantity as provided by BNFL

“-----" = No MRQ target provided.

(2) Density $=1.161 \mathrm{~g} / \mathrm{mL}$

\subsection{QC Evaluation}

Surrogate Recoveries:

The surrogate results for the pesticide spike samples were obtained from residues that had undergone only the Florisil cleanup. The sample surrogate results were obtained after an additional cleanup was performed using concentrated sulfuric acid. Therefore, the surrogate recoveries presented in Table 5.2 are from the PCB analysis. These are more conservative surrogate results since they were obtained from residues, which have undergone the additional handling of both cleanup procedures.

Specifically, the sample residues had been concentrated twice followed by an acid cleanup. Note that the pesticide spike samples which have been concentrated only once have better surrogate recoveries. The notably low TCX surrogate recovery for the solids blank is likely due to over heating during one or both of the concentration steps. The volatility of TCX, particularly in blank samples, make it susceptible to loss during concentration. 
Spike Recoveries:

Duplicate samples of both the supernatant and solids were spiked separately for each of the pesticides (Table 5.4) and for PCBs (Table 5.5). Because limited sample was available, the quantity of sample spiked was approximately half of that used for unspiked sample analysis. Laboratory control samples (LCS) consisted of PCB spiked blank water or drying agent (granulated sodium sulfate) for the solids extractions. The LCS results are presented in Table 5.5.

An unexpectedly high level of Aroclor 1254 was found in the supernatant pesticide spike sample. Correspondingly, there was a noticeably low recovery of Aroclor 1254 in the PCB spike duplicate sample. It was assumed that some inadvertent intermixing occurred during one of the sample extraction processes. The reported PCB spike recovery for sample 00-1360 is from the addition of the two results. Spike results are summarized in Tables 5.4 and 5.5 for pesticides and PCBs respectively. Concentration values are listed in the tables in parentheses following the \% recovery numbers.

Table 5.4. C104 - Pesticide Spike Recoveries

\begin{tabular}{|c|c|c|c|c|c|}
\hline \multirow[b]{5}{*}{ CAS \# } & \multirow{2}{*}{$\begin{array}{r}\text { Tank Material } \\
\text { Sample ID }\end{array}$} & \multicolumn{2}{|c|}{ C104 Supernatant } & \multirow{2}{*}{\multicolumn{2}{|c|}{$\begin{array}{c}\text { C104 Wet Centrifuged Solids } \\
00-1361\end{array}$}} \\
\hline & & & & & \\
\hline & \multirow{3}{*}{$\begin{array}{l}\text { Units } \\
\text { MDL }\end{array}$} & MS & MSD & MS & MSD \\
\hline & & $\% \operatorname{Rec}(\mu \mathrm{g} / \mathrm{L})$ & \%Rec $(\mu \mathrm{g} / \mathrm{L})$ & \%Rec ( $\mu \mathrm{g} / \mathrm{Kg})$ & \%Rec $(\mu \mathrm{g} / \mathrm{Kg})$ \\
\hline & & $2-4$ & $2-4$ & $4-8$ & $4-8$ \\
\hline $309-00-2$ & Aldrin & $102(18.4)$ & $92.8(17.5)$ & $141(113)$ & $138(115)$ \\
\hline $50-29-3$ & 4,4'-DDT & $106(38.4)$ & $99.1(37.4)$ & $87.8(140)$ & 74.7 (125) \\
\hline 58-89-9 & Gamma-BHC & $5.2(0.93)$ & $3.9(0.73)$ & $43.9(48.0)$ & $32.8(40.3)$ \\
\hline $60-57-1$ & Dieldrin & $13.0(4.7)$ & $8.2(3.1)$ & $141(225)$ & $146(244)$ \\
\hline $72-20-8$ & Endrin & $16.3(5.9)$ & $10.4(3.9)$ & $171(274)$ & $159(266)$ \\
\hline \multirow[t]{4}{*}{ 76-44-8 } & Heptachlor & $113(20.4)$ & $103(19.4)$ & $147(118)$ & $121(101)$ \\
\hline & & \% Rec & \% Rec & \% Rec & \% Rec \\
\hline & TCX (surrogate) & 65.3 & 55.7 & 63.0 & 64.6 \\
\hline & DCB (surrogate) & 61.2 & 62.7 & 84.0 & 93.4 \\
\hline
\end{tabular}

Table 5.5. C104 - PCB Spike Recoveries

\begin{tabular}{|c|c|c|c|c|c|c|c|}
\hline \multirow{3}{*}{\multicolumn{2}{|c|}{\begin{tabular}{|r} 
Tank Materia \\
Sample ID
\end{tabular}}} & \multicolumn{2}{|c|}{ C104 Supernatant } & & \multicolumn{2}{|c|}{ C104 Wet Centrifuged Solids } & \multirow{3}{*}{ LCS } \\
\hline & & \multicolumn{2}{|c|}{\begin{tabular}{|c|}
$00-1360$ \\
\end{tabular}} & LCS & \multicolumn{2}{|c|}{\begin{tabular}{|c|}
$00-1361$ \\
\end{tabular}} & \\
\hline & & MS & MSD & & MS & MSD & \\
\hline & Units & $\% \operatorname{Rec}(\mu \mathrm{g} / \mathrm{L})$ & $\% \operatorname{Rec}(\mu \mathrm{g} / \mathrm{L})$ & $\% \operatorname{Rec}(\mu \mathrm{g} / \mathrm{L})$ & $\% \operatorname{Rec}(\mu \mathrm{g} / \mathrm{Kg})$ & $\% \operatorname{Rec}(\mu \mathrm{g} / \mathrm{Kg})$ & $\% \operatorname{Rec}(\mu \mathrm{g} / \mathrm{Kg})$ \\
\hline \multirow{5}{*}{$\begin{array}{l}\text { CAS \# } \\
11097-69-1\end{array}$} & $M D L$ & \begin{tabular}{|l|}
2 \\
\end{tabular} & 2 & $\begin{array}{l}0.2 \\
\end{array}$ & $\begin{array}{c}8 \\
\end{array}$ & $\begin{array}{c}8 \\
\end{array}$ & $\begin{array}{c}4 \\
\end{array}$ \\
\hline & Aroclor 1254 & $87.3(19.5)$ & $96.7(21.4)$ & $717.8(1.4)$ & $123(172)$ & $151(202)$ & $91.1(36.5)$ \\
\hline & & \% Rec & \% Rec & \% Rec & \% Rec & \% Rec & \% Rec \\
\hline & TCX (surrogate) & 73.9 & 94.6 & 76.1 & 65.5 & 71.7 & 94.2 \\
\hline & DCB (surrogate) & 89.3 & 105 & 61.8 & 87.0 & 96.7 & 72.2 \\
\hline
\end{tabular}


Chromatographic resolution and degradation of pesticide indicator analytes was affected following a number of sample residue analyses, indicating some column degradation had occurred. Reanalysis was performed on all pesticide residues. While the methods indicator compound degradation criteria were met, the observed peak broadening impacted the retention time windows to a limited extent. For both the solids and supernatant samples, some variation was observed for duplicate samples of the single component pesticide results. However, in all cases, the results were less than ten times the MDL and this is the region where the greatest error is expected to occur. None of the results exceeded the MRQ levels. In addition to the analytes of interest specified by BNFL, additional analytes normally analyzed utilizing this method have been reported.

Distinct Aroclor patterns were observed during the PCB analysis by GC/ECD. However, the congener ratios for a given Aroclor varied substantially. Also, congeners were present which could not be attributed to any particular Aroclor observed in the samples. Confirmation analysis using gas chromatography/ mass spectrometry (GC/HRMS) was performed on the C-104 solid material extract residue. The mass spectrometer was operated at a resolution of 1000 and calibrated using a standard mixture which contained ten PCB congeners. Each congener represented the ten possible PCB homologs (levels of PCB chlorination) and were used to establish chromatographic retention time windows and mass spectrometer response factors. The GC/ECD results were confirmed by the GC/HRMS. The amount found by each method was in agreement within a factor of two. Also, the GC/HRMS instrument indicated every homolog was represented in the tank sample. Since decachlorobiphenyl was added to the sample as one of the surrogate compounds, it cannot be determined if this congener was native to the original tank material.

Although the two analytical methods agreed within a factor of two, the PCB results should be considered qualitative. The congener ratio variation observed by the GC/ECD analysis demonstrated that the sample had undergone degradation or rearrangement of the PCBs. Quantitation by comparison to Aroclor standards may have substantial error associated with the result. Calibration of the GC/ECD using the congener method can be performed, however, the calibration standards must be chosen carefully so that the full chromatographic elution range and detector responses for each homolog are well represented. Existing methods do not address this issue sufficiently for adequate application to this and other highly complex samples.

In this case, the GC/HRMS calibration used only one congener to represent the entire homolog chromatographic elution and response. While the GC/HRMS data confirms the presence of PCBs, it was not intended to provide adequate quantitation based on this calibration. Further investigation is necessary to more accurately determine the quantity of PCBs present in these samples. 


\subsection{Polychlorinated Dibenzo-p-Dioxins and Dibenzofurans Analysis}

\subsection{Introduction}

For the dioxins and furans analysis, the supernatant and solid samples were prepared in the SAL by the procedure outlined in Test Plan BNFL-29953-080, Rev. 1: Organic Extraction of C-104 Samples and sub-sampling for VOA, Headspace, and Anions (see Appendix B). Following extraction, the resulting residues were transferred from the SAL under CoC to the 329 organic laboratory for analysis of dioxins and furans.

The dioxins and furans extracts were exchanged into hexane and passed through several column cleanup procedures including silica gel and alumina to remove interfering components. After column cleanup, the resulting solutions were further concentrated. Analysis was then performed using high resolution gas chromatography/low resolution mass spectrometry (HRGC/LRMS). In the event that any dioxins or furans had been detected using HRGC/LRMS, HRGC/high resolution MS would have been used for verification. However, since no dioxin or furan compounds were found, confirmation was not required and consequently only the low-resolution mode was employed. A resolution of 1000 was utilized for the initial dioxins and furans analyses.

Dioxins and furans, typically exhibit multiple isomers. Table 6.1 lists the dioxin and furan standards analyzed to establish retention time windows and used as the basis for the determination of response factors.

Table 6.1. Standard Compounds Measured Using HRGC/LRMS

\begin{tabular}{|c|c|c|}
\hline CAS \# & Dioxin Compounds & Report ID $^{(1)}$ \\
\hline 1746-01-6 & 2,3,7,8-Tetrachlorodibenzo-p-dioxin & TCDD \\
\hline 40321-76-4 & 1,2,3,7,8-Pentachlorodibenzo-p-dioxin & PeCDD \\
\hline 57653-85-7 & 1,2,3,6,7,8-Hexachlorodibenzo-p-dioxin & $\mathrm{HxCDD}$ \\
\hline $39227-28-6$ & 1,2,3,4,7,8-Hexachlorodibenzo-p-dioxin & HxCDD \\
\hline 19408-74-3 & 1,2,3,7,8,9-Hexachlorodibenzo-p-dioxin & HxCDD \\
\hline 35822-39-4 & 1,2,3,4,6,7,8-Heptachlorodibenzo-p-dioxin & HpCDD \\
\hline $3268-87-9$ & 1,2,3,4,6,7,8,9-Octachlorodibenzo-p-dioxin & OCDD \\
\hline CAS \# & Furan Compounds & Report ID $^{(1)}$ \\
\hline 51207-31-9 & 2,3,7,8-Tetrachlorodibenzofuran & TCDF \\
\hline $57117-41-6$ & 1,2,3,7,8-Pentachlorodibenzofuran & PeCDF \\
\hline 57117-31-4 & 2,3,4,7,8-Pentachlorodibenzofuran & PeCDF \\
\hline $57117-44-9$ & 1,2,3,6,7,8-Hexachlorodibenzofuran & HxCDF \\
\hline 72918-21-9 & 1,2,3,7,8,9-Hexachlorodibenzofuran & $\mathrm{HxCDF}$ \\
\hline 70648-26-9 & 1,2,3,4,7,8-Hexachlorodibenzofuran & $\mathrm{HxCDF}$ \\
\hline 60851-34-5 & 2,3,4,6,7,8-Hexachlorodibenzofuran & $\mathrm{HxCDF}$ \\
\hline $67562-39-4$ & 1,2,3,4,6,7,8-Heptachlorodibenzofuran & HpCDF \\
\hline 55673-89-7 & 1,2,3,4,7,8,9-Heptachlorodibenzofuran & HpCDF \\
\hline $39001-02-0$ & 1,2,3,4,6,7,8,9-Octachlorodibenzofuran & OCDF \\
\hline
\end{tabular}

${ }^{(1)}$ Report ID is shorthand notation for dioxins and furans for use in results tables 
The data presented in this report were obtained utilizing procedures, instrumentation, and data systems for dioxins and furans analysis of radioactive materials.

\subsection{Sample Preparation}

\subsubsection{Supernatants and Solids}

Following methylene chloride extraction of the supernatant samples and methylene chloride-acetone extraction of the solids, the extracts for dioxins and furans analysis were exchanged into hexane. The hexane residues from both the supernatant samples and the solids samples were then processed through an extensive cleanup procedure to remove potential interfering components.

The hexane residues were first washed with concentrated sulfuric acid, $20 \% \mathrm{KOH}$, and $5 \% \mathrm{NaCl}$ in a separatory funnel. The washed hexane extract was passed through a column of anhydrous sodium sulfate to remove water. The hexane extract was then applied to the top of a silica gel column and eluted with hexane. The eluate was concentrated to approximately $1 \mathrm{~mL}$ using a K-D apparatus, and added to an alumina column. The concentrated solution was then eluted with $60 \%$ methylene chloride in hexane $(\mathrm{v} / \mathrm{v})$ and collected. The resulting eluate was concentrated to approximately $1 \mathrm{~mL}$ using a K-D apparatus, and then reduced to a final volume of $200 \mu \mathrm{L}$ using nitrogen blow-down techniques for subsequent analysis using HRGC/LRMS.

\subsubsection{Laboratory Control Standard, Glassware Blank, and Silica Gel Cleanup}

For the laboratory control standard (LCS), $100 \mathrm{~mL}$ of doubly-distilled water was spiked with a pre-measured volume of spiking materials and extracted with three 25-mL portions of methylene chloride. The LCS was extracted in like manner to the supernatants (as described above in Section 6.2.1), except that the LCS was extracted in the laboratory instead of the SAL hot cells.

A glassware blank was prepared to demonstrate that that the laboratory glassware was free of interferants under the conditions of analysis. The blank was prepared by rinsing various glassware associated with sample preparation and analysis including separatory funnels, beakers, graduated cylinders, K-D flasks, glass columns, and storage vials with $50 \mathrm{~mL}$ of methylene chloride. The rinsates were transferred to a K-D flask, exchanged into hexane, and reduced in volume to approximately $2 \mathrm{~mL}$. The hexane extract was then further purified, concentrated, and analyzed as described under Section 6.2.1 above. The purpose of a glassware blank was to demonstrate that there was no contamination resulting from the glassware; therefore, the glassware blank was not put through the column cleanup (silica gel and alumina) procedure.

In order to confirm that the silica gel column chromatography material was contaminant free, approximately $500 \mathrm{~g}$ was extracted with methylene chloride-acetone. The resulting solution was concentrated to approximately $200 \mu \mathrm{L}$ and analyzed using HRGC/LRMS.

\subsubsection{Instrumentation}

The analytical instrumentation used for the analysis of dioxins and furans consisted of a gas chromatograph equipped with a $5 \mathrm{~m} \times 0.32 \mathrm{~mm}$ HP retention gap (uncoated and deactivated) column followed by an RTX-5 (60 m x $0.25 \mathrm{~mm}, 0.25 \mu \mathrm{m}$ film thickness, Restek) column. Analyses were performed using on-column injection techniques and auto sampler injections. The JEOL highresolution mass spectrometer (HRMS) system was operated in the low-resolution mass spectrometer (LRMS) mode. A description of the instrumentation is shown in Table 6.2. 
Table 6.2. Dioxins and Furans Analysis Instrumentation

\begin{tabular}{||l|l|c|c||}
\hline \hline System/Instrument & Manufacturer & Model Number & M\&TE Number $^{(\mathbf{1})}$ \\
\hline \hline GC & Hewlett-Packard & 5890 & WD11062 \\
\hline HRMS & JEOL & SX-102/SX-102 & WD11061 \\
\hline
\end{tabular}

(7) Measuring and Test Equipment

\subsection{Analysis Results}

The dioxins and furans results for C-104 are presented in Table 6.3. The CAS numbers have been omitted since there are multiple dioxin and furan isomers that are not included as standards. For example, if a peak is detected in the TCDD retention time window with a slightly different retention time than that of the standard, the exact TCDD isomer cannot be identified since it does not match the standard. Per SW-846 Method 8280 protocol, if multiple isomers are detected in the appropriate retention time window, the multiple isomers are summed to provide a single dioxin or furan result. No dioxin and furan isomers were detected in any of the samples.

Table 6.3. C-104 Dioxins and Furans Results

\begin{tabular}{|c|c|c|c|c|c|c|c|c|}
\hline \multirow{2}{*}{$\begin{array}{r}\text { Tank Material } \\
\text { Sample ID }\end{array}$} & \multicolumn{4}{|c|}{ C-104 Supernatant } & \multicolumn{4}{|c|}{ C-104 Wet Centrifuged Solids } \\
\hline & \multirow{2}{*}{$\begin{array}{l}\text { MDL } \\
\mu \mathrm{g} / \mathrm{L}\end{array}$} & $\begin{array}{l}00-01360 \\
\text { Proc Blk }\end{array}$ & $\begin{array}{c}00-01360 \\
\text { Sample }\end{array}$ & $\begin{array}{l}\text { 00-01360 } \\
\text { Duplicate }\end{array}$ & \multirow{2}{*}{$\begin{array}{c}\text { MDL } \\
\mu \mathrm{g} / \mathrm{Kg}\end{array}$} & \multirow{2}{*}{$\begin{array}{c}\text { 00-01361 } \\
\text { Proc Blk } \\
\mu g / K g\end{array}$} & \multirow{2}{*}{$\begin{array}{c}\begin{array}{c}\text { 00-01361 } \\
\text { Sample }\end{array} \\
\mu g / \mathrm{Kg} \\
\end{array}$} & \multirow{2}{*}{$\begin{array}{c}00-01361 \\
\text { Duplicate } \\
\mu \mathrm{g} / \mathrm{Kg} \\
\end{array}$} \\
\hline Units & & $\mu g / L$ & $\mu g / L$ & $\mu g / L$ & & & & \\
\hline TCDD & 0.01 & $\mathrm{U}$ & $\mathrm{U}$ & $\mathrm{U}$ & 0.04 & $\mathrm{U}$ & $\mathrm{U}$ & $\mathrm{U}$ \\
\hline TCDF & 0.01 & $\mathrm{U}$ & $\mathrm{U}$ & $\mathrm{U}$ & 0.04 & $\mathrm{U}$ & $\mathrm{U}$ & $\mathrm{U}$ \\
\hline PeCDD & 0.04 & $\mathrm{U}$ & $\mathrm{U}$ & $\mathrm{U}$ & 0.08 & $\mathrm{U}$ & $\mathrm{U}$ & $\mathrm{U}$ \\
\hline PeCDF & 0.04 & $\mathrm{U}$ & $\mathrm{U}$ & U & 0.08 & U & $\mathrm{U}$ & $\mathrm{U}$ \\
\hline HxCDD & 0.04 & $\mathrm{U}$ & $\mathrm{U}$ & $\mathrm{U}$ & 0.08 & $\mathrm{U}$ & $\mathrm{U}$ & $\mathrm{U}$ \\
\hline HxCDF & 0.04 & U & $\mathrm{U}$ & U & 0.08 & U & $\mathrm{U}$ & U \\
\hline HpCDD & 0.04 & $\mathrm{U}$ & $0.002 \mathrm{~J}$ & $\mathrm{U}$ & 0.08 & $\mathrm{U}$ & $\mathrm{U}$ & $\mathrm{U}$ \\
\hline HpCDF & 0.04 & $\mathrm{U}$ & $\mathrm{U}$ & $\mathrm{U}$ & 0.08 & $\mathrm{U}$ & $\mathrm{U}$ & $\mathrm{U}$ \\
\hline OCDD & 0.08 & U & $\mathrm{U}$ & U & 0.16 & U & $\mathrm{U}$ & U \\
\hline OCDF & 0.08 & U & $0.005 \mathrm{~J}$ & U & 0.16 & U & $\mathrm{U}$ & $\mathrm{U}$ \\
\hline
\end{tabular}

(1) Multiple isomers possible in retention time window; each isomer has unique CAS \#. Component represents sum of dioxins or furans meeting retention time window and ion abundance ratio criteria. $\mathrm{U}=$ not detected; results less than MDL

$\mathrm{J}=$ detected and quantified, but results less than MDL. Analysis met ion abundance ratio and retention time criteria.

\subsection{QC Evaluation}

The QC evaluation focuses on: a) ion abundance ratios and response factors for the standards; b) ion abundance ratios for the samples, duplicates, MSs and MSDs; and c) the spike recovery results from the analyses of the MSs for both liquids and solids.

\subsubsection{Ion Abundance Ratios and Response Factors --- Standards}

The theoretical ion abundance ratios and control limits are listed in Table 6.4. These ratios are applicable to both the LRMS and HRMS. The matrix spiking solutions contained both ${ }^{13} \mathrm{C}$-labeled 
and unlabeled standards. All samples, including MSs, were spiked with labeled internal standards. The ion ratios for both the native (unlabeled) and the labeled components must meet the criteria shown in Table 6.4. The letter designations $\mathrm{M}, \mathrm{M}+2$, and $\mathrm{M}+4$ refer to the parent ion (M) and the corresponding additional masses associated with the chlorine isotope pattern.

Table 6.4. Theoretical Ion Abundance Ratios and Control Limits

\begin{tabular}{||c|c|c|c|c||}
\hline \hline $\begin{array}{c}\text { Number of } \\
\text { Cl atoms }\end{array}$ & Ion Type & \multirow{2}{*}{$\begin{array}{c}\text { Theoretical } \\
\text { Abundance Ratio }\end{array}$} & \multicolumn{2}{|c|}{ Control Limits } \\
\cline { 4 - 5 } & $\mathrm{M} / \mathrm{M}+2$ & 0.77 & 0.65 & 0.89 \\
\hline \hline 4 & $\mathrm{M}+2 / \mathrm{M}+4$ & 1.55 & 1.32 & 1.78 \\
\hline 5 & $\mathrm{M}+2 / \mathrm{M}+4$ & 1.24 & 1.05 & 1.43 \\
\hline 6 & 1.04 & 0.88 & 1.20 \\
\hline 7 & $\mathrm{M}+2 / \mathrm{M}+4$ & 0.89 & 0.76 & 1.02 \\
\hline 8 & $\mathrm{M}+2 / \mathrm{M}+4$ & \multicolumn{3}{|l}{} \\
\hline
\end{tabular}

Appendix E contains the ion abundance ratio QC data for the native and labeled components of the standards.

The percent relative standard deviations for the average response factors are less than $15 \%$ as required by USEPA SW-846 Method 8280 (low resolution MS method), except for components:

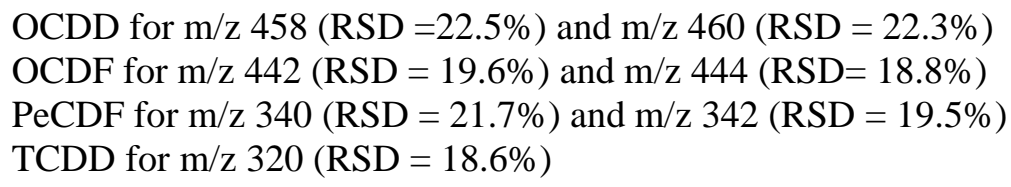

However, the percent relative standard deviation for the average response factors are required to be less than 30\% for high resolution mass spectrometry (Method 8290). The 15\% criteria has been applied to data obtained from low resolution quadrupole mass spectrometry. The data obtained in this study is from a high resolution, magnetic sector mass spectrometer operated in the low resolution mode. There may be deviations from the $15 \%$ low resolution criteria using the high resolution instrument. This is an area requiring further study. In order to verify that the data are not adversely affected, a continuous calibration verification standard was analyzed during the sample set. The concentrations were calculated based on the response factors and compared with the known concentration values. The calculated concentration vs. the known concentrations agreed very well. Based on this data, it would appear that the data and the ability to measure dioxins and furans are not affected by several components with percent relative standard deviations greater than $15 \%$.

The peak areas obtained and used in the calculations are affected by the condition of the mass spectrometry source and chromatography. This factor is discussed more thoroughly in Section 6.4.

\subsubsection{Ion Abundance Ratios - Samples, Duplicates, and Matrix Spikes}

The ion abundance ratios for both the native and labeled components for all samples, duplicates, MSs, MSDs, and process blanks are listed in Appendix E The ion abundance ratio is a major criteria for identifying dioxins and furans. If the ion abundance ratio is not within the control limits listed in Table 6.4, the component is not identified as a dioxin or furan even though the retention times may be consistent with dioxins and furans. Table 6.5 summarizes all of the ion abundance ratio data. 
Table 6.5. Acceptance Criteria Summary of Ion Abundance Ratios

\begin{tabular}{|c|c|c|c|c|c|c|c|c|c|c|c|c|c|c|c|c|c|c|c|c|c|}
\hline Sample ID & 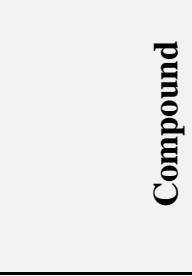 & 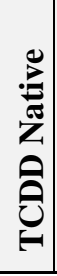 & 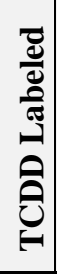 & 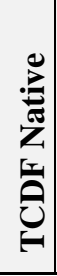 & 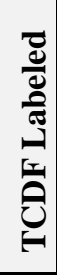 & 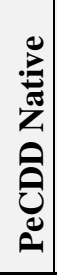 & 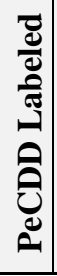 & 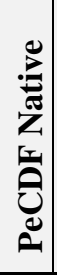 & 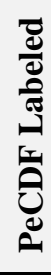 & 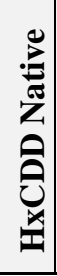 & 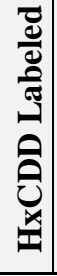 & 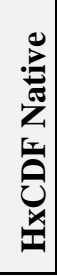 & 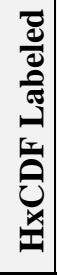 & 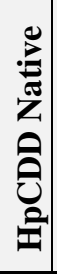 & 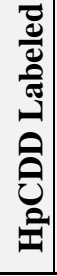 & 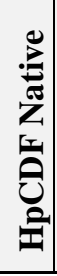 & 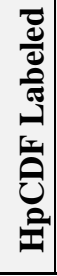 & 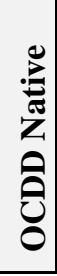 & 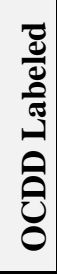 & 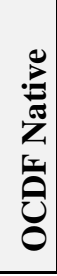 & 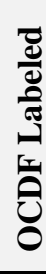 \\
\hline \multirow{5}{*}{$\begin{array}{l}\text { C-104 } \\
\text { Supernatant }\end{array}$} & Proc Blank & & $\mathrm{p}$ & & $\mathrm{p}$ & & $\mathrm{p}$ & & $\mathrm{p}$ & & $\mathrm{p}$ & & $\mathrm{p}$ & & $\mathrm{p}$ & & $\mathrm{p}$ & & $\mathrm{p}$ & & $\mathrm{p}$ \\
\hline & Sample & & $p$ & & $\mathrm{p}$ & & $\mathrm{p}$ & & $\mathrm{p}$ & & $\mathrm{p}$ & & $p$ & & $\mathrm{p}$ & & $\mathrm{p}$ & & $\mathrm{p}$ & & $\mathrm{p}$ \\
\hline & Duplicate & & $\mathrm{p}$ & & $\mathrm{p}$ & & $\mathrm{p}$ & & $\mathrm{p}$ & & $\mathrm{p}$ & & $\mathrm{p}$ & & $\mathrm{p}$ & & $\mathrm{p}$ & & $\mathrm{p}$ & & $\mathrm{p}$ \\
\hline & MS & $\mathrm{p}$ & $\mathrm{p}$ & $\mathrm{p}$ & $\mathrm{p}$ & $\mathrm{p}$ & $\mathrm{p}$ & $\mathrm{p}$ & $\mathrm{p}$ & $\mathrm{p}$ & $\mathrm{p}$ & $\mathrm{p}$ & $\mathrm{p}$ & $\mathrm{p}$ & $\mathrm{p}$ & $\mathrm{p}$ & $\mathrm{p}$ & $\mathrm{p}$ & $\mathrm{p}$ & $\mathrm{p}$ & $\mathrm{p}$ \\
\hline & MSD & p & p & $\mathrm{p}$ & p & p & $p$ & p & p & $\mathrm{p}$ & p & $\mathrm{p}$ & p & p & p & p & p & $\mathrm{p}$ & p & p & $p$ \\
\hline \multirow{5}{*}{$\begin{array}{l}\text { C-104 } \\
\text { Wet } \\
\text { Centrifuged } \\
\text { Solids }\end{array}$} & Proc Blank & & $\mathrm{p}$ & & $\mathrm{p}$ & & $\mathrm{p}$ & & $\mathrm{p}$ & & $\mathrm{p}$ & & $\mathrm{p}$ & & $\mathrm{p}$ & & $\mathrm{p}$ & & $\mathrm{P}$ & $\mathrm{p}$ & $\mathrm{p}$ \\
\hline & Sample & & $\mathrm{p}$ & & $\mathrm{p}$ & & $\mathrm{p}$ & & $\mathrm{f}$ & & $\mathrm{p}$ & & $\mathrm{p}$ & & $\mathrm{p}$ & & $\mathrm{p}$ & & $\mathrm{p}$ & $\mathrm{p}$ & $\mathrm{p}$ \\
\hline & Duplicate & & $\mathrm{p}$ & & $\mathrm{p}$ & & $\mathrm{p}$ & & $p$ & & $\mathrm{p}$ & & $\mathrm{p}$ & & $\mathrm{p}$ & & $\mathrm{p}$ & & $\mathrm{p}$ & & $\mathrm{p}$ \\
\hline & MS & $\mathrm{p}$ & $\mathrm{p}$ & $\mathrm{p}$ & $\mathrm{p}$ & $\mathrm{p}$ & $\mathrm{p}$ & $\mathrm{p}$ & $\mathrm{p}$ & $\mathrm{p}$ & $\mathrm{p}$ & $\mathrm{p}$ & $\mathrm{p}$ & $\mathrm{p}$ & $\mathrm{p}$ & $\mathrm{p}$ & $\mathrm{p}$ & $\mathrm{p}$ & $\mathrm{p}$ & $\mathrm{p}$ & $\mathrm{p}$ \\
\hline & MSD & $\mathrm{p}$ & $\mathrm{p}$ & $\mathrm{p}$ & $\mathrm{p}$ & $\mathrm{p}$ & $\mathrm{p}$ & $\mathrm{p}$ & $\mathrm{p}$ & $\mathrm{p}$ & $\mathrm{p}$ & $\mathrm{p}$ & $\mathrm{p}$ & $\mathrm{p}$ & $\mathrm{p}$ & $\mathrm{p}$ & $\mathrm{p}$ & $\mathrm{p}$ & $\mathrm{p}$ & $\mathrm{p}$ & $\mathrm{p}$ \\
\hline LCS & Standard & $\mathrm{p}$ & $\mathrm{p}$ & $\mathrm{p}$ & $\mathrm{p}$ & $\mathrm{p}$ & $\mathrm{p}$ & $\mathrm{p}$ & $\mathrm{p}$ & $\mathrm{p}$ & $\mathrm{p}$ & $\mathrm{p}$ & $\mathrm{p}$ & $\mathrm{p}$ & $\mathrm{p}$ & $\mathrm{p}$ & $\mathrm{p}$ & $\mathrm{p}$ & $\mathrm{p}$ & $\mathrm{p}$ & $\mathrm{p}$ \\
\hline
\end{tabular}

$\mathrm{p}$ = pass; peak detected at dioxins and furans retention time and ion abundance ratio met acceptance criteria from Table 6.4

$\mathrm{f}=$ fail; peak detected at dioxins/furans retention time but ion abundance ratio does not meet criteria from Table 6.4

blank = No signal or peak area detected; ion abundance ratio undefined

For C-104 supernatant and solids MS, MSD, and LCS samples, all native and labeled compounds met the ion abundance ratio acceptance criteria. For the process blanks, samples and duplicates, only one of the 110 labeled compounds analyses failed to meet the ion abundance ratio acceptance criteria; labeled PeCDF in the solids sample did not meet the ion abundance criteria. There is no simple explanation why this particular isomer did not meet the abundance ratio acceptance criteria. In previous analyses of AN-107 and AW-101, several isomers did not meet the ion abundance ratio criteria (Klinger et al., 2000).

\subsubsection{Dioxins and Furans Matrix Spike Recoveries}

The recoveries for the MSs and MSDs for C-104 supernatants and wet centrifuged solids are detailed in Table 6.6. The CAS numbers are included to identify the components in the matrix spiking solution. All ion abundance ratios for both the native and labeled components in the MSs and MSDs met the criteria listed in Table 6.4.

Most of the recoveries are in the range of $75-125 \%$. An interesting but unexplainable item is the apparent lower recovery for HxCDD compared to the other components in all samples analyzed, except the LCS. At this point, there is no reasonable explanation for this observation. 
Table 6.6. C-104 - Dioxins and Furans Spike Recoveries

\begin{tabular}{|c|c|c|c|c|c|c|}
\hline \multirow[b]{4}{*}{ CAS \# } & \multirow{4}{*}{$\begin{array}{r}\text { Tank Material } \\
\text { Sample ID } \\
\text { Units } \\
\end{array}$} & \multirow{2}{*}{\multicolumn{2}{|c|}{$\begin{array}{c}\text { C-104 Supernatant } \\
00-01360 \\
\end{array}$}} & \multirow{2}{*}{\multicolumn{2}{|c|}{$\begin{array}{c}\text { C-104 Wet Centrifuged } \\
\text { Solids } \\
00-01361 \\
\end{array}$}} & \multirow[t]{3}{*}{ LCS } \\
\hline & & & & & & \\
\hline & & MS & MSD & MS & MSD & \\
\hline & & Rec & Rec & Rec & Rec & Rec \\
\hline 1746-01-6 & TCDD & $115 \%$ & $101 \%$ & $106 \%$ & 994\% & $108 \%$ \\
\hline $51207-31-9$ & TCDF & $99 \%$ & $106 \%$ & $105 \%$ & $88 \%$ & $104 \%$ \\
\hline 40321-76-4 & PeCDD & $116 \%$ & $113 \%$ & $92 \%$ & $78 \%$ & $106 \%$ \\
\hline 57117-41-6 & PeCDF & $109 \%$ & $103 \%$ & $96 \%$ & $92 \%$ & $103 \%$ \\
\hline 57653-85-7 & HxCDD & $79 \%$ & $55 \%$ & $75 \%$ & $65 \%$ & $96 \%$ \\
\hline $57117-44-9$ & $\mathrm{HxCDF}$ & $86 \%$ & $102 \%$ & $91 \%$ & $83 \%$ & $95 \%$ \\
\hline 35822-39-4 & HpCDD & $102 \%$ & $117 \%$ & $108 \%$ & $77 \%$ & $101 \%$ \\
\hline 67562-39-4 & HpCDF & $102 \%$ & $106 \%$ & $94 \%$ & $89 \%$ & $104 \%$ \\
\hline $3268-87-9$ & OCDD & $117 \%$ & $113 \%$ & $89 \%$ & $97 \%$ & $106 \%$ \\
\hline 39001-02-0 & OCDF & $125 \%$ & $124 \%$ & $89 \%$ & $98 \%$ & $104 \%$ \\
\hline
\end{tabular}

\subsection{Other Observations (Deviations/Concerns/Issues)}

The dioxins and furans analyses were performed by LRMS. If any dioxins or furans had been detected, HRMS would have been performed for confirmation. At lower resolution, the mass spectrometer has higher sensitivity but less specificity. The resolving power of a mass spectrometer is a measure of its ability to separate two ions of any defined mass difference. Basically, for two overlapping peaks $M_{1}$ and $M_{2}$, the resolution may be defined in terms of the mass difference $\left(M_{2}-M_{1}\right)$ between them. The resolution is then defined as $\mathrm{M}_{1} /\left(\mathrm{M}_{2}-\mathrm{M}_{1}\right)$. The HRMS method requires a resolution of 10,000 . At 10,000 resolution a mass at $\mathrm{m} / \mathrm{z}$ of 300.00 is separated from a mass at $\mathrm{m} / \mathrm{z}$ of 300.03. For each group of ions, a lock mass is assigned in high resolution. The analyses were performed in low-resolution mode. In low-resolution mode the resolution was set at 1,000. At 1,000 resolution a mass at $\mathrm{m} / \mathrm{z}$ of 300.00 is distinguished from a mass at $\mathrm{m} / \mathrm{z} 300.30$.

A four-point calibration was performed rather than a five-point calibration as specified in SW-846 Method 8290. The concentration of the standards ranged from 0.5 to $200 \mu \mathrm{g} / \mathrm{L}$ for TCDD and TCDF, 5.0 to $2000 \mu \mathrm{g} / \mathrm{L}$ for OCDF and OCDD, and 2.5 to $1000 \mu \mathrm{g} / \mathrm{L}$ for all other compounds. The concentrations of solutions were made for detection using a quadruple mass spectrometer; the instrument used in these studies was a high resolution, magnetic sector mass spectrometer and was approximately 100 times more sensitive than the quadruple instrument. The values for the highest concentration standards were not used for calculating the average response factor due to the fact that the low-resolution mode was used for the analysis. In the low-resolution mode the concentration versus peak area response was not linear over the entire concentration range. The concentration versus peak area response for the highest concentration standard was outside the linear dynamic range of the instrument. For the highest concentration standard solution, the detector was saturated. This phenomenon was also observed in previous tank waste analyses (Klinger et al., 2000). For the highest concentration standard solutions, the detector was saturated.

Analyses of the glassware blank and silica gel extract showed no indication of potential interfering contaminants. 
On-column injection was used throughout the analyses. As analyses progressed, small pieces of the septum became lodged in the retention gap. After several injections, chromatographic quality was effected by the production of irregular peak shapes. The solution to this problem used at the time was to change the septum and remove a small portion of the retention gap column each time. However, typically, after only several injections, small pieces of septum were again present in the retention gap. This problem was solved after the analyses were complete by changing the inlet configuration.

The cleanup procedure used for dioxins and furans was very labor intensive and time consuming. After following the cleanup steps listed in SW-846 method, there are several places where time could be saved and the cost greatly reduced in future work. As an example, the method states that the sample must be eluted through a silica gel column, concentrated, and then eluted through an alumina column, and then concentrated prior to analysis. An alternative approach would use one column packed with both silica gel and alumina. The sample would be eluted through one column containing the two packing materials, concentrated, and analyzed. Studies would first need to be performed to insure that the recoveries were not affected. If the recoveries were comparable (through two columns vs. one), both time for cleanup would be reduced (thus improving analytical throughput and reducing turnaround time) and a large cost savings would be realized. There are other possible areas in the sample cleanup that could be combined to provide additional economies as well. 


\subsection{Organic Anions Analysis}

\subsection{Introduction}

Analyses of organic anions were performed on both the supernatant and solids from samples of tank waste material from Tank C-104 following sub-sampling in the SAL per Test Plan BNFL-29953-080 Rev. 1. The supernatant samples were passed through cation exchange resin material to reduce the radioactivity to a sufficient low level to be safely handled in the laboratory. The solid samples were leached at ambient temperature with water, filtered, and the resulting solution passed through cation exchange resin to reduce the radioactivity levels. The supernatant and solids were aliquotted and prepared in the SAL and transferred under CoC to the analytical laboratory for organic anion analysis by ion chromatography (IC).

\subsection{Sample Preparation}

Tank samples from C-104 were prepared in the SAL. For the supernatants, a 1-mL sample was accurately weighed and then passed through a column of cation exchange resin to reduce the radioactivity level. Similarly for the solids, an approximate 1-g sample was accurately weighed, leached at ambient temperature with a known volume (approximately $5 \mathrm{~mL}$ ) of distilled water for 12 hours, and then filtered. The resulting solution was then passed through a cation exchange column. The activity reduction was performed as per Test Plan BNFL-29953-014, "Activity Reduction Via Cation Exchange for Carboxylate Analysis". The treatment within the SAL resulted in an approximate 20 -fold dilution (weight/weight) into a dilute caustic matrix that is not significantly different from the caustic matrix of the original sample. An additional 90-fold dilution was performed to dilute the major inorganic ions (nitrate and nitrite) to levels that prevent overloading the capacity of the analytical column. Previous experience (Campbell, 1997; Sharma et al., 1998) has demonstrated that ion-exchange sites within the IC column apparently do not recover quickly from an overload of these inorganic species. That can result in non-uniform elution of the weakly retained analytes (e.g. acetate and formate).

Matrix spikes and MSDs were prepared in the laboratory after the MS and MSD samples were eluted through the cation exchange resin. Previous studies on samples from this tank have shown that organic material was neither introduced nor removed with the use of cation exchange resin (Campbell et al., 1998). Spiking solutions were prepared using oxalic acid and sodium formate, in deionized water. A laboratory control standard (LCS) was prepared from independent materials, and diluted to a value within the bounds of the calibration curve.

\subsection{Instrumentation}

The analytical instrumentation utilized for the analysis of low molecular weight organic acids consisted of an ion chromatograph (IC) unit equipped with a conductivity detector. A Dionex AS-11 separation column and AG-11 guard column were used at ambient temperature with a $25-\mu \mathrm{L}$ sample loop. An anion suppressor was used. The flow rate of the mobile phase was $2.0 \mathrm{~mL} / \mathrm{min}$. A description of the IC system is provided in Table 7.1. 
Table 7.1. Ion Chromatography Instrumentation

\begin{tabular}{||l|l|l|l||}
\hline \multicolumn{1}{|c|}{ System/Instrument } & \multicolumn{1}{|c|}{ Manufacturer } & \multicolumn{1}{|c||}{ Model Number } & \multicolumn{1}{c|}{ M\&TE ${ }^{\mathbf{( 1 )}}$ Number } \\
\hline \hline IC System & Dionex & 500 DX & WD 24293 \\
\hline Conductivity Detector & Dionex & CD20 & WD 24295 \\
\hline
\end{tabular}

(1) Measuring and Test Equipment

The IC gradient conditions were: (a) $0.0 \mathrm{~min} 0 \% 100 \mathrm{mM} \mathrm{NaOH}, 98.1 \%$ deionized water and 1.9\% 5 $\mathrm{mM} \mathrm{NaOH}$; (b) $6.4 \mathrm{~min} 0 \% 100 \mathrm{mM} \mathrm{NaOH}, 0 \%$ deionized water and $100 \% 5 \mathrm{mM} \mathrm{NaOH}$; and (c) $18.4 \mathrm{~min} 35 \% 100 \mathrm{mM} \mathrm{NaOH}, 0$ \% deionized water and 65\% $5 \mathrm{mM} \mathrm{NaOH}$. The mobile phase contained a gradient of deionized water and a weak solution of $\mathrm{NaOH}$.

\subsection{Analysis Result}

The results of the analysis of the C-104 supernatant and wet centrifuged solids samples are listed below in Table 7.2.

Acetate co-elutes with glycolate under typical analysis conditions and requires the use of an alternate column for separation from glycolate. Without additional separation, one can not unequivocally state whether or not the observed peak contains only acetate, only glycolate, a combination of both anions, or a possible unknown contaminant. Tank waste and solubility studies have shown that the results are dependent on tank waste type. In other words, for tanks with different fill histories, the dominant organic anions in the waste may be primarily glycolate, primarily acetate, or a combination of both anions (Sharma et al., 1998, Camaioni et al., 1998, Barney 1997, Ashby et al., 1994.)

For C-104 analyses, no acetate/glycolate peak was detected in the supernatants or solids above the MDL. In view of the fact that acetate and glycolate have similar response factors, the reported acetate MDL can be used to bound the upper acetate/glycolate concentration. Interference from fluoride makes this determination questionable and is discussed in detail in Section 7.6.

Table 7.2. IC Organic Anion Results

\begin{tabular}{|c|c|c|c|c|c|c|c|c|c|c|}
\hline \multirow[b]{3}{*}{ CAS \# } & \multirow{3}{*}{$\begin{array}{r}\text { Tank Material } \\
\text { Sample ID } \\
\text { Units }\end{array}$} & \multicolumn{4}{|c|}{ C-104 Supernatant } & \multicolumn{4}{|c|}{ C-104 Wet Centrifuged Solids } & \multirow{3}{*}{$\begin{array}{c}\text { Maximum } \\
\mu \mathrm{g} / \mathrm{g}^{(2)} \\
\text { of Slurry }\end{array}$} \\
\hline & & \multirow{2}{*}{\begin{tabular}{|c|}
$M^{(1)}$ \\
$\mu \mathrm{g} / \mathrm{mL}$
\end{tabular}} & \multirow{2}{*}{\begin{tabular}{|c|}
$\begin{array}{c}00-01360 \\
\text { Proc Blk }\end{array}$ \\
$\mu \mathrm{g} / \mathrm{mL}$ \\
\end{tabular}} & \multirow{2}{*}{$\frac{\text { Sample }}{\mu \mathrm{g} / \mathrm{mL}}$} & \multirow{2}{*}{\begin{tabular}{|c|} 
Duplicate \\
$\mu \mathrm{g} / \mathrm{mL}$ \\
\end{tabular}} & \multirow{2}{*}{$\begin{array}{c}\mathrm{MDL}^{(1)} \\
\mu \mathrm{g} / \mathrm{g}\end{array}$} & \multirow{2}{*}{\begin{tabular}{|c|}
$\begin{array}{c}00-01361 ~ p b \\
\text { Proc Blk }\end{array}$ \\
$\mu \mathrm{g} / \mathrm{g}$ \\
\end{tabular}} & \multirow{2}{*}{\begin{tabular}{|c|} 
Sample \\
$\mu \mathrm{g} / \mathrm{g}$ \\
\end{tabular}} & \multirow{2}{*}{\begin{tabular}{|c|} 
Duplicate \\
$\mu \mathrm{g} / \mathrm{g}$ \\
\end{tabular}} & \\
\hline & & & & & & & & & & \\
\hline 144-62-7 & Oxalate & 780 & $\mathrm{U}$ & 1090 & 980 & 540 & $\mathrm{U}$ & 121230 & 3300 & 1600 \\
\hline $64-18-6$ & Formate & 1020 & $\mathrm{U}$ & 2670 & 2120 & 720 & $\mathrm{U}$ & 750 & 2200 & 2300 \\
\hline $79-10-7$ & Acrylate & 780 & $\mathrm{U}$ & $\mathrm{U}$ & $\mathrm{U}$ & 540 & $\mathrm{U}$ & $\mathrm{U}$ & $\mathrm{U}$ & $U$ \\
\hline $64-19-7$ & Acetate $^{(3)}$ & 2640 & $\bar{U}$ & $\overline{\mathrm{U}}$ & $\bar{U}$ & 600 & $\bar{U}$ & $\bar{U}$ & $\bar{U}$ & $\bar{U}$ \\
\hline
\end{tabular}

(1) $\mathrm{MDL}=$ Method detection limit based on instrument detection limit and sample quantity

(2) Maximum slurry $\mu \mathrm{g} / \mathrm{g}$ calculated using results of Tables 2.1 (weight fractions) and 2.2 (supernatant density) See Section 1.0

(3) Acetate and glycolate are not resolved; results or MDL represent bounding upper concentration 


\subsection{QC Evaluation}

No organic anions of interest were detected in the blank samples. The MDLs stated in Table 7.2 are assumed to be adequate, since no MRQs were established by BNFL for the organic anions measured. The sample intended as a MS was analyzed, then spiked, and then reanalyzed. Matrix spike data were collected by adding an amount of oxalate and formate, which would double the peak area of the native analyte in the sample. Table 7.3 presents the MS and MSD recoveries and LCS recovery results for the C-104 supernatants and wet centrifuged solids. Spike recoveries for LCS , MSs, and MSDs ranged from $77 \%$ to $142 \%$; several spikes failed to meet the acceptance criteria of $75 \%$ to $125 \%$; i.e., oxalate for the C-104 solids MSD and formate for the C-104 solids MS and MSD.

Table 7.3. IC Organic Anions Matrix Spike Recoveries

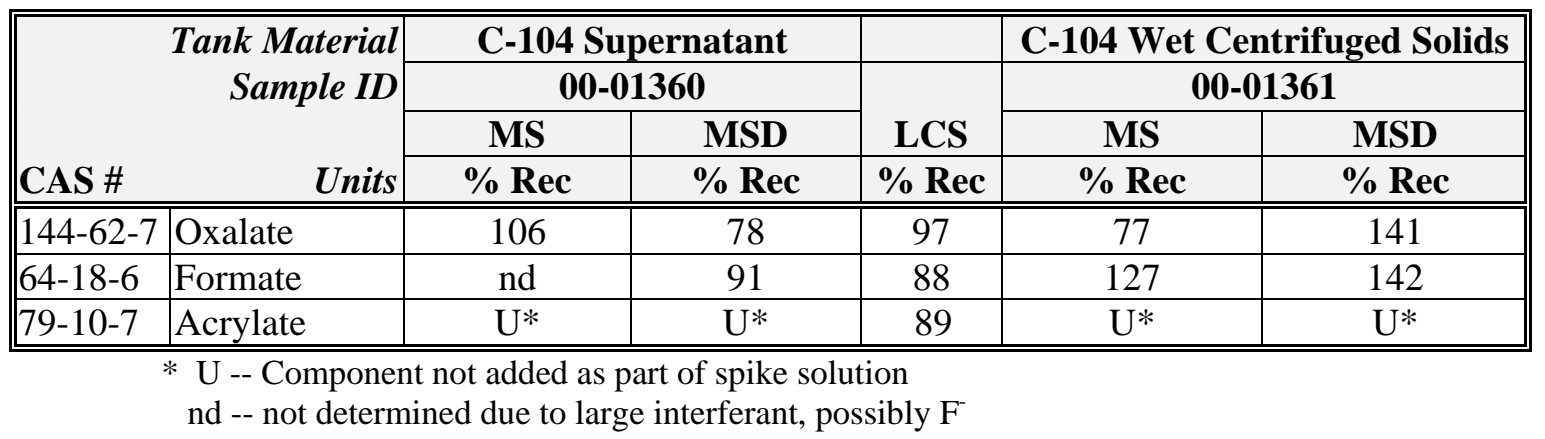

Acetate was not included in the MS and MSD due to interference from $\mathrm{F}^{-}$. Formate was detected in the C-104 supernatant MSD but not in the MS and is discussed in more detail in the following section. The continuous calibration verification (CCV) solution contained all of the analytes. The CCV data collected at the start of each day gave a maximum deviation of $13 \%$ for acrylate; other analytes afforded $10 \%$ deviation or less from the expected values. The calculated values were generated from 4-point curves with multiple data collected at each dilution point. This calibration data was sufficient for calculation of all quantitative values.

\subsection{Other Observations (or Deviations/Concerns/Issues)}

For these samples, there was a large early eluting interfering material thought to be fluoride $\left(\mathrm{F}^{-}\right)$. Although the samples were not spiked with $\mathrm{F}^{-}$to verify its presence, previous experience has indicated that the early eluting component is probably $\mathrm{F}^{-}$. An experiment was conducted using purified calcium oxide as a precipitant to remove this interfering component. Preliminary indications are that calcium oxide may provide a method to improve the chromatography of samples that contain $\mathrm{F}^{-}$. A problem arises in ion chromatography when there is a large amount of a slightly retained ion such as $\mathrm{F}^{-}$in the matrix. All monovalent ions that elute in the timeframe close to $\mathrm{F}^{-}$are affected in peak shape and (to a lesser extent) retention time. This effect is illustrated in Figures 7.1 through 7.4. Figure 7.1 is an IC chromatogram of a solution composed of acetate (peak 2), acrylate (peak 3) and formate (peak 4). Figure 7.2 is an IC chromatogram of a C-104 MS solids sample. Peak 2 is probably $\mathrm{F}^{-}$and peak 3 is formate in this chromatogram. A large amount of $\mathrm{F}^{-}$is sufficient to overlap with acetate, making a determination of acetate impossible by this IC separation. The peak shape of other monovalent anions is also severely affected, which adversely affects the quantitation and lowlevel detection of formate and acrylate. Thus, one of the formate spike results is not available due to the adverse affects of $\mathrm{F}^{-}$. This is illustrated in Figures 7.3 and 7.4. Figure 7.3 is an IC chromatogram of $\mathrm{C}-104$ MS supernatant sample. Peak 3 is possibly $\mathrm{F}^{-}$and peak 4 is formate. The chromatography of formate is affected by the presence of $\mathrm{F}^{-}$; the peak is not measurable. Figure 7.4 is an IC 
chromatogram of C-104 supernatant MSD. Peak 2 is possibly $\mathrm{F}^{-}$and peak 3 is formate. The peak broadening effect due to $\mathrm{F}^{-}$is more severe in the MS sample; a rerun of the sample showed the same result. Later eluting ions (nitrate, oxalate, sulfate, citrate) are not subject to this loading effect by $\mathrm{F}^{-}$ since a re-focusing of the analyte is possible after $\mathrm{F}^{-}$has been eluted from the column.

It is possible that ion chromatographic separation of carboxylates in the presence of $\mathrm{F}^{-}$could be improved by addition of a precipitant, such as calcium ion. This treatment would necessitate determination of oxalate first, followed by analysis of samples in which $\mathrm{F}^{-}$has been reduced or removed. 


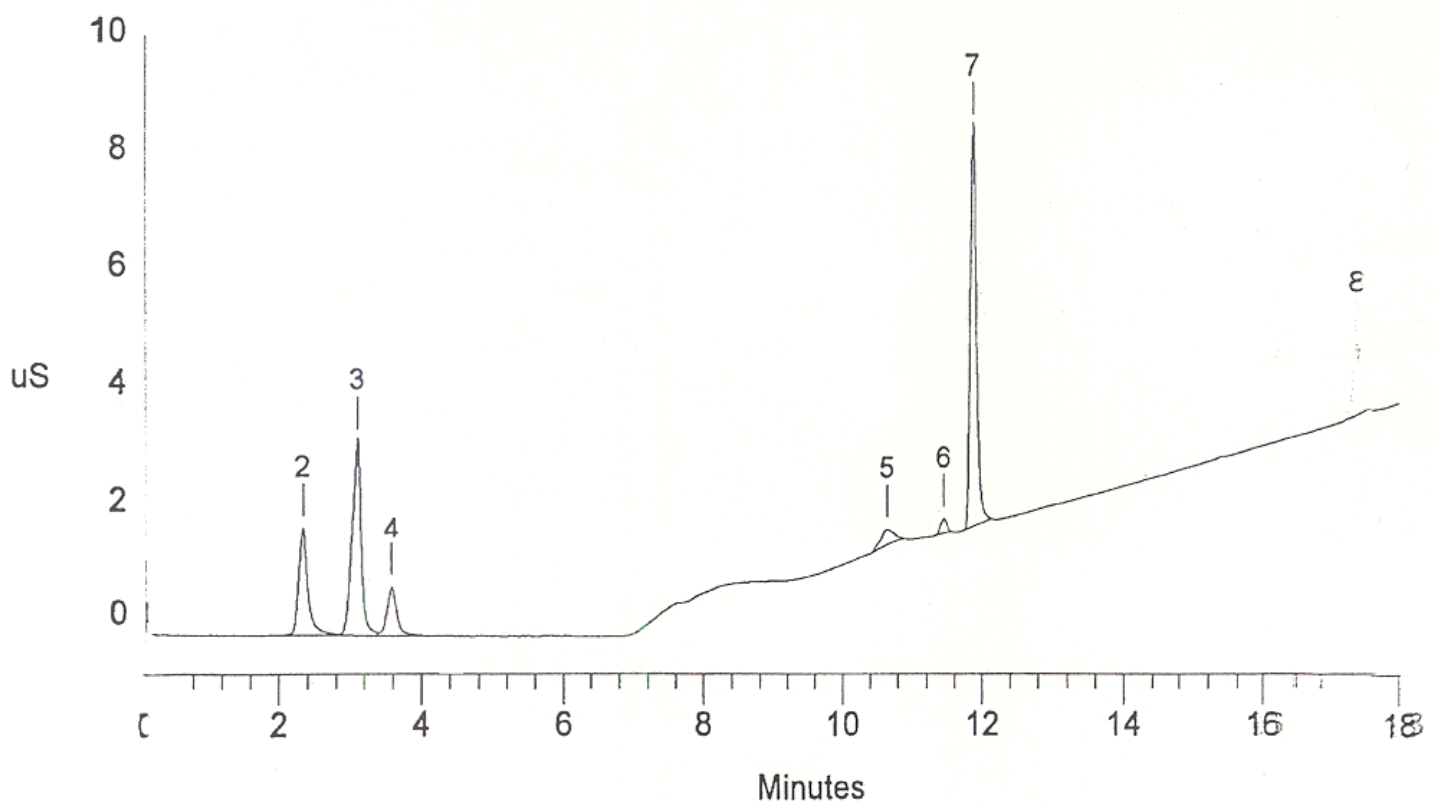

Figure 7.1. IC Chromatogram of Standard Solution. Peak 2-acetate; 3-acrylate; 4formate; 5-carbonate; 6-sulfate; 7-oxalate

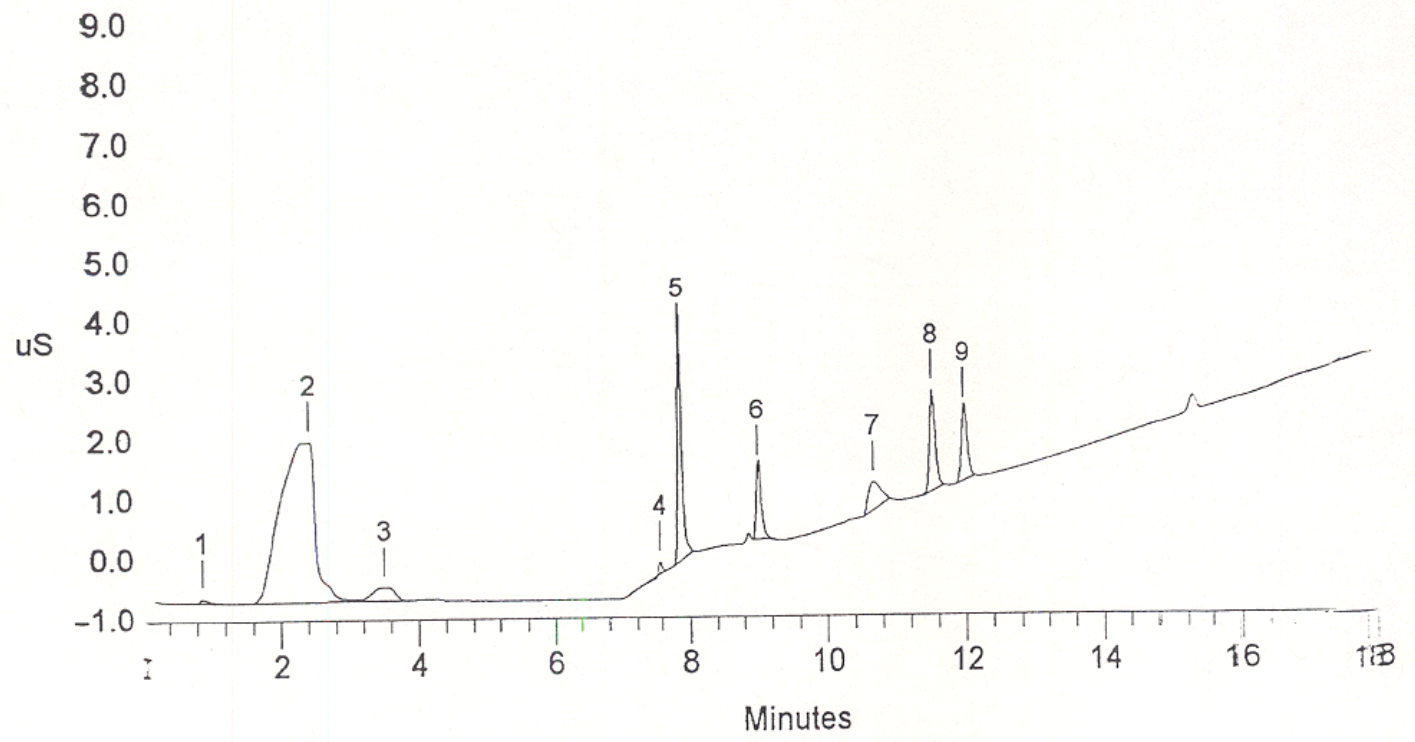

Figure 7.2. IC Chromatogram of C-104 Solids MS Sample. Peak 2-possibly F'; Peak 3formate; 4-chloride; 5-nitrate; 6-unknown; 7-carbonate; 8-sulfate; 9-oxalate 


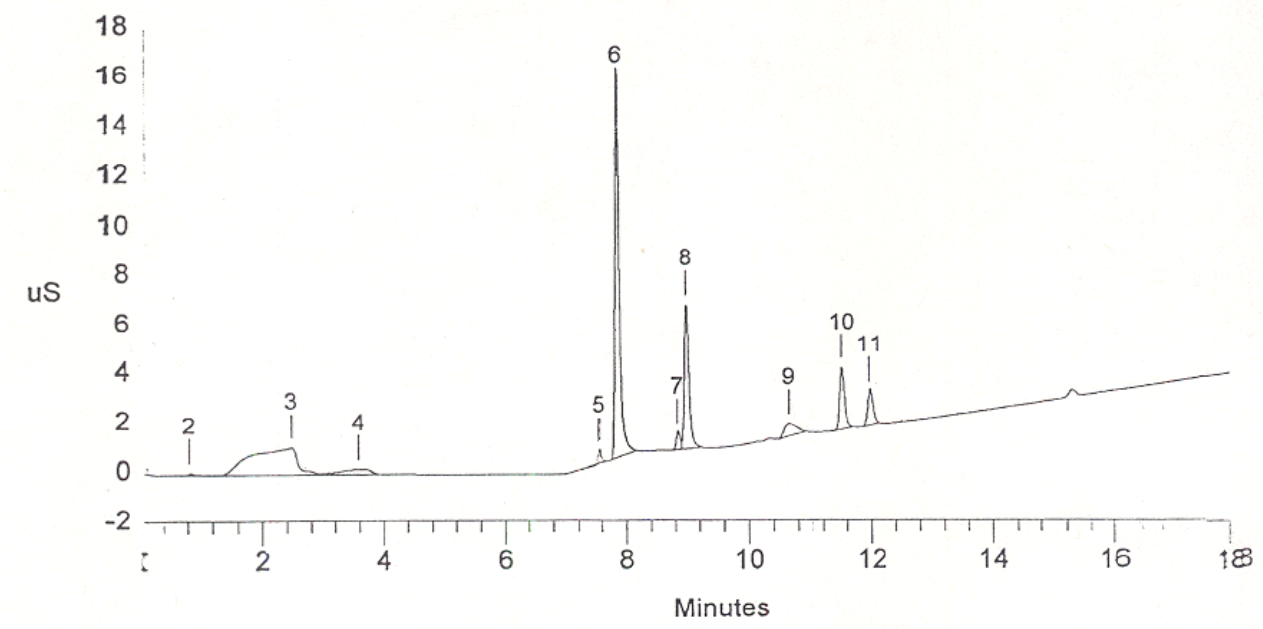

Figure 7.3. IC Chromatogram of C-104 Supernatant MS Sample. Peak 3-possibly F-; 4formate; 5-chloride; 6-nitrate; 7-unknown; 9-carbonate; 10-sulfate; 11-oxalate

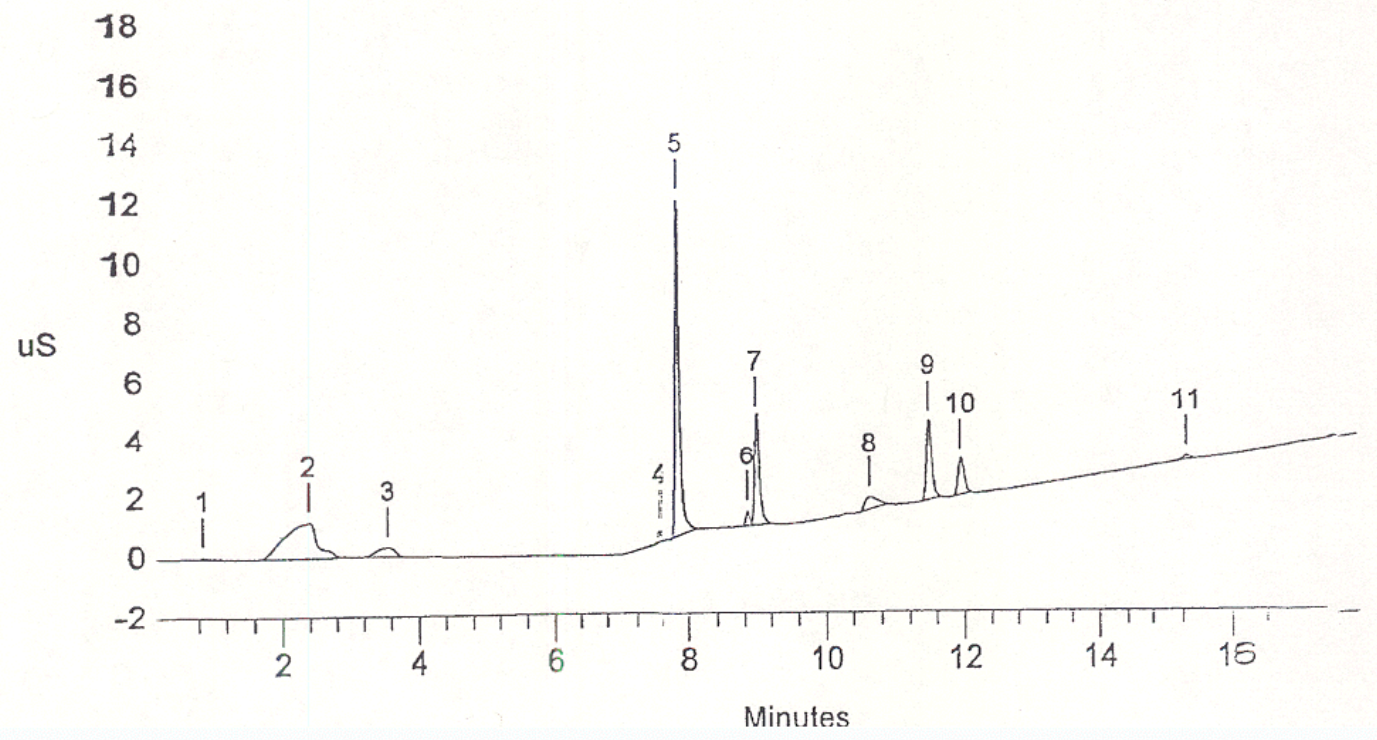

Figure 7.4. IC Chromatogram of C-104 Supernatant MSD. Peak 2-possibly F'; 3formate; 4-chloride; 6-nitrate; 6-unknown; 7-unknown; 8-carbonate; 9-sulfate; and 10oxalate 


\subsection{Headspace Analysis}

\section{Introduction}

Headspace analyses were performed on the supernatant of tank waste material from Tank C-104 following sub-sampling in the SAL per Test Plan BNFL-29953-080 Rev. 1. The samples were prepared in the SAL and transferred under CoC to the laboratory for analysis. Analyses were performed using an automated headspace sampler interfaced to a gas chromatographic/mass spectrometric (GC/MS) system. Test Plan BNFL-29953-026 Rev. 0: “Analysis for Volatile Constituents using Headspace Gas Chromatography Mass Spectrometry” provides details of the procedure used for this analysis. Analytes of interest include methanol, ethanol, 1-propanol, 2-propanol, n-butanol, 1-methylpropanol, 2-methyl-2-propanol, and triethylamine.

\subsection{Sample Preparation}

Tank samples from C-104 were prepared in the SAL. Sample aliquots of $1 \mathrm{~mL}$ were placed in 10 -mL headspace vials and immediately sealed using crimp-top septa. The samples were then transported to the 329 organic laboratory for subsequent analysis. Immediately prior to analysis, internal standards and surrogate compounds were added through the septa.

\subsection{Instrumentation}

The analytical instrumentation utilized for the analysis of volatile components by headspace consists of an automated headspace analyzer interfaced to a GC/MS system. A description of the system is provided in Table 8.1 .

Table 8.1. Headspace Instrumentation

\begin{tabular}{||l|l|c|c||}
\hline \multicolumn{1}{|c|}{ System/Instrument } & Manufacturer & Model Number & M\&TE $^{\mathbf{( 1 )}}$ Number \\
\hline \hline Headspace Sampler & Hewlett-Packard & 7964 & WD 25715 \\
\hline Gas Chromatograph & Hewlett-Packard & 5890 & WD 14120 \\
\hline Mass Spectrometer & Hewlett-Packard & 5972 & WD 17020 \\
\hline
\end{tabular}

(1) Measuring and Test Equipment

\subsection{Analysis Results}

The headspace analysis results for BNFL specified target compounds are presented in Tables 8.2. Headspace analysis for the analytes of interest was performed on the supernatants only. As seen in Table 8.3, the target MRQ (after adjusting for density) for triethylamine was not met. There was not good comparison of the results between the sample and a duplicate. A reanalysis of the samples confirmed these results. The crimp top to the duplicate sample was found to be slightly loose and the analytes may have been lost prior to analysis.

As is typical of many Hanford tank materials, a substantial amount of normal paraffin hydrocarbons (NPH) were found to be present in the sample primarily as undecane $(55 \mu \mathrm{g} / \mathrm{mL})$, dodecane (90 $\mu \mathrm{g} / \mathrm{mL})$, tridecane $(110 \mu \mathrm{g} / \mathrm{mL})$, and tetradecane $(30 \mu \mathrm{g} / \mathrm{mL})$. These and other tentatively identified compounds (TICs) are not included in Table 8.2 because they were not part of the target list. Quantitation for the those compounds was based on an assumed response factor taken from the 
internal standard and should be considered as approximate. The duplicate sample contained about twice the quantity of NPH as that found in the sample which may indicate homogeneity issues are a contributor to the poor comparability of the target analytes. NPH oxidation products were also found in lesser quantities. These constituents included unsaturated similarly sized straight chain and branched hydrocarbons, as well as ketones such as dodecanones and undecanones.

Table 8.2. C-104 Results - Headspace Analysis

\begin{tabular}{|c|c|c|c|c|c|c|}
\hline & $\begin{array}{r}\text { Sample ID } \\
\text { Units }\end{array}$ & $\begin{array}{l}\text { MDL } \\
\mu \mathrm{g} / \mathrm{mL}\end{array}$ & $\begin{array}{c}00-1360 \\
\text { Method Blank } \\
\mu \mathrm{g} / \mathrm{mL}\end{array}$ & $\begin{array}{c}\text { 00-1360 } \\
\text { Process Blank } \\
\mu \mathrm{g} / \mathrm{mL}\end{array}$ & $\begin{array}{c}00-1360 \\
\text { Sample } \\
\mu \mathrm{g} / \mathrm{mL}\end{array}$ & $\begin{array}{c}\text { 00-1360 } \\
\text { Duplicate } \\
\mu \mathrm{g} / \mathrm{mL} \\
\end{array}$ \\
\hline CAS \# & BNFL Compound List & & & & & \\
\hline $67-56-1$ & Methanol & 5 & $\mathrm{U}$ & $\mathrm{U}$ & 16 & $\mathrm{U}$ \\
\hline $64-17-5$ & Ethanol & 1 & 2.6 & $2.2 \mathrm{~B}$ & $8.0 \mathrm{~B}$ & $2.9 \mathrm{~B}$ \\
\hline $67-63-0$ & 2-Propanol & 1 & $\mathrm{U}$ & $\mathrm{U}$ & $\mathrm{U}$ & $\mathrm{U}$ \\
\hline $75-65-0$ & 2-Methyl-2-propanol & 1 & $\mathrm{U}$ & $\mathrm{U}$ & $\mathrm{U}$ & $\mathrm{U}$ \\
\hline $71-23-8$ & 1-Propanol & 1 & $\mathrm{U}$ & $\mathrm{U}$ & 2.7 & $\mathrm{U}$ \\
\hline 78-92-2 & 2-Butanol & 1 & $\mathrm{U}$ & $\mathrm{U}$ & $\mathrm{U}$ & $\mathrm{U}$ \\
\hline $71-36-3$ & n-Butanol & 1 & $\mathrm{U}$ & $\mathrm{U}$ & 28 & $\mathrm{U}$ \\
\hline $121-44-8$ & Triethylamine & 20 & $\mathrm{U}$ & $\mathrm{U}$ & $15 \mathrm{~J}$ & $\mathrm{U}$ \\
\hline \multicolumn{2}{|c|}{ Surrogate Compound } & & \% Rec & \% Rec & \% Rec & $\%$ Rec \\
\hline \multicolumn{2}{|c|}{ Methanol- $\mathrm{d}_{4}$} & & 105 & 122 & 104 & 101 \\
\hline
\end{tabular}

"J" = Compound was detected below the level of quantitation

"B" = Compound was present in the method blank

Table 8.3. Target Headspace Minimum Reportable Quantities

\begin{tabular}{||l|l|c|c||}
\hline \multicolumn{1}{|c|}{ Units } & $\begin{array}{c}\text { Solids Target } \\
\text { MRQ }^{(\mathbf{1})} \\
\mu \mathbf{g} / \mathbf{K g}\end{array}$ & $\begin{array}{c}\text { Supernatant Target MRQ } \\
\text { (Density = 1.161 g/mL) } \\
\mu \mathbf{g} / \mathbf{m L}\end{array}$ \\
\hline \hline CAS \# & BNFL Compound List & & ------ \\
\hline $67-56-1$ & Methanol & ----- & ----- \\
\hline $64-17-5$ & Ethanol & ----- & ----- \\
\hline $67-63-0$ & 2-Propanol & ----- & ----- \\
\hline $75-65-0$ & 2-Methyl-2-propanol & ----- & ----- \\
\hline $71-23-8$ & 1-Propanol & ----- & ----- \\
\hline $78-92-2$ & 2-Butanol & ----- & 1.0 \\
\hline $71-36-3$ & n-Butanol & 900 & 0.6 \\
\hline $121-44-8$ & Triethylamine & 500 & \\
\hline
\end{tabular}

(1) MRQ =Minimum Reportable Quantity

“-----” = No MRQ target provided 


\subsection{QC Evaluation}

Response for the internal standard, ethanol- $\mathrm{d}_{6}$, varied substantially (almost a factor of three) throughout the analytical batch. This affected the detection limits for methanol and triethylamine. In addition, the surrogate recoveries for methanol- $\mathrm{d}_{4}$ were slightly affected. However, the surrogate recovery variation appears primarily to be attributable to variation of the internal standard response as well. Matrix spike and MSD recoveries are presented in Table 8.4. Fifty micrograms of each analyte was added to the sample.

Table 8.4. C-104 Headspace Matrix Spike Recoveries

\begin{tabular}{|c|c|c|c|}
\hline & \multirow{3}{*}{$\begin{array}{c}\text { Sample ID } \\
\text { Units } \\
\end{array}$} & \multicolumn{2}{|c|}{ 00-1360 } \\
\hline & & \multirow{3}{*}{$\begin{array}{c}\text { MS } \\
\text { \% Rec } \\
\end{array}$} & \multirow{2}{*}{$\begin{array}{c}\text { MSD } \\
\% \text { Rec } \\
\end{array}$} \\
\hline & & & \\
\hline CAS \# & BNFL Compound List & & \\
\hline $67-56-1$ & Methanol & 113 & 106 \\
\hline $64-17-5$ & Ethanol & 95.0 & 95.3 \\
\hline $67-63-0$ & 2-Propanol & 98.9 & 100 \\
\hline $75-65-0$ & 2-Methyl-2-propanol & 85.1 & 87.0 \\
\hline 71-23-8 & 1-Propanol & 97.8 & 101 \\
\hline $78-92-2$ & 2-Butanol & 95.6 & 97.8 \\
\hline $71-36-3$ & n-Butanol & 93.8 & 82.7 \\
\hline $121-44-8$ & Triethylamine & 51.8 & 45.4 \\
\hline \multicolumn{2}{|c|}{ Surrogate Compound } & \% Rec & \% Rec \\
\hline & Methanol- $\mathrm{d}_{4}$ & 103 & 108 \\
\hline
\end{tabular}

Recoveries were calculated after subtraction of the results from the sample analysis. The recoveries are reasonable in general with the exception of triethylamine, which had a lower recovery than expected. This method has typically performed well for methanol and shows promise as an effective technique for the analysis of triethylamine. Further development and evaluation will be necessary to improve the stability performance of this technique and sensitivity for triethylamine. 


\subsection{REFERENCES}

Ashby, EC. et al. 1994. Synthetic Waste Chemical Mechanism Studies, WHC-EP-0823, Westinghouse Hanford Company, Richland, Washington.

Barney, GL. 1996. Solubilities of Significant Organic Compounds in HLW Tank Supernate Solutions-FY 1996 Progress Report, WHC-EP-0899, Westinghouse Hanford Company, Richland, Washington.

Camaioni, DM., WD. Samuels, JC Linehan, SA Clauss, AK Sharma, KL. Wahl, JA Campbell. 1996. Organic Tanks Safety Program, FY 96 Waste Aging Studies, PNNL-11312, Pacific Northwest National Laboratory, Richland, Washington.

Camaioni, DM., WD., Samuels, JC., Linehan, ST Autry, AK Sharma, MA Lilga, MO Hogan, SA Clauss, KL. Wahl, JA Campbell. 1998. Organic Tanks Safety Program, FY 96 Waste Aging Studies Final Report, PNNL-11909 Rev. 1, Pacific Northwest National Laboratory, Richland, Washington.

Challis, BC, N. Carman, et al. 1994 Peptide Nitrosations. Nitrosamines and Related N-Nitroso Compounds. Chemistry and Biochemistry R.N. Loeppky and C.J. Michejda. Washington DC, American Chemical Society. 553: 74-92.

Campbell, JA. 1997. Organic Analysis Progress Report FY 1997. PNNL-1738, Pacific Northwest National Laboratory, Richland, Washington.

Sharma, AK, SA Clauss, GM Mong, KL Wahl, JA Campbell. 1998. “Analysis and Quantification of Organic Acids in Simulated Hanford Tank Waste and Hanford Tank Waste.” J. of Chromatography, 805, 101-107.

Klinger, GS, MW Urie, JA Campbell, SA Clauss, TW Clauss, EW Hoppe, GM Mong, and AK Sharma. 2000. Organic Analysis of AW-101 and AN-107 Tank Waste. PNWD-2461, Battelle, Pacific Northwest Division, Richland, Washington.

Fiskum, SK, et al. 2000. Inorganic and Radiochemical Analysis of 241-C-104 Tank Waste, PNNL-13364, Pacific Northwest National Laboratory, Richland, Washington. 


\section{Appendix A: PNNL Test Plan For C-104 Sample Compositing, Bnfl-29953-31, Rev. 0}




\section{PNNL Test Plan}

Document No.: BNFL-TP-29953-031

Rev. No.: 0

Title: C-104 Sample Compositing

\begin{tabular}{|c|c|}
\hline Work Location: 325/SFO & Page 1 of 5 \\
\hline Author: Paul Bredt & \multirow{2}{*}{$\begin{array}{l}\text { Effective Date: Upon Final Signature } \\
\text { Supersedes Date: New }\end{array}$} \\
\hline Use Category Identification: Reference & \\
\hline $\begin{array}{l}\text { Identified Hazards: } \\
\text { Radiological } \\
\text { Hazardous Materials } \\
\text { Physical Hazards } \\
\text { Hazardous Environment } \\
\text { Other: }\end{array}$ & $\begin{array}{l}\text { Required Reviewers: } \\
\text { X Author } \\
\text { X Technical Reviewer } \\
\text { X RPL Manager } \\
\text { X Project Manager } \\
\text { X RPG Quality Engineer } \\
\text { BNFL }\end{array}$ \\
\hline
\end{tabular}

Are One-Time Modifications Allowed to this Procedure? X X Yes _ _ No

NOTE: If Yes, then modifications are not anticipated to impact safety. For documentation requirements of a modification see SBMS or the controlling Project QA Plan as appropriate.

On-The Job Training Required?

Yes or

$\mathrm{X}$ No

FOR REVISIONS:

Is retraining to this procedure required? ___ Yes $\quad \mathrm{X}$ No

Does the OJT package associated with this procedure require revision to reflect procedure changes?

$\begin{array}{llll}\text { Yes } & \text { No } & \mathrm{X} \text { N/A } & \text { Date }\end{array}$

Author Signature on File

Technical Reviewer Signature on File

RPL Manager Signature on File

Project Manager Signature on File

RPG Quality Engineer Signature on File

BNFL 


\section{Applicability}

This Test Plan describes work to be performed under Task 2.01, LAW and HLW Feed

Characterization. This work is defined under BNFL letter W375-98-0018 dated September 29, 1998.

Approximately $1.7 \mathrm{~L}$ of material from Tank 241-C-104 has been transferred from the 222-S

laboratory to the 325 HLRF. All of this material is to be used to prepare a C-104 composite.

Homogenous subsamples of the composite are to be collected for delisting and permitting activities as

well as for select research and development activities.

Subsamples will be withdrawn from the composite in a manner which will provide representative samples for chemical and radiochemical analysis and physical testing. To support the delisting and permitting, this test plan will generate samples that will allow measurement of chemical properties of the waste that are both precise and accurate. Integrity of the subsamples will be maintained consistent with prior sampling and storage history. No preservation or temperature control of the subsamples are planned. Sampling protocols in SW-846 are not strictly applicable since these protocols are targeted at sampling in the field.

\section{Quality Control}

Quality control has been implemented in the work instructions.

Since this document will be used to record an experimental process, markups as specified in the RPL Operations manual section $\mathbf{1 6 . 6}$ will be allowed. The staff member performing the change initials markups to this Test Plan. The Cognizant Scientist overseeing the work initials and dates changes to the Test Plan. Changes made by the Cognizant Scientist do not require additional reviews or approvals. If changes occur to multiple pages then the Cognizant scientist shall note the effected pages and initialize the note. Superseded text shall be lined out, but not obscured, initialed and dated.

\section{M\&TE List:}

Balance 1:

$$
\text { Calib ID }
$$

Location

Balance 2:

$$
\text { Calib ID }
$$$$
\text { Location }
$$

Thermocouple:

$$
\begin{aligned}
& \text { Calib ID } \\
& \text { Location }
\end{aligned}
$$

Digital Thermometer:

Calib ID
Location

Calib Exp Date

Calib Exp Date

Calib Exp Date

Thermocouple type

Calib Exp Date 


\section{Work Instructions}

1) The composite is to be prepared in a 3L stainless steel vessel. Secondary containment will be used to allow recovery from a possible breach of a 3L vessel or failure of the tap valve. The recommended parts for the kettles are listed below. Viton O-rings are to be used for sealing the vessel. No grease is to be used. Assemble the vessel in the hot cell.

\begin{tabular}{|l|l|l|}
\hline Description & Part & Vendor \\
\hline UHMWPE packed 3/4” Ball Valve & SS-63ES12 & Seattle Valve and Fitting \\
\hline $\begin{array}{l}\text { 5”ID x 9.87” pipe nipple with } \\
\text { 6.75” Comflat flange }\end{array}$ & FNF0500 & Varian \\
\hline 6.75” blank off flange & F06750000NC4 & Varian \\
\hline 6.75” viton gasket & FG0675VU & Varian \\
\hline Nut and bolt set & FB0600C06 & Varian \\
\hline Clamping ring & Z12,171-1 & Sigma-Aldrich \\
\hline 3/4” swagelok to pipe thread & SS-12-TA-1-12 & Seattle Valve and Fitting \\
\hline Stir rod & $14-500-18$ & Fischer \\
\hline Total & & \\
\hline
\end{tabular}

2) Weigh the sample jars listed below to $\pm 0.01 \mathrm{~g}$. Transfer all material from the jars to the mixing vessel. If necessary, use supernatant from the jars or vessel to rinse the solids into the vessel. Reweigh the empty jars and record the mass to $\pm 0.01 \mathrm{~g}$ in the space provided.

\begin{tabular}{|l|l|l|l|}
\hline Sample Label & Mass (Full) & Mass (Empty) & Mass Transferred \\
\hline 16273 & & & \\
\hline 16274 & & & \\
\hline 16275 & & & \\
\hline 16276 & & & \\
\hline 16277 & & & \\
\hline 16278 & & & \\
\hline 16279 & & & \\
\hline 16280 & & & \\
\hline 16281 & & & \\
\hline 16282 & & & \\
\hline 16283 & & & \\
\hline 16284 & & & \\
\hline 16285 & & & \\
\hline 16286 & & & \\
\hline
\end{tabular}

3) The goal of this step is to homogenize the sample using as little force as possible. Stir the sample by slowly increasing the motor speed until the solids are mobilized. Given this work is being conducted in a steel vessel, observations need to be made with the lid off the vessel. Stir for a minimum of one hour. Record the hot cell temperature.

Time Date Temperature ${ }^{\circ} \mathrm{C}$ 
4) While the solids are mobilized, collect $\sim 50 \mathrm{ml}$ of sample in a clean jar. This fraction is probably high in solids due to the geometry of the vessel, so return this sample to the vessel and continue to stir the vessel.

5) Collect $3 \sim 100 \mathrm{ml}$ samples in volume-graduated tared bottles listed below by removing material using the $3 / 4$ " ball valve located on the bottom of the vessel. Sufficient sample is to be collected in each jar as to minimize headspace in the jars. Weight the full bottles to $\pm 0.01 \mathrm{~g}$ and record the masses below.

\section{C-104 COMP A}

Total

Tare

Slurry

\section{C-104 COMP B}

Total

Tare

Slurry

g
g

Total

Tare

Slurry

6) Turn off the stirring motor, record the date and time. Cover the vessel using a blank flange.

Day Time

7) Allow C-104 COMP A, C-104 COMP B, and C-104 GL to settle for a minimum of 16 hours.

8) Record the date and time, and total volume of the slurries and volume of the settled solids in $\mathbf{C}$ 104 COMP A, C-104 COMP B, and C-104 GL.

Day Time

\section{C-104 COMP A}

Total

Solids $\mathrm{ml}$

$\mathrm{ml}$

\section{C-104 COMP B}

Total

Solids

\section{C-104 GL}

$\begin{array}{lll}\mathrm{ml} & \text { Total } & \mathrm{ml} \\ \mathrm{ml} & \text { Solids } & \mathrm{ml}\end{array}$

9) If the volume percent settled solids in the 5 samples are within $~ 10 \%$, then the samples are representative of the whole composite and proceed to step 10. If the volume percent settled solids vary by much more than $10 \%$, then return the slurry samples in jars C-104 COMP A, C-104 COMP B, and C-104 GL to the kettle, increase the stirring rate and repeat steps 3 through 9.

10) Turn the stirrer on and allow the system to stir for 10 minutes. While the stirrer is on, collect all the remaining material in $500 \mathrm{ml}$ jars as labeled below. It is possible that up to 3 jars may be required. Record the time and date.

Day

C-104 COMP C

Total

Tare

Slurry
Time

\section{C-104 COMP D}

Total

Tare

Slurry

$\begin{array}{ll}\text { g } & \text { Total } \\ \text { g } & \text { Tare } \\ \text { g } & \text { Slurry }\end{array}$

\section{C-104 COMP E}

Total

Tare

Slurry g

g

g 
11) Allow samples C-104 COMP C, C-104 COMP D, and C-104 COMP E to settle for at least 3 days then transfer all standing liquid on samples C-104 COMP A, C-104 COMP B, C-104 COMP C, C-104 COMP D, C-104 COMP E, and C-104 GL to $250 \mathrm{ml}$ jars as labeled below. It is possible that up to 3 jars may be required. Record the time and date.

Day

\section{C-104 SUP A}

Total

Tare

Slurry

\section{C-104 SUP B}

Total

Tare

Slurry

\section{C-104 SUP C}

Total

Tare

Slurry g

g

g Slurry g

12) Transfer sample C-104 COMP A, C-104 COMP B, C-104 GL, C-104 SUP A, C-104 SUP B, and C-104 SUP C to the SAL with a chain of custody. 
Appendix B: PNNL Test Plan For Inorganic, Organic, and Radiochemical Characterization of C-104 HLW Sample BNFL-29953-30, Rev. 1 
Document No.: BNFL-29953-030

Rev. No.: 1

Title: Inorganic, Organic and Radiochemical Characterization of C-104 HLW Sample

\begin{tabular}{|c|c|c|c|}
\hline & $\begin{array}{l}\text { Work Location: } \\
\text { 325/SFO, 325/general labs; 329/general labs }\end{array}$ & \multicolumn{2}{|l|}{ Page 1 of 9} \\
\hline & Author: Michael W. Urie & \multirow{2}{*}{\multicolumn{2}{|c|}{$\begin{array}{l}\text { Effective Date: Upon final signature } \\
\text { Supersedes Date: New }\end{array}$}} \\
\hline & Use Category Identification: Reference & & \\
\hline & $\begin{array}{l}\text { Identified Hazards: } \\
\text { Radiological } \\
\text { Hazardous Materials } \\
\text { Physical Hazards } \\
\text { Hazardous Environment } \\
\text { Other: }\end{array}$ & $\begin{array}{l}\text { Required Reviewers: } \\
\text { X Technical Reviewer } \\
\text { Building Manager } \\
\text { — Radiological Control } \\
\text { ES\&H } \\
\text { E } \text { Quality Engineer }\end{array}$ & $\begin{array}{l}\underline{X} \text { Project Manager } \\
\underline{X} \text { RPL Manager } \\
\underline{X} \text { SFO Manager } \\
\underline{X} \text { AO\&AM Manager }\end{array}$ \\
\hline
\end{tabular}

Are One-Time Modifications Allowed to this Procedure?

$$
\mathrm{X} \text { Yes } \quad \text { No }
$$

NOTE: If Yes, then modifications are not anticipated to impact safety. For documentation requirements of a modification see SBMS or the controlling Project QA Plan as appropriate.

On-The Job Training Required? $\_$Yes or $\quad \mathrm{X}$ No FOR REVISIONS:

Is retraining to this procedure required? __ Yes _

Does the OJT package associated with this procedure require revision to reflect procedure changes? _ Y Yes_ No $\underline{X}$ N/A

Author Signature on File

Technical Reviewer__ Signature on File

RPL Manager__Signature on File

SFO Manager__ Signature on File

Project Manager__ Signature on File

AO\&AM Manager__ Signature on File

Quality Engineer__ Signature on File

BNFL__ Signature on File 


\section{Applicability}

This Test Plan describes work to be performed under Task 5.0, Double Shell Tank Analytical Support Change No. 1, for tank wastes from C-104. A composite generated from Test Plan TP-29953-031, "C-104 Sample Compositing”, provide the starting material for the inorganic, organic, and radiochemical characterization of the "as received" tank waste material. Per TP-29953-031, two bottles containing approximately 340 grams of slurry and one jar containing approximately 175 grams of decanted supernatant are allocated to support the "as received" characterization analysis. The representative slurry and supernatant sub-samples are extracted from the C-104 HLW composite sample in the High Level Radiation Facility and transferred to the Shielded Analytical Laboratory for analytical sub-sampling, digestion, extraction, and distribution for analysis.

The characterization of the "as received" tank waste materials is conducted to provide key characterization information for processing, as well as to provide limited information for the permitting activities. This Test Plan covers the sub-sampling and processing of analytical samples, and the inorganic, organic and radiochemical analysis of these samples to provide both precise and accurate compositional results that meet, when possible, regulatory requirements.

This Test Plan does not cover physical properties testing on the C-104 material. Physical properties testing is to be conducted under an alternate test plan. Also, this Test Plan does not include analyses to support the dilution of the C-104 material for the CUF activities, nor does it include the inorganic and radiochemical analysis for the resulting diluted material.

\section{Prerequisites}

The majority of sub-sampling, analytical processing, and inorganic, organic and radiochemical analysis are being conducted per established and approved Battelle procedures or analytical test plans written specifically to support the work detailed in this Test Plan. The Battelle technical procedures and test plans supporting the characterization activity adhere to SW-846 protocols to the extent possible considering the limited sample volume, radiological condition, and extended target analyte list.

\section{Hazards Assessment and Mitigation}

All hazards associated with work conducted to this Test Plan have either been evaluated as part of each laboratory's Hazard Awareness Summary or as hazards unique to a specific analytical preparation or specific analytical procedures or test plans. The Hazard Awareness Summaries are posted for all laboratories in the Radiological Processing Laboratory. Hazards unique to analysis procedures are identified in the applicable procedures or test plans, and where applicable, specific Chemical Processing Permits are obtained.

\section{Quality Control}

Quality control is governed by Quality Assurance Planning Subject Area, including Exhibit "Conducting Analytical Work in Support of Regulatory Programs”. The Subject Area Exhibit specifies calibration and verification requirements for analytical systems, as well as batch processing quality control samples to monitor preparation and extraction processing (i.e., blanks, duplicates, matrix spikes, matrix spike duplicates, and laboratory control standards). This Test Plan identifies those analyses for which duplicates and matrix spikes are to be performed, and the approximate quantity of sample to be used for each analysis. 
Technical procedures used to support the characterization of the HLW material are either from Chemical Measurement Center Core Capabilities Manual or are project-specific procedures/test plans written specifically to support activities identified in this Test Plan. Necessary method modifications and deviations from technical procedures, test plans, or SW-846 protocols shall be documented in the final report.

Integrity of the sub-samples and processed samples distributed throughout the laboratory will be maintained by chain-of-custody documentation. Changes to this Test Plan (initialed markups are allowed) shall be approved by the Task Manager.

\section{Exceptions}

Based on the history of the C-104 sample, exceptions are being taken to the preservation, temperature control, and hold time requirements specified by SW-846 protocols. The samples are not preserved and no refrigeration of the samples is practical at this time. Hold times, based on sampling dates, have been exceeded prior to sample receipt and starting the analytical characterization.

In some cases, sample sizes based on SW-846 protocols are not attainable due to limited sample quantity. A limited quantity of material is available for the characterization analyses, and to the extent possible, the sample material is allocated based on the PNNL method sensitivity and ability to meet Minimum Reportable Quantities (MRQ). The sample volumes and weights used for analyses may be less than the recommended values in SW-846. The effect of small sample size on detection limits and reproducibility will be discussed in the final report. Specifically, the quantity of supernatant available for analysis is insufficient to ensure that all the MRQs are met. All the supernatant from the C-104 "as received" material is targeted to support the regulatory analyses, including inorganic, radiochemical, and organic analytes of interest.

Due to the limited sample quantity, deviations from SW-846 preparation methods may be necessary (e.g., modification to organic extraction procedure). Per the QA Planning Subject Area Exhibit, modifications (e.g., single organic extraction protocol) require Task Leader approval prior to performing the analysis. Formal method qualification of minor modifications will not be performed, but the modification will be validated by the use of duplicate, matrix spikes and surrogates. Modifications, as well as minor deviations to procedures or SW-846 protocols that do not affect data quality, will be documented in the final report.

Per discussion with WDOE and BNFL, certain analyses included in the Battelle Proposal No. 29274/30406 (for AN-107, AW-101, and C-104 tank waste materials) are not being performed, specifically, Total Oil and Grease, Sulfide, Iodide, Nitrogen, Corrosion Test, Reactive Cyanide, Reactive Sulfide, and ZHE for VOA. Also, three organic analytes (ammonium perfluorooctanoate, oxirane, and picric acid) are being omitted from the organic analysis analyte list following discussions with BNFL and WDOE. Also, per letter communication from BNFL, no TCLP extractions of the solids are being conducted for either inorganic or organic constituents.

Based on radiological dose considerations, the analytical samples may be diluted to reduce the dose to laboratory staff. This may significantly impact the ability to meet the MRQs for some analytes.

\section{Work Instructions}

A simple flowchart for the sub-sampling activity is provided in Figure A.1. The analysis methods are contained in Appendix A of the Battelle Proposal No. 29274/30406 and are not duplicated in this Test 
Plan. Analytical work is either initiated by a standard Analytical Service Request that will identify each test to be performed on the various samples and sub-samples or through the implementation of an analysis-specific test plan.

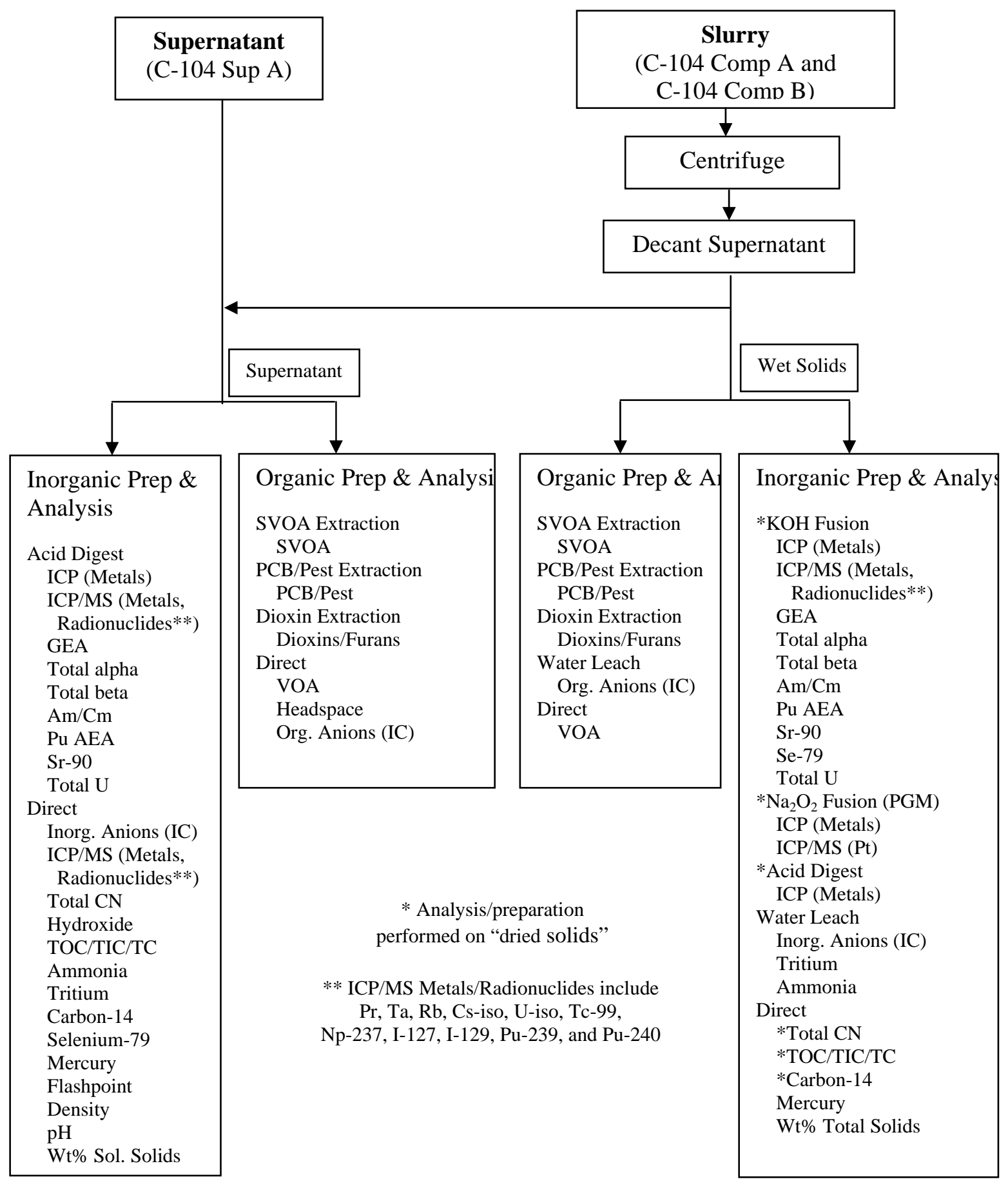

Figure B.1. Analytical Sub-Sampling Flowchart 
The starting analysis material consists of two containers of representative composite slurry and one container of decanted supernatant. The supernatant from the two slurry containers and the decanted supernatant represent essentially all of the supernatant available for characterization analysis. If slurry from the two containers have to be combined prior to sub-sampling, the entire contents of the containers shall be thoroughly homogenized, by mechanical mixing, prior to extracting any subsamples. All material sub-sampling and most analytical processing (e.g., digestions, fusions, and organic extractions) will be performed in the Shielded Analytical Laboratory due to dose levels.

\section{Sub-Sampling and Phase Separation}

The slurry and supernatant materials for "as received" characterization analysis are contained in three sample containers as described in Test Plan BNFL-29953-031. Table A.1 details the container tare values and the sample masses associated with each container.

Table B.1. “As Received” Sub-Samples for Characterization

\begin{tabular}{||l|l|c|c|c||}
\hline \multicolumn{1}{|c|}{ Sample Material } & \multicolumn{1}{|c|}{ Bottle ID } & $\begin{array}{c}\text { Bottle } \\
\text { Tare (g) }\end{array}$ & $\begin{array}{c}\text { Total } \\
\text { Mass (g) }\end{array}$ & $\begin{array}{c}\text { Supernatant or } \\
\text { Slurry Mass (g) }\end{array}$ \\
\hline \hline Composite Slurry & C-104 Comp A & 133.8 & 302.7 & 168.9 \\
\hline Composite Slurry & C-104 Comp B & 133.5 & 303.8 & 170.3 \\
\hline Supernatant & C-104 Sup A & 248.8 & 424.5 & 175.7 \\
\hline
\end{tabular}

The composite slurry samples are to be centrifuged to provide solids and supernatant phase separation. The supernatant from the slurry samples is decanted from the "wet solids" and combined with the supernatant in C-104 Sup A. The "wet solids" remaining are to be sub-sampled immediately for weight percent solids (in duplicate) and then sub-sampled for all organic analyses, water leaching analyses (i.e., anions, tritium, and ammonia), and mercury analysis as soon as practical. Following the sub-sampling for organic analysis, water leaching analyses, and mercury analysis, the remaining solids are to be dried to allow representative sub-sampling for all other analyses to be performed at a later date (i.e., without the necessity of additional weight percent solids measurements).

\section{Organic Analysis}

Special care is taken handling both the supernatants and "wet solids" to ensure sample integrity is maintained and representative sub-samples are extracted for analysis. Organic analyses (either direct or following extraction processing) are performed on the supernatant and "wet solids" fractions, and Table B.2 details the estimated sub-sampling quantities for each analysis. Table B.4 identifies the organic analyte list and associates each compound with an analysis method. Organic compounds other than those listed in Appendix A that are identified during analysis will be noted in the final report.

Test plans will be used to establish the extraction protocols for each extraction process used to generate samples for organic analysis (i.e., SVOA, PCB/Pest, and/or Dioxin). In order to conserve sample material, the Matrix Spikes and Matrix Spike Duplicates may be prepared using half the sample size used for the Sample and Duplicate.

\section{Inorganic and Radiochemistry Sub-Sampling}

Where required by the analysis method, sample preparation by digestion, fusion, or leaching are performed to established and approved Battelle procedures. Table B.3 details the estimated 
sub-sampling quantities of the supernatants, "wet solids”, and "dried solids”. Inorganic analytes and radionuclides of interest are included in Table B.5. Inorganic analytes and radionuclides other than those listed in Table F.5 that are identified during analysis will be noted in the final report.

\section{Analytical Service Request and Special Laboratory Instructions}

This Test Plan details the sub-sampling and sample quantity requirements for processing the HLW C-104 "as received" material for inorganic, radiochemistry, and organic analysis. The Analytical Service Request form is to be used to assign unique sample identification numbers to all samples and to identify specific analyses to be performed on each sub-sample. As part of the ASR, special laboratory instructions are to be provided to the laboratory staff to ensure that all sub-sampling and preparation activities are accomplished per this Test Plan. The ASR and the special instruction require review and approval of the Task Leader and become part of the project record once approved and implemented. Changes to the ASR or special instructions also require the approval of the Task Leader.

Table B.2. Organic Analytical Sub-Sampling Quantities Required ${ }^{(1)}$

\begin{tabular}{|c|c|c|c|c|c|}
\hline Phase & $\begin{array}{l}\text { Analysis or } \\
\text { Procedure }\end{array}$ & Sample & Duplicate & MS/MSD & SW-846 ${ }^{(2)}$ \\
\hline \multirow[t]{5}{*}{ Wet Solids } & VOA & $0.5 \mathrm{~g}$ & $0.5 \mathrm{~g}$ & $0.5 \mathrm{~g}$ & $5 g$ \\
\hline & Water Leach (IC Org.) & $1 \mathrm{~g}$ & $1 \mathrm{~g}$ & $1 \mathrm{~g}$ & $\mathrm{n} / \mathrm{a}$ \\
\hline & Extraction (SVOA) & $5 \mathrm{~g}$ & $5 \mathrm{~g}$ & $5 \mathrm{~g}$ & $30 \mathrm{~g}$ \\
\hline & Extraction (PCB/Pest) & $5 g$ & $5 \mathrm{~g}$ & $5 \mathrm{~g}$ & $30 \mathrm{~g}$ \\
\hline & Extraction (Dioxins) & $5 \mathrm{~g}$ & $5 \mathrm{~g}$ & $5 \mathrm{~g}$ & $30 \mathrm{~g}$ \\
\hline \multirow{2}{*}{\multicolumn{2}{|c|}{$\begin{array}{r}\text { Sub Total } \\
\text { Total } \\
\end{array}$}} & $16.5 \mathrm{~g}$ & $16.5 \mathrm{~g}$ & $16.5 \mathrm{~g}$ & \\
\hline & & \multicolumn{3}{|c|}{$49.5 \mathrm{~g}$} & \\
\hline \multirow[t]{6}{*}{ Supernatant } & VOA & $2 \mathrm{ml}$ & $2 \mathrm{ml}$ & $2 \mathrm{ml}$ & $5 \mathrm{ml}$ \\
\hline & Headspace & $2 \mathrm{ml}$ & $2 \mathrm{ml}$ & $2 \mathrm{ml}$ & $10 \mathrm{~g}$ \\
\hline & IC (organic anions) & $1 \mathrm{ml}$ & $1 \mathrm{ml}$ & $1 \mathrm{ml}$ & $\mathrm{n} / \mathrm{a}$ \\
\hline & Extraction (SVOA) & $35 \mathrm{ml}$ & $35 \mathrm{ml}$ & $35 \mathrm{ml}$ & $3000 \mathrm{ml}$ \\
\hline & Extraction (PCB/Pest) & $35 \mathrm{ml}$ & $35 \mathrm{ml}$ & $35 \mathrm{ml}$ & $3000 \mathrm{ml}$ \\
\hline & Extraction (Dioxins) & $10 \mathrm{ml}$ & $10 \mathrm{ml}$ & $10 \mathrm{ml}$ & $3000 \mathrm{ml}$ \\
\hline \multirow{2}{*}{\multicolumn{2}{|c|}{$\begin{array}{r}\text { Sub Total } \\
\text { Total }\end{array}$}} & $85 \mathrm{ml}$ & $85 \mathrm{ml}$ & $85 \mathrm{ml}$ & \\
\hline & & \multicolumn{3}{|c|}{$255 \mathrm{ml}$} & \\
\hline
\end{tabular}

(1) Subsampling quantities are estimates; actual quantities used for the analyses will be dictated by the total quantity of material available for analysis.

(2) Typical SW-846 total volume for sample, duplicate, matrix spike, and matrix spiked duplicate extraction 
Table B.3. Inorganic/Radiochemistry Analytical Sub-Sampling Quantities Required ${ }^{(1)}$

\begin{tabular}{|c|c|c|c|c|c|}
\hline Phase & Analysis or Procedure & Sample & Duplicate & MS & SW-846 ${ }^{(2)}$ \\
\hline \multirow[t]{7}{*}{ Dried Solids } & "Acid Digest (ICP, ICP/MS) & $1 \mathrm{~g}$ & $1 \mathrm{~g}$ & $1 \mathrm{~g}$ & $3 \mathrm{~g}$ \\
\hline & $\begin{array}{l}\text { KOH Fusion (ICP,ICP/MS, } \\
\text { Radiochemistry) }\end{array}$ & $0.3 \mathrm{~g}$ & $0.3 \mathrm{~g}$ & $0.3 \mathrm{~g}$ & $\mathrm{n} / \mathrm{a}$ \\
\hline & $\mathrm{Na}_{2} \mathrm{O}_{2}$ Fusion (ICP, ICP/MS) & $0.3 \mathrm{~g}$ & $0.3 \mathrm{~g}$ & $0.3 \mathrm{~g}$ & $\mathrm{n} / \mathrm{a}$ \\
\hline & Total CN & $0.5 \mathrm{~g}$ & $0.5 \mathrm{~g}$ & $0.5 \mathrm{~g}$ & $75 \mathrm{~g}$ \\
\hline & TOC/TIC/TC & $0.5 \mathrm{~g}$ & $0.5 \mathrm{~g}$ & $0.5 \mathrm{~g}$ & $\mathrm{n} / \mathrm{a}$ \\
\hline & Carbon-14 & $0.5 \mathrm{~g}$ & $0.5 \mathrm{~g}$ & $0.5 \mathrm{~g}$ & $\mathrm{n} / \mathrm{a}$ \\
\hline & Selenium-79 & $1 \mathrm{~g}$ & $1 \mathrm{~g}$ & $1 \mathrm{~g}$ & $\mathrm{n} / \mathrm{a}$ \\
\hline \multirow[t]{3}{*}{ Wet Solids } & Wt\% Solids & $3 g$ & $3 g$ & $\mathrm{n} / \mathrm{a}$ & $\mathrm{n} / \mathrm{a}$ \\
\hline & $\begin{array}{l}\text { Water Leach (IC, Ammonia, } \\
\text { H-3) }\end{array}$ & $2 \mathrm{~g}$ & $2 \mathrm{~g}$ & $2 \mathrm{~g}$ & $\mathrm{n} / \mathrm{a}$ \\
\hline & Mercury & $0.3 \mathrm{~g}$ & $0.3 \mathrm{~g}$ & $0.3 \mathrm{~g}$ & $0.6 \mathrm{~g}$ \\
\hline \multirow{2}{*}{\multicolumn{2}{|c|}{$\begin{array}{r}\text { Sub Totals } \\
\text { Total }\end{array}$}} & $9.4 \mathrm{~g}$ & $9.4 \mathrm{~g}$ & $6.4 \mathrm{~g}$ & \\
\hline & & \multicolumn{3}{|c|}{$25.2 \mathrm{~g}$} & \\
\hline \multirow[t]{13}{*}{ Supernatant } & $\begin{array}{l}\text { Acid Digest (ICP, ICP/MS, } \\
\text { Radiochemistry) }\end{array}$ & $8 \mathrm{ml}$ & $8 \mathrm{ml}$ & $8 \mathrm{ml}$ & $300 \mathrm{ml}$ \\
\hline & Dilution (ICP/MS) & $1 \mathrm{ml}$ & $1 \mathrm{ml}$ & $1 \mathrm{ml}$ & $\mathrm{n} / \mathrm{a}$ \\
\hline & IC (inorganic anions) & $1 \mathrm{ml}$ & $1 \mathrm{ml}$ & $1 \mathrm{ml}$ & $\mathrm{n} / \mathrm{a}$ \\
\hline & Mercury & $1 \mathrm{ml}$ & $1 \mathrm{ml}$ & $1 \mathrm{ml}$ & $300 \mathrm{ml}$ \\
\hline & Total CN & $1 \mathrm{ml}$ & $1 \mathrm{ml}$ & $1 \mathrm{ml}$ & $1500 \mathrm{ml}$ \\
\hline & TOC/TIC/TC & $1 \mathrm{ml}$ & $1 \mathrm{ml}$ & $1 \mathrm{ml}$ & $\mathrm{n} / \mathrm{a}$ \\
\hline & Carbon-14 & $1 \mathrm{ml}$ & $1 \mathrm{ml}$ & $1 \mathrm{ml}$ & $\mathrm{n} / \mathrm{a}$ \\
\hline & Ammonia & $2 \mathrm{ml}$ & $2 \mathrm{ml}$ & $\mathrm{n} / \mathrm{a}$ & $\mathrm{n} / \mathrm{a}$ \\
\hline & Tritium (H-3) & $2 \mathrm{ml}$ & $2 \mathrm{ml}$ & $2 \mathrm{ml}$ & $\mathrm{n} / \mathrm{a}$ \\
\hline & Hydroxide $(\mathrm{OH}) \& \mathrm{pH}$ & $5 \mathrm{ml}$ & $5 \mathrm{ml}$ & $\mathrm{n} / \mathrm{a}$ & $\mathrm{n} / \mathrm{a}$ \\
\hline & Flashpoint & $2 \mathrm{ml}$ & $2 \mathrm{ml}$ & $\mathrm{n} / \mathrm{a}$ & $150 \mathrm{ml}$ \\
\hline & Total Dissolved Solids & $5 \mathrm{ml}$ & $5 \mathrm{ml}$ & $\mathrm{n} / \mathrm{a}$ & $\mathrm{n} / \mathrm{a}$ \\
\hline & Density & $2 \mathrm{ml}$ & $2 \mathrm{ml}$ & $\mathrm{n} / \mathrm{a}$ & $\mathrm{n} / \mathrm{a}$ \\
\hline \multirow{2}{*}{\multicolumn{2}{|c|}{$\begin{array}{r}\text { Sub Totals } \\
\text { Total }\end{array}$}} & $32 \mathrm{ml}$ & $32 \mathrm{ml}$ & $16 \mathrm{ml}$ & \\
\hline & & \multicolumn{3}{|c|}{$80 \mathrm{ml}$} & \\
\hline
\end{tabular}

(1) Subsampling quantities are estimates; actual quantities used for the analyses will be dictated by the total quantity of material available for analysis.

(2) Typical SW-846 total volume for sample, duplicate, and matrix spike. 
Table B.4. Organic Analytes of Interest List and MRQs

\begin{tabular}{|c|c|c|c|c|c|}
\hline \multirow{2}{*}{\multicolumn{2}{|c|}{\begin{tabular}{|l|l|} 
CAS & Compound/Element
\end{tabular}}} & \multirow{2}{*}{$\begin{array}{l}\text { MRQ } \\
\mu \mathrm{g} / \mathrm{Kg}\end{array}$} & \multirow[b]{2}{*}{$\overline{\text { CAS }}$} & \multirow[b]{2}{*}{ Compound/Element } & \multirow{2}{*}{$\begin{array}{l}\text { MRQ } \\
\mu \mathrm{g} / \mathrm{Kg}\end{array}$} \\
\hline & & & & & \\
\hline \multicolumn{6}{|c|}{ PNL-ALO-346(9056) } \\
\hline $144-62-7$ & Oxalic acid & ----- & 64-19-7 & Acetic acid & $\begin{array}{ll}---- \\
--1\end{array}$ \\
\hline $64-18-6$ & Formic acid & ----- & $79-10-7$ & 2-Propenoic acid & $\overline{-----}$ \\
\hline \multicolumn{6}{|c|}{ PNL-ALO-346(3810/5021) } \\
\hline $121-44-8$ & Triethylamine & 500 & 71-23-8 & n-Propyl alcohol (1-propanol) & ----- \\
\hline $64-17-5$ & Ethyl alcohol & 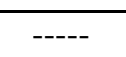 & $71-36-3$ & n-Butyl alcohol & 900 \\
\hline 67-56-1 & Methyl alcohol (Methanol) & $\begin{array}{ll}---- \\
\end{array}$ & $75-65-0$ & 2-Methyl-2-propanol & ----- \\
\hline 67-63-0 & 2-Propyl alcohol (Isopropanol) & ----- & $78-92-2$ & 1-Methylpropyl alcohol (2-butanol) & $\begin{array}{c}---- \\
-1\end{array}$ \\
\hline \multicolumn{6}{|c|}{ PNL-ALO-346(8082) } \\
\hline 1336-36-3 & Polychlorinated biphenyls (PCBs) & 3300 & $58-89-9$ & gamma-BHC (Lindane) & $\begin{array}{l}---- \\
\end{array}$ \\
\hline $309-00-2$ & Aldrin & 22 & $60-57-1$ & Dieldrin & 43 \\
\hline $319-84-6$ & alpha-BHC & 22 & $72-20-8$ & Endrin & 43 \\
\hline $319-85-7$ & beta-BHC & 22 & $72-54-8$ & 4,4 '-DDD & $\begin{array}{ll}--- \\
\end{array}$ \\
\hline $465-73-6$ & Isodrin & 22 & 76-44-8 & Heptachlor & 22 \\
\hline $50-29-3$ & 4,4'-DDT & ---- & $8001-35-2$ & Toxaphene & 900 \\
\hline \multicolumn{6}{|c|}{ PNL-ALO-345(8270C) } \\
\hline $100-00-5$ & p-Nitrochlorobenzene & ----- & 2234-13-1 & Octachloronaphthalene & ----- \\
\hline $100-25-4$ & 1,4-Dinitrobenzene & 800 & $50-32-8$ & Benzo(a)pyrene & 1100 \\
\hline $100-51-6$ & Benzyl alcohol & ----- & $53-70-3$ & Dibenz[a,h]anthracene & 2700 \\
\hline $106-46-7$ & 1,4-Dichlorobenzene & $\begin{array}{c}---- \\
--1\end{array}$ & $541-73-1$ & 1,3-Dichlorobenzene & $\begin{array}{ll}---- \\
\end{array}$ \\
\hline $108-95-2$ & Phenol & 2100 & $62-75-9$ & N-Nitroso-N,N-dimethylamine & 800 \\
\hline $110-86-1$ & Pyridine & 5300 & $67-72-1$ & Hexachloroethane & $\begin{array}{ll}---- \\
\end{array}$ \\
\hline $1319-77-3$ & Cresol (1) & ----- & $82-68-8$ & Pentachloronitrobenzene (PCNB) & 1600 \\
\hline $95-48-7$ & 2-Methylphenol (Cresol isomer) & ----- & $87-68-3$ & Hexachlorobutadiene & 1900 \\
\hline $106-44-5$ & 4-Methylphenol (Cresol isomer) & ----- & $87-86-5$ & Pentachlorophenol & $\begin{array}{ll}---- \\
\end{array}$ \\
\hline $117-81-7$ & Di-sec-octyl phthalate & ----- & $88-85-7$ & 2-sec-Butyl-4,6-dinitrophenol (Dinoseb) & $\begin{array}{l}---- \\
-\end{array}$ \\
\hline $117-84-0$ & n-dioctyl phthalate & $\begin{array}{c}---- \\
\end{array}$ & $91-20-3$ & Naphthalene & $\begin{array}{ll}---- \\
\end{array}$ \\
\hline 118-74-1 & Hexachlorobenzene & 3300 & $92-52-4$ & 1,1`-Biphenyl & $\begin{array}{ll}---- \\
\end{array}$ \\
\hline $120-82-1$ & 1,2,4-Trichlorobenzene & $\begin{array}{ll}---- \\
\end{array}$ & $95-50-1$ & 1,2-Dichlorobenzene & 2000 \\
\hline $122-39-4$ & N,N-Diphenylamine (2) & 4300 & $98-86-2$ & Acetophenone & 3200 \\
\hline 126-73-8 & Tributyl phosphate & $\begin{array}{ll}---- \\
\end{array}$ & $98-95-3$ & Nitrobenzene & 4700 \\
\hline $128-37-0$ & 2,6-Bis(tert-butyl)-4-methylphenol & $\begin{array}{c}---- \\
-1\end{array}$ & & & \\
\hline \multicolumn{6}{|c|}{ TEST Plan per 8290} \\
\hline $1746-01-6$ & 2,3,7,8-Tetrachlorodibenzo-p-dioxin & ----- & $57117-31-4$ & 2,3,4,7,8-Pentachlorodibenzofuran & $\begin{array}{ll}---- \\
\end{array}$ \\
\hline 19408-74-3 & 1,2,3,7,8,9-Hexachlorodibenzo-p-dioxin & $\begin{array}{c}---- \\
\end{array}$ & 57117-41-6 & 1,2,3,7,8-Pentachlorodibenzofuran & ----- \\
\hline $3268-87-9$ & 1,2,3,4,6,7,8,9-Octachlorodibenzo-p-dioxin & ----- & $57117-44-9$ & 1,2,3,6,7,8-Hexachlorodibenzofuran & ----- \\
\hline 35822-39-4 & 1,2,3,4,6,7,8-Heptachlorodibenzo-p-dioxin & $\begin{array}{c}---- \\
\end{array}$ & $57653-85-7$ & 1,2,3,6,7,8-Hexachlorodibenzo-p-dioxin & $\begin{array}{ll}---- \\
\end{array}$ \\
\hline $39001-02-0$ & 1,2,3,4,6,7,8,9-Octachlorodibenzofuran & $\begin{array}{c}---- \\
\end{array}$ & 60851-34-5 & 2,3,4,6,7,8-Hexachlorodibenzofuran & $\begin{array}{ll}---- \\
\end{array}$ \\
\hline 39227-28-6 & 1,2,3,4,7,8-Hexachlorodibenzo-p-dioxin & $\begin{array}{c}---- \\
\end{array}$ & 67562-39-4 & 1,2,3,4,6,7,8-Heptachlorodibenzofuran & ----- \\
\hline 40321-76-4 & 1,2,3,7,8-Pentachlorodibenzo-p-dioxin & ------ & 70648-26-9 & 1,2,3,4,7,8-Hexachlorodibenzofuran & $\begin{array}{ll}---- \\
\end{array}$ \\
\hline 51207-31-9 & 2,3,7,8-Tetrachlorodibenzofuran & $\begin{array}{c}---- \\
\end{array}$ & 72918-21-9 & 1,2,3,7,8,9-Hexachlorodibenzofuran & $\begin{array}{cc}---- \\
\end{array}$ \\
\hline $55673-89-7$ & 1,2,3,4,7,8,9-Heptachlorodibenzofuran & $\begin{array}{ll}---- \\
\end{array}$ & & & \\
\hline \multicolumn{6}{|c|}{ PNL-ALO-335(8260B) } \\
\hline $100-41-4$ & Ethyl benzene & 3300 & $141-78-6$ & Acetic acid ethyl ester & 11000 \\
\hline
\end{tabular}




\begin{tabular}{|c|c|c|c|c|c|}
\hline \multirow{2}{*}{\multicolumn{2}{|c|}{\begin{tabular}{|l|l|}
\multicolumn{2}{|l|}{} \\
CAS & Compound/Element \\
\end{tabular}}} & \multirow{2}{*}{$\begin{array}{l}\text { MRQ } \\
\mu g / K g\end{array}$} & \multirow[b]{2}{*}{ CAS } & \multirow[b]{2}{*}{ Compound/Element } & \multirow{2}{*}{$\begin{array}{l}\text { MRQ } \\
\mu g / K g\end{array}$} \\
\hline & & & & & \\
\hline & Styrene & ----- & $142-82-5$ & n-Heptane & ----- \\
\hline $10061-01-5$ & cis-1,3-Dichloropropene & 6000 & $287-92-3$ & Cyclopentane & ----- \\
\hline 10061-02-6 & trans-1,3-Dichloropropene & 6000 & $4170-30-3$ & 2-Butenaldehyde (2-Butenal) & $\begin{array}{l}---- \\
\end{array}$ \\
\hline $106-35-4$ & 3-Heptanone & $\begin{array}{ll}---- \\
\end{array}$ & $56-23-5$ & Carbon tetrachloride & 2000 \\
\hline $106-42-3$ & p-Xylene \& m-Xylene & 3300 & $563-80-4$ & 3-Methyl-2-butanone & $\begin{array}{ll}---- \\
\end{array}$ \\
\hline $106-93-4$ & Ethylene dibromide & 5000 & 591-78-6 & 2-Hexanone & $\begin{array}{l}---- \\
-9\end{array}$ \\
\hline $106-97-8$ & Butane & ----- & $627-13-4$ & Nitric acid, propyl ester & $\begin{array}{ll}---- \\
\end{array}$ \\
\hline $106-99-0$ & 1,3-Butadiene & ----- & $684-16-2$ & Hexafluoroacetone (3) & 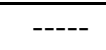 \\
\hline $107-02-8$ & Acrolein & ----- & $67-64-1$ & 2-Propanone (Acetone) & 53300 \\
\hline $107-05-1$ & 3-Chloropropene & 10000 & $67-66-3$ & Chloroform & 2000 \\
\hline $107-06-2$ & 1,2-Dichloroethane & 2000 & $71-43-2$ & Benzene & 3300 \\
\hline $107-12-0$ & Propionitrile & 120000 & 71-55-6 & 1,1,1-Trichloroethane & 2000 \\
\hline $107-13-1$ & Acrylonitrile & 28000 & 74-83-9 & Bromomethane & 5000 \\
\hline $107-87-9$ & 2-Pentanone & ----- & $74-87-3$ & Chloromethane & 10000 \\
\hline $108-10-1$ & 4-Methyl-2-pentanone & 11000 & $75-00-3$ & Chloroethane & $\begin{array}{l}---- \\
\end{array}$ \\
\hline $108-38-3$ & m-Xylene (See 106-42-3) & 3300 & 75-01-4 & 1-Chloroethene & 2000 \\
\hline $108-87-2$ & Methylcyclohexane & ----- & 75-05-8 & Acetonitrile & 12700 \\
\hline $108-88-3$ & Toluene & 3300 & 75-09-2 & Dichloromethane (Methylene Chloride) & 10000 \\
\hline $108-90-7$ & Chlorobenzene & 2000 & $75-15-0$ & Carbon disulfide & $\begin{array}{l}---- \\
\end{array}$ \\
\hline 108-94-1 & Cyclohexanone & $\begin{array}{ll}---- \\
\end{array}$ & $75-34-3$ & 1,1-Dichloroethane & 2000 \\
\hline $109-66-0$ & n-Pentane & ----- & $75-35-4$ & 1,1-Dichloroethene & 2000 \\
\hline $109-99-9$ & Tetrahydrofuran & ----- & 75-43-4 & Dichlorofluoromethane & ----- \\
\hline $110-12-3$ & 5-Methyl-2-hexanone & ----- & $75-45-6$ & Chlorodifluoromethane & $\begin{array}{ll}---- \\
\end{array}$ \\
\hline $110-43-0$ & 2-Heptanone & ----- & 75-69-4 & Trichlorofluoromethane & 10000 \\
\hline $110-54-3$ & n-Hexane & ----- & 75-71-8 & Dichlorodifluoromethane & 2400 \\
\hline $110-82-7$ & Cyclohexane & $\begin{array}{l}---- \\
\end{array}$ & $76-13-1$ & 1,2,2-Trichloro-1,1,2-trifluoroethane & 10000 \\
\hline $110-83-8$ & Cyclohexene & ----- & 76-14-2 & 1,2-Dichloro-1,1,2,2-tetrafluoroethane & $\begin{array}{ll}---- \\
\end{array}$ \\
\hline $111-65-9$ & n-Octane & ----- & $78-87-5$ & 1,2-Dichloropropane & ----- \\
\hline $111-84-2$ & n-Nonane & $\begin{array}{c}---- \\
\end{array}$ & $78-93-3$ & 2-Butanone & 12000 \\
\hline $123-19-3$ & 4-Heptanone & $\begin{array}{ll}---- \\
\end{array}$ & 79-00-5 & 1,1,2-Trichloroethane & 2000 \\
\hline $123-38-6$ & n-Propionaldehyde & $\begin{array}{ll}---- \\
\end{array}$ & 79-01-6 & 1,1,2-Trichloroethylene & 2000 \\
\hline $123-86-4$ & Acetic acid n-butyl ester & ----- & $79-34-5$ & 1,1,2,2-Tetrachloroethane & 2000 \\
\hline 123-91-1 & 1,4-Dioxane & ----- & $95-47-6$ & o-Xylene & 3300 \\
\hline $126-98-7$ & 2-Methyl-2-propenenitrile & 28000 & $96-22-0$ & 3-Pentanone & $\begin{array}{c}---- \\
\end{array}$ \\
\hline $127-18-4$ & 1,1,2,2-Tetrachloroethene & 2000 & & & \\
\hline \multicolumn{2}{|c|}{ PNL-ALO-345(8270C) -Standards Unavailable } & & \multicolumn{3}{|c|}{ PNL-ALO-346(8260B) - Very reactive } \\
\hline 1321-64-8 & Pentachloronaphthalene & ----- & $57-14-7$ & 1,1-Dimethylhydrazine & ----- \\
\hline $1335-87-1$ & Hexachloronaphthalene & $\begin{array}{c}---- \\
\end{array}$ & $60-34-4$ & Methylhydrazine & $\begin{array}{ll}---- \\
\end{array}$ \\
\hline $1335-88-2$ & Tetrachloronaphthalene & ----- & $624-83-9$ & Methyl isocyanate & ----- \\
\hline \multicolumn{6}{|c|}{ Deleted per BFNL } \\
\hline $3825-26-1$ & Ammonium perfluorooctanoate & ----- & 88-89-1 & Picric acid & ----- \\
\hline 75-21-8 & Oxirane & ----- & & & \\
\hline \multicolumn{6}{|c|}{$\begin{array}{l}\text { (1) Cresol measured as independent Methylpl } \\
\text { (2) Not be distinguished from Diphenylamine } \\
\text { (3) Toxic gas, not previously analyzed } \\
\text { (4) “----“" = No MRQ provided by BNFL }\end{array}$} \\
\hline
\end{tabular}


Table B.5. Inorganic and Radiochemistry Analytes of Interest List

(Note: No MRQs Provided For Inorganic Analytes or Radionuclides of Interest)

\begin{tabular}{|c|c|c|}
\hline \multicolumn{3}{|l|}{ ICP Analytes } \\
\hline Silver & Iron & Antimony \\
\hline Aluminum & Potassium & Selenium \\
\hline Arsenic & Lanthanum $^{(1)}$ & Silicon \\
\hline Boron & Lithium & Tin \\
\hline Barium & Magnesium & Strontium $^{(1)}$ \\
\hline Beryllium & Manganese & Tellurium ${ }^{(1)}$ \\
\hline Bismuth & Molybdenum & Thorium $^{(1)}$ \\
\hline Calcium & Sodium & Titanium $^{(1)}$ \\
\hline Cadmium & Neodymium $^{(1)}$ & Thallium \\
\hline Cerium $^{(1)}$ & Nickel & Uranium \\
\hline Cobalt & Phosphorus & Vanadium \\
\hline Chromium & Lead & Tungsten \\
\hline Copper & Palladium & Yttrium \\
\hline Dysprosium & Rhodium & Zinc \\
\hline Europium & Ruthenium $^{(1)}$ & Zirconium \\
\hline \multicolumn{3}{|l|}{ IC Analytes } \\
\hline Bromide & Nitrate & Phosphate \\
\hline Chloride & Fluoride & \\
\hline \multicolumn{3}{|l|}{ ICP-MS Analytes } \\
\hline Iodine-127 & Plutonium-240 & Uranium-233 \\
\hline Iodine-129 & Praseodymium & Uranium-234 \\
\hline Neptunium-237 & Rubidium & Uranium-235 \\
\hline Platinum & Tantalum & Uranium-236 \\
\hline Plutonium-239 & Technitium-99 & Uranium-238 \\
\hline \multicolumn{3}{|l|}{ Radiochemistry Analytes } \\
\hline Alpha, Total & Cobalt-60 & Plutonium-241 \\
\hline Antimony-125 (GEA) & Curium-242 (AEA) & Ruthenium-106/Rhodium-106 \\
\hline Americium-241 (AEA) & Curium-243/244 (AEA) & Selenium-79 \\
\hline Americium-241 (GEA) $^{(1)}$ & Europium-154 (GEA) & Strontium-90/Yttrium-90 \\
\hline Beta, Total & Europium-155 (GEA) & Tin-126 (GEA) \\
\hline Carbon-14 & Niobium-94 (GEA) & Tritium \\
\hline Cesium-134 (GEA) & Plutonium-238 & Uranium-Fluorimetry \\
\hline Cesium-137 (GEA) & Plutonium-239/240 ${ }^{(1)}$ & \\
\hline \multicolumn{3}{|l|}{ Other Analytes ${ }^{(1)}$} \\
\hline Ammonia/Ammonium & Mercury & Wt\% Dissolved Solids \\
\hline Cyanide & pH (Supernatant) & Wt\% Suspended Solids \\
\hline Flashpoint (Supernatant) & Total Organic Carbon & \\
\hline Hydroxide (Supernatant) & Total Inorganic Carbon & \\
\hline \multicolumn{3}{|c|}{ Analytes Not Analyzed per Change Request Proposal } \\
\hline Total Nitrogen & Total Sulfur & Total Iodine \\
\hline Total Oil/Grease & Reactive Sulfur & Reactive Cyanide \\
\hline SS Corrosion Testing & TCLP Extractions/Analysis & \\
\hline
\end{tabular}

(1) Additional Analytes of Interest Measured and Reported 
Appendix C: PNNL Test Plan for Organic Extraction of C-104 Samples and Sub-sampling for VOA, Headspace, and Anions, BNFL-29953-080, Rev. No. 1 


\section{PNNL Test Plan}

Document No.: BNFL-29953-080

Rev. No.: 1

Title: Organic Extraction of C-104 Samples and sub-sampling for VOA, Headspace, and Anions

Work Location:

325/SFO, 325/general labs; 329/general labs

Author: Michael W. Urie

Use Category Identification: Reference

Identified Hazards:

$\underline{X}$ Radiological

$\underline{\mathrm{x}}$ Hazardous Materials

- Physical Hazards

- Hazardous Environment

- Other:
Page 1 of 17

Effective Date: Upon final signature Supersedes Date: New

Required Reviewers:

$\underline{X}$ Technical Reviewer $\underline{X}$ Project Manager

Building Manager $\quad \underline{X}$ RPL Manager

_ Radiological Control $\underline{X}$ SFO Manager

ES\&H

$\underline{X}$ Quality Engineer

Are One-Time Modifications Allowed to this Procedure?

$$
\mathrm{X} \text { Yes } \quad \text { No }
$$

NOTE: If Yes, then modifications are not anticipated to impact safety. For documentation requirements of a modification see SBMS or the controlling Project QA Plan as appropriate.

\section{On-The Job Training Required? __ Yes or $\quad \mathrm{X}$ No FOR REVISIONS:}

Is retraining to this procedure required? __ Yes _

Does the OJT package associated with this procedure require revision to reflect procedure changes? _ Y Yes_ No $\underline{X} \mathrm{~N} / \mathrm{A}$

\section{pproval}

Signature

Date

Author (VOA, SVOA)/Reviewer_ Signature on File

Author (PCB, Headspace)/Reviewer_ Signature on File

Author (Dioxins/Furans, Anions)/Reviewer

Signature on File

RPL Manager__ Signature on File

SFO Manager

Signature on File

Project Manager/Reviewer__Signature on File

AO\&AM Manager__ Signature on File

Quality Engineer__ Signature on File 


\section{Applicability}

This Organic Extraction Test Plan describes work to be performed under Test Plan TP-29953-030, Inorganic, Organic and Radiochemical Characterization of C-104 Samples. These samples are slurries, which contain solids, and decanted liquid. Together these samples provide the starting material for the organic characterization of the "as received" materials. Per the TP-29953-030, two bottles containing about 340 grams of slurry and one jar containing about 175 grams of supernatant will be sub-sampled for VOA, headspace analysis, organic anions, SVOA, pesticide/PCB, and Dioxin/Furan analysis, as well as inorganic and radiochemistry analysis specified in the test plan. Sub-sampling and dilutions for VOA and headspace analysis will be performed prior to beginning extractions so as not to contaminate these sub-samples with solvent vapors.

Based on the history of the samples, and the limited quantities available, exceptions are being taken to the preservation, temperature control, sample size, and hold time requirements specified by SW-846 protocols. The choice of spiking solutions and extraction solvents is based upon SW-846 methods 8270C, 8081A/8082 and 8290 guidelines, where applicable.

This revision provides final documentation for the actual work performed for phase separation of the C-104 slurry, sub-sampling activities for the VOA and Headspace analyses, and the organic extraction process performed for preparing the SVOA, PCB, and Dioxin/Furan samples.

\section{Hazards Assessment and Mitigation}

The radioactive work conducted under this Test Plan is comprised of analytical organic analysis preparative operations that have been conducted routinely in the RPL and 329 Facilities. The organic extractions with small quantities of methylene chloride or methylene chloride/acetone mixtures have been performed in the Shielded Analytical Laboratory (SAL) many times and are included as a standard preparative activity on the RPL Analytical Service Request. The organic solvent extraction operations are included in the SAL work authorization. Since all of the analytical preparative operations fall within current work authorizations, no further assessment of the hazards is detailed in this Test Plan.

\section{Quality Control}

Per TP-29953-030, quality control is governed by PNNL's web-based Quality Assurance Planning Subject Area, “Conducting Analytical Work in Support of Regulatory Programs”. The organic analyses will be performed in duplicate using a sample size that will closely meet regulatory reporting level for waste material. Sample sizes are specified in Test Plan TP-29953-030. Surrogate spike compounds will be added to the sample, sample duplicate, and matrix spikes in order to provide information on analyte recoveries. Separate laboratory control samples (LCS) will be prepared outside the hot-cell.

Integrity of the sub-samples and processed extracts distributed throughout the laboratory will be maintained by chain-of-custody documentation. The Task Manager shall approve changes to this Test Plan (initialed markups are allowed).

\section{Work Instructions}

An extraction scheme for the SVOA extraction activity is provided in Figure C.1. Extraction schemes for PCB/pesticide and dioxin extractions are provided in Figures C.2 and C.3, respectively. 
Total dissolved solids of the supernatant and weight percent solids of the centrifuged solids will be determined prior to sub-sampling and extracting.

The extractions of these C-104 HLW samples will be performed in the Shielded Analytical Laboratory within the 325 facility.

\section{Total Dissolved Solids and Weight Percent Solids Determination}

Because these samples may contain reduced iron or other magnetically separable particles, a magnetic stir-bar and magnetic stir table should not be used. A better approach is to perform the stirring with an impeller-type stirrer, such as a Teflon coated spatula rotated by a variable speed drill. After a few minutes of stirring, and once the solids appear to be suspended, a 1-g to 3-g aliquot is placed in a tared graduated centrifuge tube, weighed, and centrifuged at 1000 RPM for approximately one hour. After centrifuging, note and record the volume of both the liquid and the solids in the tube. Decant the liquid into a tared beaker, weigh and dry at $105^{\circ} \mathrm{C}$ overnight. Weigh the beaker after at least 12 hours of drying to determine the total dissolved solids for the supernatant. Weight percent solids determination will be performed on the centrifuged solids, remaining in the centrifuge tube, in accordance with PNL-ALO-504.

\section{Separation of the Wet Solids from the Slurry}

Centrifugation of the slurry (i.e., C104 Comp A and C104 Comp B) may be more convenient than filtration for the separation of the wet solids from the slurry. In order to centrifuge the 120 -mL jars, they must first be balanced to $\pm 1 \mathrm{~g}$. Weigh each jar and transfer the appropriate quantity of liquid from the heavier jar to the lighter jar to balance them. Place the jars in clean polyethylene sleeves, and centrifuge at no greater than 1000 RPM for 1 hour. As a precaution, it is prudent to perform a "dry-run" first, using balanced jars containing approximately $100 \mathrm{~mL}$ of deionized water, and centrifuging at 1100 RPM. After the jars containing the slurries have been centrifuged, carefully remove them from the centrifuge and the plastic sleeves. Carefully decant the supernatant into a clean jar or combine with the jar containing C-104 supernatant (i.e., container C104 SUP. A) if room is available in the container. Weigh the jar containing the wet centrifuged solids, and record this weight on the benchsheet. In the event the total quantities of supernatant and wet solids are less than those listed in test plan BNFL-29953-30, contact Michael W. Urie, 376-9454.

\section{Sub-sampling for VOA and Headspace analysis}

VOA and headspace aliquots shall be made prior to introducing methylene chloride, or other solvents, into the hot-cells.

Headspace samples should be aliquotted into clean 10 -mL headspace vials and sealed with a septalined cap immediately afterward. A 1-mL supernatant sample, sample duplicate, sample triplicate and blank will be prepared for each sample as described in Test Plan TP-29953-030, Table C.2. (Note: The sample triplicate is an additional sub-sample not identified in TP-29953-030.) A 1-mL supernatant matrix spike and matrix spike duplicate will also be aliquotted at this time. The headspace vials should be tared on an analytical balance, and each 1-mL aliquot weighed and recorded, so that the density of the supernatant can be determined during this step. Additionally, 50-microliter aliquots each of the supernatant sample, sample duplicate, sample triplicate, matrix spike, and matrix spike duplicate shall also be prepared to permit quantitation of analytes that may be outside the calibration range for a 1-mL sample size. 
VOA samples should be aliquotted into clean $40-\mathrm{mL}$ VOA vials and sealed with a septa-lined cap immediately afterward. A 2-mL supernatant sample, sample duplicate and blank will be prepared for each sample as described in Test Plan TP-29953-030. A 1-mL supernatant matrix spike, and matrix spike duplicate will also be aliquotted at this time. Additionally, 50-microliter aliquots of each the supernatant sample, sample duplicate, matrix spike, matrix spike duplicate shall also be prepared to permit quantitation of analytes that maybe outside the calibration range for a 2-mL sample size.

Half gram aliquots of the wet centrifuged solids will be aliquotted into clean $40-\mathrm{mL}$ VOA vials, diluted with organic-free water to a volume of $5 \mathrm{~mL}$ and sealed immediately with a septa-lined cap. The aliquots for the VOA MS and MSD shall be 0.25-g rather than the 0.5-g aliquots used for the sample and duplicate. In a like manner, a second set of wet centrifuged solids will be aliquotted using a 50-mg sample size for each the sample, duplicate, MS and MSD.

VOA and headspace samples will be transferred from the hot-cell immediately after preparation. For further guidance or questions regarding VOA sub-sampling contact George S. Klinger, 372-0448. For further guidance or questions regarding headspace sub-sampling contact Eric W. Hoppe, 376-2126.

\section{Extraction Samples for SVOA, PCB/Pesticides and Dioxins Analysis}

General Comments:

- The quantities of the sample, sample duplicate, matrix spike, and matrix spike duplicate are given in Table C.2 of Test Plan BNFL-29953-030 and restated in Section 2.1.

- Teflon separatory funnels, with FEP caps, are used for the liquid-liquid extraction processing and Teflon centrifuge tubes are used for the subsequent solids ultrasonic processing.

- $\quad$ Phosphoric acid is used to adjust the $\mathrm{pH}$ prior to extraction of the liquids, as appropriate.

- A small $(0.5 \mathrm{ml})$ portion of the liquid is potentiometricly titrated to determine the quantity of phosphoric acid required to adjust the $\mathrm{pH}$ of the sample. The amount of precipitate formed during acidification will be evaluated and the precipitate extracted separately, if required.

- Spiking solutions will be added to the sample prior to extraction. If solids formed as a result of $\mathrm{pH}$ adjustment warrant a separate extraction step, additional spikes will not be added as these extracts will be recombined with the "like" phase extracts.

The nominal MDLs for liquids and solids are shown in Tables B.1 and B.2, respectively. The surrogate spikes and quantities added are shown in Table C.3. The appropriate spiking materials shall be provided by G. Klinger for SVOA, by E. Hoppe for pesticides/PCB, and J. Campbell for dioxins/furans.

Table C.1. Liquid portion HLW organic analysis MDLs

\begin{tabular}{|lcc||}
\hline \multicolumn{1}{|c}{ Analysis } & MDL (ppb, 1 L water) & MDL (ppb, 25 mL \\
& & sample) \\
\hline Semivolatiles & 10 to 25 & 400 to 1000 \\
Pesticides and PCBs & 0.1 to 1 & 4 to 40 \\
Dibenzodioxins and Dibenzofurans & $1 \times 10^{-4}$ to $1 \times 10^{-3}$ & $4 \times 10^{-3}$ to $4 \times 10^{-2}$ \\
\hline
\end{tabular}


Table C.2. Solid Portion HLW Organic Analysis MDLs

\begin{tabular}{|l|c|c||}
\hline \multicolumn{1}{|c|}{ Analysis } & MDL (ppm, 1 g solid) & $\begin{array}{c}\text { MDL (ppm, 5 g } \\
\text { sample) }\end{array}$ \\
\hline Semivolatiles & 10 to 25 & 2 to 5 \\
\hline $\begin{array}{l}\text { Pesticides and PCBs } \\
\text { Dibenzodioxins and } \\
\text { Dibenzofurans }\end{array}$ & 0.1 to 1 & 0.02 to 0.2 \\
\hline
\end{tabular}

Table C.3. Surrogate Spike Compounds and Levels Added to Samples

\begin{tabular}{|c|c|c|}
\hline Analysis & Spike Compounds & $\begin{array}{c}\text { Amounts Added } \\
(\mu \mathrm{g})\end{array}$ \\
\hline Semivolatiles & $\begin{array}{l}\text { phenol- } \mathrm{d}_{5} \\
\text { 2-fluorophenol } \\
\text { 2-chlorophenol- } \mathrm{d}_{4} \\
\text { 2,4,6-tribromophenol } \\
\text { 1,2-dichlorobenzene- } \\
\mathrm{d}_{4} \\
\text { nitrobenzene- }_{5} \\
\text { 2-fluorobiphenyl } \\
\text { p-terphenyl- } \mathrm{d}_{14}\end{array}$ & $\begin{array}{l}75 \\
75 \\
75 \\
75 \\
50 \\
50 \\
50 \\
50\end{array}$ \\
\hline $\begin{array}{l}\text { Dibenzodioxins and } \\
\text { Dibenzofurans }\end{array}$ & $\begin{array}{l}{ }^{13} \mathrm{C}_{12}-2,3,7,8 \text { TCDD } \\
{ }^{13} \mathrm{C}_{12}-2,3,7,8 \text { TCDF } \\
{ }^{13} \mathrm{C}_{12}-1,2,3,7,8 \text { PeCDD } \\
{ }^{13} \mathrm{C}_{12}-1,2,3,7,8 \text { PeCDF } \\
{ }^{13} \mathrm{C}_{12}-2,3,4,7,8 \text { PeCDF } \\
{ }^{13} \mathrm{C}_{12}-1,2,3,4,7,8 \\
{ }^{\mathrm{HxCDD}}{ }^{13} \mathrm{C}_{12}-1,2,3,6,7,8 \\
{ }^{\mathrm{H} x C D D} \\
{ }^{13} \mathrm{C}_{12}-1,2,3,4,7,8 \\
{ }^{\mathrm{HxCDF}} \\
{ }^{13} \mathrm{C}_{12}-1,2,3,6,7,8 \\
{ }^{\mathrm{HxCDF}} \\
{ }^{13} \mathrm{C}_{12}-1,2,3,7,8,9 \\
{ }^{\mathrm{HxCDF}} \\
{ }^{13} \mathrm{C}_{12}-2,3,4,6,7,8 \\
{ }_{\mathrm{HxCDF}} \\
{ }^{13} \mathrm{C}_{12}-1,2,3,4,6,7,8 \\
\mathrm{HpCDD}^{13} \mathrm{C}_{12}-1,2,3,4,6,7,8 \\
\mathrm{HpCDF} \\
{ }^{13} \mathrm{C}_{12}-1,2,3,4,7,8,9 \\
{ }_{\mathrm{HpCDF}} \\
{ }^{13} \mathrm{C}_{12}-\mathrm{OCDD}\end{array}$ & $\begin{array}{c}0.05 \\
0.05 \\
0.05 \\
0.05 \\
0.05 \\
0.05 \\
0.05 \\
0.05 \\
0.05 \\
0.05 \\
0.05 \\
0.05 \\
0.05 \\
0.05 \\
0.1\end{array}$ \\
\hline Pesticides and PCBs & $\begin{array}{l}\text { tetrachloro-m-xylene } \\
\text { decachlorobiphenyl }\end{array}$ & $\begin{array}{l}0.040 \\
0.040 \\
\end{array}$ \\
\hline
\end{tabular}




\section{Extraction of the supernatant portion of the HLW samples}

Extractions for the SVOA supernatant sample and duplicate are performed on 20-mL aliquots, with the extractions for the SVOA matrix spike and matrix spike duplicates being performed on 10-mL aliquots.

Extractions for all pesticides and PCB supernatant samples are performed on 10-mL aliquots. And, extractions for dioxins/furans supernatant sample and duplicate are performed on 15-mL aliquots, with the extractions for the dioxins/furans matrix spike and matrix spike duplicate being performed on 7.5-mL aliquots. The quantity of matrix spike used is given in Table C.4. Extraction blanks shall be prepared using the same quantity of organic-free water as the quantity of supernatant sample. Stepwise instructions for performing the extractions are given in the appropriate sections..

\section{Semivolatiles}

As shown in Figure C.1, the supernatant portion of the as received sample is diluted with $25 \mathrm{~mL}$ of $0.01 \mathrm{~N} \mathrm{NaOH}$ (prepared from organic-free water) prior to extraction. Following dilution the supernatant sample is extracted three times with equal portions of methylene chloride.

The supernatant sample is then $\mathrm{pH}$ adjusted by slow drop-wise addition of phosphoric acid while the sample is cooled in an ice-bath during the acidification. The pH-adjusted supernatant sample is extracted three times with equal portions of methylene chloride.

If during the acidification process any solids are formed at a relative quantity $>1 \%$ by volume, the solids are separated, desiccated with sodium sulfate, and ultrasonic extracted three times using equal portions of methylene chloride.

All SVOA extracts from the supernatant portion of the as received sample are combined and concentrated to $1 \mathrm{~mL}$ outside the hot-cells.

\section{Pesticides/PCB}

As shown in Figure C.2, the supernatant portion of the as received sample is diluted with $25 \mathrm{~mL}$ of $0.01 \mathrm{~N} \mathrm{NaOH}$ (prepared from organic-free water) prior to extraction. Following dilution the supernatant sample is extracted three times with equal portions of methylene chloride.

The supernatant sample is then $\mathrm{pH}$ adjusted by slow drop-wise addition of phosphoric acid while the sample is cooled in an ice-bath during the acidification. The $\mathrm{pH}$-adjusted supernatant sample is extracted three times with equal portions of methylene chloride.

If during the acidification process any solids are formed at a relative quantity $>1 \%$ by volume, the solids are separated, desiccated with sodium sulfate, and ultrasonic extracted three times using equal portions of a 1:1 methylene chloride/acetone mixture.

All extracts from the supernatant portion of the as received sample are combined and concentrated to $1 \mathrm{~mL}$ outside the hot-cells.

\section{Dioxins/Furans}

Adjustment of the $\mathrm{pH}$ is presumed not to be necessary for the dioxin/furan extractions. To dilute the sample, $25 \mathrm{~mL}$ of $0.01 \mathrm{~N} \mathrm{NaOH}$ (prepared from organic-free water) will be added to the sample prior to extraction. As shown in Figure C.3, a supernatant sample is extracted (liquid-liquid) three times with equal portions of methylene chloride. The extracts from the supernatant portion of the as received sample are combined and concentrated to $1 \mathrm{~mL}$ outside the hot-cells. 


\section{Extraction of the centrifuged solids portion of the HLW samples}

The solid sample and duplicate will be extracted using $5 \mathrm{~g}$ of the solids portion of the as received sample. A matrix spike and spike duplicate will be extracted using $2.5 \mathrm{~g}$ of sample. The quantity of matrix spike used is given in Table C.4. Leach blanks shall be prepared using the same quantity of organic-free water as the quantity of $0.01 \mathrm{~N} \mathrm{NaOH}$ added to the sample. Stepwise instructions for performing the extractions are given in the appropriate sections.

\section{SVOAs}

As shown in Figure C.1, the solids portion of the as received sample is leached (with ultrasonic agitation) once with $50 \mathrm{~mL}$ of organic-free $0.01 \mathrm{~N} \mathrm{NaOH}$ solution. Based upon the earlier dissolution test using a 0.5 -g aliquot, any solids remaining at a level greater than $1 \%$ of the original solids portion are separated and extracted separately. The $\mathrm{NaOH}$ leachate (i.e., dissolved solids) is extracted three times with equal portions of methylene chloride.

The $\mathrm{NaOH}$ leachate is then $\mathrm{pH}$ adjusted by slow drop-wise addition of phosphoric acid while the sample is cooled in an ice-bath during the acidification. If a solid precipitate is formed at a relative quantity of $>1 \%$ by volume, it is separated and extracted separately. The $\mathrm{pH}$-adjusted $\mathrm{NaOH}$ leachate is extracted three times with equal portions of methylene chloride.

The undissolved solids and any solids formed during the acidification process are combined, desiccated with sodium sulfate, and ultrasonic extracted three times using methylene chloride.

All SVOA extracts from the solids portion of the as received sample are combined and concentrated to $1 \mathrm{~mL}$ outside the hot cells.

\section{Pesticide/PCBs}

As shown in Figure C.2, the solids portion of the sample is leached (with ultrasonic agitation) twice with $40 \mathrm{~mL}$ of organic-free $0.01 \mathrm{~N} \mathrm{NaOH}$ solution. Based upon the earlier dissolution test using a 0.5 -g aliquot, any solids remaining at a level greater than $1 \%$ of the original solids portion are separated and extracted separately. The $\mathrm{NaOH}$ leachate (i.e., dissolved solids) is extracted three times with equal portions of methylene chloride.

The $\mathrm{NaOH}$ leachate is then $\mathrm{pH}$ adjusted by slow drop-wise addition of phosphoric acid while the sample is cooled in an ice-bath during the acidification. If a solid precipitate is formed at a relative quantity of $>1 \%$ by volume, it is separated and extracted separately. The $\mathrm{pH}$-adjusted $\mathrm{NaOH}$ leachate is extracted three times with equal portions of methylene chloride.

The undissolved solids and any solids formed during the acidification process are combined, desiccated with sodium sulfate, and ultrasonic extracted three times using a 1:1 methylene chloride/acetone solution.

All pesticide/PCB extracts from the solids portion of the as received sample are combined and concentrated to $1 \mathrm{~mL}$ outside the hot-cells.

\section{Dioxins/Furans}

As shown in Figure C.3, no liquids will be added to the solid portion of the solids sample, as was done for the SVOA and pesticide/PCB extractions. The dioxin extractions do not require a $\mathrm{pH}$ adjustment of the wet centrifuged solids. A desiccant is mixed with the wet solids to retain any water, and the desiccated solids are ultrasonically extracted three times with a 1:1 methylene 
chloride/acetone solution. The dioxin extracts are combined and concentrated to $1 \mathrm{~mL}$ outside the hot-cells.

\section{Preparation and Extraction of Matrix Spikes and LCS for SVOA, Dioxins/Furans and pesticide/PCB analysis}

A separate LCS will be prepared for each analysis outside the hot-cells using the sample reagents used for the extraction of the HLW samples. The LCS matrix will consist of 1 Liter of distilled water. The LCSs will be extracted using liquid-liquid extraction. The LCSs will be spiked with the compounds and levels listed in Table C.4. Separate LCSs will be prepared for SVOA, Dioxin/Furans, pesticides, and PCBs. The LCS will be spiked with the same surrogates as listed in Table C.3.

Table C.4. Laboratory Control Sample Spiking Level

\begin{tabular}{|c|c|c|}
\hline CAS Reg. No. & Compound & $\mu g$ \\
\hline \multicolumn{3}{|c|}{ Semivolatile MS and LCS spike compounds } \\
\hline $100-51-6$ & Benzyl alcohol & 50 \\
\hline $106-46-7$ & 1,4-Dichlorobenzene & 50 \\
\hline $108-95-2$ & Phenol & 50 \\
\hline $117-81-7$ & Di-sec-octyl phthalate & 50 \\
\hline $117-84-0$ & n-dioctyl phthalate & 50 \\
\hline $118-74-1$ & Hexachlorobenzene & 50 \\
\hline $120-82-1$ & 1,2,4-Trichlorobenzene & 50 \\
\hline $50-32-8$ & Benzo(a)pyrene & 50 \\
\hline $53-70-3$ & Dibenz[a,h]anthracene & 50 \\
\hline $541-73-1$ & 1,3-Dichlorobenzene & 50 \\
\hline $62-75-9$ & N-Nitroso-N,N-dimethylamine & 50 \\
\hline $67-72-1$ & Hexachloroethane & 50 \\
\hline $87-68-3$ & Hexachlorobutadiene & 50 \\
\hline $87-86-5$ & Pentachlorophenol & 50 \\
\hline $91-20-3$ & Naphthalene & 50 \\
\hline $95-50-1$ & 1,2-Dichlorobenzene & 50 \\
\hline $98-95-3$ & Nitrobenzene & 50 \\
\hline $100-00-5$ & p-Nitrochlorobenzene & 50 \\
\hline $100-25-4$ & 1,4-Dinitrobenzene & 50 \\
\hline $110-86-1$ & Pyridine & 50 \\
\hline $122-39-4$ & N,N-Diphenylamine & 50 \\
\hline $126-73-8$ & Tributyl phosphate & 50 \\
\hline $128-37-0$ & 2,6-Bis(tert-butyl)-4-methylphenol & 50 \\
\hline $1319-77-3$ & Cresol & 50 \\
\hline 2234-13-1 & Octachloronaphthalene & 50 \\
\hline $82-68-8$ & Pentachloronitrobenzene (PCNB) & 50 \\
\hline $88-85-7$ & 2-sec-Butyl-4,6-dinitrophenol (Dinoseb) & 50 \\
\hline $92-52-4$ & 1,1'-Biphenyl & 50 \\
\hline $98-86-2$ & Acetophenone & 50 \\
\hline \multicolumn{3}{|c|}{ PCB MS and LCS spike compounds } \\
\hline 11097-69-1 & PCB Aroclor 1254 & 0.5 \\
\hline \multicolumn{3}{|c|}{ Pesticides MS and LCS spike compounds } \\
\hline $58-89-9$ & Gamma-BHC & 0.2 \\
\hline
\end{tabular}




\begin{tabular}{|c|c|c|}
\hline CAS Reg. No. & Compound & $\mu g$ \\
\hline $50-29-3$ & 4, 4'-DDT & 0.8 \\
\hline $72-20-8$ & Endrin & 0.8 \\
\hline $76-44-8$ & Heptachlor & 0.2 \\
\hline $309-00-2$ & Aldrin & 0.2 \\
\hline $60-57-1$ & Dieldrin & 0.8 \\
\hline \multicolumn{3}{|c|}{ Dioxins/Furans MS and LCS spike compounds } \\
\hline $1746-01-6$ & 2,3,7,8-Tetrachlorodibenzo-p-dioxin (TCDD) & 8.0 \\
\hline 40321-76-4 & 1,2,3,7,8-Pentachlorodibenzo-p-dioxin (PeCDD) & 40 \\
\hline 57653-85-7 & 1,2,3,6,7,8-Hexachlorodibenzo-p-dioxin (HxCDD) & 40 \\
\hline $35822-39-4$ & 1,2,3,4,6,7,8-Heptachlorodibenzo-p-dioxin (HpCDD) & 40 \\
\hline $3268-87-9$ & 1,2,3,4,6,7,8,9-Octachlorodibenzo-p-dioxin (OCDD) & 80 \\
\hline $51207-31-9$ & 2,3,7,8-Tetrachlorodibenzofuran (TCDF) & 8.0 \\
\hline 57117-41-6 & 1,2,3,7,8-Pentachlorodibenzofuran (PeCDF) & 40 \\
\hline $57117-44-9$ & 1,2,3,6,7,8-Hexachlorodibenzofuran (HxCDF) & 40 \\
\hline $67562-39-4$ & 1,2,3,4,6,7,8-Heptachlorodibenzofuran (HpCDF) & 40 \\
\hline $39001-02-0$ & 1,2,3,4,6,7,8,9-Octachlorodibenzofuran (OCDF) & 80 \\
\hline
\end{tabular}

\section{Preparation of Organic Anion Samples}

The organic anion sample preparation uses a sodium-form of a cation exchange column to remove most of the radioactive cesium and strontium to reduce the overall radioactivity in the samples. Organic anion samples (1-mL supernatant samples and $1 \mathrm{~g}$ wet solids samples) are prepared in accordance with procedure AOAM-03. For further guidance and questions regarding execution of this procedure contact James A. Campbell, 376-0899.

\section{Initial Testing}

\section{Determination of Titration Curves for Supernatants and Soluble Fraction of Wet Centrifuged}

\section{$\underline{\text { Solids }}$}

1) Transfer a $0.5-\mathrm{mL}$ aliquot of the supernatant (or soluble solids fraction) into a tared $100-\mathrm{mL}$ beaker and weigh.

2) Add $10 \mathrm{~mL}$ of $0.01 \mathrm{~N}$ sodium hydroxide solution (prepared from organic-free water) and a clean magnetic stir bar to the beaker containing the aliquot. Measure and record the initial $\mathrm{pH}$.

3) Titrate the sample to $\mathrm{pH} 2$ using $0.1 \mathrm{~N} \mathrm{H}_{3} \mathrm{PO}_{4}$ solution. Record the acid volume, temperature and $\mathrm{pH}$ at $\Delta 0.1-0.2 \mathrm{pH}$ units. Note the acid volume and $\mathrm{pH}$ at the point where any precipitation begins to occur, or redissolve. Repeat this titration using $0.1 \mathrm{~N} \mathrm{HNO}_{3}$ solution.

4) Using the titration spreadsheet, plot the curves for both the supernatant and soluble solids fraction.

5) Closely examine the curves. Find a region of the curve where the $\mathrm{pH}$ is near 6.5 and exhibits some buffering behavior. Calculate the quantity of acid needed per gram of sample to adjust the $\mathrm{pH}$ to the midpoint of this region. Review the data with the cognizant scientist prior to adjusting the $\mathrm{pH}$ of the extraction sample. 


\section{Determination of Insoluble Solids Content}

1) Transfer a 0.5-g aliquot of the centrifuged solids into a tared centrifuge tube and weigh.

2) Add $10 \mathrm{~mL}$ of $0.01 \mathrm{~N} \mathrm{NaOH}$ solution in 1-mL aliquots. After each addition, swirl the centrifuge tube for a few minutes and observe and record any dissolution of the solid that appears to occur after each addition. If all of the solids dissolve before $10 \mathrm{~mL}$ of $0.01 \mathrm{~N} \mathrm{NaOH}$ solution have been added, record this volume for use in Step 1, Sections 6 and 7.

3) Centrifuge the tube at the highest safe speed for the centrifuge tube for approximately 15 minutes. Carefully decant the liquid portion and reweigh the centrifuge tube containing the residual centrifuged solids.

4) Calculate the percentage of solids remaining.

5) If the solids remaining are less than one percent of the original wet solids, $0.01 \mathrm{~N} \mathrm{NaOH}$ solution water should be added to the solids and then extracted as a liquid sample. If the solids remaining are greater than $1 \%$ then the dissolved portion will be extracted as a liquid and the insoluble solids will be extracted using ultrasonication extraction.

\section{Stepwise Instructions for Preparation of Semi-volatile Organic Samples}

Note: Prior to performing SVOA extractions, perform activities defined in Sections 1.0 and 1.1 and Section 5.0. Figure C.1 provides a schematic of the following steps.

\section{Solids}

1) Transfer 5-g aliquot (2.5-g aliquot for MS and MSD) of the centrifuged solids to a tared 200-mL centrifuge tube and weigh.

2) Add the surrogate spiking solution to all samples (including blank) and the target compound spiking solution to the MS and MSD. Use the entire contents of the vial(s) provided for spiking. After transferring the contents of the spiking vial to the sample, add approximately $0.2 \mathrm{~mL}$ of methylene chloride to the vial(s) and transfer this rinsate to the sample.

3) Add $50 \mathrm{~mL}$ of organic-free $0.01 \mathrm{~N} \mathrm{NaOH}$ solution to the centrifuge tube and ultrasonicate (pulsed) for 2 minutes.

4) Centrifuge the tube and decant the liquid into a tared bottle, labeled SVOA C-104 SF1, and weigh. Set aside the wet solids for ultrasonic extraction (Step 7).

5) Transfer the $\mathrm{NaOH}$ leachate sample to a centrifuge tube and while stirring vigorously, very slowly adjust the $\mathrm{pH}$ of the soluble solids to near 6.5and verify final $\mathrm{pH}$. This step should be done using an ice bath to cool the sample.

Note: The quantity of acid required for adjusting the $\mathrm{pH}$ to near 6.5 is determined by titrating an aliquot of the $\mathrm{NaOH}$ leachate (i.e., soluble solids fraction) per Section 5.1. 
Note: If solids are formed that do not redissolve, centrifuge and decant the liquid into a separatory funnel. Cap the centrifuge tube containing the wet solids and set aside for ultrasonic extraction (Step 7).

6) Transfer leachate to a separatory funnel and perform a set of three sequential separatory funnel shakeout extractions of the $\mathrm{pH}$-adjusted liquid using $25-\mathrm{mL}$ portions of methylene chloride. Collect and combine the three extracts in the 250-mL amber bottle labeled as designated below.

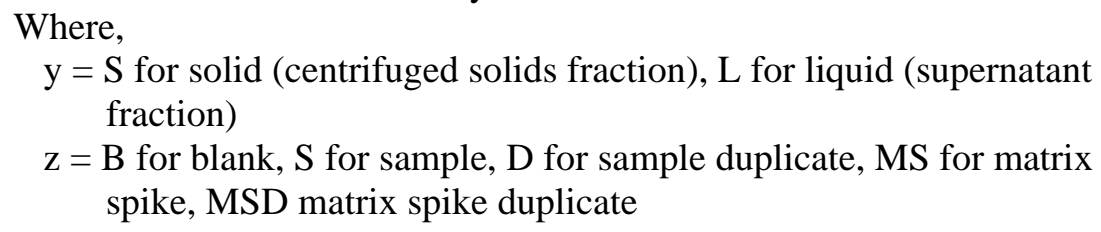

7) Combine the solids reserved in Step 4 and any solids formed in Step 5 and add 2-3 times amount of anhydrous sodium sulfate desiccant and stir with a glass or metal rod until a sandy texture is obtained.

8) Add $25 \mathrm{~mL}$ of methylene chloride and ultrasonicate (pulsed) for 2 minutes. Settle (or centrifuge if necessary) and decant the extract into the $250-\mathrm{mL}$ amber bottle labeled in Step 6.

9) Repeat Step 8 two additional times and combine the extracts.

\section{Supernatant}

1) Transfer 20-mL aliquot (10-mL aliquot for MS and MSD) of the C-104 supernatant into a separatory funnel and dilute with $25 \mathrm{~mL}$ of $0.01 \mathrm{~N} \mathrm{NaOH}$.

2) Add the surrogate spiking solution to all samples (including blank) and the target compound spiking solution to the MS and MSD. Use the entire contents of the vial(s) provided for spiking. After transferring the contents of the spiking vial to the sample, add approximately $0.2 \mathrm{~mL}$ of methylene chloride to the vial(s) and transfer this rinsate to the sample.

3) Perform three sequential separatory funnel shakeout extractions of the supernatant using 25-mL portions of methylene chloride. Collect and combine the three extracts in a $250-\mathrm{mL}$ amber bottle labeled as designated in Section 6.1 Step 6.

4) Transfer the sample to a centrifuge tube and while stirring vigorously, very slowly adjust the $\mathrm{pH}$ of the sample with the quantity of acid calculated in Section 5.1 for supernatant sample and verify final $\mathrm{pH}$. This step should be done using an ice bath to cool the sample.

Note: If solids are formed that do not redissolve, centrifuge and decant the liquid back into the separatory funnel used in Step 1. Cap the centrifuge tube containing the wet solids and set aside for ultra-sonic extraction.

5) Transfer supernatant to the separatory funnel used in Step 1 and perform a second set of three sequential separatory funnel shakeout extractions of the $\mathrm{pH}$-adjusted liquid using 25-mL portions of methylene chloride. Collect and combine the three extracts in the 250-mL amber bottle labeled in Step 3. 
6) To any solids formed in Step 4, add 2-3 times amount of anhydrous sodium sulfate desiccant and stir with a glass or metal rod until a sandy texture is obtained.

7) Add $25 \mathrm{ml}$ of methylene chloride and ultrasonicate (pulsed) for 2 minutes. Settle (or centrifuge if necessary) and decant the extract into the $250-\mathrm{mL}$ amber bottle labeled in Step 3.

8) Repeat Step 7 two additional times and combine the extracts.

For further guidance and questions regarding execution of these steps, and those described in Appendix A, for extraction of SVOA samples contact George S. Klinger, 372-0448.

\section{Stepwise Instructions for Preparation of Pesticide/PCB Organic Samples}

Note: Prior to performing pesticide/PCB extractions, perform activities defined in Sections 1.0 and 1.1 and Section 5.0. Figure C.2 provides a schematic of the following steps.

\section{Solids}

1) Transfer 5-g aliquot (2.5-g aliquot for MS and MSD) of the centrifuged solids to a tared 200-mL centrifuge tube and weigh.

2) Add the surrogate spiking solution to all samples (including blank) and the target compound spiking solution to the MS and MSD. Use the entire contents of the vial(s) provided for spiking. After transferring the contents of the spiking vial to the sample, add approximately $0.2 \mathrm{~mL}$ of methylene chloride to the vial(s) and transfer this rinsate to the sample.

3) Add $40 \mathrm{~mL}$ of organic-free $0.01 \mathrm{~N} \mathrm{NaOH}$ solution to the centrifuge tube and ultrasonicate (pulsed) for 2 minutes.

4) Centrifuge the tube and decant the liquid into a tared bottle, labeled PPCB C-104 SF1.

5) Repeats Steps 3 and 4 and weigh bottle PPCB C-104 SF1. Set aside the wet solids for ultrasonic extraction (Step 8).

6) Transfer the $\mathrm{NaOH}$ leachate sample to a centrifuge tube and while stirring vigorously, very slowly adjust the $\mathrm{pH}$ of the soluble solids to near 6.5 and verify final $\mathrm{pH}$. This step should be done using an ice bath to cool the sample.

Note: The quantity of acid required for adjusting the $\mathrm{pH}$ to near 6.5 is determined by titrating an aliquot of the $\mathrm{NaOH}$ leachate (i.e., soluble solids fraction) per Section 5.1.

Note: If solids are formed that do not redissolve, centrifuge and decant the liquid into a separatory funnel. Cap the centrifuge tube containing the wet solids and set aside for ultrasonic extraction (Step 8).

7) Transfer leachate to a separatory funnel and perform a set of three sequential separatory funnel shakeout extractions of the $\mathrm{pH}$-adjusted liquid using $25-\mathrm{mL}$ portions of methylene chloride. Collect and combine the three extracts in the $250-\mathrm{mL}$ amber bottle labeled as designated below.

Where,

$$
\text { C104-P-y-z }
$$


$\mathrm{y}=\mathrm{S}$ for solid (centrifuged solids fraction), $\mathrm{L}$ for liquid (supernatant fraction)

$\mathrm{z}$ = B for blank, S for sample, D for sample duplicate, MS for PCB matrix spike, MSD for PCB matrix spike duplicate, MSP for pesticide spike, MSDP for pesticide matrix spike duplicate

8) Combine the solids reserved in Step 5 and any solids formed in Step 6 and add 2-3 times amount of anhydrous sodium sulfate desiccant and stir with a glass or metal rod until a sandy texture is obtained.

9) Add $25 \mathrm{ml}$ of methylene chloride/acetone mixture (1:1) and ultrasonicate (pulsed) for 2 minutes. Settle (or centrifuge if necessary) and decant the extract into the $250-\mathrm{mL}$ amber bottle labeled in Step 7.

10) Repeat Step 9 two additional times and combine the extracts.

\section{Supernatant}

1) Transfer 10 -mL aliquot of the $\mathrm{C}$-104 supernatant into a separatory funnel and dilute with $25 \mathrm{~mL}$ of $0.01 \mathrm{~N} \mathrm{NaOH}$.

2) Add the surrogate spiking solution to all samples (including blank) and the target compound spiking solution to the MS and MSD. Use the entire contents of the vial(s) provided for spiking. After transferring the contents of the spiking vial to the sample, add approximately $0.2 \mathrm{~mL}$ of methylene chloride to the vial(s) and transfer this rinsate to the sample.

3) Perform three sequential separatory funnel shakeout extractions of the supernatant using 25-mL portions of methylene chloride. Collect and combine the three extracts in a $250-\mathrm{mL}$ amber bottle labeled as designated in Section 7.1 Step 7.

4) Transfer the sample to a centrifuge tube and while stirring vigorously, very slowly adjust the $\mathrm{pH}$ of the sample with the quantity of acid calculated in Section 5.1 for supernatant sample and verify final $\mathrm{pH}$. This step should be done using an ice bath to cool the sample.

Note: If solids are formed that do not redissolve, centrifuge and decant the liquid back into the separatory funnel used in Step 1. Cap the centrifuge tube containing the wet solids and set aside for ultra-sonic extraction.

5) Transfer supernatant to the separatory funnel used in Step 1 and perform a second set of three sequential separatory funnel shakeout extractions of the liquid using 25-mL portions of methylene chloride. Collect and combine the three extracts in the 250-mL amber bottle labeled in Step 3.

6) To any solids formed in Step 4. Add 2-3 times amount of anhydrous sodium sulfate desiccant and stir with a glass or metal rod until a sandy texture is obtained.

7) Add $25 \mathrm{ml}$ of methylene chloride/acetone mixture (1:1) and ultrasonicate (pulsed) for 2 minutes. Settle (or centrifuge if necessary) and decant the extract into the 250-mL amber bottle labeled in Step 3.

8) Repeat Step 7 two additional times and combine the extracts. 
For further guidance and questions regarding execution of these steps for pesticide/PCB extractions, contact Eric W. Hoppe, 376-2126.

\section{Stepwise Instructions for Preparation of Dioxin/Furan Samples}

Note: Prior to performing Dioxin/Furan extractions, perform activities defined in Sections 1.0 and 1.1 and Section 5.0. Figure C.3 provides a schematic of the following steps.

1) Transfer 5-g aliquots (5-g aliquot for MS and MSD) of the centrifuged solids to a tared 200-mL centrifuge tube and weigh. Add the labeled spiking solution (i.e., surrogates) to all samples (including blank) and the unlabeled spiking solution (i.e., spikes) to the MS and MSD. Use the entire contents of the vial(s) provided for spiking. After transferring the contents of the spiking vial to the sample, add approximately $0.2 \mathrm{~mL}$ of methylene chloride to the vial(s) and transfer this rinsate to the sample.

2) Add 2-3 times the amount of anhydrous sodium sulfate desiccant. Stir with glass or metal rod until it forms a sandy texture. Add $25 \mathrm{~mL}$ of methylene chloride/acetone mixture (1:1) and ultrasonicate (pulsed) for 2 minutes. Settle (or centrifuge, if necessary) and decant the extract into 250-mL amber bottle labeled as indicated below. Repeat methylene chloride/acetone extraction two more times and combine extracts.

C104-D-y-z

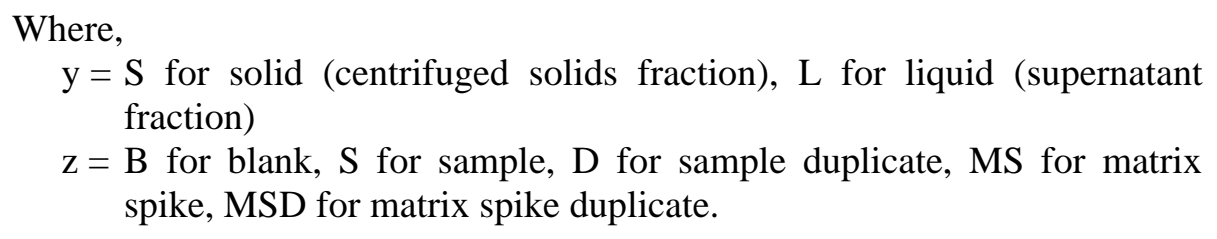

3) Transfer $15 \mathrm{~mL}$ of the C-104 supernatant (7.5 mL for MS and MSD) into a separatory funnel and add $25 \mathrm{~mL}$ of $0.01 \mathrm{~N} \mathrm{NaOH}$ to the separatory funnel. Add the labeled spiking solution (i.e., surrogates) to all samples (including blank) and the unlabeled spiking solution (i.e., spikes) to the MS and MSD. Use the entire contents of the vial(s) provided for spiking. After transferring the contents of the spiking vial to the sample, add approximately $0.2 \mathrm{~mL}$ of methylene chloride to the vial(s) and transfer this rinsate to the sample.

4) Perform three sequential separatory funnel shakeout extractions of the supernatant using three 25$\mathrm{mL}$ portions of methylene chloride. Collect and combine the three extracts in a 250-mL amber bottle labeled in Step 2.

For further guidance and questions regarding execution of these steps contact James A. Campbell, 376-0899. 


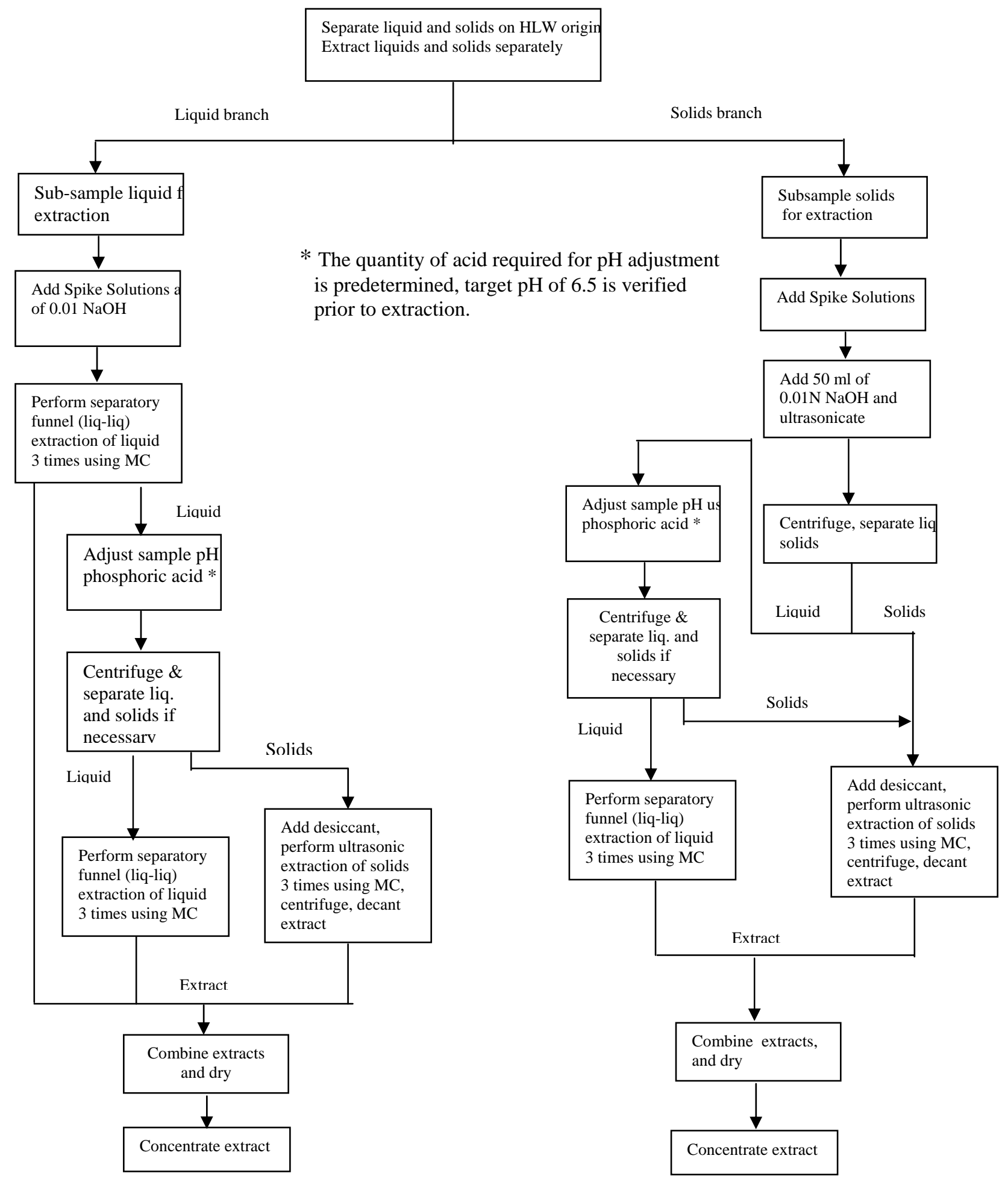

Figure C.1. SVOA Extraction Process Diagram 


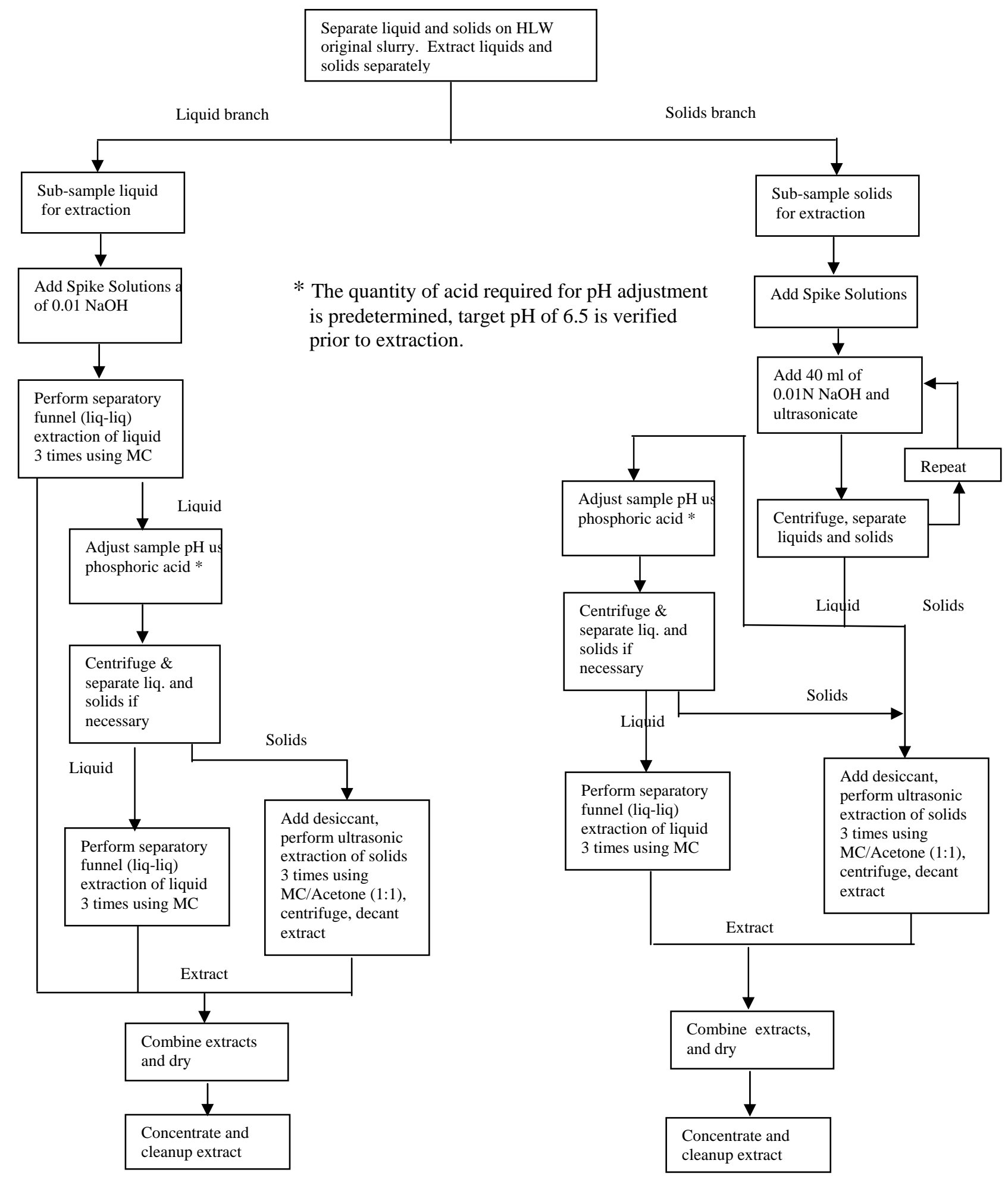

Figure C.2. Pesticide/PCB Extraction Process Diagram 


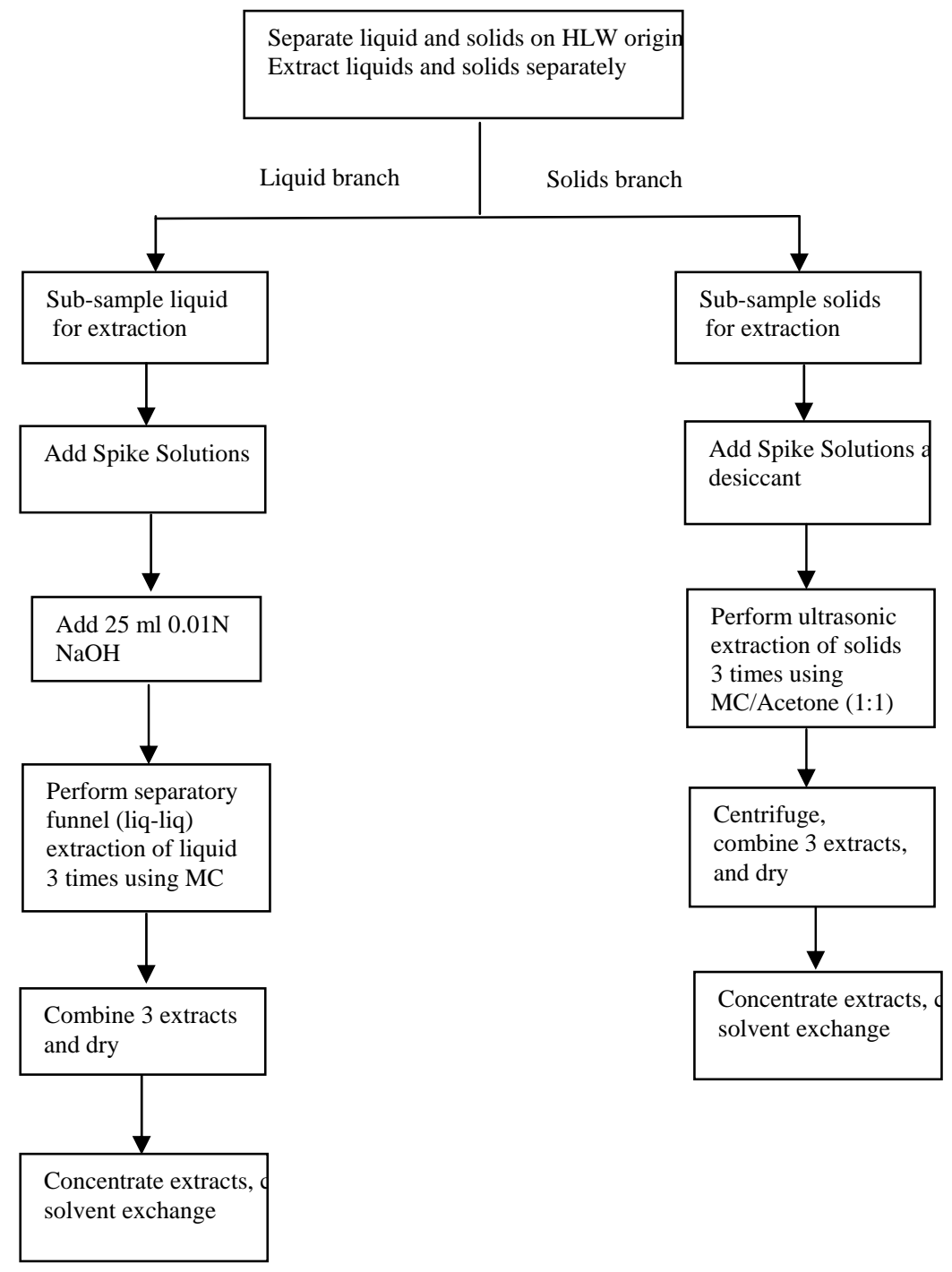

Figure C.3. Dioxin/Furan Extraction Process Diagram 


\section{Appendix A1: Semivolatile Research Sample}

Prior work done on AW-101 and AN-107 samples using phosphoric acid to adjust the $\mathrm{pH}$ was complicated by large quantities of formed solids. It is assumed that some of the formed solids were the results of aluminum precipitation at $\mathrm{pH}$ less than 11 and greater than 3 . It is also likely that some of the formed solids were insoluble phosphates, which were formed upon addition of the phosphoric acid.

The use of nitric acid to adjust the $\mathrm{pH}$ of the sample to $\mathrm{pH} 3$ may have certain advantages in reducing or eliminating "formed solids" in the supernatant and the soluble portion of the centrifuged solids. Additionally, it is likely that phosphate acts in a similar fashion to sulfate in its ability to catalyze nitrate (which is present in the C-104 material at a concentration of approximately 30,000 ppm) to form the reactive nitronium ion $\left({ }^{+} \mathrm{NO}_{3}\right)$, which is a powerful nitrating agent for a variety of organics.

Nitric acid alone produces only a small quantity of "auto-catalyzed" nitronium ion. We believe that the use of nitric acid, rather than phosphoric acid, to adjust the $\mathrm{pH}$ of the sample may eliminate or reduce formed solids, thus reducing the number of extraction steps, and also reduce or eliminate the quantity of nitration "artifacts".

Reaction of organic amines, such as chelator fragments found in some tank samples, with nitrous acid (HONO) may also be reduced by the addition of nitric acid.

In order to test this idea for application to potential future work, one additional semivolatile sample (supernatant only) will be processed using the procedure described in Sections 5.1 and 6, using $0.1 \mathrm{~N}$ nitric acid, rather than phosphoric acid, for the titration of the sample and $\mathrm{pH}$ adjustment during the extraction.

The supernatant used for this test is to be decanted/pipetted from container "C104 COMP E". 
Appendix D: Volatile Organic Analysis Result Forms 
Lab Name: PNNL

Contract: $\mathrm{Cl04}$

SAS NO.:

Lab Code: PNNL Case No.:

\section{HOTCELLBLK}

Matrix: (soil/water) WATER

Sample wt/vol: $\quad 5.000(\mathrm{~g} / \mathrm{mL}) \mathrm{ML}$

Level: (low/med) LOW

$\div$ Moisture: not dec.

GC Column: DB-62475M X 2.55UM ID: 0.45 (mm)

Soil Extract Volume:

(UI)
Lab Sample ID: 00-1360-CB

Lab File ID: 00040617

Date Received:

Date Analyzed: 04/07/0

Dilution Factor: 1.0

Soil Aliquot Volume:

(uL)
CAS NO. CONCENTRATION UNITS:

CAS NO. COMPOUND $(\mathrm{ug} / \mathrm{L}$ or $\mathrm{ug} / \mathrm{kg}) \mathrm{UG} / \mathrm{L}$

\begin{tabular}{|c|}
\hline 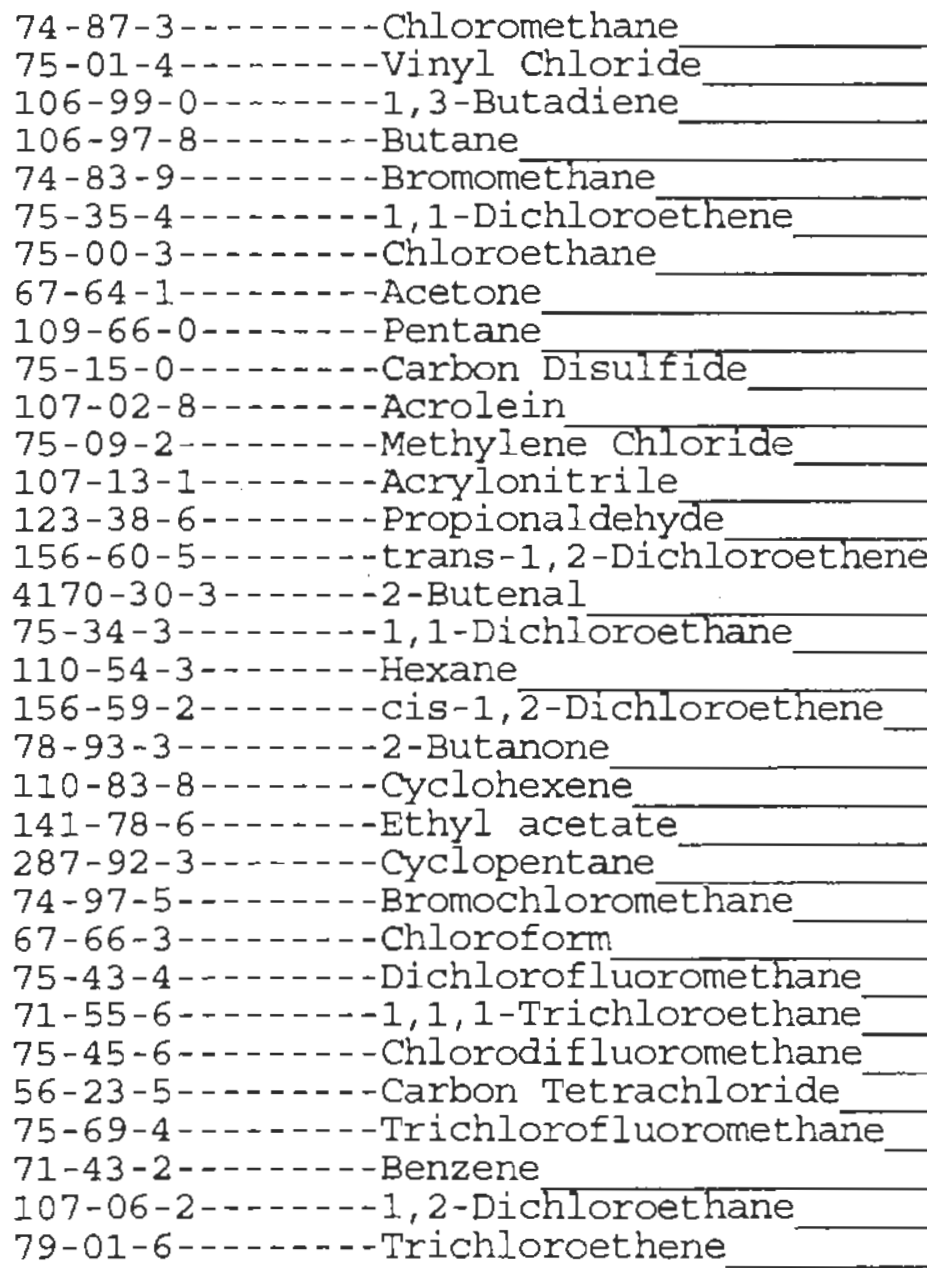 \\
\hline
\end{tabular}

\begin{tabular}{|r|l|l|}
\hline 10 & $\mathrm{U}$ \\
10 & $\mathrm{U}$ \\
5 & $\mathrm{U}$ \\
5 & $\mathrm{U}$ \\
10 & $\mathrm{U}$ \\
10 & $\mathrm{U}$ \\
10 & $\mathrm{U}$ \\
2 & $\mathrm{~J}$ \\
5 & $\mathrm{U}$ \\
10 & $\mathrm{U}$ \\
5 & $\mathrm{U}$ \\
19 & $\mathrm{~B}$ \\
5 & $\mathrm{U}$ \\
5 & $\mathrm{U}$ \\
10 & $\mathrm{U}$ \\
5 & $\mathrm{U}$ \\
10 & $\mathrm{U}$ \\
11 & \\
10 & $\mathrm{U}$ \\
10 & $\mathrm{U}$ \\
5 & $\mathrm{U}$ \\
5 & $\mathrm{U}$ \\
5 & $\mathrm{U}$ \\
10 & $\mathrm{U}$ \\
10 & $\mathrm{U}$ \\
5 & $\mathrm{U}$ \\
10 & $\mathrm{U}$ \\
5 & $\mathrm{U}$ \\
10 & $\mathrm{U}$ \\
5 & $\mathrm{U}$ \\
10 & $\mathrm{U}$ \\
10 & $\mathrm{U}$ \\
10 & $\mathrm{U}$ \\
& \\
\hline & \\
\hline &
\end{tabular}


Lab Name: PNNL

Contract: C104

Lab Code: PNNL

Case No.:

Matrix: (soil/water) WATER

Sample wt/vol: $\quad 5.000(\mathrm{~g} / \mathrm{mL}) \mathrm{ML}$

Level: (low/med) LOW

$\div$ Moisture: not dec.

GC Column: DB-624 75M X 2.55UM ID: 0.45 (mm)

Soil Extract Volume: (uL)

SAS NO. :

SDG No.: 2

Lab Sample ID: 00-1360-CB

Iab File ID: 00040617

Date Received:

Date Analyzed: 04/07/0

Soil Aliquot Volume:

HOTCELLBLK

Dilution Factor: 1.0 (UL)

CAS NO.

COMPOUND

CONCENTRATION UNITS:

$(\mathrm{ug} / \mathrm{L}$ or $\mathrm{ug} / \mathrm{Kg}$ ) UG/L

Q

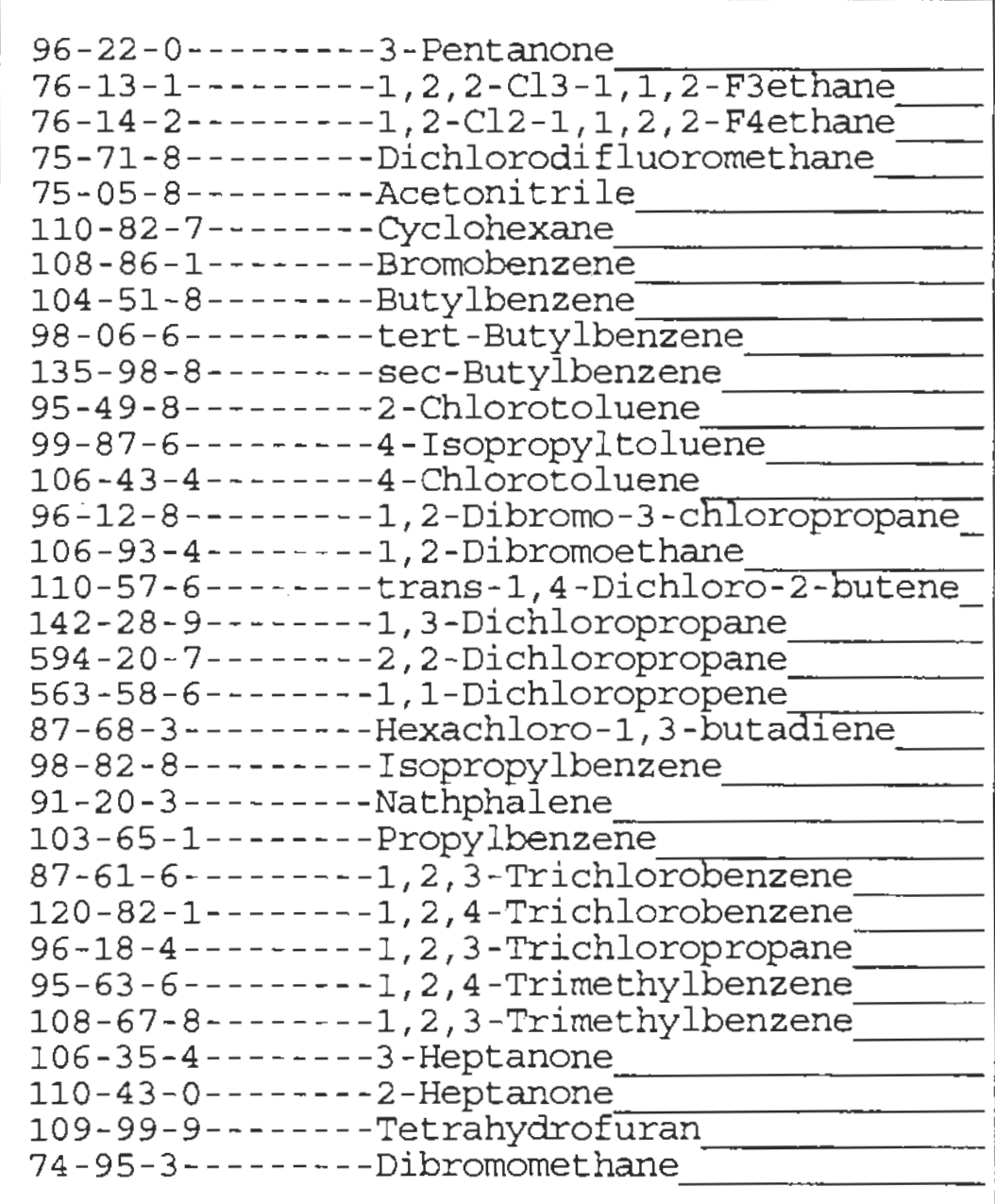


Lab Name: PNNL

Contract: $\mathrm{Cl04}$

Lab Code: PNNL

Case No.:

Matrix: (soil/water) WATER

Sample wt/vol:

$5.000(\mathrm{~g} / \mathrm{mL}) \mathrm{ML}$

Level: (low/med) LOW

$\%$ Moisture: not dec.

GC Column: DB-624 75M X 2.55UM ID: 0.45 (mm) (uL)

Soil Extract Volume:

CAS NO.

COMPOUND
SAS NO. :

SDG No : : 2

Lab Sample ID: 00-1360-CB

Lab File ID: 00040617

Date Received:

Date Analyzed: 04/07/0

Dilution Factor: 1.0

Soil Aliquot volume: (uL) CONCENTRATION UNITS: (ug/L or $u g / \mathrm{kg}$ ) UG/L

Q

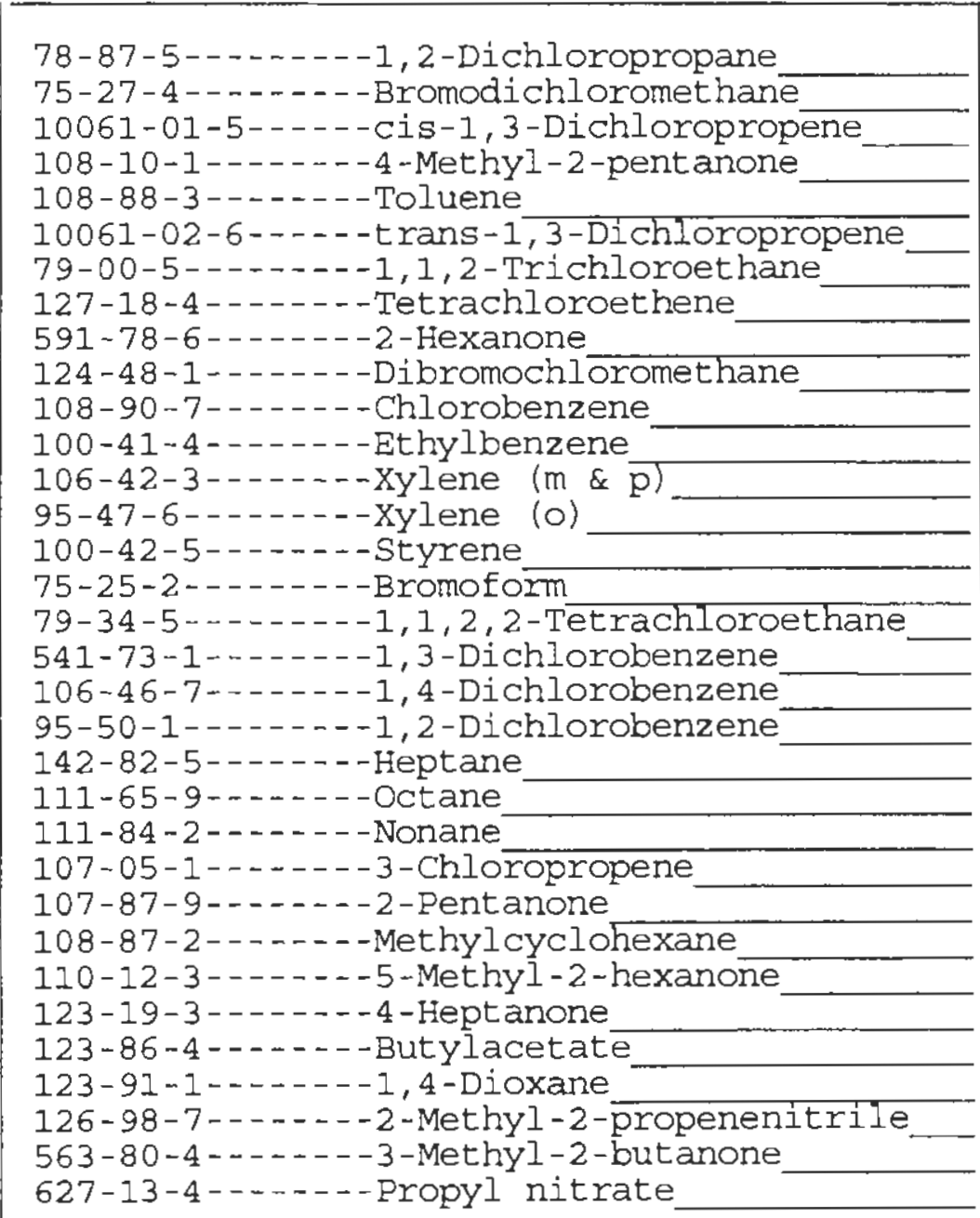

$10 \mathrm{U}$

$10 \mathrm{U}$

$10 \mathrm{U}$

$10 \mathrm{U}$

$10 \mathrm{U}$

$10 \mathrm{U}$

$10 \mathrm{U}$

$10 \mathrm{U}$

$10 \mathrm{U}$

$10 \mathrm{U}$

$10 . \mathrm{U}$

$10 \mathrm{U}$

$10 \mathrm{U}$

$10 . \mathrm{U}$

$10 . \mathrm{U}$

$10 \mathrm{U}$

$10 \mid \mathrm{U}$

$10 \mathrm{U}$

$10 \mathrm{U}$

$10 \mathrm{U}$

$5 \mathrm{U}$

$5 \mathrm{U}$

$5 \mathrm{U}$

$10 \mathrm{U}$

$5 \mathrm{U}$

$5 \mathrm{U}$

$5 \mid \mathrm{U}$

$5 \mathrm{U}$

$5 \mathrm{U}$

$5 \mathrm{U}$

$5 \mathrm{U}$

$5 \mathrm{U}$

5 
Lab Name: PNNL

Contract: $\mathrm{C} 104$

Lab Code: PNNL Case No.:

Matrix: (soil/water) SOIID

Sample wt/vol:

$(g / m L) \quad G$

Level: (low/med) LOW

\% Moisture: not dec.

GC Column: DB-624 75M X 2.55UM ID: 0.45 (mm) Soil Extract Volume: (uL)
SAS NO.:
EPA SAMPLE NO.

HOTCEIJBLKD

SDG NO.: 2

Lab Sample ID: 00-1360-CBD

Lab File ID: 00040623

Date Received:

Date Analyzed: 04/07/0

Dilution Factor: 1.0

Soil Aliquot Volume: (uL) CONCENTRATION UNITS:

CAS NO. COMPOUND $\quad\langle\mathrm{ug} / \mathrm{L}$ or $\mathrm{ug} / \mathrm{Kg}\rangle \mathrm{UG} / \mathrm{KG}$

$Q$

74-87-3--.-.--Chloromethane

75-01-4-...--vinyl Chloride

106-99-0-..--1, 3-Butadiene

106-97-8--.---Butane

74-83-9--n---Bromomethane

75-35-4---n-1,1-Dichloroethene

75-00-3-...--Chloroethane

67-64-1--..---Acetone

109-66-0-.-.--Pentane

75-15-0---.---Carbon Dísulfide

107-02-8-...--Acrolein

75-09-2-...--Methylene Chloride

107-13-1-----Acrylonitrile

123-38-6-..---Propionaldehyde

156-60-5-...-trans-1,2-Dichloroethene

4170-30-3--..-2-Butenal

75-34-3-...--1,1-Dichloroethane

110-54-3-..--Hexane

156-59-2-...--cis-1, 2-Dichloroethene

78-93-3-n-.--2-Butanone

110-83-8--.--Cyclohexene

141-78-6------Ethyl acetate

287-92-3--.---Cyclopentane

74-97-5-1..---Bromochloromethane

67-66-3-...-Chloroform

75-43-4---.--Dichlorofluoromethane

71-55-6-- - - 1, 1, 1-Trichloroethane

75-45-6--.---Chlorodifluoromethane

56-23-5-..---Carbon Tetrachloride

75-69-4- - - - - Trichlorofluoromethane

$71-43-2-\cdots----B e n z e n e$

107-06-2------1, 2-Dichloroethane

79-01-6---.---Trichloroethene

\begin{tabular}{r|l|}
50 & $\mathrm{U}$ \\
50 & $\mathrm{U}$ \\
50 & $\mathrm{U}$ \\
50 & $\mathrm{U}$ \\
50 & $\mathrm{U}$ \\
50 & $\mathrm{U}$ \\
50 & $\mathrm{U}$ \\
5 & $\mathrm{~J}$ \\
50 & $\mathrm{U}$ \\
50 & $\mathrm{U}$ \\
50 & $\mathrm{U}$ \\
4 & $\mathrm{JB}$ \\
50 & $\mathrm{U}$ \\
50 & $\mathrm{U}$ \\
50 & $\mathrm{U}$ \\
50 & $\mathrm{U}$ \\
50 & $\mathrm{U}$ \\
50 & $\mathrm{U}$ \\
50 & $\mathrm{U}$ \\
50 & $\mathrm{U}$ \\
50 & $\mathrm{U}$ \\
50 & $\mathrm{U}$ \\
50 & $\mathrm{U}$ \\
50 & $\mathrm{U}$ \\
50 & $\mathrm{U}$ \\
50 & $\mathrm{U}$ \\
50 & $\mathrm{U}$ \\
50 & $\mathrm{U}$ \\
50 & $\mathrm{U}$ \\
50 & $\mathrm{U}$ \\
50 & $\mathrm{U}$ \\
50 & $\mathrm{U}$ \\
50 & $\mathrm{U}$ \\
5 & \\
\hline
\end{tabular}

OLMO3.C 
Lab Name: PNNL

Lab Code: PNNL

Case No.:

Matrix: (soil/water) SOLID

Sample wt/vol:

Level: (low/med) LoW $(g / m L) \quad G$

\% Moisture: not dec.

GC Column: DB-624 75M X 2.55UM ID: 0.45 (mm) (uL)
Soil Extract Volume:
Contract: $\mathrm{C} 104$

SAS NO. :
HOTCELLBLKD
Iab Sample ID: 00-1360-CBD

Lab File ID: $\quad 00040623$

Date Received:

Date Analyzed: 04/07/0

Dilution Factor: 1.0

Soil Aliquot Volume: (uL) CONCENTRATION UNITS:

CAS NO.

COMPOUND (ug/L or ug/Kg) UG/KG

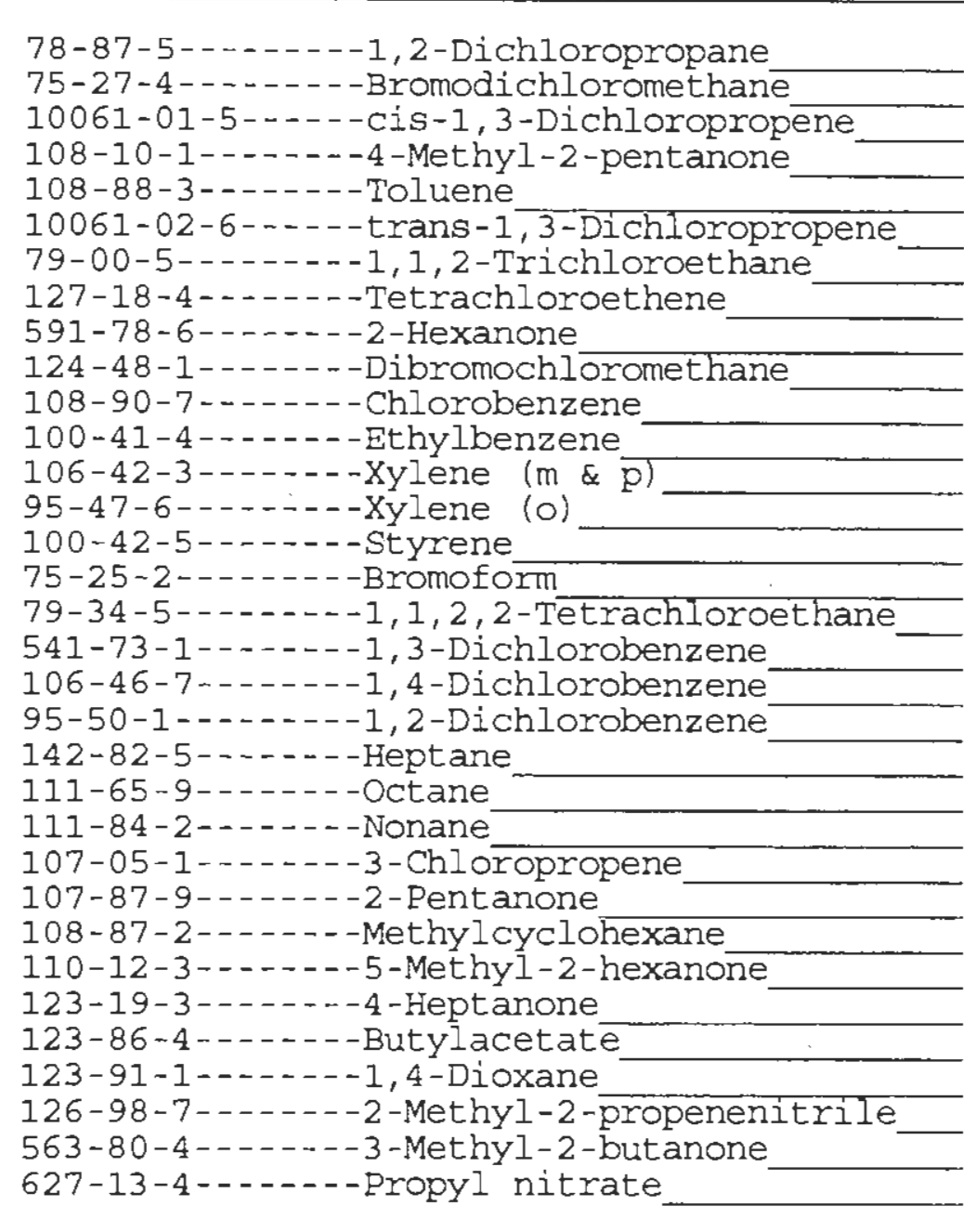

$78-87-5-\cdots----1,2-$ Dichloropropane

75-27-4--..---Bromodichloromethane 108-10-1------4-Methyl-2-pentanone 108-88-3-------Toluene

061-02-6----trans-1, 3-Dichloropropen

127-18-4-..----Tetrachloroethene

$591-78-6-\ldots---2-$ Hexanone

124-48-1- - - - -Dibromochloromethane

106-42-3-----xylene (m \& $\mathrm{p}$ )

95-47-6-------Xylene (o)

100-42-5--.----Styrene

$75-25-2-------$ Bromoform

79-34-5-...--1, 1, 2, 2-Tetrachloroethane

106 $13-1--1,3-D i c h l o r o b e n z e n e$

$95-50-1-\ldots \ldots--1,2-D i c h l o r o b e n z e n e$

142-82-5-..---Heptane

$111-65-9------$ Octane

$111-84-2-\cdots---$ Nonane

107-87-9-------2-Pentanone

108-87-2-- - - -Methylcyclohexane

$110-12-3-\cdots--5$ - Methyl-2-hexanone

123-19-3--..--4-Heptanone

123-86-4-- - - -Butylacetate

$123-91-1 \ldots-\cdots-1,4-$ Dioxane

126-98-7------2-Methyl-2-propenenitrile

627-13-4--..--2ropyl nitrate
$50 \mathrm{U}$

$50 \mathrm{U}$

$50 \mathrm{U}$

50 U

50 U

$50 \mathrm{U}$

$50 \mathrm{U}$

$50 \mathrm{U}$

$50 \mathrm{U}$

$50 \mathrm{U}$

$50 \mathrm{U}$

$50 \mathrm{U}$

$50 \mathrm{U}$

$50 \mathrm{U}$

50 U

50 U

50 U

$50 . \mathrm{U}$

50 U

$50 \mathrm{U}$

$50 \mathrm{U}$

$50 \mathrm{U}$

50 U

$50 \mathrm{U}$

50 U

$50 \quad \mathrm{U}$

50 U

50 . U

50 , U

$50 \mid \mathrm{U}$

$50 \mathrm{U}$

$50 \mathrm{U}$

50 U 
IA

VOLATILE ORGANICS ANALYSIS DATA SHEET
Lab Name: PNNL

Lab code: PNNL

Case No.:

Matrix: (soil/water) SOLID

Sample wt/vol:

Level: (low/mea) Low

Moisture: not dec.

GC Column: DB-624 75M X 2.55UM ID: 0.45 (mm)

Soil Extract Volume: (uIs) $(\mathrm{g} / \mathrm{mL}) \quad \mathrm{G}$

55UM ID: 0.45 (mm)
Contract: $\mathrm{Cl} 04$

SAS NO.:
EPA SAMPLE NO.

HOTCELLBLKD

Lab Sample ID: 00-1360-CBD

Lab File ID: 00040623

Date Received:

Date Analyzed: 04/07/0

SDG NO.: 2

CAS NO.

COMPOUND
CONCENTRATION UNITS:

(ug/L or $\mathrm{ug} / \mathrm{Kg}$ ) UG/KG
(uIs)

\begin{tabular}{|c|}
\hline 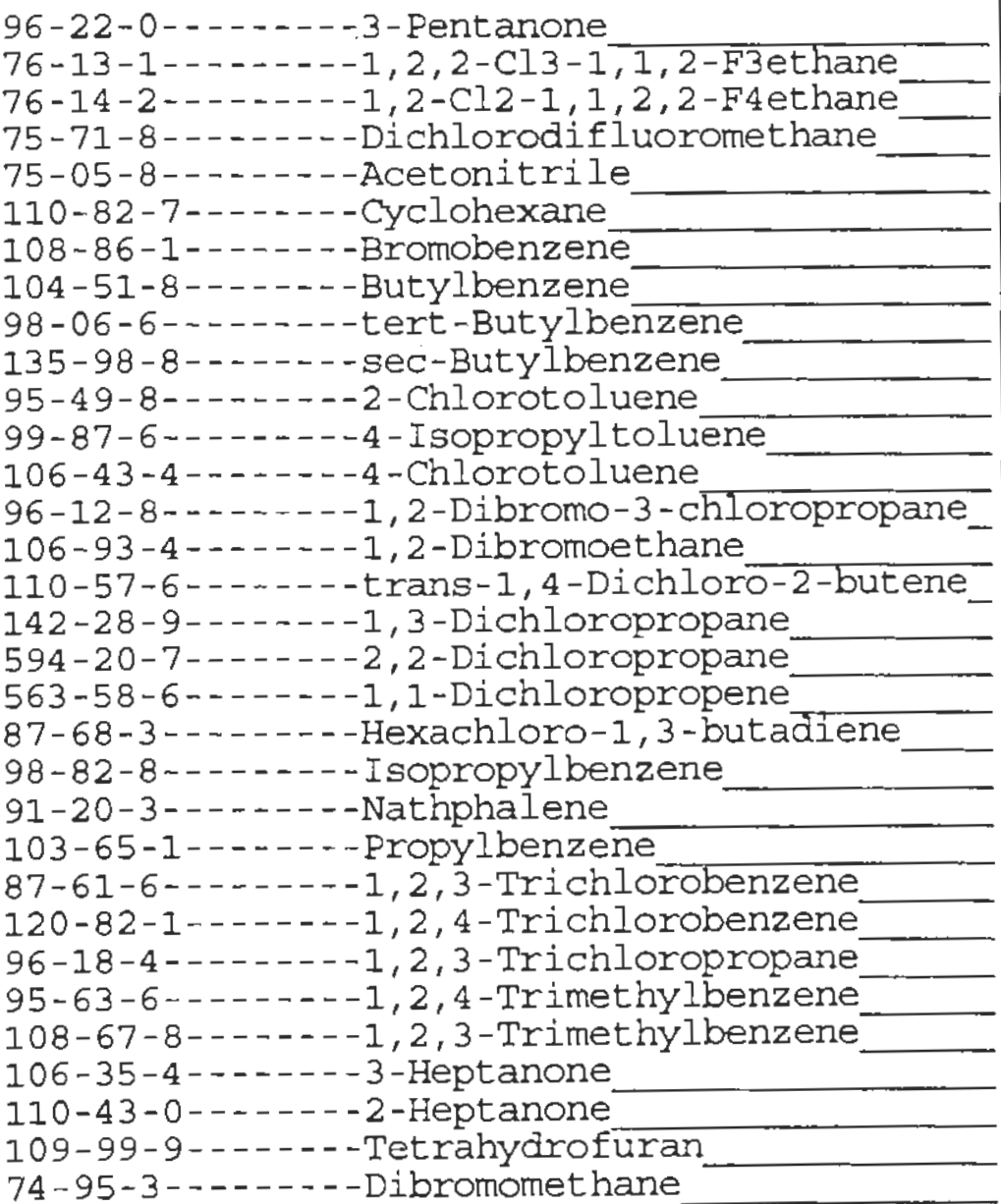 \\
\hline
\end{tabular}

FORM I VOA

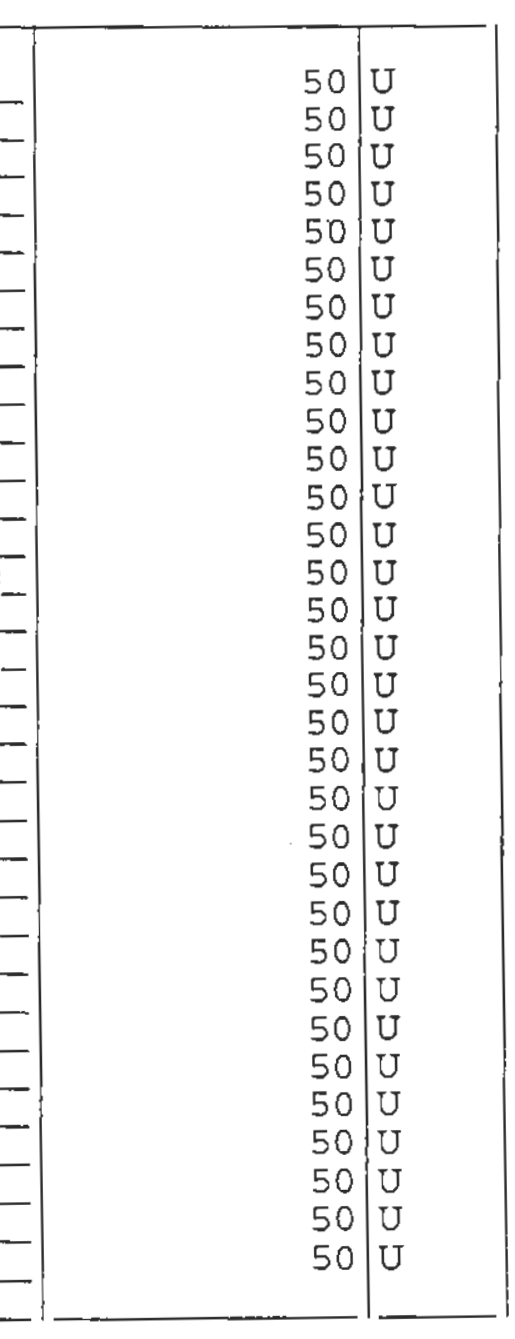


Lab Name: PNNL

Lab Code: PNNL

Matrix: (soil/water) WATER

Sample wt/vol: $\quad 5.000(\mathrm{~g} / \mathrm{mL}) \mathrm{ML}$

Level: (low/med) Low

言 Moisture: not dec.

GC Colum: DB-624 75M X 2.55UM ID: 0.45 (mm)

Soil Extract Volume: (UL)

COMPOUND CAS NO.
Contract: C104

SAS NO. :
EPA SAMPLE NO.

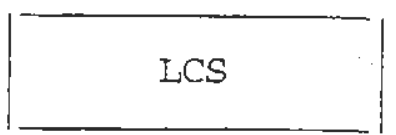

SDG No.: 29274

Lab Sample ID: LCS

Lab File ID: 00040614

Date Received:

Date Analyzed: 04/06/0

(mm) Dilution Factor: 1.0

Soil Aliquot Volume: (UL) CONCENTRATION UNITS: (ug/L or $\mathrm{ug} / \mathrm{Kg}$ ) UG/L

Q

\begin{tabular}{|c|}
\hline 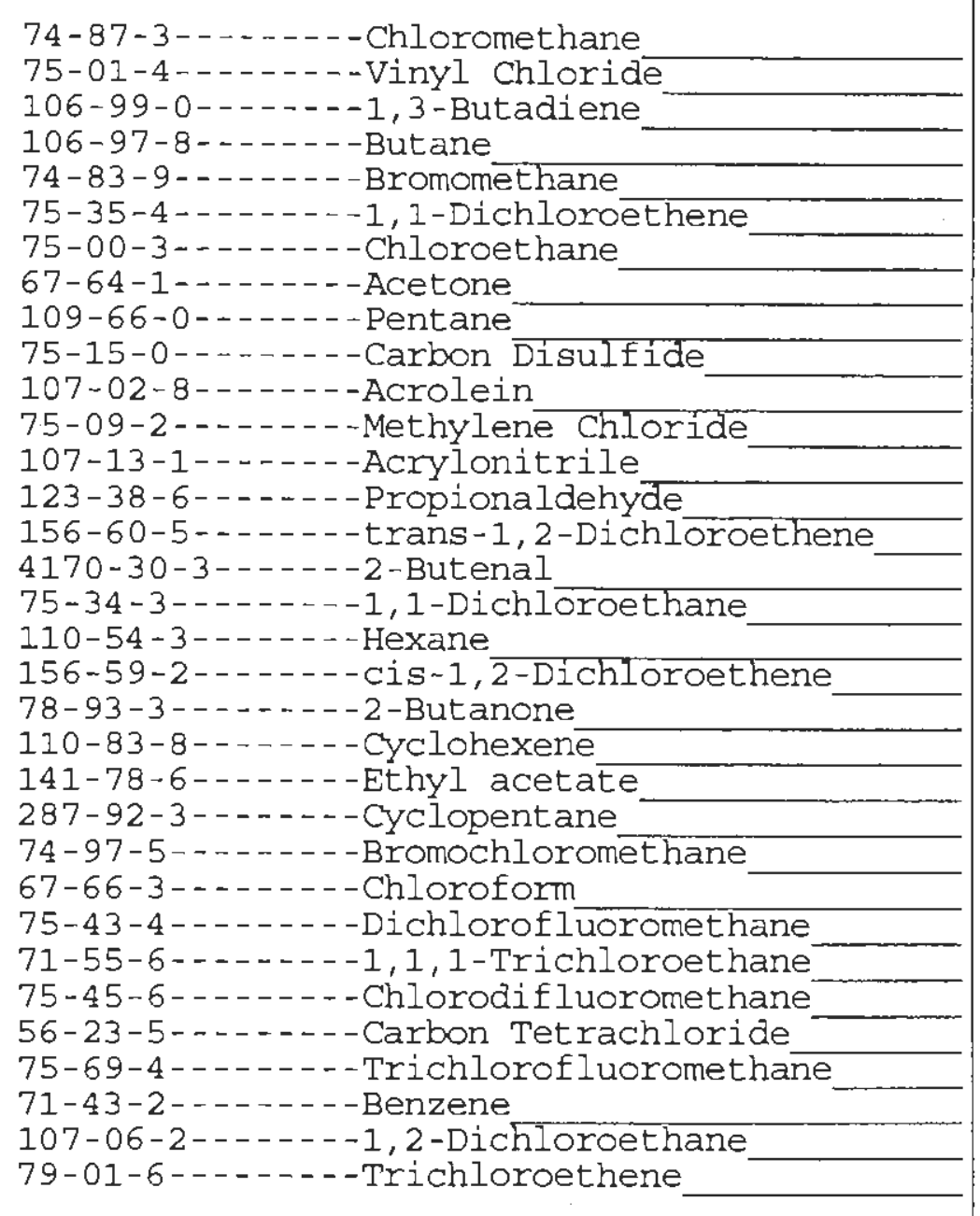 \\
\hline
\end{tabular}

\begin{tabular}{|l|l}
210 \\
200 \\
210 \\
200 \\
240 \\
220 \\
230 \\
190 \\
200 \\
210 \\
220 \\
210 \\
210 \\
180 \\
220 \\
250 \\
220 \\
210 \\
220 \\
220 \\
210 \\
220 \\
220 \\
210 \\
220 \\
260 \\
210 \\
190 \\
210 \\
190 \\
220 \\
240 \\
220 \\
\end{tabular}


Lab Name: FNNL

Lab Code: PNNL
Contract: $\mathrm{Cl04}$

SAS NO. :
LCS

SDG No.: 29274
Matrix: (soil/water) WATER

Sample wt/vol:

$5.000(\mathrm{~g} / \mathrm{mL}) \mathrm{ML}$

Level: (low/med) Low

- Moisture: not dec.

GC Column: $\mathrm{DB}-62475 \mathrm{M}$ X $2.55 \mathrm{UM}$ ID: 0.45 (mm)

Soil Extract Volume: (UI)
Lab Sample ID: LCS

Lab File ID: 00040614

Date Received:

Date Analyzed: 04/06/0

Dilution Factor: 1.0

Soil Aliquot Volume: (uL)

CONCENTRATION UNITS:

CAS NO. COMPOUND (ug/L or $\mathrm{ug} / \mathrm{Kg}) \mathrm{UG} / \mathrm{L}$

Q

95-22-0---- - - - 3-Pentanone

76-13-1-...--1, 2, 2-Cl3-1, 1, 2-F 3ethane

$76-14-2-\cdots---1,2-\mathrm{Cl} 2-1,1,2,2-\mathrm{F} 4$ ethane

75-71-8--..---Dichlorodifluoromethane

75-05-8--.---Acetonitrile

110-82-7-...--Cyclohexane

108-86-1-...--Bromobenzene

104-51-8--.----Butylbenzene

98-06-6---.---tert-Butylbenzene

135-98-8------sec-Butylbenzene

95-49-8--...--2-Chlorotoluene

99-87-6-- - - - -4-Isopropyltoluene

106-43-4----- - 4-Chlorotoluene

96-12-8---n---1, 2-Dibromo-3-chioropropane

106-93-4--..--1,2-Dibromoethane

110-57-6---.--trans-1, 4-Dichloro-2-butene

142-28-9------1, 3-Dichloropropane

594-20-7--.--- 2, 2-Dichloropropane

563-58-6------1,1-Dichloropropene

87-68-3-...-- - Hexachloro-1, 3-butadiene

98-82-8------- Isopropylbenzene

91 - 20-3------- Nathphalene

103-65-1-.---- - Propylbenzene

87-61-6-....--1,2,3-Trichlorobenzene

120-82-1--.---1, 2, 4-Trichlorobenzene

96-18-4-------1, 2, 3-Trichloropropane

95-63-6-------1, 2,4-Trimethylbenzene

108-67-8------1,2,3-Trimethylbenzene

106-35-4---.--3-Heptanone

110-43-0--..--2-Heptanone

109-99-9-- - - - - Tetrahyarofuran

74-95-3-...-..-Dibromomethane

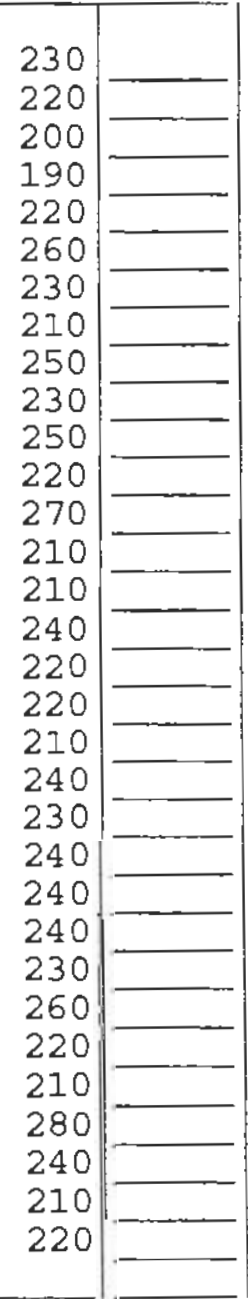


Lab Name: PNNL

Lab Code: PNNL
Contract: C104

SAS NO. :
EPA SAMPIE NO.

LCS

SDG NO.: 29274
Matrix: (soil/water) WATER

Sample wt/vol:

$5.000(\mathrm{~g} / \mathrm{mL}) \mathrm{ML}$

Level: (Iow/med) LoW

$\%$ Moisture: not dec.

GC Column: $\mathrm{DB}-62475 \mathrm{M} \times 2.55 \mathrm{UM}$ ID: 0.45 (mm)

Soil Extract volume: (uL)

CAS NO.

COMPOUND
Lab Sample ID: LCS

Lab File ID: 00040614

Date Received:

Date Analyzed: 04/06/0

Dilution Factor: 1.0

Soil Aliquot volume: (uL)

$(\mathrm{ug} / \mathrm{L}$ or $\mathrm{ug} / \mathrm{Kg}) \mathrm{UG} / \mathrm{L} \quad \mathrm{Q}$

78-87-5-1---1, 2-Dichloropropane

75-27-4-- - - - Bromodichloromethane

10061-01-5-----cis-1, 3-Dichloropropene

108-10-1--.---4-Methyl-2-pentanone

108-88-3-...--Toluene

10061-02-6-----trans-1,3-Dichloropropene

79-00-5--.---1,1,2-Trichloroethane

127-18-4--..--Tetrachloroethene

591-78-6-1-.--2-Hexanone

124-48-1-..---Dibromochloromethane

108-90-7--.----Chlorobenzene

100-41-4-------Ethylbenzene

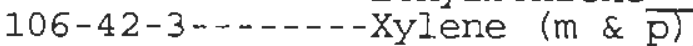

95-47-6--.---XYlene (o)

100-42-5-------styrene

75-25-2--.----Bromoform

79-34-5-..----1, 1, 2, 2-Tetrachloroethane

541-73-1-----1, 3-Dichlorobenzene

106-46-7--.-- -1, 4-Dichlorobenzene

95-50-1------1,2-Dichlorobenzene

142-82-5--.---Heptane

$111-65-9-----$-Octane

$111-84-2-\cdots-\cdots-$ Nonane

107-05-1-..---3-Chloropropene

107-87-9-------2-Pent anone

108-87-2-...-Methylcyclohexane

110-12-3--.---5-Methyl-2-hexanone

123-19-3------4-Heptanone

123-86-4------Butylacetate

123-91-1------1,4-Dioxane

126-98-7- - - - -2-Methyl-2-propenenitrile

563-80-4------3-Methyl-2-butanone

627-13-4------Propyl nitrate

$\mid \begin{array}{ll}250 \\ 220 \\ 220 \\ 230 \\ 230 \\ 220 \\ 220 \\ 220 \\ 230 \\ 220 \\ 220 \\ 250 \\ 260 \\ 260 \\ 270 \\ 220 \\ 230 \\ 240 \\ 240 \\ 230 \\ 210 \\ 210 \\ 230 \\ 240 \\ 220 \\ 230 \\ 220 \\ 240 \\ 250 \\ 250 \\ 240 \\ 200 \\ 240 \\ \\ \end{array}$


Lab Name: PNNL

Contract: C104

Lab code: PNNL.

Case No.:

Matrix: (soil/water) WATER

Sample wt/vol:

$5.000(\mathrm{~g} / \mathrm{mL}) \mathrm{ML}$

Level: (low/med) LOW

: Moisture: not dec.

GC Column: $\mathrm{DB}-62475 \mathrm{M} \times 2.55 \mathrm{UM}$ ID : 0.45 (nm)

Soil Extract Volume: (uL)

SAS NO. :

SDG No.: 2

Lab Sample ID: VBLKO2

Lab File ID: 00040616

Date Received:

Date Analyzed: 04/07/0

Dilution Factor: 1.0

Soil Aliquot Volume: (uL) CONCENIRATION UNITS :

CAS NO.

COMPOUND

(ug/L or $\mathrm{ug} / \mathrm{Kg}$ ) UG/L

Q

\begin{tabular}{|c|}
\hline 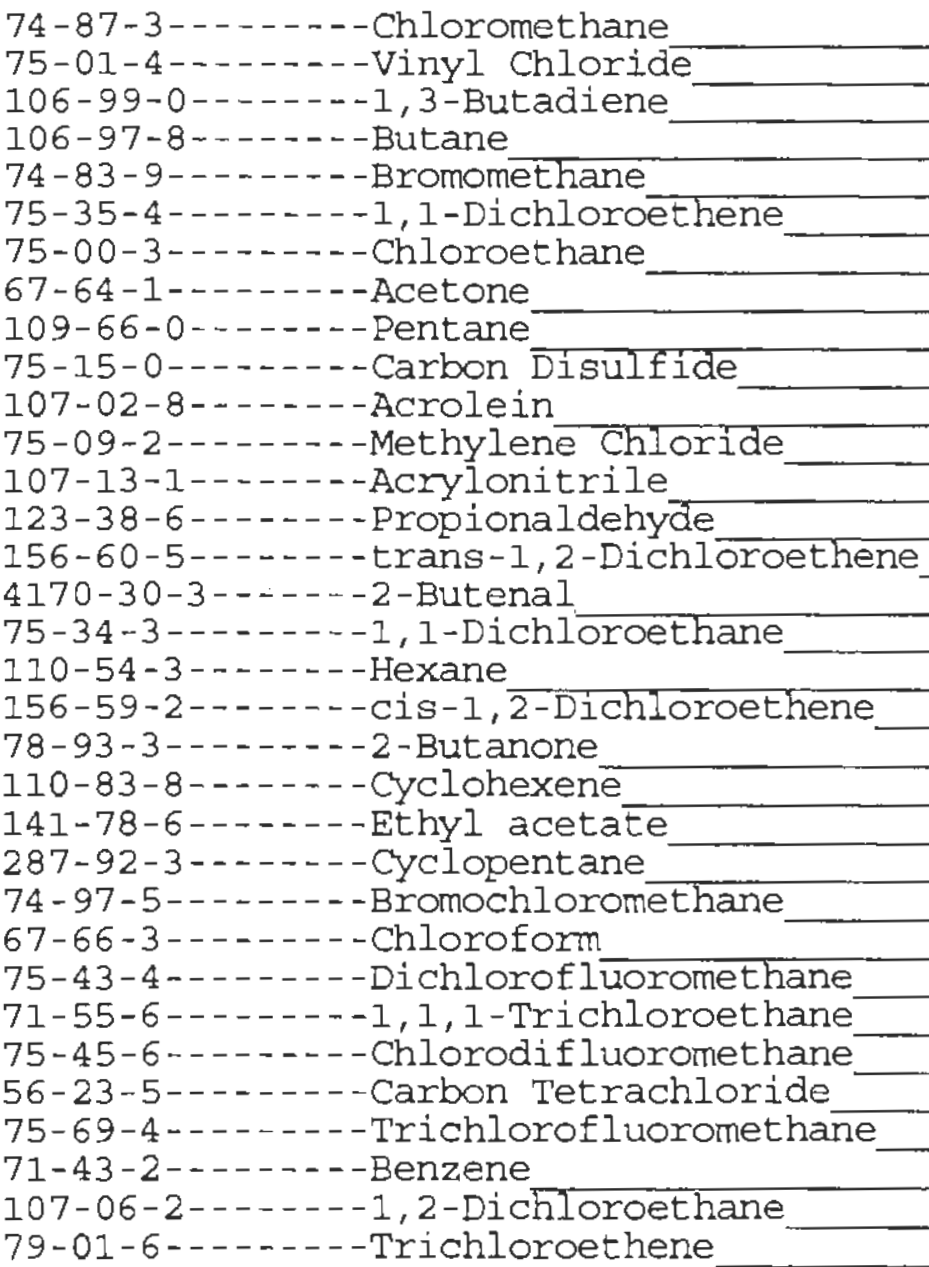 \\
\hline
\end{tabular}

\begin{tabular}{|r|l|}
10 & $U$ \\
10 & $U$ \\
5 & $U$ \\
5 & $U$ \\
10 & $U$ \\
10 & $U$ \\
10 & $U$ \\
10 & $U$ \\
5 & $U$ \\
10 & $U$ \\
5 & $U$ \\
0.5 & $J$ \\
5 & $U$ \\
5 & $U$ \\
10 & $U$ \\
5 & $U$ \\
10 & $U$ \\
5 & $U$ \\
10 & $U$ \\
10 & $U$ \\
5 & $U$ \\
5 & $U$ \\
5 & $U$ \\
10 & $U$ \\
10 & $U$ \\
5 & $U$ \\
10 & $U$ \\
5 & $U$ \\
10 & $U$ \\
5 & $U$ \\
10 & $U$ \\
10 & $U$ \\
10 & $U$ \\
- & \\
\hline &
\end{tabular}


Lab Name: PNNL

Lab Code: PNNL

Case No.:

Matrix: (soil/water) WATER

Sample wt/vol:

$5.000(\mathrm{~g} / \mathrm{mL}) \mathrm{ML}$

Level: (low/med) LOW

음 Moisture: not dec.

GC Column: DB-624 75M X 2.55UM ID: 0.45 (mm)

Soil Extract Volume: (uL)
Contract : $\mathrm{C} 104$

SAS NO.:

Lab Sample ID: VBLKO2

Lab File ID: 00040616

Date Received:

Date Analyzed: 04/07/0

Dilution Factor: 1.0

Soil Aliquot Volume: (UI)

CAS NO.

COMPOUND

CONCENTRATION UNITS :

(ug/L or ug/Kg) UG/I

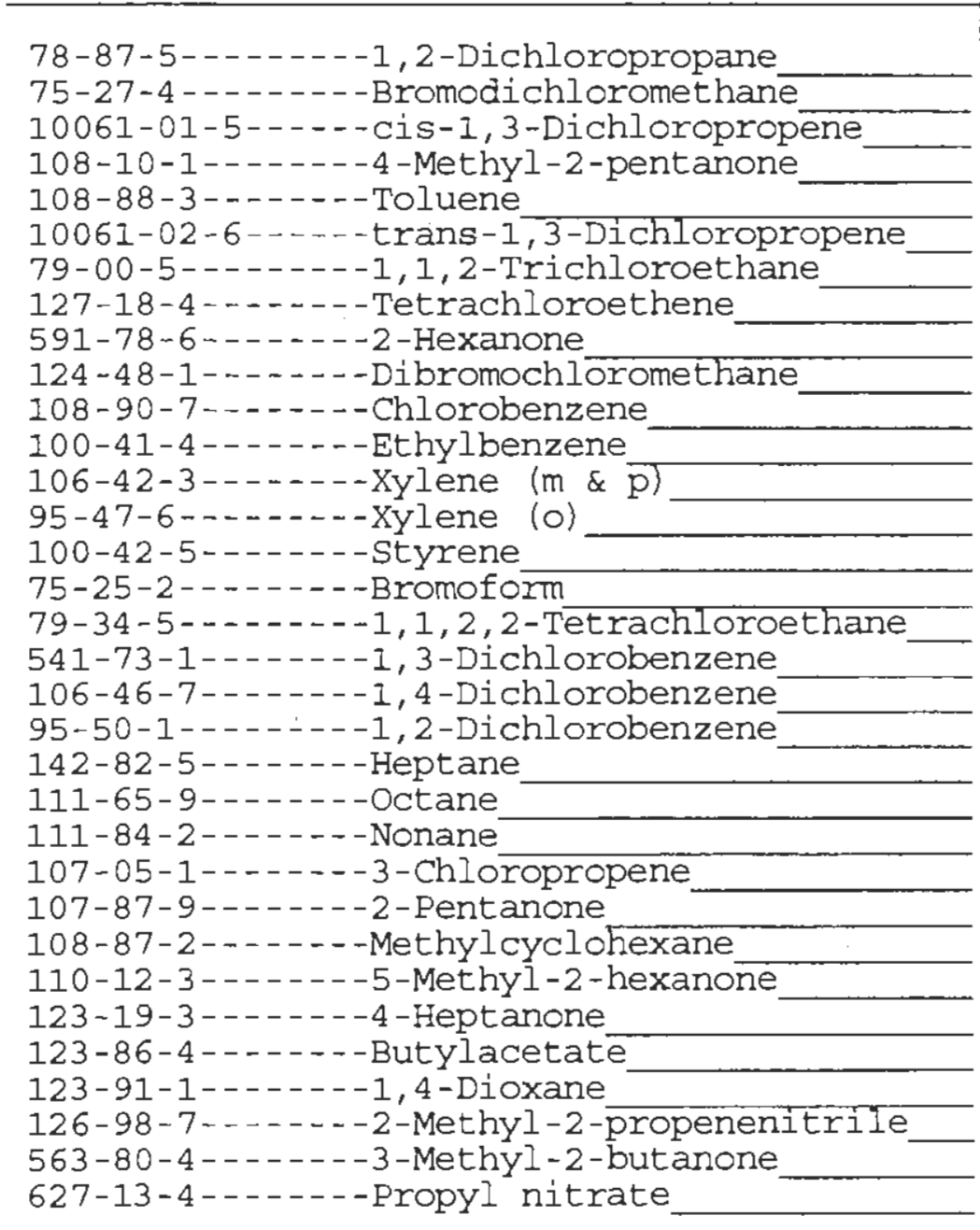

$10 \mathrm{U}$

$10 \mathrm{U}$

$10 \mathrm{U}$

$10 \mathrm{U}$

$10 \mathrm{U}$

$10 \mathrm{U}$

$10 \mathrm{U}$

$10 \mathrm{U}$

$10 \mathrm{U}$

$10 \mathrm{U}$

$10 \mathrm{U}$

$10 \mathrm{U}$

$10 \mathrm{U}$

$10 \mathrm{U}$

$10 \mathrm{U}$

$10 \mathrm{U}$

$10 \mathrm{U}$

$10 \mathrm{U}$

$10 \mathrm{U}$

$10 \mathrm{U}$

$5 \mathrm{U}$

5 U

$5 \mathrm{U}$

$10 \mathrm{U}$

$5 \mathrm{U}$

$5 \mathrm{U}$

5 U

5 U

$5 \mathrm{U}$

$5 \mathrm{U}$

$5 \mathrm{U}$

$5: \mathrm{U}$

$5 \mid \mathrm{U}$ 
Lab Name: PNNL

Lab Code: PNNL

Case No.:

Matrix: (soil/water) WATER

Sample wt/vol:

$5.000(\mathrm{~g} / \mathrm{mL}) \mathrm{ML}$

Level: (low/med) LOW

\% Moisture: not dec.

GC Column: $\mathrm{DB}-62475 \mathrm{M} \times 2.55 \mathrm{UM}$ ID: 0.45 (mm)

Soil Extract Volume: (UL)
Contract: $\mathrm{C} 104$

SAS NO. :
EPA SAMPLE NO.

\section{METHOD BLANK}

SDG NO.: 2

Lab Sample ID: VBLKO2

Lab File ID: 00040616

Date Received:

Date Analyzed: 04/07/0

(mri) Dilution Factor: 1.0

Soil Aliquot Volume: (uL) CONCENTRATION UNITS: $(\mathrm{ug} / \mathrm{L}$ or $\mathrm{ug} / \mathrm{Kg}) \mathrm{UG} / \mathrm{L}$

Q

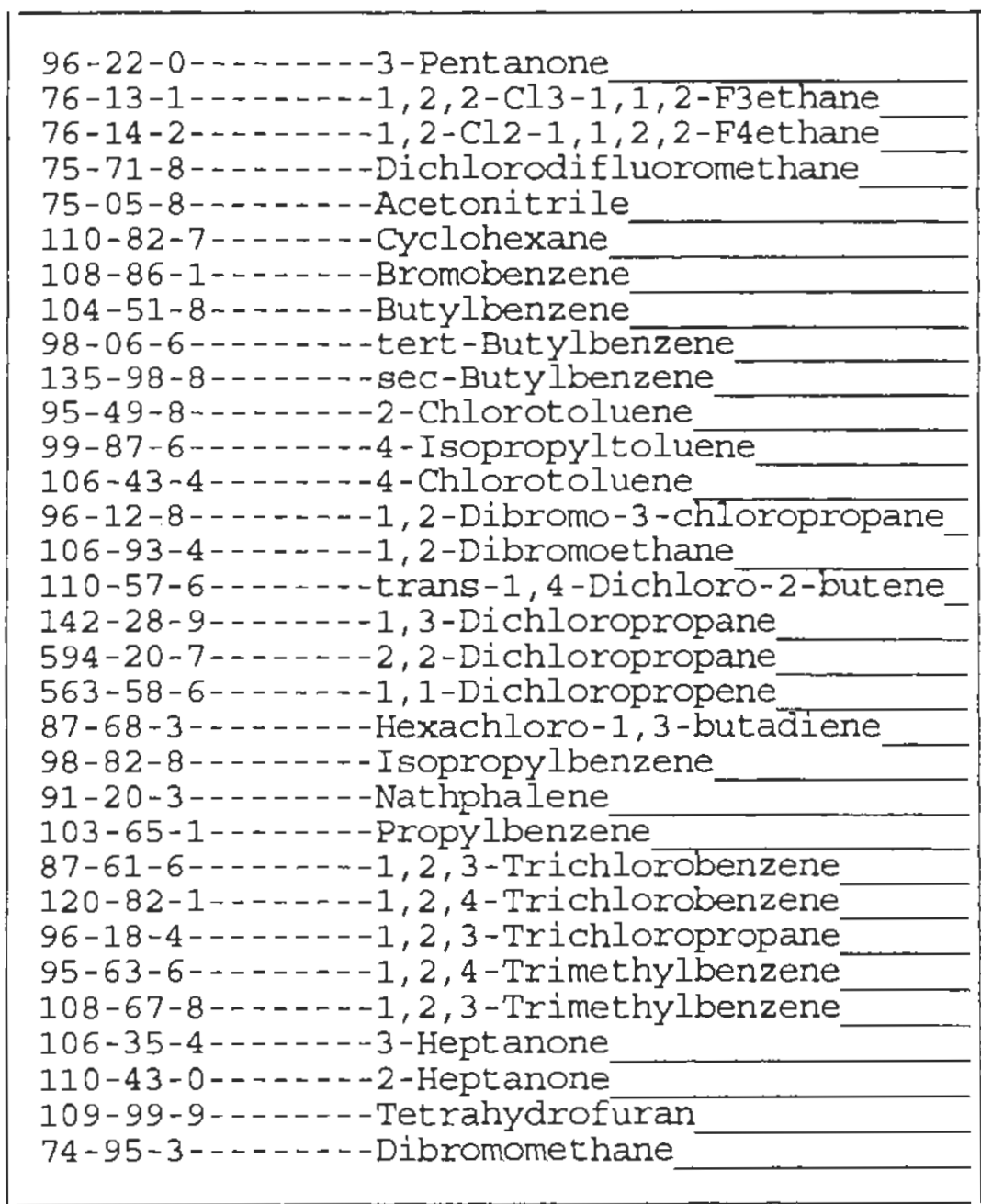

\begin{tabular}{|r|r|r|}
5 & $U$ \\
5 & $U$ \\
5 & $U$ \\
5 & $U$ \\
5 & $U$ \\
5 & $U$ \\
10 & $U$ \\
10 & $U$ \\
10 & $U$ \\
10 & $U$ \\
10 & $U$ \\
10 & $U$ \\
10 & $U$ \\
10 & $U$ \\
10 & $U$ \\
10 & $U$ \\
10 & $U$ \\
10 & $U$ \\
10 & $U$ \\
10 & $U$ \\
10 & $U$ \\
10 & $U$ \\
10 & $U$ \\
10 & $U$ \\
10 & $U$ \\
10 & $U$ \\
10 & $U$ \\
10 & $U$ \\
5 & $U$ \\
5 & $U$ \\
5 & $U$ \\
10 & $U$ \\
& & \\
\hline &
\end{tabular}


Lab Name: PNNL

Lab Code: PNNL

Case No. :

Matrix: (soil/water) SoLID

Sample wt/vol:

$(\mathrm{g} / \mathrm{mL}) \mathrm{G}$

Level: (low/med) LOW

$\%$ Moisture: not dec.

GC Column: DB-624 75M X 2.55UM ID: 0.45 (mm)

Soil Extract Volume: (uL)
Contract: $\mathrm{C} 104$

SAS NO.:

Lab Sample ID: VBLKO3

Lab File ID: 00040622

Date Received:

Date Analyzed: 04/07/0

CAS NO

COMPOUND

CONCENIRATION UNITS:

$(\mathrm{ug} / \mathrm{L}$ or $\mathrm{ug} / \mathrm{Kg}) \mathrm{UG} / \mathrm{KG}$

Dilution Factor: 1.0

Soil Aliquot Volume: (uL)

74-87-3-...--Chloromethane

75-01-4-.....-Vinyl Chloride

106-99-0-...-1, 3-Butadiene

106-97-8--.---Butane

74-83-9--..---Bromomethane

75-35-4-------1, I-Dichloroethene

75-00-3-....--Chloroethane

67-64-1-1-.--Acetone

109-66-0------Pentane

75-15-0-------Carbon Disulfide

107-02-8.....-Acrolein

75-09-2--.---Methylene chloride

107-13-1--.---Acrylonitrile

123-38-6-------Propionaldehyce

156-60-5- - ...-trans-1, 2-Dichloroethene

4170-30-3-..--2-Butenal

75-34-3--.---1, 1-Dichloroethane

$110-54-3-\cdots---$ Hexane

156-59-2-..---cis-1, 2-Dichloroethene

78-93-3-------2-Butanone

110-83-8-..--Cyclohexene

141-78-6-..--Ethyl acetate

287-92-3--.---Cyclopentane

74-97-5-------Bromochloromethane

67-66-3.......-Chloroform

75-43-4--------Dichlorofluoromethane

71-55-6-...--1,1,1-Trichloroethane

75-45-6- - - . -Chlorodifluoromethane

56-23-5---1---Carbon Tetrachloride

75-69-4-..---Trichlorof luoromet hane

$71-43-2-\cdots-\cdots-$ Benzene

107-06-2------1,2-Dichloroethane

79-01-6-2..-.Trichloroethene 
IA

VOLATILE ORGANICS ANALYSIS DATA SHEET
Lab Name: PNNL

Contract: $\mathrm{C} 104$

Lab Code: PNNL

Case No.:

Matrix: (soil/water) SOLID

Sample wt/vol:

$(g / m L) \quad G$

Level: (low $/ \mathrm{med})$ LOW

․․․ Moisture: not dec.

GC Column: DB-624 75M X 2.55UM ID: 0.45 (mm)

Soil Extract Volume: (U)

COMPOUND

SAS NO.:

CAS NO.
EPA SAMPLE NO.

METHOD BLANK

SDG No.: 2

Lab Sample ID: VBLKO3

Lab File ID: 00040622

Date Received:

Date Analyzed: 04/07/0

$$
\text { COMPOTND }
$$

78-87-5-------1,2-Dichloropropane

75-27-4--.----Bromodichloromethane

10061-01-5-----cis-1,3-Dichloropropene

108-10-1------4-Methyl-2-pentanone

108-88-3--.--- Toluene

10061-02-6-- - --trans-1,3-Dichloropropene

79-00-5------1,1,2-Trichloroethane

127-18-4---..-Tetrachloroethene

591-78-6-...--2-Hexanone

124-48-1------Dibromochloromethane

108-90-7--.---Chlorobenzene

100-41-4------Ethylbenzene

106-42-3-...-.xylene (m\& $\mathrm{p})$

95-47-6-...-.Xylene (o)

100-42-5------styrene

$75-25-2-\ldots-1-$ - Bromoform

$79-34-5 \ldots \ldots-1,1,2,2-$ Tetrachloroethane

541-73-1-..---1, 3-Dichlorobenzene

106-46-7--.--1,4-Dichlorobenzene

95-50-1-...--1, 2-Dichlorobenzene

$142-82-5------$ Heptane

$111-65-9-\cdots--$-octane

111-84-2--.---Nonane

107-05-1-----3-Chloropropene

107-87-9-------2-Pentanone

108-87-2--.---Methylcyclohexane

110-12-3-.----5-Methyl-2-hexanone

123-19-3--.---4-Heptanone

123-86-4--..--Butylacetate

123-91-1--.---1,4-Dioxane

126-98-7-------2-Methyl-2-propenenitrile

563-80-4-------3-Methyl-2-butanone

627-13-4------Propyl nitrate

Soil Aliquot volume: (uL)

CONCENTRATION UNITS:

(ug/L or $\mathrm{ug} / \mathrm{Kg}$ ) UG/KG

Q

\begin{tabular}{|c|c|c|}
\hline 50 & $\mathrm{U}$ \\
50 & $\mathrm{U}$ \\
50 & $\mathrm{U}$ \\
50 & $\mathrm{U}$ \\
50 & $\mathrm{U}$ \\
50 & $\mathrm{U}$ \\
50 & $\mathrm{U}$ \\
50 & $\mathrm{U}$ \\
50 & $\mathrm{U}$ \\
50 & $\mathrm{U}$ \\
50 & $\mathrm{U}$ \\
50 & $\mathrm{U}$ \\
50 & $\mathrm{U}$ \\
50 & $\mathrm{U}$ \\
50 & $\mathrm{U}$ \\
50 & $\mathrm{U}$ \\
50 & $\mathrm{U}$ \\
50 & $\mathrm{U}$ \\
50 & $\mathrm{U}$ \\
50 & $\mathrm{U}$ \\
50 & $\mathrm{U}$ \\
50 & $\mathrm{U}$ \\
50 & $\mathrm{U}$ \\
50 & $\mathrm{U}$ \\
50 & $\mathrm{U}$ \\
50 & $\mathrm{U}$ \\
50 & $\mathrm{U}$ \\
50 & $\mathrm{U}$ \\
50 & $\mathrm{U}$ \\
50 & $\mathrm{U}$ \\
50 & $\mathrm{U}$ \\
50 & $\mathrm{U}$ \\
50 & $\mathrm{U}$ \\
& & \\
\hline
\end{tabular}


Lab Name: PNNL

Contract : $\mathrm{C} 104$

Lab Code: PNNL

Case No.:

Matrix: (soil/water) SOLID

Sample wt/vol:

$(g / m L) G$

Level: (low $/ \mathrm{med}$ )

LOW

\% Moisture: not dec.

GC Column: $\mathrm{DB}-62475 \mathrm{M} \times 2.55 \mathrm{UM}$ ID: 0.45 (mm)

Soil Extract Volume: (uL)
SAS NO.:

SDG No. : 2

Lab Sample ID: VBLK03

Lab File ID: 00040622

Date Received:

Date Analyzed: 04/07/0

Dilution Factor: 1.0

Soil Aliquot Volume: (uL) CONCENTRATION UNITS:

CAS NO.

COMPOUND (ug/L or $\mathrm{ug} / \mathrm{Kg}$ ) UG/KG

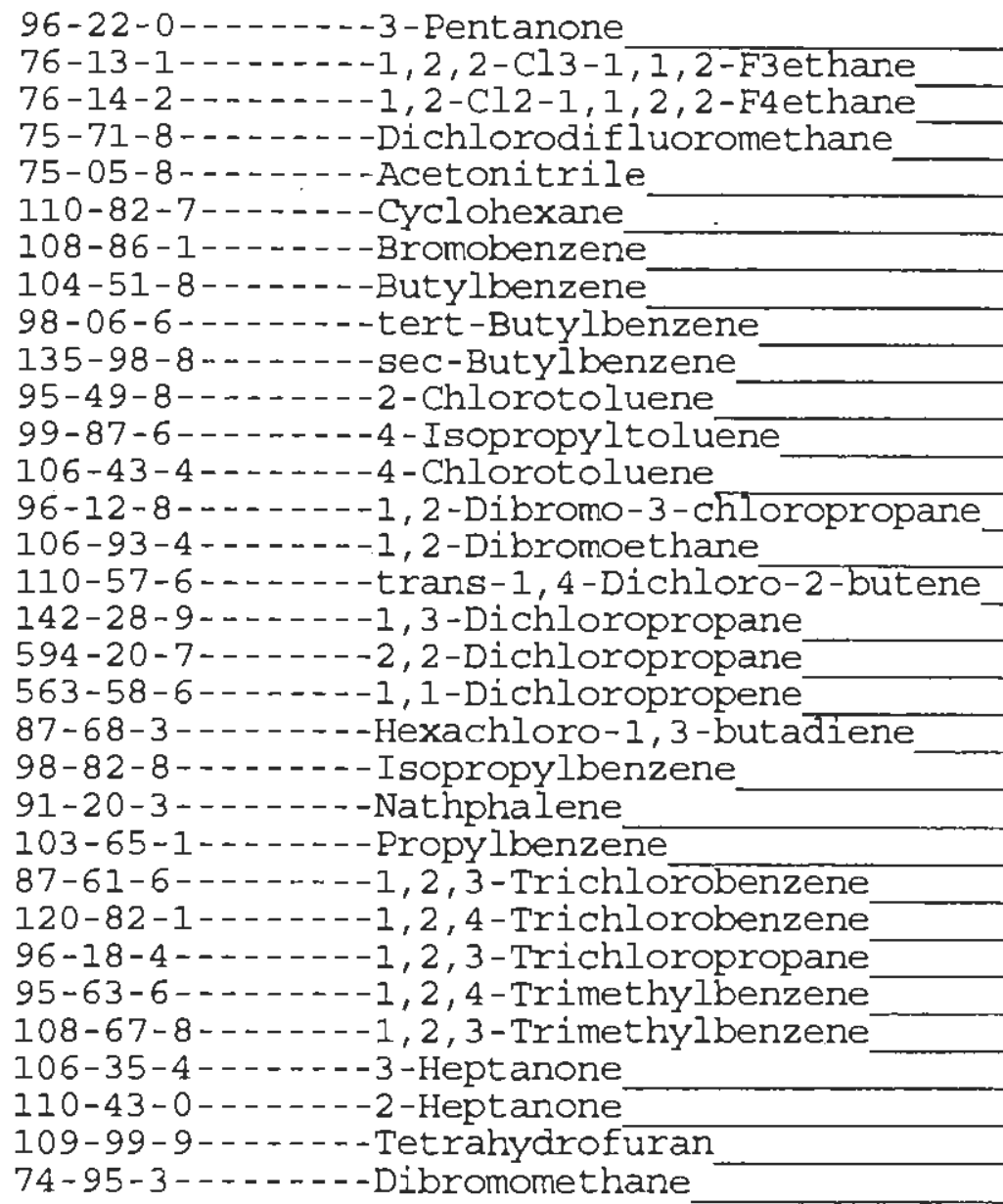


$1 \mathrm{~A}$

VOLATILE ORGANICS ANALYSIS DATA SHEET
Lab Name: PNNL,

Contract: $\mathrm{ClO} 4$

Lab Code: PNNL

Case No.:
SAS NO.:
EPA SAMPLE NO.

C104SUP
Matrix: (soil/water) WATER

Sample wt/vol: $\quad 5.000(\mathrm{~g} / \mathrm{mL}) \mathrm{ML}$

Level: (low/med) LoW

: Moisture: not dec.

GC Column: $\mathrm{DB}-62475 \mathrm{M} \times 2.55 \mathrm{UM}$ ID: 0.45 (mm)

Soil Extract Volume:

(u士)

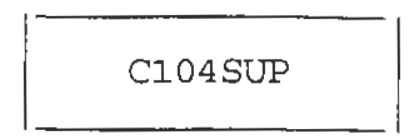

SDG No.: 2

Lab Sample ID: 00-1360

Lab File ID: 00040618

Date Received:

Date Analyzed: 04/07/0

Dilution Factor: 100.0

Soil Aliquot volume:

(uL)

CONCENTRATION UNITS :

CAS NO.

COMPOUND (ug/L or $\mathrm{ug} / \mathrm{Kg}$ ) UG/L

\begin{tabular}{r|l|}
1000 & $\mathrm{U}$ \\
1000 & $\mathrm{U}$ \\
500 & $\mathrm{U}$ \\
500 & $\mathrm{U}$ \\
1000 & $\mathrm{U}$ \\
1000 & $\mathrm{U}$ \\
1000 & $\mathrm{U}$ \\
1000 & \\
500 & $\mathrm{U}$ \\
1000 & $\mathrm{U}$ \\
500 & $\mathrm{U}$ \\
8000 & $\mathrm{U}$ \\
500 & $\mathrm{U}$ \\
500 & $\mathrm{U}$ \\
1000 & $\mathrm{U}$ \\
500 & $\mathrm{U}$ \\
1000 & $\mathrm{U}$ \\
5000 & \\
1000 & $\mathrm{U}$ \\
290 & $\mathrm{~J}$ \\
500 & $\mathrm{U}$ \\
500 & $\mathrm{U}$ \\
500 & $\mathrm{U}$ \\
1000 & $\mathrm{U}$ \\
1000 & $\mathrm{U}$ \\
500 & $\mathrm{U}$ \\
1000 & $\mathrm{U}$ \\
500 & $\mathrm{U}$ \\
1000 & $\mathrm{U}$ \\
500 & $\mathrm{U}$ \\
1000 & $\mathrm{U}$ \\
1000 & $\mathrm{U}$ \\
1000 & $\mathrm{U}$ \\
\hline & \\
\hline
\end{tabular}


Lab Name: PNNL

Lab Code: PNNL

Case No.:

Matrix: (soil/water) WATER

Sample wt/vol:

$5.000(\mathrm{~g} / \mathrm{mL}) \mathrm{ML}$

Level: (low/med) LOW

\% Moisture: not dec.

GC Column: DB-624 75M X 2.55UM ID: 0.45 (mm)

Soil Extract Volume: (uL)
Contract : $\mathrm{C} 104$

SAS NO. :
EPA SAMPLE NO.

C104SUP

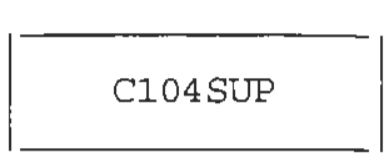

SDG NO.: 2

Lab Sample ID: 00-1360

Lab File ID: 00040618

Date Received:

Date Analyzed: 04/07/0

mm) Dilution Factor: 100.0

Soil Aliquot Volume: (uL) CONCENTRATION UNITS: (ug/L or $u g / \mathrm{Kg}$ ) UG/L

\begin{tabular}{|c|}
\hline 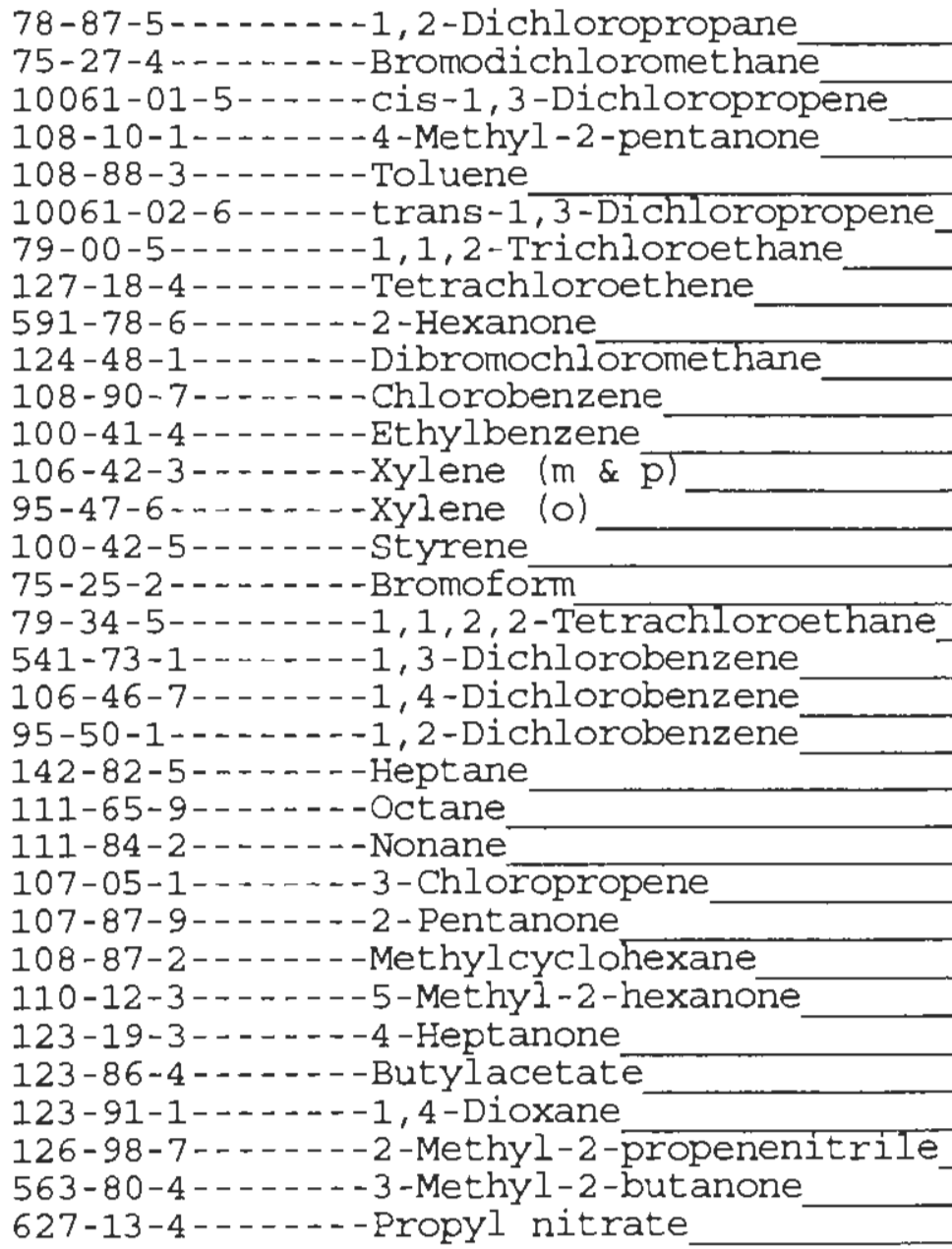 \\
\hline
\end{tabular}

\begin{tabular}{|r|l|}
\hline 1000 & $\mathrm{U}$ \\
1000 & $\mathrm{U}$ \\
1000 & $\mathrm{U}$ \\
1000 & $\mathrm{U}$ \\
1000 & $\mathrm{U}$ \\
1000 & $\mathrm{U}$ \\
1000 & $\mathrm{U}$ \\
1000 & $\mathrm{U}$ \\
24 & $\mathrm{~J}$ \\
1000 & $\mathrm{U}$ \\
1000 & $\mathrm{U}$ \\
1000 & $\mathrm{U}$ \\
1000 & $\mathrm{U}$ \\
1000 & $\mathrm{U}$ \\
1000 & $\mathrm{U}$ \\
1000 & $\mathrm{U}$ \\
1000 & $\mathrm{U}$ \\
1000 & $\mathrm{U}$ \\
1000 & $\mathrm{U}$ \\
1000 & $\mathrm{U}$ \\
1900 & - \\
3800 & - \\
6200 & \\
1000 & $\mathrm{U}$ \\
500 & $\mathrm{U}$ \\
500 & $\mathrm{U}$ \\
500 & $\mathrm{U}$ \\
500 & $\mathrm{U}$ \\
500 & $\mathrm{U}$ \\
500 & $\mathrm{U}$ \\
500 & $\mathrm{U}$ \\
500 & $\mathrm{U}$ \\
500 & $\mathrm{U}$ \\
& \\
\hline 100 & \\
\hline 100
\end{tabular}


$I \mathrm{~A}$

VOLATILE ORGANICS ANALYSIS DATA SHEET
Lab Name: PNNL

Labo Code: PNNL

Case No. :

Matrix: (soil/water) WATER

Sample wt/vol:

$5.000(\mathrm{~g} / \mathrm{mL}) \mathrm{ML}$

Level: (low/med) LOW

o Moisture: not dec.

GC Column: DB-624 75M X 2.55UM ID: 0.45 (rmm)

Soil Extract Volume: (uL)

Contract: $\mathrm{C} 104$

SAS NO. :

Lab Sample ID: 00-1360

Lab File ID: 00040618

Date Received:

Date Analyzed: 04/07/0

Dilution Factor: 100.0

Soil Aliquot volume: (ut)

CAS NO.

COMPOUND

CONCENTRATION UNITS:

(ug/L or $\mathrm{ug} / \mathrm{Kg}$ ) UG/L

96-22-0--------3-Pentanone

76-13-1-...--1,2,2-C13-1, 1, 2-F3ethane

76-14-2------1,2-Cl2-1, 1,2,2-F4ethane

75-71-8-..----Dichlorodifluoromethane

75-05-8-----Acetonitrile

110-82-7---.--Cyclohexane

108-86-1-...--Bromobenzene

104-51-8-...---Butylbenzene

98-06-6------tert-Butylbenzene

135-98-8--.---sec-Butylbenzene

95-49-8------2-Chlorotoluene

99-87-6-..--4-Isopropyl toluene

106-43-4------4-Chlorotoluene

96-12-8-------1,2-Dibromo-3-chloropropane

106-93-4------1,2-Dibromoethane

110-57-6--..-trans-1,4-Dichloro-2-butene

142-28-9-n---1,3-Dichloropropane

594-20-7----2,2-Dichloropropane

563-58-6----1,1-Dichloropropene

87-68-3 - - - -Hexachloro-1, 3-butadiene

98-82-8---.---Isopropyl benzene

91-20-3-...---Nathphalene

103-65-1-------Propylbenzene

87-61-6-...--1,2,3-Trichlorobenzene

120-82-1---n-1,2,4-Trichlorobenzene

96-18-4--.--1,2,3-Trichloropropane

95-63-6------1, 2,4-Trimethylbenzene

108-67-8-----1,2,3-Trimethylbenzene

106-35-4------3-Hept anone

110-43-0-.-.--2-Heptanone

109-99-9-.----Tetrahydrofuran

74-95-3--.---Dibromomethane

\begin{tabular}{|r|r|l|}
500 & $\mathrm{U}$ \\
500 & $\mathrm{U}$ \\
500 & $\mathrm{U}$ \\
500 & $\mathrm{U}$ \\
500 & $\mathrm{U}$ \\
500 & $\mathrm{U}$ \\
1000 & $\mathrm{U}$ \\
1000 & $\mathrm{U}$ \\
1000 & $\mathrm{U}$ \\
1000 & $\mathrm{U}$ \\
1000 & $\mathrm{U}$ \\
1000 & $\mathrm{U}$ \\
1000 & $\mathrm{U}$ \\
1000 & $\mathrm{U}$ \\
1000 & $\mathrm{U}$ \\
1000 & $\mathrm{U}$ \\
1000 & $\mathrm{U}$ \\
1000 & $\mathrm{U}$ \\
1000 & $\mathrm{U}$ \\
1000 & $\mathrm{U}$ \\
1000 & $\mathrm{U}$ \\
1000 & $\mathrm{U}$ \\
1000 & $\mathrm{U}$ \\
1000 & $\mathrm{U}$ \\
1000 & $\mathrm{U}$ \\
1000 & $\mathrm{U}$ \\
1000 & $\mathrm{U}$ \\
1000 & $\mathrm{U}$ \\
74 & $\mathrm{~J}$ \\
997 & $\mathrm{~J}$ \\
500 & $\mathrm{U}$ \\
1000 & $\mathrm{U}$ \\
& & \\
\hline
\end{tabular}


Lab Name: PNNL

Contract: C104

Lab Code: PNNL

Case No.:

Matrix: (soil/water) WATER

Sample wt/vol: $\quad 5.000(\mathrm{~g} / \mathrm{mL}) \mathrm{ML}$

Level: (low/med) LOW

$\therefore$ Moisture: not dec.

GC Column: $\mathrm{DB}-62475 \mathrm{M} \times 2.55 \mathrm{UM}$ ID: 0.45 (mm) (uL)
SAS NO. :
Soil Extract Volume:
EPA SAMPLE NO.

C104SUPD

Soil Aliquot Volume: (uL)

CAS NO.

COMPOUND

CONCENTRATION UNITS:

(ug/L or $\mathrm{ug} / \mathrm{Kg}$ ) UG/L

$Q$

Lab Sample ID: 00-1360D

Lab File ID: 00040619

Date Received:

Date Analyzed: 04/07/0

Dilution Factor: 100.0

\begin{tabular}{|c|}
\hline 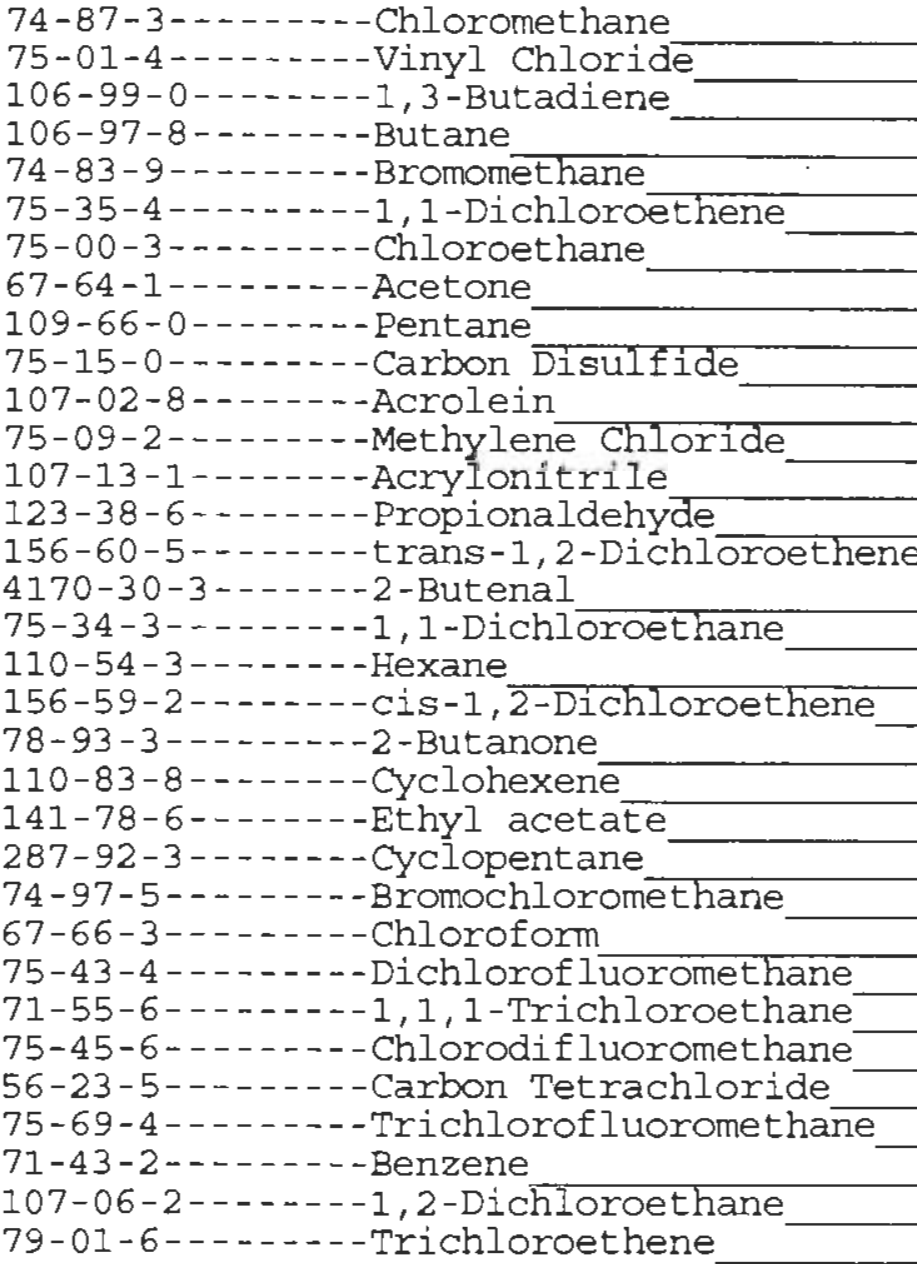 \\
\hline
\end{tabular}

OLMO 3.0 
Lab Name: PNNL

Lab Code: PNNL
Contract: $\mathrm{ClO4}$

Case No.:
SAS NO. :
Matrix: (soil/water) WATER

Sample wt/vol:

$5.000(\mathrm{~g} / \mathrm{mL}) \mathrm{ML}$

Level: (low/med) LOW

\% Moisture: not dec.

GC Column: $\mathrm{DB}-62475 \mathrm{M} \times 2.55 \mathrm{UM}$ ID: 0.45 (mm) (uL)
Lab Sample ID: 00-1360D

Lab File ID: 00040619

Date Received:

Date Analyzed: 04/07/0

Dilution Factor: 100.0
Soil Extract volume:

CAS NO.
COMPOUND
CONCENTRATION UNITS:

(ug/L or $\mathrm{ug} / \mathrm{Kg}$ ) UG/L

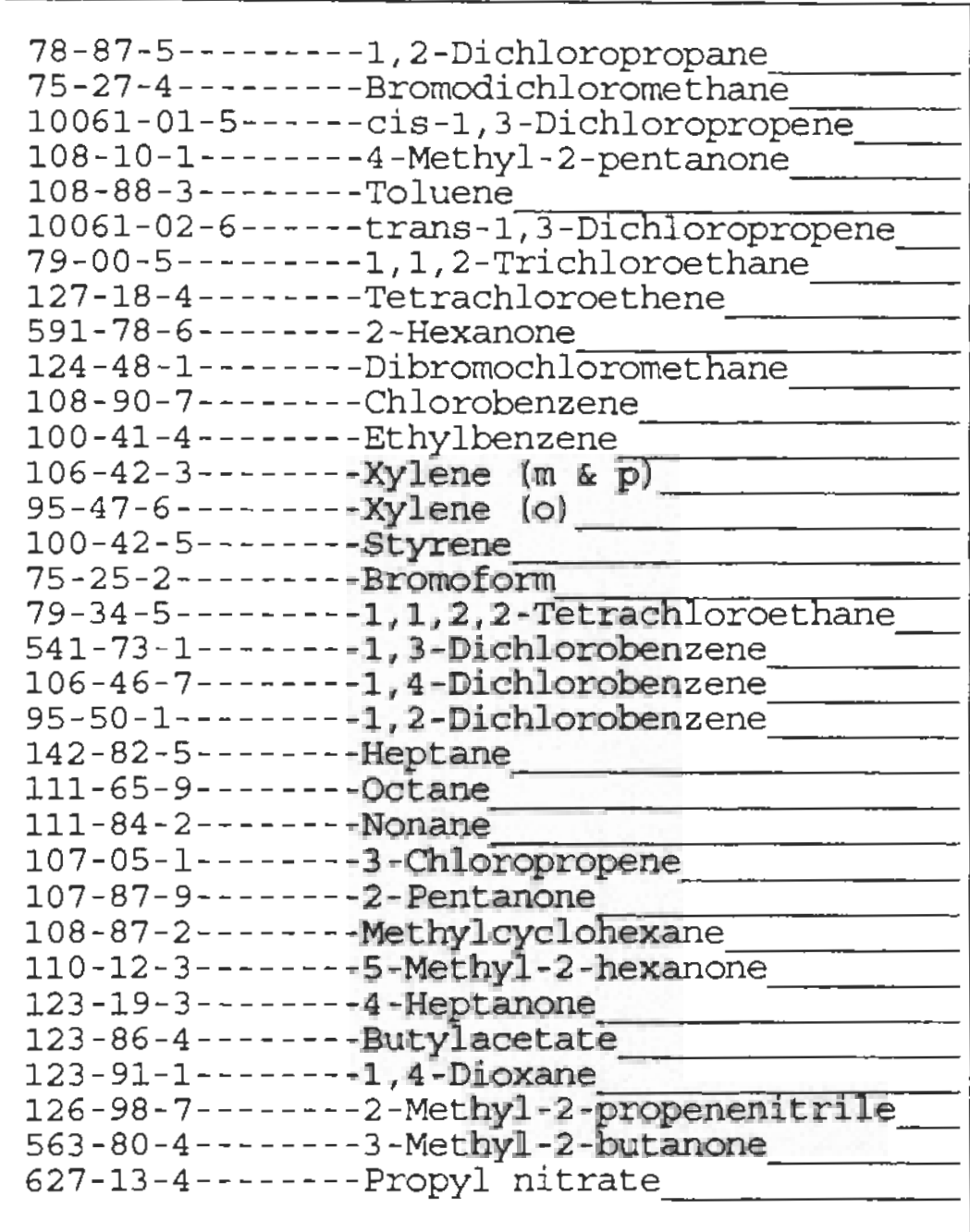

\begin{tabular}{r|l}
1000 & $\mathrm{U}$ \\
1000 & $\mathrm{U}$ \\
1000 & $\mathrm{U}$ \\
1000 & $\mathrm{U}$ \\
1000 & $\mathrm{U}$ \\
1000 & $\mathrm{U}$ \\
1000 & $\mathrm{U}$ \\
1000 & $\mathrm{U}$ \\
1000 & $\mathrm{U}$ \\
1000 & $\mathrm{U}$ \\
1000 & $\mathrm{U}$ \\
1000 & $\mathrm{U}$ \\
1000 & $\mathrm{U}$ \\
1000 & $\mathrm{U}$ \\
1000 & $\mathrm{U}$ \\
1000 & $\mathrm{U}$ \\
1000 & $\mathrm{U}$ \\
1000 & $\mathrm{U}$ \\
1000 & $\mathrm{U}$ \\
1000 & $\mathrm{U}$ \\
500 & $\mathrm{U}$ \\
500 & $\mathrm{U}$ \\
500 & $\mathrm{U}$ \\
1000 & $\mathrm{U}$ \\
500 & $\mathrm{U}$ \\
500 & $\mathrm{U}$ \\
500 & $\mathrm{U}$ \\
500 & $\mathrm{U}$ \\
500 & $\mathrm{U}$ \\
500 & $\mathrm{U}$ \\
500 & $\mathrm{U}$ \\
500 & $\mathrm{U}$ \\
500 & $\mathrm{U}$ \\
& \\
\hline
\end{tabular}


Lab Name: PNNL

Lab Code: PNNL

Case No.:

Matrix: (soil/water) WATER

Sample wt/vol:

$5.000(\mathrm{~g} / \mathrm{mL}) \mathrm{ML}$

Level: (low/med) LOW

: Moisture: not dec.

GC Column: DB-624 75M X 2.55UM ID: 0.45 (mm) (uL)
Contract: C104

SAS NO. :

\section{C104 SUPD}

SDG No. : 2

Lab Sample ID: 00-1360D

Lab File ID: 00040619

Date Received:

Date Analyzed: 04/07/0

Dilution Factor: 100.0

Soil Aliquot volume: (UI) CONCENTRATION UNITS:

CAS NO.

COMPOUND

Q

\begin{tabular}{|c|c|c|}
\hline 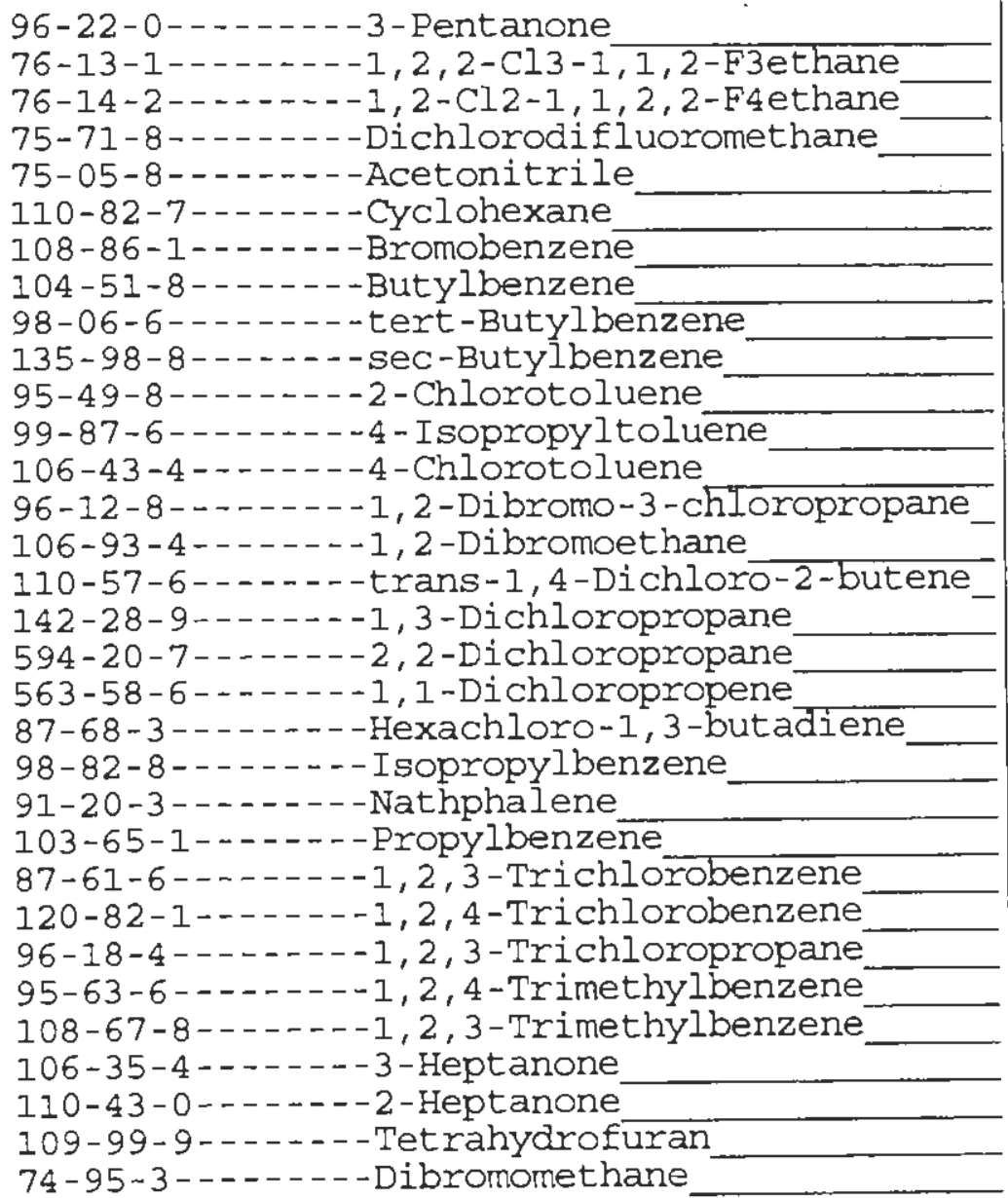 & $\begin{array}{r}500 \\
500 \\
500 \\
500 \\
0.0 \\
500 \\
1000 \\
1000 \\
1000 \\
1000 \\
1000 \\
1000 \\
1000 \\
1000 \\
1000 \\
1000 \\
1000 \\
1000 \\
1000 \\
1000 \\
1000 \\
1000 \\
1000 \\
1000 \\
1000 \\
1000 \\
1000 \\
1000 \\
500 \\
500 \\
500 \\
1000\end{array}$ & $\begin{array}{l}U \\
U \\
U \\
U \\
U \\
U \\
U \\
U \\
U \\
U \\
U \\
U \\
U \\
U \\
U \\
U \\
U \\
U \\
U \\
U \\
U \\
U \\
U \\
U \\
U \\
U \\
U \\
U \\
U \\
U \\
U \\
U\end{array}$ \\
\hline
\end{tabular}


IA

VOLATILE ORGANICS ANALYSIS DATA SHEET
Lab Name: PNNL

Contract: $\mathrm{C104}$

Lab Code: PNNL

Case No.:

Matrix: (soil/water) WATER

Sample wt/vol: $\quad 5.000(\mathrm{~g} / \mathrm{mL}) \mathrm{ML}$

Level: (low/med) LOW

\% Moisture: not dec.

GC Column: $\mathrm{DB}-62475 \mathrm{M} \times 2.55 \mathrm{UM}$ ID: 0.45 (mm)

Soil Extract Volume: (UL)

SAS NO.:
ERA SAMPLE NO.

\section{C104 SUPMS}

SDG No. : 2

Lab Sample ID: 00-01360MS

Lab File ID: 00040620

Date Received:

Date Analyzed: 04/07/0

(milution Factor: 100.0

Soil Aliquot Volume: (uL) CONCENTRATION UNITS:

CAS NO.

COMPOUND (ug/L or ug/Kg) UG/L

Q

74-87-3---n--Chloromethane

75-01-4-.-.--vinyl Chloride

106-99-0-----1, 3-Butadiene

106-97-8---.--Butane

74-83-9-.-n--Bromomethane

75-35-4------1, 1-Dichloroethene

75-00-3-------Chloroethane

67-64-1-...--.-Acetone

109-66-0-.-.--Pentane

75-15-0-.-.--Carbon Disulfide

107-02-8-...-Acrolein

75-09-2--..--Methylene Chloride

107-13-1-..--Acrylonitrile

123-38-6--..--Propionaldehyde

156-60-5---.--trans-1, 2-Dichloroethene

4170-30-3-..--2-Butenal

75-34-3--.--1,1-Dichloroethane

110-54-3--.---Hexane

156-59-2-...-cis-1, 2-Dichloroethene

78-93-3----.--2-Butanone

110-83-8--.---cyclohexene

141-78-6--.---Ethyl acetate

287-92-3-----Cyclopentane.

74-97-5-..--Bromochloromethane

67-66-3-..---. Chloroform

75-43-4-------Dichlorofluoromethane

71-55-6-----1, 1, 1-Trichloroethane

75-45-6-...--Chlorodifluoromethane

56-23-5-...-.-Carbon Tetrachloride

75-69-4-1-.-- Trichlorofluoromethane

71-43-2--..---Benzene

107-06-2--.--1,2-Dichloroethane

79-01-6-...--Trichloroethene 
Lab Name: PNNL

Contract : $\mathrm{C} 104$

Lab Code: PNNL

Case No. :

Matrix: (soil/water) WATER

Sample wt/vol: $\quad 5.000(\mathrm{~g} / \mathrm{mL}) \mathrm{ML}$

Level: $\quad$ (Iow $/ \mathrm{med}$ ) LOW

SAS NO. :

Lab Sample ID: 00-01360MS

Lab File ID: 00040620

Date Received:

Date Analyzed: 04/07/0

GC Column: DB-624 75M X 2.55UM ID: 0.45 (mm)

Soil Extract Volume:

(uI)

Soil Aliquot Volume:

(uL)

CONCENTRATION UNITS:

CAS NO.

COMPOUND
(ug/L or $\mathrm{ug} / \mathrm{Kg}$ ) UG/L
C104SUPMS

SDG NO. : 2

\begin{tabular}{|c|}
\hline 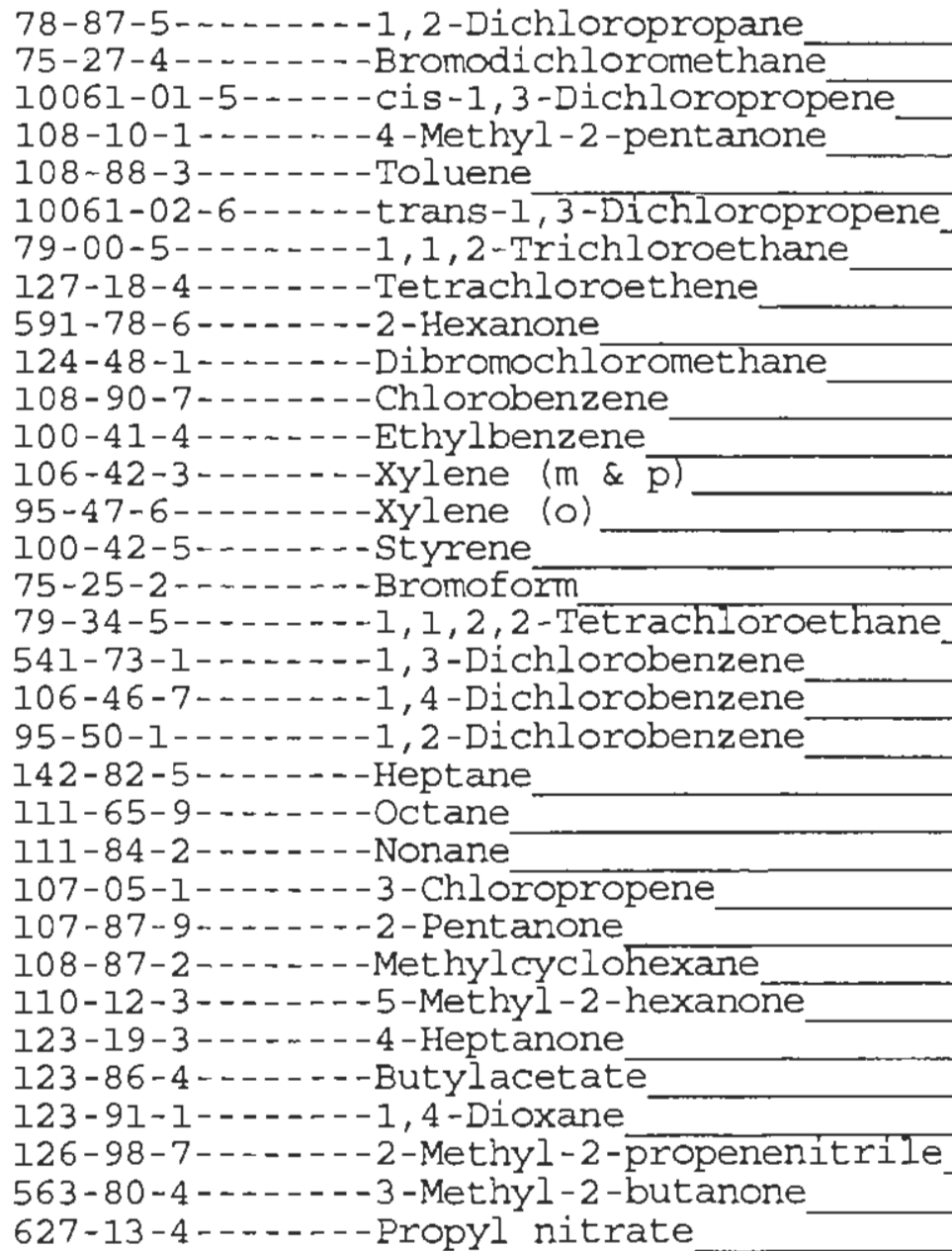 \\
\hline
\end{tabular}

\begin{tabular}{r|l}
5000 & $\mathrm{U}$ \\
5000 & $\mathrm{U}$ \\
5000 & $\mathrm{U}$ \\
15000 & \\
2300 & $\mathrm{~J}$ \\
5000 & $\mathrm{U}$ \\
5000 & $\mathrm{U}$ \\
5000 & $\mathrm{U}$ \\
3000 & $\mathrm{~J}$ \\
5000 & $\mathrm{U}$ \\
1900 & $\mathrm{~J}$ \\
5000 & $\mathrm{U}$ \\
5000 & $\mathrm{U}$ \\
5000 & $\mathrm{U}$ \\
5000 & $\mathrm{U}$ \\
5000 & $\mathrm{U}$ \\
5000 & $\mathrm{U}$ \\
5000 & $\mathrm{U}$ \\
5000 & $\mathrm{U}$ \\
5000 & $\mathrm{U}$ \\
1100 & $\mathrm{~J}$ \\
590 & $\mathrm{~J}$ \\
420 & $\mathrm{~J}$ \\
5000 & $\mathrm{U}$ \\
3000 & \\
1400 & $\mathrm{~J}$ \\
14000 & \\
2700 & \\
2500 & $\mathrm{U}$ \\
14000 & \\
15000 & \\
14000 & \\
2200 & $\mathrm{~J}$ \\
\hline & \\
\hline
\end{tabular}


Lab Name: PNNL

Lab Code: PNNL

Case No.:

Matrix: (soil/water) WATER

Sample wt/vol:

$5.000(\mathrm{~g} / \mathrm{mL}) \mathrm{ML}$

Level: (low/med) LOW

\% Moisture: not dec.

GC Column: DB-624 75M X 2.55UM ID: 0.45 (mm)

Soil Extract Volume:

(uL)
Contract : $\mathrm{ClO4}$

SAS NO.:

C104SUPMS

SDG No.: 2

Lab Sample ID: 00-01360MS

Lab File ID: 00040620

Date Received:

Date Analyzed: 04/07/0

Dilution Factor: 100.0

Soil Aliquot Volume: (uL)

CONCENTRATION UNITS:

CAS NO.

COMPOUND

$(\mathrm{ug} / \mathrm{L}$ or $\mathrm{ug} / \mathrm{Kg}) \mathrm{UG} / \mathrm{L}$

Q

96-22-0--n---3-Pentanone

76-13-1--.---1, 2, 2-Cl3-1, 1, 2-E3ethane

76-14-2---.--1,2-Cl2-1,1,2,2-F4ethane

75-71-8------Dichlorodifluoromethane

75-05-8-----Acetonitrile

110-82-7-----Cyclohexane

108-86-1--.--Bromobenzene

104-51-8---.---Butylbenzene

98-06-6------tert-Butylbenzene

135-98-8------sec-Butylbenzene

95-49-8------2-Chlorotoluene

99-87-6-..---4-Isopropyltoluene

106-43-4--.--4-Chlorotoluene

96-12-8------1, 2-Dibromo-3-chloropropane

106-93-4-----1, 2-Dibromoethane

110-57-6--...-trans-1,4-Dichloro-2-butene

142-28-9--.--1,3-Dichloropropane

594-20-7-2..-2,2-Dichloropropane

$563-58-6-\ldots-1,1-D i c h l o r o p r o p e n e$

87-68-3-...--Hexachloro-1,3-butadiene

98-82-8-1-n-.--Isopropylbenzene

91-20-3-...--Nathphalene

103-65-1-...--Propylbenzene

87-61-6-...-1,2,3-Trichlorobenzene

120-82-1-...-1,2,4-Trichlorobenzene

96-18-4-----1, 2,3-Trichloropropane

95-63-6-...-1, 2,4-Trimethylbenzene

108-67-8--.--1,2,3-Trimethylbenzene

106-35-4--1----3-Heptanone

110-43-0--.--2-Heptanone

109-99-9-...--Tetrahydrofuran

74-95-3--1---Dibromomethane

\begin{tabular}{r|l|}
15000 & \\
1700 & $J$ \\
2300 & $\mathrm{~J}$ \\
9200 & - \\
3200 & \\
2000 & $\mathrm{~J}$ \\
5000 & $\mathrm{U}$ \\
5000 & $\mathrm{U}$ \\
5000 & $\mathrm{U}$ \\
5000 & $\mathrm{U}$ \\
5000 & $\mathrm{U}$ \\
5000 & $\mathrm{U}$ \\
5000 & $\mathrm{U}$ \\
5000 & $\mathrm{U}$ \\
5000 & $\mathrm{U}$ \\
5000 & $\mathrm{U}$ \\
5000 & $\mathrm{U}$ \\
5000 & $\mathrm{U}$ \\
5000 & $\mathrm{U}$ \\
5000 & $\mathrm{U}$ \\
5000 & $\mathrm{U}$ \\
5000 & $\mathrm{U}$ \\
5000 & $\mathrm{U}$ \\
5000 & $\mathrm{U}$ \\
5000 & $\mathrm{U}$ \\
5000 & $\mathrm{U}$ \\
5000 & $\mathrm{U}$ \\
5000 & $\mathrm{U}$ \\
3900 & \\
14000 & \\
690 & $\mathrm{~J}$ \\
5000 & $\mathrm{U}$ \\
& \\
\hline &
\end{tabular}


Lab Name: PNNL Contract: $\mathrm{ClO4}$ SAS NO. :

Lab Code: PNNL

Case No.:
EPA SAMPLE NO.

C104SUPMSD
Matrix: (soil/water) WATER

Sample wt/vol:

$5.000(\mathrm{~g} / \mathrm{mL}) \mathrm{MI}$

Level: (low/med) Low

: Moisture: not dec.

GC Column: DB-624 75M X 2.55UM ID: 0.45 (mm)

Soil Extract volume: (uL)

COMPOUND
CAS NO.
Lab Sample ID: 00-01360MSD

Lab File ID: 00040621

Date Received:

Date Analyzed: 04/07/0

Dilution Factor: 100.0

Soil Aliquot volume: (UL) CONCENTRATION UNITS: (ug/L or $\mathrm{ug} / \mathrm{Kg}$ ) UG/L

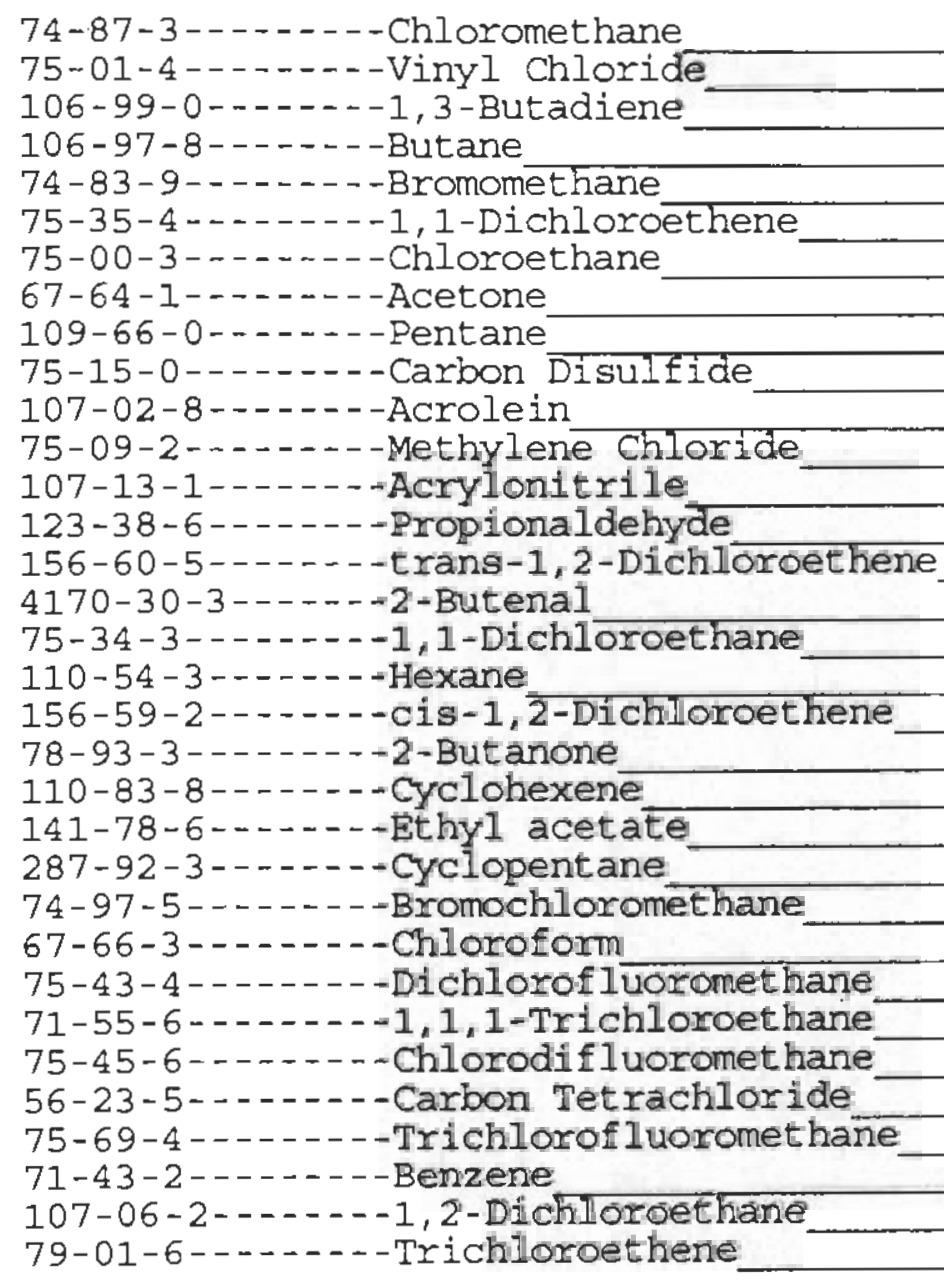

\begin{tabular}{|r|l|}
5000 & $\mathrm{U}$ \\
5000 & $\mathrm{U}$ \\
2500 & $\mathrm{U}$ \\
2500 & $\mathrm{U}$ \\
5000 & $\mathrm{U}$ \\
5000 & $\mathrm{U}$ \\
5000 & $\mathrm{U}$ \\
160000 & $\mathrm{E}$ \\
2500 & $\mathrm{U}$ \\
5000 & $\mathrm{U}$ \\
2500 & $\mathrm{U}$ \\
79000 & $\mathrm{~B}$ \\
13000 & \\
120000 & $\mathrm{E}$ \\
5000 & $\mathrm{U}$ \\
160000 & $\mathrm{E}$ \\
5000 & $\mathrm{U}$ \\
23000 & \\
5000 & $\mathrm{U}$ \\
5000 & $\mathrm{U}$ \\
2500 & $\mathrm{U}$ \\
2500 & $\mathrm{U}$ \\
2500 & $\mathrm{U}$ \\
5000 & $\mathrm{U}$ \\
5000 & $\mathrm{U}$ \\
2500 & $\mathrm{U}$ \\
5000 & $\mathrm{U}$ \\
2500 & $\mathrm{U}$ \\
5000 & $\mathrm{U}$ \\
2500 & $\mathrm{U}$ \\
960 & $\mathrm{~J}$ \\
5000 & $\mathrm{U}$ \\
5000 & $\mathrm{U}$ \\
\hline & \\
\hline
\end{tabular}


Lab Name: PNNL

Lab Code: PNNL

Case No.:

Matrix: (soil/water) WATER

Sample wt/vol:

$5.000(g / m L) \quad M L$

Level: (low/med) LOW

$\therefore$ Moisture: not dec.

GC Column: DB-624 75M X 2.55UM ID: 0.45 (mm)

Soil Extract Volume: (uL)

CAS NO.

COMPOUND
Contract : $\mathrm{C} 104$

SAS NO.:

SDG No.: 2
C104SUPMSD

Lab Sample ID: 00-01360MSD

Lab File ID: $\quad 00040621$

Date Received:

Date Analyzed: 04/07/0

Dilution Factor: 100.0

Soil Aliquot Volume:

(uL)

CONCENTRATION UNITS:

$(\mathrm{ug} / \mathrm{L}$ or $\mathrm{ug} / \mathrm{Kg}) \mathrm{UG} / \mathrm{L}$

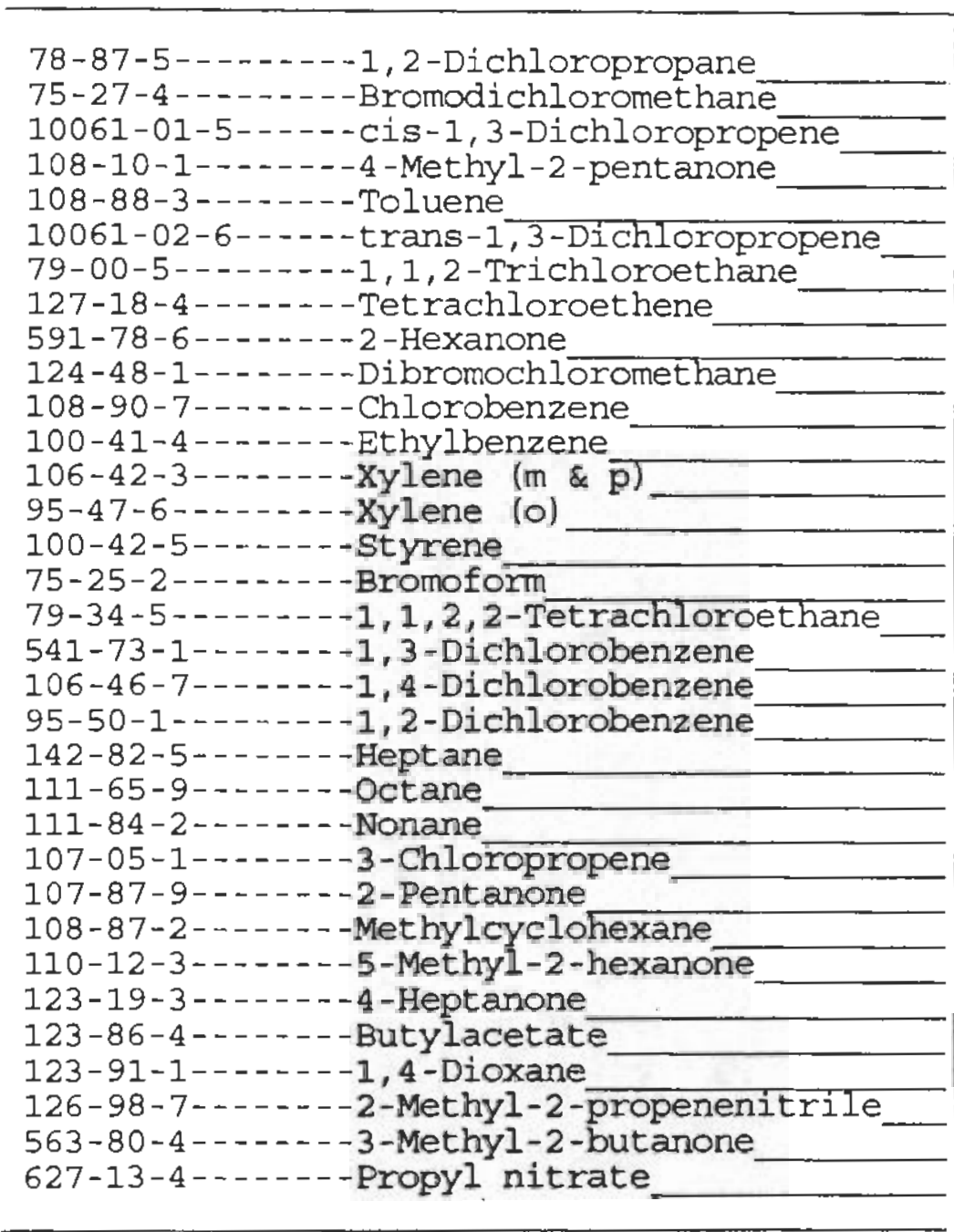

\begin{tabular}{r|r|l|}
5000 & $\mathrm{U}$ \\
5000 & $\mathrm{U}$ \\
5000 & $\mathrm{U}$ \\
16000 & \\
760 & $\mathrm{~J}$ \\
5000 & $\mathrm{U}$ \\
5000 & $\mathrm{U}$ \\
5000 & $\mathrm{U}$ \\
14000 & \\
5000 & $\mathrm{U}$ \\
830 & $\mathrm{~J}$ \\
5000 & $\mathrm{U}$ \\
5000 & $\mathrm{U}$ \\
5000 & $\mathrm{U}$ \\
5000 & $\mathrm{U}$ \\
5000 & $\mathrm{U}$ \\
5000 & $\mathrm{U}$ \\
5000 & $\mathrm{U}$ \\
5000 & $\mathrm{U}$ \\
5000 & $\mathrm{U}$ \\
2500 & $\mathrm{U}$ \\
2500 & $\mathrm{U}$ \\
2500 & $\mathrm{U}$ \\
5000 & $\mathrm{U}$ \\
15000 & \\
2200 & $\mathrm{~J}$ \\
2500 & $\mathrm{U}$ \\
12000 & - \\
11000 & \\
110000 & $\mathrm{E}$ \\
15000 & \\
16000 & \\
2500 & $\mathrm{U}$ \\
\hline
\end{tabular}


Lab Name: PNNL

Contract: C104

Lab Code: PNNL

Case No.:

Matrix: (soil/water) WATER

Sample wt/vol:

$5.000(\mathrm{~g} / \mathrm{mL}) \mathrm{ML}$

Level: (low/med) LOW

․․․ Moisture: not dec.

GC Column: DB-624 75M X 2.55UM ID: 0.45 (mm)

Soil Extract volume: (UL) CAS NO. COMPOUND (ug/L or $\mathrm{ug} / \mathrm{Kg}$ ) UG/I
SAS NO.:

SDG No.: 2
EPA SAMPLE NO.

C104SUFMSD

Lab Sample ID: 00-01360MSD

Iab File ID: 00040621

Date Received:

Date Analyzed: 04/07/0

Dilution Factor: 100.0

Soil Aliquot Volume: (UL) CONCENTRATION UNITS:
$(\mathrm{ug} / \mathrm{L}$ or $\mathrm{ug} / \mathrm{Kg})$ UG/L

Q

96-22-0---.---3-Pentanone

76-13-1--.---1, 2, 2-Cl3-1,1, 2-F3ethane

76-14-2-------1, 2-Cl2-1, 1, 2, 2-F4ethane

75-71-8-------Dichlorodifluoromethane

75-05-8--...-Acetonitrile

110-82-7------Cyclohexane

108-86-1-..--- Bromobenzene

$104-51-8------$ - Butylbenzene

98-06-6--------tert-Butyl benzene

135-98-8-.--- - sec-Butylbenzene

95-49-8-.-----2-Chlorotoluene

99-87-6--.----4- Isopropyl toluene

106-43-4-...--4-Chlorotoluene

96-12-8-------1, 2-Dibromo-3-chloropropane

106-93-4------1,2-Dibromoethane

110-57-6---.--trans-1,4-Dichloro-2-butene

142-28-9-------1,3-Dichloropropane

594-20-7------2, 2-Dichloropropane

563-58-6-..--1, 1-Dichloropropene

87-68-3-2.----Hexachloro-1, 3-butadiene

98-82-8--.--..- Isopropylbenzene

$91-20-3-------$ Nathphalene

103-65-1------Propylbenzene

87-61-6-------1, 2,3-Trichlorobenzene $120-82-1-\ldots---1,2,4-$ Trichlorobenzene

96-18-4------1, 2, 3-Trichloropropane

$95-63-6 \ldots-\ldots-1,2,4-$ Trimethylbenzene

108-67-8------1, 2, 3-Trimethylbenzene

106-35-4--.---3-Heptanone

110-43-0-..---2-Heptanone

109-99-9-..- - - Tetrahyärofuran

74-95-3--------Dibromomethane.

\begin{tabular}{r|l|}
17000 & \\
2500 & $\mathrm{U}$ \\
2500 & $\mathrm{U}$ \\
2500 & $\mathrm{U}$ \\
2500 & $\mathrm{U}$ \\
2500 & $\mathrm{U}$ \\
5000 & $\mathrm{U}$ \\
5000 & $\mathrm{U}$ \\
5000 & $\mathrm{U}$ \\
5000 & $\mathrm{U}$ \\
5000 & $\mathrm{U}$ \\
5000 & $\mathrm{U}$ \\
5000 & $\mathrm{U}$ \\
5000 & $\mathrm{U}$ \\
5000 & $\mathrm{U}$ \\
5000 & $\mathrm{U}$ \\
5000 & $\mathrm{U}$ \\
5000 & $\mathrm{U}$ \\
5000 & $\mathrm{U}$ \\
5000 & $\mathrm{U}$ \\
5000 & $\mathrm{U}$ \\
5000 & $\mathrm{U}$ \\
5000 & $\mathrm{U}$ \\
5000 & $\mathrm{U}$ \\
5000 & $\mathrm{U}$ \\
5000 & $\mathrm{U}$ \\
5000 & $\mathrm{U}$ \\
5000 & $\mathrm{U}$ \\
16000 & \\
2100 & $\mathrm{~J}$ \\
4200 & \\
5000 & $\mathrm{U}$ \\
& \\
\hline
\end{tabular}

OLM0 3.0 
Lab Name: PNNL

Lab Code: PNNL

Case No.:

Matrix: (soil/water) SOLID

Sample wt/vol:

$0.1(\mathrm{~g} / \mathrm{mL}) \mathrm{G}$

Level: (low/med) LOW

o Moisture: not dec.

GC Column: DB-624 75M X 2.55UM ID: 0.45 (mm)

Soil Extract Volume: (ut)

Contract: $\mathrm{ClO4}$

SAS NO. :

SDG NO.: 2
C1045OL

EPA SAMPLE NO.
CAS NO.
COMPOUND
Lab Sample ID: 00-01361

Lab File ID: 00040624

Date Received:

Date Analyzed: 04/07/0

Dilution Factor: 1.0

Soil Aliquot Volume: (UI)

CONCENTRATION UNITS:

(ug/L or $\mathrm{ug} / \mathrm{kg}$ ) UG/KG

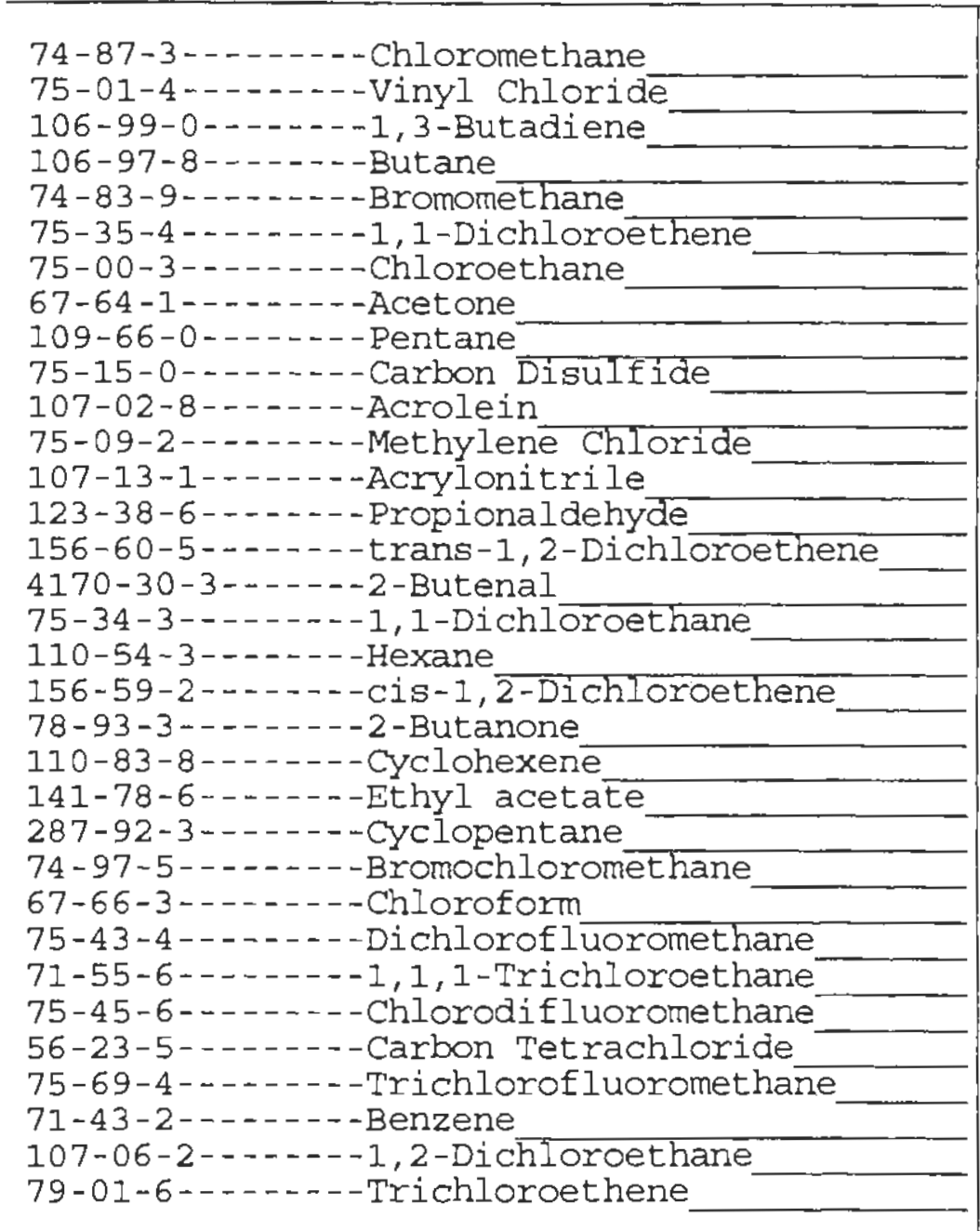


Lab Name: PNNL

Lab code: PNNL

Case No. :

Matrix: (soil/water) SOIID

Sample wt/vol:

$0.1(g / m L) G$

Level: (low $/ \mathrm{med}$ ) LOW

: Moisture: not dec.

GC Column: DB-624 75M X 2.55UM ID: 0.45 (nm)

Soil Extract Volume: (uL)

CAS NO.

COMPOUND
Contract: $\mathrm{C} 104$

SAS NO. :

SDG NO. : 2

Lab Sample ID: 00-01361

Lab File ID: 00040624

Date Received:

Date Analyzed: 04/07/0

Dilution Factor: 1.0

Soil Aliquot volume: (uL)
CONCENTRATION UNITS :

(ug/L or $\mathrm{ug} / \mathrm{kg}$ ) UG/KG

\begin{tabular}{|c|}
\hline 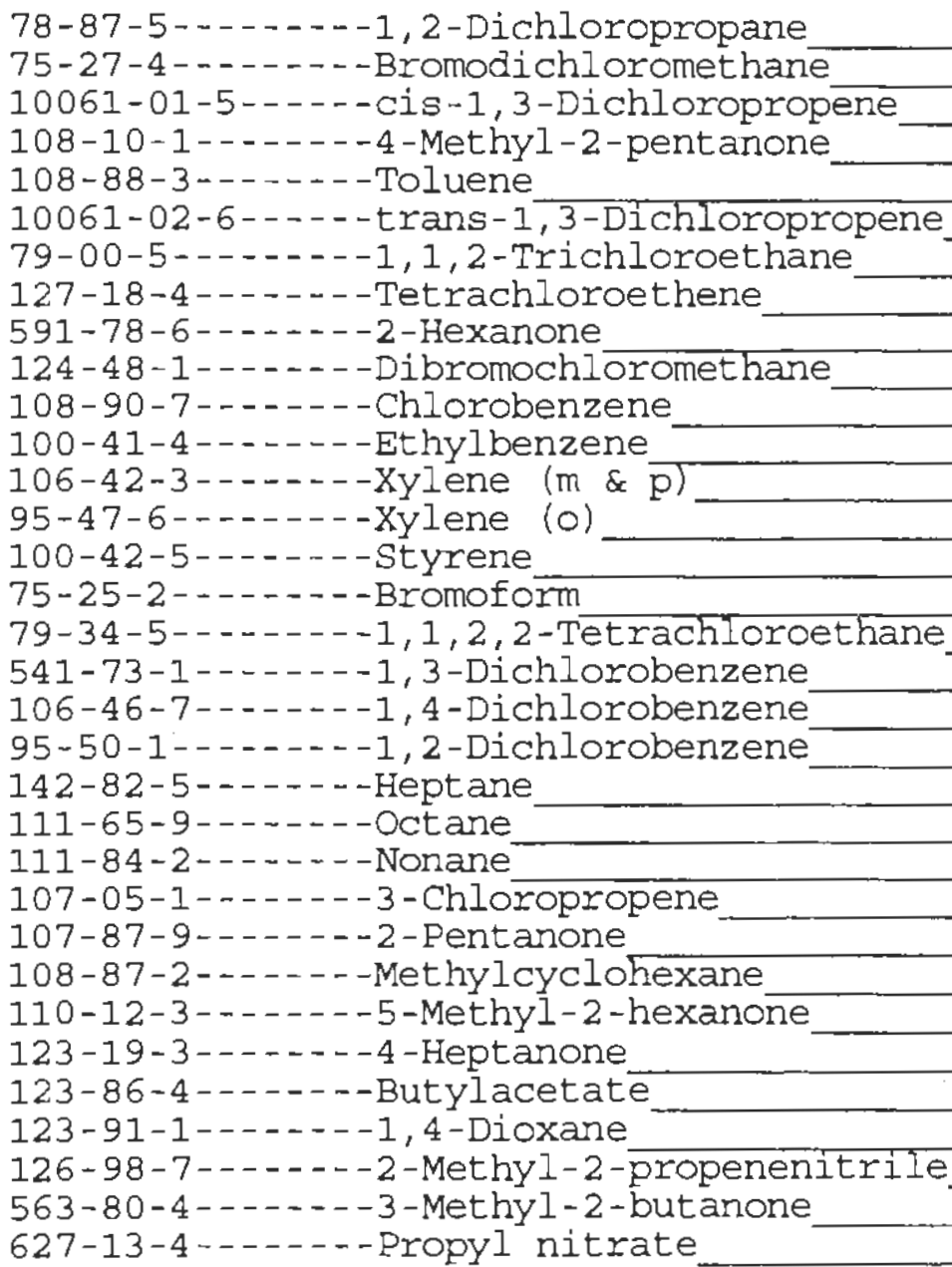 \\
\hline
\end{tabular}

FORM I VOA

\begin{tabular}{|r|r|l|}
400 & $\mathrm{U}$ \\
400 & $\mathrm{U}$ \\
400 & $\mathrm{U}$ \\
400 & $\mathrm{U}$ \\
400 & $\mathrm{U}$ \\
400 & $\mathrm{U}$ \\
400 & $\mathrm{U}$ \\
400 & $\mathrm{U}$ \\
130 & $\mathrm{~J}$ \\
400 & $\mathrm{U}$ \\
400 & $\mathrm{U}$ \\
26 & $\mathrm{~J}$ \\
400 & $\mathrm{U}$ \\
400 & $\mathrm{U}$ \\
400 & $\mathrm{U}$ \\
400 & $\mathrm{U}$ \\
400 & $\mathrm{U}$ \\
400 & $\mathrm{U}$ \\
400 & $\mathrm{U}$ \\
400 & $\mathrm{U}$ \\
5200 & \\
3400 & \\
2900 & \\
400 & $\mathrm{U}$ \\
40 & $\mathrm{~J}$ \\
400 & $\mathrm{U}$ \\
400 & $\mathrm{U}$ \\
52 & $\mathrm{~J}$ \\
400 & $\mathrm{U}$ \\
400 & $\mathrm{U}$ \\
400 & $\mathrm{U}$ \\
400 & $\mathrm{U}$ \\
30 & $\mathrm{~J}$ \\
\hline & \\
\hline & \\
\hline
\end{tabular}

\section{C1 04 SOL}

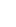


Lab Name: PNNL

Lab Code: PNNL

Case No.:

Matrix: (soil/water) SOLID

Sample wt/vol:

$0.1(g / \pi \Psi) G$

Level: (low/med) LOW

: Moisture: not dec.

GC Column: DB-624 75M X 2.55UM ID: 0.45 (mm)

Soil Extract Volume: (uI)
Contract: $\mathrm{ClO} 4$

SAS NO. :
EPA SAMPIE NO.

C104SOL

SDG No.: 2

Lab Sample ID: 00-01361

Lab File ID: 00040624

Date Received:

Date Analyzed: 04/07/0

Dilution Factor: 1.0

Soil Aliquot Volume:

(ü)

CONCENTRAIION UNITS:

CAS NO. COMPOUND (ug/L or $\mathrm{ug} / \mathrm{Kg}) \mathrm{UG} / \mathrm{KG}$

$96-22-0-\cdots---3-$ Pentanone

$76-13-1-\ldots-\ldots-1,2,2-C 13-1,1,2-F 3 e t h a n e$

76-14-2-----1,2-Cl2-1,1,2,2-F4ethane

75-71-8--...-Dichlorodifluoromethane

75-05-8--..--Acetonitrile

110-82-7-n---Cyclohexane

108-86-1-..---Bromobenzene

104-51-8------Butylbenzene

98-06-6-..---tert-Butylbenzene

135-98-8--.--s-sec-Butylbenzene

95-49-8--.--2-Chlorotoluene

99-87-6--..--4-Isopropyltoluene

106-43-4--n--4-Chlorotoluene

96-12-8--..--1,2-Dibromo-3-chloropropane

106-93-4-----1,2-Dibromoethane

110-57-6-..---trans-1, 4-Dichloro-2-butene

142-28-9---.-1, 3-Dichloropropane

594-20-7--.--2, 2-Dichloropropane

563-58-6--.--1, 1-Dichloropropene

87-68-3-...--Hexachloro-1, 3-butadiene

98-82-8-------Isopropylbenzene

91-20-3-...--Nathphalene

103-65-1-...--Propylbenzene

87-61-6-...--1, 2,3-Trichlorobenzene

120-82-1-...-1,2,4-Trichlorobenzene

96-18-4_....-1,2,3-Trichlaropropane

95-63-6-..---1, 2,4-Trimethylbenzene

$108-67-8 \ldots-\cdots-1,2,3-T r i m e t h y l b e n z e n e$

106-35-4-.---3-Heptanone

110-43-0-.-.--2-Heptanone

109-99-9-..--Tetrahydrofuran

74-95-3--.---Dibromomethane 
Lab Name: PNNL

Lab Code: PNNL

Case No. :

Matrix: (soil/water) SOLID

Sample wt/vol:

$0.1(\mathrm{~g} / \mathrm{mL}) \mathrm{G}$

Level: (low/med) LOW

\% Moisture: not dec.

GC Column: DB-624 75M X 2.55UM ID: 0.45 (mm) (uL)

Soil Extract Volume:

Contract: C104

SAS NO. :

SDG No. : 2

Lab Sample ID: 00-01361D

Lab File ID: 00040625

Date Received:

Date Analyzed: 04/07/0

Dilution Factor: 1.0

Soil Aliquot Volume: (uL) CONCENTRATION UNITS:

CAS NO.

COMPOUND

$Q$

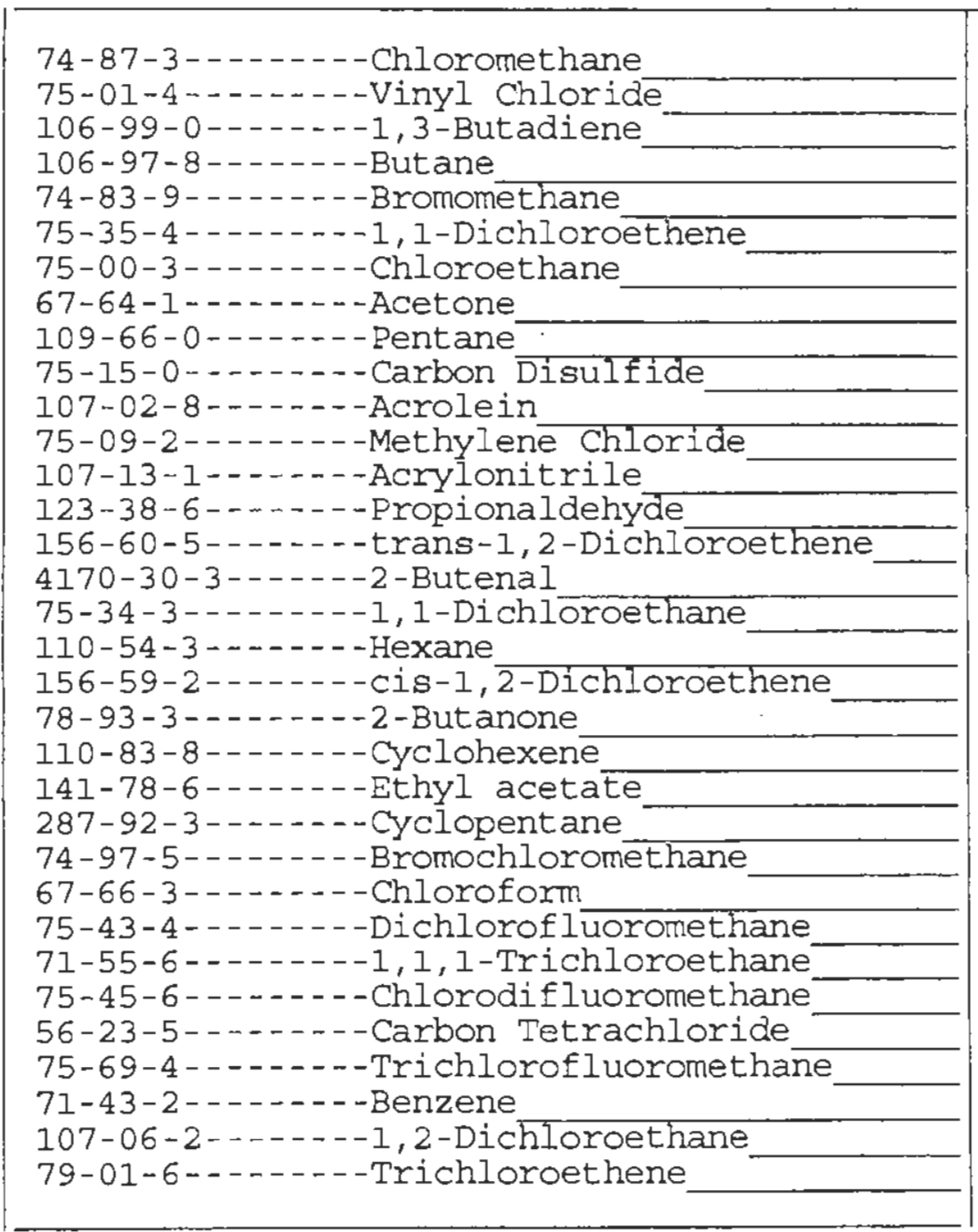

\begin{tabular}{r|l|}
750 & $\mathrm{U}$ \\
750 & $\mathrm{U}$ \\
750 & $\mathrm{U}$ \\
3000 & \\
750 & $\mathrm{U}$ \\
750 & $\mathrm{U}$ \\
750 & $\mathrm{U}$ \\
430 & $\mathrm{~J}$ \\
7400 & \\
750 & $\mathrm{U}$ \\
750 & $\mathrm{U}$ \\
1900 & $\mathrm{~B}$ \\
990 & \\
1100 & \\
750 & $\mathrm{U}$ \\
750 & $\mathrm{U}$ \\
750 & $\mathrm{U}$ \\
9200 & \\
750 & $\mathrm{U}$ \\
320 & $\mathrm{~J}$ \\
750 & $\mathrm{U}$ \\
750 & $\mathrm{U}$ \\
750 & $\mathrm{U}$ \\
750 & $\mathrm{U}$ \\
750 & $\mathrm{U}$ \\
750 & $\mathrm{U}$ \\
750 & $\mathrm{U}$ \\
750 & $\mathrm{U}$ \\
750 & $\mathrm{U}$ \\
750 & $\mathrm{U}$ \\
60 & $\mathrm{~J}$ \\
750 & $\mathrm{U}$ \\
750 & $\mathrm{U}$ \\
& \\
\hline
\end{tabular}


Lab Name: PNNL

Lab Code: PNNL,
Contract: $\mathrm{C} 104$

SAS NO.:

C104SOLD

Case No.:

Lab Sample ID: 00-01361D

Sample wt/vol:

$0.1(\mathrm{~g} / \mathrm{mL}) \mathrm{G}$

Lab File ID: 00040625

Level: (low/med) LOW

Date Received:

\% Moisture: not dec.

GC Column: DB-624 75M X 2.55UM ID: 0.45 (mm)

Date Analyzed: 04/07/0

Soil Extract Volume: (u)

Dilution Factor: 1.0

Soil Aliquot Volume: (uL) CONCENTRATION UNITS:

CAS NO.

COMPOUND (ug/L or $\mathrm{ug} / \mathrm{Kg}$ ) UG/KG

$Q$

78-87-5-- - - - 1, 2-Dichloropropane

75-27-4--1----Bromodichloromethane 10061-01-5-..-cis-1,3-Dichloropropene 108-10-1---.--4-Methyl-2-pentanone 108-88-3-..-- Toluene

10061-02-6-----trans-1,3-Dichloropropene

79-00-5-...--1,1,2-Trichloroethane

127-18-4--.---Tetrachloroethene

591-78-6--.---2-Hexanone

124-48-1-.----Dibromochioromethane

108-90-7-...--Chlorobenzene

100-41-4-..--.-Ethylbenzene

106-42-3-...-Xylene (m\& p)

95-47-6-...-Xylene (0)

100-42-5--.---styrene

75-25-2-1..-- Bromoform

79-34-5-..---1, I, 2, 2-Tetrachloroethane

541-73-1-...-1,3-Dichlorobenzene

106-46-7--.--1, 4-Dichlorobenzene

95-50-1-....-1,2-Dichlorobenzene

142-82-5-..--Heptane

$111-65-9-\ldots-$ - Octane

111-84-2--.--Nonane

107-05-1-...--3-Chloropropene

107-87-9--. - - -2-Pentanone

108-87-2-1.---Methylcyclohexane

110-12-3--.---5-Methyl-2-hexanone

123-19-3--..--4-Heptanone

123-86-4------Butylacetate

123-91-1--.---1,4-Dioxane

126-98-7-- - -2-Methyl-2-propenenitrile

563-80-4------3-Methyl-2-butanone

627-13-4--.---Propyl nitrate.

\begin{tabular}{|r|l|}
750 & $\mathrm{U}$ \\
750 & $\mathrm{U}$ \\
750 & $\mathrm{U}$ \\
750 & $\mathrm{U}$ \\
750 & $\mathrm{U}$ \\
750 & $\mathrm{U}$ \\
750 & $\mathrm{U}$ \\
750 & $\mathrm{U}$ \\
270 & $\mathrm{~J}$ \\
750 & $\mathrm{U}$ \\
750 & $\mathrm{U}$ \\
40 & $\mathrm{~J}$ \\
750 & $\mathrm{U}$ \\
750 & $\mathrm{U}$ \\
750 & $\mathrm{U}$ \\
750 & $\mathrm{U}$ \\
750 & $\mathrm{U}$ \\
750 & $\mathrm{U}$ \\
750 & $\mathrm{U}$ \\
750 & $\mathrm{U}$ \\
6300 & - \\
4600 & - \\
4500 & \\
750 & $\mathrm{U}$ \\
99 & $\mathrm{~J}$ \\
750 & $\mathrm{U}$ \\
750 & $\mathrm{U}$ \\
100 & $\mathrm{~J}$ \\
750 & $\mathrm{U}$ \\
750 & $\mathrm{U}$ \\
750 & $\mathrm{U}$ \\
750 & $\mathrm{U}$ \\
40 & $\mathrm{~J}$ \\
\hline & \\
\hline
\end{tabular}


Lab Name: PNNL

Lab Code: PNNL

Case No. :

Matrix: (soil/water) SOLID

Sample wt/vol:

$0.1(\mathrm{~g} / \mathrm{mL}) \mathrm{G}$

Level: (low/med) LOW

$\%$ Moisture: not dec.

GC Columr: DB-624 75M X 2.55UM ID: 0.45 (mm)

Soil Extract Volume: (uL)
Contract : C104

SAS NO. :
C104SOLD

SDG No. : 2

Lab Sample ID: 00-01361D

Lab File ID: 00040625

Date Received:

Date Analyzed: 04/07/0

(mm) Dilution Factor: 1.0

Soil Aliquot Volume:

(uL)

CONCENTRATION UNITS:

CAS NO: COMPOUND $\quad$ (ug/L or $\mathrm{Lg} / \mathrm{Kg}$ ) UG/KG

$750 \mathrm{U}$

$750 \mathrm{U}$

$750 ! \mathrm{U}$

$750 \mathrm{U}$

$750 \mathrm{U}$

$750 \mathrm{U}$

$750 \mathrm{U}$

$750 \mathrm{U}$

$750 \mathrm{U}$

$750 \mathrm{U}$

$750 \mathrm{U}$

$750 \mathrm{U}$

$750 \mathrm{U}$

$750 \mathrm{U}$

$750 \mathrm{U}$

$750 \mathrm{U}$

$750 \mathrm{U}$

$750 \mathrm{U}$

$750 \mathrm{U}$

$750 \mathrm{U}$

$750 \mathrm{U}$

$750 . \mathrm{U}$

$750 \mathrm{U}$

750 U

750 U

750 U

$750 \mathrm{U}$

$750 \mathrm{U}$

800

810

$750 \mathrm{U}$

750 
Lab Name: PNNL

Lab Code: PNNL

Case No.:

Matrix: (soil/water) SOLID

Sample wt/vol: $\quad 0.7(\mathrm{~g} / \mathrm{mL}) \mathrm{G}$

Level: (low/med) LOW

\% Moisture: not dec.

GC Column: DB-624 75M X 2.55UM ID: 0.45 (mm)

Soil Extract Volume:

(UL)

Contract: $\mathrm{C} 104$

SAS NO. :

EPA SAMPLE NO.

C104SOLMS

SDG No.: 2

Lab Sample ID: 00-01361MS

Lab File ID: 00040626

Date Received:

Date Analyzed: 04/07/0

Dilution Factor: 1.0

Soil Aliquot Volume: (uL) CONCENTRATION UNITS:

CAS NO.

COMPOUND $(\mathrm{ug} / \mathrm{L}$ or $\mathrm{ug} / \mathrm{kg}) \mathrm{UG} / \mathrm{KG}$

\begin{tabular}{|c|}
\hline 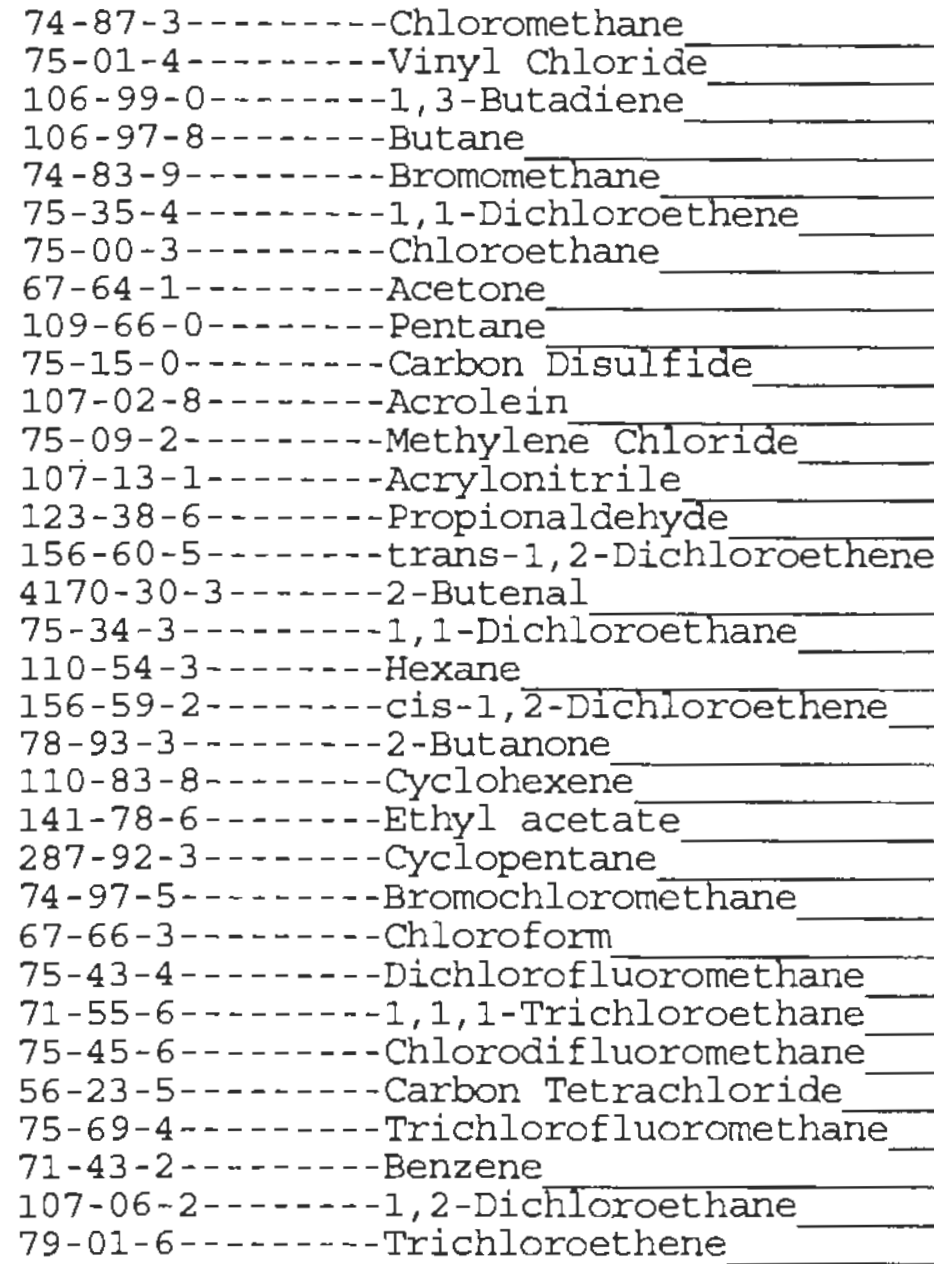 \\
\hline
\end{tabular}

\begin{tabular}{r|r|l|}
20 & $\mathrm{~J}$ \\
71 & $\mathrm{U}$ \\
280 & \\
60 & $\mathrm{~J}$ \\
71 & $\mathrm{U}$ \\
31 & $\mathrm{~J}$ \\
71 & $\mathrm{U}$ \\
28 & $\mathrm{~J}$ \\
67 & $\mathrm{~J}$ \\
71 & $\mathrm{U}$ \\
71 & $\mathrm{U}$ \\
61 & $\mathrm{JB}$ \\
24 & $\mathrm{~J}$ \\
150 & \\
71 & $\mathrm{U}$ \\
71 & $\mathrm{U}$ \\
71 & $\mathrm{U}$ \\
100 & \\
71 & $\mathrm{U}$ \\
270 & \\
13 & $\mathrm{~J}$ \\
71 & $\mathrm{U}$ \\
32 & $\mathrm{~J}$ \\
71 & $\mathrm{U}$ \\
71 & $\mathrm{U}$ \\
20 & $\mathrm{~J}$ \\
71 & $\mathrm{U}$ \\
23 & $\mathrm{~J}$ \\
71 & $\mathrm{U}$ \\
71 & $\mathrm{U}$ \\
35 & $\mathrm{~J}$ \\
71 & $\mathrm{U}$ \\
24 & $\mathrm{~J}$ \\
& \\
\hline & \\
\hline
\end{tabular}


Lab Name: PNNL

Lab Code: PNNL

Case No.:

Matrix: (soil/water) SOLID

Sample wt/vol:

$0.7(g / m L) \quad G$

Level: (low/med) Low

\% Moisture: not dec.

GC Column: DB-624 75M X 2.55UM ID: 0.45 (mn) Soil Extract Volume: (uI)

CAS NO.

COMPOUND
Contract: C104

SAS NO.:

SDG No.: 2

Lab Sample ID: 00-01361MS

Lab File ID: 00040626

Date Received:

Date Analyzed: 04/07/0

Dilution Factor: 1.0

Soil Aliquot Volume: (u山)
CONCENIRATION UNITS:

(ug/L or $\mathrm{ug} / \mathrm{Kg}$ ) UG/KG

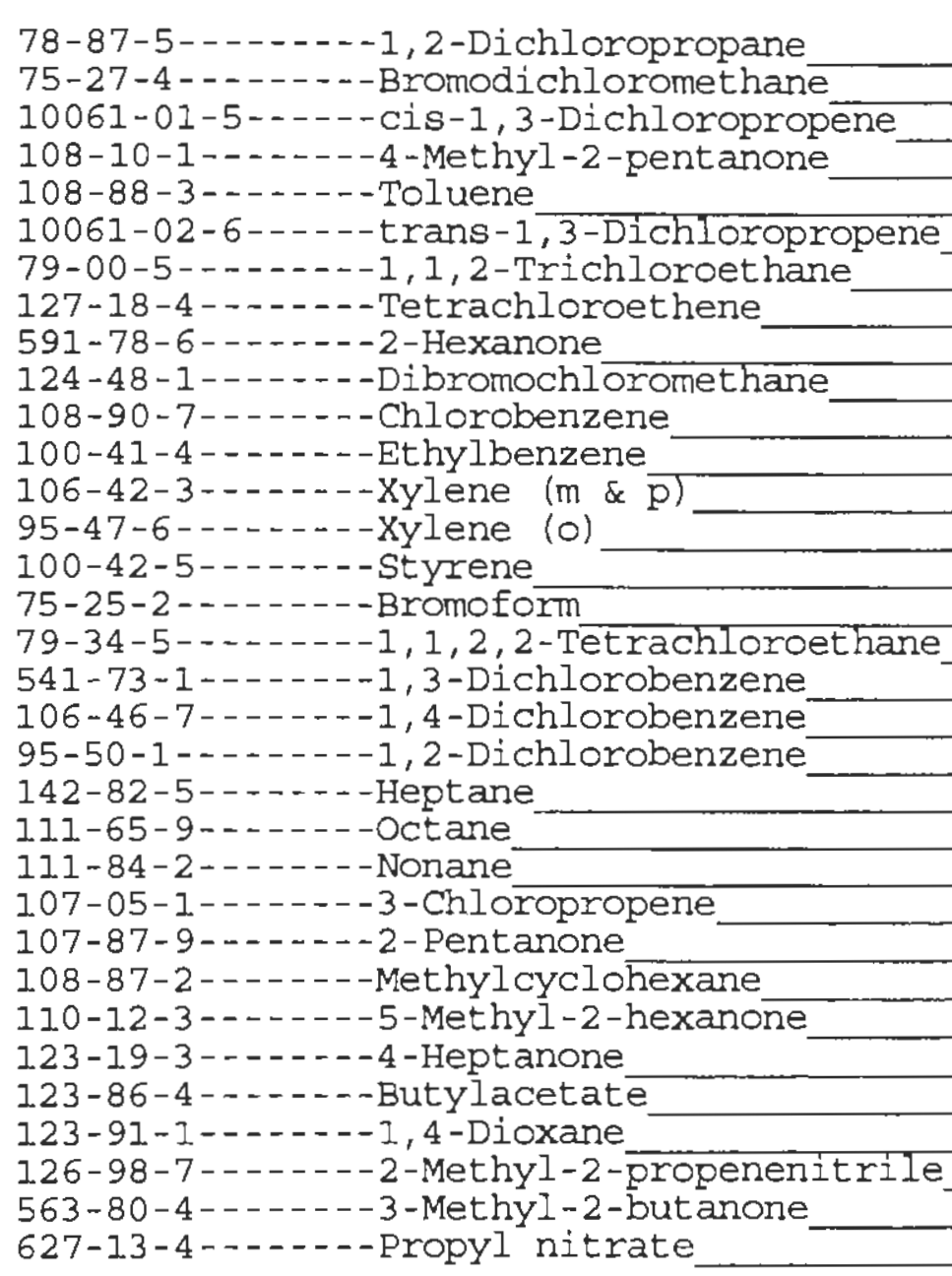

\section{C104SOLMS}


Lab Name: PNNL

Lab Code: PNNL
Contract: $\mathrm{ClO} 4$

\section{C104SOIMS}

SAS NO.:

SDG NO. : 2

Lab Sample ID: 00-01361MS

Lab File ID: 00040626

Date Received:

Date Aralyzed: 04/07/0

$\div$ Moisture: not dec.

GC Column: DB-624 75M X 2.55UM ID: 0.45 (mm)

Dilution Factor: 1.0

Soil Extract Volume: (u士)

Soil Aliquot volume: (uL) CONCENTRATION UNITS :

CAS NO.

COMPOUND

(ug/L or $\mathrm{ug} / \mathrm{Kg}$ ) UG/KG

Q

\begin{tabular}{|c|}
\hline 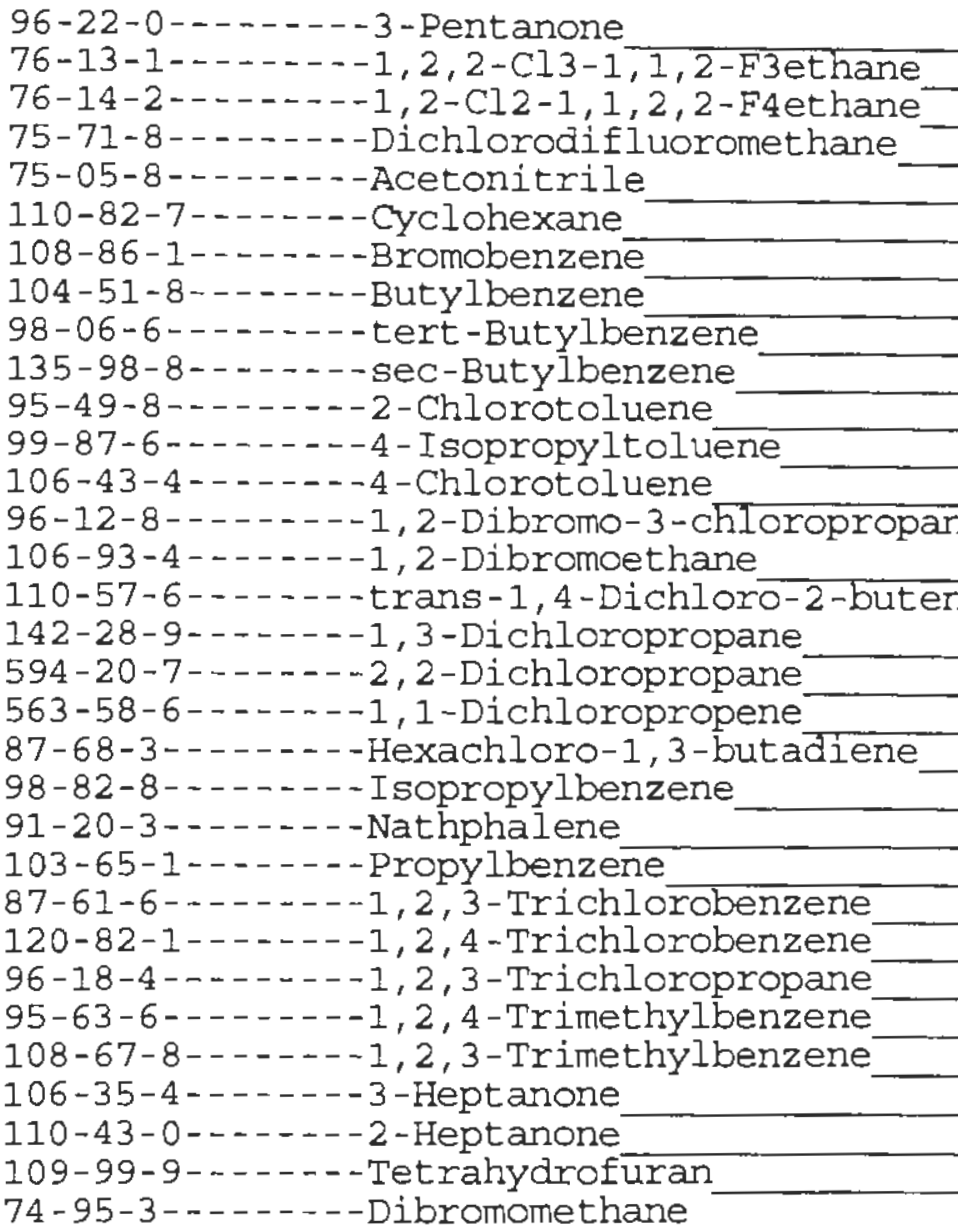 \\
\hline
\end{tabular}


Lab Name: PNNL

Lab Code: PNNL

Case No. :

Matrix: (soil/water) SOLID

Sample wt/vol:

$0.1(g / \mathrm{mL}) \quad G$

Level: (low/med) LOW

\% Moisture: not dec.

GC Column: $\mathrm{DB}-62475 \mathrm{M} \times 2.55 \mathrm{UM}$ ID: 0.45 (mm)

Soil Extract Volume: (uL)
Contract: $\mathrm{ClO}$

SAS NO.:
EPA SAMPLE NO.

CI04 SOLMSD

SDG NO.: 2

Lab Sample ID: 00-01361MSD

Lab File ID: 00040627

Date Received:

Date Analyzed: 04/07/0

(milution Factor: 1.0

Soil Aliquot volume:

(uL)

CONCENIRATION UNITS:

CAS NO. COMPOUND $(\mathrm{ug} / \mathrm{L}$ or $\mathrm{ug} / \mathrm{kg}\rangle \mathrm{UG} / \mathrm{KG}$

\begin{tabular}{|c|}
\hline 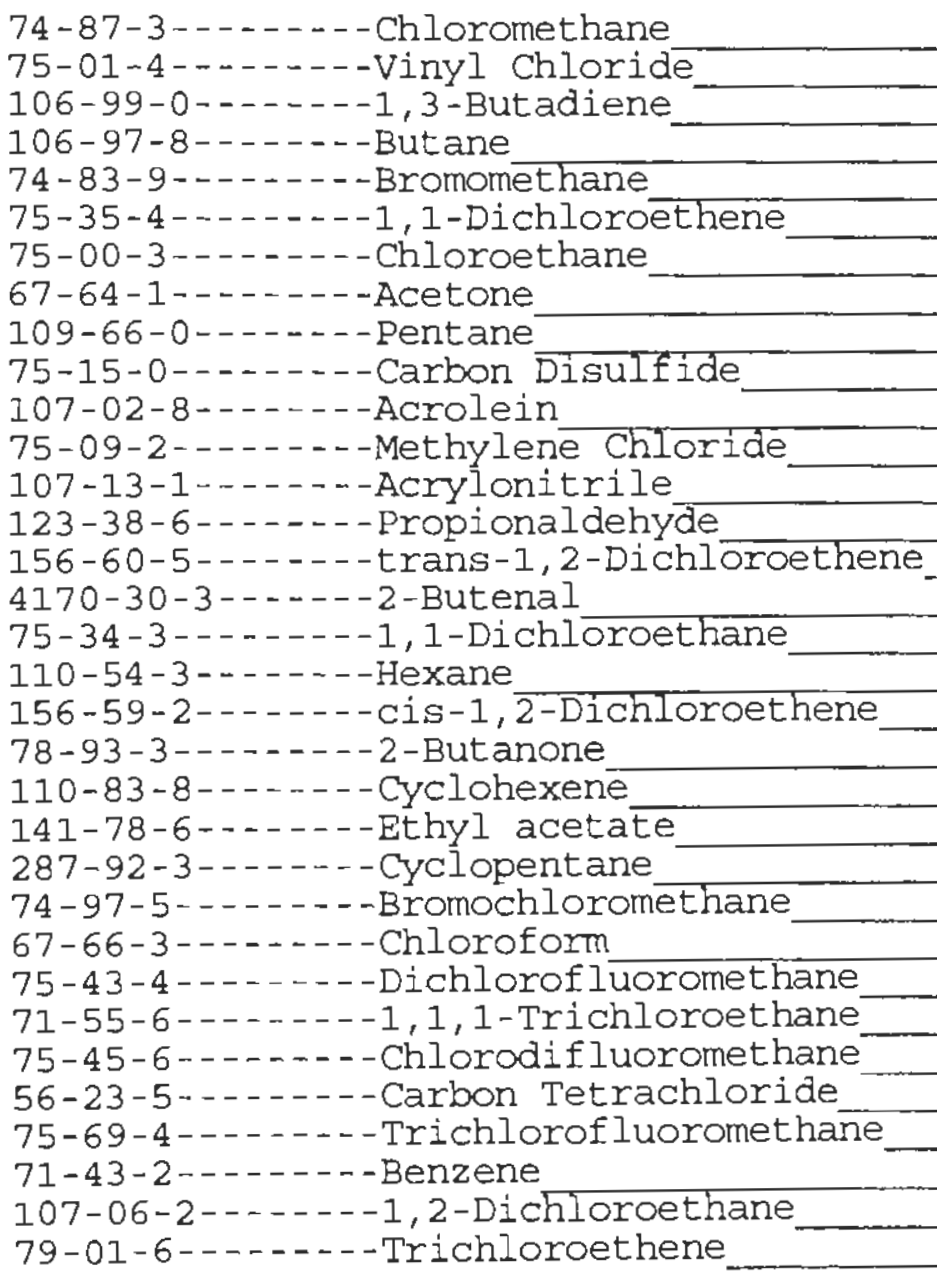 \\
\hline
\end{tabular}

\begin{tabular}{|r|l|}
10 & $\mathrm{~J}$ \\
360 & $\mathrm{U}$ \\
2900 & \\
22 & $\mathrm{~J}$ \\
360 & $\mathrm{U}$ \\
28 & $\mathrm{~J}$ \\
360 & $\mathrm{U}$ \\
33 & $\mathrm{~J}$ \\
120 & $\mathrm{~J}$ \\
360 & $\mathrm{U}$ \\
360 & $\mathrm{U}$ \\
830 & $\mathrm{~B}$ \\
22 & $\mathrm{~J}$ \\
680 & \\
360 & $\mathrm{U}$ \\
17 & $\mathrm{~J}$ \\
360 & $\mathrm{U}$ \\
120 & $\mathrm{~J}$ \\
360 & $\mathrm{U}$ \\
1300 & \\
12 & $\mathrm{~J}$ \\
360 & $\mathrm{U}$ \\
15 & $\mathrm{~J}$ \\
360 & $\mathrm{U}$ \\
360 & $\mathrm{U}$ \\
18 & $\mathrm{~J}$ \\
360 & $\mathrm{U}$ \\
22 & $\mathrm{~J}$ \\
360 & $\mathrm{U}$ \\
360 & $\mathrm{U}$ \\
34 & $\mathrm{~J}$ \\
360 & $\mathrm{U}$ \\
22 & $\mathrm{~J}$ \\
& \\
\hline & \\
\hline
\end{tabular}


Lab Name: PNNL

Lab Code: PNNL

Matrix: (soil/water) SOLID

Sample wt/vol:

$0.1(g / m L) \quad G$

Level: (low/med) LOW

$\%$ Moisture: not dec.

GC Column: DB-624 75M X 2.55UM ID: 0.45 (nm)

Soil Extract Volume: (uI)

CAS NO.
Case No. :
Contract: $\mathrm{ClO} 4$

SAS NO. :
EPA SAMPLE NO.

C104SOLMSD

Lab Sample ID: 00-01361MSD

Lab File ID: 00040627

Date Received:

Date Analyzed: 04/07/0

Dilution Factor: 1.0

Soil Aliquot Volume: (uL) CONCENTRATION UNITS:

(ug/L or $\mathrm{ug} / \mathrm{kg}$ ) UG/KG

$Q$

78-87-5--.---1, 2-Dichloropropane

75-27-4---.--Bromodichloromethane

10061-01-5-.--cis-1, 3-Dichloropropene

108-10-1--.---4-Methyl-2-pentanone

108-88-3--n-- Toluene

10061-02-6-----trans-1,3-Dichloropropene

79-00-5---.-1,1,2-Trichloroethane

127-18-4------Tetrachloroethene

591-78-6------2-Hexanone

124-48-1-2..--Dibromochloromethane

108-90-7-..---Chlorobenzene

100-41-4------Ethylbenzene

106-42-3-...-.-Xylene (m \& p)

95-47-6------Xylene (o)

100-42-5-.-.--styrene

75-25-2--- - - - Bromoform

79-34-5------1, 1,2,2-Tetrachloroethane

$541-73-1-\ldots-1,3-$ Dichlorobenzene

106-46-7-..--1, 4-Dichlorobenzene

95-50-1--...-1, 2-Dichlorobenzene

142-82-5-...--Heptane

111-65-9-..---octane

$111-84-2-\ldots-.-N o n a n e$

107-05-1-...-3-Chloropropene

107-87-9-...-2-2entanone

108-87-2-.---Methylcyclohexane

110-12-3---.-5-Methyl-2-hexanone

123-19-3--.---4-Heptanone

123-86-4-..--Butylacetate

123-91-1-..---1,4-Dioxane

126-98-7--..--2-Methyl-2-propenenitrile

563-80-4------3-Methyl-2-butanone

627-13-4--.---Propyl nitrate 
Lab Name: PNNL

Lab Code: PNNL

Case No.:
Contract : $\mathrm{Cl} 04$

SAS NO.:
EPA SAMPLE NO.

C104SOLMSD
Matrix: (soil/water) SOLID

Sample wt/vol:

$0.1(\mathrm{~g} / \mathrm{mL}) \quad \mathrm{G}$

Level: (Iow/med) LOW

\% Moisture: not dec.

GC Column: DB-624 75M X 2.55UM ID: 0.45 (mm) (UI)
Lab Sample ID: 00-01361MSD

Lab File ID: $\quad 00040627$

Date Received:

Date Analyzed: 04/07/0

Dilution Factor: 1.0

Soil Aliquot Volume: (UI) CONCENTRATION UNITS : (ug/L or $\mathrm{ug} / \mathrm{Kg}$ ) UG/KG

Q
96-22-0-- - - - - 3-Pentanone

76-13-1-....-1, 2, 2-Cl3-1, 1, 2-F3ethane

76-14-2--..--1, 2-C12-1,1, 2, 2-F4ethane

75-71-8-...--DichIorodifluoromethane

75-05-8--.-.--Acetonitrile

110-82-7-n-..-Cyclohexane

108-86-1-....-Bromobenzene

104-51-8--.---Butylbenzene

98-06-6-------tert-Butylbenzene

135-98-8------sec-Butylbenzene

95-49-8-...-- 2-Chlorotoluene

99-87-6-- - - - - 4-Isopropyl toluene

106-43-4------4-Chlorotoluene

96-12-8---- - - 1, 2-Dibromo-3-chloropropane

106-93-4-.----1,2-Dibromoethane

110-57-6-------trans-1, 4-Dichloro-2-butene

142-28-9------1,3-Dichloropropane

594-20-7------2,2-Dichloropropane

563-58-6------1, 1-Dichloropropene

87-68-3-.....-Hexachloro-1,3-butadiene

98-82-8-..-..- I sopropylbenzene

$91-20-3-\ldots-\ldots-N a t h p h a l e n e$

103-65-1.....-- Propylbenzene

87-61-6-..... 1, 2, 3-Trichlorobenzene

120-82-1-.--- 1,2,4-Trichlorobenzene

96-18-4--..-- 1, 2, 3-Trichloropropane

95-63-6--.----1, 2, 4-Trimethylbenzene

108-67-8-...--1,2,3-Trimethylbenzene

106-35-4------ - 3-Heptanone

110-43-0--..--2-Heptanone

109-99-9-- - - - - Tetrahydrofuran

74-95-3--------Dibromomethane

\begin{tabular}{r|l|}
1200 & \\
16 & $\mathrm{~J}$ \\
7 & $\mathrm{~J}$ \\
200 & $\mathrm{~J}$ \\
14 & $\mathrm{~J}$ \\
14 & $\mathrm{~J}$ \\
360 & $\mathrm{U}$ \\
360 & $\mathrm{U}$ \\
360 & $\mathrm{U}$ \\
360 & $\mathrm{U}$ \\
360 & $\mathrm{U}$ \\
360 & $\mathrm{U}$ \\
360 & $\mathrm{U}$ \\
360 & $\mathrm{U}$ \\
360 & $\mathrm{U}$ \\
68 & $\mathrm{~J}$ \\
360 & $\mathrm{U}$ \\
360 & $\mathrm{U}$ \\
360 & $\mathrm{U}$ \\
360 & $\mathrm{U}$ \\
360 & $\mathrm{U}$ \\
360 & $\mathrm{U}$ \\
360 & $\mathrm{U}$ \\
360 & $\mathrm{U}$ \\
360 & $\mathrm{U}$ \\
1600 & \\
360 & $\mathrm{U}$ \\
360 & $\mathrm{U}$ \\
48 & $\mathrm{~J}$ \\
1500 & \\
7 & $\mathrm{~J}$ \\
360 & $\mathrm{U}$ \\
& \\
\hline
\end{tabular}


Lab Name: PNNL

Contract: $\mathrm{C104}$

Lab Code: PNNL

Case No.:

Matrix: (soil/water) WATER

Sample wt/vol:

$5.000(\mathrm{~g} / \mathrm{mL}) \mathrm{ML}$

Level: (low/med) Low

\% Moisture: not dec.

GC Column: DB-624 75M X 2.55UM ID: 0.45 (mm)

Soil Extract Volume: (ut)

Number TICs found: 5
EPA SAMPLE NO.

\section{LCS}

SDG No. : 2
Lab Sample ID: LCS

Lab File ID: 00040614

Date Received:

Date Analyzed: 04/06/0

Dilution Factor: 1.0

Soil Aliquot Volume:

(UL)

CONCENTRATION UNITS:

(ug/L or $u g / \mathrm{kg}$ ) ug/L

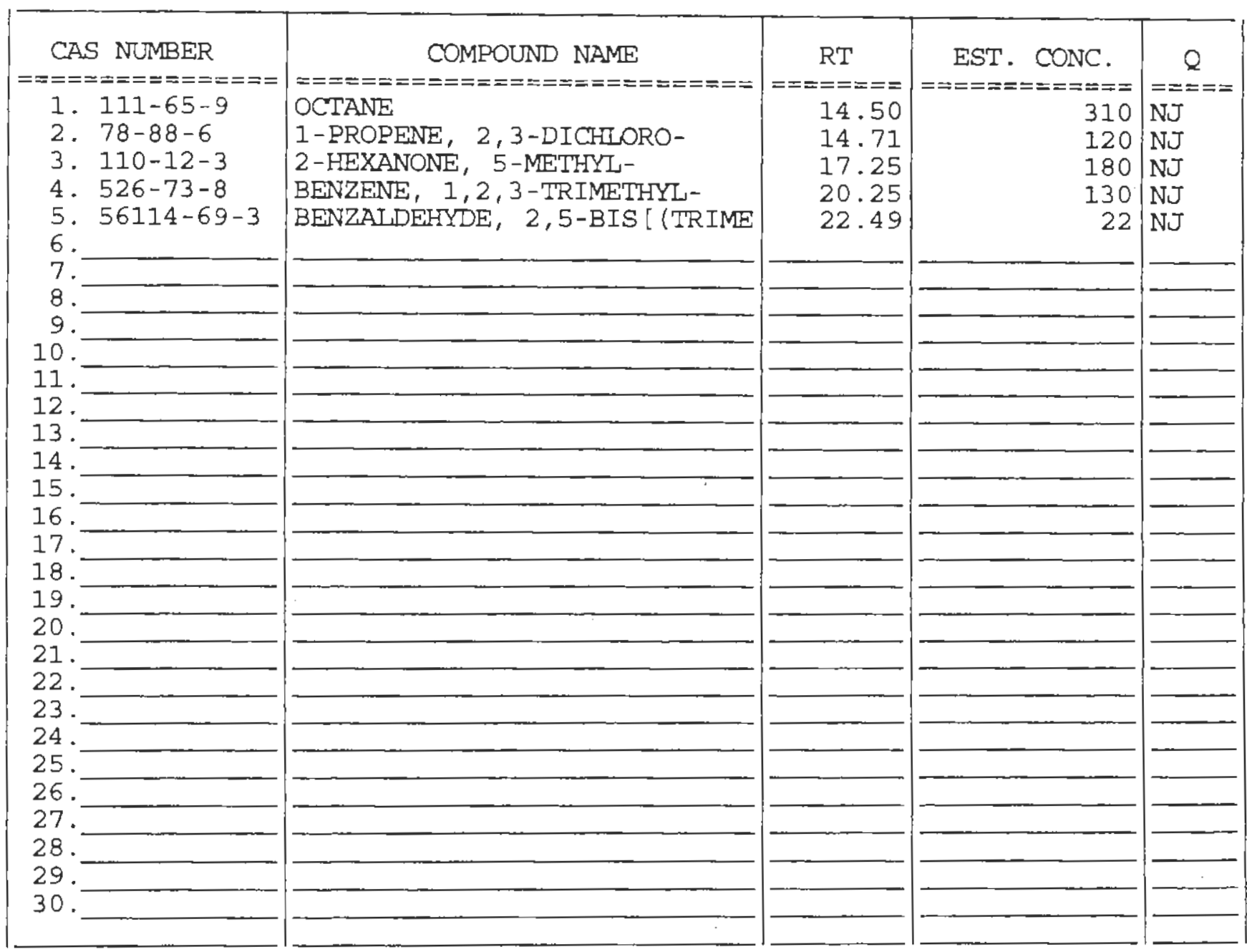


Lab Name: PNNL

Contract: $\mathrm{C104}$

Lab code: PNNL

Case No. :

Matrix: (soil/water) WATER

Sample wt/vol:

$5.000(\mathrm{~g} / \mathrm{mL}) \mathrm{ML}$

Level: (low/med) IOW

\% Moisture: not dec.

SAS NO. :
EPA SAMPLE NO.

\section{METHOD BLANK}

GC Column: DB-624 75M X 2.55UM ID: 0.45 (mm)

Lab Sample ID: VBLKO2

Lab File ID: 00040616

Date Received:

Date Analyzed: 04/07/0

Soil Extract Volume: (UL)

Dilution Factor: 1.0

Soil Aliquot volume: (uL)

Number TICs found: 2 CONCENTRATION UNITS : (ug/L or $u g / \mathrm{kg}$ ) ug/L

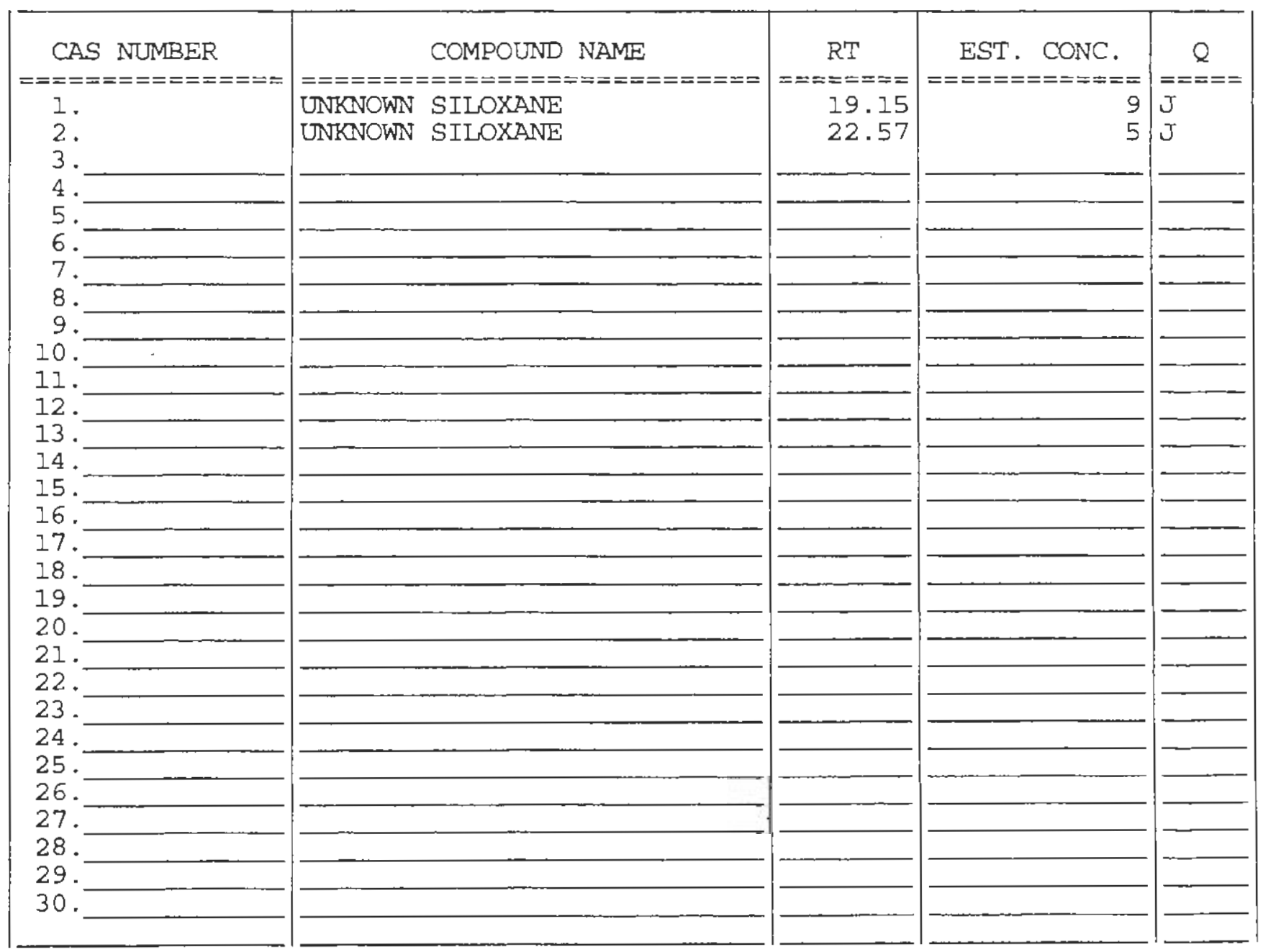


Lab Name: PNNL

Contract: $\mathrm{Cl04}$

Lab code: PNNL

Case No.:

Matrix: (soil/water) SOLID

Sample wt/vol:

$0.0(\mathrm{~g} / \mathrm{mL}) \mathrm{G}$

Level: (low/med) LOW

$\because$ Moisture: not dec.

GC Column: $\mathrm{DB}-62475 \mathrm{M} \times 2.55 \mathrm{UM}$ ID: 0.45 (mm)

Soil Extract Volume: (uL)

Number TICs found: 2
EPA SAMPLE NO.

METHOD BLANK

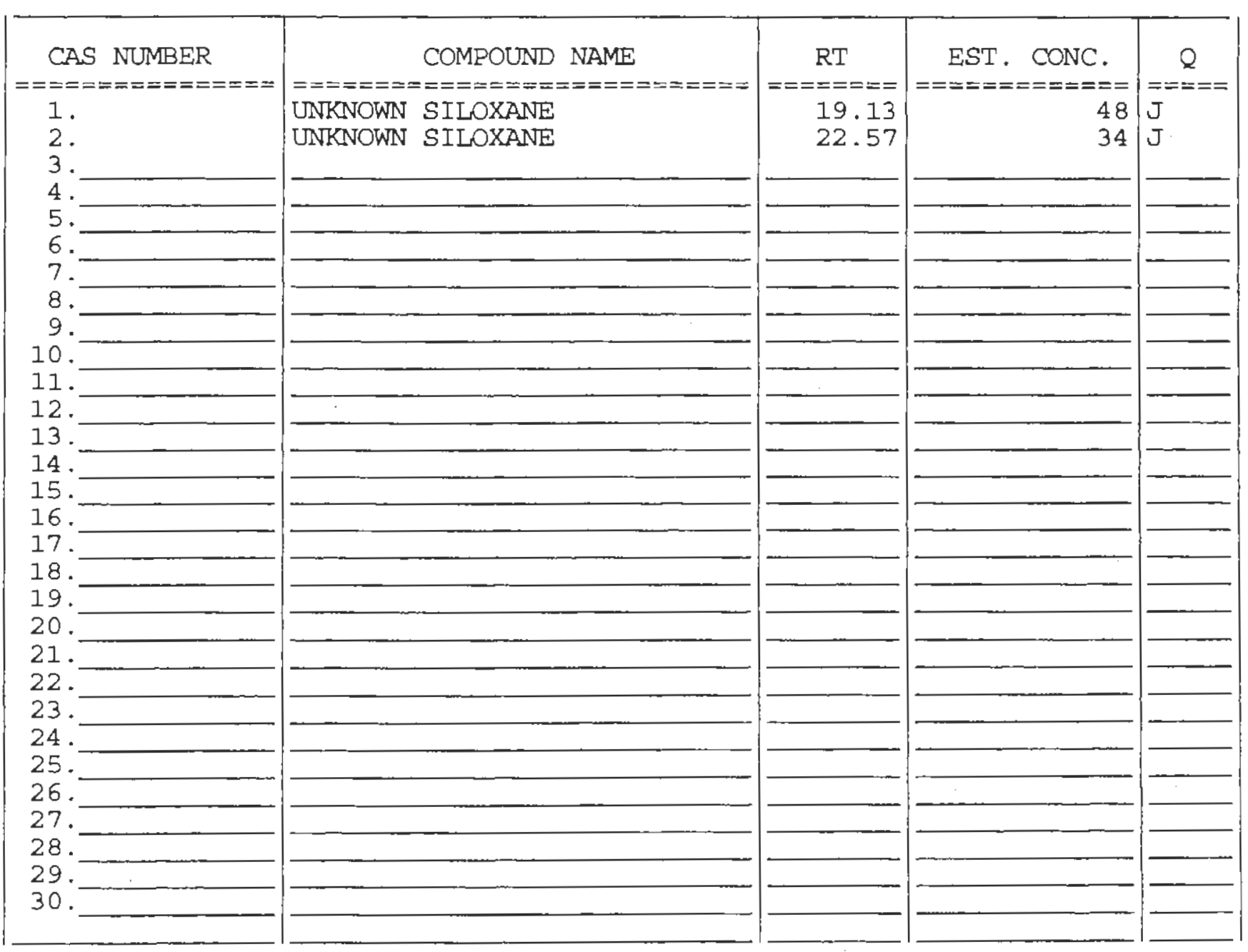

CONCENTRATION UNITS:

$(\mathrm{ug} / \mathrm{L}$ or $\mathrm{ug} / \mathrm{Kg}$ ) $\mathrm{ug} / \mathrm{Kg}$

Lab Sample ID: VBLK03

Lab File ID: 00040622

Date Received:

Date Analyzed: 04/07/0

Soil AIiquot volume:

(uL)

Dilution Factor: 1.0 
Lab Name: PNNL

Contract: C104

Lab code: PNNL

Case No. :

Matrix: (soil/water) WATER

Sample wt/vol:

$5.000(\mathrm{~g} / \mathrm{mL}) \mathrm{ML}$

Level: (low/med) LOW

$\div$ Moisture: not dec.

GC Column: DB-624 75M X 2.55UM ID: 0.45 (mm)

Soil Extract Volume:

Number TICs found: 3
EPA SAMPLE NO.

\section{HOTCELIBLK}

SDG NO. : 2
Lab Sample ID: 00-1360-CB

Lab File ID: 00040617

Date Received:

Date Analyzed: 04/07/0

Dilution Factor: 1.0

Soil Aliquot volume: (ư)

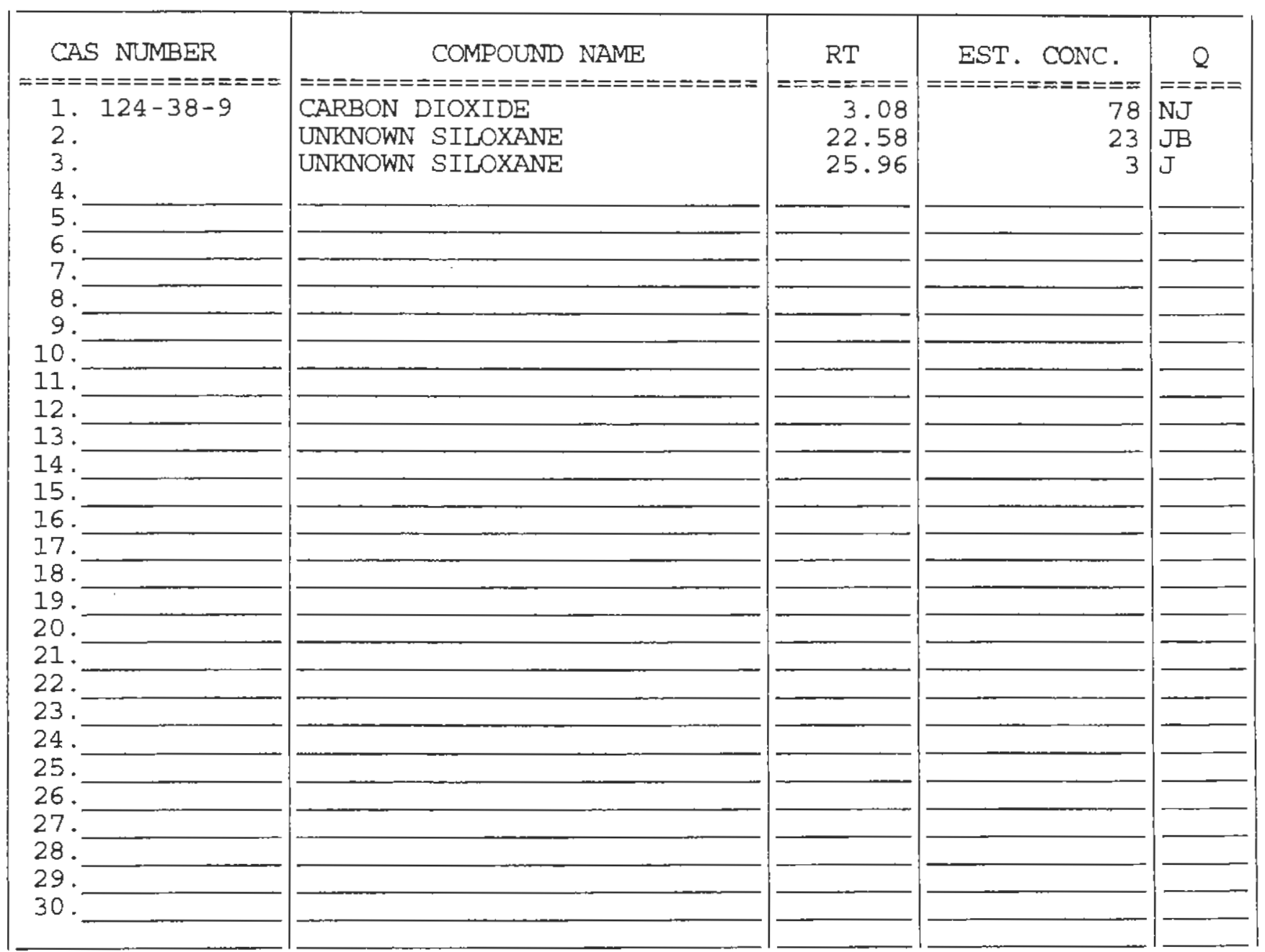


Lab Name: PNNL

Contract: C104

Lab Code: PNNL

Case No. :

SAS NO :

EPA SAMPLE NO.

Matrix: (soil/water) SOLID

Lab Sample ID: 00-1360-CBD

Sample wt/vol:

$0.0(\mathrm{~g} / \mathrm{mL}) \mathrm{G}$

Lab File ID: 00040623

Level: (low/med) LOW

Date Received:

$\because$ Moisture: not dec.

Date Analyzed: 04/07/0

GC Column: DB-624 75M X 2.55UM ID: 0.45 (mm)

Dilution Factor: 1.0

Soil Extract Volume: (uL)

Soil Aliquot Volume:

Number TICs found: 2

CONCENTRATION UNITS :

(ug/L or $\mathrm{ug} / \mathrm{Kg}$ ) $\mathrm{ug} / \mathrm{Kg}$

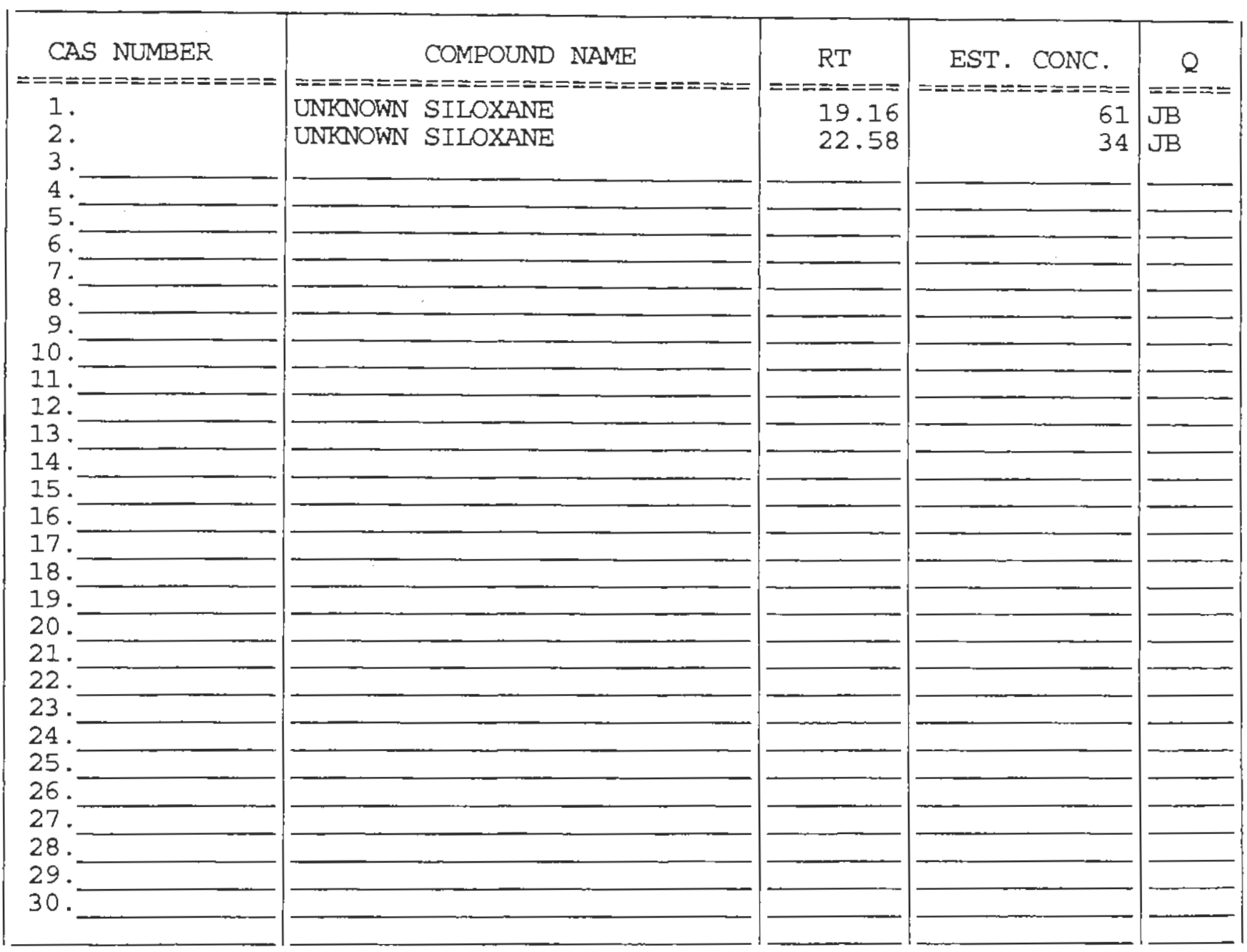


Lab Name: PNNL

Contract : C104

Lab Code: PNNL

Case No.:

SAS NO. :

CI04SUP

Matrix: (soil/water) WATER

Sample wt/vol: $\quad 5.000(\mathrm{~g} / \mathrm{mL}) \mathrm{ML}$

Level: (low/med) LOW

\% Moisture: not dec.

GC Column: DB-624 75M X 2.55UM ID: 0.45 (mm)

Soil Extract Volume:

(UL)

Number TICs found: 10
Lab Sample ID: 00-1360

Lab File ID: 00040618

Date Received:

Date Analyzed: 04/07\%

Dilution Factor: 100.0

Soil AIiquot volume: (uL)

CONCENTRATION UNITS:

(ug/L or $\mathrm{ug} / \mathrm{Kg}$ ) $\mathrm{ug} / \mathrm{L}$

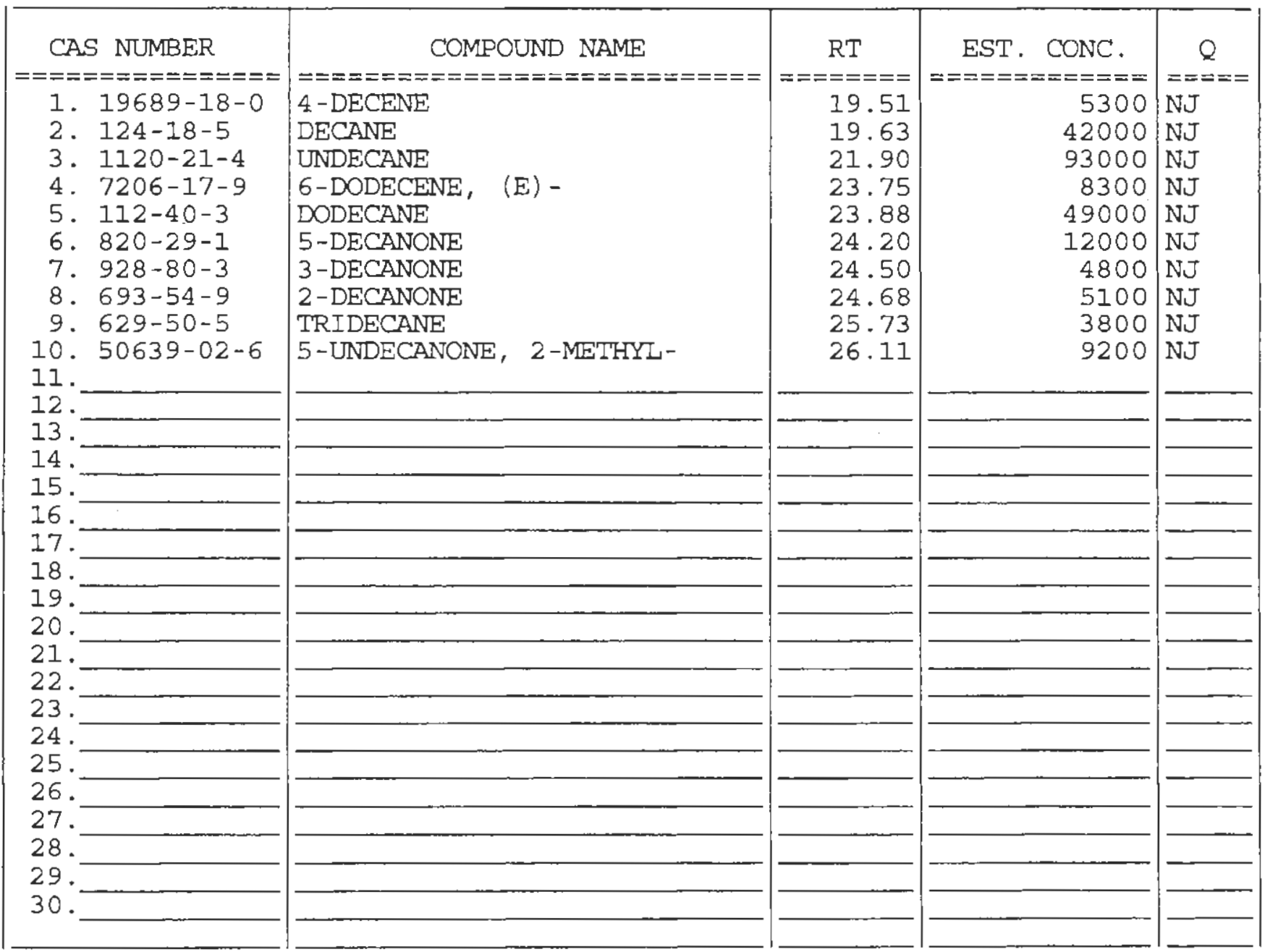


Lab Name: PNNL

Contract: C104

Lab Code: PNNL

Case No. :

Matrix: (soil/water) WATER

Sample wt/vol: $\quad 5.000(\mathrm{~g} / \mathrm{mL}) \mathrm{ML}$

Level: (low/med) LOW

\% Moisture: not dec.

SAS NO.:
EPA SAMPLE NO.

C104SUPD

GC Column: $\mathrm{DB}-62475 \mathrm{M} \mathrm{X} 2.55 \mathrm{UM}$ ID: 0.45 (mm)

Lab Sample ID: 00-1360D

Lab File ID: 00040619

Date Received:

Date Analyzed: 04/07/0

Soil Extract volume: (UL)

Dilution Factor: 100.0

Soil Aiquot volume:

Number TICs found: 0

CONCENTRATION UNITS:

(ug/L or $\mathrm{ug} / \mathrm{kg}$ ) ug/L

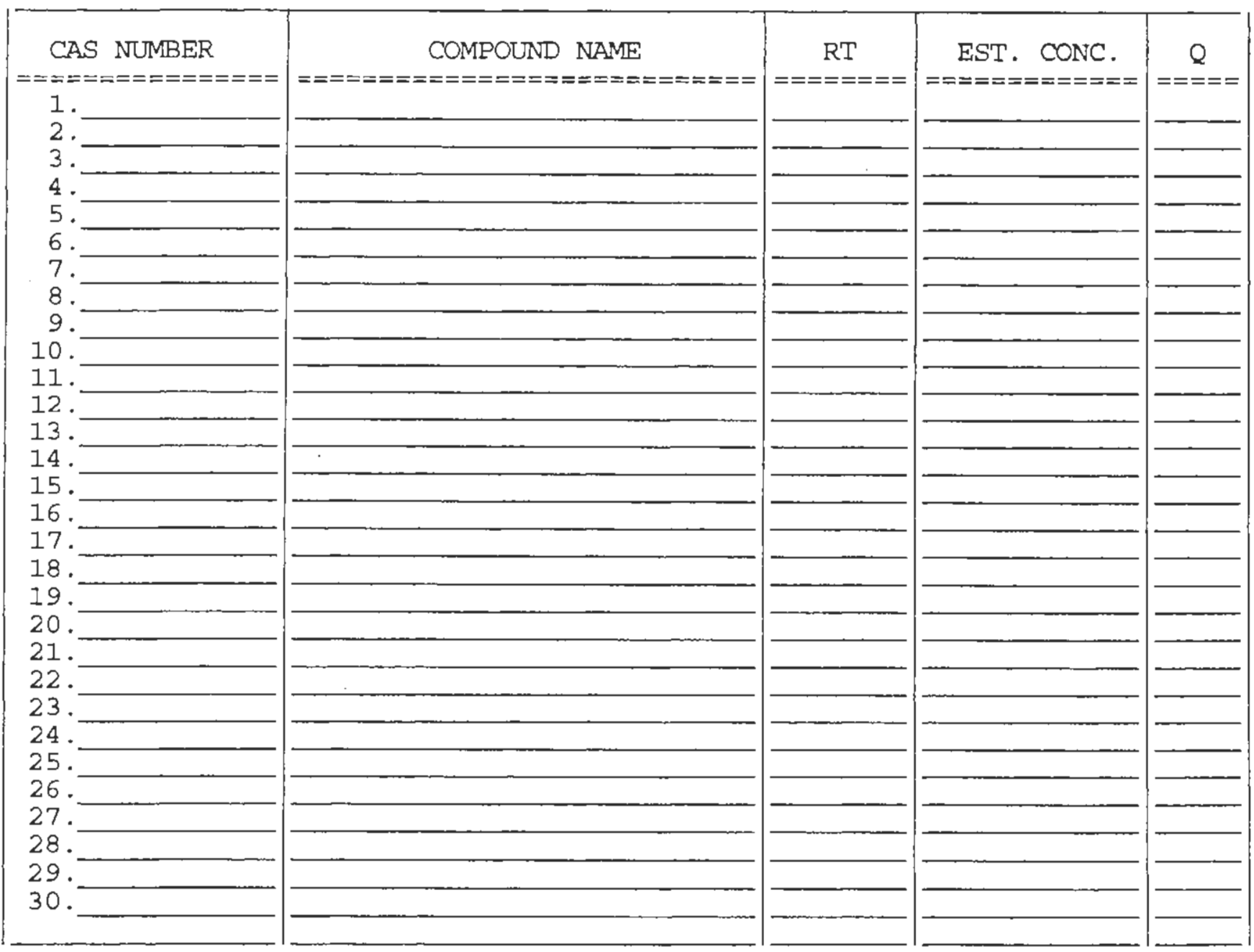


Lab Name: PNNL

Lab Code: PNNL

Case No.:

Matrix: (soil/water) SOLID

Sample wt/vol:

$0.1(g / \pi L) \quad G$

Level: (low/med) Low

$\because$ Moisture: not dec.

GC Column: $\mathrm{DB}-62475 \mathrm{M} \times 2.55 \mathrm{UM}$ ID: 0.45 (mn)

Soil Extract Volume: (uL)
Contract: $\mathrm{ClO4}$

SAS NO. :

\section{C104SOL}

SDG NO. : 2

Lab Sample ID: 00-0136I

Lab File ID: 00040624

Date Received:

Date Analyzed: 04/07/0

Soil Aliquot Volume:

Dilution Factor: 1.0

Number TICs found: 20 CONCENTRATION UNITS :

(ug/L or $\mathrm{ug} / \mathrm{Kg}$ ) $\mathrm{ug} / \mathrm{Kg}$

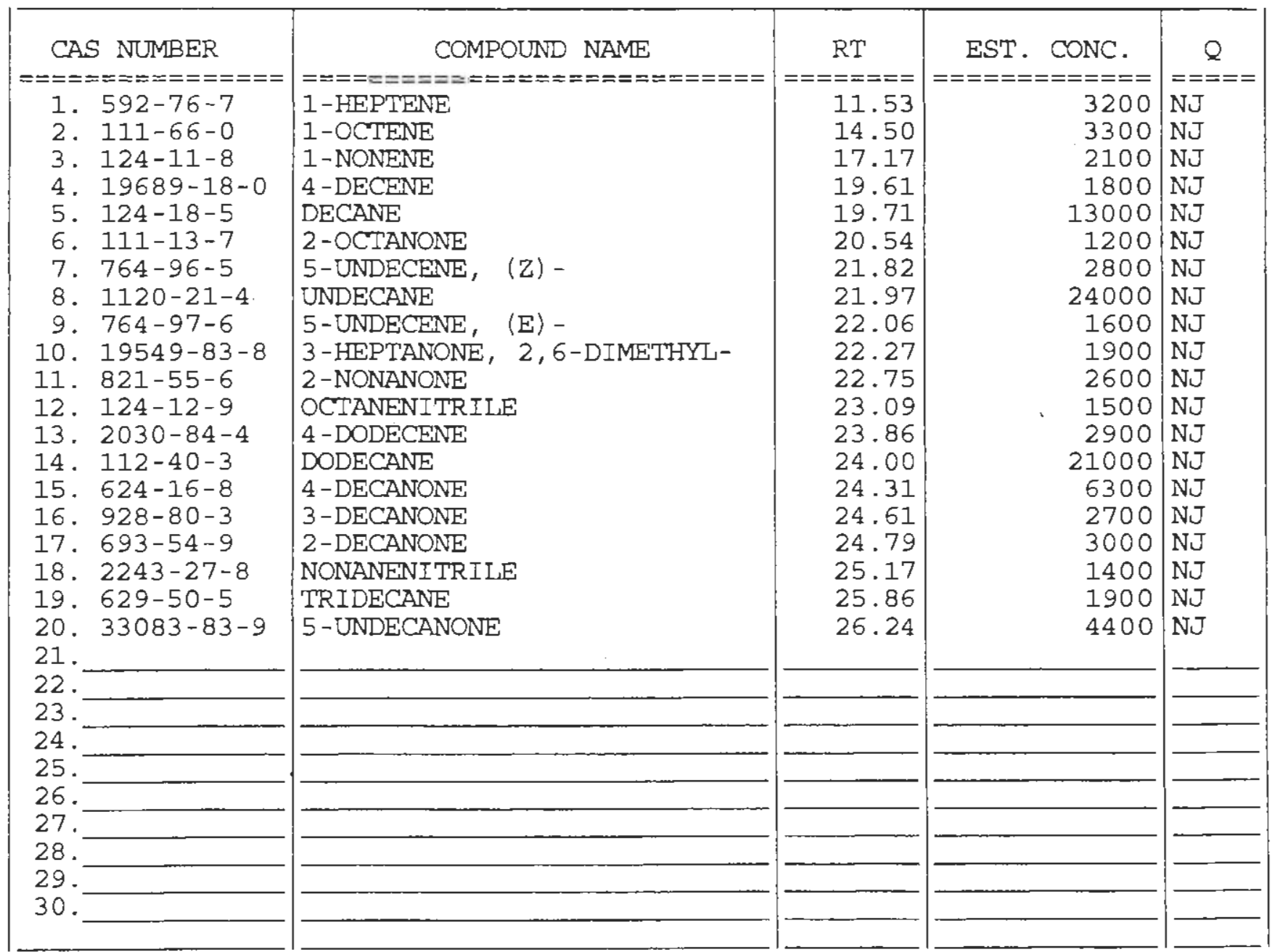


Lab Name: PNNL

Lab Code: PNNL

Case No. :

Matrix: (soil/water) SOLID

Sample wt/vol: $\quad 0.1(\mathrm{~g} / \mathrm{mL}) \mathrm{G}$

Level: (low/med) Low

\% Moisture: not dec.

GC Colum: DB-624 75M X 2.55UM ID: 0.45 (mm)

Soil Extract Volume: (uL)

Number TICs found: 19
Contract: $\mathrm{C} 104$

SAS NO.:
EPA SAMPLE NO.

C104SOLD

SDG No. : 2

Lab Sample ID: 00-01361D

Lab File ID: $\quad 00040625$

Date Received:

Date Analyzed: 04/07/0

Dilution Factor: 1.0

Soil Aliquot Volume: (uL)

CONCENTRATION UNITS:

(ug/L or $\mathrm{ug} / \mathrm{Kg}$ ) ug/Kg

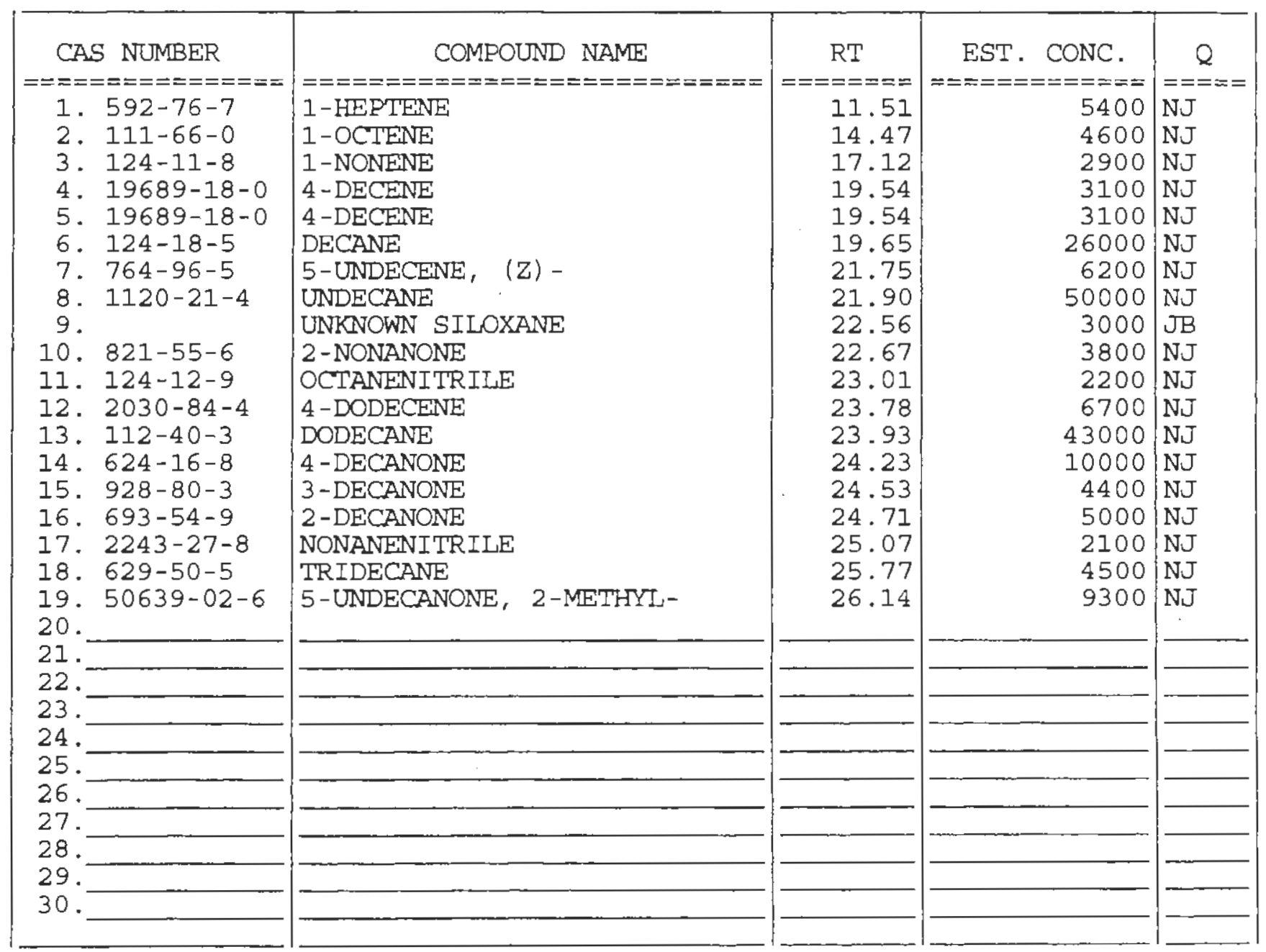


Lab Name: PNNL

Lab Code; PNNL
Contract: $\mathrm{C} 104$

SAS NO.:
SDG No. : 2

\section{Level : (low/med) IOW}

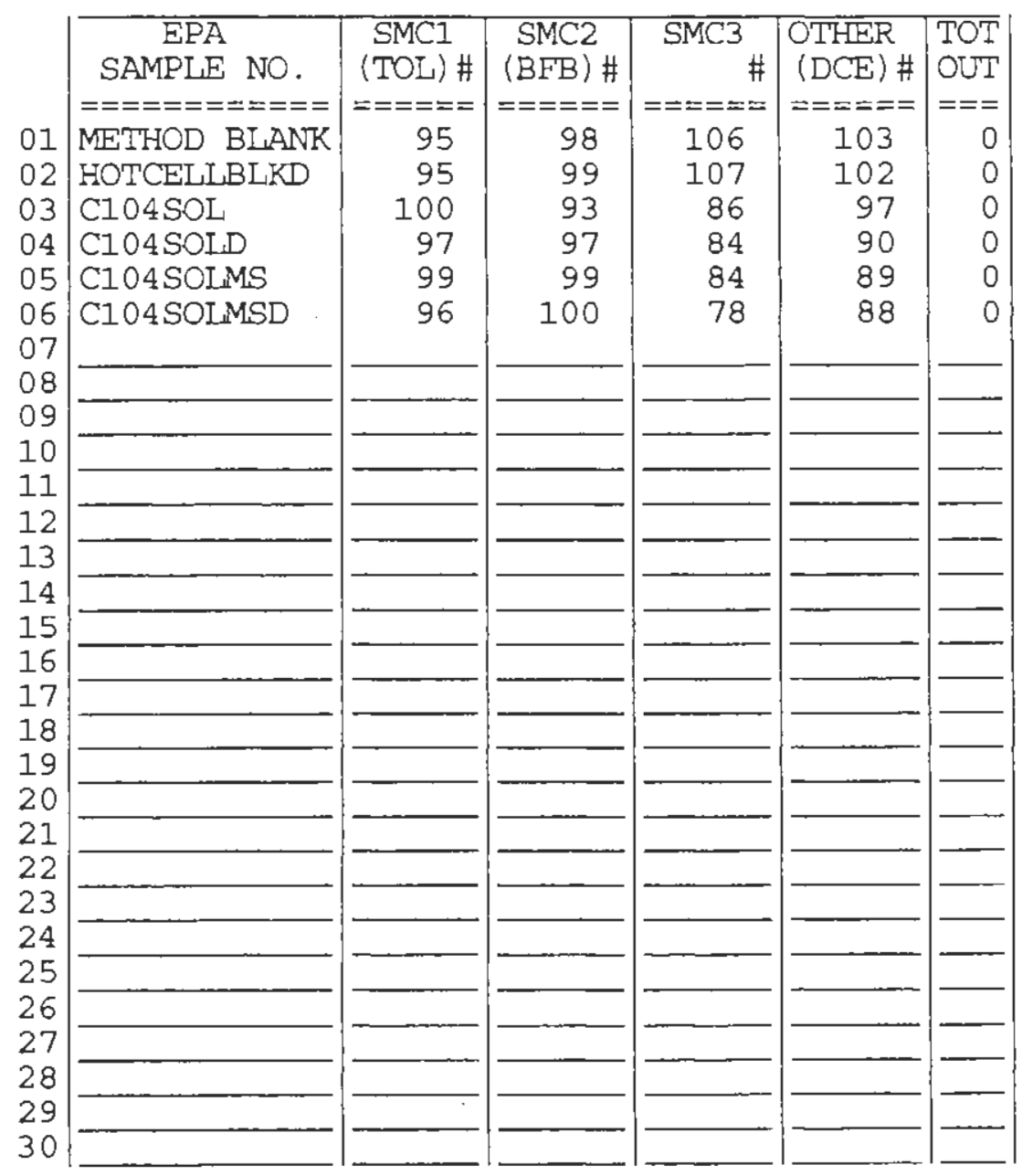

$$
\text { SMC1 (TOL) = Toluene-d8 }
$$

SMC2 $(\mathrm{BFB})=$ Bromofluorobenzene

SMC3 $=$ Dibromof Iuoromethane

OTHER $(D C E)=1,2-$ Dichloroethane-d4

\section{QC LIMITS}

$(84-138)$

$(59-113)$

$(0-150)$

$(70-121)$

\# Column to be used to flag recovery values

* Values outside of contract required QC limits 


\section{WATER VOLATILE SYSTEM MONITORING COMPOUND RECOVERY}

Lab Name: PNNL

Lab Code: PNNL
Case No.:
Contract: $\mathrm{ClO4}$

SAS NO.:

SDG No.: 2

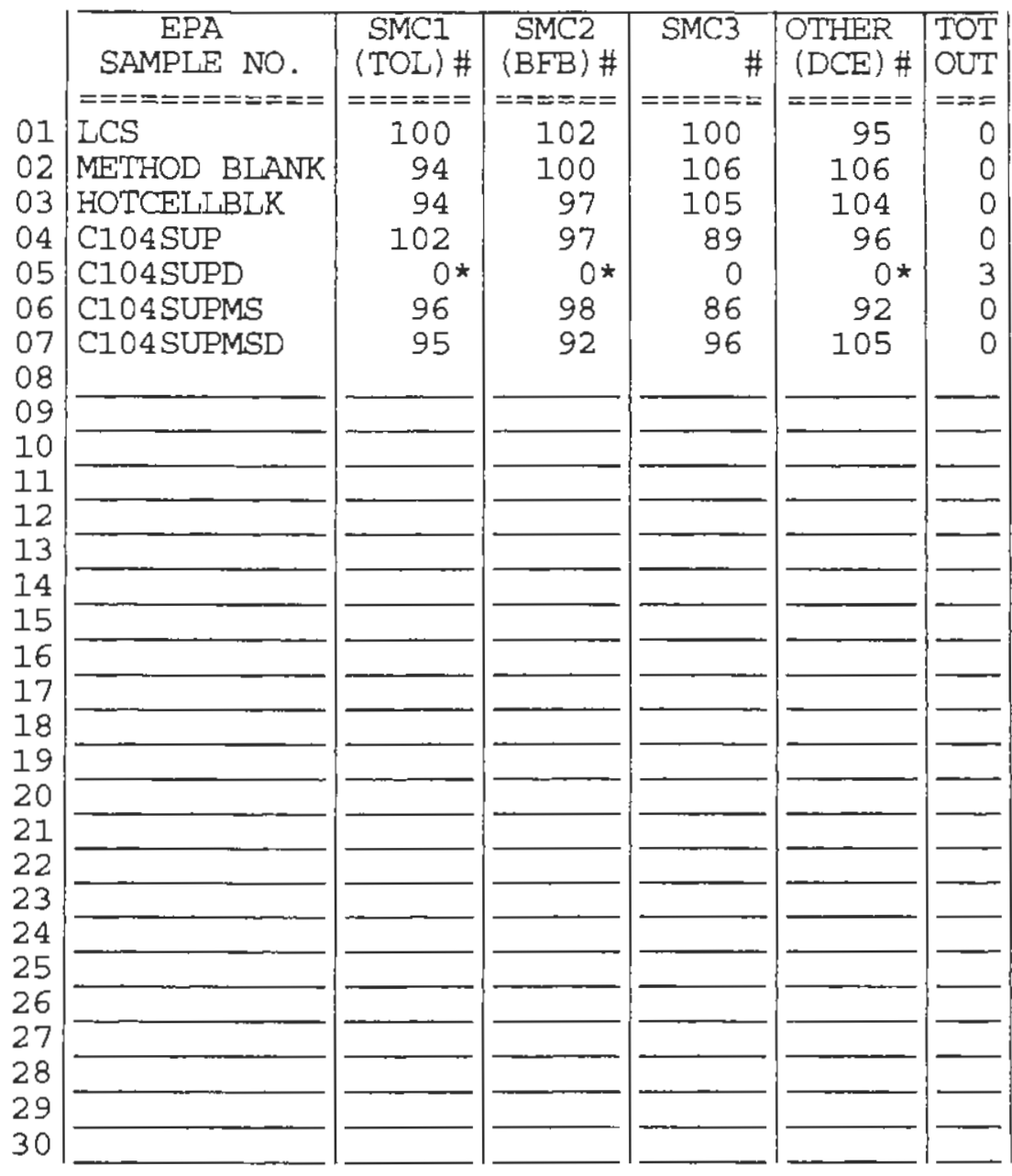

$$
\begin{aligned}
& \text { SMC1 (TOL) = Toluene-d8 } \\
& \text { SMC2 }(\mathrm{BFB})=\text { Bromof luorobenzene } \\
& \text { SMC3 }=\text { Dibromofluoromethane } \\
& \text { OTHER }(D C E)=1,2-\text { Dichloroethane-d4 } \\
& \text { QC LIMITS } \\
& (88-110) \\
& (86-115) \\
& (0-150) \\
& (76-114)
\end{aligned}
$$


$3 A$

WATER VOLATILE MATRIX SPIKE/MATRIX SPIKE DUPLICATE RECOVERY

Lab Name: PNNL

Contract: $\mathrm{C} 104$

Lab Code: PNNL

Case No.:

SAS NO.:

SDG No.: 2

Matrix Spike - EPA Sample No.: C104SUP

\begin{tabular}{|c|c|c|c|c|c|}
\hline COMPOUND & $\begin{array}{l}\text { SPIKE } \\
\text { ADDED } \\
\text { (ng) }\end{array}$ & $\begin{array}{l}\text { SAMPLE } \\
\text { AMOUNT } \\
(\mathrm{ng})\end{array}$ & $\begin{array}{l}\text { MS } \\
\text { AMOUNT } \\
\text { (ng) }\end{array}$ & $\begin{array}{c}\mathrm{MS} \\
\frac{\circ}{\circ} \\
\mathrm{REC} \#\end{array}$ & $\begin{array}{l}\text { QC. } \\
\text { LIMITS } \\
\text { REC. }\end{array}$ \\
\hline 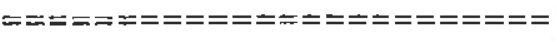 & $==x== \pm===$ & $============$ & 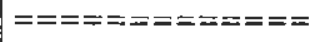 & $=\approx==\approx=$ & $===\Omega==$ \\
\hline Butane & $\begin{array}{l}150 \\
190\end{array}$ & 0.0 & $\begin{array}{l}130 \\
140\end{array}$ & $\begin{array}{l}87 \\
74\end{array}$ & $0-200$ \\
\hline 1,1-Dichloroethene & 190 & 0.0 & 140 & 74 & $61-145$ \\
\hline Acetone & 150 & 50 & 160 & 73 & $0-200$ \\
\hline Pentane & 150 & 0.0 & 79 & 53 & $0-200$ \\
\hline Acrylonitrile & 150 & 0.0 & 120 & 80 & $0-200$ \\
\hline 2-Butenal & 150 & 0.0 & 0.0 & 0 & $0-200$ \\
\hline Hexane & 150 & 250 & 250 & 0 & $0-200$ \\
\hline Cyclohexene & 150 & 0.0 & 66 & 44 & $0-200$ \\
\hline Ethyl acetate & 150 & 0.0 & 0.0 & 0 & $0-200$ \\
\hline Cyclopentane & 150 & 0.0 & 150 & 100 & $0-200$ \\
\hline Dichlorofluoromethane & 150 & 0.0 & 96 & 64 & $0-200$ \\
\hline Chlorodifluoromethane & 150 & 0.0 & 110 & 73 & $0-200$ \\
\hline Benzene & 190 & 0.0 & 180 & 95 & $76-127$ \\
\hline Trichloroethene & 190 & 0.0 & 120 & $63 *$ & $71-120$ \\
\hline Toluene & 190 & 0.0 & 110 & $58 *$ & $76-125$ \\
\hline 2-Hexanone & 150 & 1 & 150 & 99 & $0-200$ \\
\hline Chlorobenzene & 190 & 0.0 & 93 & $49 *$ & $75-130$ \\
\hline Heptane & 150 & 93 & 56 & $-25 *$ & $0-200$ \\
\hline Octane & 150 & 190 & 29 & $-107 *$ & $0-200$ \\
\hline Nonane & 150 & 310 & 21 & $-193^{*}$ & $0-200$ \\
\hline 2-Pentanone & 150 & 0.0 & 150 & 100 & $0-200$ \\
\hline Methylcyclohexane & 150 & 0.0 & 71 & 47 & $0-200$ \\
\hline 4-Heptanone & 150 & 0.0 & 130 & 87 & $0-200$ \\
\hline Butylacetate & 150 & 0.0 & 0.0 & 0 & $0-200$ \\
\hline Propyl nitrate & 150 & 0.0 & 110 & 73 & $0-200$ \\
\hline $1,2,2-\mathrm{Cl} 3-1,1,2-\mathrm{F} 3$ ethan & 150 & 0.0 & 87 & 58 & $0-200$ \\
\hline $1,2-\mathrm{Cl} 2-1,1,2,2-\mathrm{F} 4$ ethan & 150 & 0.0 & 120 & 80 & $0-200$ \\
\hline Acetonitrile & 150 & 0.0 & 160 & 107 & $0-200$ \\
\hline
\end{tabular}

* Values outside of QC limits

COMMENTS : 
WATER VOLATILE MATRIX SPIKE/MATRIX SPIKE DUPLICATE RECOVERY

Lab Name: PNNL

Contract : C104

Lab Code: PNNL

Case No.:

SAS NO. :

SDG NO.: 2

Matrix Spike - EPA Sample No.: C104SUP

\begin{tabular}{|c|c|c|c|c|c|}
\hline COMPOUND & $\begin{array}{c}\text { SPIKE } \\
\text { ADDED } \\
\text { (ng) }\end{array}$ & $\begin{array}{c}\text { SAMPILE } \\
\text { AMOUNT } \\
\text { (ng) }\end{array}$ & $\begin{array}{c}\text { MS } \\
\text { AMOUNT } \\
\text { (ng) }\end{array}$ & $\begin{array}{c}\mathrm{MS} \\
\frac{\circ}{0} \\
\mathrm{REC} \mathrm{\#}\end{array}$ & $\begin{array}{c}\text { QC. } \\
\text { LIMITS } \\
\text { REC. }\end{array}$ \\
\hline 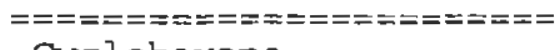 & $= \pm======$ & 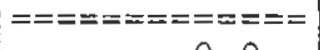 & $====== \pm=====$ & $===ニ=ニ$ & $=====$ \\
\hline Cyclohexane & $\begin{array}{l}150 \\
150\end{array}$ & 0.0 & $\begin{array}{r}98 \\
790\end{array}$ & $\begin{array}{r}65 \\
724\end{array}$ & $0-200$ \\
\hline $\begin{array}{l}\text { 3-Heptanone } \\
\text { Tetrahydrofuran }\end{array}$ & $\begin{array}{l}150 \\
150\end{array}$ & 0.0 & $\begin{array}{r}190 \\
34\end{array}$ & $\begin{array}{r}144 \\
23\end{array}$ & $0-200$ \\
\hline
\end{tabular}

\# Colum to be used to flag recovery and RPD values with an asterisk

* Values outside of QC limits

COMMENTS : 
$3 \mathrm{~A}$.

WATER VOLATILE MATRIX SPIKE/MATRIX SPIKE DUPLICATE RECOVERY

Lab Name: PNNL

Contract: $\mathrm{Cl} 04$

Lab code: PNNI

Case No.:

SAS NO. :

SDG NO.: 2

Matrix Spike - EPA Sample No.: C104SUP

\begin{tabular}{|c|c|c|c|c|c|c|}
\hline COMPOUND & $\begin{array}{l}\text { SPIKE } \\
\text { ADDED } \\
\text { (ng) }\end{array}$ & $\begin{array}{c}\text { MSD } \\
\text { AMOUNT } \\
\text { (ng) }\end{array}$ & $\begin{array}{l}\text { MSD } \\
\frac{\circ}{\circ} \\
\text { REC \# }\end{array}$ & $\stackrel{\stackrel{\circ}{\circ}}{R P D ~ \#}$ & $\begin{array}{rl}Q C & L I \\
R P D & \end{array}$ & $\begin{array}{l}\text { MITS } \\
\text { REC. }\end{array}$ \\
\hline 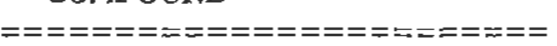 & $========$ & $============$ & $=====$ & $=====$ & $=====$ & $=====$ \\
\hline Butane & 0.0 & 0.0 & $999 *$ & & 0 & $0-\quad 0$ \\
\hline 1,1-Dichloroethene & 500 & 0.0 & 0 * & & 14 & $61-145$ \\
\hline Acetone & 0.0 & 1600 & $999 *$ & $173 *$ & 0 & $0-\quad 0$ \\
\hline Pentane & 0.0 & 0.0 & $999 *$ & & 0 & $0-$ \\
\hline Acrylonitrile & 0.0 & 130 & $999 *$ & $170 *$ & 0 & $0-$ \\
\hline 2-Butenal & 0.0 & 1600 & 999* & & 0 & $0-$ \\
\hline Hexane & 0.0 & 230 & 999 * & $200 *$ & 0 & $0-$ \\
\hline Cyclohexene & 0.0 & 0.0 & $999 *$ & & 0 & $0-$ \\
\hline Ethyl acetate & 0.0 & 0.0 & 999 * & & 0 & $0-$ \\
\hline Cyclopentane & 0.0 & 0.0 & $999 *$ & & 0 & $0-$ \\
\hline Dichiorofluoromethane & 0.0 & 0.0 & $999 *$ & & 0 & $0-$ \\
\hline Chlorodifluoromethane & 0.0 & 0.0 & 999 * & & 0 & $0-0$ \\
\hline Benzene & 500 & 48 & $10 *$ & 162 * & 11 & $76-127$ \\
\hline Trichloroethene & 500 & 0.0 & 0 * & & 14 & $71-120$ \\
\hline Toluene & 500 & 38 & 8 * & 152 * & 13 & $76-125$ \\
\hline 2-Hexanone & 0.0 & 140 & $999 *$ & 164 * & 0 & $0-0$ \\
\hline Chlorobenzene & 500 & 42 & 8 * & 144 * & 13 & $75-130$ \\
\hline Heptane & 0.0 & 0.0 & 999 * & & 0 & $0-\quad 0$ \\
\hline Octane & 0.0 & 0.0 & 999 * & & 0 & $0-$ \\
\hline Nonane & 0.0 & 0.0 & 999 * & & 0 & $0-$ \\
\hline 2-Pentanone & 0.0 & 150 & 999 * & 164 * & 0 & $0-$ \\
\hline Methylcyclohexane & 0.0 & 22 & $999 *$ & $182^{\star}$ & 0 & $0-$ \\
\hline 4-Heptanone & 0.0 & 120 & 999 * & $168^{\star}$ & 0 & $0-$ \\
\hline Butylacetate & 0.0 & 110 & $999 *$ & & 0 & $0-$ \\
\hline Propyl nitrate & 0.0 & 0.0 & $999 *$ & & 0 & $0-$ \\
\hline $1,2,2-C 13-1,1,2-F 3$ ethan & 0.0 & 0.0 & 999 * & & 0 & $0-$ \\
\hline $1,2-C 12-1,1,2,2-F 4$ ethan & 0.0 & 0.0 & $999 *$ & & 0 & $0-$ \\
\hline Acetonitrile & 0.0 & 0.0 & $999 *$ & & 0 & $0-$ \\
\hline
\end{tabular}

\# Column to be used to flag recovery and RPD values with an asterisk

* Values outside of QC limits

COMMENTS : 
WATER VOLATILE MATRIX SPIKE/MATRIX SPIKE DUPLICATE RECOVERY

Lab Name: FNNL

Contract: $\mathrm{C} 104$

Lab Code: PNNL

Case No. :

SAS NO.:

SDG No.: 2

Matrix Spike - EPA Sample No.: C104SUP

\begin{tabular}{|c|c|c|c|c|c|c|}
\hline & $\begin{array}{l}\text { SPIKE } \\
\text { ADDED }\end{array}$ & $\begin{array}{c}\text { MSD } \\
\text { AMOUNT }\end{array}$ & $\begin{array}{c}\text { MSD } \\
\frac{\circ}{6}\end{array}$ & $\div$ & QC L. & MITS \\
\hline COMPOUND & (ng) & (ng) & REC \# & RPD \# & $\mathrm{RPD}$ & REC. \\
\hline 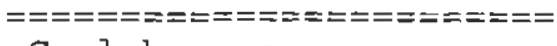 & $=========$ & 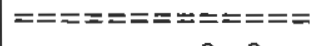 & $=\approx====$ & $====\approx=$ & $======$ & $=====-$ \\
\hline Cyclohexane & 0.0 & 0.0 & $999 *$ & & 0 & 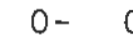 \\
\hline 3-Heptanone & 0.0 & 160 & $999 *$ & 156 * & 0 & $0-$ \\
\hline Tetrahydrofuran & 0.0 & 42 & $999 *$ & $191 *$ & 0 & $0-$ \\
\hline
\end{tabular}

\# Column to be used to flag recovery and RPD values with an asterisk

* Values outside of QC limits

RPD: 12 out of 31 outside limits

Spike Recovery: 37 out of 62 outside limits

COMMENTS : 
SOLID VOLATILE MATRIX SPIKE/MATRIX SPIKE DUPLICATE RECOVERY

Lab Name: PNNL

Contract: $\mathrm{C} 104$

Lab Code: PNNL

Case $\mathrm{No}_{+}$:

SAS NO. :

SDG No.: 2

Matrix Spike - EPA Sample No.: C104SOL Level:(low/med) LOW

\begin{tabular}{|c|c|c|c|c|c|}
\hline COMPOUND & $\begin{array}{c}\text { SPIKE } \\
\text { ADDED } \\
\text { (ng) }\end{array}$ & $\begin{array}{l}\text { SAMPLE } \\
\text { AMOUNT } \\
\text { (ng) }\end{array}$ & $\begin{array}{c}\text { MS } \\
\text { AMOUNT } \\
\text { (ng) }\end{array}$ & $\begin{array}{l}\text { MS } \\
\stackrel{\circ}{\circ} \\
\operatorname{REC} \#\end{array}$ & $\begin{array}{l}\text { QC. } \\
\text { LIMITS } \\
\text { REC. }\end{array}$ \\
\hline $\begin{array}{l}===============\approx======= \\
\text { Butane }\end{array}$ & $========$ & $=====:======0$ & $=======:=====$ & $=====$ & $=====$ \\
\hline & $\begin{array}{l}150 \\
190\end{array}$ & $\begin{array}{r}260 \\
0.0\end{array}$ & 300 & $\begin{array}{l}27 \\
79\end{array}$ & $\begin{array}{r}0-200 \\
61-145\end{array}$ \\
\hline Acetone & 150 & 24 & 140 & 77 & $0-200$ \\
\hline Fentane & 150 & 690 & 340 & $-233 *$ & $0-200$ \\
\hline Acrylonitrile & 150 & 0.0 & 120 & 80 & $0-200$ \\
\hline 2-Butenal & 150 & 0.0 & 0.0 & 0 & $0-200$ \\
\hline Hexane & 150 & 870 & 510 & $-240 *$ & $0-200$ \\
\hline Cyclohexene & 150 & 0.0 & 65 & 43 & $0-200$ \\
\hline Ethyl acetate & 150 & 0.0 & 0.0 & 0 & $0-200$ \\
\hline Cyclopentane & 150 & 0.0 & 160 & 107 & $0-200$ \\
\hline Dichlorofluoromethane & 150 & 0.0 & 100 & 67 & $0-200$ \\
\hline Chlorodifluoromethane & 150 & 0.0 & 110 & 73 & $0-200$ \\
\hline Benzene & 190 & 3 & 180 & 93 & $76-127$ \\
\hline Trichloroethene & 190 & 0.0 & 120 & 63 * & $71-120$ \\
\hline Toluene & 190 & 0.0 & 120 & $63 *$ & $76-125$ \\
\hline 2-Hexanone & 150 & 16 & 160 & 96 & $0-200$ \\
\hline Chlorobenzene & 190 & 0.0 & 87 & $46^{\star}$ & $75-130$ \\
\hline Heptane & 150 & 640 & 190 & $-300^{*}$ & $0-200$ \\
\hline octane & 150 & 420 & 79 & $-227 *$ & $0-200$ \\
\hline Nonane & 150 & 350 & 50 & $-200 *$ & $0-200$ \\
\hline 2-Pentanone & 150 & 5 & 150 & 97 & $0-200$ \\
\hline Methylcyclohexane & 150 & 0.0 & 69 & 46 & $0-200$ \\
\hline 4-Heptanone & 150 & 6 & 130 & 83 & $0-200$ \\
\hline Butylacetate & 150 & 0.0 & 0.0 & 0 & $0-200$ \\
\hline Propyl nitrate & 150 & 4 & 100 & 64 & $0-200$ \\
\hline $1,2,2-\mathrm{Cl} 3-1,1,2$-F3ethan & 150 & 0.0 & 98 & 65 & $0-200$ \\
\hline $1,2-\mathrm{Cl} 2-1,1,2,2-\mathrm{F}$ sethan & 150 & 0.0 & 120 & 80 & $0-200$ \\
\hline Acetonitrile & 150 & 0.0 & 170 & 113 & $0-200$ \\
\hline
\end{tabular}

* Values outside of QC limits

COMMENTS: 
SOLID VOLATILE MATRIX SPIKE/MATRIX SPIKE DUPLICATE RECOVERY

Lab Name: PNNL

Contract: C104

Lab Code: PNNL

Case No.:

SAS NO.:

SDG NO. : 2

Matrix Spike - EPA Sample No.: C104SOL Level:(10w/med) LOW

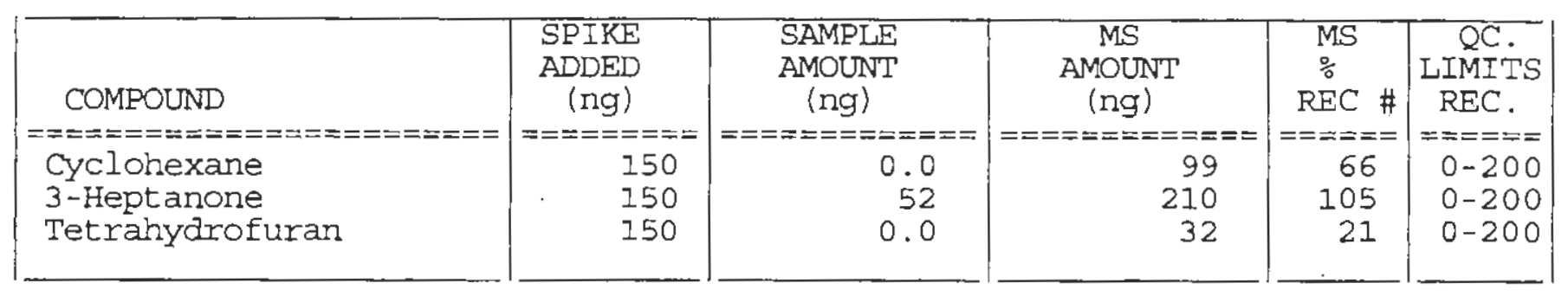

\# Column to be used to flag recovery and RPD values with an asterisk

* Values outside of QC limits

COMMENTS : 
Lab Name: PNNL

Contract: $\mathrm{Cl04}$

Lab Code: PNNL

Case No.:

SAS NO.:

SDG NO.: 2

Matrix Spike - EPA Sample No.: C104SOL Level: (low/med) LOW

\begin{tabular}{|c|c|c|c|c|c|c|}
\hline & $\begin{array}{l}\text { SPIKE } \\
\text { ADDED }\end{array}$ & $\begin{array}{c}\text { MSD } \\
\text { AMOUNT }\end{array}$ & $\begin{array}{c}\text { MSD } \\
\frac{\circ}{0}\end{array}$ & $\%$ & \multicolumn{2}{|c|}{ QC LIMITS } \\
\hline COMPOUND & (ng) & (ng) & REC \# & RPD \# & RPD & REC. \\
\hline 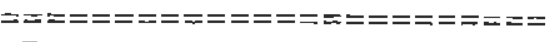 & $=======\mathrm{=}$ & 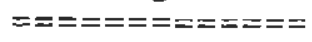 & $=====$ & $=====$ & $=====$ & $==x===$ \\
\hline Butane & 150 & 110 & $-100 *$ & -348 & 50 & $0-200$ \\
\hline 1,1-Dichloroethene & 190 & 140 & 74 & 6 & 14 & $61-145$ \\
\hline Acetone & 150 & 160 & 91 & 17 & 50 & $0-200$ \\
\hline Pentane & 150 & 600 & $-60 *$ & -118 & 50 & $0-200$ \\
\hline Acrylonitrile & 150 & 110 & 73 & 9 & 50 & $0-200$ \\
\hline 2-Butenal & 150 & 87 & 58 & & 50 & $0-200$ \\
\hline Hexane & 150 & 620 & $-167 \star$ & -36 & 50 & $0-200$ \\
\hline Cyclohexene & 150 & 60 & 40 & 7 & 50 & $0-200$ \\
\hline Ethyl acetate & 150 & 0.0 & 0 & & 50 & $0-200$ \\
\hline Cyclopentane & 150 & 77 & 51 & $71 *$ & 50 & $0-200$ \\
\hline Dichlorofluoromethane & 150 & 89 & 59 & 13 & 50 & $0-200$ \\
\hline Chlorodifluoromethane & 150 & 110 & 73 & 0 & 50 & $0-200$ \\
\hline Benzene & 190 & 170 & 88 & 6 & 11 & $76-127$ \\
\hline Trichloroethene & 190 & 110 & 58 * & 8 & 14 & $71-120$ \\
\hline Toluene & 190 & 100 & $53^{\star}$ & $17 \star$ & 13 & $76-125$ \\
\hline 2-Hexanone & 150 & 170 & 103 & 7 & 50 & $0-200$ \\
\hline Chlorobenzene & 190 & 73 & $38 *$ & 19 * & 13 & $75-130$ \\
\hline Heptane & 150 & 210 & $-287 *$ & -4 & 50 & $0-200$ \\
\hline Octane & 150 & 60 & $-240 *$ & -6 & 50 & $0-200$ \\
\hline Nonane & 150 & 31 & $-213^{\star}$ & -6 & 50 & $0-200$ \\
\hline 2-Pentanone & 150 & 160 & 103 & 6 & 50 & $0-200$ \\
\hline Methylcyclohexane & 150 & 61 & 41 & 11 & 50 & $0-200$ \\
\hline 4-Heptanone & 150 & 130 & 83 & 0 & 50 & $0-200$ \\
\hline Butylacetate & 150 & 11 & 7 & & 50 & $0-200$ \\
\hline Propyl nitrate & 150 & 110 & 71 & 10 & 50 & $0-200$ \\
\hline $1,2,2-C 13-1,1,2-F 3$ ethan & 150 & 79 & 53 & 20 & 50 & $0-200$ \\
\hline $1,2-\mathrm{Cl} 2-1,1,2,2-\mathrm{F} 4$ ethan & 150 & 34 & 23 & II* & 50 & $0-200$ \\
\hline Acetonitrile & 150 & 68 & 45 & 86 * & 50 & $0-200$ \\
\hline
\end{tabular}

\# Column to be used to flag recovery and RPD values with an asterisk

* Values outside of QC limits

COMMENTS : 
Lab Name: PNNL

Lab Code: PNNL

Matrix Spike - EPA Sample No.: Cl04SOL
Contract: $\mathrm{C} 104$

SAS NO.:
SDG NO.: 2
Case No.:

Level : (low/med) LOW

\begin{tabular}{|c|c|c|c|c|c|c|}
\hline & $\begin{array}{l}\text { SPIKE } \\
\text { ADDED }\end{array}$ & $\begin{array}{c}\text { MSD } \\
\text { AMOUNT }\end{array}$ & $\begin{array}{c}\text { MSD } \\
\frac{\mathrm{o}}{6}\end{array}$ & $\%$ & \multicolumn{2}{|c|}{ QC LIMITS } \\
\hline COMPOUND & (ng) & (ng) & REC \# & RPD \# & RED & REC. \\
\hline 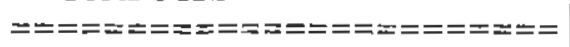 & $=====\Omega===$ & 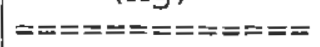 & $=====$ & $==x===$ & $======$ & $======$ \\
\hline Cyclohexane & 150 & 68 & 45 & 38 & 50 & $0-200$ \\
\hline 3-Heptanone & 150 & 240 & 125 & 17 & 50 & $0-200$ \\
\hline Tetrahydrofuran & 150 & 35 & 23 & 9 & 50 & $0-200$ \\
\hline
\end{tabular}

\# Column to be used to flag recovery and RPD values with an asterisk

* Values outside of QC limits

RPD: 5 out of 31 outside limits

Spike Recovery: 17 out of 62 outside limits

COMMENTS : 
Lab Name: PNNL

Contract: $\mathrm{C} 104$

EPA SAMPLE NO.

Lab code: PNNL

Case No. :

SAS NO. :

METHOD BLANK

Lab File ID: 00040616

Lab Sample ID: VBLK02

Date Analyzed: 04/07/0

Time Analyzed: 0037

GC Column: DB-624 75M X 2.55UMID: 0.45 (mm)

Heated Purge: $(Y / N) Y$

Instrument ID: HPI

THIS METHOD BLANK APPLIES TO THE FOIIOWING SAMPLES, MS and MSD:

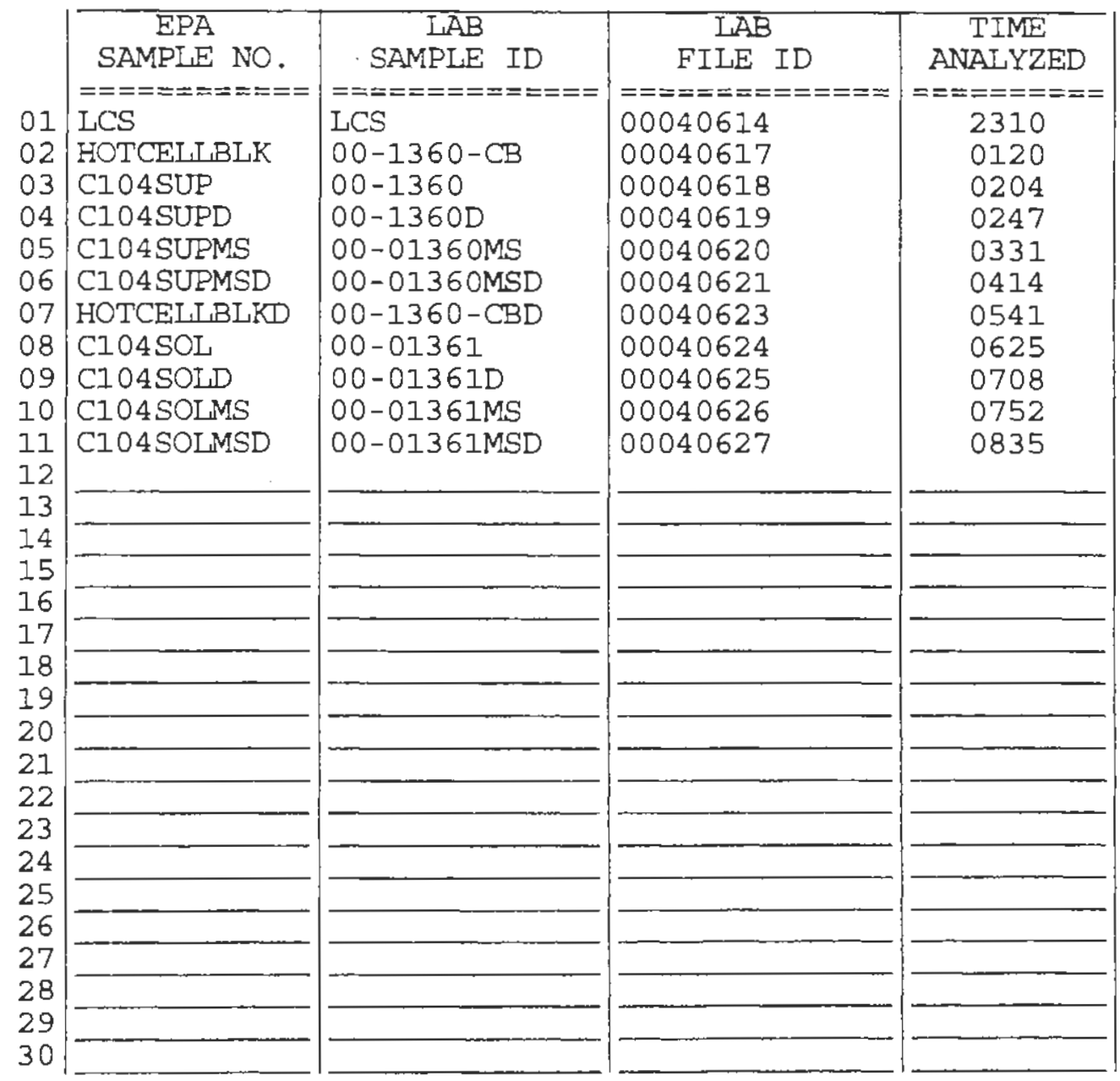

COMMENTS:

page 1 of 1 
Lab Name: PNNI Contract: $\mathrm{ClO4}$

Lab Code: PNNL

Case No.:
SAS NO.:
EPA SAMPLE NO.

\section{METHOD BLANK}

Lab File ID: 00040622

Date Analyzed: 04/07/0

GC Column: DB-62475M X 2.55UMID: 0.45 (mm)

Instrument ID: HPI
Lab Sample ID: VBLKO3

Time Analyzed: 0458

THIS METHOD BLANK APPLIES TO THE FOLLOWING SAMPLES, MS and MSD:

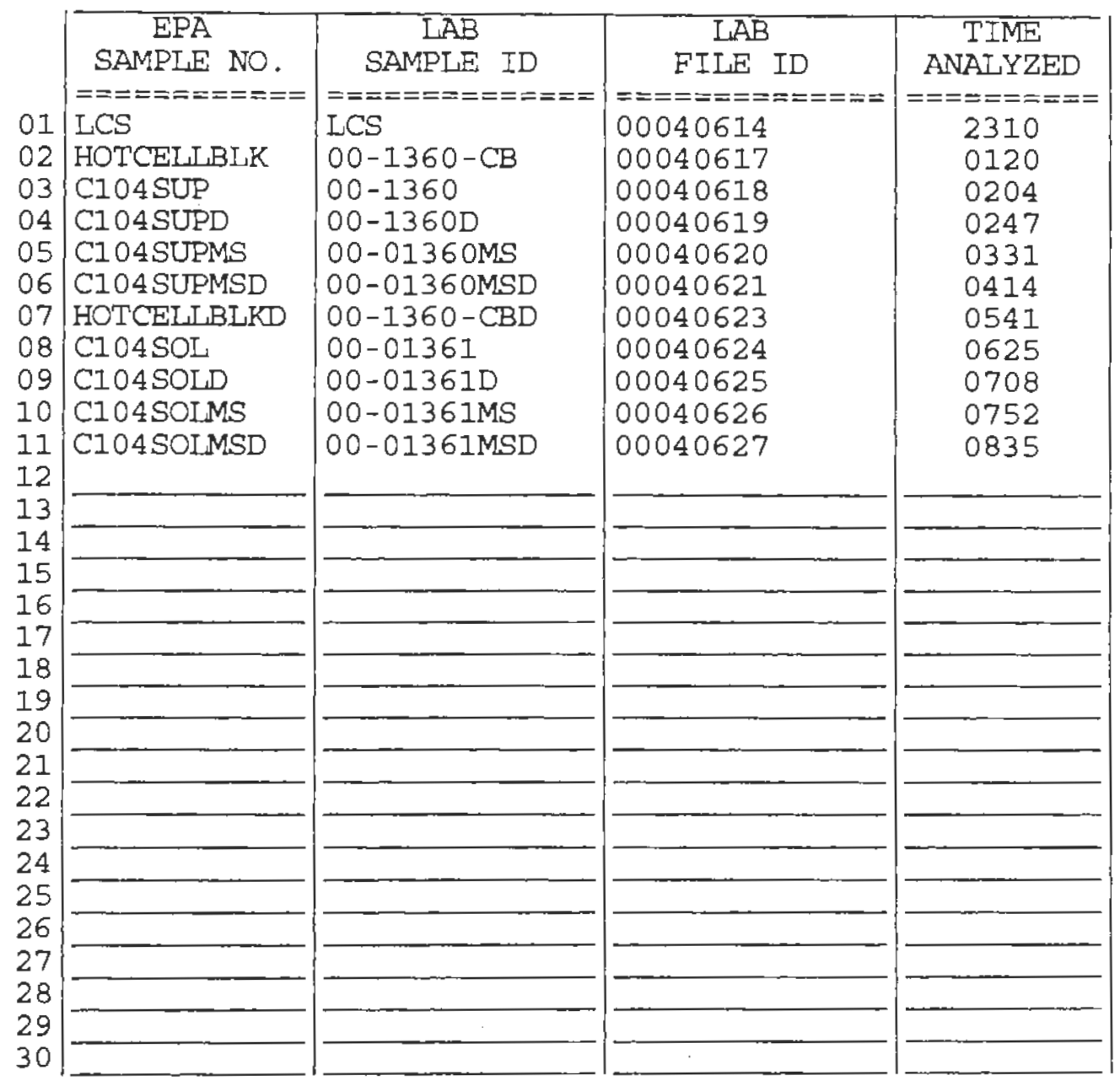

COMMENTS :

Heated Purge: $(Y / N) \quad Y$ 
VOLATILE ORGANIC INSTRUMENT PERFORMANCE CHECK BROMOFLUOROBENZENE (BFB)

Lab Name: PNNL

Lab Code: PNNL

Lab File ID: 00040601

Instrument ID: HP1

GC Columin:
Contract: C104

Case No.:

SAS NO. :

SDG NO.: 2

BFB Injection Date: 04/06/0

BFB Injection Time: 1345

Heated Purge: $(Y / N) \mathrm{N}$

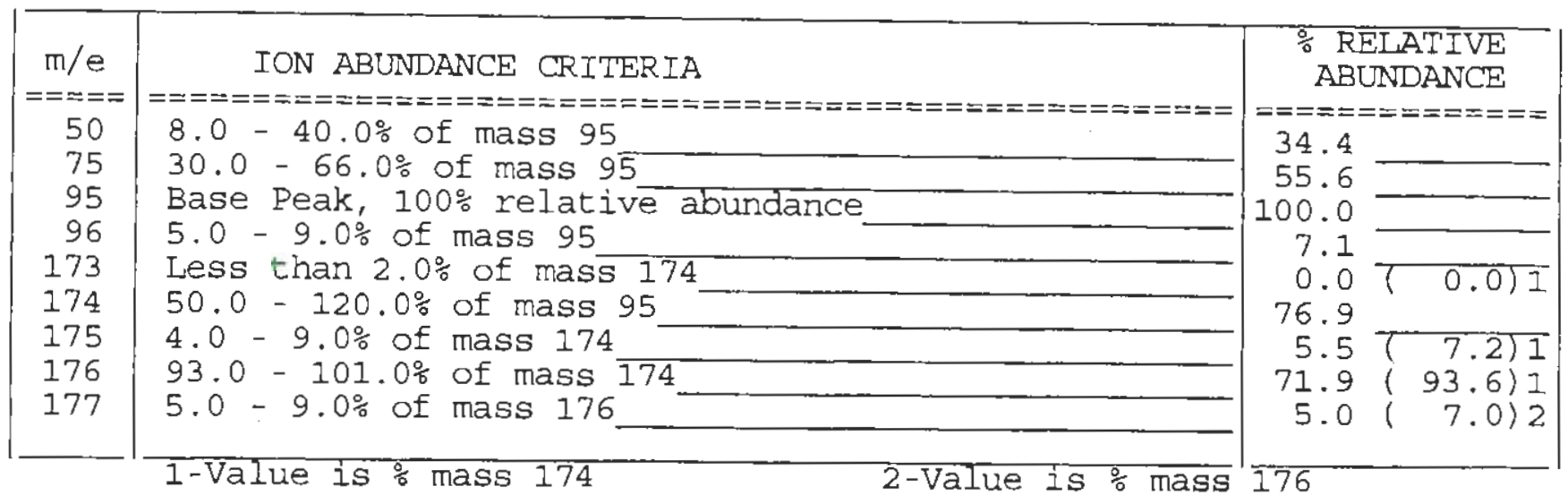

THIS CHECK APPLIES TO THE FOLLOWING SAMPLES, MS, MSD, BLANKS, AND STANDARDS:

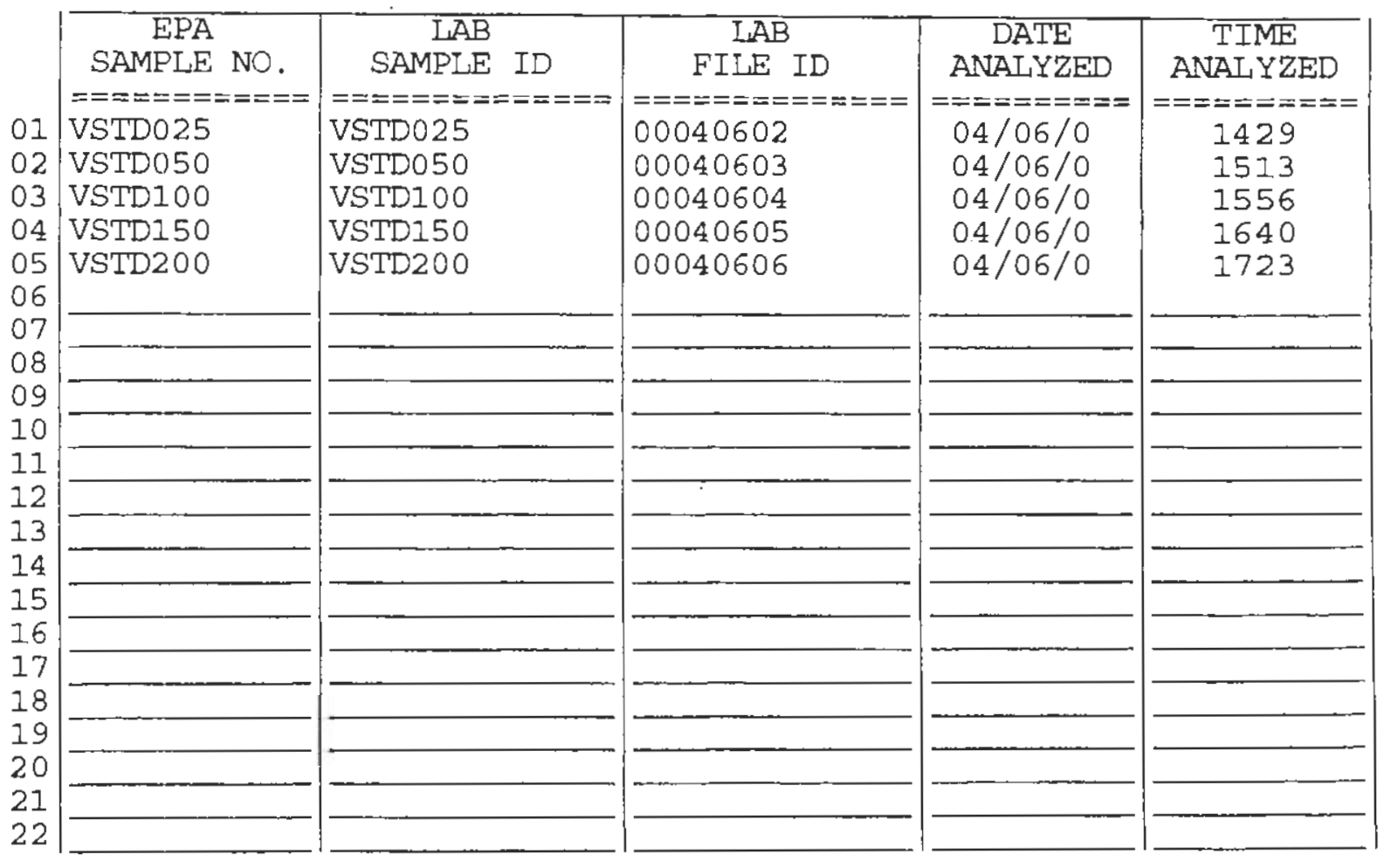

page 1 of 1 


\section{$5 \mathrm{~A}$}

VOLATILE ORGANIC INSTRUMENT PERFORMANCE CHECK

BROMOFLUOROBENZENE (BFB)

Lab Name: PNNL

Lab Code: PNNL

Lab File ID: 00040612

Instrument ID: HPI

GC Column:

Contract: $\mathrm{C} 104$

Case No.:

SAS NO. :
SDG No.: 2

BFB Injection Date: 04/06/0

BFB Injection Time: 2143

Heated Purge: ( $Y / N$ ) N

\begin{tabular}{|c|c|c|}
\hline $\begin{array}{l}\mathrm{m} / \mathrm{e} \\
====\end{array}$ & $\begin{array}{l}\text { ION ABUNDANCE CRITERIA } \\
=====\approx========0=0=0\end{array}$ & $\begin{array}{l}\% \text { REIATIVE } \\
\text { ABUNDANCE }\end{array}$ \\
\hline $\begin{array}{c}===== \\
50\end{array}$ & 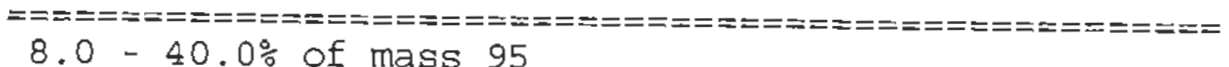 & 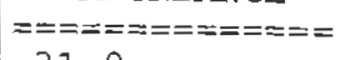 \\
\hline 75 & $30.0-66.0 \%$ of mass 95 & 31.0 \\
\hline 95 & Base Peak, $100 \%$ relative abundance & 100.0 \\
\hline 96 & $5.0-9.0 \%$ of mass 95 & 6.9 \\
\hline 173 & Less than $2.0 \%$ of mass 174 & $0.07 \overline{(0.0) 1}$ \\
\hline 174 & $50.0-120.0 \%$ of mass 95 & 82.3 \\
\hline 175 & $4.0-9.0 \%$ of mass 174 & $5.7(6.9) 1$ \\
\hline 176 & $93.0-101.0 \%$ of mass $\overline{174}$ & $80.9(98.3) 1$ \\
\hline 17 & $b .0-9.0 \%$ of mass 176 & $5.4(6.7) 2$ \\
\hline
\end{tabular}

THIS CHECK APPLIES TO THE FOLLONING SAMPLES, MS, MSD, BLANKS, AND STANDARDS:

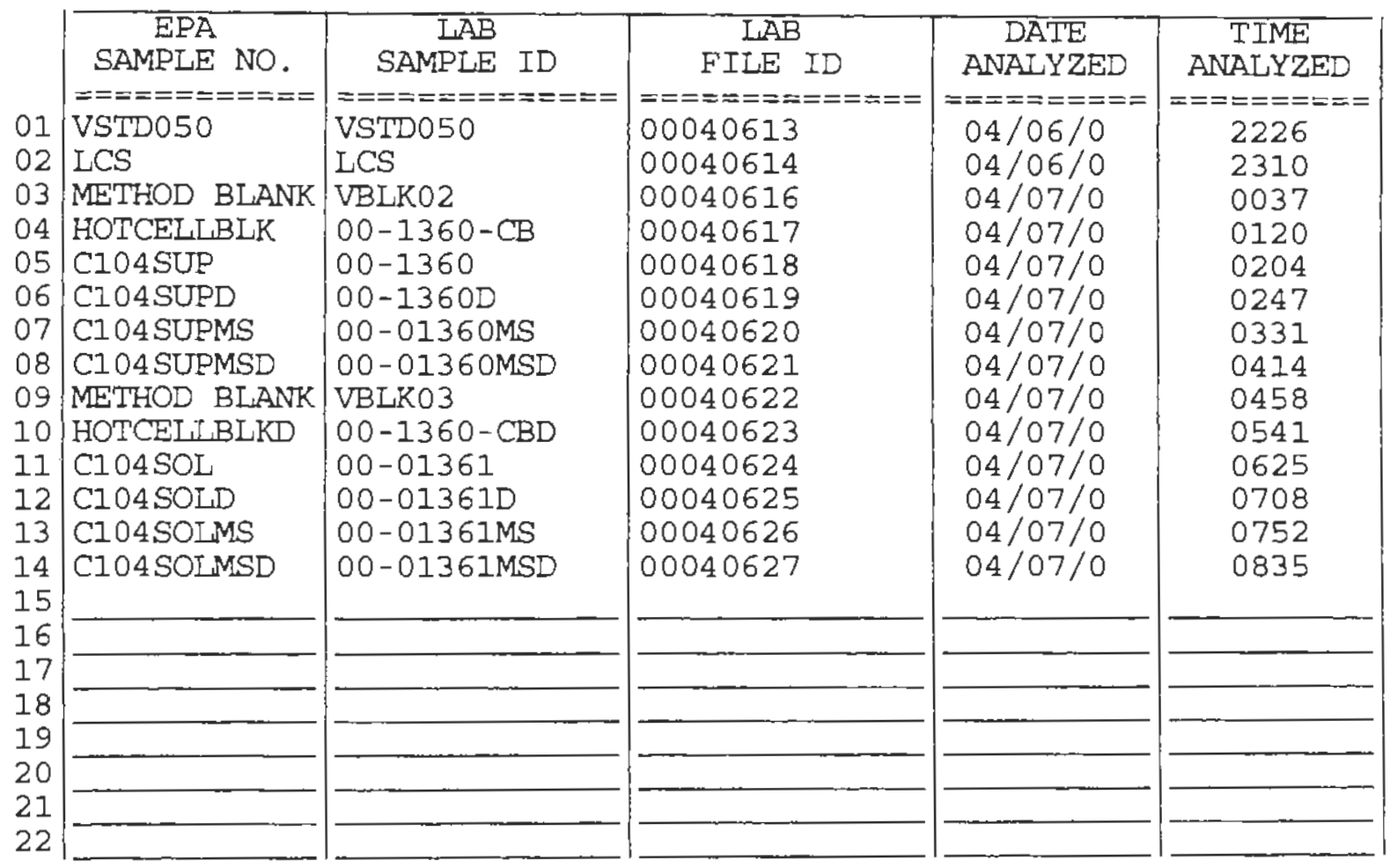

page 1 of 1 
6A
VOLATILE ORGANICS INITIAL CALIBRATION DATA

Lab Name: PNNL

Contract: $\mathrm{ClO4}$

Lab Code: PNNL Case No.

SAS NO. :

SDG No.: 2

Instrument ID: HPI

Calibration Date(s): 04/06/0 04/06/0

Heated Purge: ( $Y / N)$ Y Calibration Time(s) : 1429

1723

GC Column: DB-624 75M X 2.55UM ID: 0.45 (mm)

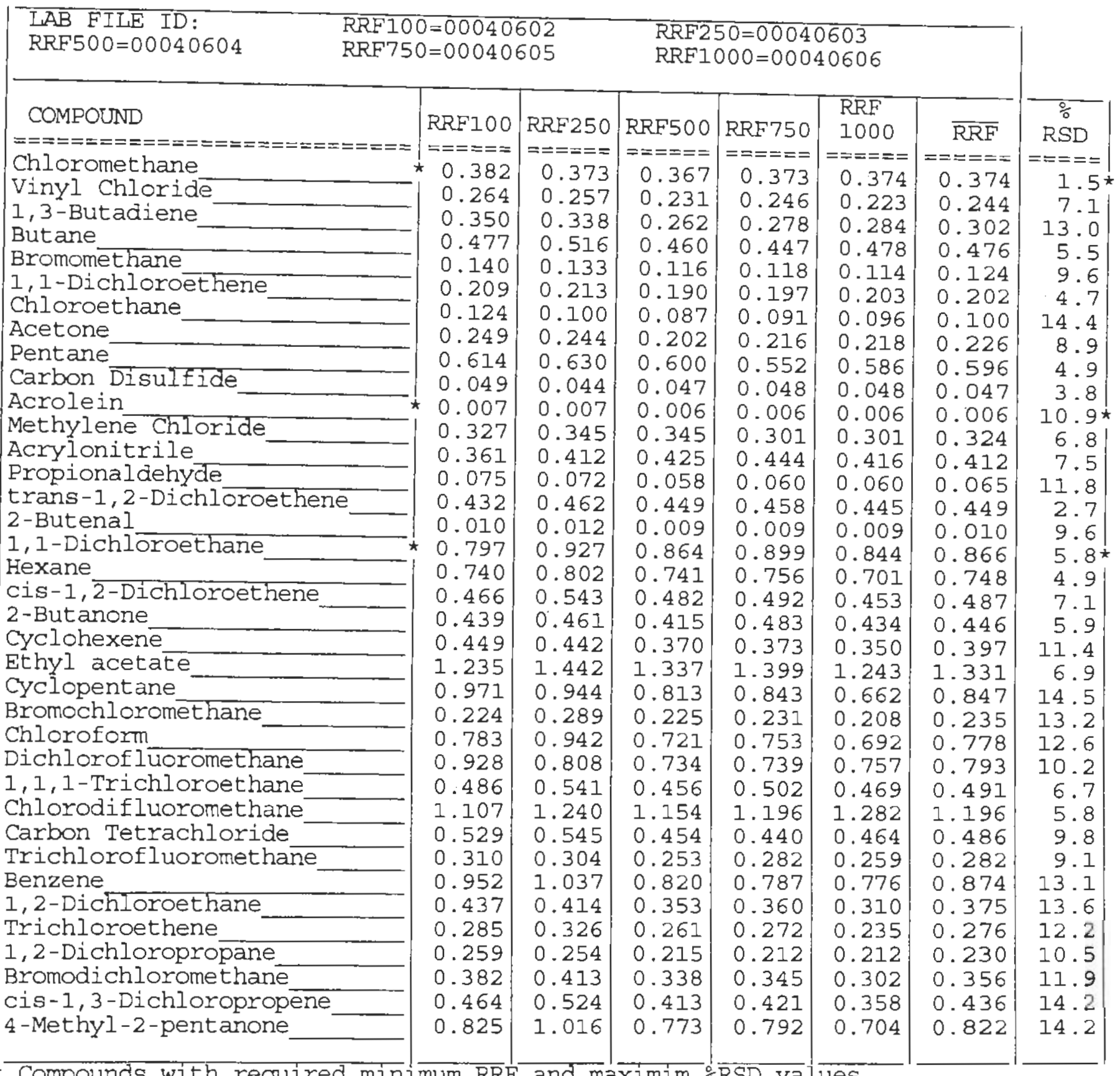

Compounds with required minimum RRF and maximim oRSD values

All other compounds must meet a minimim RRF of 0.010 .

page 1 of 3 
6A

VOLATILE ORGANICS INITIAL CALIBRATION DATA

Lab Name: PNNL

Contract : C104

Lab Code: PNNL

Case No.:

SAS NO. :

SDG No.: 2

Instrument ID: $\mathrm{HPI}$

Calibration Date(s) : 04/06/0

$04 / 06 / 0$

Heated Purge: ( $\mathrm{Y} / \mathrm{N}\rangle$

Calibration Time(s) : 1429

1723

GC Column: DB-624 75M X 2.55UM ID: 0.45 (mm)

\begin{tabular}{|c|c|c|c|c|c|c|c|}
\hline $\begin{array}{l}\text { IAB FILE ID: } \\
\text { RRF500=00040604 }\end{array}$ & $=000406$ & $\begin{array}{l}502 \\
505\end{array}$ & $\begin{array}{l}\text { RRF2 } \\
\text { RRF1 }\end{array}$ & $\begin{array}{l}50=0004 \\
500=000\end{array}$ & 0603 & & \\
\hline COMPOUND & RRF100 & IRRF250 & RRF500 & RRF750 & $\begin{array}{l}\text { RRF } \\
1000\end{array}$ & $\overline{\mathrm{PRF}}$ & RSD \\
\hline 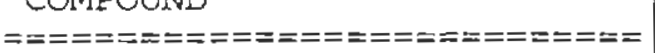 & $\approx=====$ & $=====$ & $==ニ===$ & $===\approx==$ & $=\approx=\approx==$ & $=====$ & $=====$ \\
\hline Toluene & 0.703 & 0.828 & 0.685 & 0.680 & 0.636 & 0.706 & 10.2 \\
\hline trans-1, 3 -Dichloropropene & 0.377 & 0.410 & 0.351 & 0.352 & 0.306 & & 10.7 \\
\hline 1,1,2-Trichloroethane & 0.243 & 0.304 & 0.249 & 0.260 & 0.235 & 0.258 & 10.4 \\
\hline Tetrachloroethene & 0.260 & 0.254 & 0.226 & 0.212 & 0.196 & 0.230 & 11.9 \\
\hline 2-Hexanone & 0.594 & 0.736 & 0.591 & 0.611 & 0.545 & 0.615 & 11.6 \\
\hline Dibromochloromethane & 0.285 & 0.388 & 0.311 & 0.332 & 0.300 & 323 & 12.5 \\
\hline Chlorobenzene & 0.747 & 0.784 & 0.699 & 0.675 & 0.577 & 0.696 & 11.4 * \\
\hline Ethylbenzene & 0.394 & 0.386 & 0.354 & 0.335 & 0.284 & 0.351 & 12.6 \\
\hline Xylene $(m \& \bar{p})$ & 0.787 & 0.764 & 0.628 & 0.637 & 0.559 & 0.675 & 14.3 \\
\hline Xylene $(0)$ & 0.476 & 0.443 & 0.373 & 0.371 & 0.339 & 0.400 & 14.1 \\
\hline styrene & 0.762 & 0.724 & 0.666 & 0.644 & 0.601 & 0.679 & 9.5 \\
\hline Bromoform & 0.202 & 0.277 & 0.237 & 0.255 & 0.231 & 0.240 & $11.5^{\star}$ \\
\hline $1,1,2,2$-Tetrachloroethane & 0.396 & 0.393 & 0.333 & 0.326 & 0.317 & 0.353 & $10.8 \star$ \\
\hline 1,3-Dichlorobenzene & 0.699 & 0.632 & 0.562 & 0.524 & 0.487 & 0.581 & 14.61 \\
\hline 1,4-Dichlorobenzene & 0.684 & 0.674 & 0.607 & 0.670 & 0.545 & 0.636 & 9.3 \\
\hline 1,2-Dichlorobenzene & 0.713 & 0.697 & 0.598 & 0.619 & 0.576 & 0.641 & 9.5 \\
\hline Heptane & 0.210 & 0.206 & 0.169 & 0.165 & 0.155 & 0.181 & 13.9 \\
\hline Octane & 0.128 & 0.136 & 0.112 & 0.104 & 0.099 & 0.116 & 13.7 \\
\hline Nonane & 0.095 & 0.089 & 0.073 & 0.075 & 0.066 & 0.080 & 14.8 \\
\hline 3-Chloropropene & 0.489 & 0.459 & 0.426 & 0.438 & 0.448 & 0.452 & 5.3 \\
\hline 2-Pentanone & 0.097 & 0.114 & 0.090 & 0.093 & 0.079 & 0.0 & 13.3 \\
\hline Methylcyclohexane & 0.741 & 0.760 & 0.602 & 0.619 & 0.588 & 0.662 & 12.4 \\
\hline 5-Methyl-2-hexanone & 0.523 & 0.561 & 0.540 & 0.520 & 0.523 & 0.533 & 3.3 \\
\hline 4-Heptanone & 0.976 & 1.146 & 0.906 & 0.888 & 0.768 & 0.937 & 14,8 \\
\hline Butylacetate & 1.213 & 1.324 & 1.113 & 1.039 & 0.948 & 1.127 & 13.0 \\
\hline 1,4-Dioxane & 0.031 & 0.028 & 0.027 & 0.026 & 0.024 & 0.027 & $8.9 \times$ \\
\hline 2-Methyl-2-propenenitrile & 0.425 & 0.469 & 0.381 & 0.386 & 0.333 & 0.399 & 12.8 \\
\hline 3-Methyl-2-butanone & 0.125 & 0.144 & 0.115 & 0.118 & 0.100 & 0.120 & 13.5 \\
\hline Propyl nitrate & 0.572 & 0.695 & 0.562 & 0.551 & 0.485 & 0.573 & 13.3 \\
\hline 3 -Pentanone & 0.482 & 0.528 & 0.443 & 0.448 & 0.414 & 0.463 & 9.4 \\
\hline $1,2,2-C 13-1, \overline{1,2-F 3 e t h a n e}$ & 0.382 & 0.358 & 0.355 & 0.336 & 0.339 & 0.354 & 5.1 \\
\hline $1,2-\mathrm{Cl} 2-1,1,2,2-F 4$ ethane & 0.447 & 0.406 & 0.395 & 0.407 & 0.381 & 0.4 & 6.1 \\
\hline Dichlorodifluoromethane_. & 0.995 & 1.057 & 0.916 & 1.019 & 0.817 & 0.961 & 9.9 \\
\hline Acetonitrile & 0.090 & 0.085 & 0.080 & 0.077 & 0.091 & 0.085 & 7.2 \\
\hline Cyclohexane & 1.214 & 1.278 & 1.038 & 1.019 & 0.930 & 1.096 & 13.2 \\
\hline Bromobenzene & 0.393 & 0.390 & 0.333 & 0.336 & 0.302 & 0.351 & 11.2 \\
\hline Butylbenzene- & 0.328 & 0.351 & 0.306 & 0.321 & 0.293 & 0.320 & 6.9 \\
\hline
\end{tabular}

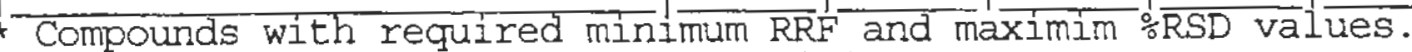

A1] other compounds must meet a minimim RRF of 0.010 .

page 2 of 3

FORM VI VOA

OLMO3.0 
$6 \mathrm{~A}$

VOLATILE ORGANICS INITIAL CALIBRATION DATA

Lab Name: PNNL

Contract : $\mathrm{C} 104$

Lab Code: PNNL

Case No.:

SAS NO. :

SDG NO. : 2

Instrument ID: HPI

Calibration Date(s): 04/06/0

$04 / 06 / 0$

Heated Furge: $(Y / N)$ Y Calibration Time $(s): 1429$

1723

GC Column: DB-624 75M X 2.55UM ID: 0.45 (mm)

\begin{tabular}{|c|c|c|c|c|c|c|c|}
\hline $\begin{array}{l}\text { LAB FILE ID } \\
\text { RRF } 500=00040604\end{array}$ & $\begin{array}{l}0=00040 \\
0=00040\end{array}$ & & $\begin{array}{l}\text { RRF2 } \\
\text { RRF1 }\end{array}$ & $\begin{array}{l}50=0004 \\
000=000\end{array}$ & $\begin{array}{l}0603 \\
40606\end{array}$ & & \\
\hline COMPOUND & RRF100 & RRF250 & RRF500 & RRF750 & $\begin{array}{l}\text { RRF } \\
1000\end{array}$ & $R R F$ & RSD \\
\hline 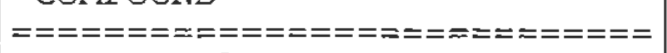 & $=====$ & $======$ & $======$ & $==\Xi==2$ & $=====$ & $======$ & $====$ \\
\hline tert-Butylbenzene & 1.123 & 1.063 & 0.876 & 0.888 & 0.787 & 0.947 & 14.8 \\
\hline sec-Butyibenzene_- & 1.419 & 1.389 & 1.199 & 1.255 & 1.153 & 1.283 & 9.1 \\
\hline 2-Chlorotoluene & 1.026 & 1.056 & 0.892 & 0.882 & 0.832 & 0.938 & 10.4 \\
\hline 4-Isopropyl toluene & 1.032 & 1.008 & 0.863 & 0.947 & 0.842 & 0.938 & 9.0 \\
\hline 4-Chlorotoluene & 1.207 & 1.166 & 1.015 & 0.925 & 0.989 & 1.060 & 11.4 \\
\hline 1,2-Dibromo-3-chloropropane & 0.109 & 0.126 & 0.106 & 0.116 & 0.105 & 0.112 & 7.8 \\
\hline 1,2-Dibromoethane & 0.262 & 0.353 & 0.285 & 0.298 & 0.266 & 0.293 & 12.5 \\
\hline trans-1,4-Dichloro-2-butene & 0.024 & 0.023 & 0.020 & 0.020 & 0.022 & 0.022 & 7.9 \\
\hline 1,3-Dichloropropane & 0.525 & 0.546 & 0.444 & 0.408 & 0.414 & 0.467 & 13.7 \\
\hline 2,2-Dichloropropane & 0.344 & 0.389 & 0.320 & 0.321 & 0.292 & 0.333 & 10.9 \\
\hline 1,1-Dichloropropene & 0.597 & 0.689 & 0.532 & 0.540 & 0.474 & 0.566 & 14.4 \\
\hline Hexachloro-1,3-butadiene & 0.338 & 0.342 & 0.289 & 0.281 & 0.276 & 0.305 & 10.6 \\
\hline Isopropylbenzene & 1.192 & 1.178 & 1.047 & 0.998 & 0.962 & 1.075 & 9.7 \\
\hline Nathphalene & 1.126 & 1.108 & 0.952 & 1.008 & 0.964 & 1.032 & 7.9 \\
\hline Propylbenzene & 1.578 & 1.502 & 1.288 & 1.226 & 1.182 & 1.355 & 12.9 \\
\hline 1,2,3-Trichlorobenzene & 0.475 & 0.492 & 0.407 & 0.435 & 0.398 & 0.441 & 9.4 \\
\hline $1,2,4$-Trichlorobenzene & 0.531 & 0.512 & 0.448 & 0.463 & 0.419 & 0.475 & 9.7 \\
\hline $1,2,3$-Trichloropropane & 0.452 & 0.412 & 0.368 & 0.354 & 0.328 & 0.383 & 12.8 \\
\hline $1,2,4$-Trimethylbenzene & 1.309 & 1.156 & 0.964 & 1.054 & 0.958 & 1.088 & 13.5 \\
\hline $1,2,3$-Trimethylbenzene & 1.539 & 1.422 & 1.150 & 1.215 & 1.122 & 1.290 & 14.1 \\
\hline 3-Heptanone & 0.713 & 0.761 & 0.646 & 0.632 & 0.595 & 0.669 & 10.0 \\
\hline 2-Heptanone & 0.890 & 1.048 & 0.841 & 0.836 & 0.727 & 0.868 & 13.5 \\
\hline Tetrahydrofuran & 1.330 & 1.388 & 1.238 & 1.227 & 1.263 & 1.289 & 5.3 \\
\hline Dibromomethane & 0.183 & 0.205 & 0.163 & 0.167 & 0.148 & 0.173 & 12.5 \\
\hline 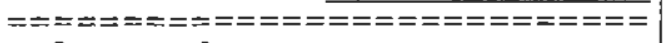 & $======$ & $======$ & $======$ & $=====$ & $======$ & $======$ & 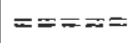 \\
\hline Toluene-d8 & 1.047 & 1.150 & 1.062 & 1.080 & 1.105 & 1.089 & 3.7 \\
\hline Bromofluorobenzene & 0.533 & 0.529 & 0.533 & 0.537 & 0.556 & 0.538 & 2.0 \\
\hline Dibromof Iuoromethane & 0.501 & 0.493 & 0.490 & 0.492 & 0.507 & 0.497 & 1.4 \\
\hline 1,2 -Dichloroethane-d & 0.707 & 0.675 & 0.684 & 0.689 & 0.697 & 0.690 & 1.8 \\
\hline & & & & & & & \\
\hline & & & & & & & \\
\hline & & & & & & & \\
\hline & & & & & & & \\
\hline & & & & & & & \\
\hline & & & & & & & \\
\hline & & & & & & & \\
\hline
\end{tabular}

Compounds with required minimum RRF and maximim $\% \overline{R S D}$ values.

All other compounds must meet a minimim RRF of 0.010 .

page 3 of 3 
$7 \mathrm{~A}$

VOLATILE CONTINUING CAIIBRATION CHECK

Lab Name: PNNL

Lab Code: PNNL

Instrument ID: HPI

Lab File ID: 00040613

Heated Purge: $(\mathrm{Y} / \mathrm{N}) \mathrm{Y}$
Contract: $\mathrm{ClO} 04$

SAS NO.:
Case No.:
SDG No.: 29274

GC Column: DB-624 75M X 2.55UM ID: 0.45 (mm)

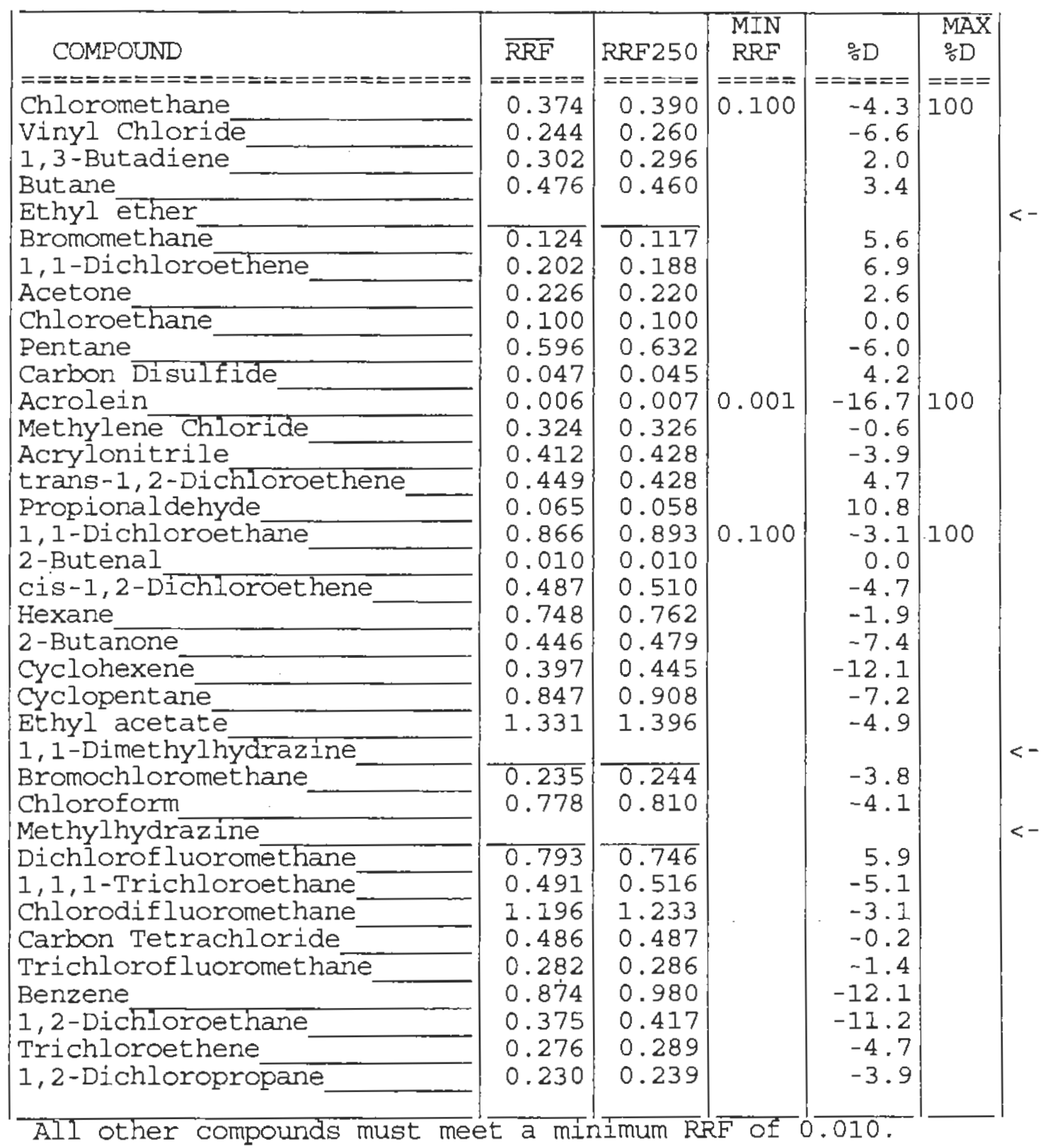

Calibration Date: 04/06/0 Time: 2226

Init. Calib. Date (s) : 04/06/0 04/06/0

Init. Calib. Times: $1429 \quad 1723$ 
$7 \mathrm{~A}$

VOLATILE CONTINUING CALIBRATION CHECK

Lab Name: PNNL

Lab Code: PNNL

Instrument ID: HPI

Lab File ID: 00040613

Heated Purge: $(Y / N) Y$

GC Column:
Contract: $\mathrm{C} 104$

SAS NO. :

SDG No.: 29274

Calibration Date: 04/06/0 Time: 2226

Init. Calib. Date(s): 04/06/0 04/06/0

Init. Calib. Times: $1429 \quad 1723$

$(\mathrm{mm})$

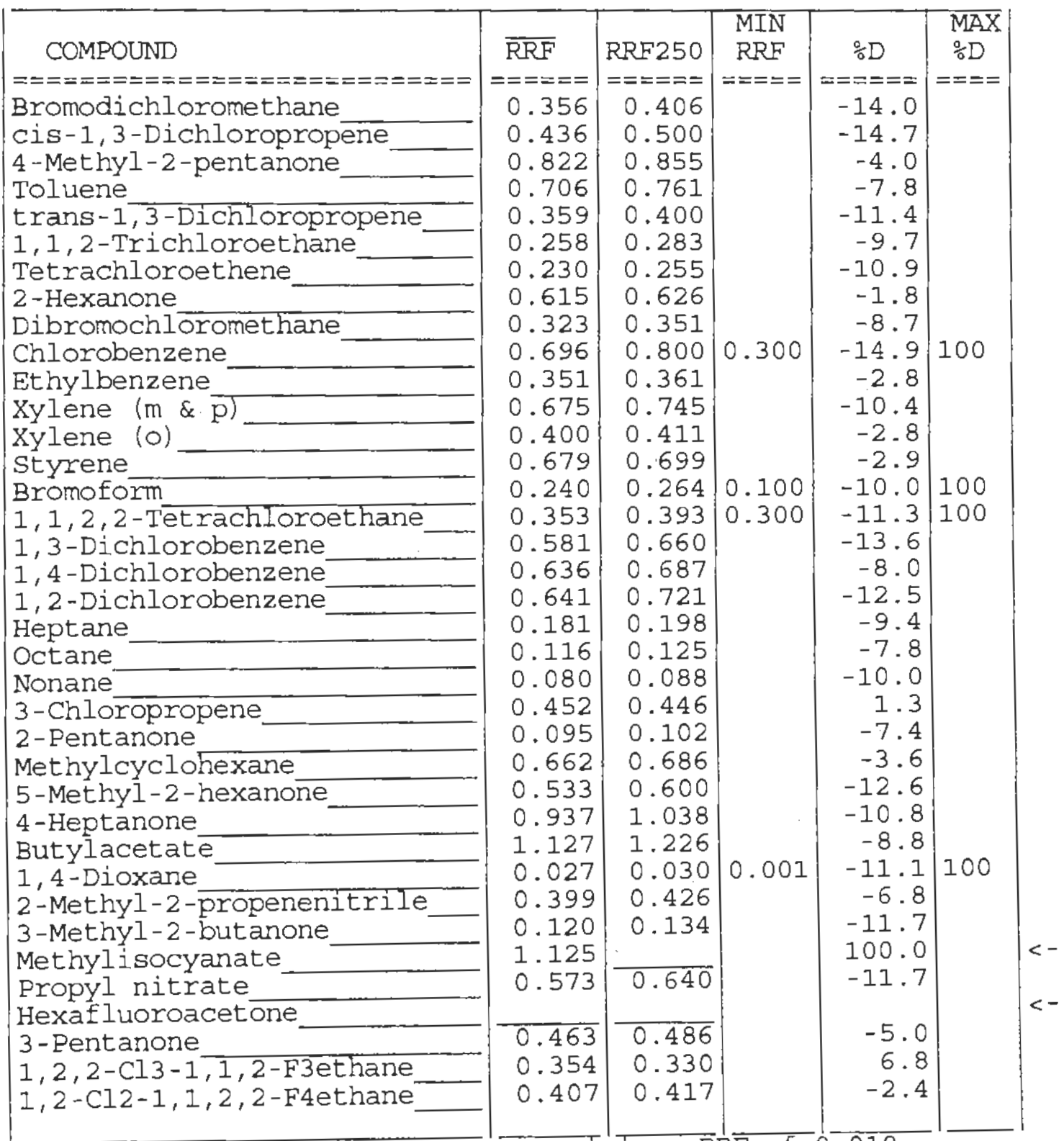

All other compounds must meet a minimum RRF of 0.010 . 
$7 A$

VOLATILE CONTINUING CALIBRATION CHECK

Lab Name: PNNL

Lab Code: PNNL

Instrument ID: HPI

Lab File ID: 00040613

Heated Purge: $(Y / N) Y$

GC Column: DB-624 75M X 2.55UM ID: 0.45 (mm)
Contract: $\mathrm{C} 104$

SAS NO. :

SDG No.: 29274

Calibration Date: 04/06/0 Time: 2226

Init. Calib. Date(s) = 04/06/0 04/06/0

Init. Calib. Times: $1429 \quad 1723$

\begin{tabular}{|c|c|c|c|c|c|}
\hline COMPOUND & $\overline{\mathrm{R} R F}$ & RRF250 & $\begin{array}{l}\text { MIN } \\
\text { RRF }\end{array}$ & $\% \mathrm{D}$ & $\begin{array}{l}\text { MAXX } \\
\because D\end{array}$ \\
\hline 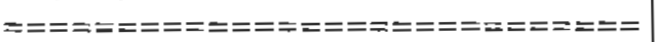 & $=== \pm==$ & $===\approx==$ & $=====$ & $======$ & $=== \pm$ \\
\hline Dichlorodifluoromethane & 0.961 & 0.969 & & -0.8 & \\
\hline Acetonitrile & 0.085 & 0.082 & & 3.5 & \\
\hline Cyclohexane & 1.096 & 1.205 & & -9.9 & \\
\hline Bromobenzene & 0.351 & 0.389 & & -10.8 & \\
\hline Butylbenzene & 0.320 & 0.367 & & -14.7 & \\
\hline tert-Butylbenzene & 0.947 & 1.019 & & -7.6 & \\
\hline sec-Butylbenzene & 1.283 & 1.385 & & -8.0 & \\
\hline 2-Chlorotoluene & 0.938 & 1.000 & & -6.6 & \\
\hline 4-Isopropyltoluene & 0.938 & 1.067 & & -13.8 & \\
\hline 4-Chlorotoluene & 1.060 & 1.066 & & -0.6 & \\
\hline 1,2-Dibromo-3-chloropropane_ & 0.112 & 0.123 & & -9.8 & \\
\hline 1,2-Dibromoethane & 0.293 & 0.316 & & -7.8 & \\
\hline trans-1,4-Dichloro-2-butene & 0.022 & 0.023 & & -4.5 & \\
\hline 1,3-Dichloropropane & 0.467 & 0.535 & & -14.6 & \\
\hline 2,2-Dichloropropane & 0.333 & 0.347 & & -4.2 & \\
\hline 1,1-Dichloropropene & 0.566 & 0.607 & & -7.2 & \\
\hline Hexachloro-1,3-butadiene. & 0.305 & 0.325 & & -6.6 & \\
\hline Iodomethane & & & & & \\
\hline Isopropylbenzene & 1.075 & 1.133 & & -5.4 & \\
\hline Nathphalene & 1.032 & 1.128 & & -9.3 & \\
\hline Propylbenzeñe & 1.355 & 1.508 & & -11.3 & \\
\hline 1,2,3-Trichlorobenzene, & 0.441 & 0.478 & & -8.4 & \\
\hline 1,2,4-Trichlorobenzene & 0.475 & 0.507 & & -6.7 & \\
\hline 1,2,3-Trichloropropane & 0.383 & 0.389 & & -1.6 & \\
\hline $1,2,4$-Trimethylbenzene & 1.088 & $1+214$ & & -11.6 & \\
\hline $1,2,3$-Trimethylbenzene & 1.290 & 1.457 & & -12.9 & \\
\hline Butanol & & & & & \\
\hline 2-Propañol & & & & & \\
\hline 1-Propanol & 0.025 & & & 100.0 & \\
\hline 2-Methyl-2-propanol & & & & & \\
\hline 2-Butanol & & & & & \\
\hline 3-Heptanone & 0.669 & 0.666 & & 0.4 & \\
\hline 2-Heptanone & 0.868 & 0.944 & & -8.8 & \\
\hline Tetrahydrofuran & 1.289 & 1.453 & & -12.7 & \\
\hline Dibromomethane & 0.173 & 0.191 & & -10.4 & \\
\hline 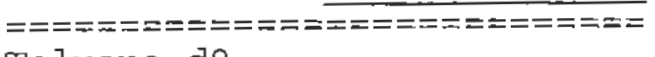 & $======$ & $== \pm==$ & $==== \pm$ & $=====$ & $\approx===$ \\
\hline Toluene-d8 & 1.089 & 1.061 & & 2.6 & \\
\hline
\end{tabular}

Al1 other compounds must meet a minimum $R R \bar{F}$ of 0.010 .

page 3 of 4 
$7 A$

VOLATILE CONTINUING CALIBRATION CHECK

Lab Name: PNNL

Contract: $\mathrm{Cl04}$

Lab code: PNNL

Case No.:

SAS NO. :

SDG No.: 29274

Instrument ID: HPI

Calibration Date: 04/06/0

Time: 2226

Lab File ID: 00040613

Init. Calib. Date(s): 04/06/0

$04 / 06 / 0$

Heated Purge: $(\mathrm{Y} / \mathrm{N}) \mathrm{Y}$

Init. Calib. Times: 1429

1723

GC Column: DB-62475M X 2.55UM ID: 0.45 (mm)

\begin{tabular}{|c|c|c|c|c|c|}
\hline $\begin{array}{l}\text { COMPOUND } \\
========================= \\
\text { Bromofluorobenzene. } \\
\text { Dibromofluoromethane } \\
\text { 1, } 2 \text {-Dichloroethane-d } \overline{4}\end{array}$ & $\begin{aligned} \mathrm{RRF} \\
====== \\
0.538 \\
0.497 \\
0.690\end{aligned}$ & $\begin{array}{r}\text { RRF2 } 20 \\
===== \\
0.534 \\
0.486 \\
0.727\end{array}$ & $\begin{array}{c}\text { MIN } \\
\text { RRF } \\
=====\end{array}$ & 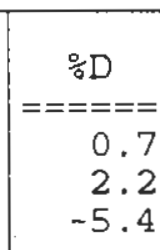 & $\begin{array}{l}\text { MAX } \\
\frac{\mathrm{a}}{6 \mathrm{D}} \\
====\end{array}$ \\
\hline
\end{tabular}

All other compounds must meet a minimum RRF of 0.010 . 
$8 \mathrm{~A}$

VOLATILE INTERNAL STANDARD AREA AND RT SUMMARY

Lab Name: PNNL

Lab code: PNNL

Lab File ID (Standard): 00040613

Instrument ID: HP1

GC Column: DB-624 75M X 2.55UM ID: 0.45 (mm)
Contract: C104

SAS NO.:
SDG No. : 2

Date Analyzed: 04/06/0

Time Analyzed: 2226

Heated Purge: $(Y / N)$ Y

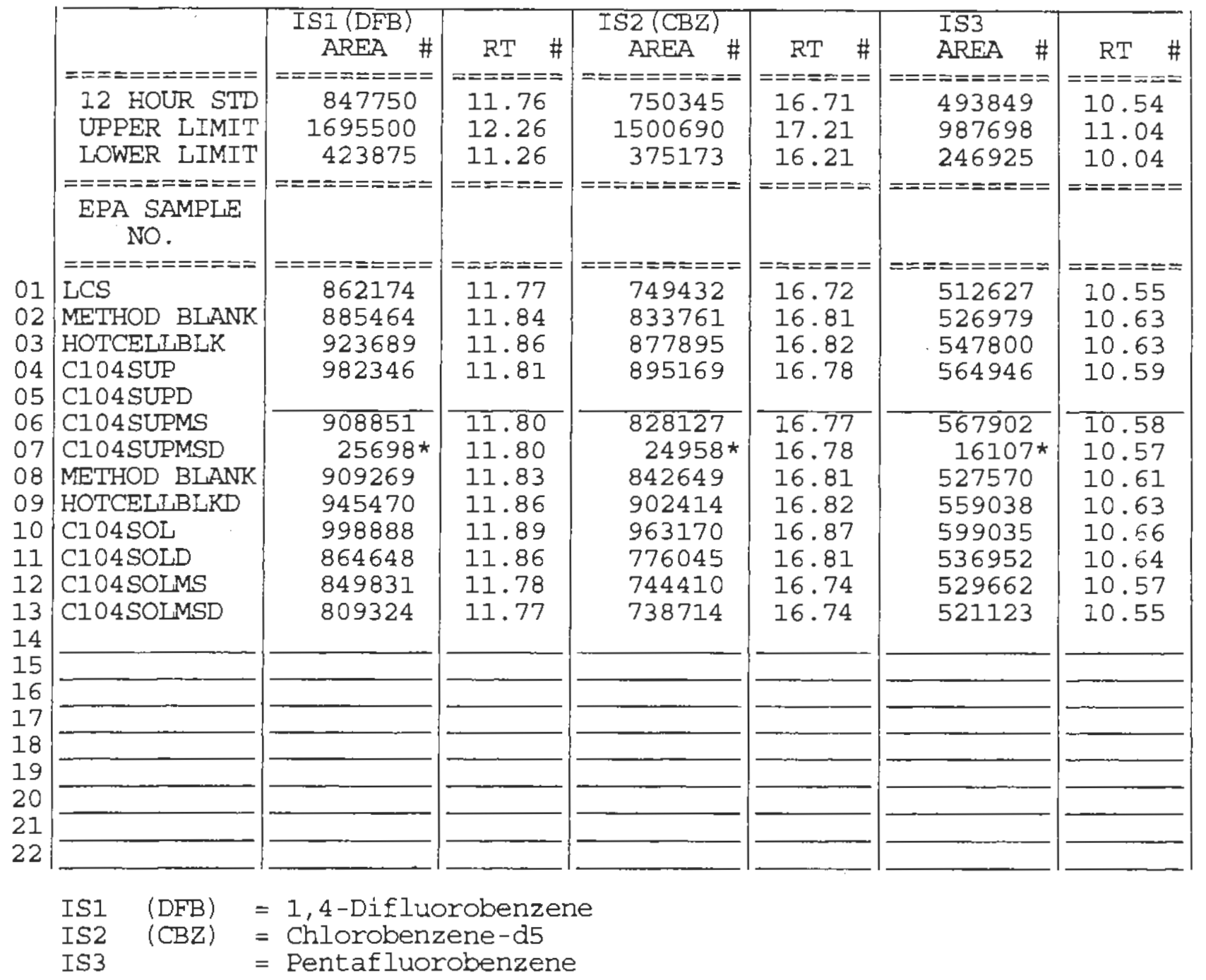

AREA UPPER LIMIT $=+100 \%$ of internal standard area

AREA LOWER LIMIT $=-50 \%$ of internal standard area

RT UPPER LIMIT $=+0.50$ minutes of internal standard RT

RT LOWER LIMIT $=-0.50$ minutes of internal standard RT

\# Column used to flag values outside QC limits with an asterisk.

* Values outside of QC limits.

page 1 of 2 
Lab Name: PNNL,

Lab Code: PNNL

Case No.:

Lab File ID (Standard): 00040613

Instrument ID: HP1

GC Column: DB-624 75M X 2.55UM ID: 0.45 (mm)
Contract : $\mathrm{C} 104$

SAS NO.:

SDG NO. : 2

Date Analyzed: 04/06/0

Time Analyzed: 2226

Heated Purge: $(Y / N) Y$

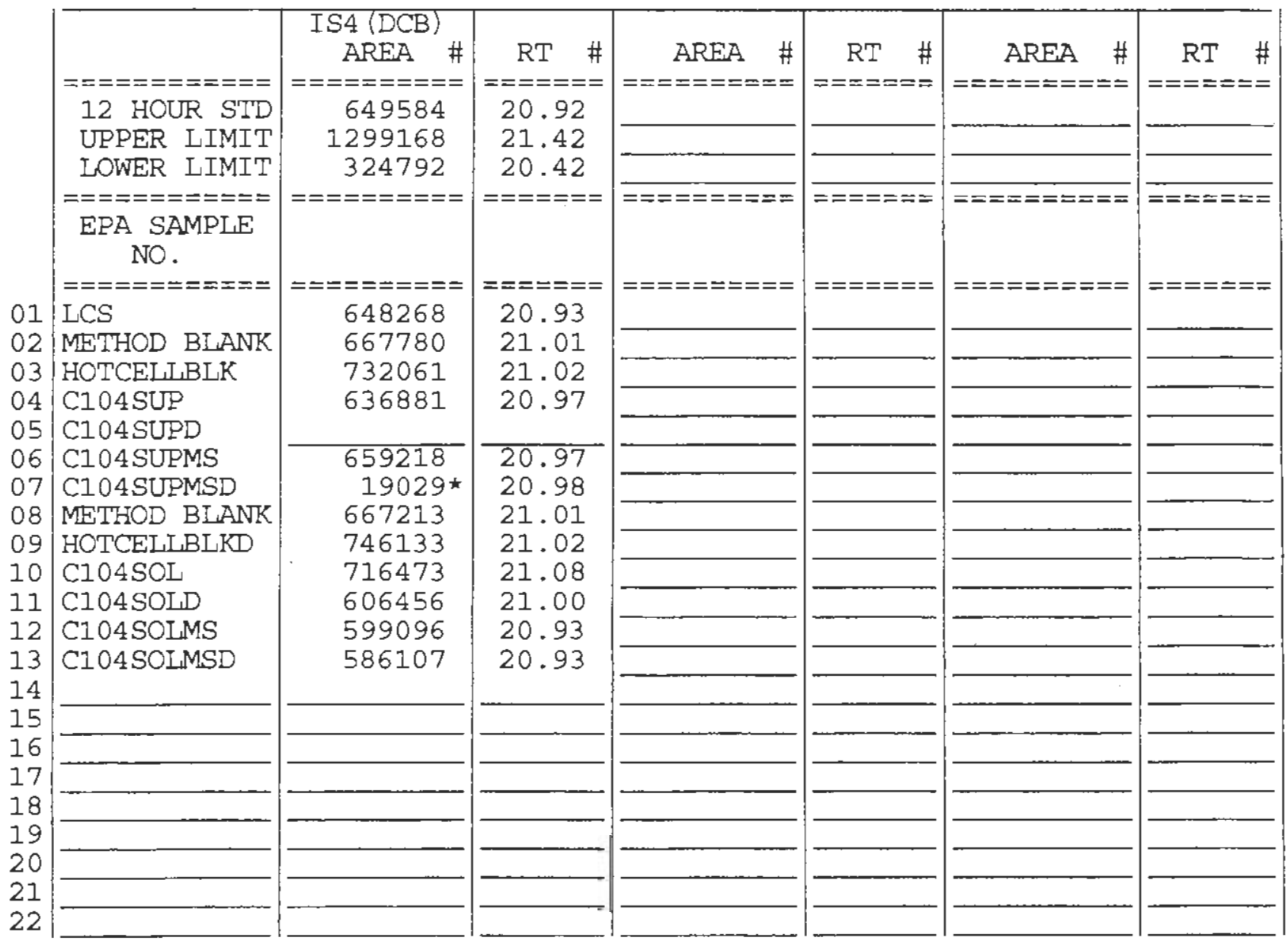

IS4 $(\mathrm{DCB})=1,4-\mathrm{Dich}$ lorobenzene- $\mathrm{d} 4$

AREA UPPER LIMIT $=+100 \%$ of internal standard area AREA LOWER LIMIT $=-50 \%$ of internal standard area RT UPPER LIMIT $=+0.50$ minutes of internal standard RT RT LOWER LIMIT $=-0.50$ minutes of internal standard RT

\# Column used to flag values outside QC limits with an asterisk.

* Values outside of QC limits. 
Appendix E: Semi-Volatile Organic Analysis Result Forms

E.1 
Lab Name: PNNL

Lab Code: PNNL
Contract: $\mathrm{ClO}$

Case No.:
SAS NO.:

SDG No.: 000819
Matrix: (soil/water) SUPERNATAN

Sample wt/vol:

$(g / m L) \quad M L$

Level : (low/med) LOW

$\%$ Moisture:

decanted: $(Y / N)$

Concentrated Extract Volume: 1000 (uL)

Injection Volume:

(UL)
$\mathrm{C} 104-\mathrm{SLB}$

Lab Sample ID: 00-1360-SLB

Lab File ID: 00081904

Date Received:

Date Extracted:

Date Analyzed: 08/19/0

Dilution Factor: 1.0

GPC Cleanup: (Y/N) N $\mathrm{NH}$ :

CAS NO.

COMPOUND

CONCENTRATION UNITS: $(\mathrm{ug} / \mathrm{L}$ or $\mathrm{ug} / \mathrm{Kg}$ ) UG/L

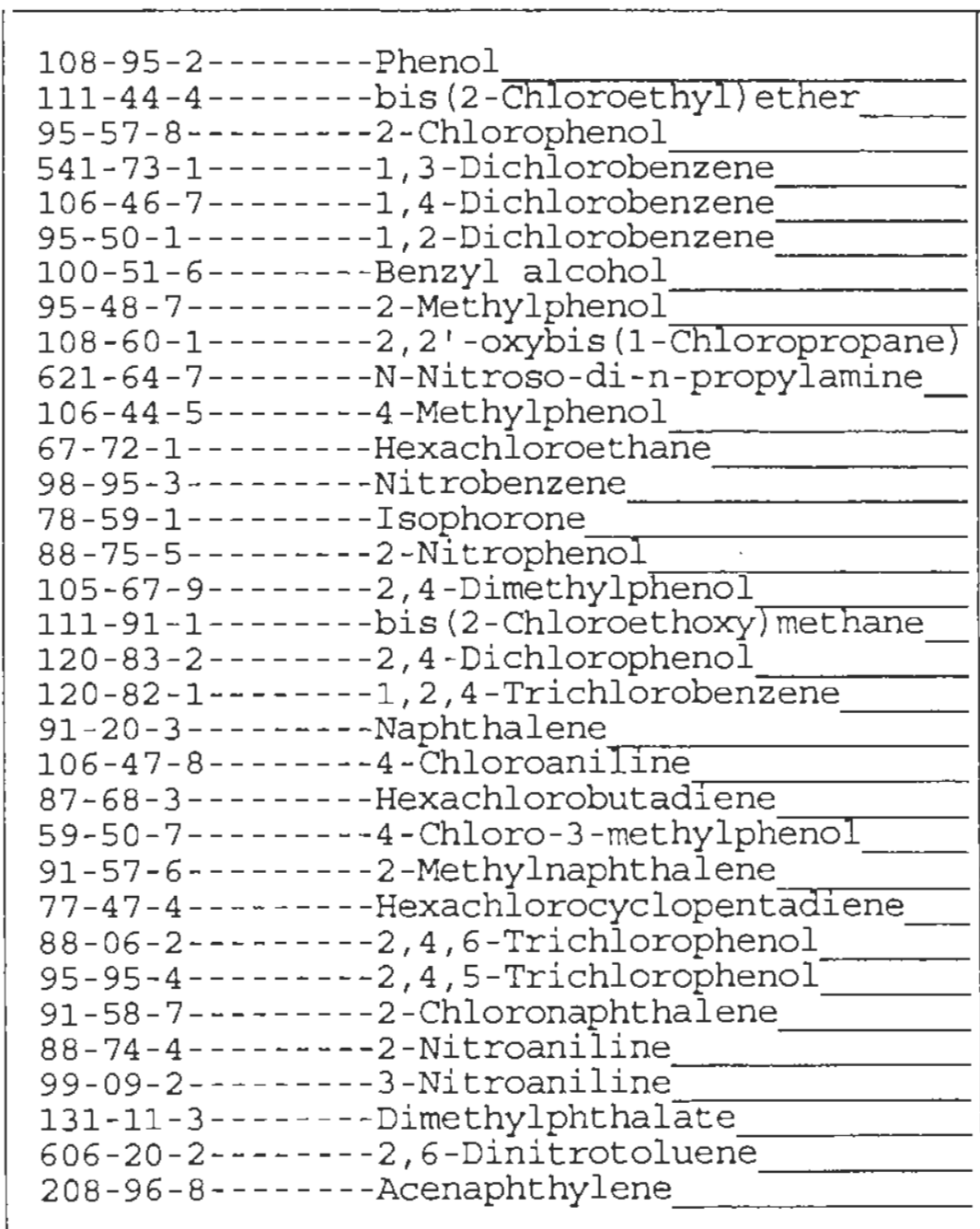

\begin{tabular}{|r|l|}
560 & $\mathrm{U}$ \\
560 & $\mathrm{U}$ \\
560 & $\mathrm{U}$ \\
560 & $\mathrm{U}$ \\
560 & $\mathrm{U}$ \\
560 & $\mathrm{U}$ \\
560 & $\mathrm{U}$ \\
1700 & \\
560 & $\mathrm{U}$ \\
560 & $\mathrm{U}$ \\
2900 & \\
560 & $\mathrm{U}$ \\
560 & $\mathrm{U}$ \\
560 & $\mathrm{U}$ \\
560 & $\mathrm{U}$ \\
560 & $\mathrm{U}$ \\
560 & $\mathrm{U}$ \\
560 & $\mathrm{U}$ \\
560 & $\mathrm{U}$ \\
560 & $\mathrm{U}$ \\
560 & $\mathrm{U}$ \\
560 & $\mathrm{U}$ \\
560 & $\mathrm{U}$ \\
560 & $\mathrm{U}$ \\
560 & $\mathrm{U}$ \\
560 & $\mathrm{U}$ \\
560 & $\mathrm{U}$ \\
560 & $\mathrm{U}$ \\
560 & $\mathrm{U}$ \\
560 & $\mathrm{U}$ \\
560 & $\mathrm{U}$ \\
560 & $\mathrm{U}$ \\
560 & $\mathrm{U}$ \\
\hline & - \\
\hline
\end{tabular}


Lab Name: PNNL

Contract: $\mathrm{Cl} 04$

CIO4-SIB

Lab code: PNNL

Case No.:

SAS NO.:

SDG NO.: 000819

Matrix: (soil/water) SUPERNATAN

Sample wt/vol:

$(g / \mathrm{mL}) \mathrm{ML}$

Level: (low $/ \mathrm{med})$

LOW

\% Moisture:

decanted: $(\mathrm{Y} / \mathrm{N})$

Concentrated Extract Volume: 1000 (uL)

Injection Volume: (UL)

GPC Cleanup: $(\mathrm{Y} / \mathrm{N}) \mathrm{N} \quad \mathrm{pH}$ :
Lab Sample ID: 00-1360-SLB

Lab File ID: 00081904

Date Received:

Date Extracted:

Date Analyzed: 08/19/0

Dilution Factor: 1.0

CONCENTRATION UNITS:

CAS NO.

COMPOUND

(ug/L or $u g / K g$ ) UG/L

$Q$

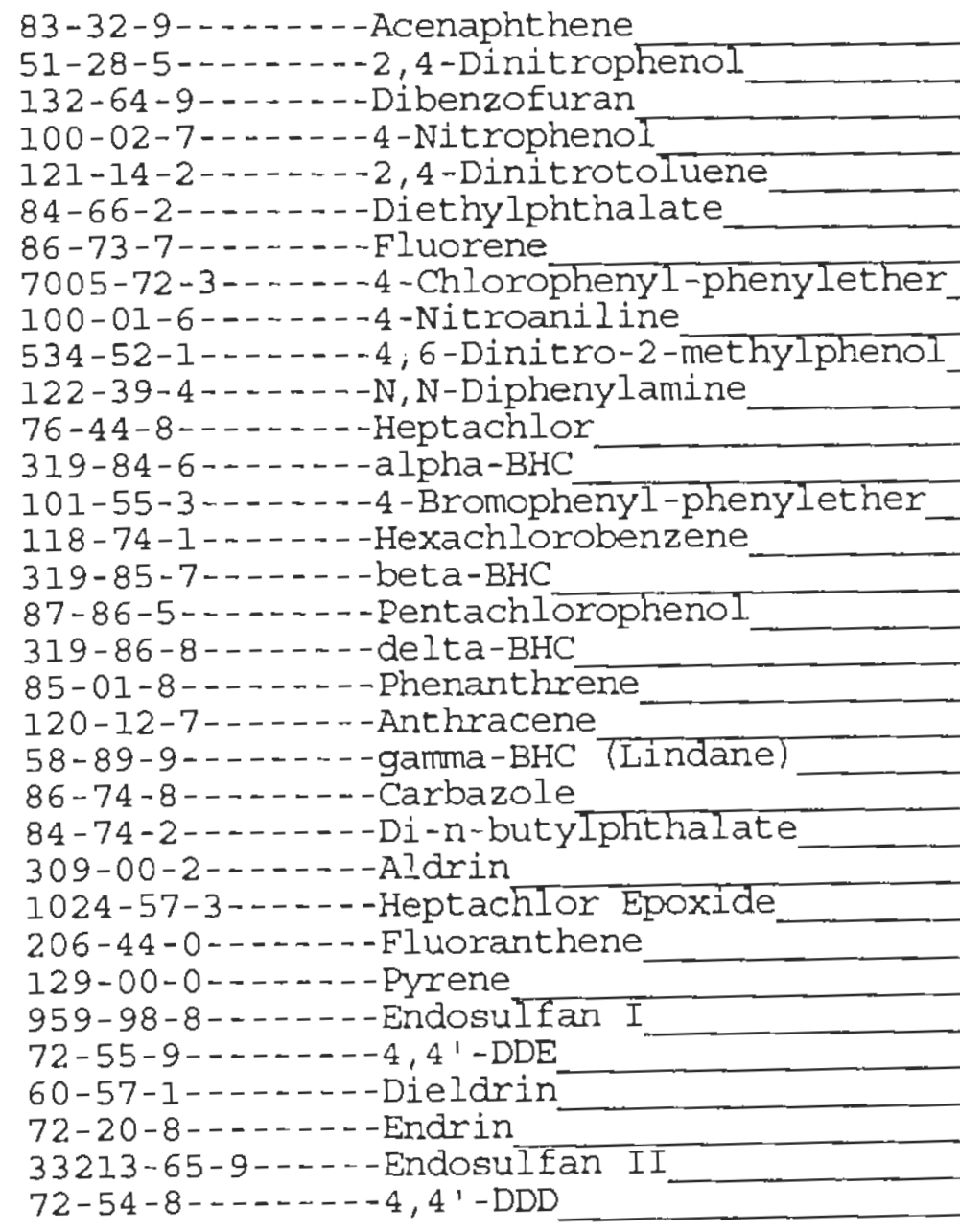

\begin{tabular}{|l|l|l|}
\hline 560 & $\mathrm{U}$ \\
560 & $\mathrm{U}$ \\
560 & $\mathrm{U}$ \\
560 & $\mathrm{U}$ \\
560 & $\mathrm{U}$ \\
560 & $\mathrm{U}$ \\
560 & $\mathrm{U}$ \\
560 & $\mathrm{U}$ \\
560 & $\mathrm{U}$ \\
560 & $\mathrm{U}$ \\
560 & $\mathrm{U}$ \\
560 & $\mathrm{U}$ \\
560 & $\mathrm{U}$ \\
560 & $\mathrm{U}$ \\
560 & $\mathrm{U}$ \\
560 & $\mathrm{U}$ \\
560 & $\mathrm{U}$ \\
560 & $\mathrm{U}$ \\
560 & $\mathrm{U}$ \\
560 & $\mathrm{U}$ \\
560 & $\mathrm{U}$ \\
560 & $\mathrm{U}$ \\
560 & $\mathrm{U}$ \\
560 & $\mathrm{U}$ \\
560 & $\mathrm{U}$ \\
560 & $\mathrm{U}$ \\
560 & $\mathrm{U}$ \\
560 & $\mathrm{U}$ \\
560 & $\mathrm{U}$ \\
560 & $\mathrm{U}$ \\
560 & $\mathrm{U}$ \\
560 & $\mathrm{U}$ \\
560 & $\mathrm{U}$ \\
& & \\
\hline & \\
\hline & \\
\hline
\end{tabular}


Lab Name: PNNL

Contract: $\mathrm{ClO4}$

C104-SLB

Lab Code: PNNL Case No.:

SAS NO. :

SDG No. : 000819

Matrix: (soil/water) SUPERNATAN

Sample wt/vol:

Level: (low/med) LOW

\% Moisture:

Concentrated Extract Volume: 1000 (UL)

Injection Volume: (uL)

Lab Sample ID: 00-1360-SLB

Lab File ID: 00081904

Date Received:

Date Extracted:

Date Analyzed: 08/19/0

Dilution Factor: 1.0

GPC Cleanup: (Y/N) N $\mathrm{pH}$ :

CAS NO.

COMPOUND

CONCENTRATION UNITS:

(ug/L or $\mathrm{ug} / \mathrm{Kg}$ ) UG/L

$Q$

85-68-7--..--Butylbenzylphthalate

1031-07-8-..--Endosulfan Sulfate

50-29-3--- - - -4, 4'-DD'T

53494-70-5-----Endrin ketone

56-55-3-------Benzo (a) anthracene

91-94-1--..---3,3'-Dichlorobenzidine

218-01-9------Chrysene

72-43-5---...-Methoxychlor

117-81-7------Bis (2-Ethyl hexyl) phthalate

117-84-0-.---Di-n-octylphthalate

205-99-2-- - - Benzo (b) Eluoranthene

207-08-9-...---Benzo (k) fluoranthene

50-32-8-------Benzo (a) pyrene

193-39-5----- - Indeno $(1,2,3-c d)$ pyrene

53-70-3---.--Dibenz $(\mathrm{a}, \mathrm{h})$ anthracene

191-24-2-- - --Benzo $(g, h, i)$ perylene

110-86-1.....-.-Pyridine

126-73-8------Tributyl phosphate

62-75-9--.--N-Nitrosodimethylamine

98-86-2---1---Acetophenone

100-00-5-- - - - 1-Chloro-4-nitrobenzene

92-52-4------Biphenyl

100-25-4--.--1,4-Dinitrobenzene

128-37-0-..---Butylated Hydroxytoluene

82-68-8-- - - - - Pentachloronitrobenzene

88-85-7------- Dinoseb

2234-13-1-- ---Octachloronaphthalene

10595-95-6-- - -N-Nitrosomethylethylamine

55-18-5-......-N-Nitrosodiethylamine

62-50-0--.---Ethyl methane sulfonate

$62-53-3-\cdots--$ - Analine

76-01-7-.---- Pentachloroethane

930-55-2-...-.-N-Nitrosopyrolidine

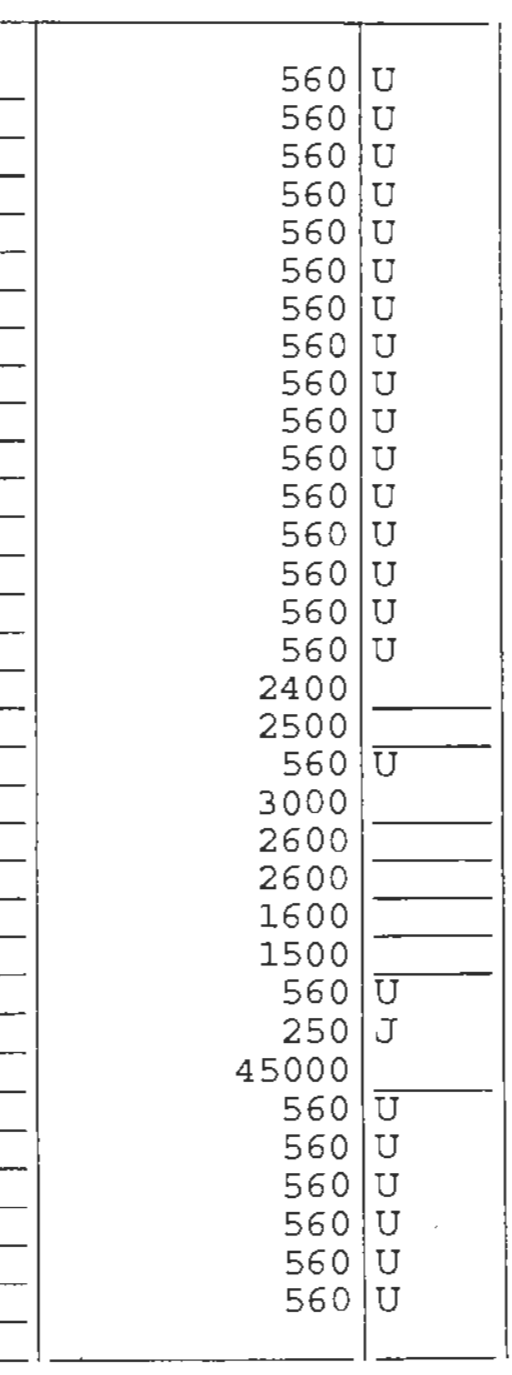

FORM I SV-3 
Lab Name: PNNL

Lab code: PNNL
Contract: $\mathrm{C} 104$

SAS NO. :
C1O4-SLB

SDG No.: 000819
Matrix: (soil/water) SUPERNATAN

Sample wt/vol:

Level: (low/med)

$(g / m L) \mathrm{ML}$

LOW

\% Moisture:

decanted: $(\mathrm{Y} / \mathrm{N})$

Concentrated Extract Volume: 1000 (uI)

Injection volume: (uL)

GPC Cleanup: $(\mathrm{Y} / \mathrm{N}) \mathrm{N} \quad \mathrm{pH}$ :
Lab Sample ID: 00-1360-SLB

Lab File ID: 00081904

Date Received:

Date Extracted:

Date Analyzed: 08/19/0

Dilution Factor: 1.0

CAS NO.

COMPOUND

CONCENTRATION UNITS:

(ug/L or $\mathrm{ug} / \mathrm{Kg}$ ) UG/L

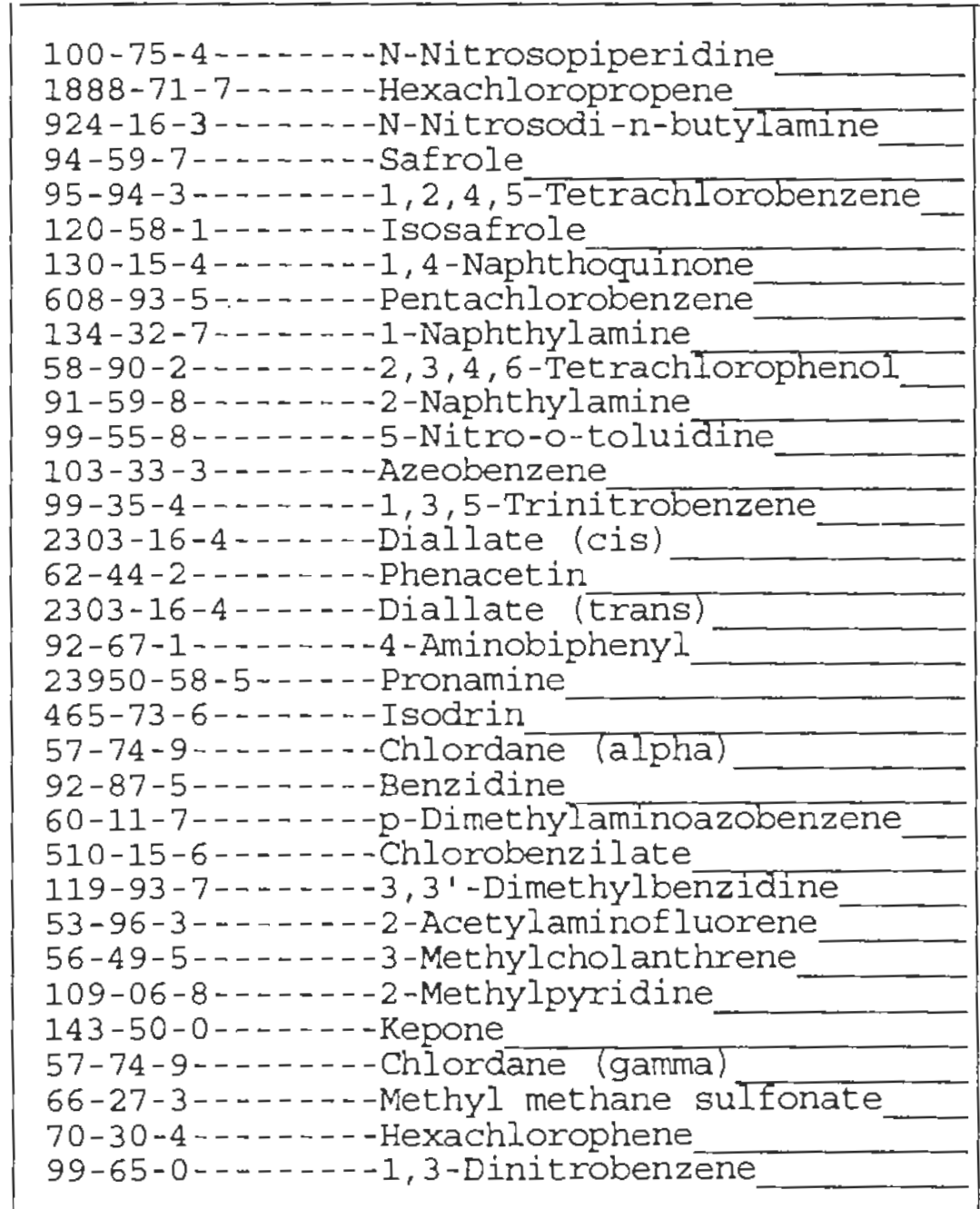


Lab Name: PNNL

Contract: $\mathrm{C} 104$
EPA SAMPLE NO.

C104-SLB
Lab Code: PNNL Case No.:

Matrix: (soil/water) SUPERNATAN

Sample wt/vol:

(g/mI) $M L$

Level: (low/med) LOW

\% Moisture:

decanted: $(Y / N)$

SAS NO. :
SDG No.: 000819

Lab Sample ID: 00-1360-SLB Lab File ID: 00081904 :

Date Received:

Date Extracted:

Date Analyzed: 08/19/0

Dilution Factor: 1.0 Injection Volume: (u)

GPC Cleanup: (Y/N) N $\mathrm{pH}$ :

$\begin{array}{ll} & \text { CONCENTRATION UNITS: } \\ \text { CAS NO. COMPOUND } & (\mathrm{ug} / \mathrm{L} \text { or } \mathrm{ug} / \mathrm{Kg}) \mathrm{UG} / \mathrm{L}\end{array}$

87-65-0----2--2,6-Dichlorophenol

$5 6 0 \longdiv { \mathrm { U } }$ 
Lab Name: PNNL

Lab code: PNNL
Contract: C104

Case No.:
SAS NO.:
CIO4-SLD

SDG No.: 000819
Matrix: (soil/water) SUPERNATAN

Sample wt/vol:

Level: (low/med)

$\div$ Moisture:

Concentrated Extract Volume: 1000 (uL) Injection volume: (uI)
Lab Sample ID: 00-1360-SLD

Lab File ID: 00081906

Date Received:

Date Extracted:

Date Analyzed: 08/19/0

Dilution Eactor: 1.0

GPC Cleanup: $(\mathrm{Y} / \mathrm{N}) \mathrm{N} \quad \mathrm{pH}$ :

CONCENTRATION UNITS: CAS NO. COMPOUND (ug/L or $\mathrm{ug} / \mathrm{Kg}$ ) UG/L

$Q$

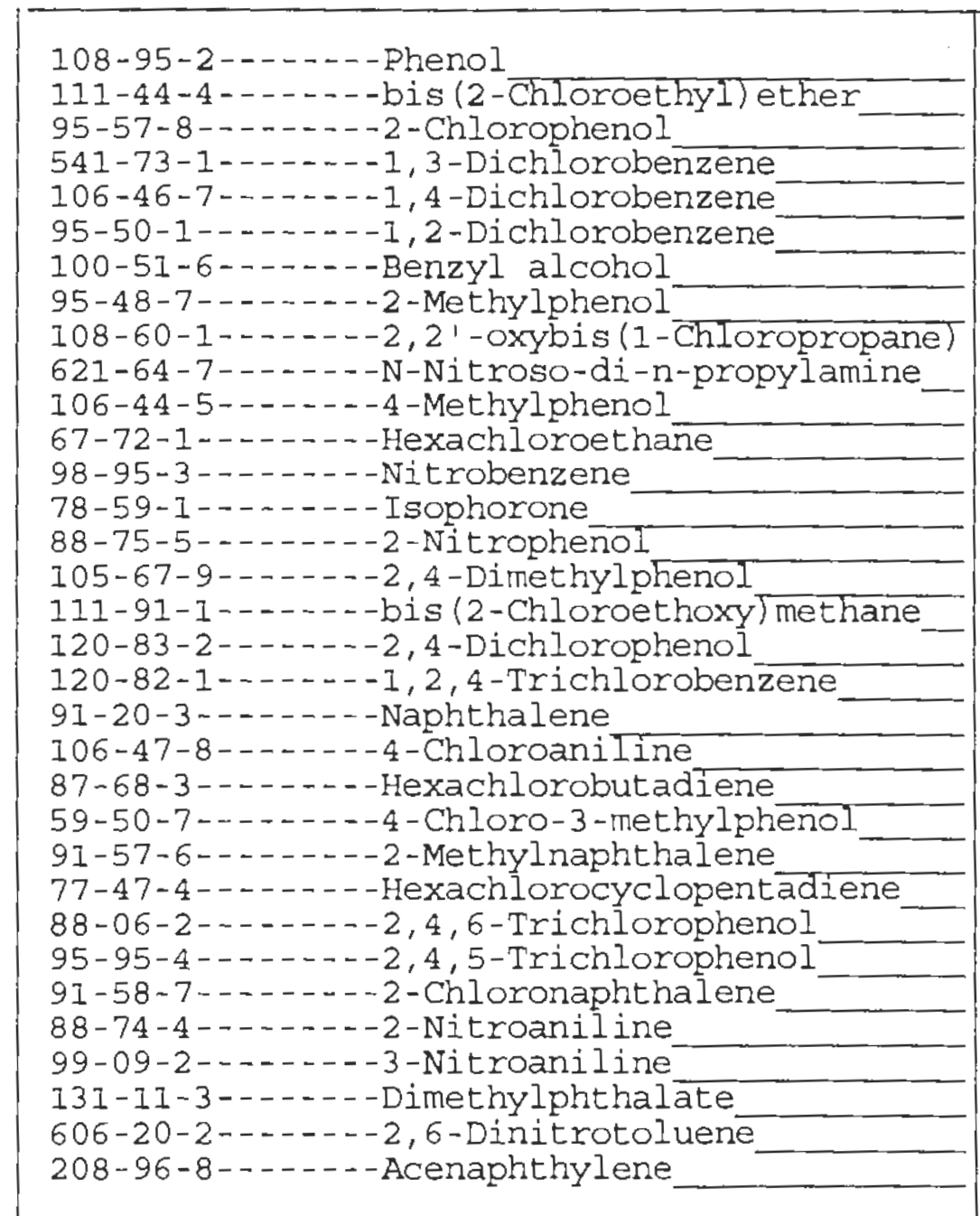


Lab Name: PNNL

Lab Code: PNNL

Matrix: (soil/water) SUPERNATAN

Sample wt/vol:

$(\mathrm{g} / \mathrm{mL}) \mathrm{ML}$

Level : (low/med)

LOW

$\div$ Moisture:

decanted: $(\mathrm{Y} / \mathrm{N})$

Contract : $\mathrm{ClO}$

SAS NO. :

Lab Sample ID: 00-1360-SID

Lab File ID: 00081906

Date Received:

Date Extracted:

Concentrated Extract Volume: 1000 (UL)

Injection volume:

(ut)

Date Aralyzed: 08/19/0

Dilution Factor: 1.0

GPC Cleanup: $\quad(\mathrm{Y} / \mathrm{N}) \mathrm{N} \quad \mathrm{pH}$ :

CONCENTRATION UNITS:

CAS NO.

COMPOUND

$(\mathrm{ug} / \mathrm{L}$ or $\mathrm{ug} / \mathrm{Kg})$ UG/L

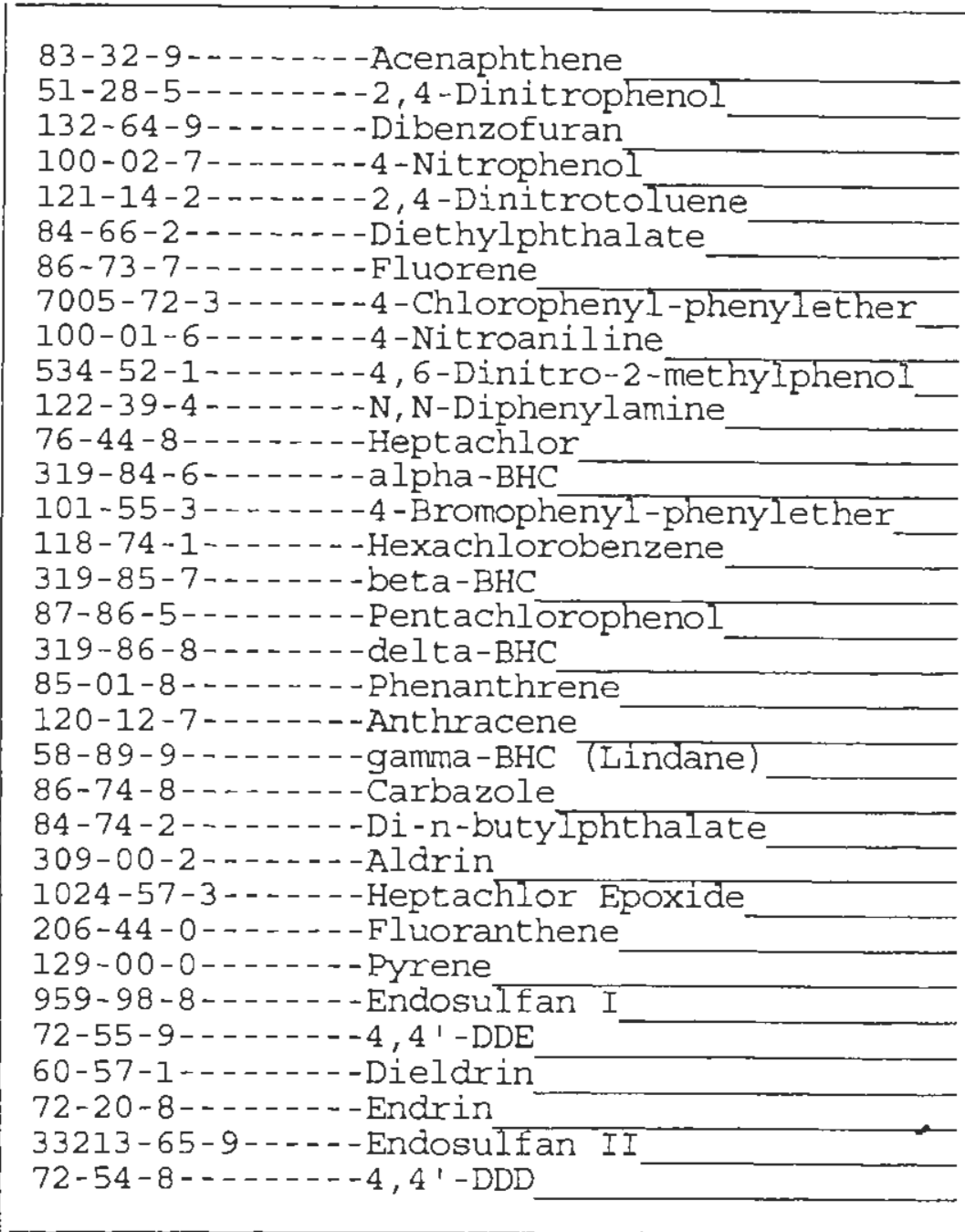

\begin{tabular}{|l|l|l|}
560 & $\mathrm{U}$ \\
560 & $\mathrm{U}$ \\
560 & $\mathrm{U}$ \\
560 & $\mathrm{U}$ \\
560 & $\mathrm{U}$ \\
560 & $\mathrm{U}$ \\
560 & $\mathrm{U}$ \\
560 & $\mathrm{U}$ \\
560 & $\mathrm{U}$ \\
560 & $\mathrm{U}$ \\
560 & $\mathrm{U}$ \\
560 & $\mathrm{U}$ \\
560 & $\mathrm{U}$ \\
560 & $\mathrm{U}$ \\
560 & $\mathrm{U}$ \\
560 & $\mathrm{U}$ \\
560 & $\mathrm{U}$ \\
560 & $\mathrm{U}$ \\
560 & $\mathrm{U}$ \\
560 & $\mathrm{U}$ \\
560 & $\mathrm{U}$ \\
560 & $\mathrm{U}$ \\
560 & $\mathrm{U}$ \\
560 & $\mathrm{U}$ \\
560 & $\mathrm{U}$ \\
560 & $\mathrm{U}$ \\
560 & $\mathrm{U}$ \\
560 & $\mathrm{U}$ \\
560 & $\mathrm{U}$ \\
560 & $\mathrm{U}$ \\
560 & $\mathrm{U}$ \\
560 & $\mathrm{U}$ \\
560 & $\mathrm{U}$ \\
& \\
\hline
\end{tabular}


Lab Name: PNNL

Lab Code: PNNL

Case No.:
Contract: $\mathrm{Cl} 04$

SAS NO.:
C104-SLD

SDG No. : 000819
Matrix: (soil/water) SUPERNATAN

Sample wt/vol:

Level: (low/med)

$(g / m L) \quad M L$

: Moisture:

Concentrated Extract Volume: 1000 (uL)

Injection volume: (uL)
Lab Sample ID: 00-1360-SLD

Lab File ID: 00081906

Date Received:

Date Extracted:

Date Analyzed: 08/19/0

Dilution Factor: 1.0

GPC Cleanup: $(\mathrm{Y} / \mathrm{N}) \mathrm{N} \quad \mathrm{PH}$ :

CAS NO.

COMPOUND

CONCENTRATION UNITS:

(ug/L or $\mathrm{ug} / \mathrm{kg}$ ) UG/L

$Q$

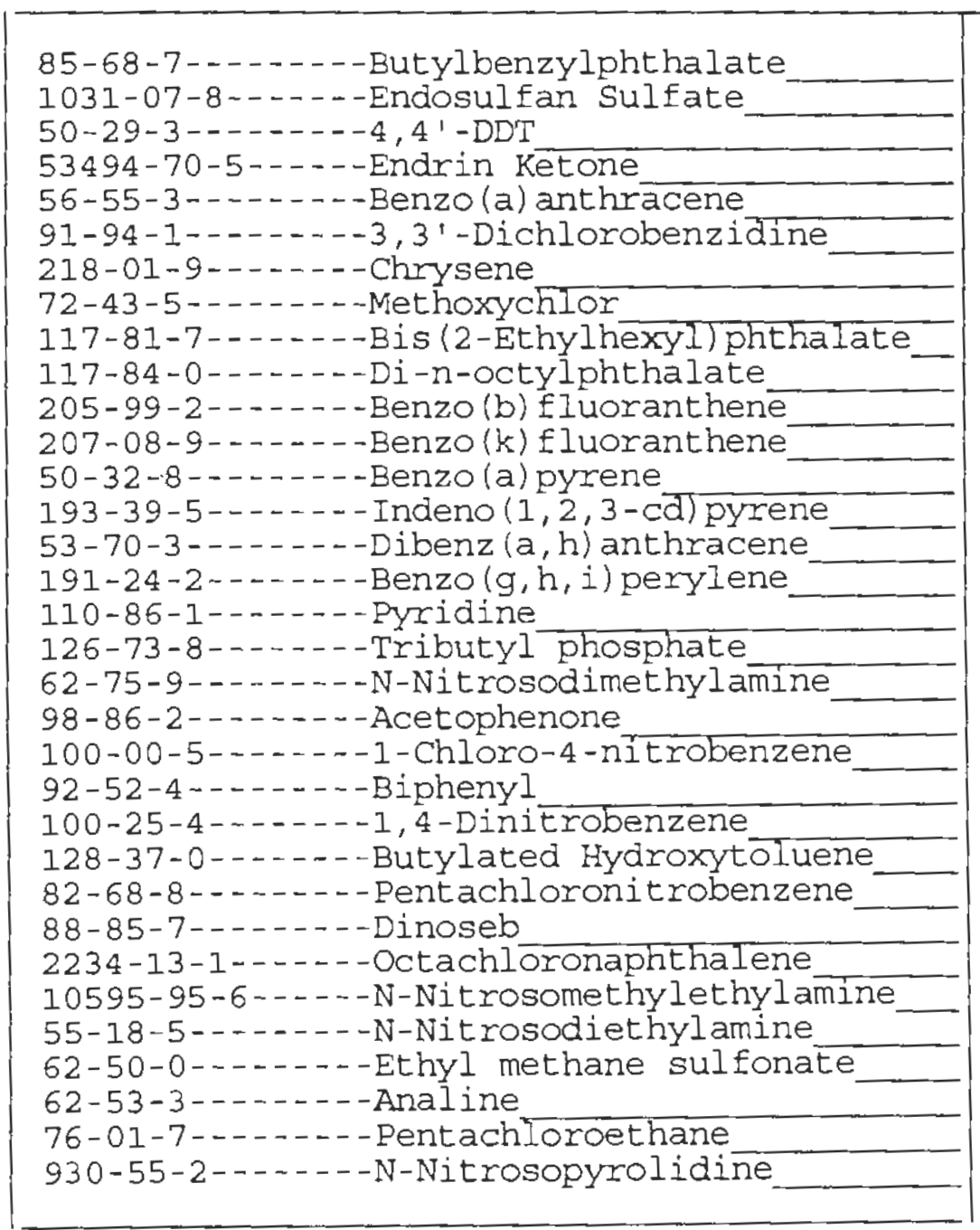


Lab Name: PNNL

Lab Code: PNNL

Case No.:
Contract: $\mathrm{C} 104$

SAS NO.:
C104-SLD

SDG No.: 000819
Matrix: (soil/water) SURERNATAN

Sample wt/vol:

Level: (low/med) LOW

$\because$ Moisture:

decanted: $(Y / N)$

Concentrated Extract Volume: 1000 (u)

Injection Volume: (u士)

$\{\mathrm{g} / \mathrm{mL}\rangle \mathrm{ML}$

GPC Cleanup: $\quad(Y / N) N$

$\mathrm{pH}$ :
Lab Sample ID: 00-1360-SLD

Lab File ID: 00081906

Date Received:

Date Extracted:

Date Analyzed: 08/19/0

Dilution Factor: 1.0

CAS NO.

COMPOUND

CONCENTRATION UNITS: (ug/L or $\mathrm{ug} / \mathrm{Kg}$ ) UG/L

$Q$

100-75-4----- - N-Nitrosopiperidine

1888-71-7-----Hexachloropropene

924-16-3--..--N-Nitrosodi-n-butylamine

94-59-7--------Safrole

95-94-3-------1, 2, 4, 5-Tetrachlorobenzene

120-58-1--- - - - Isosafrole

$130-15-4-------1,4-$ Naphthoquinone

608-93-5--.----Pentachlorobenzene

134-32-7--..--1-Naphthylamine

58-90-2-- - - - 2, 3, 4, 6-Tetrachlorophenol

$91-59-8-\cdots-\cdots-2-N a p h t h y l a m i n e$

99-55-8------- 5-Nitro-o-toluidine

103-33-3------Azeobenzene

$99-35-4 \ldots-\ldots--1,3,5-T r i n i t r o b e n z e n e$

2303-16-4-----Diallate (cis)

62-44-2--------Phenacetin

2303-16-4--.---Diallate (trans)

92-67-1--- - - -4-Aminobiphenyl

23950-58-5------Pronamine

465-73-6-...--- Isodrin

57-74-9--..-.-Chlordane (alpha)

92-87-5-....--Benzidine

60-11-7-....- - p-Dimethylaminoazobenzene

510-15-6-- - - - Chlorobenzilate

119-93-7.....-3,3'-Dimethylbenzidine

53-96-3-..---2-Acetylaminofluorene

56-49-5-...-.-3-Methyl cholanthrene

109-06-8--- - - 2-Methylpyridine

143-50-0------ Kepone

57-74-9-...-- Chlordane (gamma)

66-27-3-..----Methyl methane sulfonate

70-30-4-- - - - -Hexachlorophene

99-65-0-.----1,3-Dinitrobenzene
$560 \mathrm{U}$

$560 \mathrm{U}$

$560 \mathrm{U}$

$560 \mathrm{U}$

$560 . \mathrm{U}$

$560 \mathrm{U}$

$10 \mathrm{~J}$

$560 \mathrm{U}$

$560 \mathrm{U}$

$560 . \mathrm{U}$

$560 \mathrm{U}$

$560 \mathrm{U}$

$560 . \mathrm{U}$

$560 \mathrm{U}$

$560 \mathrm{U}$

$560 \mathrm{U}$

$560 \mathrm{U}$

$560 \mathrm{U}$

$560 \mathrm{U}$

$560 \mathrm{U}$

$560 \mathrm{U}$

$1900 \mathrm{~B}$

$560 \mathrm{U}$

$560 \mathrm{U}$

$560 \mathrm{U}$

$560 \mathrm{U}$

$560 \cdot \mathrm{U}$

$510 \mathrm{~J}$

$560 \mathrm{U}$

$560 \mathrm{U}$

$560 \mathrm{U}$

$560 \mathrm{U}$

$560 \mathrm{U}$ 
Lab Name: PNNL

Contract: $\mathrm{C} 104$

Lab code: PNNL

Case No.:

SAS NO.:

SDG NO.: 000819

Matrix: (soil/water) SUPERNATAN

Lab Sample ID: 00-1360-SID

Sample wt/vol:

( $g / \mathrm{mL}) \mathrm{ML}$

Lab File ID:

00081906

Level: (low/med) LOW

Date Received:

\% Moisture:

decanted: $(\mathrm{Y} / \mathrm{N})$

Date Extracted:

Concentrated Extract Volume: 1000 (uL)

Date Analyzed: 08/19/0

Injection volume: (U)

Dilution Factor: 1.0

GPC Cleanup: $(\mathrm{Y} / \mathrm{N}) \mathrm{N} \quad \mathrm{pH}$ :

CAS NO. COMPOUND

CONCENTRATION UNITS:

(ug/L or $u g / \mathrm{kg}$ ) UG/L

$Q$

87-65-0...-2,6-Dichlorophenol_ $560 \mid \mathrm{U}$


Lab Name: BNNL

Lab Code: PNNL
Contract: $\mathrm{C} 104$

SAS NO. :
C104-SLE
Matrix: (soil/water) SUPERNATAN

Sample wt/vol:

Level: (low/med) LOW

\% Moisture:

Concentrated Extract Volume: 1000 (LI)

Injection volume: (uL)
Lab Sample ID: 00-1360-SLE

Lab File ID: 00081909

Date Received:

Date Extracted:

Date Analyzed: 08/19/0

Dilution Factor: 1.0

GPC Cleanup: (Y/N) N $\mathrm{pH}$ :

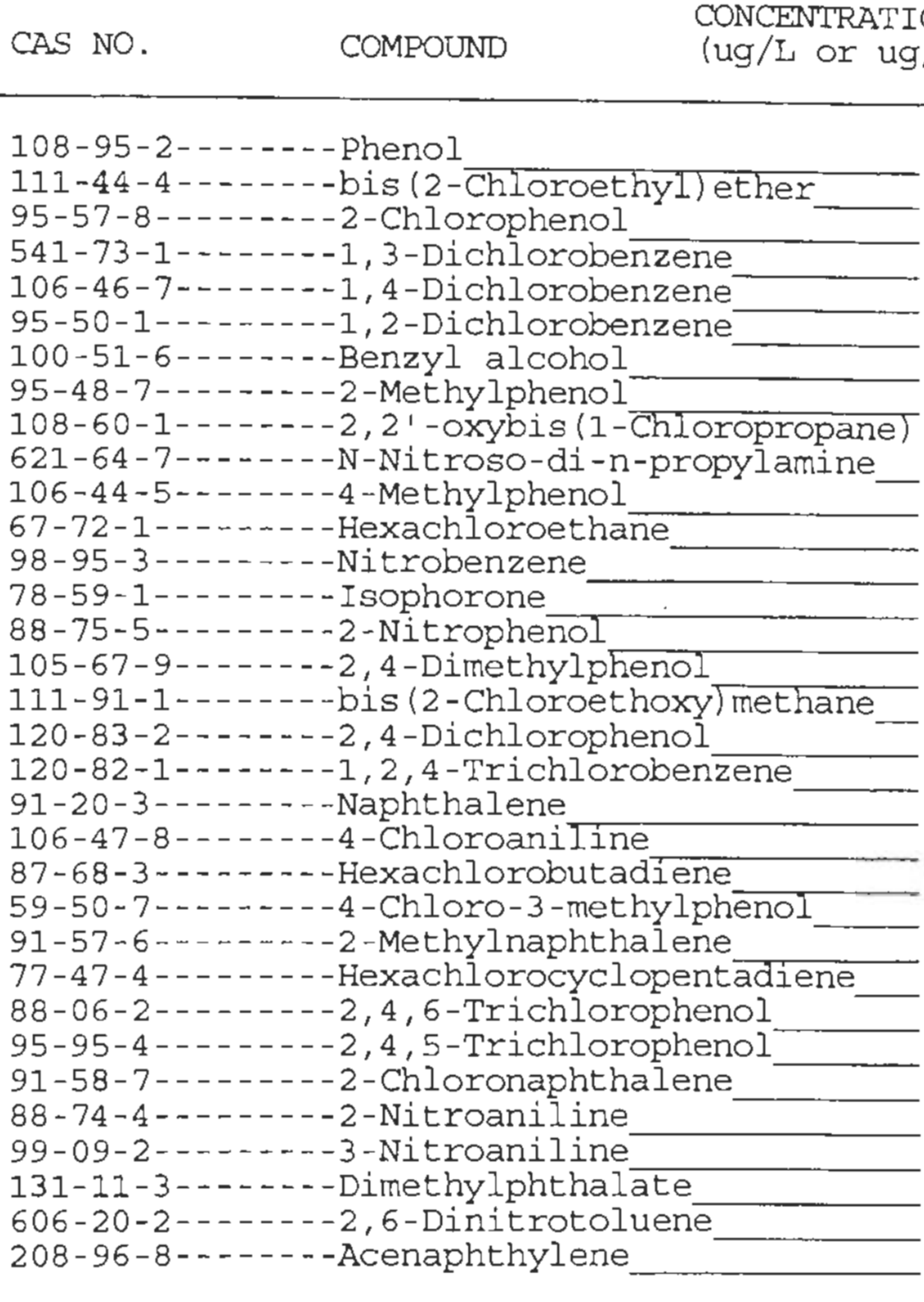

FORM I SV-I 
Lab Name: PNNL

Lab Code: PNNL
Contract: $\mathrm{ClO4}$

Case No.:
SAS NO.:
C104-SLE
Matrix: (soil/water) SUPERNATAN

Sample wt/vol:

Leve 1: (low/med) LOW

$\because$ Moisture:

decanted: $(\mathrm{Y} / \mathrm{N})$

Concentrated Extract Volume: 1000 (UL)

Injection Volume: (UL)

Lab Sample ID: 00-1360-SIE

Lab File ID: 00081909

Date Received:

Date Extracted:

Date Aralyzed: 08/19/0

Dilution Factor: 1.0

GPC Cleanup: (Y/N) N $\mathrm{pH}$ :

CAS NO.

COMPOUND

CONCENTRATION UNITS:

( $\mathrm{ug} / \mathrm{L}$ or $\mathrm{ug} / \mathrm{Kg}$ ) UG/L

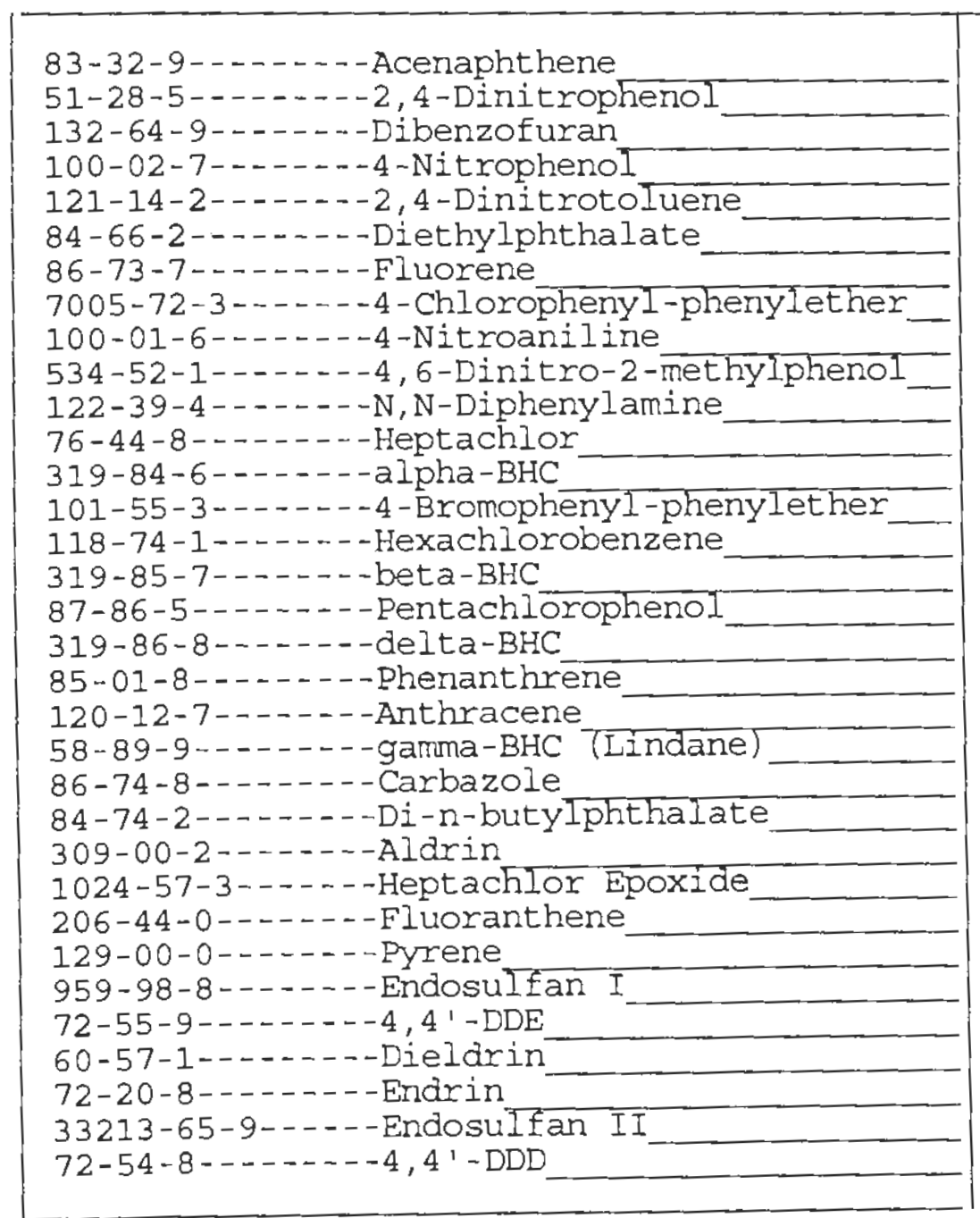


Lab Name: PNNL

Lab Code: PNNL
Contract: $\mathrm{Cl04}$

SAS NO. :
C104-SLE

SDG No.: 000819
Matrix: (soil/water) SUPERNATAN

Sample wt/vol:

Level: (low/med) LOW

\% Moisture:

Concentrated Extract Volume: 1000 (UL)

Injection volume: (UL)

Lab Sample ID: 00-1360-SLE

Lab File ID: 00081909

Date Received:

Date Extracted:

Date Analyzed: 08/19/0

Dilution Factor: 1.0

GPC Cleanup: $\quad(\mathrm{Y} / \mathrm{N}) \mathrm{N} \quad \mathrm{pH}$ :

CAS NO.

COMPOUND

CONCENTRATION UNITS:

(ug/L or $\mathrm{ug} / \mathrm{Kg}$ ) UG/L

$Q$

\begin{tabular}{|c|}
\hline 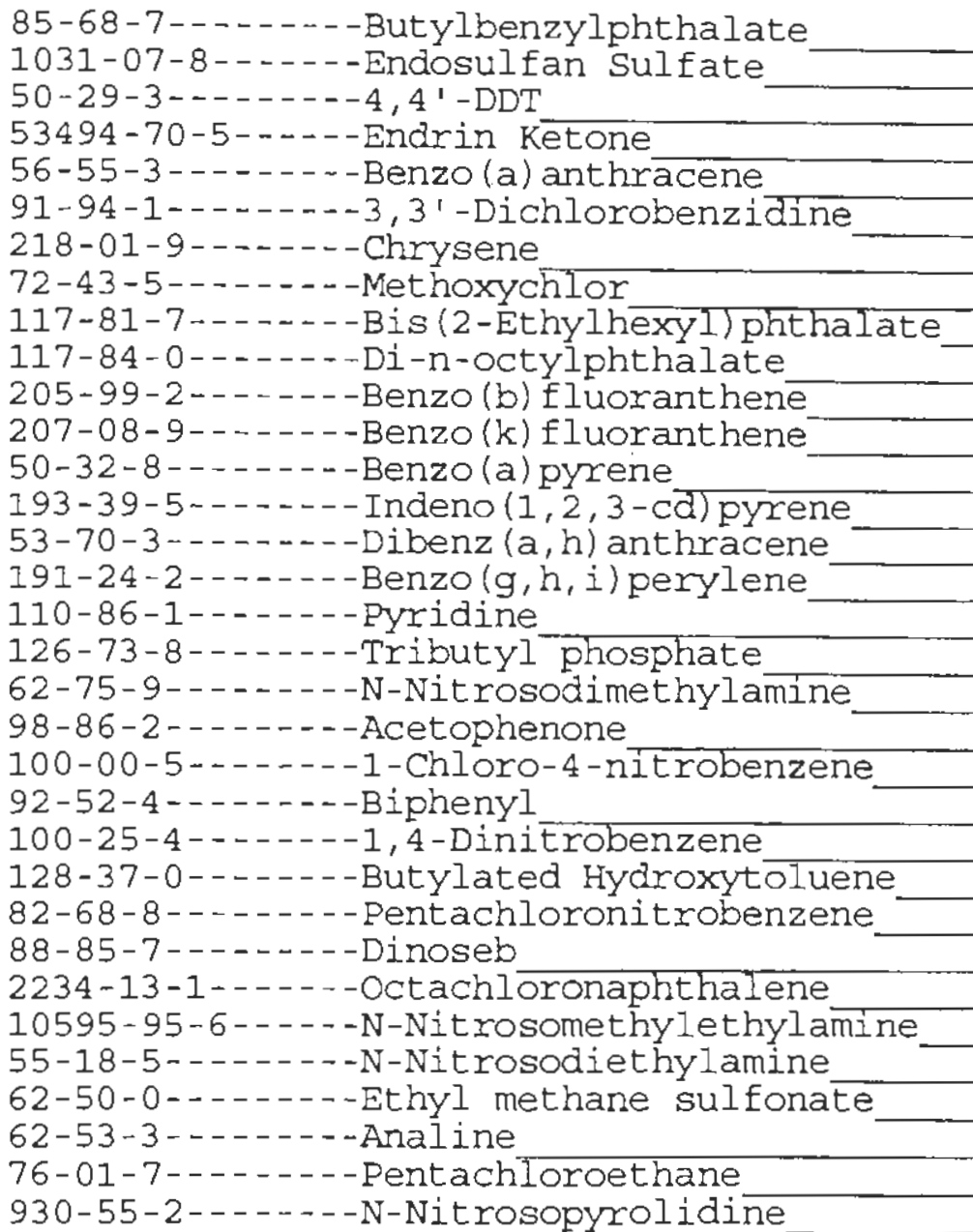 \\
\hline
\end{tabular}

FORM I SV-3

\begin{tabular}{|r|l|}
560 & $\mathrm{U}$ \\
560 & $\mathrm{U}$ \\
560 & $\mathrm{U}$ \\
560 & $\mathrm{U}$ \\
560 & $\mathrm{U}$ \\
560 & $\mathrm{U}$ \\
560 & $\mathrm{U}$ \\
560 & $\mathrm{U}$ \\
58 & $\mathrm{~J}$ \\
560 & $\mathrm{U}$ \\
560 & $\mathrm{U}$ \\
560 & $\mathrm{U}$ \\
560 & $\mathrm{U}$ \\
560 & $\mathrm{U}$ \\
560 & $\mathrm{U}$ \\
560 & $\mathrm{U}$ \\
240 & $\mathrm{JB}$ \\
2300 & $\mathrm{~B}$ \\
4900 & \\
1300 & $\mathrm{~B}$ \\
1100 & $\mathrm{~B}$ \\
240000 & $\mathrm{~B}$ \\
430000 & $\mathrm{~B}$ \\
560 & $\mathrm{U}$ \\
560 & $\mathrm{U}$ \\
2600 & $\mathrm{~B}$ \\
0.0 & $\mathrm{JB}$ \\
64 & $\mathrm{~J}$ \\
560 & $\mathrm{U}$ \\
560 & $\mathrm{U}$ \\
560 & $\mathrm{U}$ \\
560 & $\mathrm{U}$ \\
560 & $\mathrm{U}$ \\
& \\
\hline & \\
\hline
\end{tabular}

OLM03.0 
Lab Name: PNNL

Contract: $\mathrm{C} 104$

C104-SLE

Lab Code: PNNL

Case No.:

SAS NO.:

SDG No.: 000819

Matrix: (soil/water) SUPERNATAN

Sample wt/vol:

$(g / m L) M L$

Level: (low/med)

LOW

$\div$ Moisture:

decanted: $(\mathrm{Y} / \mathrm{N})$

Concentrated Extract Volume: 1000 (uI)

Injection Volume:

(UL)

GPC Clearup: $(Y / N) \mathrm{N} \quad \mathrm{pH}$ :
Lab Sample ID: 00-1360-SLE

Lab File ID: 00081909

Date Received:

Date Extracted:

Date Analyzed: $08 / 19 / 0$

Dilution Factor: 1.0

CAS NO.

COMPOUND

CONCENTRATION UNITS:

$(u g / L$ or $u g / \mathrm{kg})$ UG/L

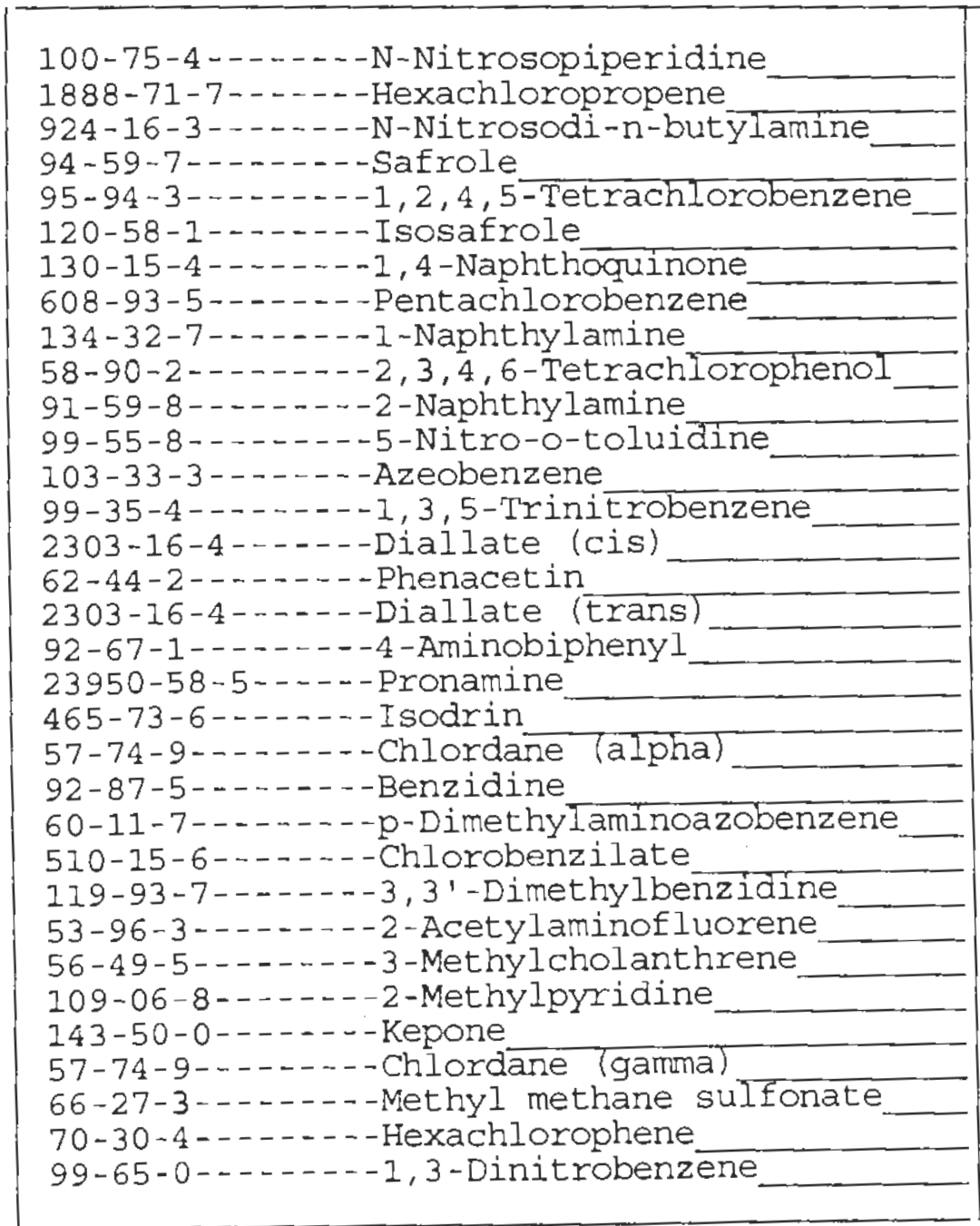


Lab Name: PNNL

Contract: $\mathrm{ClO4}$

CIO4-SIE

Lab Code: PNNL

Case No.:

SAS NO.:

SDG NO.: 000819

Matrix: (soil/water) SUPERNATAN

Lab Sample ID: 00-1360-SLE

Sample wt/vol:

$(g / m L) M L$

Lab File ID: 00081909

Level: (low $/ \mathrm{med}$ ) LOW

Date Received:

음 Moisture:

decanted: $(Y / N)$

Date Extracted:

Concentrated Extract Volume: 1000 (uL)

Date Analyzed: 08/19/0

Injection Volume: (u工)

Dilution Factor: 1.0

GPC Cleanup: $(\mathrm{Y} / \mathrm{N}) \mathrm{N} \quad \mathrm{pH}$ :

CAS NO

COMPOUND

CONCENTRATION UNITS:

(ug/L or $\mathrm{ug} / \mathrm{Kg}$ ) UG/L.

Q

87-65-0-..---2,6-Dichlorophenol_______ 
Lab Name: PNNL

Lab Code: PNNL

Case No.:

Matrix: (soil/water) SUPERNATAN

Sample wt/vol:

(g/mL) $M L$

Level: (low/med) LOW

\% Moisture:

decanted: $(Y / N)$

Concentrated Extract Volume: 1000 (uL)

Injection Volume: (uL)

Contract: $\mathrm{ClO} 04$

SAS NO.:

Lab Sample ID: 00-I360-SLMS

Lab File ID: $\quad 00081907$

Date Received:

Date Extracted:

Date Analyzed: 08/19/0

Dilution Factor: 1.0

GPC Cleanup: $(Y / N) N \quad p H:$

CAS NO.

COMPOUND

CONCENTRATION UNITS:

$(\mathrm{ug} / \mathrm{L}$ or $\mathrm{ug} / \mathrm{kg})$ UG/L

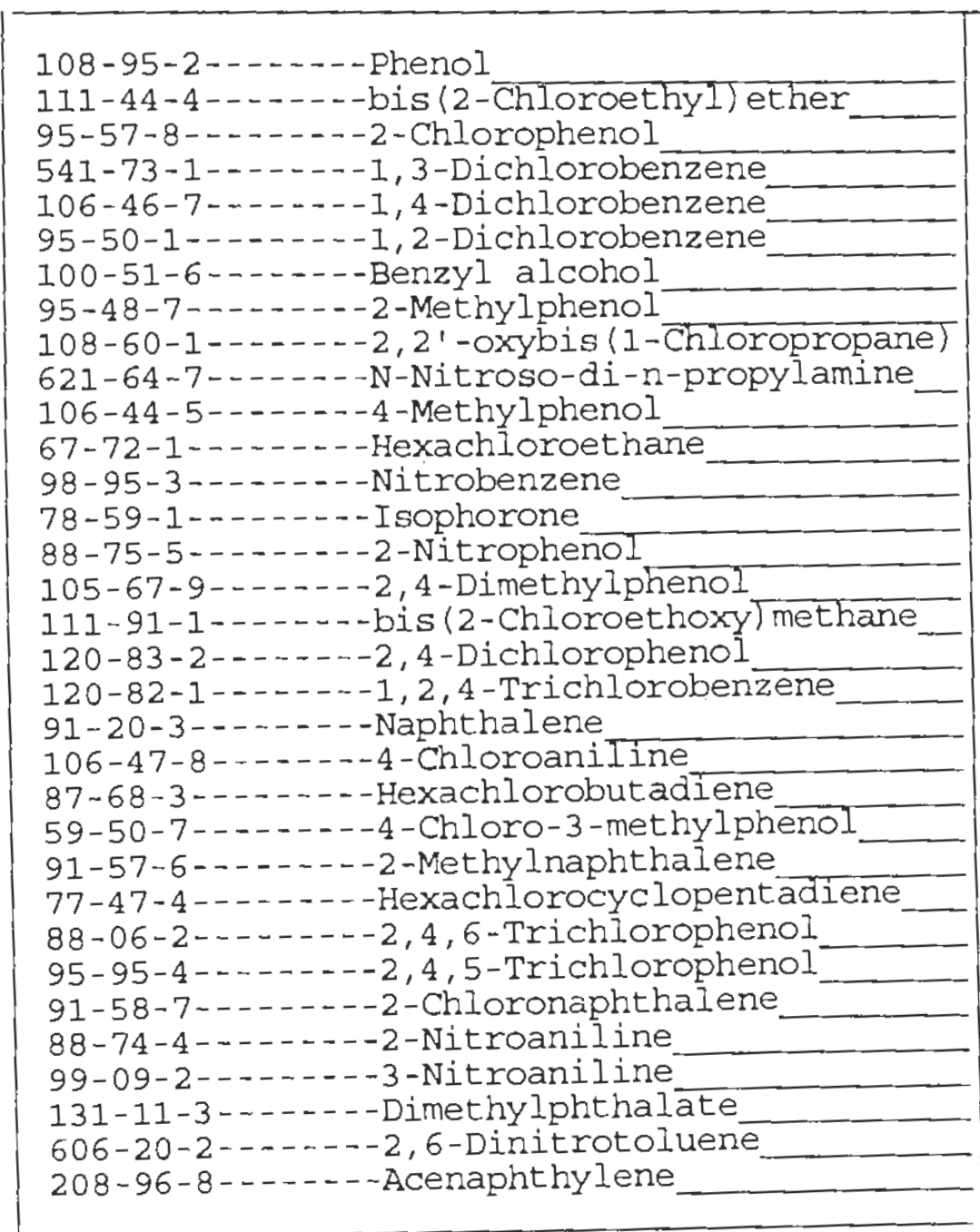

\begin{tabular}{r|l|l|}
1800 & \\
560 & $\mathrm{U}$ \\
1800 & \\
560 & $\mathrm{U}$ \\
1100 & \\
560 & $\mathrm{U}$ \\
560 & $\mathrm{U}$ \\
2900 & $\mathrm{~B}$ \\
560 & $\mathrm{U}$ \\
2200 & \\
4800 & $\mathrm{U}$ \\
560 & $\mathrm{U}$ \\
560 & $\mathrm{U}$ \\
560 & $\mathrm{U}$ \\
560 & $\mathrm{U}$ \\
560 & $\mathrm{U}$ \\
560 & $\mathrm{U}$ \\
560 & $\mathrm{U}$ \\
1600 & \\
560 & $\mathrm{U}$ \\
560 & $\mathrm{U}$ \\
560 & $\mathrm{U}$ \\
2000 & \\
560 & $\mathrm{U}$ \\
560 & $\mathrm{U}$ \\
560 & $\mathrm{U}$ \\
560 & $\mathrm{U}$ \\
560 & $\mathrm{U}$ \\
560 & $\mathrm{U}$ \\
560 & $\mathrm{U}$ \\
560 & $\mathrm{U}$ \\
560 & $\mathrm{U}$ \\
560 & $\mathrm{U}$ \\
\hline & \\
\hline & \\
\hline
\end{tabular}

FORM I SV-1 
Lab Name: PNNL

Contract: C104

Lab Code: PNNL

Case No.:

Matrix: (soil/water) SUPERNATAN

Sample wt/vol:

$(g / m L) M$

Level: (low/med) LOW

\% Moisture:

decanted: ( $\mathrm{Y} / \mathrm{N})$

Concentrated Extract Volume: 1000 (uL)

Injection Volume: (uL)
C104-SYMS

SAS NO.:

SDG No.: 000819

Lab Sample ID: 00-1360-SLMS

Lab File ID: 00081907

Date Received:

Date Extracted:

Date Analyzed: 08/19/0

Dilution Factor: 1.0

CONCENTRATION UNITS: $(\mathrm{ug} / \mathrm{L}$ or $\mathrm{ug} / \mathrm{Kg}) \mathrm{UG} / \mathrm{L}$
CAS NO.

$(Y / N) \quad N$

pH:

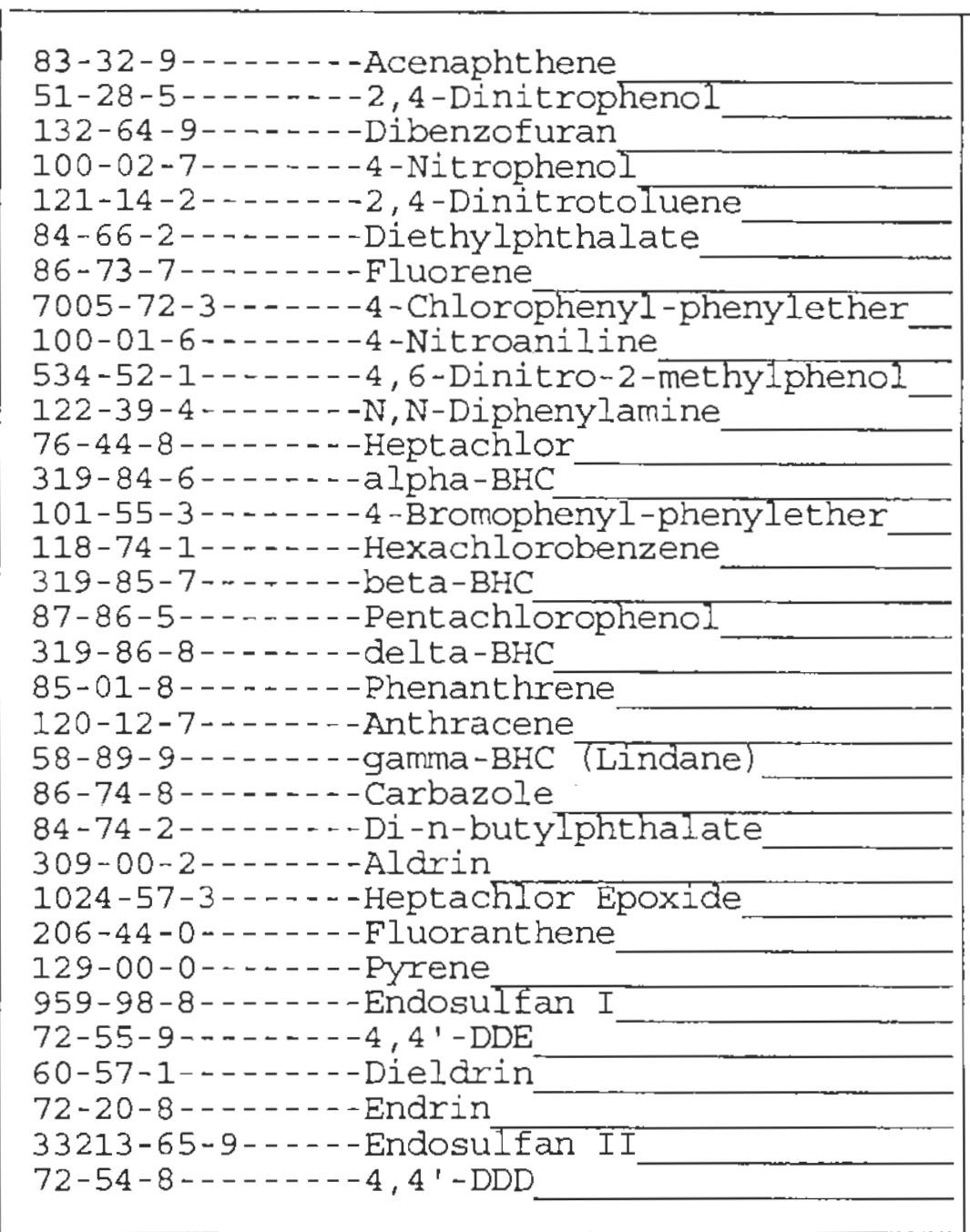

FORM I SV-2

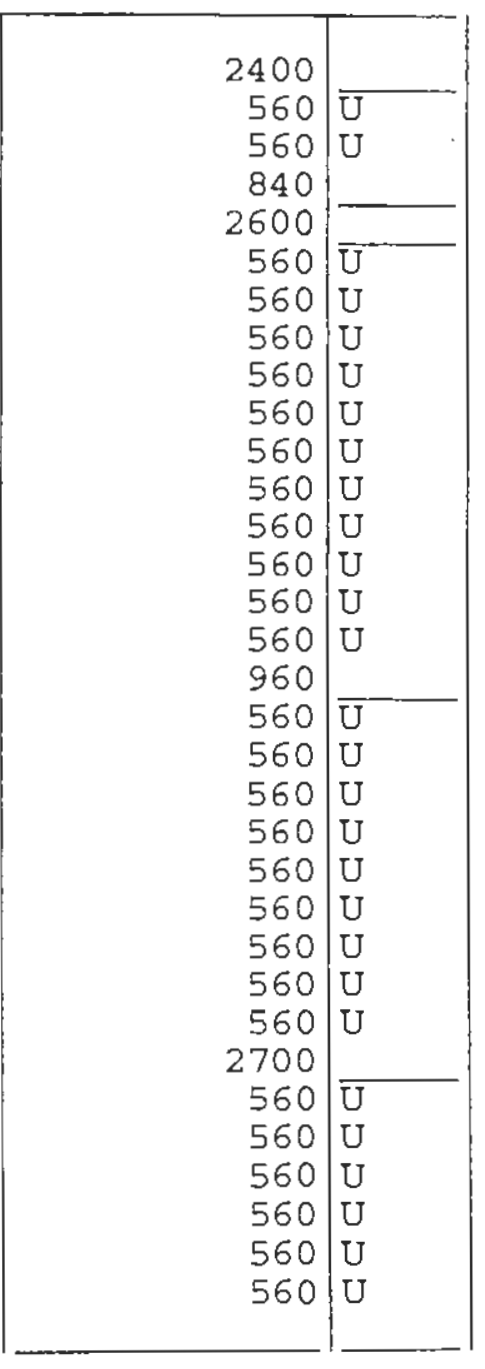

OLMO 3.0 
Lab Name: PNNL

Lab Code: PNNL
Contract: C104

Case No.:
SAS NO.:

\section{C104-SLMS}

Matrix: (soil/water) SUPERNATAN

Sample wt/vol:

(g/mL) ML

Level: (low $/$ med) Low

\% Moisture: decanted: $(\mathrm{Y} / \mathrm{N})$

Concentrated Extract Volume: 1000 (uL) Injection Volume: (uL)
Lab Sample ID: 00-1360-SLMS

Lab File ID: 00081907

Date Received:

Date Extracted:

Date Analyzed: 08/19/0

Dilution Factor: 1.0
GPC Cleanup:
$(Y / N) N$
$\mathrm{pH}:$

CAS NO.

COMPOUND

CONCENTRATION UNITS: (ug/L, or $\mathrm{ug} / \mathrm{Kg}$ ) UG/L

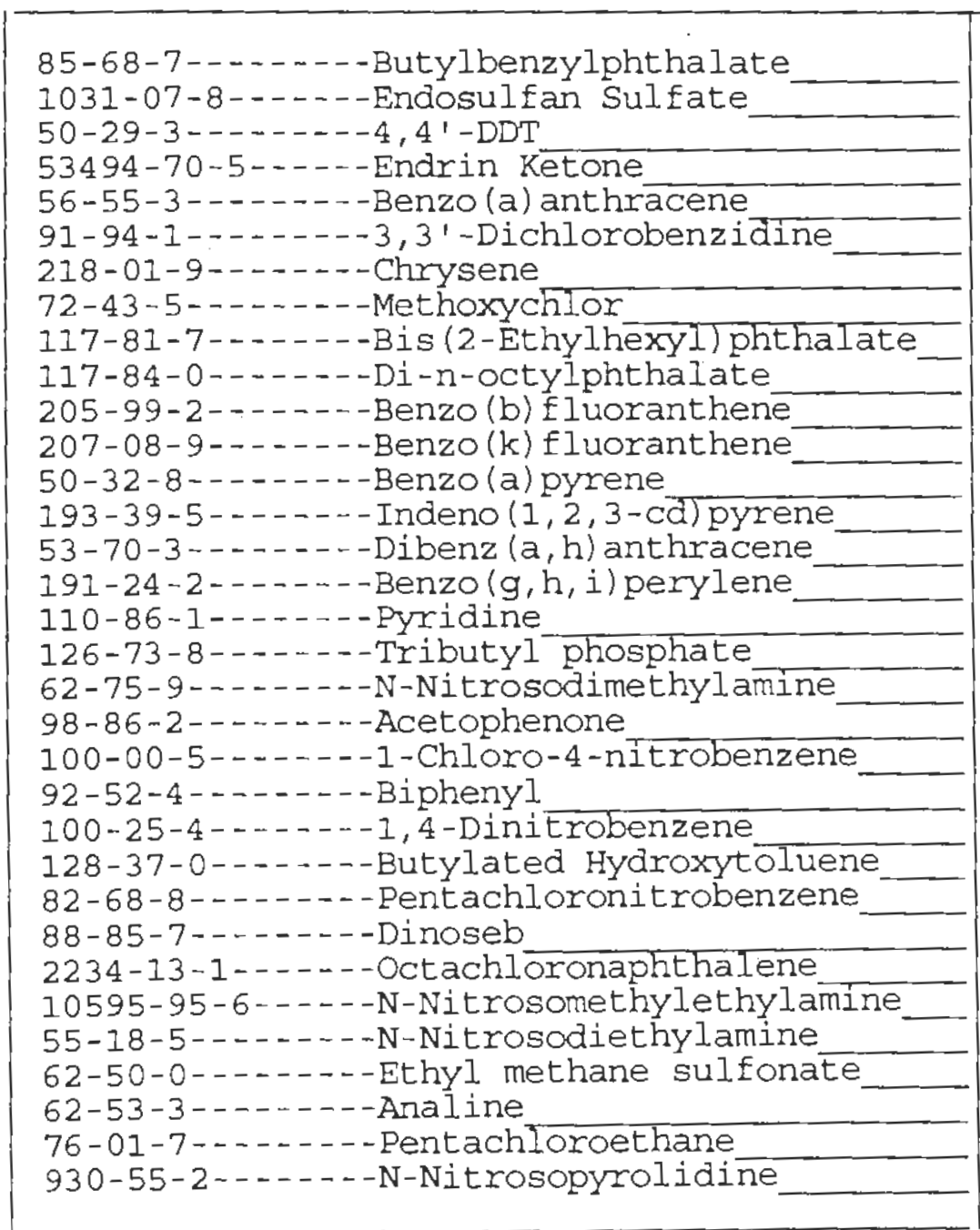


Lab Name: PNNL

Contract : $\mathrm{C104}$

Lab Code: PNNL

Case No.:

SAS NO. :
Matrix: (soil/water) SUPERNATAN

Sample wt/vol:

Level: (low/med)

$(g / \mathrm{mL}) \mathrm{ML}$

\section{LOW}

$\because$ Moisture:

decanted: $(\mathrm{Y} / \mathrm{N})$

Concentrated Extract Volume: 1000 (uL)

Injection Volume: (uL)
EPA SAMPLE NO.

C104-SIMS

SDG No.: 000819

Lab Sample ID: 00-1360-SLMS

Lab File ID: 00081907

Date Received:

Date Extracted:

Date Anaiyzed: 08/19/0

Dilution Factor: 1.0

CONCENTRATION UNITS: (ug/L or $\mathrm{ug} / \mathrm{Kg}$ ) UG/L

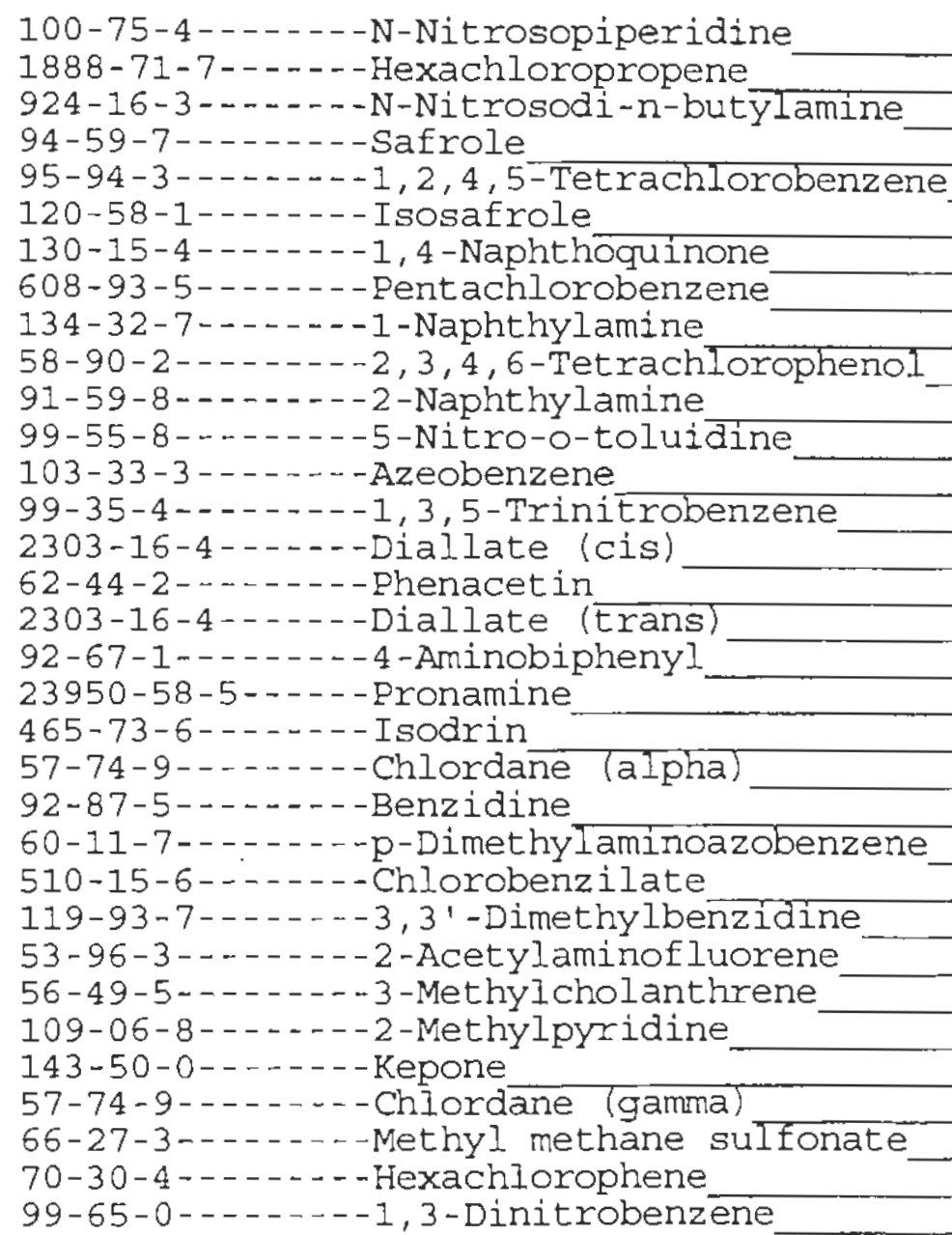

\begin{tabular}{|c|c|}
\hline 560 & $\mathrm{U}$ \\
\hline 560 & $\mathrm{U}$ \\
\hline 560 & $\mathrm{U}$ \\
\hline 560 & $\mathrm{U}$ \\
\hline 560 & $\mathrm{U}$ \\
\hline 560 & $\mathrm{U}$ \\
\hline 560 & U \\
\hline 560 & $\mathrm{U}$ \\
\hline 560 & $\mathrm{U}$ \\
\hline 560 & $\mathrm{U}$ \\
\hline 2 & 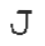 \\
\hline 560 & U \\
\hline 560 & $\mathrm{U}$ \\
\hline 560 & $U$ \\
\hline 560 & $\mathrm{U}$ \\
\hline 560 & $\mathrm{U}$ \\
\hline 560 & $\mathrm{U}$ \\
\hline 560 & $\mathrm{U}$ \\
\hline 560 & $U$ \\
\hline 560 & $U$ \\
\hline 560 & $\mathrm{U}$ \\
\hline 2500 & B \\
\hline 560 & $U$ \\
\hline 560 & $\mathrm{U}$ \\
\hline 560 & $U$ \\
\hline 560 & $U$ \\
\hline 560 & $U$ \\
\hline 160 & $J$ \\
\hline 560 & $U$ \\
\hline 560 & U \\
\hline 560 & U \\
\hline 560 & $U$ \\
\hline 560 & $U$ \\
\hline
\end{tabular}


Lab Name: PNNL

Lab code: PNNL

Case No.:

Matrix: (soil/water) SUPERNATAN

Sample wt/vol:

Level: (Low/med) LOW

$(g / \pi L) \quad M L$

: Moisture:

decanted: $(\mathrm{Y} / \mathrm{N})$

Contract: $\mathrm{C} 104$

SAS NO. :

EPA SAMPLE NO.

CI04-SLMS

Lab Sample ID: 00-1360-SLMS

Lab File ID: 00081907 :

Date Received:

Date Extracted:

Concentrated Extract Volume: 1000 (uL)

Injection Volume: (uL)

Date Analyzed: $08 / 19 / 0$

Dilution Factor: 1.0

GPC Cleanup: $(\mathrm{Y} / \mathrm{N}) \mathrm{N} \quad \mathrm{pH}$ :

CONCENTRATION UNITS:

CAS NO. COMPOUND $\quad$ (ug/L or $\mathrm{ug} / \mathrm{Kg}$ U UG/L

$Q$

87-65-0-...--2,6-Dichlorophenol 
Lab Name: PNNL

Lab Code: PNNL

Matrix: (soil/water) SUPERNATAN

Sample wt/vol:

(g/mL) $\mathrm{ML}$

Level: (low/med)

LOW

음 Moisture:

decanted: $(\Psi / N)$

Concentrated Extract Volume: 1000 (UL)

Injection Volume: (UL)

Contract: $\mathrm{C} 104$

SAS NO. :
EPA SAMPLE NO.

C104-SLMSD

SDG No.: 000819

GPC Cleanup: $(Y / N) N \quad p H$;

CAS NO.

COMPOUND

CONCENTRATION UNITS:

(ug/L or ug/Kg) UG/L

Lab Sample ID: 00-1360-SLMSD

Lab File ID: 00081908

Date Received:

Date Extracted:

Date Analyzed: 08/19/0

Dilution Factor: 1.0

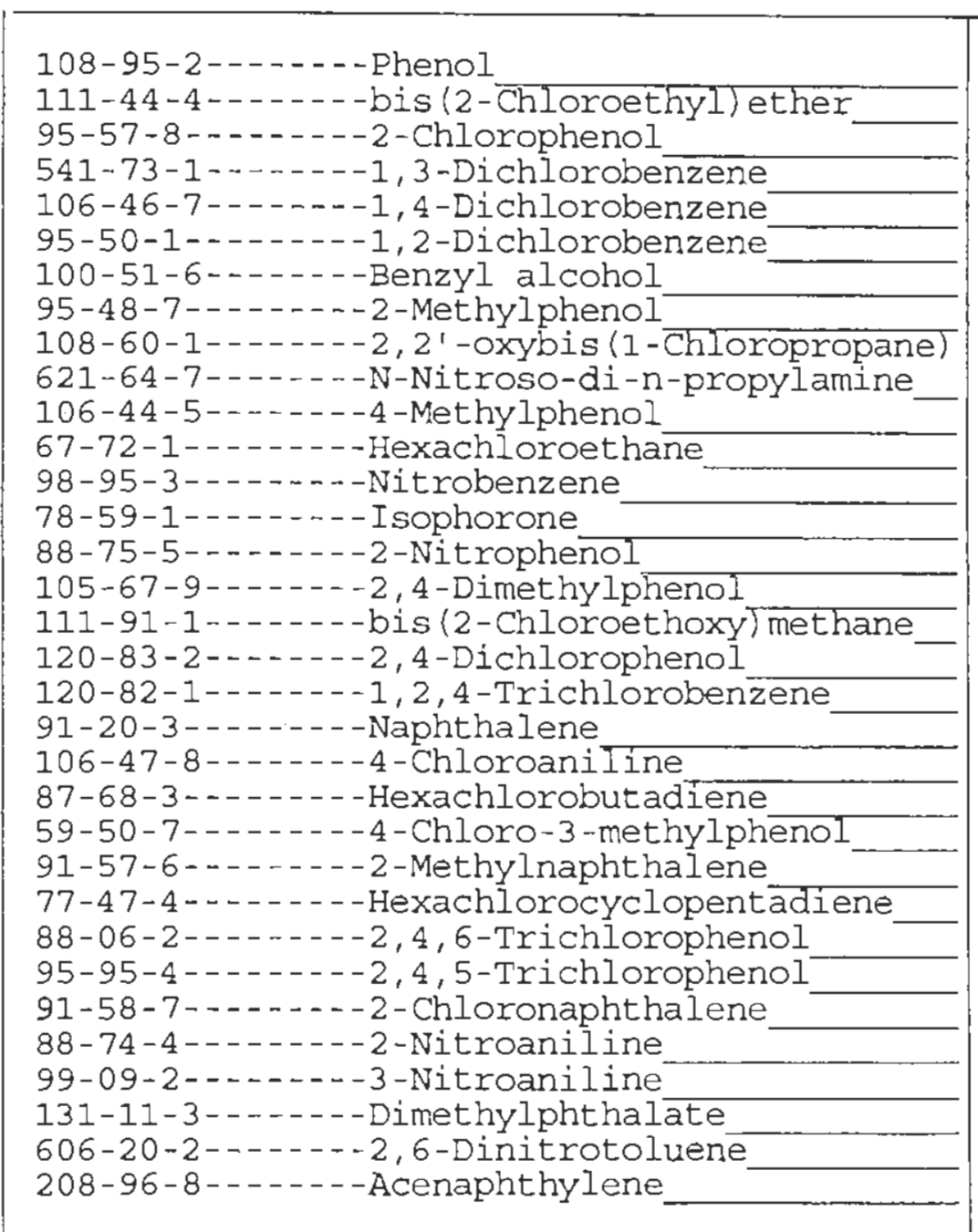


Lab Name: PNNL

Lab Code: PNNL
Contract: $\mathrm{C} 104$

SAS NO. :
EPA SAMPLE NO.

C104-SLMSD
Matrix: (soil/water) SUPERNATAN

Sample wt/vol:

$(g / \mathrm{mL}) \mathrm{MI}$

Level: (low $/ \mathrm{med}$ ) LOW

\% Moisture:

decanted: $\langle Y / N\rangle$

Concentrated Extract Volume: 1000 (uL)

Injection volume:

(uL)

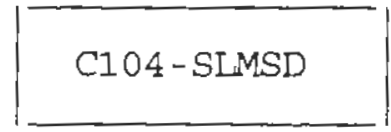

SDG No.: 000819

GPC Cleanup: (Y/N) $\mathrm{N} \quad \mathrm{pH}$ :

Lab Sample ID: 00-1360-SLMSD

Lab File ID: 00081908

Date Received:

Date Extracted:

Date Analyzed: $08 / 19 / 0$

Dilution Factor: I. 0

CONCENIRATION UNITS: $(\mathrm{ug} / \mathrm{L}$ or $\mathrm{ug} / \mathrm{kg}) \mathrm{UG} / \mathrm{L}$

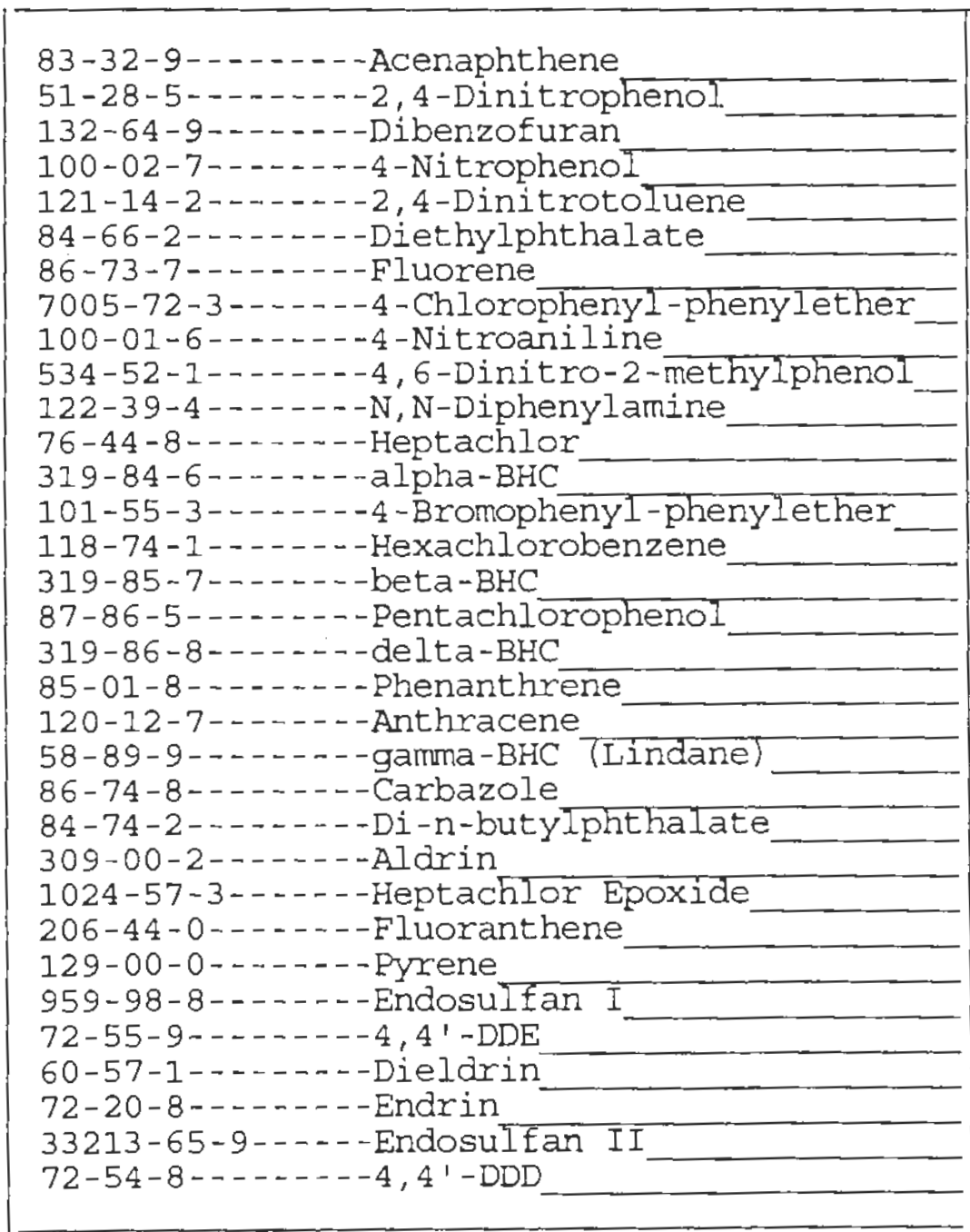

\begin{tabular}{r|l|}
2100 & \\
560 & $\mathrm{U}$ \\
560 & $\mathrm{U}$ \\
1500 & \\
2400 & \\
560 & $\mathrm{U}$ \\
560 & $\mathrm{U}$ \\
560 & $\mathrm{U}$ \\
560 & $\mathrm{U}$ \\
560 & $\mathrm{U}$ \\
560 & $\mathrm{U}$ \\
560 & $\mathrm{U}$ \\
560 & $\mathrm{U}$ \\
560 & $\mathrm{U}$ \\
560 & $\mathrm{U}$ \\
560 & $\mathrm{U}$ \\
1100 & \\
560 & $\mathrm{U}$ \\
560 & $\mathrm{U}$ \\
560 & $\mathrm{U}$ \\
560 & $\mathrm{U}$ \\
560 & $\mathrm{U}$ \\
560 & $\mathrm{U}$ \\
560 & $\mathrm{U}$ \\
560 & $\mathrm{U}$ \\
560 & $\mathrm{U}$ \\
2300 & \\
560 & $\mathrm{U}$ \\
560 & $\mathrm{U}$ \\
560 & $\mathrm{U}$ \\
560 & $\mathrm{U}$ \\
560 & $\mathrm{U}$ \\
560 & $\mathrm{U}$ \\
& \\
\hline
\end{tabular}


Lab Name: PNNL

Lab code: PNNL
Contract: C104

SAS NO.:
C104-SLMSD
Matrix: (soil/water) SUPERNATAN

Sample wt/vol:

Level: (low/med) LOW

\% Moisture:

Concentrated Extract Volume: 1000(uT) Injection Volume: (uL)
Lab Sample ID: 00-1360-SLMSD

Lab File ID: 00081908

Date Received:

Date Extracted:

Date Analyzed: 08/19/0

Dilution Factor: 1.0

GPC Cleanup: $(\mathrm{Y} / \mathrm{N}) \mathrm{N} \quad \mathrm{pH}$ :

CAS NO.

COMPOUND

CONCENTRATION UNITS:

(ug/L or $\mathrm{ug} / \mathrm{Kg}$ ) UG/L

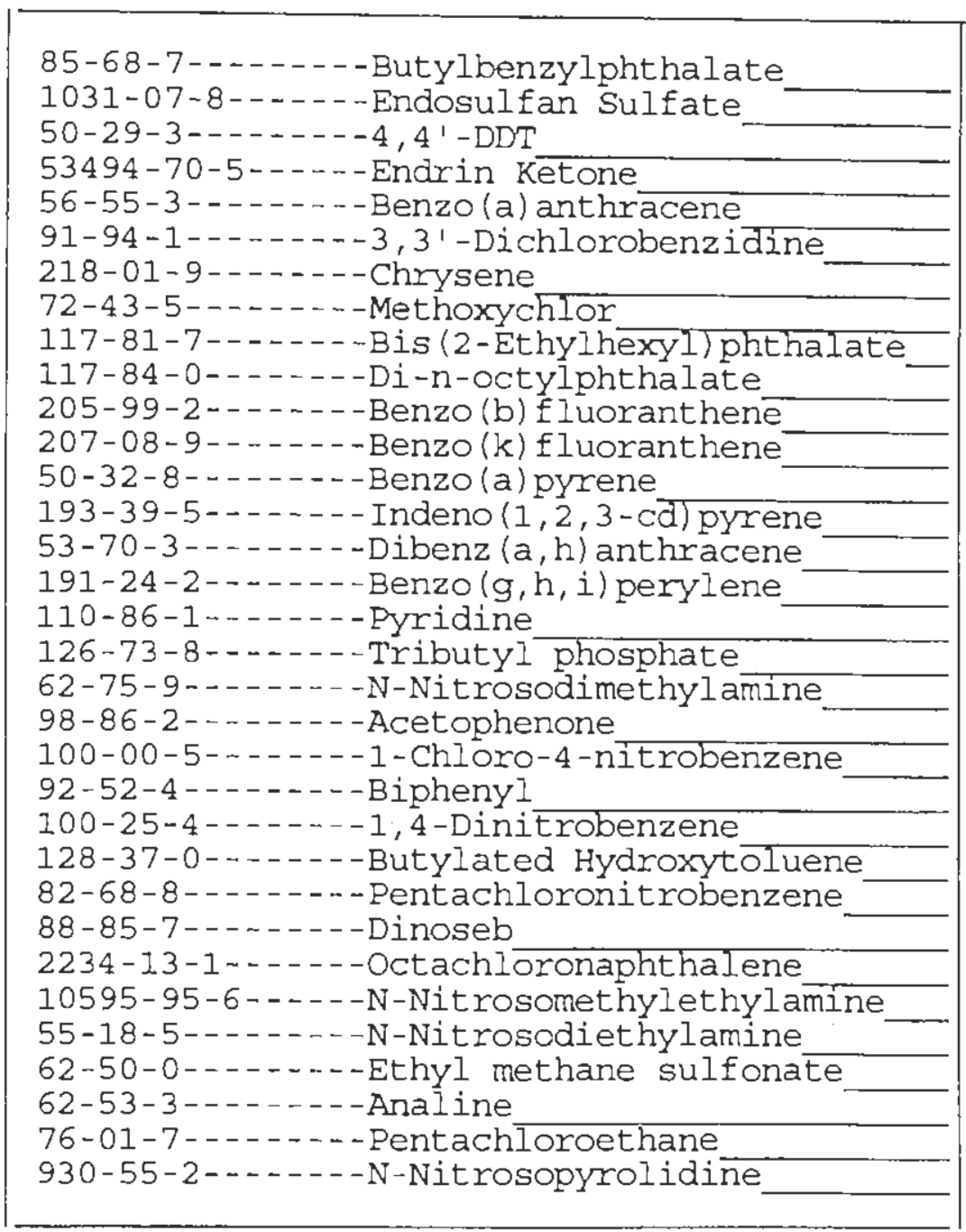


Lab Name: PNNL

Lab code: PNNL
Contract: $\mathrm{Cl04}$

Case No.:
SAS NO. :

\section{CIO4-SLMSD}

Matrix: (soil/water) SUPERNATAN

Sample wt/vol:

Level: (low/med) LoW

음 Moisture:

Concentrated Extract Volume: 1000 (UI) Injection Volume: (ui)

Lab Sample ID: 00-1360-SIMSD

Lab File ID: 00081908

Date Received:

Date Extracted:

Date Analyzed: 08/19/0

Dilution Factor: 1.0
GPC Cleanup:
$(Y / N) N$
$\mathrm{pH}:$

CONCENTRATION UNITS:

CAS NO.

COMPOUND

(ug/L or $\mathrm{ug} / \mathrm{Kg}$ ) UG/L

\begin{tabular}{|c|}
\hline 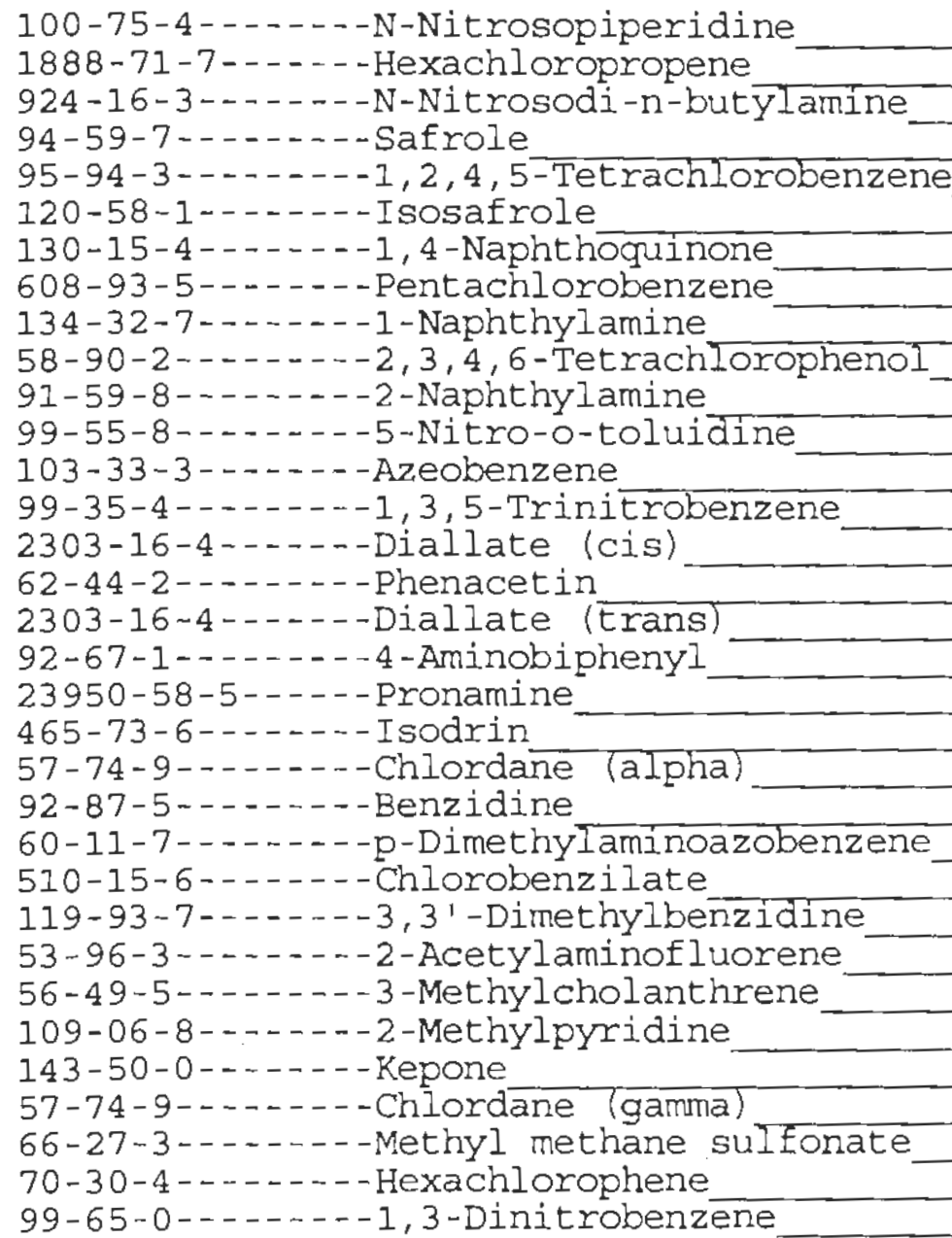 \\
\hline
\end{tabular}


Lab Name: PNNL

Lab Code: PNNL

Case No. :

Matrix: (soil/water) SUPERNATAN

Sample wt/vol: $(\mathrm{g} / \mathrm{mL}) \mathrm{ML}$

Level: (low/med) IOW

: Moisture: decanted: $(\mathrm{Y} / \mathrm{N})$

Concentrated Extract Volume: 1000 (uL) Injection volume: (uI)
EPA SAMPLE NO.

C104-SIMSD
Contract: $\mathrm{C} 104$

SAS NO. :
SDG NO. : 000819

Lab Sample ID: 00-1360-SLMSD

Lab File ID: 00081908

Date Received:

Date Extracted:

Date Analyzed: 08/19/0

Dilution Factor: 1.0 GPC Cleanup: (Y/N) N $\mathrm{pH}$ :

CONCENTRATION UNITS:

CAS NO. COMPOUND (ug/L or $\mathrm{ug} / \mathrm{Kg}$ ) UG/L
87-65-0--n---2,6-Dichlorophenol 
Lab Name: PNNL

Lab code: PNNL
Contract: C104

SAS NO.:
EPA SAMPLE NO.

C104-SLS
Matrix: (soil/water) SUPERNATAN

Sample wt/vol:

$(\mathrm{g} / \mathrm{mL}) \mathrm{ML}$

Leve 1: (low/med)

LOW

\% Moisture:

decanted: $(Y / N)$

Concentrated Extract Volume: 1000 (ut) Injection Volume: (ut)
Lab Sample ID: 00-1360-SLS

Lab File ID: 00081905

Date Received:

Date Extracted:

Date Analyzed: 08/19/0

Dilution Factor: 1.0

GPC Cleanup: $\quad(Y / N) \mathrm{N} \quad \mathrm{pH}$ :

CAS NO.

COMPOUND

CONCENTRATION UNITS:

(ug/L or $\mathrm{ug} / \mathrm{Kg}$ ) UG/L

$Q$

108-95-2-...-- - Phenol

111-44-4-..--bis (2-Chioroethyl) ether

95-57-8-...--2-Chlorophenol

541-73-1-..--1,3-Dichlorobenzene

106-46-7--.--1,4-Dichlorobenzene

95-50-1-...-1, 2-Dichlorobenzene

100-51-6-....-Benzyl alcohol

95-48-7-...--2-Methylphenol

108-60-1-...--2,2'-oxybis (1-Chloropropane)

62I-64-7--.---N-Nitroso-di-n-propylamine

106-44-5-...-4-Methylphenol

67-72-1-.....-Hexachloroethañe

98-95-3-....-Nitrobenzene

78-59-1-...--Isophorone

88-75-5-n-.--2-Nitropheñl

105-67-9-...-2,4-Dimethylphenol

111-91-1-....-bis (2-Chloroethoxy) methane

120-83-2-..--2,4-Dichlorophenol

120-82-1-...-1,2,4-Trichlorobenzene

91-20-3-...--Naphthalene

106-47-8-...-4-Chloroaniline

87-68-3-....- Hexachlorobutadiene

59-50-7-...--4-Chloro-3-methylphenol

91-57-6-...-2-Methylnaphthalene

77-47-4-...--Hexachlorocyclopentadiene

88-06-2-...--2,4,6-Trichlorophenol

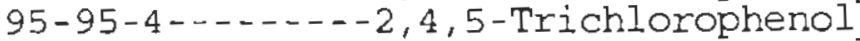

91-58-7--..-2-Chloronaphthalene

88-74-4-...-2-Nitroaniline

99-09-2-...--3-Nitroaniline

131-11-3-...-Dimethylphthalate

606-20-2--.-2,6-Dinitrotoluene.

208-96-8-..--Acenaphthylene

\begin{tabular}{l|l|}
560 & $\mathrm{U}$ \\
560 & $\mathrm{U}$ \\
560 & $\mathrm{U}$ \\
560 & $\mathrm{U}$ \\
560 & $\mathrm{U}$ \\
560 & $\mathrm{U}$ \\
560 & $\mathrm{U}$ \\
560 & $\mathrm{U}$ \\
560 & $\mathrm{U}$ \\
560 & $\mathrm{U}$ \\
560 & $\mathrm{U}$ \\
560 & $\mathrm{U}$ \\
560 & $\mathrm{U}$ \\
560 & $\mathrm{U}$ \\
560 & $\mathrm{U}$ \\
560 & $\mathrm{U}$ \\
560 & $\mathrm{U}$ \\
560 & $\mathrm{U}$ \\
560 & $\mathrm{U}$ \\
560 & $\mathrm{U}$ \\
560 & $\mathrm{U}$ \\
560 & $\mathrm{U}$ \\
560 & $\mathrm{U}$ \\
560 & $\mathrm{U}$ \\
560 & $\mathrm{U}$ \\
560 & $\mathrm{U}$ \\
560 & $\mathrm{U}$ \\
560 & $\mathrm{U}$ \\
560 & $\mathrm{U}$ \\
560 & $\mathrm{U}$ \\
560 & $\mathrm{U}$ \\
560 & $\mathrm{U}$ \\
560 & $\mathrm{U}$ \\
& \\
&
\end{tabular}

FORM I SV-I 
Lab Name: PNNL

Lab Code: PNNL

Case No.:

Matrix: (soil/water) SUPERNATAN

Sample wt/vol:

$(g / m L) M L$

Level: (low/med) LOW

\% Moisture :

decanted: $(\mathrm{Y} / \mathrm{N})$

Concentrated Extract Volume: 1000 (UL)

Injection Volume: (UL)

Contract: $\mathrm{C} 104$

SAS NO. :

Lab Sample ID: 00-1360-SLS

Lab File ID: 00081905

Date Received:

Date Extracted:

Date Analyzed: 08/19/0

Dilution Factor: 1.0

SDG No. : 000819

GPC Cleanup: $(\mathrm{Y} / \mathrm{N}) \mathrm{N} \quad \mathrm{pH}$ :

CAS NO.

COMPOUND

CONCENTRATION UNITS:

(ug/L or $\mathrm{ug} / \mathrm{Kg}$ ) UG/L

C104-SLS

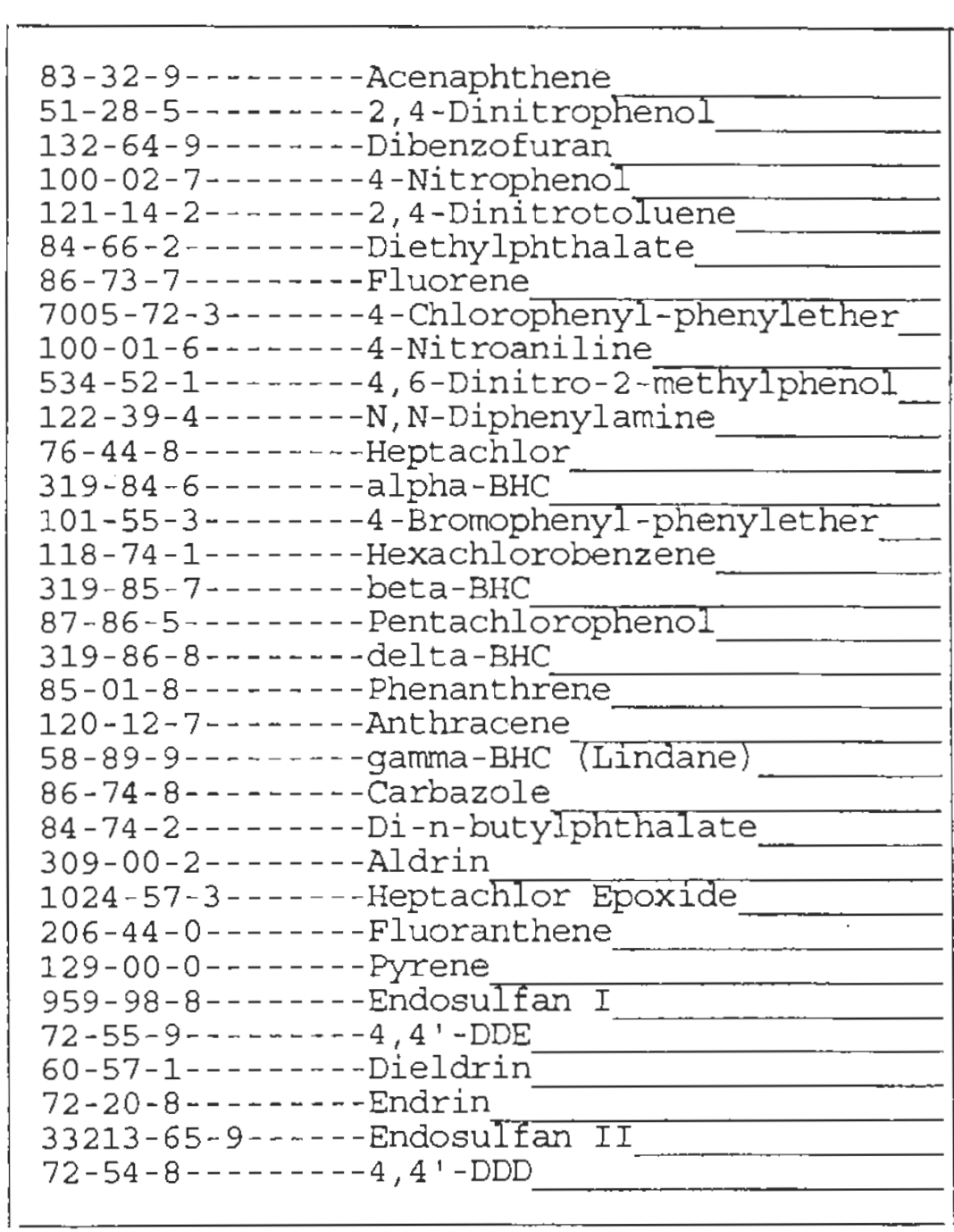


Lab Name: PNNJ,

Irab Code: PNNL
Contract: $\mathrm{ClO} 4$

Case No.:
SAS NO. :
C104-SLS
Matrix: (soil/water) SUPERNATAN

Sample wt/vol:

Level: (low $/ \mathrm{med})$ LOW

: Moisture:

decanted: $(\mathrm{Y} / \mathrm{N})$

Concentrated Extract Volume: 1000 (uL) Injection Volume: (UL) ( $\mathrm{g} / \mathrm{mL}) \mathrm{ML}$ GPC Cleanup: $(Y / N) \quad N$ $\mathrm{pH}:$
Lab Sample ID: 00-1360-SLS

Lab File ID: 00081905

Date Received:

Date Extracted:

Date Analyzed: 08/19/0

Dilution Factor: 1.0

CAS NO. COMPOUND

CONCENTRATION UNITS: $(\mathrm{ug} / \mathrm{I}$ or $\mathrm{ug} / \mathrm{Kg}) \mathrm{UG} / \mathrm{I}$

\begin{tabular}{|c|}
\hline 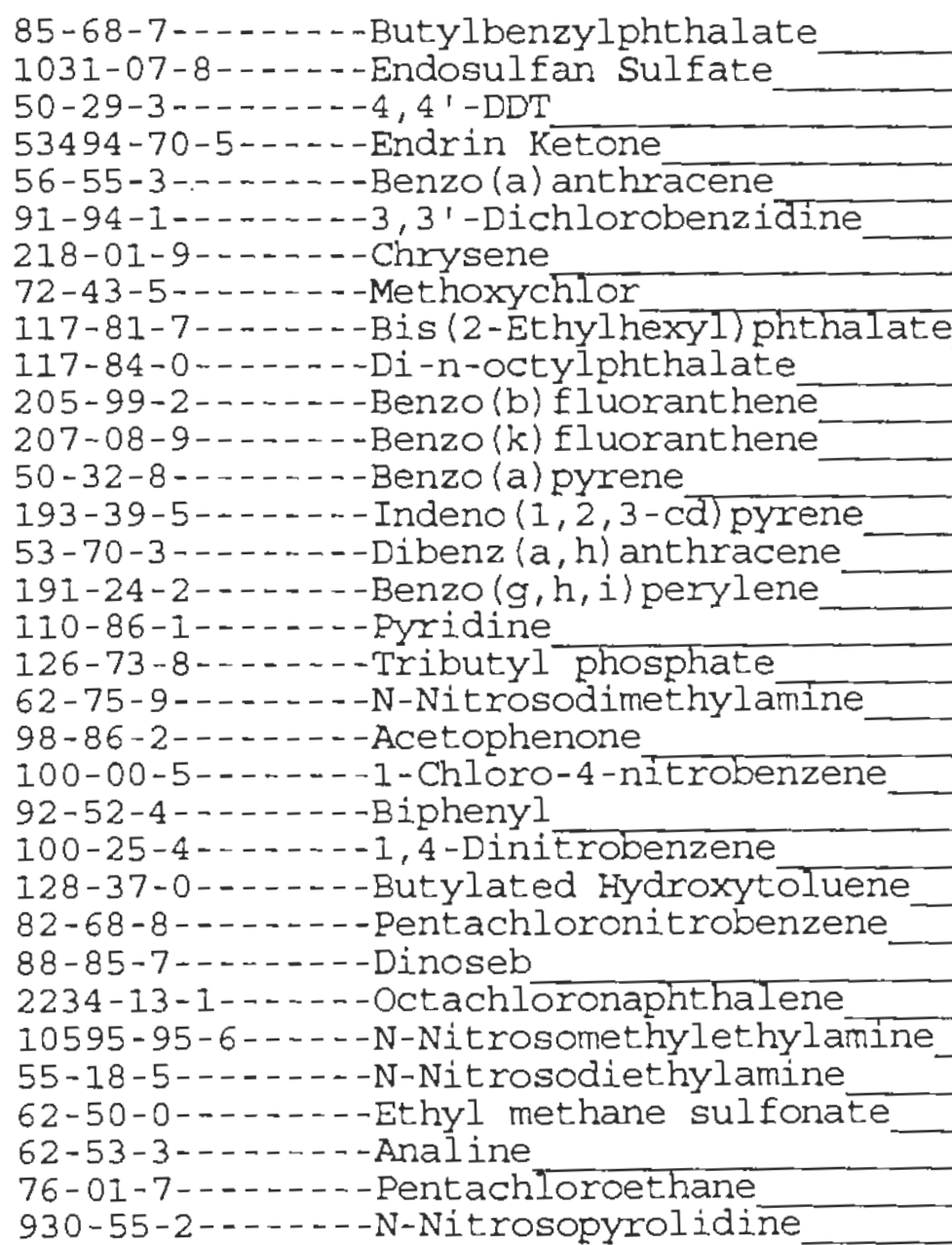 \\
\hline
\end{tabular}


Lab Name: PNNL

Matrix: (soil/water) SUPERNATAN

Sample wt/vol:

Level: (low/med) LOW

$\div$ Moisture:

decanted: $(\mathrm{Y} / \mathrm{N})$

Concentrated Extract Volume: 1000 (uw)

Injection Volume: (uI)
Lab Sample ID: 00-1360-SLS

Lab File ID: 00081905

Date Received:

Date Extracted:

Date Arlalyzed: 08/19/0

Dilution Factor: 1.0

GPC Cleanup: $(\mathrm{Y} / \mathrm{N}) \mathrm{N} \quad \mathrm{pH}$ :

CAS NO.

COMPOUND

CONCENTRATION UNITS:

(ug/L or $\mathrm{ug} / \mathrm{Kg}$ ) UG/L

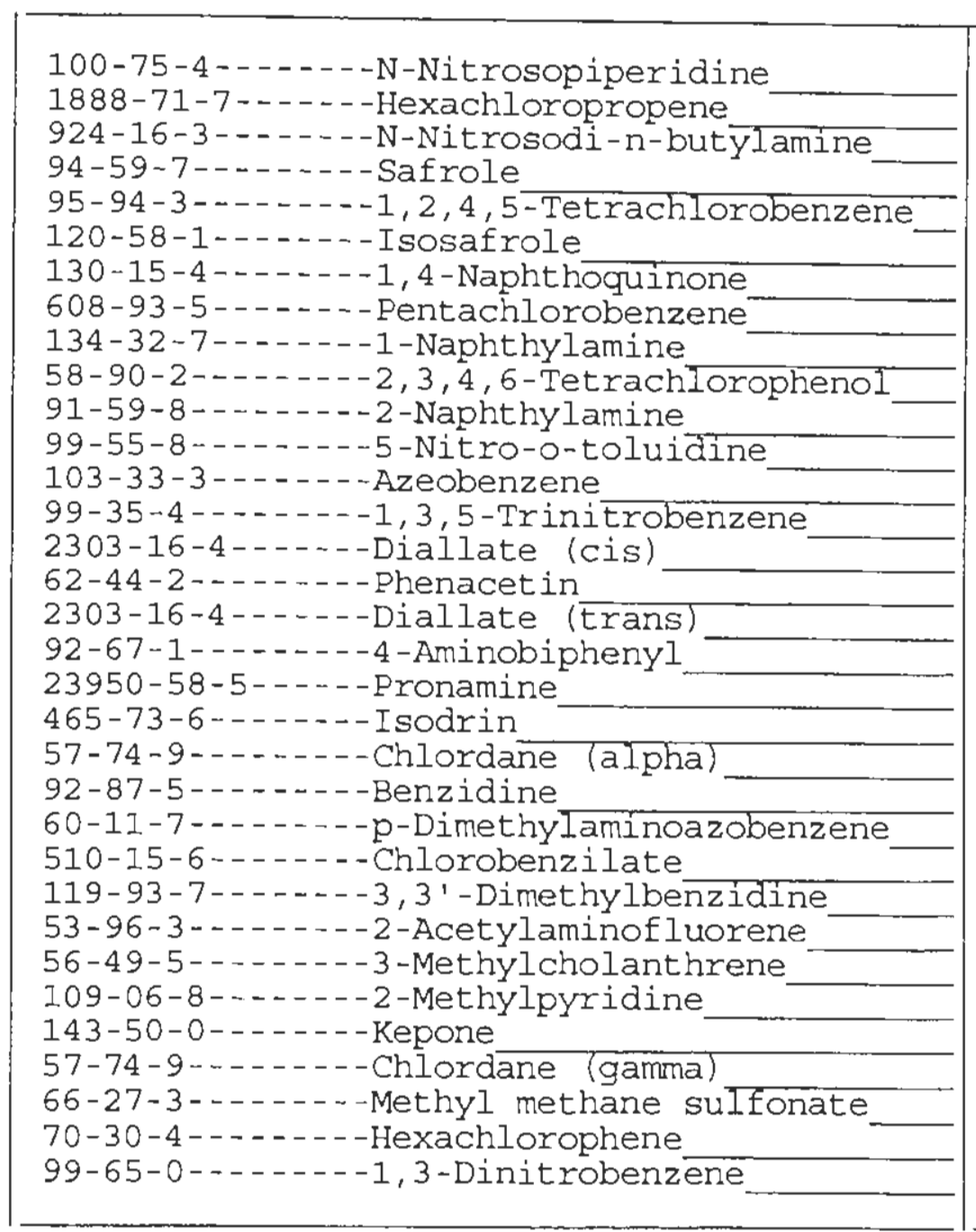


Lab Name: PNNL

Lab Code: PNNL

Case No.:

Matrix: (soil/water) SUPERNATAN

Sample wt/vol:

Level: (low $/ \mathrm{med}$ ) Low

\% Moisture: decanted: $(Y / N)$

Concentrated Extract Volume: 1000 (uL) Injection volume: (UL) contract: C104

SAS NO.:
EPA SAMPLE NO.

CIO4-SLS

SDG NO.: 000819

Lab Sample ID: 00-1360-SLS

Lab File ID: 00081905

Date Received:

Date Extracted:

Date Analyzed: 08/19/0

Dilution Factor: 1.0

GPC Cleanup: $(\mathrm{Y} / \mathrm{N}) \mathrm{N} \quad \mathrm{pH}$ :

CAS NO.

COMPOUND
CONCENIRATION UNITS:

(ug/L or $u g / \mathrm{kg}$ ) UG/L

$Q$ 
Lab Name: PNNL

Lab Code: PNNL,

Case No. :

SAS NO.:

SDG No.: 000819

Matrix: (soil/water) SoLID

Sample wt/vol:

$5.0(\mathrm{~g} / \mathrm{mL}) \quad \mathrm{G}$

Lab Sample ID: 00-1361-SSB

Level: (low $/ \mathrm{med}$ ) LOW

Lab File ID: $\quad 00081913$

\% Moisture: 0 decanted: $(\mathrm{Y} / \mathrm{N}) \mathrm{N}$

Date Received:

Concentrated Extract Volume: 1000 (UL)

Date Extracted:

Injection Volume: (uL)

Date Analyzed: 08/20/0

GPC Cleanup: $(Y / N) \mathrm{N} \quad \mathrm{pH}$ :

Dilution Factor: 1.0

CAS NO.

COMPOUND

CONCENTRATION UNITS:

(ug/I or $u g / \mathrm{kg}$ ) UG/KG

$Q$

\begin{tabular}{|c|}
\hline 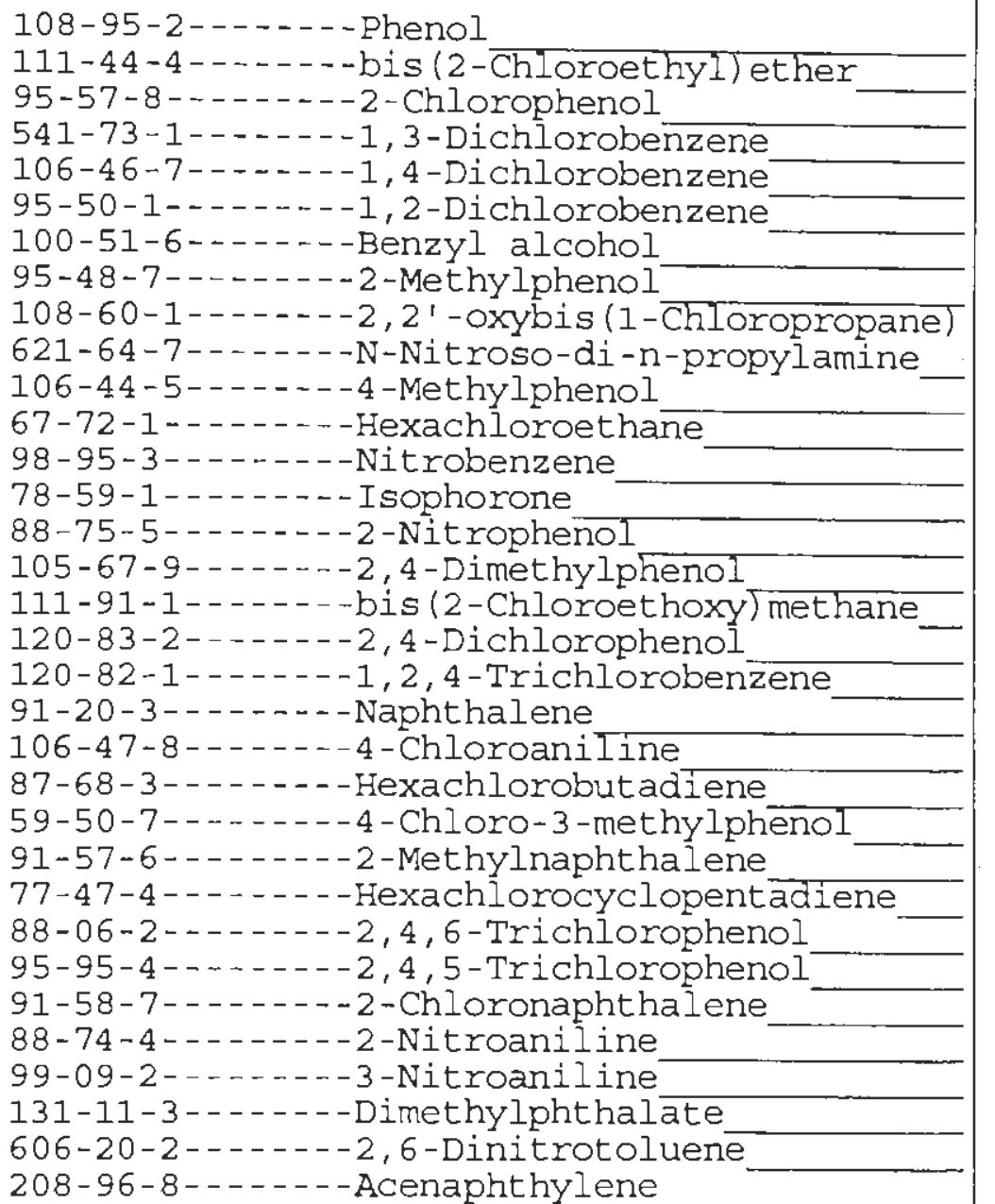 \\
\hline
\end{tabular}


Lab Name: PNNL

Lab Code: PNNL
Contract: $\mathrm{C} 104$

SAS NO. :
C104-SSB
Case No.:

Matrix: (soil/water) SOLID

Sample wt/vol:

$5.0(\mathrm{~g} / \mathrm{mL}) \mathrm{G}$

Level: (low/med) IOW

$\div$ Moisture: 0 decanted: $(Y / N)$ N

Concentrated Extract Volume: 1000 (UL)

Injection volume: (UII)
pH :
GPC Cleanup:
$\langle\mathrm{Y} / \mathrm{N}\rangle \mathrm{N}$

Lab Sample ID: 00-1361-SSB

Lab File ID: 00081913

Date Received:

Date Extracted:

Date Analyzed: 08/20/0

Dilution Factor: 1.0

CONCENTRATION UNITS:

CAS NO.

COMPOUND

$(\mathrm{ug} / \mathrm{L}$ or $\mathrm{ug} / \mathrm{Kg}) \mathrm{UG} / \mathrm{KG}$

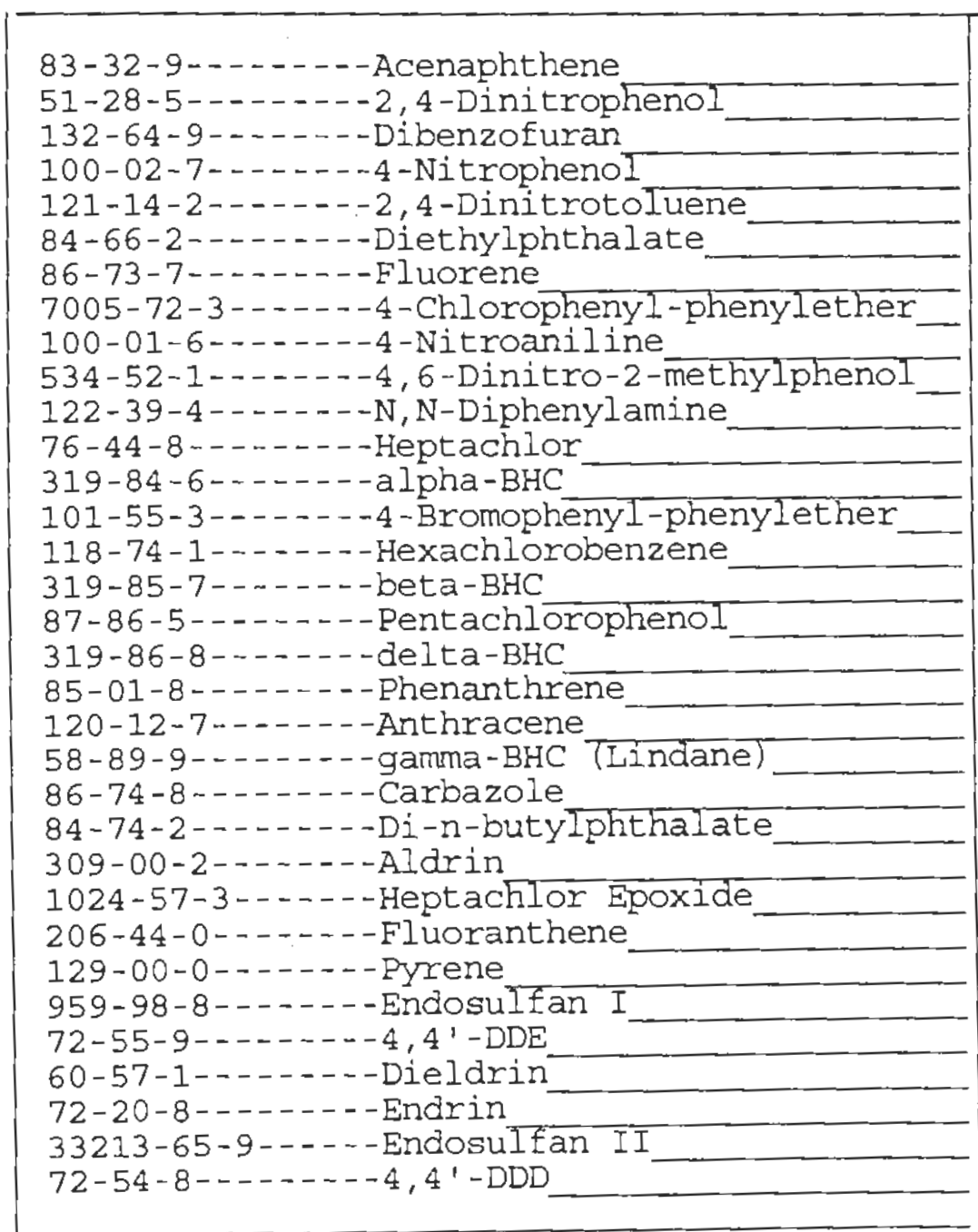

\begin{tabular}{l|l}
2000 & $U$ \\
2000 & $U$ \\
2000 & $U$ \\
2000 & $U$ \\
2000 & $U$ \\
2000 & $U$ \\
2000 & $U$ \\
2000 & $U$ \\
2000 & $U$ \\
2000 & $U$ \\
2000 & $U$ \\
2000 & $U$ \\
2000 & $U$ \\
2000 & $U$ \\
2000 & $U$ \\
2000 & $U$ \\
2000 & $U$ \\
2000 & $U$ \\
2000 & $U$ \\
2000 & $U$ \\
2000 & $U$ \\
2000 & $U$ \\
2000 & $U$ \\
2000 & $U$ \\
2000 & $U$ \\
2000 & $U$ \\
2000 & $U$ \\
2000 & $U$ \\
2000 & $U$ \\
2000 & $U$ \\
2000 & $U$ \\
2000 & $U$ \\
2000 & $U$ \\
& \\
\end{tabular}


Lab Name: PNNL

Contract: $\mathrm{ClO} 04$

Lab code: PNNL

Case No.:
C104-SSB

SDG NO.: 000819
Matrix: (soil/water) SOLID

Sample wt/vol: $\quad 5.0(\mathrm{~g} / \mathrm{mL}) \mathrm{G}$

Level: (low/med) LOW

$\because$ Moisture: 0 decanted: $(\mathrm{Y} / \mathrm{N}) \mathrm{N}$

Concentrated Extract Volume: 1000 (uL)

Injection Volume:

(UL)

GPC Cleanup: $(\mathrm{Y} / \mathrm{N}) \mathrm{N} \quad \mathrm{pH}$ :

Luab Sample ID: 00-1361-SSB

Lab File ID: 00081913

Date Received:

Date Extracted:

Date Analyzed: 08/20/0

Dilution Factor: 1.0

CAS NO.

COMPOUND

CONCENTRATION UNITS:

$(\mathrm{ug} / \mathrm{I}$ or $\mathrm{ug} / \mathrm{Kg})$ UG/KG

\begin{tabular}{|c|}
\hline 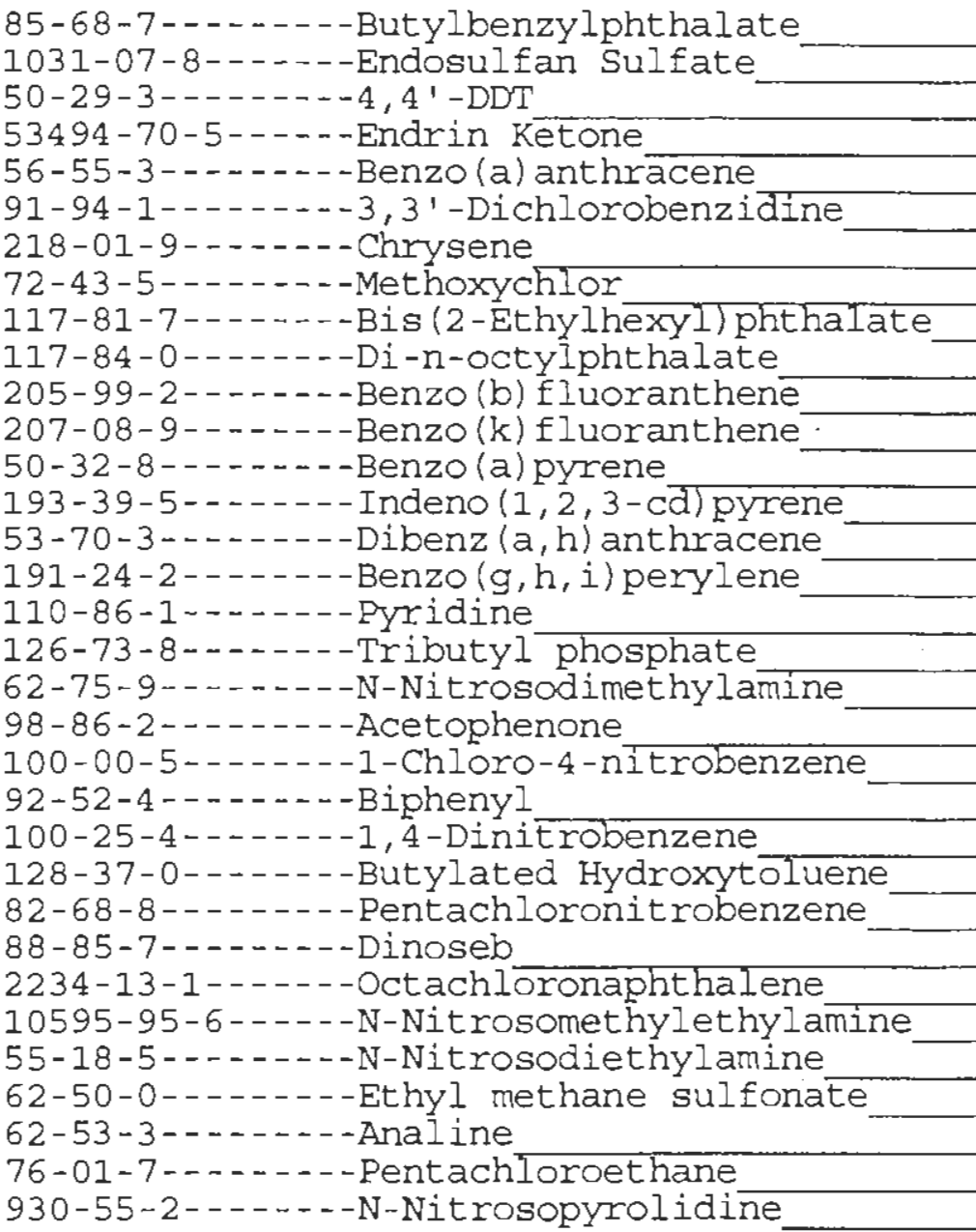 \\
\hline
\end{tabular}

\begin{tabular}{|c|c|l|}
2000 & $\mathrm{U}$ \\
2000 & $\mathrm{U}$ \\
2000 & $\mathrm{U}$ \\
2000 & $\mathrm{U}$ \\
2000 & $\mathrm{U}$ \\
2000 & $\mathrm{U}$ \\
2000 & $\mathrm{U}$ \\
2000 & $\mathrm{U}$ \\
2000 & $\mathrm{U}$ \\
2000 & $\mathrm{U}$ \\
2000 & $\mathrm{U}$ \\
2000 & $\mathrm{U}$ \\
2000 & $\mathrm{U}$ \\
2000 & $\mathrm{U}$ \\
2000 & $\mathrm{U}$ \\
2000 & $\mathrm{U}$ \\
8200 & \\
5500 & \\
2000 & $\mathrm{U}$ \\
8800 & \\
6300 & \\
\hline 6200 & \\
4400 & \\
170 & $\mathrm{~J}$ \\
2000 & $\mathrm{U}$ \\
6500 & \\
\hline 250000 & \\
2000 & $\mathrm{U}$ \\
2000 & $\mathrm{U}$ \\
2000 & $\mathrm{U}$ \\
2000 & $\mathrm{U}$ \\
2000 & $\mathrm{U}$ \\
2000 & $\mathrm{U}$ \\
\hline
\end{tabular}

FORM I SV-3

OLM03.0 
Lab Name: PNNL

Lab Code: PNNL,
Contract: $\mathrm{ClO4}$

SAS NO.:
Matrix: (soil/water) SOLID

Sarmple wt/vol:

$5.0(\mathrm{~g} / \mathrm{mL}) \quad \mathrm{G}$

Level: (low/med) LOW

\% Moisture: 0 decanted: $(\mathrm{Y} / \mathrm{N}) \mathrm{N}$

Concentrated Extract Volume: 1000 (uL)

Injection volume: (uL)
C104-SSB

SDG No.: 000819
GPC Cleanup: $(\mathrm{Y} / \mathrm{N}) \mathrm{N} \quad \mathrm{pH}$ :

CAS NO.

COMPOUND
Lab Sample ID: 00-1361-SSB

Lab File ID: 00081913

Date Received:

Date Extracted:

Date Analyzed: 08/20/0

Dilution Factor: 1.0

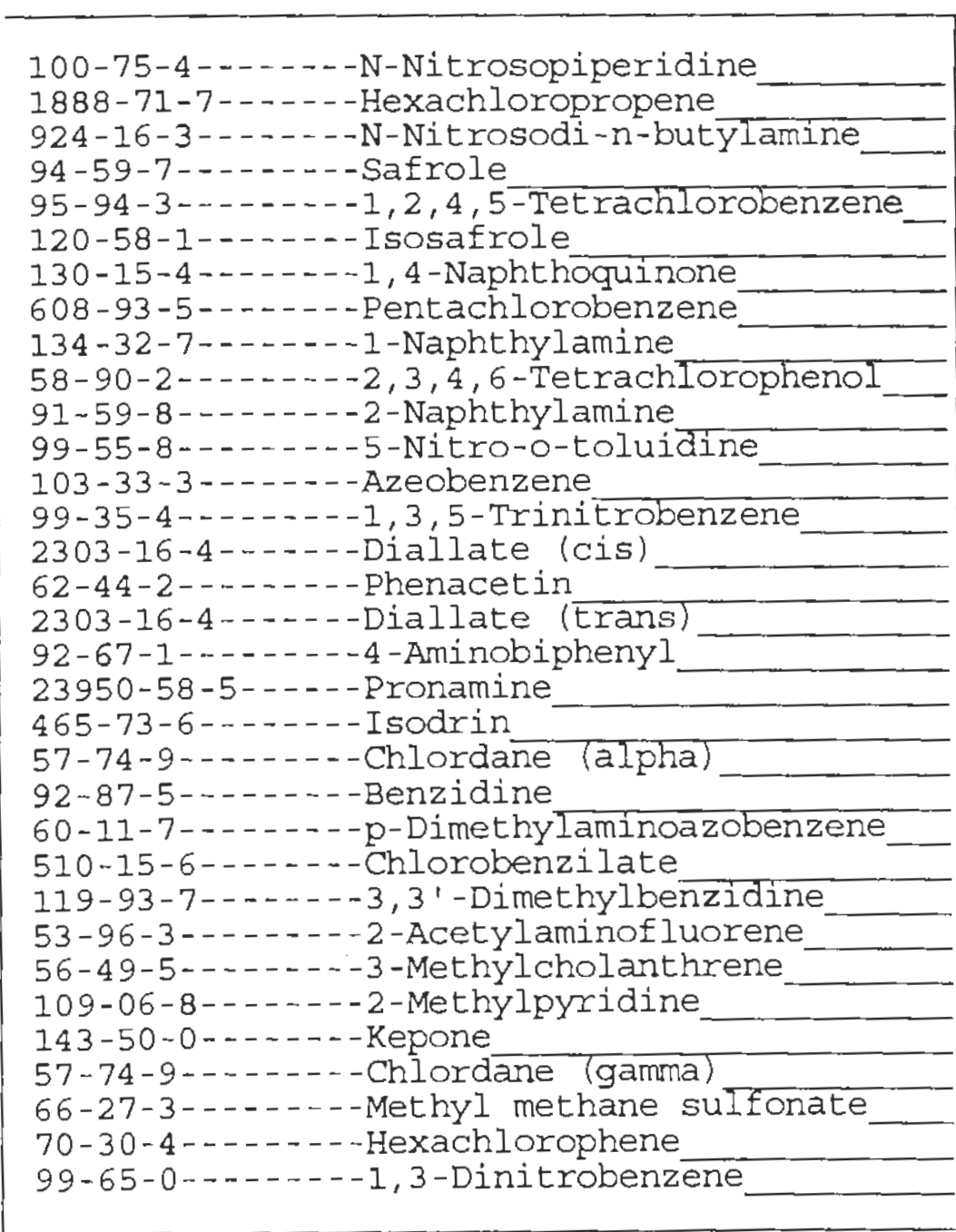

FORM I SV-4
CONCENTRATION UNITS:

(ug/L or $\mathrm{ug} / \mathrm{Kg}$ ) UG/KG

Q 
Lab Name: PNNL

Lab Code: PNNL

Case No.:

Matrix: (soil/water) SOLID

Sample wt/vol:

$5.0(\mathrm{~g} / \mathrm{mL}) \mathrm{G}$

Level: (low/med) LOW

$\because$ Moisture: 0 decanted: $(Y / N) N$

Contract: $\mathrm{C} 104$

SAS NO.:

SDG NO.: 000819

Concentrated Extract Volume: 1000 (uL)

Injection volume: (uI)

Lab Sample ID: 00-1361-SSB

Lab File ID: 00081913

Date Received:

Date Extracted:

Date Analyzed: 08/20/0

Dilution Factor: 1.0
EPA SAMPLE NO.

C104-SSB

GPC Cleanup: (Y/N) N $\mathrm{pH}$ :

CONCENIRATION UNITS:

CAS NO. COMPOUND $\quad\langle\mathrm{ug} / \mathrm{L}$ or $\mathrm{ug} / \mathrm{Kg}) \mathrm{UG} / \mathrm{KG} \quad \mathrm{Q}$

$87-65-0-\ldots-1--2,6-$ Dichlorophenol 
Lab Name: PNNL

Lab code: PNNL

Case No.:
Contract: $\mathrm{C104}$

SAS NO. :
C104-SSD
Matrix: (soil/water) SOLID

Sample wt/vol:

$4.9(\mathrm{~g} / \mathrm{mL}) \quad \mathrm{G}$

Level: (low/med) IOW

\% Moisture: 0 decanted: $\langle Y / N\rangle N$

Concentrated Extract Volume: 1000 (uU)

Injection Volume: (UI)
Lab Sample ID: 00-1361-SSD

Lab File ID: 00081915

Date Received:

Date Extracted:

Date Analyzed: $08 / 20 / 0$

Dilution Factor $\$ 10.0$
GPC Cleanup:
$(Y / N) \quad N$
$\mathrm{pH}:$

CAS NO.

COMPOUND

CONCENIRATION UNITS:

(ug/L or ug/Kg) UG/KG

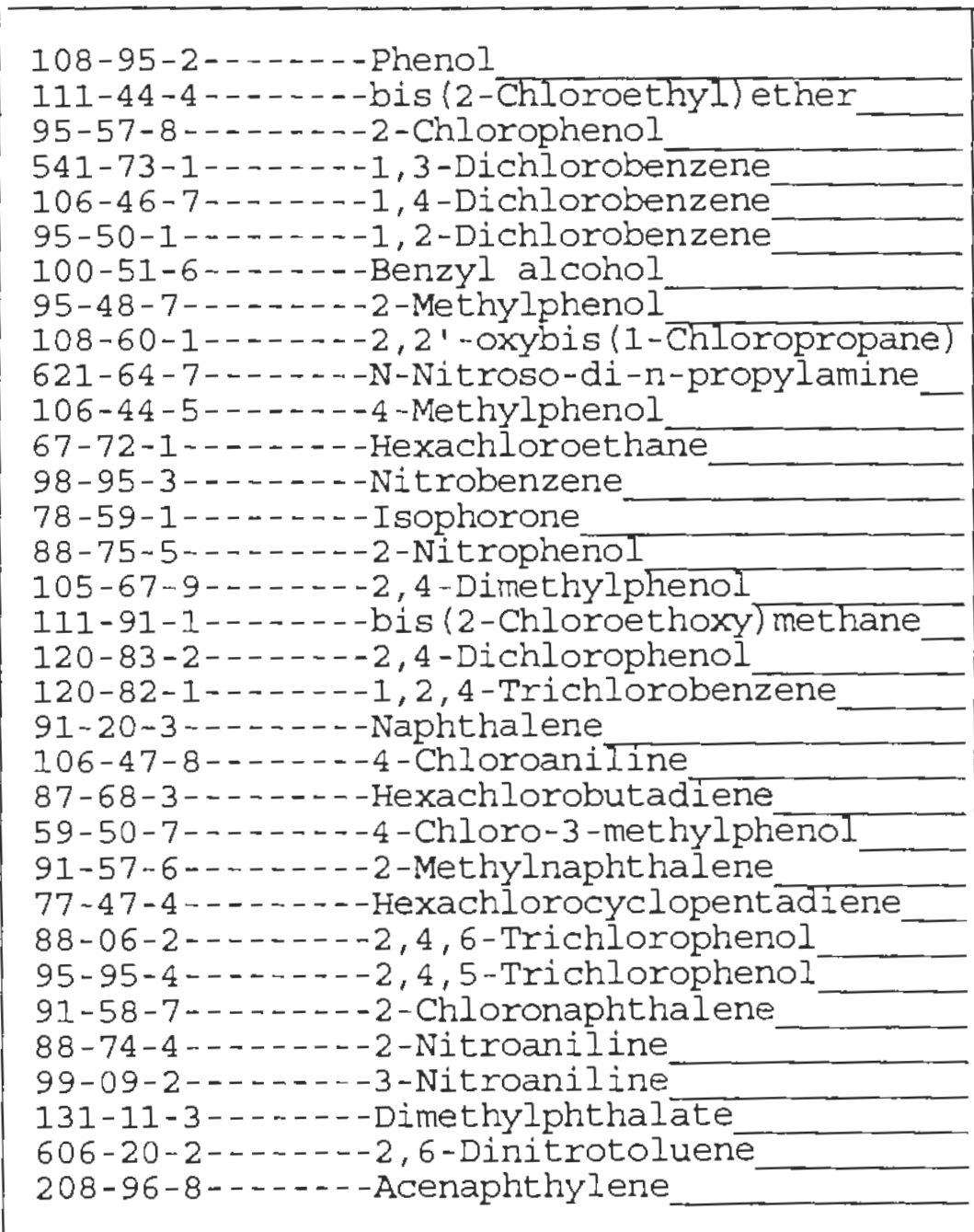

\begin{tabular}{|l|l|}
20000 & $\mathrm{U}$ \\
20000 & $\mathrm{U}$ \\
20000 & $\mathrm{U}$ \\
20000 & $\mathrm{U}$ \\
20000 & $\mathrm{U}$ \\
20000 & $\mathrm{U}$ \\
20000 & $\mathrm{U}$ \\
20000 & $\mathrm{U}$ \\
20000 & $\mathrm{U}$ \\
20000 & $\mathrm{U}$ \\
6100 & $\mathrm{~B}$ \\
20000 & $\mathrm{U}$ \\
20000 & $\mathrm{U}$ \\
20000 & $\mathrm{U}$ \\
20000 & $\mathrm{U}$ \\
20000 & $\mathrm{U}$ \\
20000 & $\mathrm{U}$ \\
20000 & $\mathrm{U}$ \\
20000 & $\mathrm{U}$ \\
20000 & $\mathrm{U}$ \\
20000 & $\mathrm{U}$ \\
20000 & $\mathrm{U}$ \\
20000 & $\mathrm{U}$ \\
20000 & $\mathrm{U}$ \\
20000 & $\mathrm{U}$ \\
20000 & $\mathrm{U}$ \\
20000 & $\mathrm{U}$ \\
20000 & $\mathrm{U}$ \\
20000 & $\mathrm{U}$ \\
20000 & $\mathrm{U}$ \\
20000 & $\mathrm{U}$ \\
20000 & $\mathrm{U}$ \\
20000 & $\mathrm{U}$ \\
& \\
\hline &
\end{tabular}


Lab Name: PNNL

Lab Code: PNNL
Contract: CI04

SAS NO. :
CI04-SSD
Matrix: (soil/water) SOLID

Sample wt/vol:

$4.9(g / m L) \quad G$

Level: (low/med)

LOW

․oisture: 0

decanted: $(\mathrm{Y} / \mathrm{N}) \mathrm{N}$

Concentrated Extract Volume: 1000 (uL)

Injection volume: (uI)

GPC Cleanup: $(\mathrm{Y} / \mathrm{N}) \mathrm{N} \quad \mathrm{pH}$ :
Lab Sample ID: 00-1361-SSD

Lab File ID: 00081915

Date Received:

Date Extracted:

Date Analyzed: 08/20/0

Dilution Factor: 10.0

CONCENTRATION UNITS:

CAS NO.

COMPOUND

(ug/L or $u g / \mathrm{kg}$ ) UG/KG

\begin{tabular}{|c|}
\hline 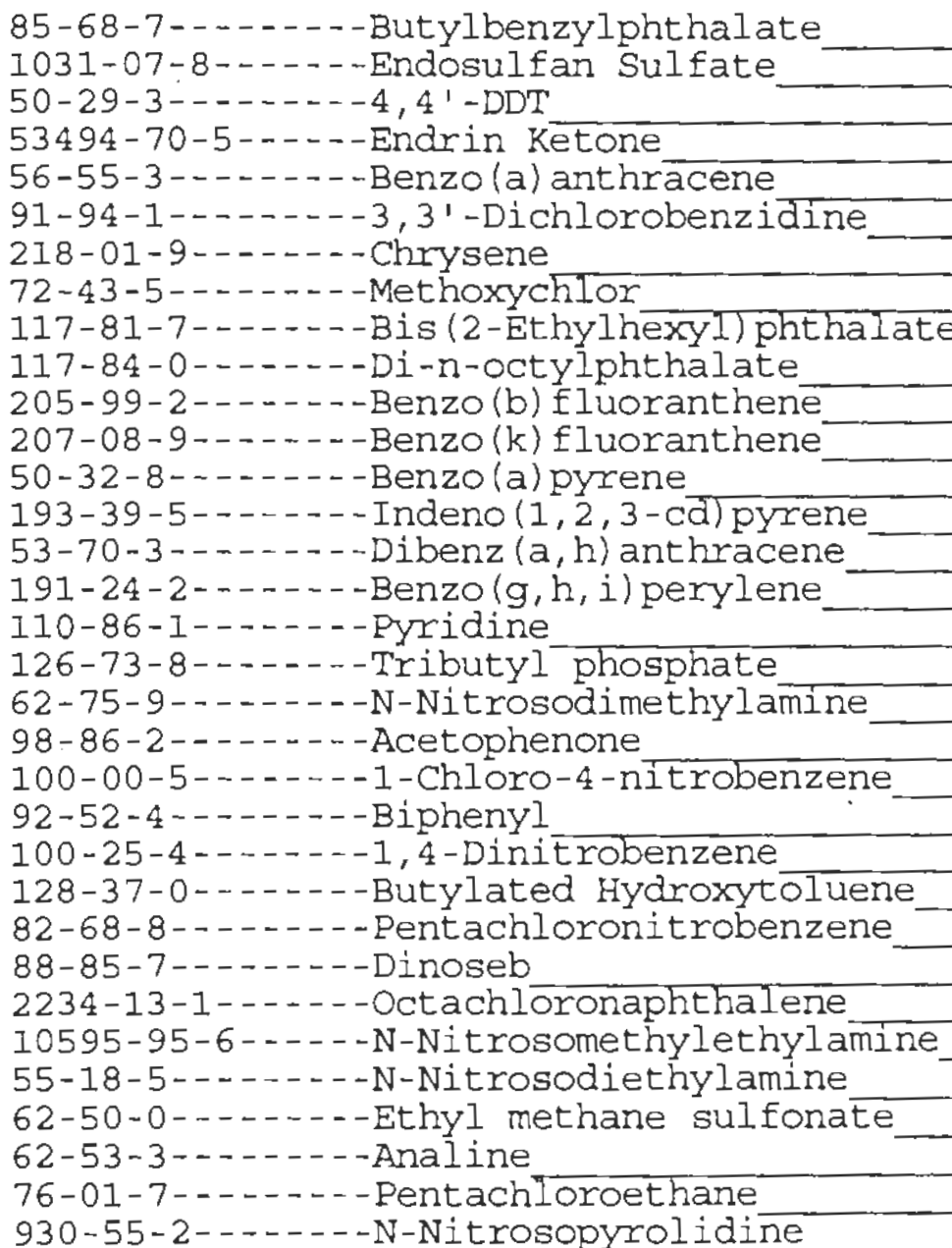 \\
\hline
\end{tabular}

\begin{tabular}{r|l|l|}
20000 & $U$ \\
20000 & $U$ \\
20000 & $U$ \\
20000 & $U$ \\
20000 & $U$ \\
20000 & $U$ \\
20000 & $U$ \\
20000 & $U$ \\
20000 & $U$ \\
20000 & $U$ \\
20000 & $U$ \\
20000 & $U$ \\
20000 & $U$ \\
20000 & $U$ \\
20000 & $U$ \\
20000 & $U$ \\
20000 & $U$ \\
50000 & $\mathrm{~B}$ \\
20000 & $\mathrm{U}$ \\
6200 & $\mathrm{JB}$ \\
2900 & $\mathrm{JB}$ \\
1700 & $\mathrm{JB}$ \\
1500 & $\mathrm{JB}$ \\
790 & $\mathrm{JB}$ \\
20000 & $\mathrm{U}$ \\
3400 & $\mathrm{JB}$ \\
51000 & $\mathrm{~B}$ \\
20000 & $\mathrm{U}$ \\
20000 & $\mathrm{U}$ \\
20000 & $\mathrm{U}$ \\
20000 & $\mathrm{U}$ \\
20000 & $\mathrm{U}$ \\
20000 & $\mathrm{U}$ \\
& \\
\hline
\end{tabular}

OLMO3.C 
Lab Name: PNNL

Lab Code: PNNL
Contract: $\mathrm{Cl04}$

SAS NO. :

C104-SSD

SDG No. : 000819

Matrix: (soil/water) SOLID

Lab Sample ID: 00-1361-SSD

Sample wt/vol:

$4.9(\mathrm{~g} / \mathrm{mL}) \mathrm{G}$

Level: (low/med)

LOW

Lab File ID: 00081915

Date Received:

$\%$ Moisture: 0 decanted: $(Y / N) N$

Date Extracted:

Concentrated Extract Volume: 1000 (uL)

Date Analyzed: 08/20/0

Injection volume: (uL)

Dilution Factor: 10.0

GPC Cleanup: (Y/N) N $\mathrm{NH}$ :

CONCENTRATION UNITS:

CAS NO. COMPOUND

(ug/L or $\mathrm{ug} / \mathrm{Kg}$ ) UG/KG

\begin{tabular}{|c|}
\hline 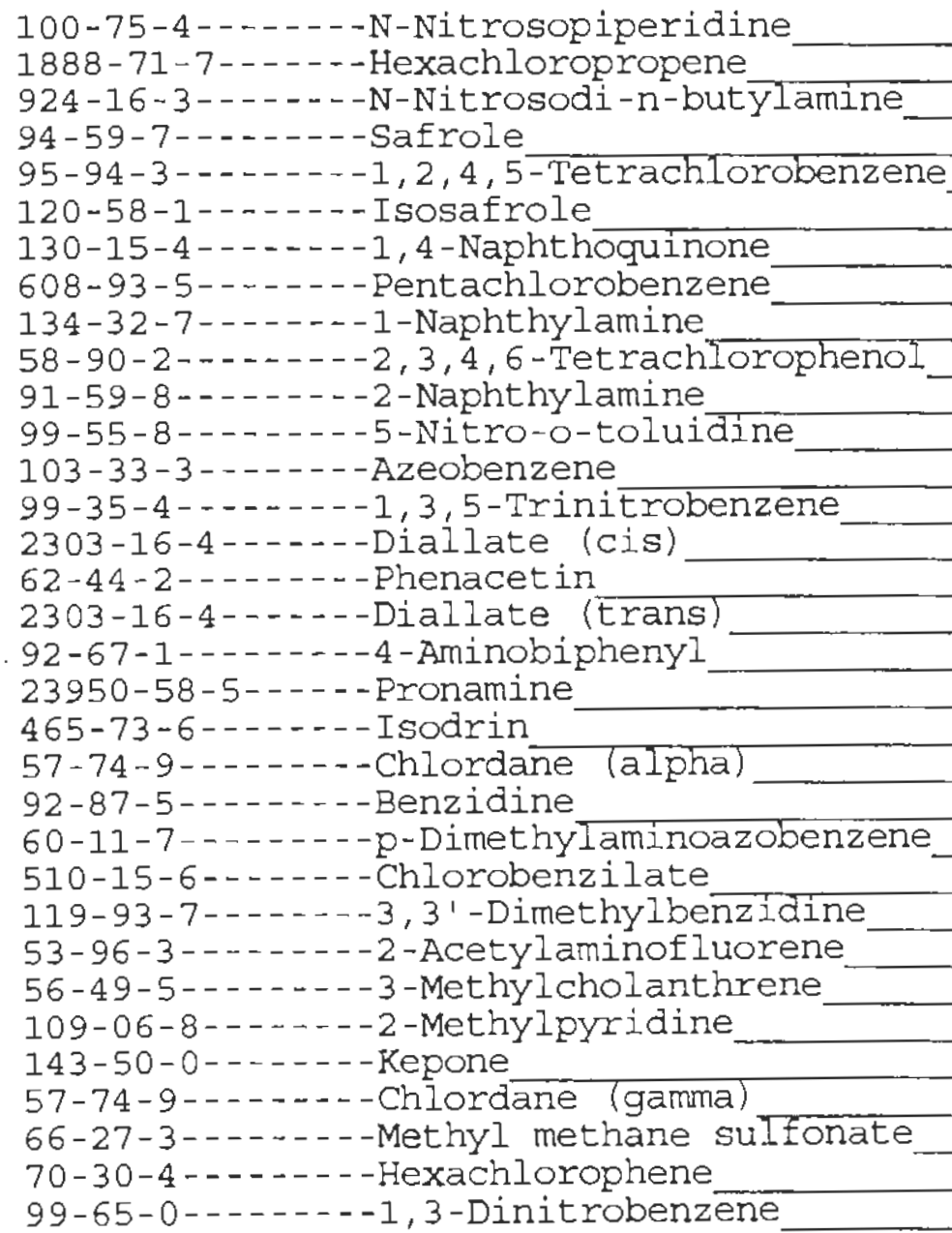 \\
\hline
\end{tabular}

\begin{tabular}{|r|r|r|}
20000 & $\mathrm{U}$ \\
20000 & $\mathrm{U}$ \\
840 & $\mathrm{~J}$ \\
20000 & $\mathrm{U}$ \\
20000 & $\mathrm{U}$ \\
20000 & $\mathrm{U}$ \\
20000 & $\mathrm{U}$ \\
20000 & $\mathrm{U}$ \\
20000 & $\mathrm{U}$ \\
20000 & $\mathrm{U}$ \\
20000 & $\mathrm{U}$ \\
20000 & $\mathrm{U}$ \\
20000 & $\mathrm{U}$ \\
20000 & $\mathrm{U}$ \\
20000 & $\mathrm{U}$ \\
20000 & $\mathrm{U}$ \\
20000 & $\mathrm{U}$ \\
20000 & $\mathrm{U}$ \\
20000 & $\mathrm{U}$ \\
20000 & $\mathrm{U}$ \\
20000 & $\mathrm{U}$ \\
20000 & $\mathrm{U}$ \\
20000 & $\mathrm{U}$ \\
20000 & $\mathrm{U}$ \\
20000 & $\mathrm{U}$ \\
20000 & $\mathrm{U}$ \\
20000 & $\mathrm{U}$ \\
20000 & $\mathrm{U}$ \\
20000 & $\mathrm{U}$ \\
20000 & $\mathrm{U}$ \\
20000 & $\mathrm{U}$ \\
20000 & $\mathrm{U}$ \\
20000 & $\mathrm{U}$ \\
\hline
\end{tabular}


Lab Name: PNNL,

Lab Code: PNNL

Case No. :

Matrix: (soil/water) SOLID

Sample wt/vol:

$4.9(\mathrm{~g} / \mathrm{mL}) \mathrm{G}$

Level: (low/med) LOW

$\%$ Moisture: 0

decanted: $(\mathrm{Y} / \mathrm{N}) \mathrm{N}$

Concentrated Extract Volume: 1000 (ut)

Injection Volume: \{UI\}
Contract: $\mathrm{C} 104$

SAS NO. :
SDG NO.: 000819

Iab Sample ID: 00-1361-SSD

Lab File ID: 00081915

Date Received:

Date Extracted:

Date Analyzed: $08 / 20 / 0$

Dilution Factor: 10.0 GPC Cleanup: $(\mathrm{Y} / \mathrm{N}\rangle \mathrm{N} \quad \mathrm{pH}$ :

CAS NO.

COMPOUND

CONCENTRATION UNITS:

(ug/L or $\mathrm{ug} / \mathrm{Kg}$ ) UG/KG

$Q$

20000 U 
Lab Name: PNNL

Lab Code: PNNL

Case No.:
Contract: $\mathrm{Cl} 04$

SAS NO.:
C104-SSMS

SDG NO.: 000819
Matrix: (soil/water) SOLID

Sample wt/vol:

$2.7(\mathrm{~g} / \mathrm{mL}) \quad \mathrm{G}$

Level: (low/med) LOW

Moisture: 0 decanted: $(\mathrm{Y} / \mathrm{N}) \mathrm{N}$

Concentrated Extract Volume: 1000 (UL)

Injection Volume: (uL)

GPC Cleanup: $\quad(\mathrm{Y} / \mathrm{N}) \mathrm{N}$

pH :
Lab Sample ID: 00-1361-SSMS

Lab File ID: 00081916

Date Received:

Date Extracted:

Date Analyzed: 08/20/0

Dilution Factor: 10.0
CAS NO.

COMPOUND

CONCENTRATION UNITS:

(ug/L or $\mathrm{ug} / \mathrm{Kg}$ ) UG/KG

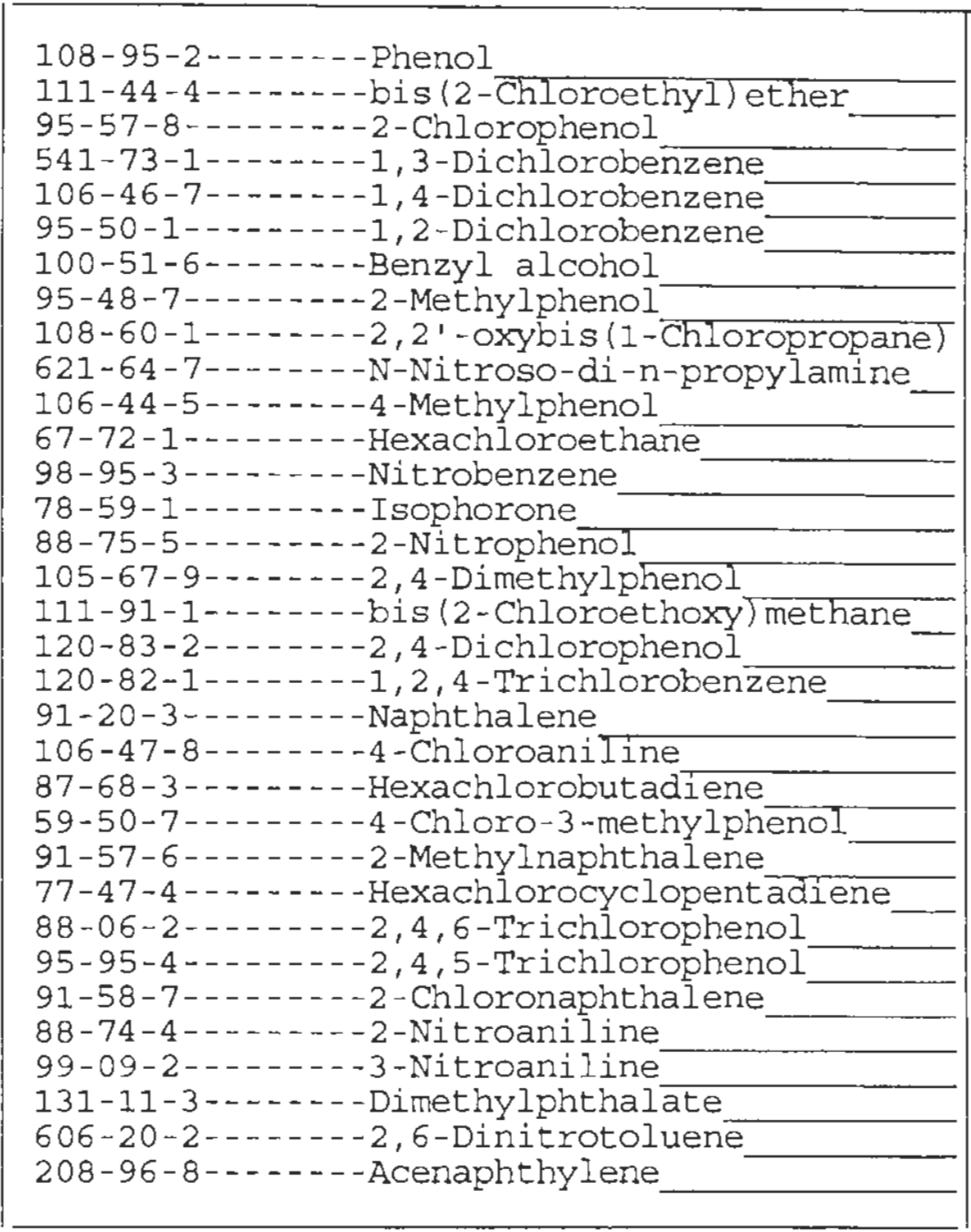

\begin{tabular}{r|l|}
7500 & $\mathrm{~J}$ \\
37000 & $\mathrm{U}$ \\
7000 & $\mathrm{~J}$ \\
37000 & $\mathrm{U}$ \\
4200 & $\mathrm{~J}$ \\
37000 & $\mathrm{U}$ \\
37000 & $\mathrm{U}$ \\
5600 & $\mathrm{JB}$ \\
37000 & $\mathrm{U}$ \\
6900 & $\mathrm{~J}$ \\
16000 & $\mathrm{JB}$ \\
37000 & $\mathrm{U}$ \\
37000 & $\mathrm{U}$ \\
37000 & $\mathrm{U}$ \\
37000 & $\mathrm{U}$ \\
37000 & $\mathrm{U}$ \\
37000 & $\mathrm{U}$ \\
37000 & $\mathrm{U}$ \\
5800 & $\mathrm{~J}$ \\
37000 & $\mathrm{U}$ \\
37000 & $\mathrm{U}$ \\
37000 & $\mathrm{U}$ \\
6500 & $\mathrm{~J}$ \\
37000 & $\mathrm{U}$ \\
37000 & $\mathrm{U}$ \\
37000 & $\mathrm{U}$ \\
37000 & $\mathrm{U}$ \\
37000 & $\mathrm{U}$ \\
37000 & $\mathrm{U}$ \\
37000 & $\mathrm{U}$ \\
37000 & $\mathrm{U}$ \\
37000 & $\mathrm{U}$ \\
37000 & $\mathrm{U}$ \\
& \\
\hline
\end{tabular}

OLMO 3.0 
Lab Name: PNNL

Lab Code: PNNL
Contract: $\mathrm{ClO4}$

Case No.:
SAS NO.:
CIO4-SSMS

SDG No.: 000819
Matrix: (soil/water) SOLID

Sample wt/vol:

$2.7(g / m L) \quad G$

Level: (low/med) IOW

$\because$ Moisture: 0 decanted: $(Y / N) \mathrm{N}$

Concentrated Extract Volume: 1000 (uL)

Injection Volume:

(UL)
Lab Sample ID: 00-1361-SSMS

Lab File ID; 00081916

Date Received:

Date Extracted:

Date Analyzed: 08/20/0

Dilution Factor: 10.0

GPC Cleanup: $(\mathrm{Y} / \mathrm{N}\rangle \mathrm{N} \quad \mathrm{pH}$ :

CAS NO.

COMPOUND

CONCENTRATION UNITS:

(ug/L or $\mathrm{Lg} / \mathrm{Kg}$ ) UG/KG

$Q$

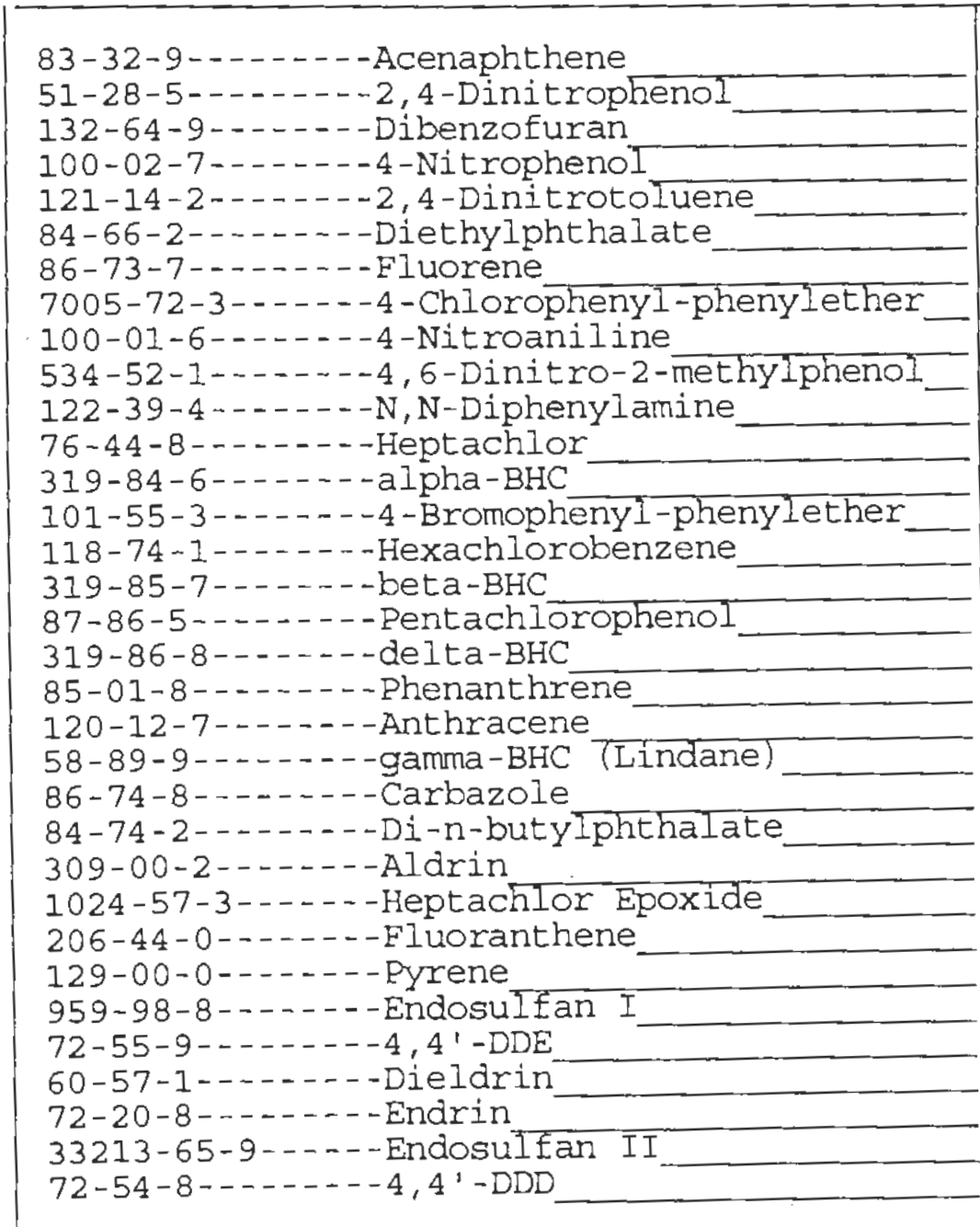

$6800 \mathrm{~J}$

$37000 \mathrm{U}$

$37000 \mathrm{U}$

$4100 \mathrm{~J}$

$8700 \mathrm{~J}$

$37000 \mathrm{U}$

37000 U

$37000 \mathrm{U}$

$37000 \mathrm{U}$

$37000 \mathrm{U}$

$37000 \mathrm{U}$

$37000 \mathrm{U}$

$37000 \mathrm{U}$

$37000 \mathrm{U}$

$37000 \mathrm{U}$

$37000 \mathrm{U}$

$37000 \mathrm{U}$

$37000 \mathrm{U}$

$37000 \mathrm{U}$

$37000 \mathrm{U}$

$37000 \mathrm{U}$

$37000 \mathrm{U}$

$37000 \mathrm{U}$

37000 U

$37000 \mathrm{U}$

$37000 \mathrm{U}$

$7800 \mathrm{~J}$

$37000 \mathrm{U}$

$37000 \mathrm{U}$

$37000 \mathrm{U}$

$37000 \mathrm{U}$

$37000 \mathrm{U}$

$37000 \mathrm{U}$ 
Lab Name: PNNL

Lab Code: PNNL

Case No. :
Contract: $\mathrm{CIO4}$

SAS NO. :
CIO4-SSMS

SDG NO. : 000819
Matrix: (soil/water) SOLID

Sample wt/vol:

$2.7(\mathrm{~g} / \mathrm{mL}) \mathrm{G}$

Level: (low/med) LOW

$\div$ Moisture: 0 decanted: $(\mathrm{Y} / \mathrm{N}) \mathrm{N}$

Concentrated Extract Volume: 1000 (uI)

Injection volume:

(uL)
Lab Sample ID: 00-1361-SSMS

Lab File ID: 00081916

Date Received:

Date Extracted:

Date Analyzed: $08 / 20 / 0$

Dilution Factor: 10.0

GPC Cleanup: (Y/N) N pH:

CAS NO.

COMPOUND

CONCENTRATION UNITS:

(ug/L or $\mathrm{ug} / \mathrm{kg}$ ) UG/KG

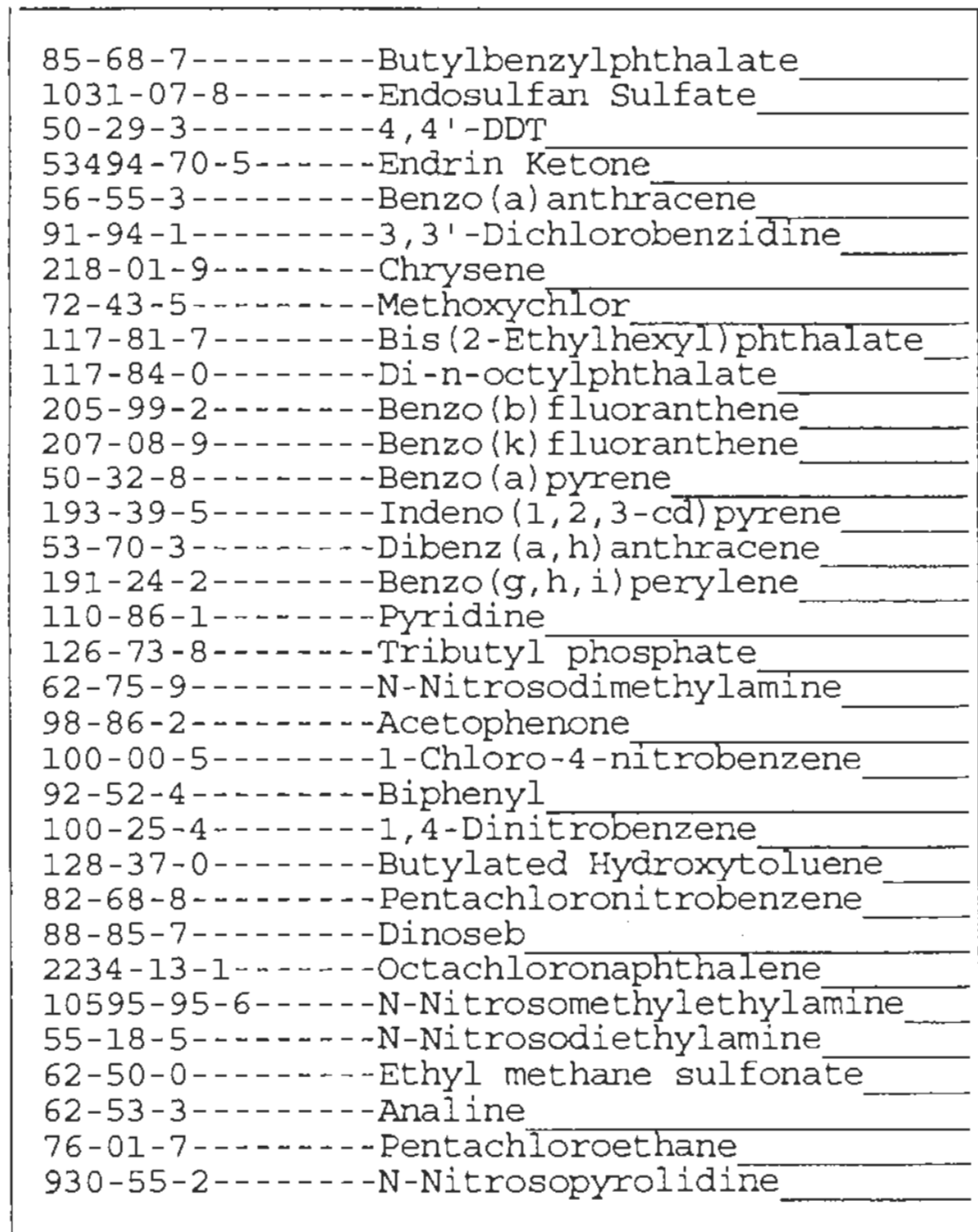

\begin{tabular}{|r|l|}
37000 & $\mathrm{U}$ \\
37000 & $\mathrm{U}$ \\
37000 & $\mathrm{U}$ \\
37000 & $\mathrm{U}$ \\
37000 & $\mathrm{U}$ \\
37000 & $\mathrm{U}$ \\
37000 & $\mathrm{U}$ \\
37000 & $\mathrm{U}$ \\
37000 & $\mathrm{U}$ \\
37000 & $\mathrm{U}$ \\
37000 & $\mathrm{U}$ \\
37000 & $\mathrm{U}$ \\
37000 & $\mathrm{U}$ \\
37000 & $\mathrm{U}$ \\
37000 & $\mathrm{U}$ \\
37000 & $\mathrm{U}$ \\
2700 & $\mathrm{JB}$ \\
92000 & $\mathrm{~B}$ \\
37000 & $\mathrm{U}$ \\
5000 & $\mathrm{JB}$ \\
6900 & $\mathrm{JB}$ \\
11000 & $\mathrm{JB}$ \\
7100 & $\mathrm{UB}$ \\
2900 & $\mathrm{JB}$ \\
37000 & $\mathrm{U}$ \\
14000 & $\mathrm{JB}$ \\
400000 & $\mathrm{~B}$ \\
37000 & $\mathrm{U}$ \\
37000 & $\mathrm{U}$ \\
37000 & $\mathrm{U}$ \\
37000 & $\mathrm{U}$ \\
37000 & $\mathrm{U}$ \\
37000 & $\mathrm{U}$ \\
& \\
\hline
\end{tabular}


Lab Name: PNNL

Lab code: PNNL

Case No.:

Matrix: (soil/water) SOLID

Sample wt/vol:

$2.7(\mathrm{~g} / \mathrm{mL}) \quad G$

Level: (low $/ \mathrm{med})$

LOW

$\div$ Moisture: 0 decanted: $(\mathrm{Y} / \mathrm{N}) \mathrm{N}$

Concentrated Extract Volume: 1000 (U工)

Injection Volume: (uL)
Contract: $\mathrm{C} 104$

SAS NO.:
C104-SSMS

SDG No.: 000819
GPC Cleanup: ( $(\mathrm{Y} / \mathrm{N}) \mathrm{N} \quad \mathrm{pH}$ :

CAS NO.
COMPOUND
Lab Sample ID: 00-1361-SSMS

Lab File ID: 00081916

Date Received:

Date Extracted:

Date Analyzed: $08 / 20 / 0$

Dilution Factor: 10.0

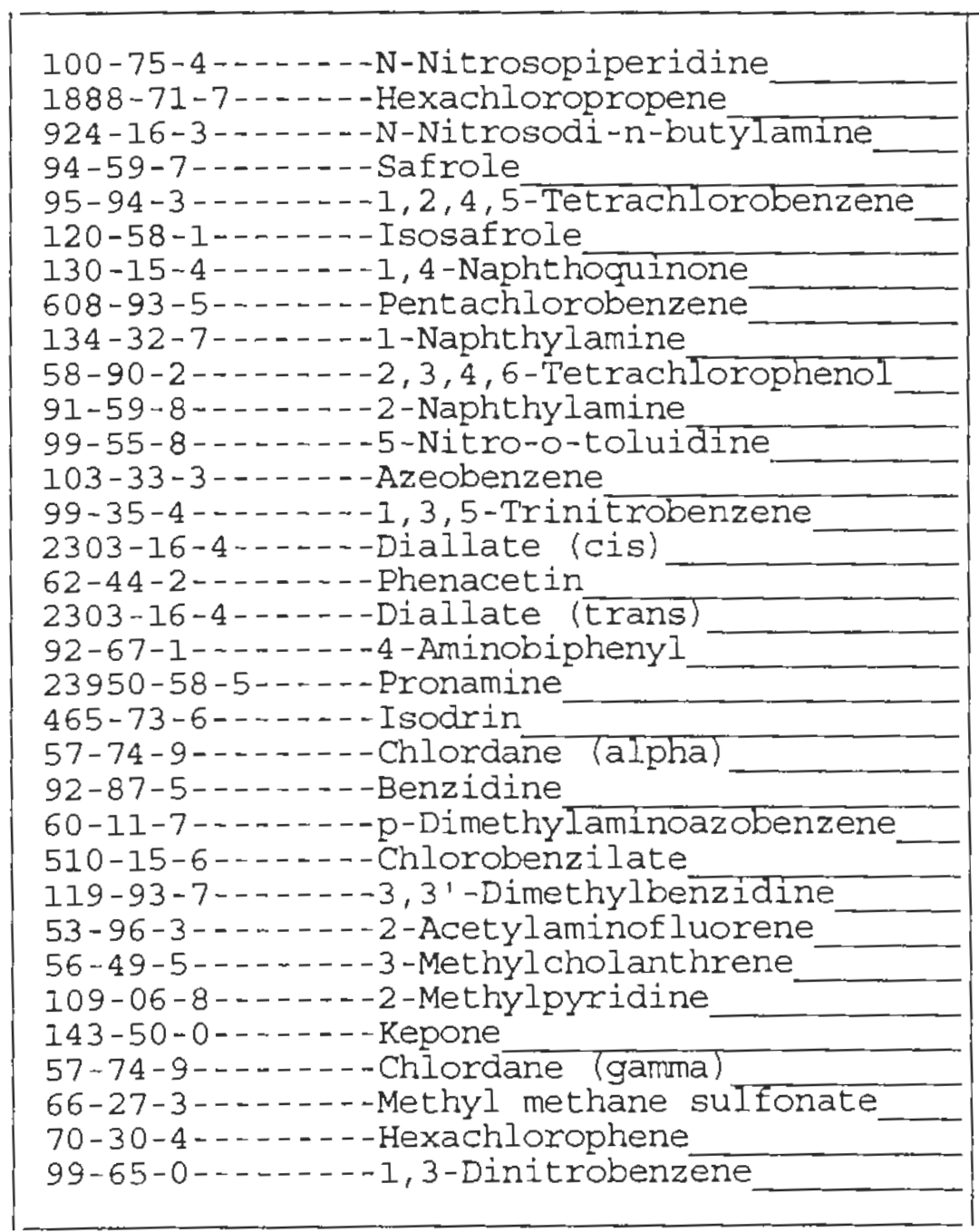

FORM I SV-4
CONCENTRATION UNITS: (ug/L or $\mathrm{ug} / \mathrm{Kg}$ ) UG/KG 
Lab Name: PNNL

Contract: $\mathrm{ClO4}$

Lab Code: PNNL

Case No.:

Matrix: (soil/water) SOLID

Sample wt/vol:

$2.7(\mathrm{~g} / \mathrm{mL}) \mathrm{G}$

Level: (low/med) LOW

\% Moisture: 0

decanted: $(Y / N) N$

SAS NO.:

Lab Sample ID: 00-1361-SSMS

Lab File ID: $\quad 00081916$

Date Received:

Date Extracted:

Concentrated Extract Volume: 1000 (uL)

Injection volume: (uL)

$\mathrm{pH}$ :

GPC Cleanup: $(\mathrm{Y} / \mathrm{N}) \mathrm{N}$
C104-SSMS

CONCENTRATION UNITS:

CAS NO.

COMPOUND

(ug/L or $\mathrm{ug} / \mathrm{Kg}$ ) UG/KG

$Q$

87-65-0-------2, 6-Dichlorophenol 
Iab Name: PNNL

Lab Code: PNNL

Case No. :

Matrix: (soil/water) SOLID

Sample wt/vol:

$2.5(\mathrm{~g} / \mathrm{mL}) \mathrm{G}$

Level: (low/med) LOW

O Moisture: 0 decanted: $(Y / N) N$

Concentrated Extract Volume: 1000 (u工)

Injection Volume: (uL)

Contract: $\mathrm{C} 104$

SAS NO.:

Lab Sample ID: 00-1361-SSMSD

Lab File ID: $\quad 00081917$

Date Received:

Date Extracted:

Date Analyzed: $08 / 20 / 0$

Dilution Factor: 10.0

GPC Clearup: $(\mathrm{Y} / \mathrm{N}\rangle \mathrm{N} \mathrm{pH}$ :

CONCENTRATION UNITS:

CAS NO.

COMPOUND

$(\mathrm{ug} / \mathrm{L}$ or $\mathrm{ug} / \mathrm{Kg})$ UG/KG

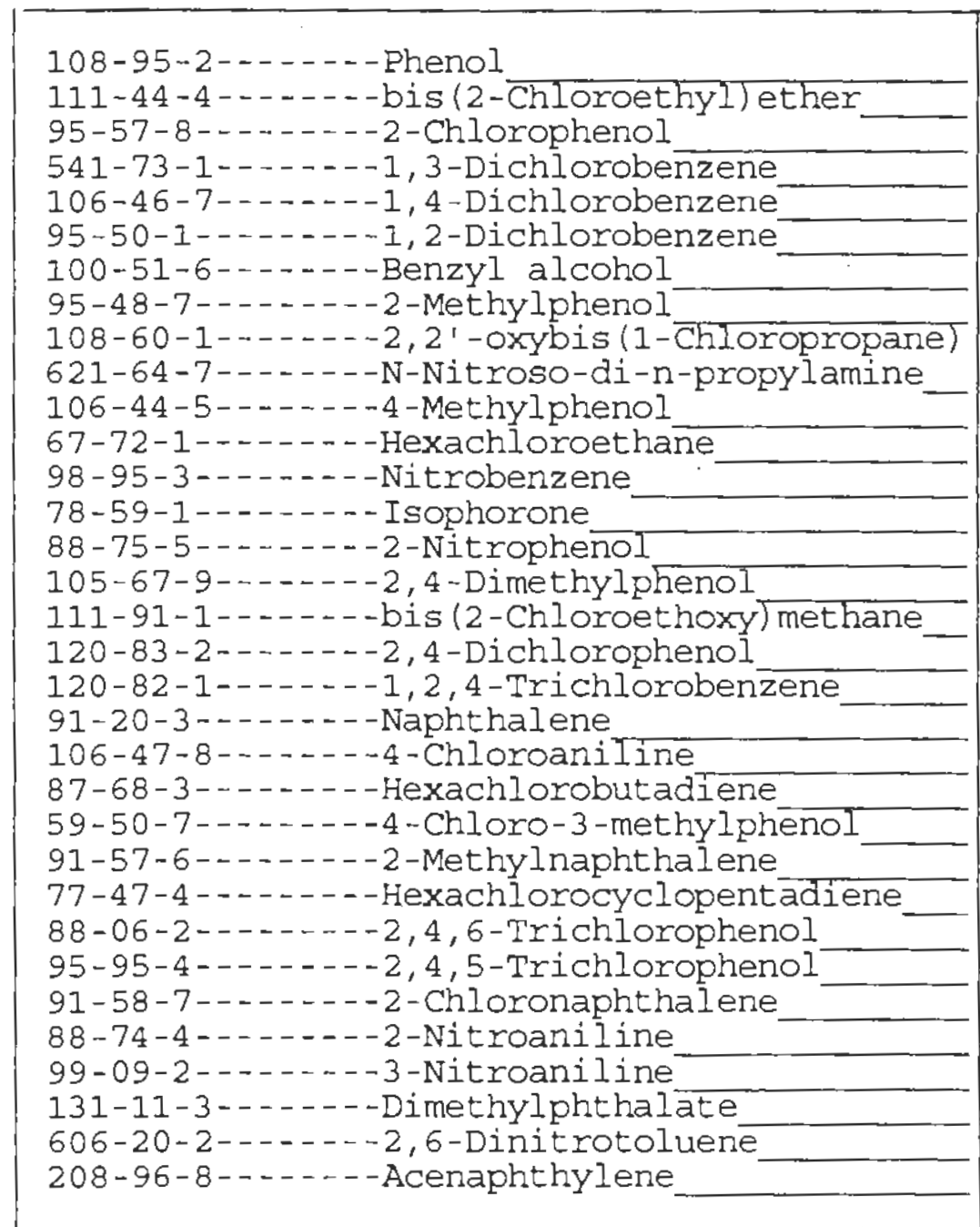

FORM I SV-1

\begin{tabular}{|r|r|}
\hline 10000 & $\mathrm{~J}$ \\
40000 & $\mathrm{U}$ \\
9200 & $\mathrm{~J}$ \\
40000 & $\mathrm{U}$ \\
40000 & $\mathrm{U}$ \\
40000 & $\mathrm{U}$ \\
40000 & $\mathrm{U}$ \\
4200 & $\mathrm{JB}$ \\
40000 & $\mathrm{U}$ \\
6300 & $\mathrm{~J}$ \\
19000 & $\mathrm{JB}$ \\
40000 & $\mathrm{U}$ \\
40000 & $\mathrm{U}$ \\
40000 & $\mathrm{U}$ \\
40000 & $\mathrm{U}$ \\
40000 & $\mathrm{U}$ \\
40000 & $\mathrm{U}$ \\
40000 & $\mathrm{U}$ \\
5000 & $\mathrm{~J}$ \\
40000 & $\mathrm{U}$ \\
40000 & $\mathrm{U}$ \\
40000 & $\mathrm{U}$ \\
11000 & $\mathrm{~J}$ \\
40000 & $\mathrm{U}$ \\
40000 & $\mathrm{U}$ \\
40000 & $\mathrm{U}$ \\
40000 & $\mathrm{U}$ \\
40000 & $\mathrm{U}$ \\
40000 & $\mathrm{U}$ \\
40000 & $\mathrm{U}$ \\
40000 & $\mathrm{U}$ \\
40000 & $\mathrm{U}$ \\
40000 & $\mathrm{U}$ \\
& \\
\hline
\end{tabular}

OLMO3. 
Lab Name: PNNL

Lab Code: PNNL

Case No.:

Matrix: (soil/water) SOLID

Sample wt/vol:

$2.5(\mathrm{~g} / \mathrm{mL}) \mathrm{G}$

Level: (low/med)

LOW

$\%$ Moisture: 0 decanted: (Y/N) N

Concentrated Extract Volume: 1000 (uL)

Injection Volume: (uL)

GPC Cleanup: (Y/N) N $\mathrm{pH}$ :

GPC Cleanup: (Y/N) N $\mathrm{pH}$ :
Contract: $\mathrm{C} 104$

SAS NO.:

SDG No.: 000819

Lab Sample ID: 00-1361-SSMSD

Lab File ID: 00081917

Date Received:

Date Extracted:

Date Analyzed: 08/20/0

Dilution Factor: 10.0

CONCENIRATION UNITS:

CAS NO.

COMPOUND

$(\mathrm{ug} / \mathrm{L}$ or $\mathrm{ug} / \mathrm{kg})$ UG/KG

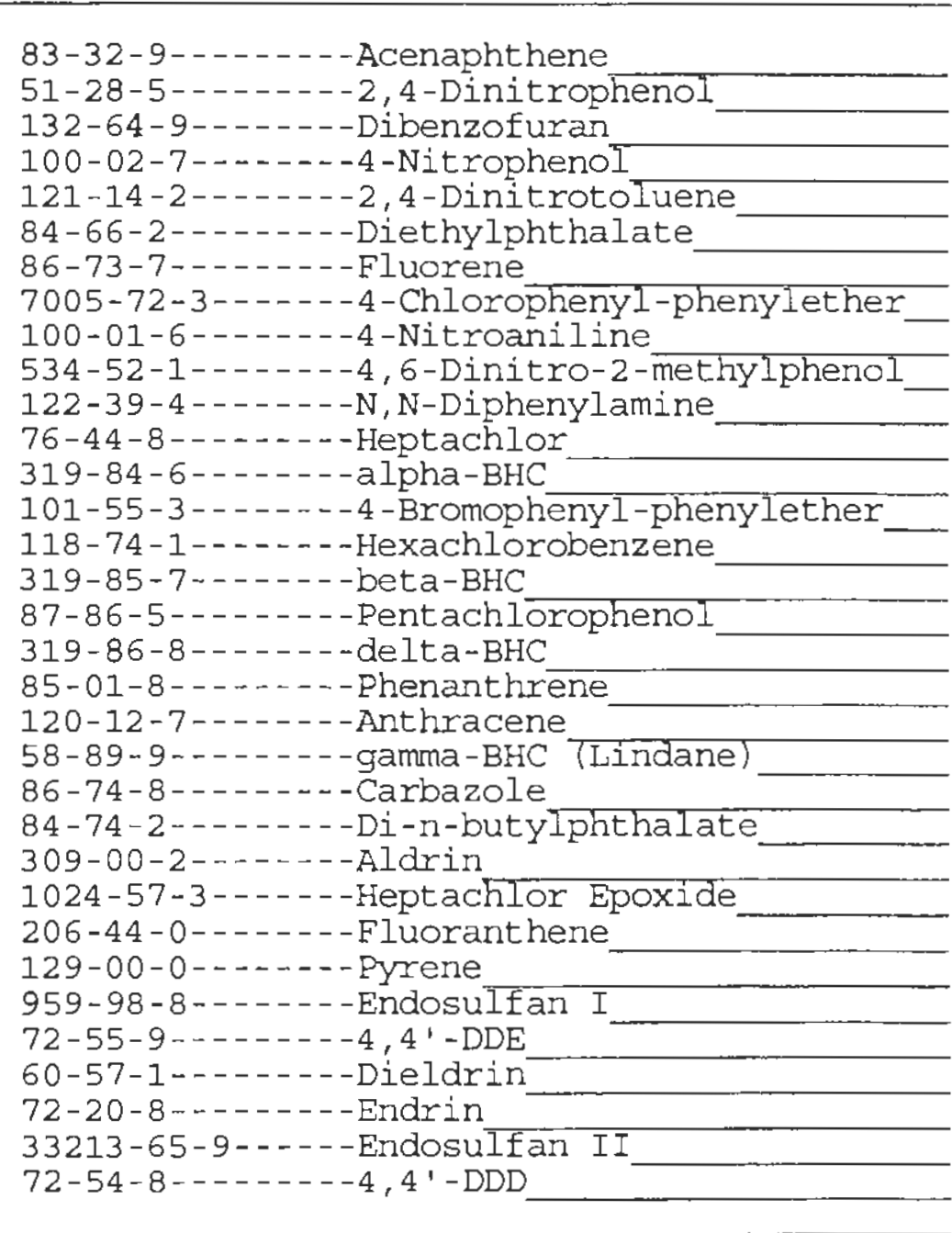

FORM I SV-2

\begin{tabular}{r|l|}
\hline 6400 & $\mathrm{~J}$ \\
40000 & $\mathrm{U}$ \\
40000 & $\mathrm{U}$ \\
4100 & $\mathrm{~J}$ \\
9600 & $\mathrm{~J}$ \\
40000 & $\mathrm{U}$ \\
40000 & $\mathrm{U}$ \\
40000 & $\mathrm{U}$ \\
40000 & $\mathrm{U}$ \\
40000 & $\mathrm{U}$ \\
40000 & $\mathrm{U}$ \\
40000 & $\mathrm{U}$ \\
40000 & $\mathrm{U}$ \\
40000 & $\mathrm{U}$ \\
40000 & $\mathrm{U}$ \\
40000 & $\mathrm{U}$ \\
40000 & $\mathrm{U}$ \\
40000 & $\mathrm{U}$ \\
40000 & $\mathrm{U}$ \\
40000 & $\mathrm{U}$ \\
40000 & $\mathrm{U}$ \\
40000 & $\mathrm{U}$ \\
40000 & $\mathrm{U}$ \\
40000 & $\mathrm{U}$ \\
40000 & $\mathrm{U}$ \\
40000 & $\mathrm{U}$ \\
7000 & $\mathrm{~J}$ \\
40000 & $\mathrm{U}$ \\
40000 & $\mathrm{U}$ \\
40000 & $\mathrm{U}$ \\
40000 & $\mathrm{U}$ \\
40000 & $\mathrm{U}$ \\
40000 & $\mathrm{U}$ \\
\hline & \\
\hline
\end{tabular}

OLMO3.0 
Lab Name: PNNL

Lab Code: PNNL

Case No. :

Matrix: (soil/water) SOLID

Sample wt/vol:

$2.5(\mathrm{~g} / \mathrm{mL}) \mathrm{G}$

Leve1: (low/med) LOW

$\because$ Moisture: 0 decanted: ( $Y / N) \mathrm{N}$

Concentrated Extract Volume: 1000 (UL)

Injection volume: 〈UL)

Contract: $\mathrm{ClO} 4$

SAS NO. :

Lab Sample ID: 00-1361-SSMSD

Lab File ID: 00081917

Date Received:

Date Extracted:

Date Analyzed: $03 / 20 / 0$

Dilution Factor: 10.0

GPC Cleanup: ( $Y / N) \mathrm{N} \quad \mathrm{pH}$ :

CONCENIRATION UNITS:

CAS NO.

COMPOUND

( $\mathrm{ug} / \mathrm{I}$ or $\mathrm{ug} / \mathrm{kg}$ ) UG/KG

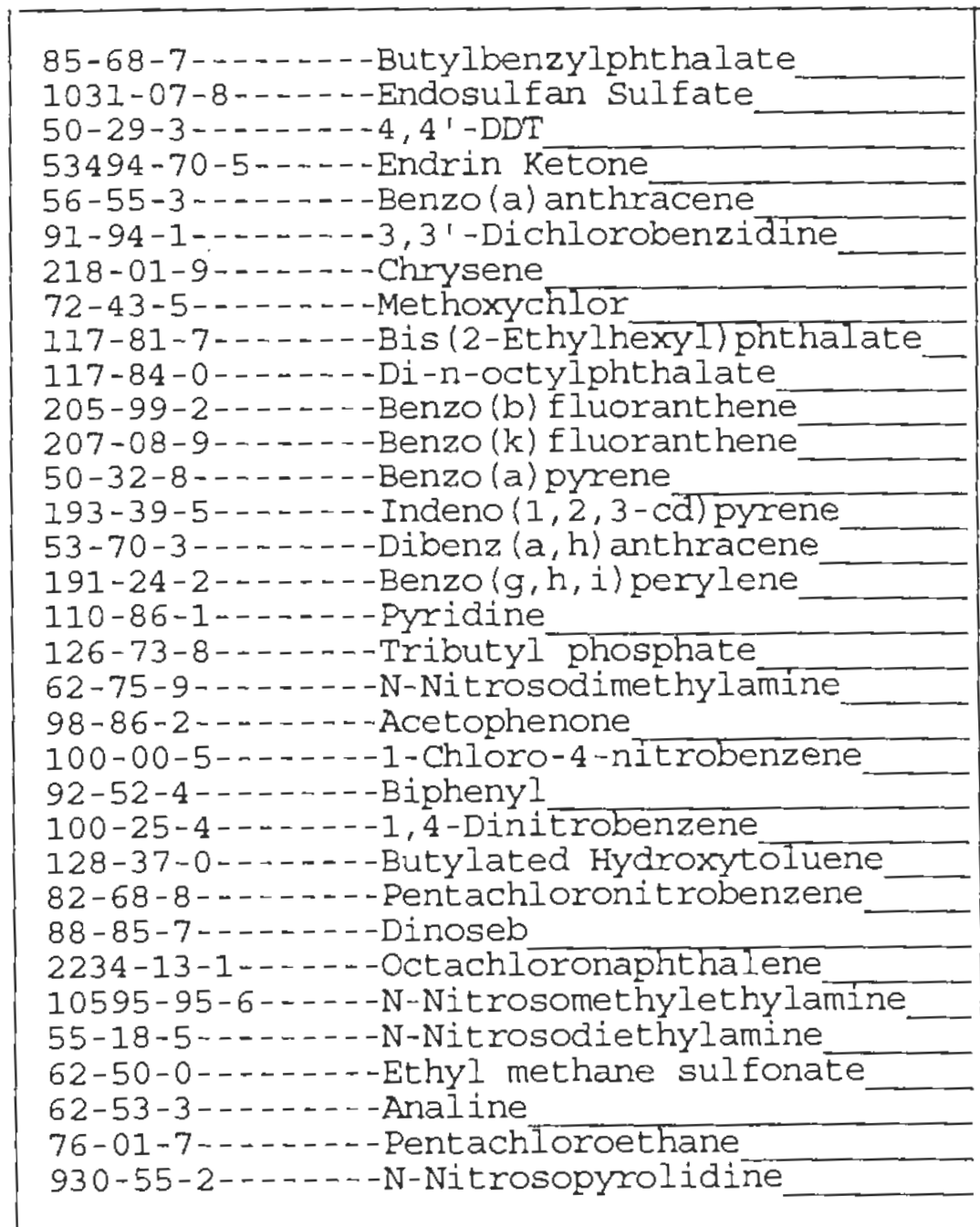

\begin{tabular}{|r|r|r|}
\hline 40000 & $\mathrm{U}$ \\
40000 & $\mathrm{U}$ \\
40000 & $\mathrm{U}$ \\
40000 & $\mathrm{U}$ \\
40000 & $\mathrm{U}$ \\
40000 & $\mathrm{U}$ \\
40000 & $\mathrm{U}$ \\
40000 & $\mathrm{U}$ \\
40000 & $\mathrm{U}$ \\
40000 & $\mathrm{U}$ \\
40000 & $\mathrm{U}$ \\
40000 & $\mathrm{U}$ \\
40000 & $\mathrm{U}$ \\
40000 & $\mathrm{U}$ \\
40000 & $\mathrm{U}$ \\
40000 & $\mathrm{U}$ \\
3300 & $\mathrm{JB}$ \\
90000 & $\mathrm{~B}$ \\
40000 & $\mathrm{U}$ \\
6000 & $\mathrm{JB}$ \\
7600 & $\mathrm{JB}$ \\
10000 & $\mathrm{JB}$ \\
11000 & $\mathrm{JB}$ \\
1800 & $\mathrm{JB}$ \\
40000 & $\mathrm{U}$ \\
20000 & $\mathrm{JB}$ \\
340000 & $\mathrm{~B}$ \\
40000 & $\mathrm{U}$ \\
40000 & $\mathrm{U}$ \\
40000 & $\mathrm{U}$ \\
40000 & $\mathrm{U}$ \\
40000 & $\mathrm{U}$ \\
40000 & $\mathrm{U}$ \\
& & - \\
\hline & & \\
\hline
\end{tabular}


Lab Name: PNNL

Lab Code: PNNL

Case No.:
Contract: $\mathrm{C} 104$

SAS NO. :
C104-SSMSD
Matrix: (soil/water) SOLID

Sample wt/vol:

$2.5(\mathrm{~g} / \mathrm{mL}) \mathrm{G}$

Level: (low $/ \mathrm{med}$ )

LOW

$\div$ Moisture: 0

decanted: $(\mathrm{Y} / \mathrm{N}) \mathrm{N}$

Concentrated Extract Volume: 1000 (uL) Injection Volume: (uL)
Lab Sample ID: 00-1361-SSMSD Lab File ID: 00081917

Date Received:

Date Extracted:

Date Analyzed: 08/20/0

Dilution Factor: 10.0

GPC Cleanup: (Y/N) N $\mathrm{pH}$ :

CONCENTRATION UNITS:

CAS NO.

COMPOUND

(ug/L or $\mathrm{ug} / \mathrm{Kg}$ ) UG/KG

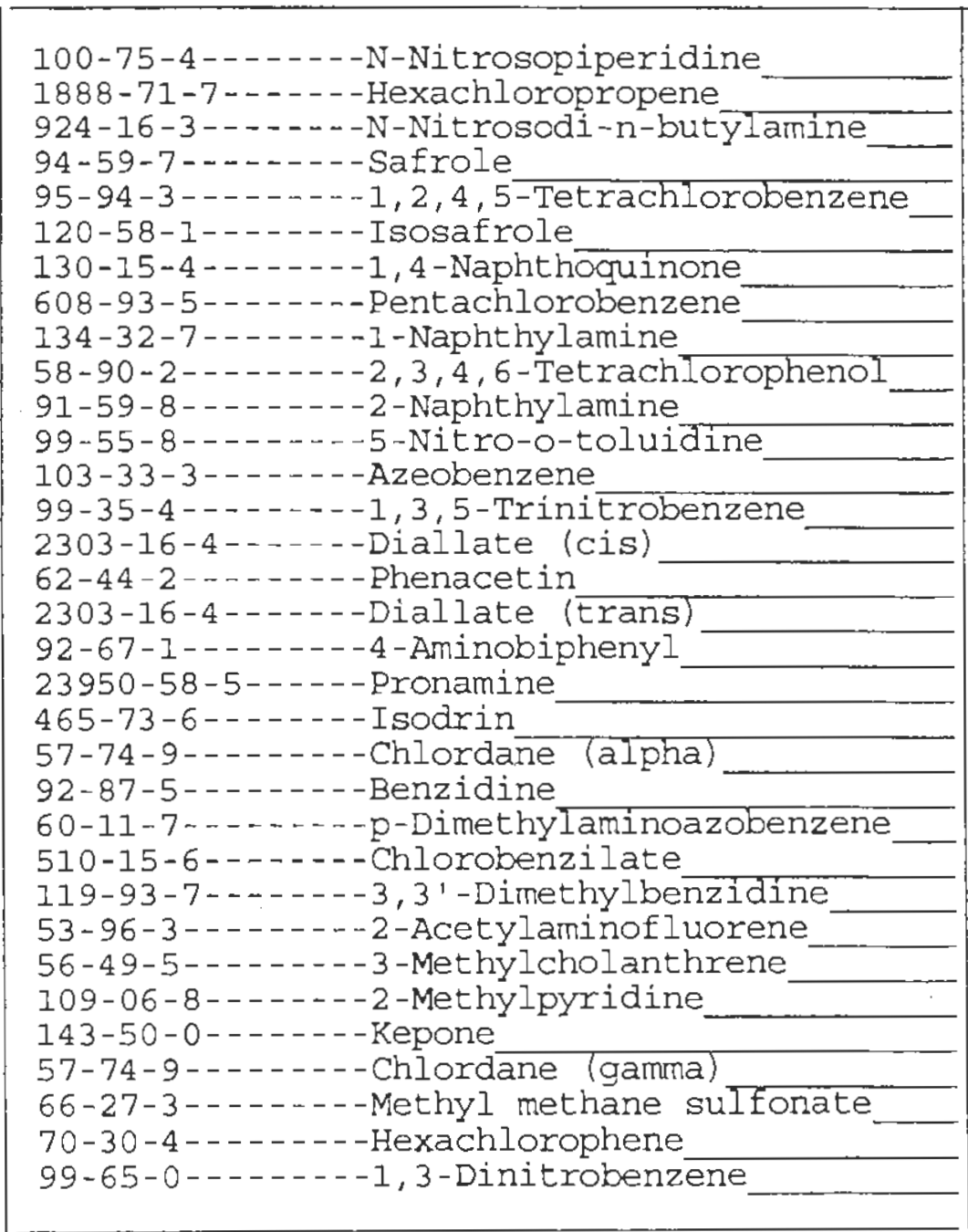

$40000 \mathrm{U}$ $40000 \mathrm{U}$ $820 \mathrm{~J}$ $40000 \mathrm{U}$ $40000 \mathrm{U}$ $40000 \mathrm{U}$ $40000 \mathrm{U}$ $40000 \mathrm{U}$ $40000 \mathrm{U}$ $40000 \mathrm{U}$ $40000 \mathrm{U}$ $40000 \mathrm{U}$ $40000 \mathrm{U}$ $40000 \mathrm{U}$ $40000 \mathrm{U}$ $40000 \mathrm{U}$ $40000 \mathrm{U}$ $40000 \mathrm{U}$ $40000 \mathrm{U}$ $40000 \mathrm{U}$ $40000 \mathrm{U}$ $40000 \mathrm{U}$ $40000 \mathrm{U}$ $40000 \mathrm{U}$ $40000 \mathrm{U}$ $40000 \mathrm{U}$ $40000 \mathrm{U}$ $40000 \mathrm{U}$ $40000 \mathrm{U}$ $40000 \mathrm{U}$ $40000 \mathrm{U}$ $40000 \mathrm{U}$ $5500 \mathrm{~J}$ 
Lab Name: PNNL

Contract: $\mathrm{ClO4}$

Case No. :

SAS NO.:

Lab Sample ID: 00-1361-SSMSD

Sample wt/vol:

$2.5(\mathrm{~g} / \mathrm{mL}) \quad \mathrm{G}$

Level: (low/med) LOW

\% Moisture: 0

decanted: $(\mathrm{Y} / \mathrm{N}) \mathrm{N}$

Concentrated Extract Volume: 1000 (UI)

Injection volume: (Uน)

GPC Cleanup: $(\mathrm{Y} / \mathrm{N}) \mathrm{N} \quad \mathrm{pH}$ :

Lab File ID: 00081917

Date Received:

Date Extracted:

Date Analyzed: 08/20/0

Dilution Factor: 10.0
EPA SAMPLE NO.

C104-SSMSD

CONCENTRATION UNITS:

CAS NO.

COMPOUND

(ug/L or $\mathrm{ug} / \mathrm{Kg}$ ) UG/KG

$Q$ 
Lab Name: PNNL

Lab code: PNNL
Contract: $\mathrm{C} 104$

Case No. :
SAS NO. :
C104-SSS

SDG No.: 000819
Matrix: (soil/water) SOLID

Sample wt/vol:

$5.3\langle\mathrm{~g} / \mathrm{mL}\rangle \mathrm{G}$

Level: (low/med) Low

$\%$ Moisture: 0 decanted: $(\mathrm{Y} / \mathrm{N}) \mathrm{N}$

Concentrated Extract Volume: 1000 (uL)

Injection Volume: (uL)
Lab Sample ID: 00-1361-SSS

Lab File ID: 00081914

Date Received:

Date Extracted:

Date Analyzed: 08/20/0

Dilution Factor: 10.0

GPC Cleanup: (Y/N) N $\mathrm{pH}$ :

CAS NO.

COMPOUND

CONCENTRATION UNITS:

(ug/L or $\mathrm{ug} / \mathrm{Kg}$ ) UG/KG

Q

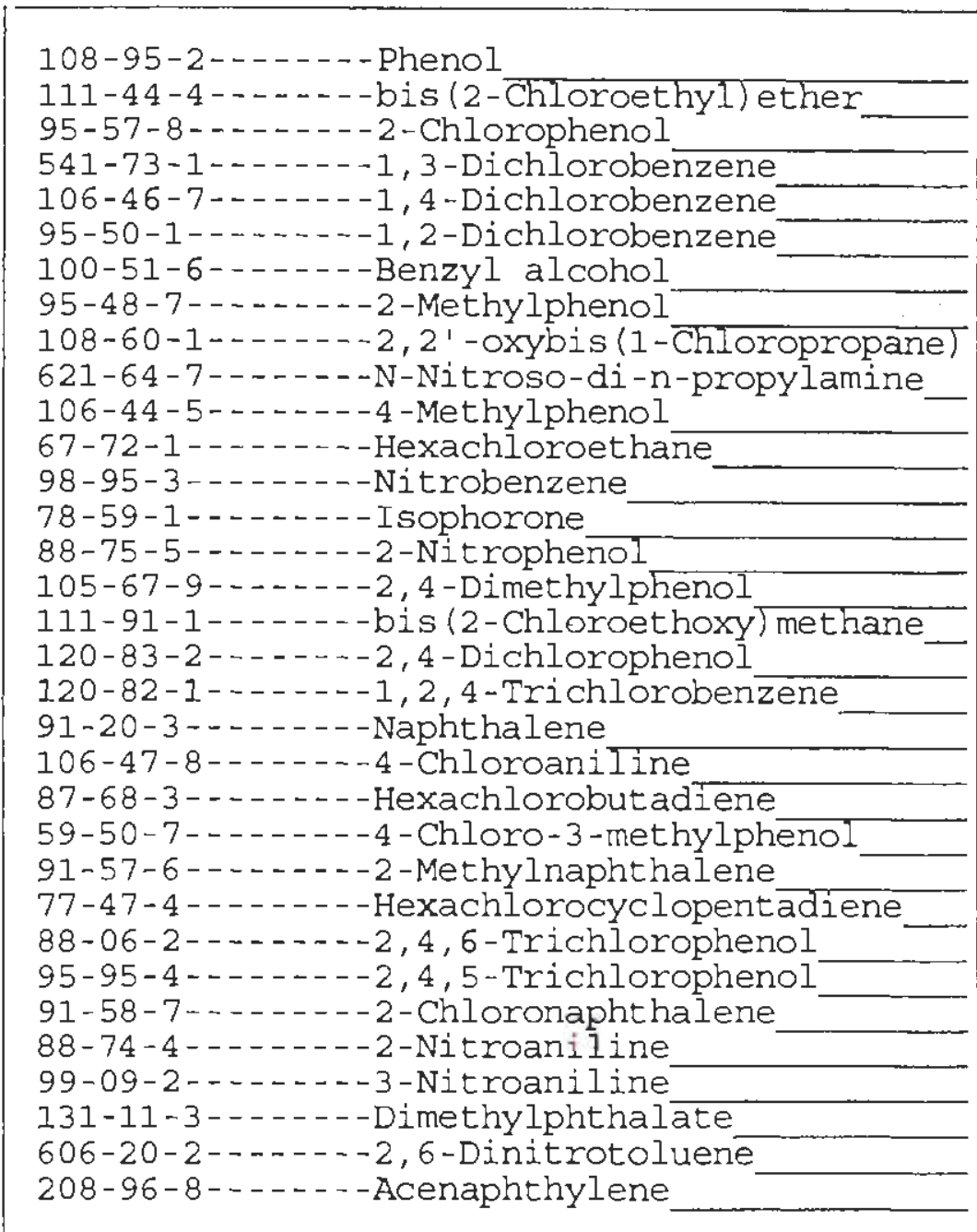

FORM I SV-1

\begin{tabular}{|l|l|l|}
19000 & $\mathrm{U}$ \\
19000 & $\mathrm{U}$ \\
19000 & $\mathrm{U}$ \\
19000 & $\mathrm{U}$ \\
19000 & $\mathrm{U}$ \\
19000 & $\mathrm{U}$ \\
19000 & $\mathrm{U}$ \\
19000 & $\mathrm{U}$ \\
19000 & $\mathrm{U}$ \\
19000 & $\mathrm{U}$ \\
19000 & $\mathrm{U}$ \\
19000 & $\mathrm{U}$ \\
19000 & $\mathrm{U}$ \\
19000 & $\mathrm{U}$ \\
19000 & $\mathrm{U}$ \\
19000 & $\mathrm{U}$ \\
19000 & $\mathrm{U}$ \\
19000 & $\mathrm{U}$ \\
19000 & $\mathrm{U}$ \\
19000 & $\mathrm{U}$ \\
19000 & $\mathrm{U}$ \\
19000 & $\mathrm{U}$ \\
19000 & $\mathrm{U}$ \\
19000 & $\mathrm{U}$ \\
19000 & $\mathrm{U}$ \\
19000 & $\mathrm{U}$ \\
19000 & $\mathrm{U}$ \\
19000 & $\mathrm{U}$ \\
19000 & $\mathrm{U}$ \\
19000 & $\mathrm{U}$ \\
19000 & $\mathrm{U}$ \\
19000 & $\mathrm{U}$ \\
19000 & $\mathrm{U}$ \\
\hline & & \\
\hline
\end{tabular}

OLMO3.0 
Lab Name: PNNL

Lab Code: PNNL
Contract: $\mathrm{ClO} 4$

SAS NO. :
C104-SSS
Matrix: (soil/water) SOIID

Sample wt/vol:

$5.3(\mathrm{~g} / \mathrm{mL}) \quad \mathrm{G}$

Level: (low/med)

\section{LOW}

$\%$ Moisture: 0

decanted: $(\mathrm{Y} / \mathrm{N}) \mathrm{N}$

Concentrated Extract Volume: 1000 (uI)

Injection volume: (uL)
Lab Sample ID: 00-1361-SSS

Lab File ID: 00081914

Date Received:

Date Extracted:

Date Analyzed: 08/20/0

Dilution Factor: 10.0

GPC Cleanup: ( $\mathrm{Y} / \mathrm{N}\rangle \mathrm{N} \mathrm{pH}$ :

CAS NO.

COMPOUND

CONCENTRATION UNITS:

$\langle\mathrm{ug} / \mathrm{L}$ or $\mathrm{ug} / \mathrm{Kg}\rangle$ UG/KG

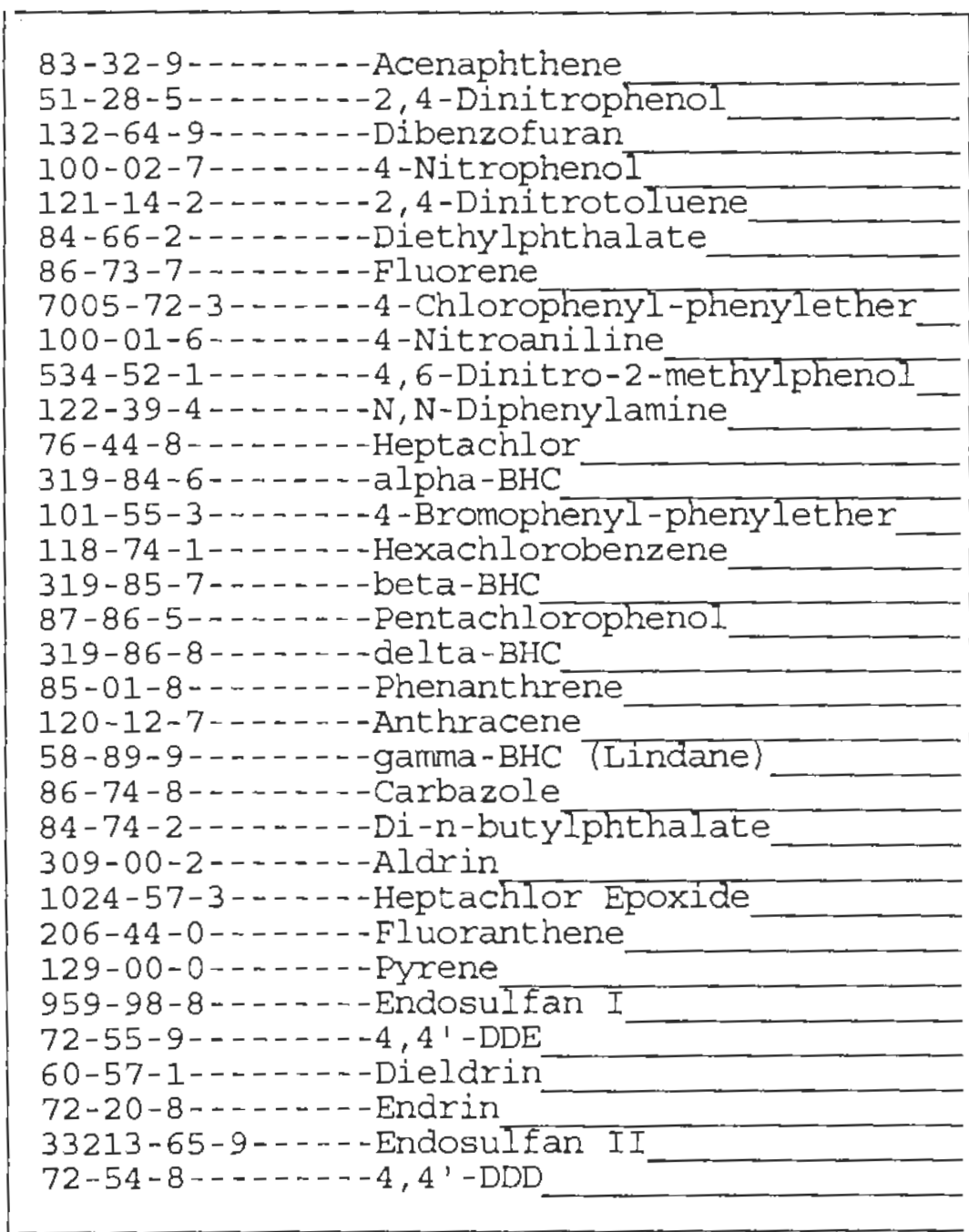

FORM I SV-2

\begin{tabular}{l|l}
19000 & $\mathrm{U}$ \\
19000 & $\mathrm{U}$ \\
19000 & $\mathrm{U}$ \\
19000 & $\mathrm{U}$ \\
19000 & $\mathrm{U}$ \\
19000 & $\mathrm{U}$ \\
19000 & $\mathrm{U}$ \\
19000 & $\mathrm{U}$ \\
19000 & $\mathrm{U}$ \\
19000 & $\mathrm{U}$ \\
19000 & $\mathrm{U}$ \\
19000 & $\mathrm{U}$ \\
19000 & $\mathrm{U}$ \\
19000 & $\mathrm{U}$ \\
19000 & $\mathrm{U}$ \\
19000 & $\mathrm{U}$ \\
19000 & $\mathrm{U}$ \\
19000 & $\mathrm{U}$ \\
19000 & $\mathrm{U}$ \\
19000 & $\mathrm{U}$ \\
19000 & $\mathrm{U}$ \\
19000 & $\mathrm{U}$ \\
19000 & $\mathrm{U}$ \\
19000 & $\mathrm{U}$ \\
19000 & $\mathrm{U}$ \\
19000 & $\mathrm{U}$ \\
19000 & $\mathrm{U}$ \\
19000 & $\mathrm{U}$ \\
19000 & $\mathrm{U}$ \\
19000 & $\mathrm{U}$ \\
19000 & $\mathrm{U}$ \\
19000 & $\mathrm{U}$ \\
19000 & $\mathrm{U}$ \\
& \\
\end{tabular}

OLMO 3.C 
Lab Name: PNNL

Lab Code: PNNL

Case No. :
Contract: $\mathrm{C} 104$

SAS NO.:

CI04-SSS

Matrix: (soil/water) SOLID

Sample wt/vol: $\quad 5.3(\mathrm{~g} / \mathrm{mL})$ G

Level: (low/med) LOW

$\div$ Moisture: 0 decanted: $(\mathrm{Y} / \mathrm{N}) \mathrm{N}$

Concentrated Extract Volume: 1000 (UL)

Injection volume: (uL)

GPC Cleanup: $\quad(\mathrm{Y} / \mathrm{N}) \mathrm{N} \quad \mathrm{pH}$ :
Lab Sample ID: 00-1361-SSS

Lab File ID: 00081914

Date Received:

Date Extracted:

Date Analyzed: 08/20/0

Dilution Factor: 10.0

SDG NO. : 000819 
Lab Name: PNNL

Lab Code: PNNI

Case No.:

Matrix: (soil/water) SOLID

Sample wt/vol:

$5.3(g / m L) \quad G$

Level: (low/med) Low

$\div$ Moisture: 0 decanted: (Y/N) N

Concentrated Extract Volume: 1000 (uL)

Injection volume: (บL)

Contract: $\mathrm{C1} 04$

SAS NO.:
SDG No.: 000819

C104-SSS

Lab Sample ID: 00-136I-SSS

Lab File ID: 00081914 :

Date Received:

Date Extracted:

Date Aralyzed: $08 / 20 / 0$

Dilution Factor: 10.0

GPC Cleanup: (Y/N) N $\mathrm{pH}$ :

CAS NO.

COMPOUND

CONCENTRATION UNITS:

(ug/L or ug/Kg) UG/KG

$Q$

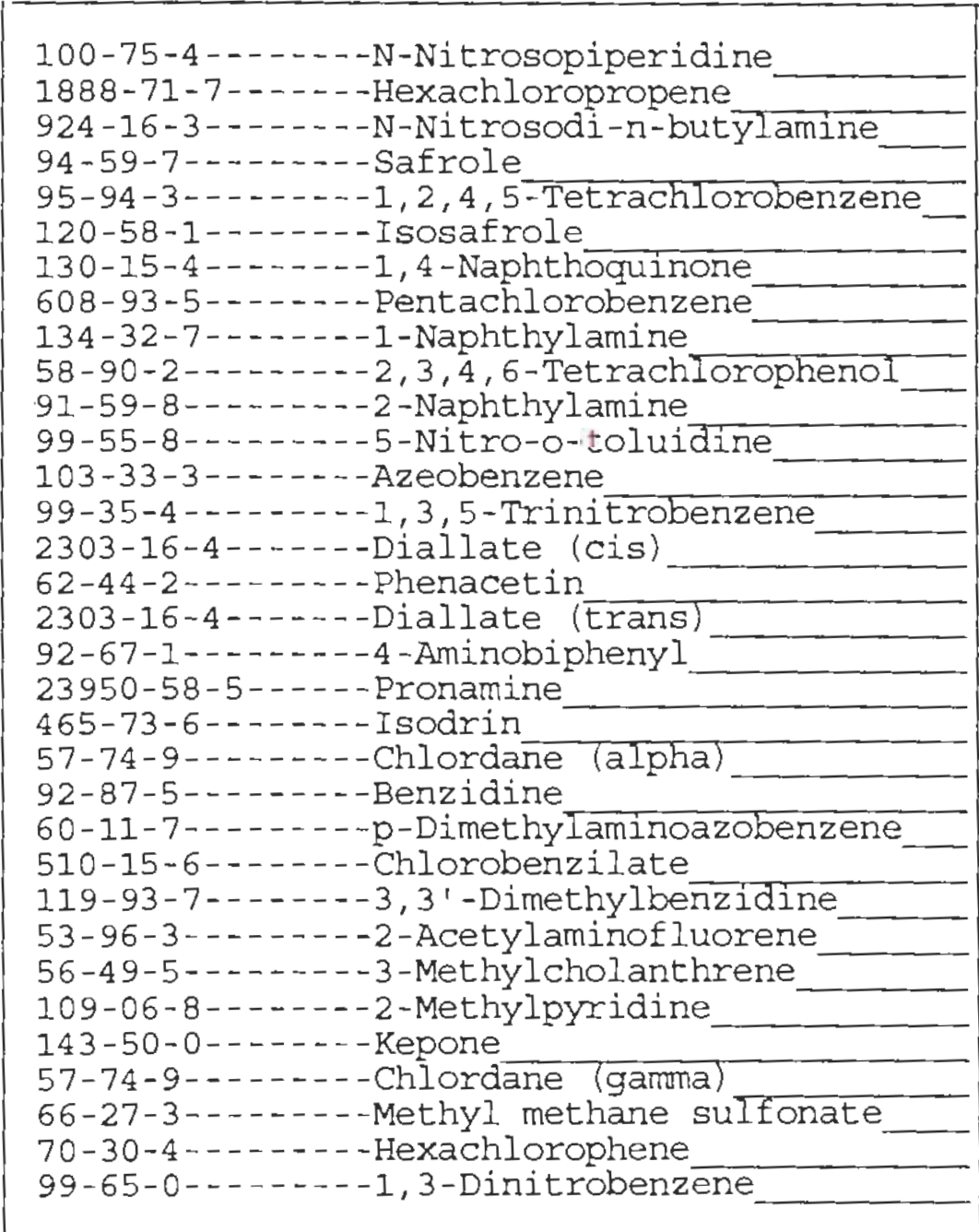

$19000 \mathrm{U}$ $19000 \mathrm{U}$

$1100 \mathrm{~J}$

$19000 \mathrm{U}$

$19000 \mathrm{U}$

19000 U

$19000 \mathrm{U}$

$19000 \mathrm{U}$

$19000 \mathrm{U}$

$19000 \mathrm{U}$

$19000 \mathrm{U}$

$19000 \mathrm{U}$

$19000 \mathrm{U}$

$19000 \mathrm{U}$

$19000 \mathrm{U}$

$19000 \mathrm{U}$

$19000 \mathrm{U}$

$19000 \mathrm{U}$

$19000 \mathrm{U}$

$19000 \mathrm{U}$

$19000 \mathrm{U}$

$4700 \mathrm{~J}$

$19000 \mathrm{U}$

$19000 \mathrm{U}$

$19000 \mathrm{U}$

$19000 \mathrm{U}$

$19000 \mathrm{U}$

$19000 \mathrm{U}$

$19000 \mathrm{U}$

$19000 \mathrm{U}$

$19000 \mathrm{U}$

$19000 \mathrm{U}$

$19000 / \mathrm{U}$ 
Lab Name: PNNL

Contract: $\mathrm{C} 104$

EPA SAMPLE NO.

Lab code: PNNL

Case No.:

SAS NO. :

SDG No. : 000819

Matrix: (soil/water) SOLID

Lab Sample ID: 00-1361-SSS

Sample wt/vol: $\quad 5.3(\mathrm{~g} / \mathrm{mL}) \mathrm{G}$ Lab File ID: 00081914 "

Level: (low/med) LOW

Date Received:

号 Moisture: 0 decanted: $(\mathrm{Y} / \mathrm{N}) \mathrm{N}$

Date Extracted:

Concentrated Extract Volume: 1000 (UL)

Date Analyzed: 08/20/0

Injection Volume: (uL)

Dilution Factor: 10.0

GPC Cleanup: $\quad(Y / N) N$

$\mathrm{pH}:$

CONCENTRATION UNITS:

CAS NO.

COMPOUND

$(\mathrm{ug} / \mathrm{I}$, or $\mathrm{ug} / \mathrm{Kg}) \cdot \mathrm{UG} / \mathrm{KG}$

$Q$

87-65-0--.---2, 6-Dichlorophenol $19000 \mathrm{U}$ 
Lab Name: PNNL

Lab Code: PNNL
Contract: $\mathrm{Cl} 104$

Case No. :
SAS NO. :

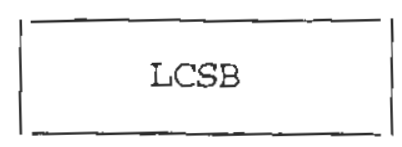

SDG NO.: 000819
Matrix: (soil/water) SOLID

Sample wt/vol:

$5.0(\mathrm{~g} / \mathrm{mL}) \mathrm{G}$

Level: (low/med) Low

$\because$ Moisture: $0 . \quad$ decanted: $\langle Y / N\rangle N$

Concentrated Extract Volume: 1000 (uI)

Injection Volume: (UI)
Lab Sample ID: LCSB

Lab File ID: 00081918

Date Received:

Date Extracted:

Date Analyzed: 08/20/0

Dilution Factor: 1.0

GPC Cleanup: $(\mathrm{Y} / \mathrm{N}) \mathrm{N} \quad \mathrm{pH}$ :

CAS NO.

COMPOUND

CONCENTRATION UNITS:

(ug/L or $\mathrm{ug} / \mathrm{Kg}$ ) UG/KG

$Q$

\begin{tabular}{|c|}
\hline 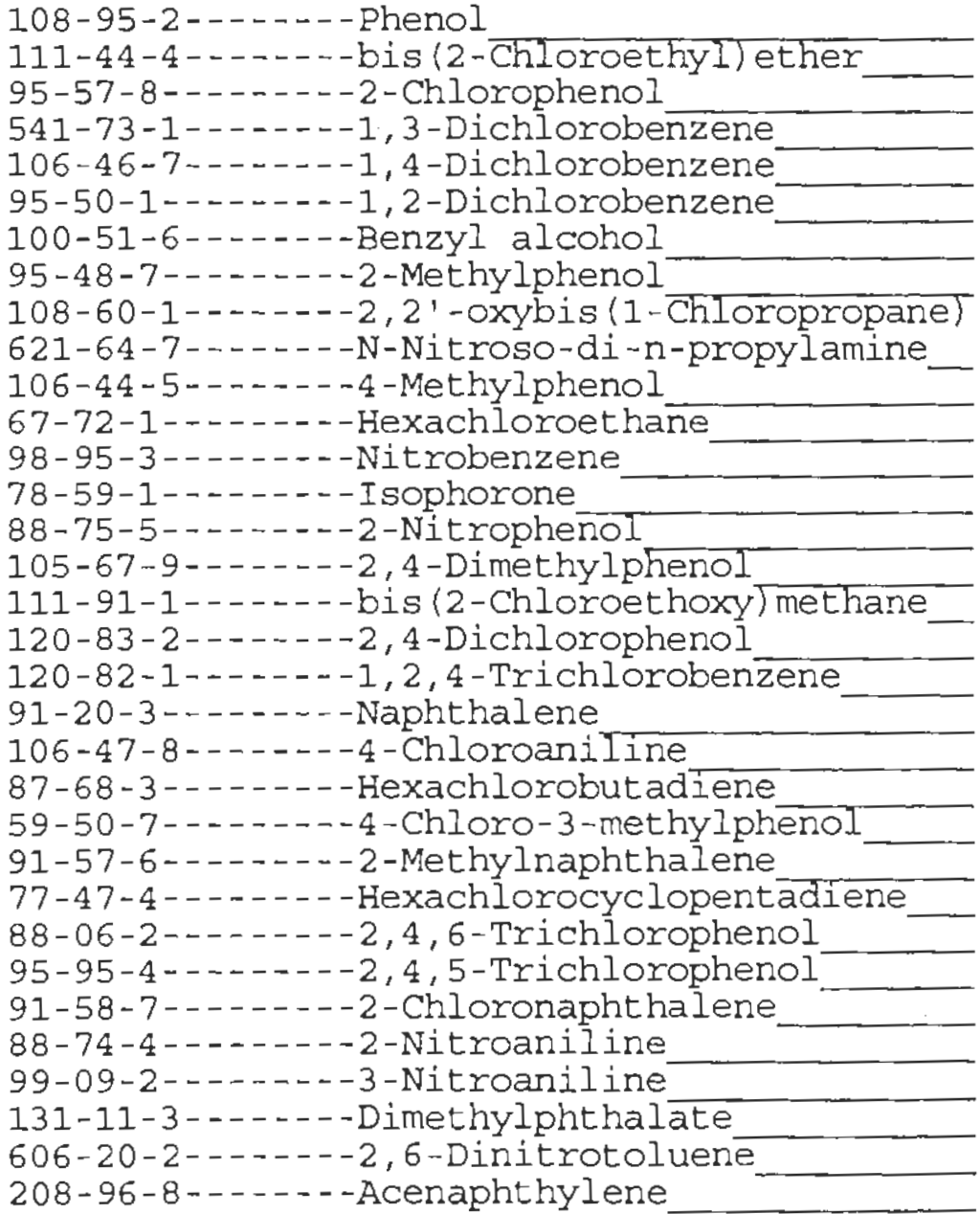 \\
\hline
\end{tabular}

FORM I SV-I

\begin{tabular}{l|l|l}
2000 & $U$ \\
2000 & $U$ \\
2000 & $U$ \\
2000 & $U$ \\
2000 & $U$ \\
2000 & $U$ \\
2000 & $U$ \\
5200 & $\mathrm{~B}$ \\
2000 & $\mathrm{U}$ \\
2000 & $\mathrm{U}$ \\
8000 & $\mathrm{~B}$ \\
2000 & $\mathrm{U}$ \\
2000 & $\mathrm{U}$ \\
2000 & $\mathrm{U}$ \\
2000 & $\mathrm{U}$ \\
2000 & $\mathrm{U}$ \\
2000 & $\mathrm{U}$ \\
2000 & $\mathrm{U}$ \\
2000 & $\mathrm{U}$ \\
2000 & $\mathrm{U}$ \\
2000 & $\mathrm{U}$ \\
2000 & $\mathrm{U}$ \\
2000 & $\mathrm{U}$ \\
2000 & $\mathrm{U}$ \\
2000 & $\mathrm{U}$ \\
2000 & $\mathrm{U}$ \\
2000 & $\mathrm{U}$ \\
2000 & $\mathrm{U}$ \\
2000 & $\mathrm{U}$ \\
2000 & $\mathrm{U}$ \\
2000 & $\mathrm{U}$ \\
2000 & $\mathrm{U}$ \\
2000 & $\mathrm{U}$ \\
& \\
&
\end{tabular}

OLMO3.0 
Lab Name: PNNL

Lab Code: PNNL
Contract: $\mathrm{ClO} 4$

Case No.:
SAS NO.:

\section{$\operatorname{LCSB}$}

SDG No.: 000819
Matrix: (soil/water) SOLID

Sample wt/vol:

$5.0(\mathrm{~g} / \mathrm{mL}) \mathrm{G}$

Level: (low/med) LOW

응 0 decanted: (Y/N) N

Concentrated Extract Volume: 1000 (UL)

Injection volume:

(uL)
Lab Sample ID: LCSB

Lab File ID: 00081918

Date Received:

Date Extracted:

Date Analyzed: 08/20/0

Dilution Factor: 1.0

GPC Cleanup: (Y/N) N $\mathrm{pH}$ :

CAS NO.

COMPOUND

CONCENTRATION UNITS :

(ug/L or $\mathrm{ug} / \mathrm{Kg}$ ) UG/KG

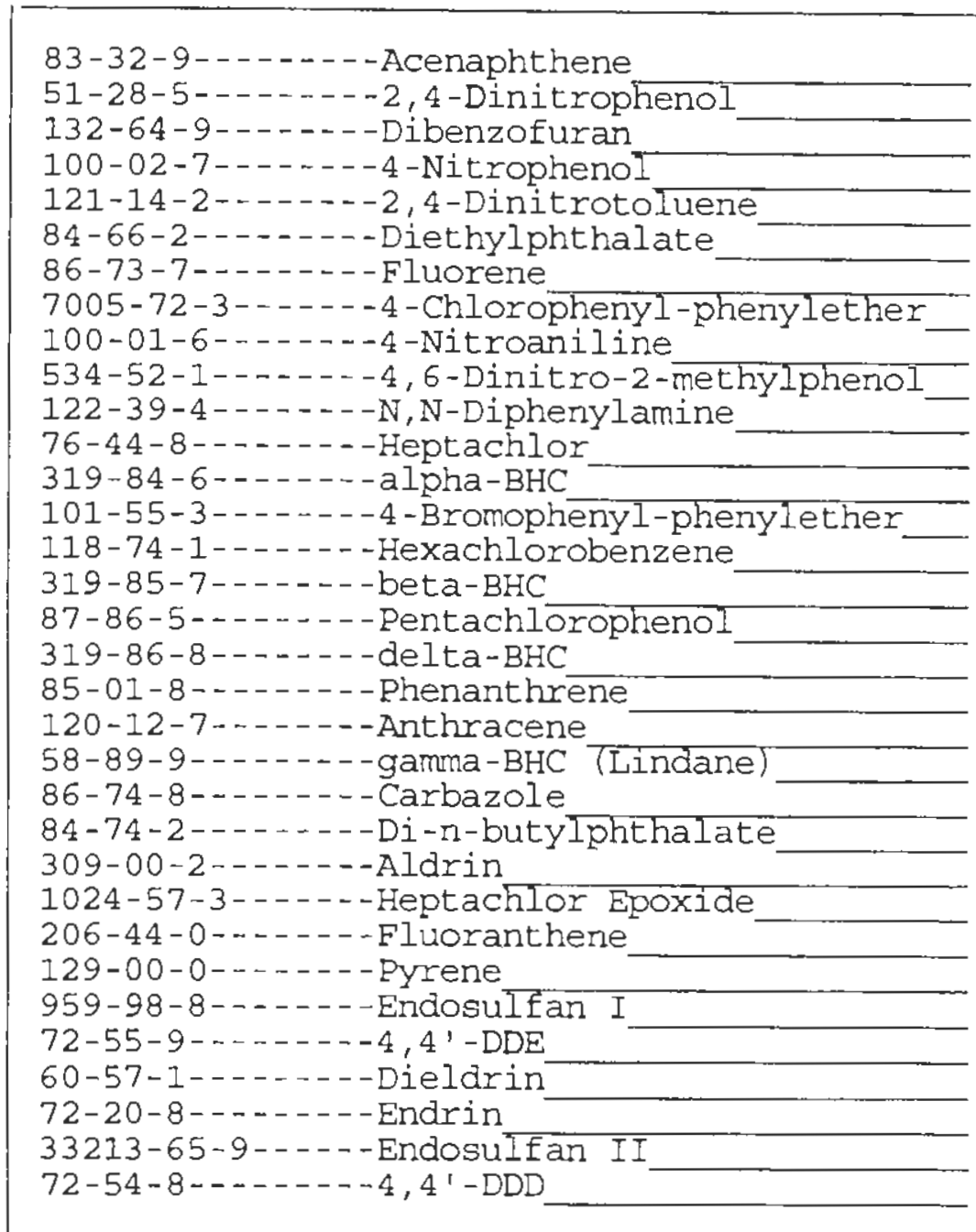

\begin{tabular}{|l|l|l|}
\hline 2000 & $\mathrm{U}$ \\
2000 & $\mathrm{U}$ \\
2000 & $\mathrm{U}$ \\
2000 & $\mathrm{U}$ \\
2000 & $\mathrm{U}$ \\
2000 & $\mathrm{U}$ \\
2000 & $\mathrm{U}$ \\
2000 & $\mathrm{U}$ \\
2000 & $\mathrm{U}$ \\
2000 & $\mathrm{U}$ \\
2000 & $\mathrm{U}$ \\
2000 & $\mathrm{U}$ \\
2000 & $\mathrm{U}$ \\
2000 & $\mathrm{U}$ \\
2000 & $\mathrm{U}$ \\
2000 & $\mathrm{U}$ \\
2000 & $\mathrm{U}$ \\
2000 & $\mathrm{U}$ \\
2000 & $\mathrm{U}$ \\
2000 & $\mathrm{U}$ \\
2000 & $\mathrm{U}$ \\
2000 & $\mathrm{U}$ \\
2000 & $\mathrm{U}$ \\
2000 & $\mathrm{U}$ \\
2000 & $\mathrm{U}$ \\
2000 & $\mathrm{U}$ \\
2000 & $\mathrm{U}$ \\
2000 & $\mathrm{U}$ \\
2000 & $\mathrm{U}$ \\
2000 & $\mathrm{U}$ \\
2000 & $\mathrm{U}$ \\
2000 & $\mathrm{U}$ \\
2000 & $\mathrm{U}$ \\
\hline & & \\
\hline &
\end{tabular}


Lab Name: PNNL

Lab Code: PNNL

Case No.:

Matrix: (soil/water) SOLID

Sample wt/vol:

$5.0(\mathrm{~g} / \mathrm{mL}) \mathrm{G}$

Level: (low/med) LOW

음 Moisture: 0 decanted: $(\mathrm{Y} / \mathrm{N}) \mathrm{N}$

Concentrated Extract Volume: 1000 (uL)

Injection volume: (uLi)

Contract: $\mathrm{ClO} 4$

SAS NO.:

Lab Sample ID: LCSB

Lab File ID: 00081918

Date Received:

Date Extracted:

Date Analyzed: 08/20/0

Dilution Factor: 1.0

GPC Cleanup: $\quad(\mathrm{Y} / \mathrm{N}) \mathrm{N} \quad \mathrm{pH}$ :

CAS NO.

COMPOUND

CONCENTRATION UNITS:

(ug/L or ug/Kg) UG/KG

\begin{tabular}{|c|}
\hline 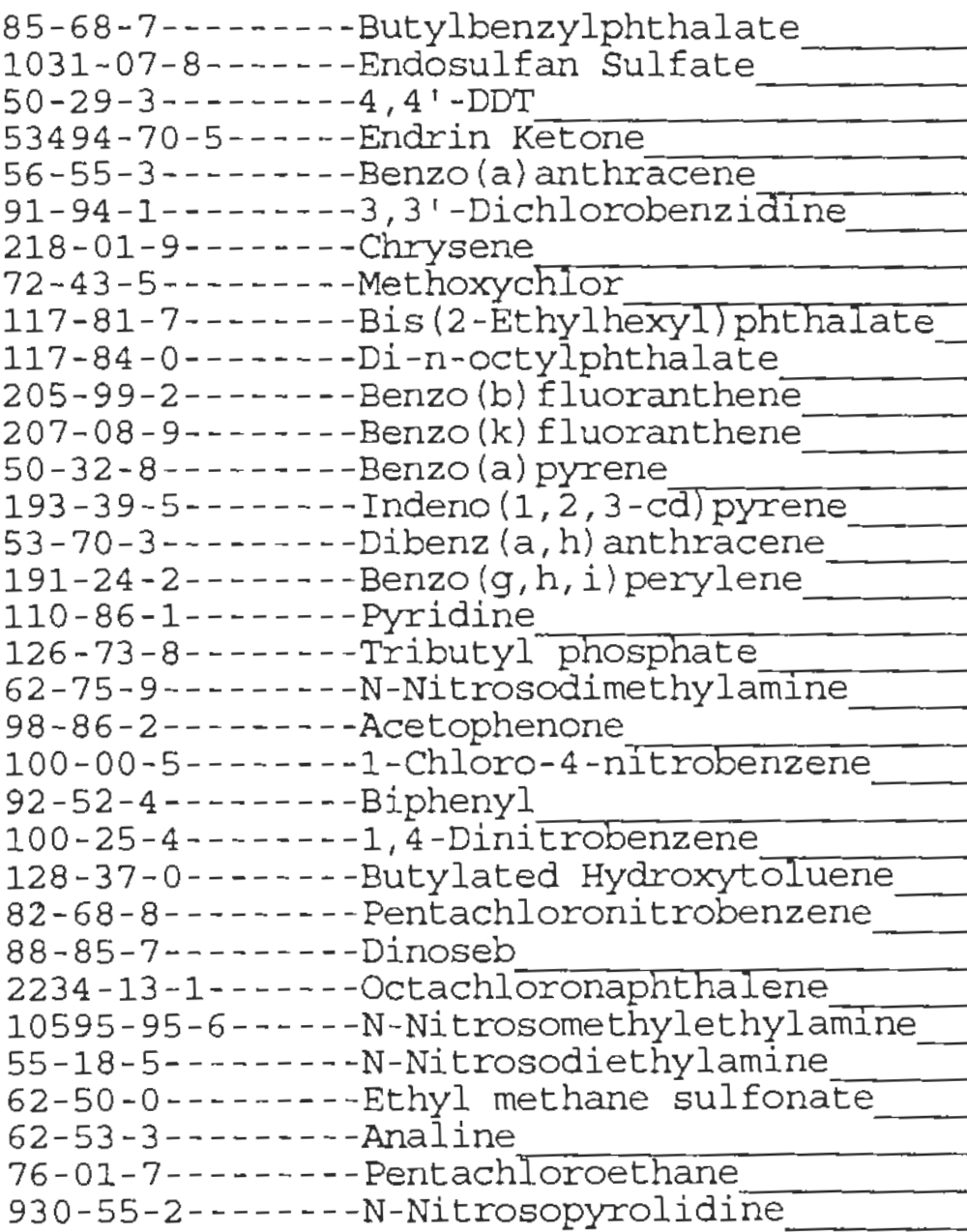 \\
\hline
\end{tabular}


Lab Name: PNNL

Lab Code: PNNL
Contract : $\mathrm{C} 104$

SAS NO. :
LCSB

SDG NO.: 000819
Matrix: (soil/water) SOLID

Sample wt/vol:

$5.0(\mathrm{~g} / \mathrm{mL}) \mathrm{G}$

Level: (low/med) LOW

$\%$ Moisture: 0 decanted: ( $\mathrm{Y} / \mathrm{N}) \mathrm{N}$

Concentrated Extract Volume: 1000 (UL)

Injection volume: (UI)

GPC Cleanup: (Y/N) N $\mathrm{pH}$ :
Lab Sample ID: LCSB

Lab File ID: 00081918

Date Received:

Date Extracted:

Date Analyzed: 08/20/0

Dilution Factor: 1.0

CAS NO.

COMPOUND

CONCENTRATION UNITS:

(ug/L or ug/Kg) UG/KG

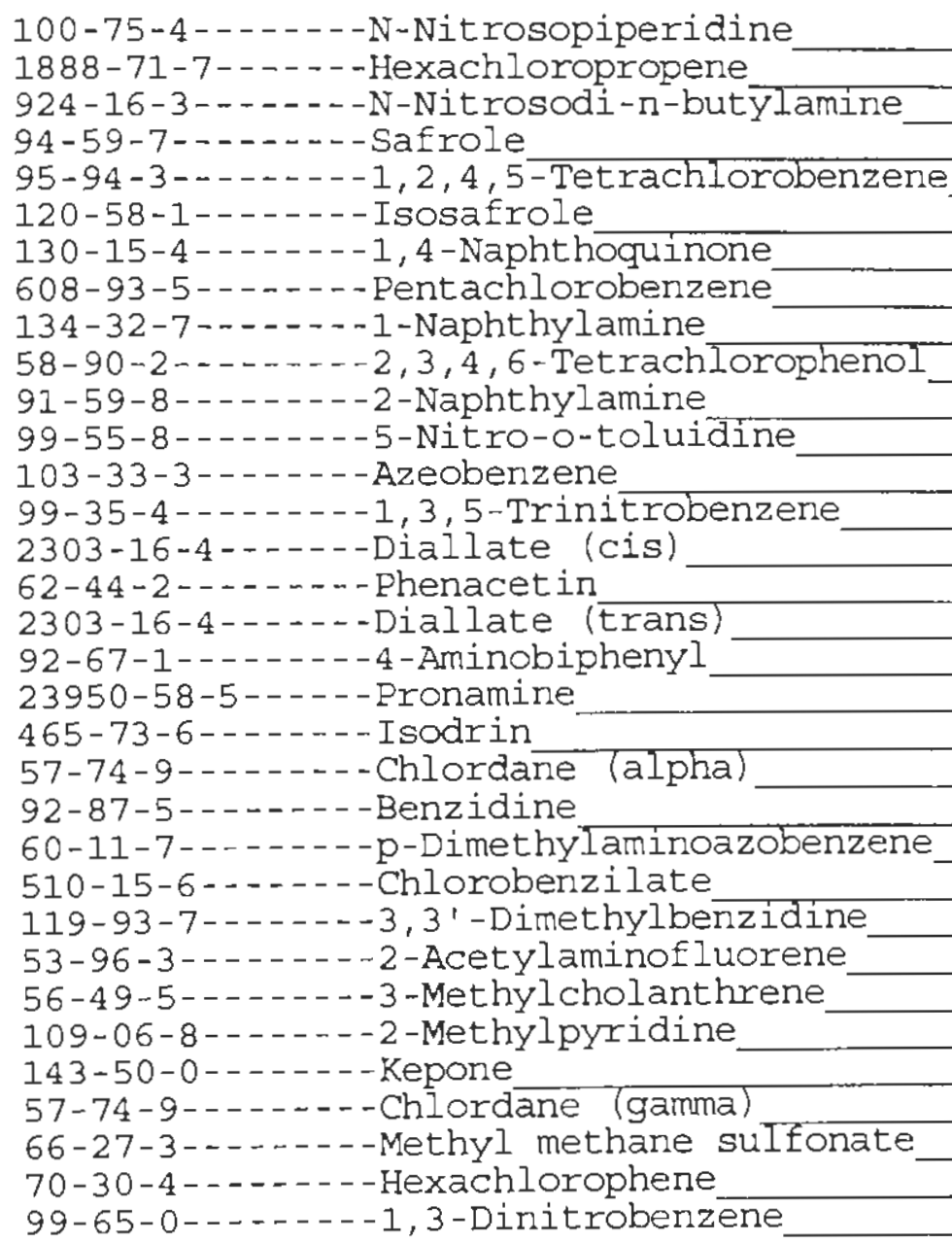

$2000 \mathrm{U}$ $2000 \mathrm{U}$ $2000 \mathrm{U}$ $2000 \mathrm{U}$ $2000 \mathrm{U}$ $2000 \mathrm{U}$ $2000 \mathrm{U}$ $2000 \mathrm{U}$ $2000: \mathrm{U}$ $2000 \mathrm{U}$ $2000 \mathrm{U}$ $2000 \mathrm{U}$ $2000 \mathrm{U}$ $2000 \mathrm{U}$ $2000 \mathrm{U}$ $2000 \mathrm{U}$ $2000 \mathrm{U}$ 2000 U $2000 \mathrm{U}$ $2000 \mathrm{U}$ $2000 \mathrm{U}$ 9000 $2000 \mathrm{U}$ $2000 \mathrm{U}$ $2000 \mathrm{U}$ $2000 \mathrm{U}$ $2000 \mathrm{U}$ $2000 \mathrm{U}$ $2000 \mathrm{U}$ $2000 . \mathrm{U}$ $2000 / \mathrm{U}$ $2000 \mathrm{U}$ 2000 
Lab Name: PNNL

Contract: C104

Lab code: PNNL

Case No. :

SAS NO.:

LCSB

Matrix: (soil/water) SOLID

Lab Sample ID: LCSB

Sample wt/vol:

$5.0(\mathrm{~g} / \mathrm{mL}) \mathrm{G}$

Lab File ID: 00081918

Level: (low/med) LOW

Date Received:

\% Moisture: 0

decanted: $(\mathrm{Y} / \mathrm{N}) \mathrm{N}$

Date Extracted:

Concentrated Extract Volume: 1000 (uL)

Date Analyzed: 08/20/0

Injection Volume:

GPC Cleanup: $\quad(\mathrm{Y} / \mathrm{N}) \mathrm{N}$ (UL)

Dilution Factor: 1.0

$\mathrm{pH}:$

\section{CAS NO.}

CONCENTRATION UNITS :

$(\mathrm{ug} / \mathrm{L}$ or $\mathrm{ug} / \mathrm{Kg})$ UG/KG Q

\begin{tabular}{|l|l|l|}
\hline $87-65-0 \ldots-2,6-D i c h l o r o p h e n o l$ & 2000 & $\mathrm{U}$ \\
\hline
\end{tabular}


Lab Name : PNNL

Lab code: PNNL
Contract: $\mathrm{C} 104$

SAS NO. :
Matrix: (soil/water) SOLID

Sample wt/vol:

$5.0(\mathrm{~g} / \mathrm{mL}) \mathrm{G}$

Level: (low/med) LOW

$\because$ Moisture: 0 decanted: ( $\mathrm{Y} / \mathrm{N}) \mathrm{N}$

Concentrated Extract Volume: 1000 (u)

Injection Volume: (uL)
$\langle\mathrm{Y} / \mathrm{N}\rangle \mathrm{N} \quad \mathrm{pH}:$
GPC Cleanup:
$(Y / N) \mathrm{N}$

\section{LCSMS}

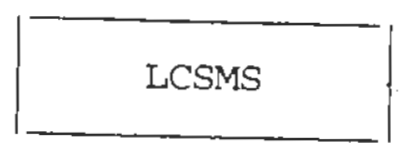

SDG NO.: 000819

Lab Sample ID: LCSMS

Lab File ID: 00081919

Date Received:

Date Extracted:

Date Analyzed: 08/20/0

Dilution Factor: 1.0

CAS NO.

COMPOUND

CONCENTRATION UNITS:

(ug/L or ug/Kg) UG/KG

\begin{tabular}{|c|}
\hline 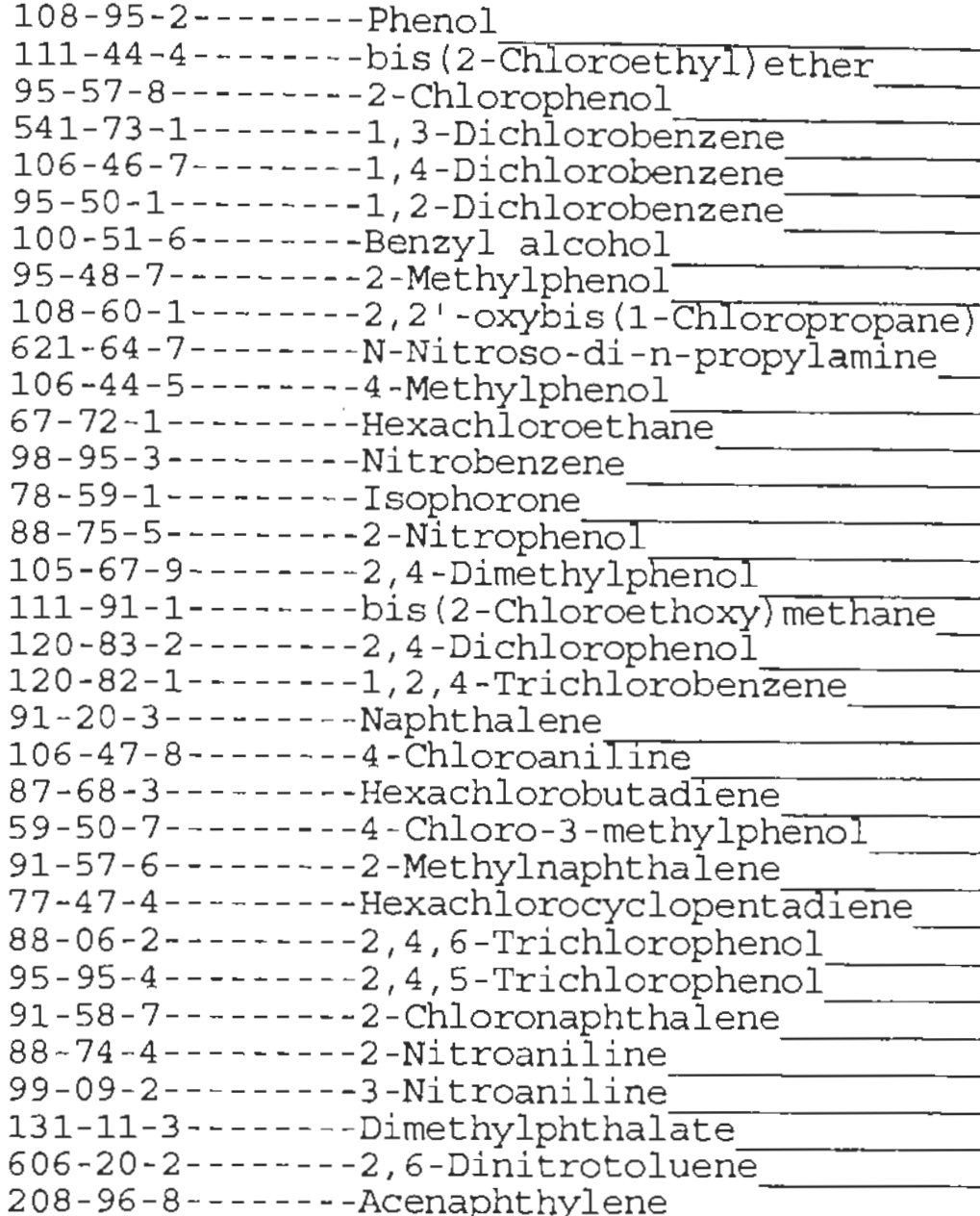 \\
\hline
\end{tabular}

\begin{tabular}{|r|r|}
\hline 3800 & \\
2000 & $\mathrm{U}$ \\
6300 & \\
2000 & $\mathrm{U}$ \\
6100 & \\
2000 & $\mathrm{U}$ \\
2000 & $\mathrm{U}$ \\
7600 & $\mathrm{~B}$ \\
2000 & $\mathrm{U}$ \\
7900 & \\
17000 & $\mathrm{~B}$ \\
2000 & $\mathrm{U}$ \\
2000 & $\mathrm{U}$ \\
2000 & $\mathrm{U}$ \\
2000 & $\mathrm{U}$ \\
2000 & $\mathrm{U}$ \\
2000 & $\mathrm{U}$ \\
2000 & $\mathrm{U}$ \\
6600 & \\
2000 & $\mathrm{U}$ \\
2000 & $\mathrm{U}$ \\
2000 & $\mathrm{U}$ \\
6600 & \\
2000 & $\mathrm{U}$ \\
2000 & $\mathrm{U}$ \\
2000 & $\mathrm{U}$ \\
2000 & $\mathrm{U}$ \\
2000 & $\mathrm{U}$ \\
2000 & $\mathrm{U}$ \\
2000 & $\mathrm{U}$ \\
2000 & $\mathrm{U}$ \\
2000 & $\mathrm{U}$ \\
2000 & $\mathrm{U}$ \\
\hline
\end{tabular}


Irab Name: PNNL,

Iab Code: PNNL

Case No.:

Contract: $\mathrm{ClO} 4$

SAS NO. :

SDG No.: 000819
Matrix: (soil/water) SOLID

Sample wt/vol:

$5.0(\mathrm{~g} / \mathrm{mL}) \mathrm{G}$

Level: (low/med)

\section{LOW}

응 Moisture: 0

decanted: $(Y / N) N$

Concentrated Extract Volume: 1000 (uL) Injection volume: (uL)

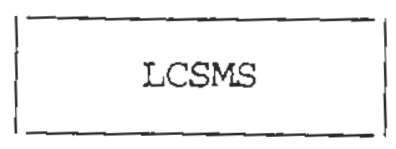

Lab Sample ID: LCSMS

Lab File ID: 00081919

Date Received:

Date Extracted:

Date Analyzed: $08 / 20 / 0$

Dilution Factor: 1.0

GPC Cleanup: $(\mathrm{Y} / \mathrm{N}) \mathrm{N} \quad \mathrm{pH}$ :

CAS NO.

COMPOUND
CONCENTRATION UNITS: $(\mathrm{ug} / \mathrm{L}$ or $\mathrm{ug} / \mathrm{Kg}) \mathrm{UG} / \mathrm{KG}$

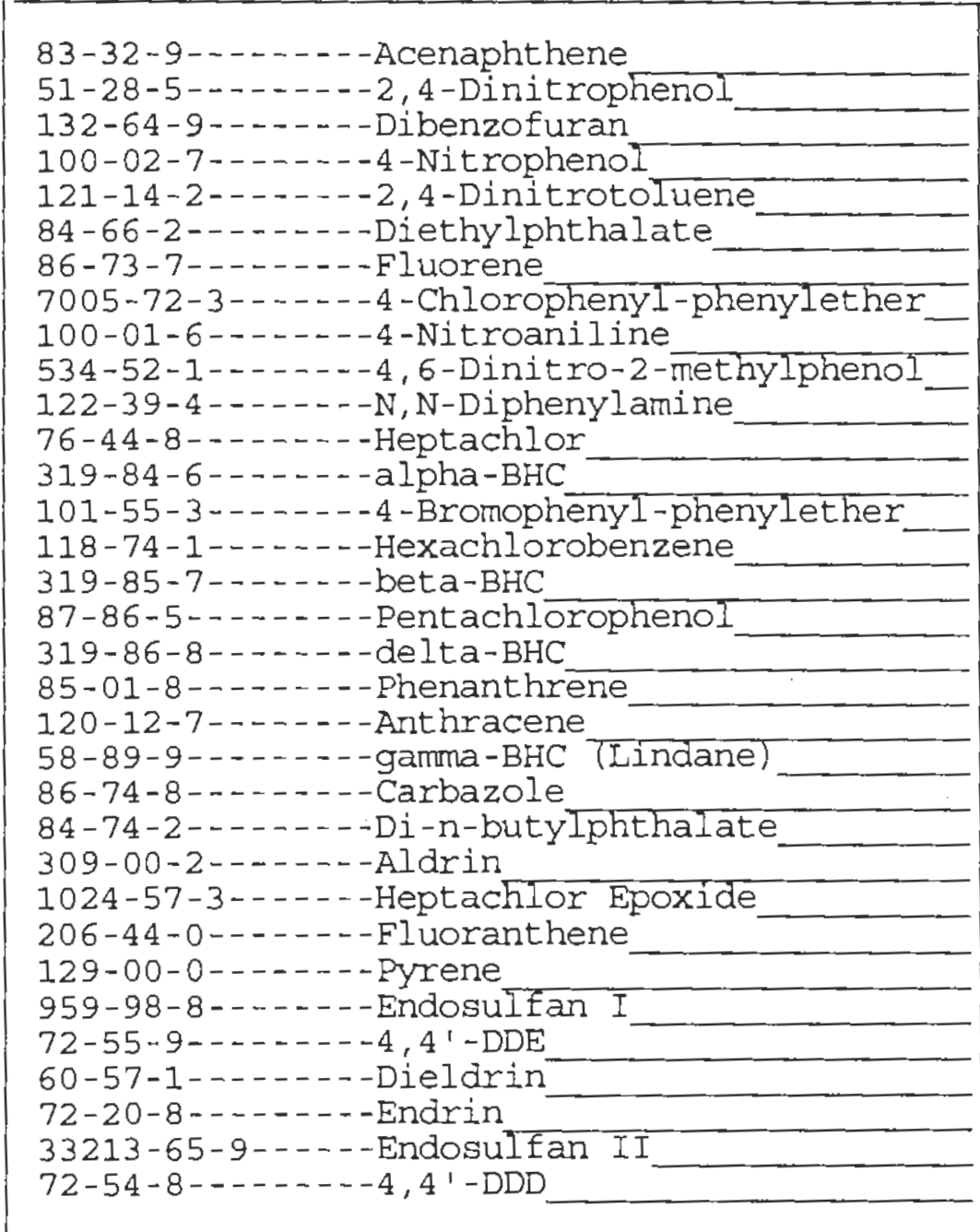

FORM I SV-2

\begin{tabular}{|l|l|l|}
7400 & \\
2000 & $\mathrm{U}$ \\
2000 & $\mathrm{U}$ \\
2100 & \\
7700 & \\
2000 & $\mathrm{U}$ \\
2000 & $\mathrm{U}$ \\
2000 & $\mathrm{U}$ \\
2000 & $\mathrm{U}$ \\
2000 & $\mathrm{U}$ \\
2000 & $\mathrm{U}$ \\
2000 & $\mathrm{U}$ \\
2000 & $\mathrm{U}$ \\
2000 & $\mathrm{U}$ \\
2000 & $\mathrm{U}$ \\
2000 & $\mathrm{U}$ \\
2000 & $\mathrm{U}$ \\
2000 & $\mathrm{U}$ \\
2000 & $\mathrm{U}$ \\
2000 & $\mathrm{U}$ \\
2000 & $\mathrm{U}$ \\
2000 & $\mathrm{U}$ \\
2000 & $\mathrm{U}$ \\
2000 & $\mathrm{U}$ \\
2000 & $\mathrm{U}$ \\
2000 & $\mathrm{U}$ \\
8900 & \\
2000 & $\mathrm{U}$ \\
2000 & $\mathrm{U}$ \\
2000 & $\mathrm{U}$ \\
2000 & $\mathrm{U}$ \\
2000 & $\mathrm{U}$ \\
2000 & $\mathrm{U}$ \\
& & \\
\hline & & \\
\hline
\end{tabular}

OLMO3.C 
Lab Name: PNNL

Lab Code: PNNL

Case No.:

Matrix: (soil/water) SOLID

Sample wt/vol: $\quad 5.0(\mathrm{~g} / \mathrm{mL}) \mathrm{G}$

Level: (low/med) LOW

Contract : $\mathrm{Cl} 104$

LCSMS

SAS NO. :

SDG No.: 000819 $\because$ Moisture: 0 decanted: $(\mathrm{Y} / \mathrm{N}) \mathrm{N}$

Concentrated Extract Volume: 1000 (uL)

Injection Volume: (uL)

GPC Cleanup: $(\mathrm{Y} / \mathrm{N}) \mathrm{N} \quad \mathrm{pH}$ :
Lab Sample ID: LCSMS

Lab File ID: 00081919

Date Received:

Date Extracted:

Date Analyzed: 08/20/0

Dilution Factor: 1.0

CAS NO.

COMPOUND

CONCENTRATION UNITS:

(ug/L or $\mathrm{ug} / \mathrm{Kg}$ ) UG/KG

Q

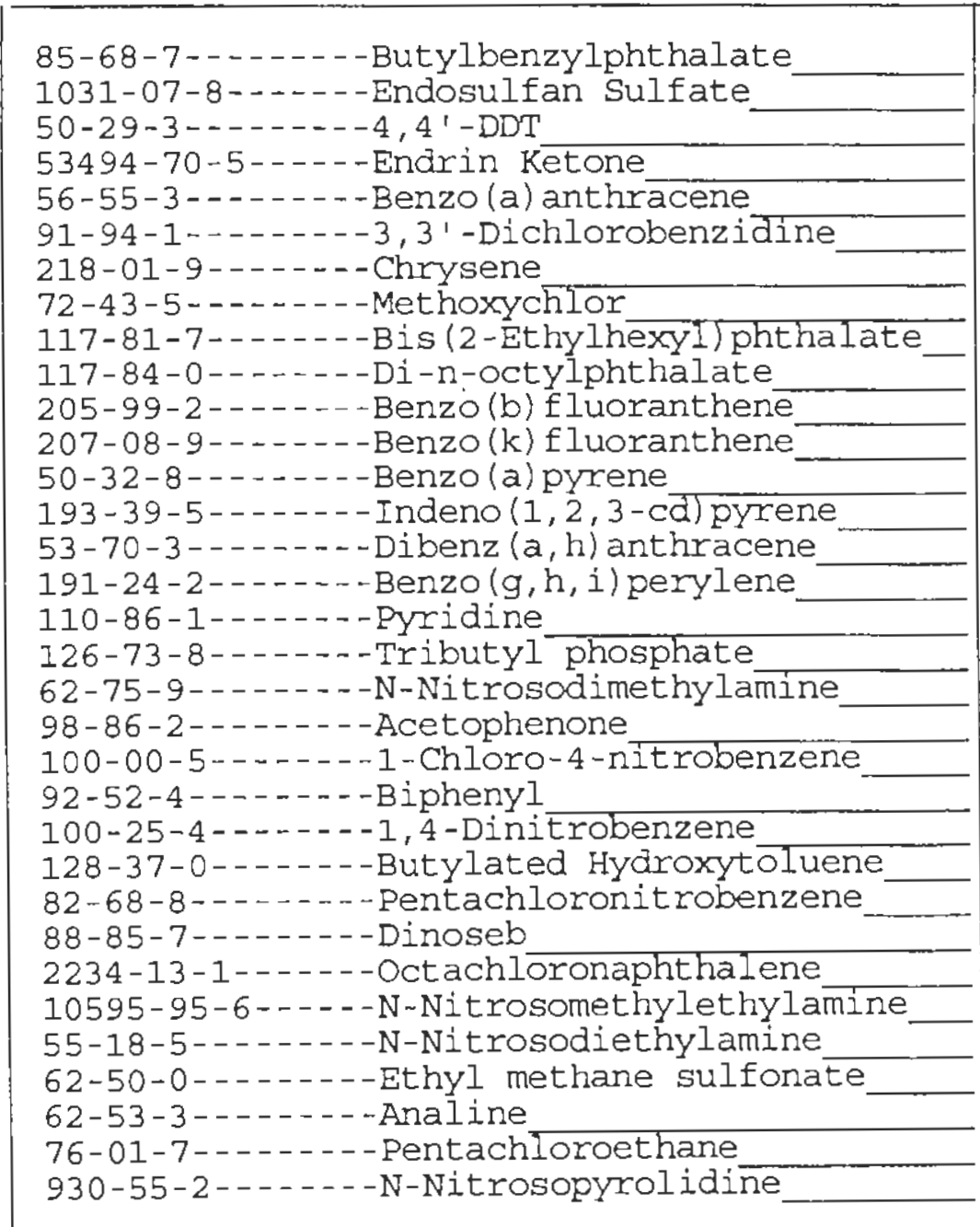


Lab Name: PNNL

Lab Code: PNNL
Contract: $\mathrm{ClO4}$

Case No.:
SAS NO. :

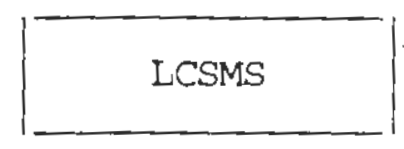

SDG NO.: 000819
Matrix: (soil/water) SoLID

Sample wt/vol:

$5.0(\mathrm{~g} / \mathrm{mL}) \quad G$

Level: (low/med) LOW

\% Moisture: 0 decanted: $(\mathrm{Y} / \mathrm{N}\rangle \mathrm{N}$

Concentrated Extract Volume: 1000 (uL)

Injection Volume: (UI)
Lab Sample ID: LCSMS

Lab File ID: 00081919 .

Date Received:

Date Extracted:

Date Analyzed: 08/20/0

Dilution Factor: 1.0
GPC Cleanup:
$(Y / N) N$
$\mathrm{pH}:$

CAS NO.

COMPOUND

CONCENTRATION UNITS:

$\langle\mathrm{ug} / \mathrm{L}$ or $\mathrm{ug} / \mathrm{kg}$ ) UG/KG

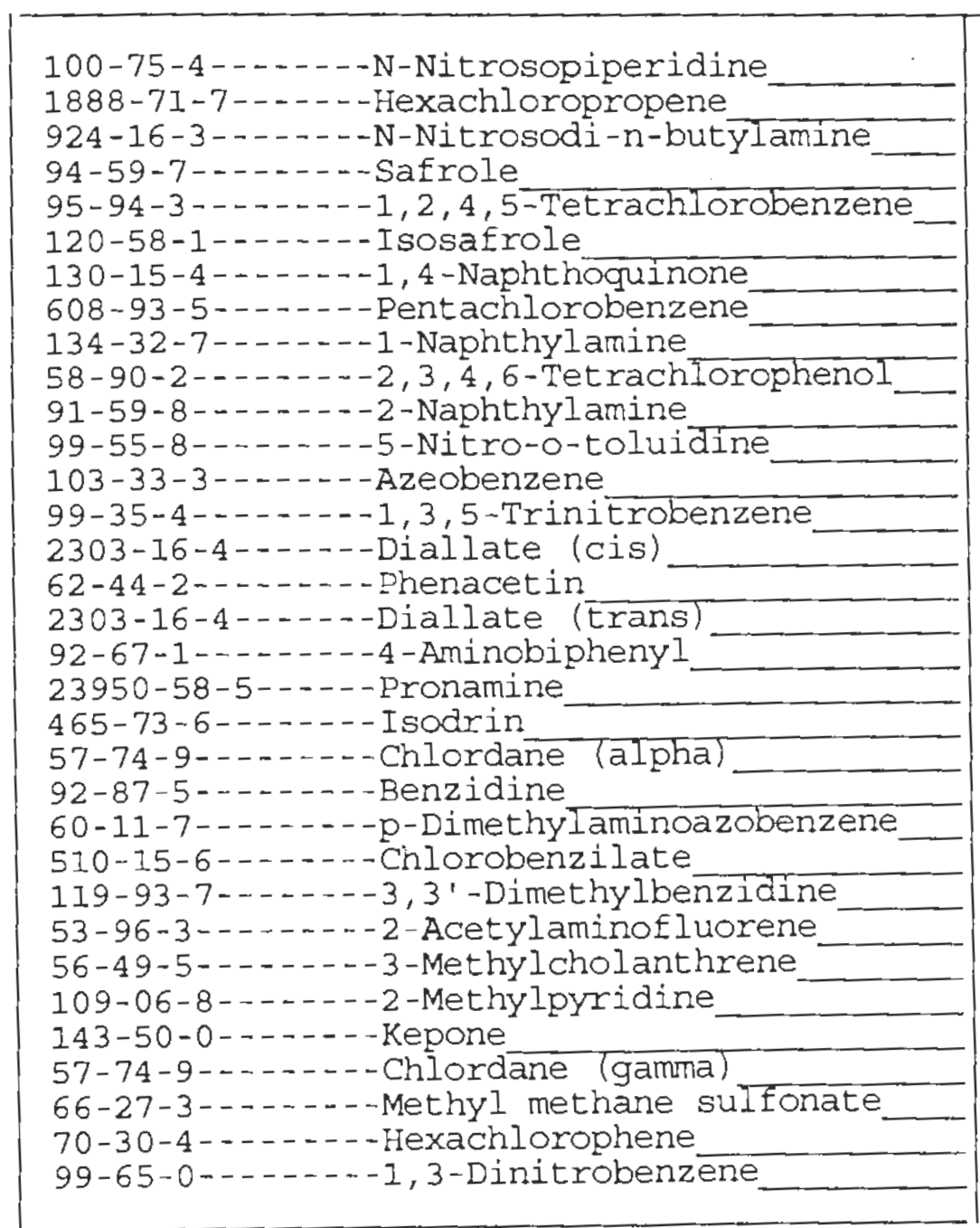

\begin{tabular}{|l|l|l|}
\hline 2000 & $\mathrm{U}$ \\
2000 & $\mathrm{U}$ \\
2000 & $\mathrm{U}$ \\
2000 & $\mathrm{U}$ \\
2000 & $\mathrm{U}$ \\
2000 & $\mathrm{U}$ \\
2000 & $\mathrm{U}$ \\
2000 & $\mathrm{U}$ \\
2000 & $\mathrm{U}$ \\
2000 & $\mathrm{U}$ \\
2000 & $\mathrm{U}$ \\
2000 & $\mathrm{U}$ \\
2000 & $\mathrm{U}$ \\
2000 & $\mathrm{U}$ \\
2000 & $\mathrm{U}$ \\
2000 & $\mathrm{U}$ \\
2000 & $\mathrm{U}$ \\
2000 & $\mathrm{U}$ \\
2000 & $\mathrm{U}$ \\
2000 & $\mathrm{U}$ \\
2000 & $\mathrm{U}$ \\
8800 & \\
2000 & $\mathrm{U}$ \\
2000 & $\mathrm{U}$ \\
2000 & $\mathrm{U}$ \\
2000 & $\mathrm{U}$ \\
2000 & $\mathrm{U}$ \\
2000 & $\mathrm{U}$ \\
2000 & $\mathrm{U}$ \\
2000 & $\mathrm{U}$ \\
2000 & $\mathrm{U}$ \\
2000 & $\mathrm{U}$ \\
2000 & $\mathrm{U}$ \\
\hline & & \\
\hline & \\
\hline
\end{tabular}


Lab Name: PNNL

Lab code: PNNL

Case No.:

Matrix: (soil/water) SolID

Sample wt/vol:

$5.0(\mathrm{~g} / \mathrm{mL}) \mathrm{G}$

Level: (low $/$ med)

LOW

言 Moisture: 0

decanted: $(\mathrm{Y} / \mathrm{N}) \mathrm{N}$

Concentrated Extract Volume: 1000 (uts)

Injection volume: (UL)

Contract : C104

SAS NO.:

EPA SAMPLE NO.

GPC Cleanup: $\quad(\mathrm{Y} / \mathrm{N}) \mathrm{N}$

$\mathrm{pH}$ :
LCSMS

SDG No.: 000819
Lab Sample ID: LCSMS

Lab File ID: 00081919

Date Received:

Date Extracted:

Date Analyzed: 08/20/0

Dilution Factor: 1.0

CAS NO. COMEOUND CONCENTRATION UNITS:

CAS NO. COMPOUND (ug/L or $\mathrm{ug} / \mathrm{Kg}) \mathrm{UG} / \mathrm{KG} \quad$

\begin{tabular}{l|l|l|}
\hline $87-65-0 \ldots-\ldots-2,6-D i c h l o r o p h e n o l$ & 2000 & $\mathrm{U}$ \\
\hline
\end{tabular}


Lab Name: PNNL

Contract: $\mathrm{C} 104$

Lab code: PNNL

Case No.:

SAS NO. :
Cl04-SLB

SDG No.: 000819

Lab Sample ID: 00-1360-SLB
Sample wt/vol:

$0.000(\mathrm{~g} / \mathrm{mL}) \mathrm{ML}$

Ievel: (low/med) Low

\% Moisture:

decanted: $(Y / N)$

Concentrated Extract Volume: 1000 (uL)

Injection volume: (uL)

GPC Cleanup: (Y/N) N

$\mathrm{pH}$ :

Number TICs found: 3

CONCENIRATION UNITS:

$(\mathrm{ug} / \mathrm{L}$ or $\mathrm{ug} / \mathrm{Kg}) \mathrm{ug} / \mathrm{L}$

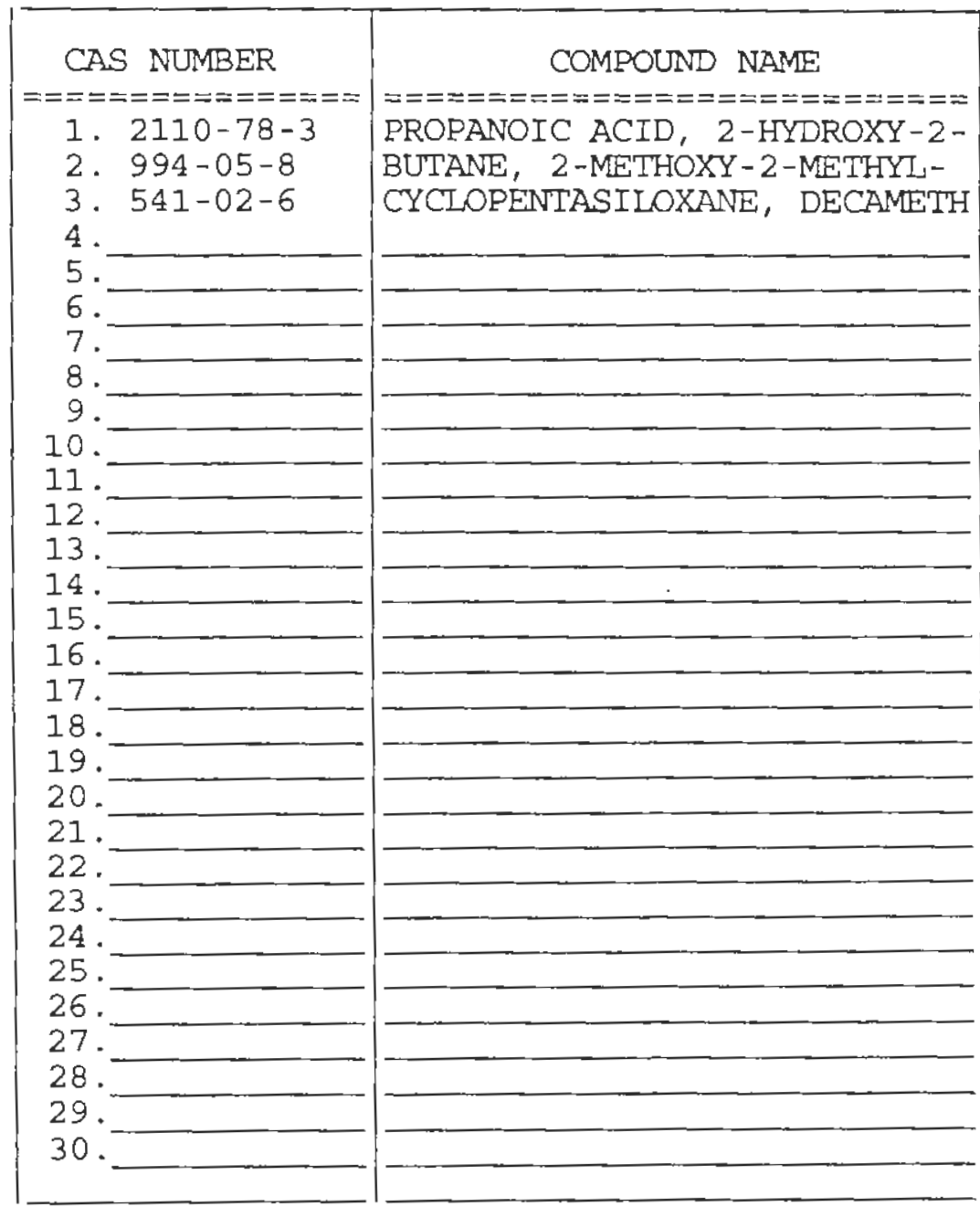

FORM I SV-TIC

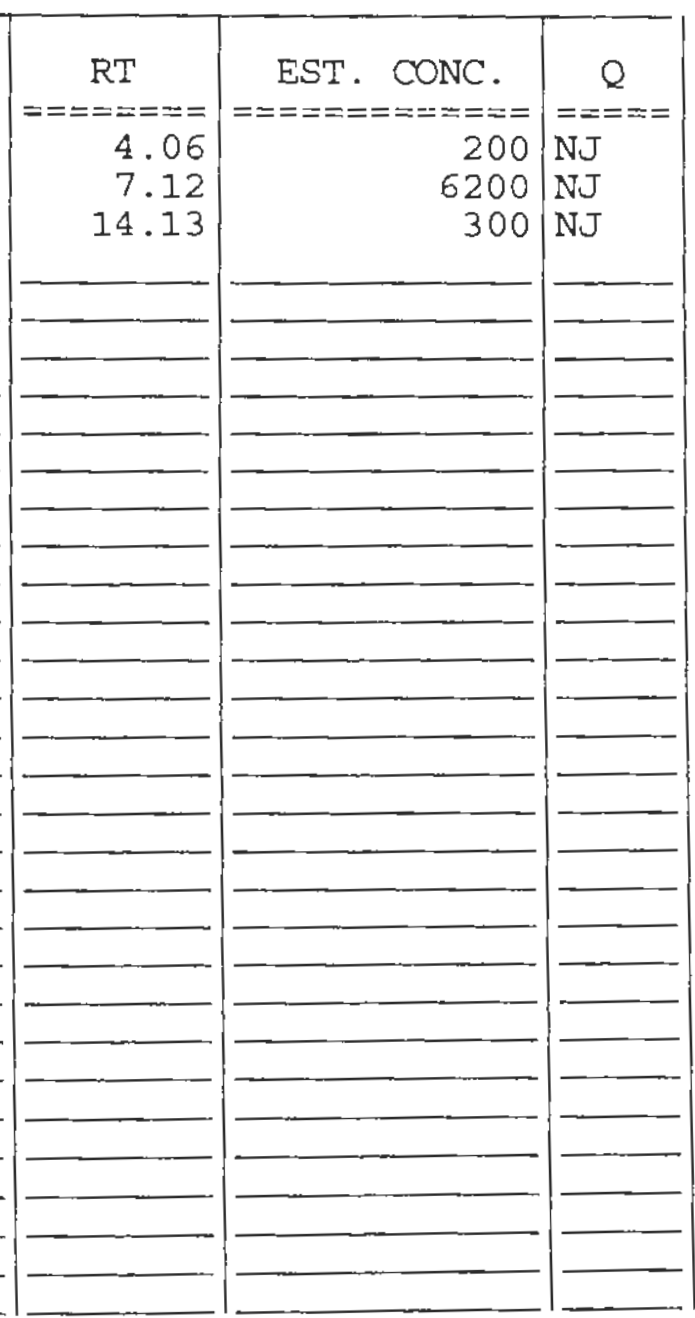

OLMO 3.0 
Lab Name: PNNL

Contract: $\mathrm{ClO}$

Lab Code: PNNL

Case No. :

SAS NO. :

$\mathrm{ClO} 4-\mathrm{SLD}$

Matrix: (soil/water) SUPERNATANT

Sample wt/vol:

$0.000(\mathrm{~g} / \mathrm{mL}) \mathrm{ML}$

Lab Sample ID: 00-1360-SLD

\section{Level: (low/med) LOW}

Lab File ID: 00081906

\% Moisture:

decanted: $(\mathrm{Y} / \mathrm{N})$

Date Received:

Concentrated Extract Volume: 1000 (UI)

Date Extracted:

Injection volume: (uL)

Date Analyzed: 08/19/0

GPC Cleanup: (Y/N) N

$\mathrm{pH}:$

Dilution Factor: 1.0

Number TICs found: 29

CONCENTRATION UNITS :

$\langle u g / L$ or $u g / K g) u g / L$

\begin{tabular}{|c|c|}
\hline 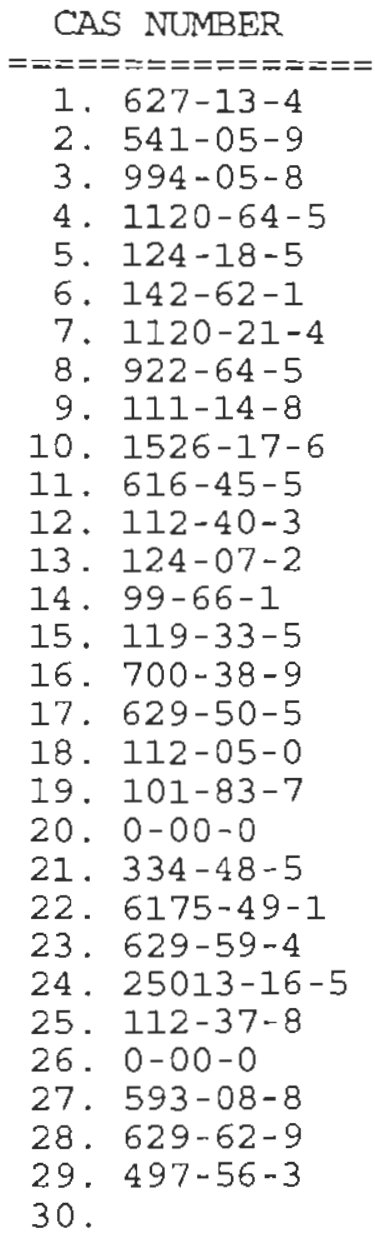 & $\begin{array}{l}\text { COMPOUND NAME } \\
===================== \\
\text { NITRIC ACID, PROPYL ESTER } \\
\text { CYCLOTRISILOXANE, HEXAMETHYL } \\
\text { BUTANE, 2-METHOXY - }- \text { METHYL- } \\
\text { OXAZOLE, 4,5-DIHYDRO-2-METHY } \\
\text { DECANE } \\
\text { HEXANOIC ACID } \\
\text { UNDECANE } \\
\text { PROPANEDINITRILE, METHYLENE- } \\
\text { HEPTANOIC ACID } \\
\text { 2-FLUORO-6-NITROPHENOL } \\
\text { 2-PYRROLIDINONE } \\
\text { DODECANE } \\
\text { OCTANOIC ACID } \\
\text { VALPROIC ACID } \\
\text { PHENOL, 4-METHYL-2-NITRO- } \\
\text { 5-METHYL-2-NITROPHENOL } \\
\text { TRIDECANE } \\
\text { NONANOIC ACID } \\
\text { CYCLOHEXANAMINE, N-CYCLOHEXY } \\
\text { PHENOL, 2-FLUORO-4-NITRO- } \\
\text { DECANOIC ACID } \\
\text { 2-DODECANONE } \\
\text { TETRADECANE } \\
\text { BUTYLATED HYDROXYANISOLE } \\
\text { UNDECANOIC ACID } \\
\text { BUTYL NONANOATE } \\
\text { 2-TRIDECANONE } \\
\text { PENTADECANE } \\
\text { PHENOL, 2-METHYL-3, 5-DINITRO }\end{array}$ \\
\hline
\end{tabular}

FORM I SV-TIC

\begin{tabular}{|c|c|c|}
\hline RT & EST. CONC. & $Q$ \\
\hline$=====z==$ & $==\approx==2=:=====$ & $===\equiv=$ \\
\hline 3.74 & 370 & $\mathrm{NJ}$ \\
\hline 6.44 & 9000 & $\mathrm{NJ}$ \\
\hline 7.16 & 5700 & NJB \\
\hline 7.53 & 8800 & $\mathrm{NJ}$ \\
\hline 11.32 & 400 & NJ \\
\hline 12.11 & 6300 & NJ \\
\hline 13.54 & 1700 & NJ \\
\hline 14.22 & 12000 & $\mathrm{NJ}$. \\
\hline 14.22 & 2700 & NJ \\
\hline 14.60 & 750 & NJ \\
\hline 15.17 & 160 & $\mathrm{NJ}$ \\
\hline 15.52 & 3300 & NJ \\
\hline 16.04 & 14000 & $\mathrm{NJ}$ \\
\hline 16.19 & 170 & $\mathrm{NJ}$ \\
\hline 16.24 & 410 & NJ \\
\hline 16.73 & 180 & $\mathrm{NJ}$ \\
\hline 17.35 & 3600 & NJ \\
\hline 17.52 & 5900 & NJ \\
\hline 17.58 & 95 & NJ \\
\hline 18.30 & 250 & NJ \\
\hline 18.74 & 1000 & $\mathrm{NJ}$ \\
\hline 18.96 & 250 & $\mathrm{NJ}$ \\
\hline 19.03 & 1200 & NJ \\
\hline 20.05 & 990 & $\mathrm{NJ}$ \\
\hline 20.20 & 1100 & NJ \\
\hline $20.4 I$ & 130 & NJ \\
\hline 20.57 & 120 & $\mathrm{NJ}$ \\
\hline $20.6 I$ & 120 & $\mathrm{NJ}$ \\
\hline 22.39 & 230 & $\mathrm{NJ}$ \\
\hline & & \\
\hline
\end{tabular}

OLMO 3.0 
Lab Name: DNNL

Lab code: PNNL
Contract: $\mathrm{C} 104$

Case No.:
SAS NO. :
EPA SAMPLE NO.

C104-SLE

Matrix: (soil/water) SURERNATANT

Sample wt/vol:

$0.000(\mathrm{~g} / \mathrm{mL}) \mathrm{ML}$

Lab Sample ID: 00-1360-SLE

Level: (low/med) IOW

: Moisture:

decanted: $(Y / N)$

Lab File ID: 00081909

Date Received:

Date Extracted:

Concentrated Extract Volume: 1000 (UI) Injection Volume: (UL)

Date Analyzed: 08/19/0

Dilution Factor: 1.0

GPC Cleanup: (Y/N) $\mathrm{N} \quad \mathrm{pH}$ :

Number TICs found: 30

CONCENTRATION UNITS:

(ug/L or $u g / \mathrm{Kg}$ ) $u g / \mathrm{L}$

\begin{tabular}{|c|c|c|c|c|}
\hline 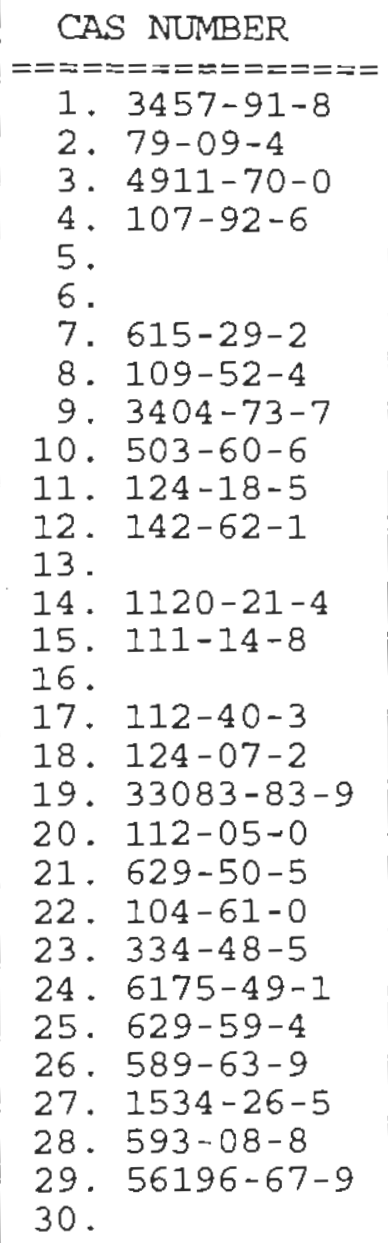 & 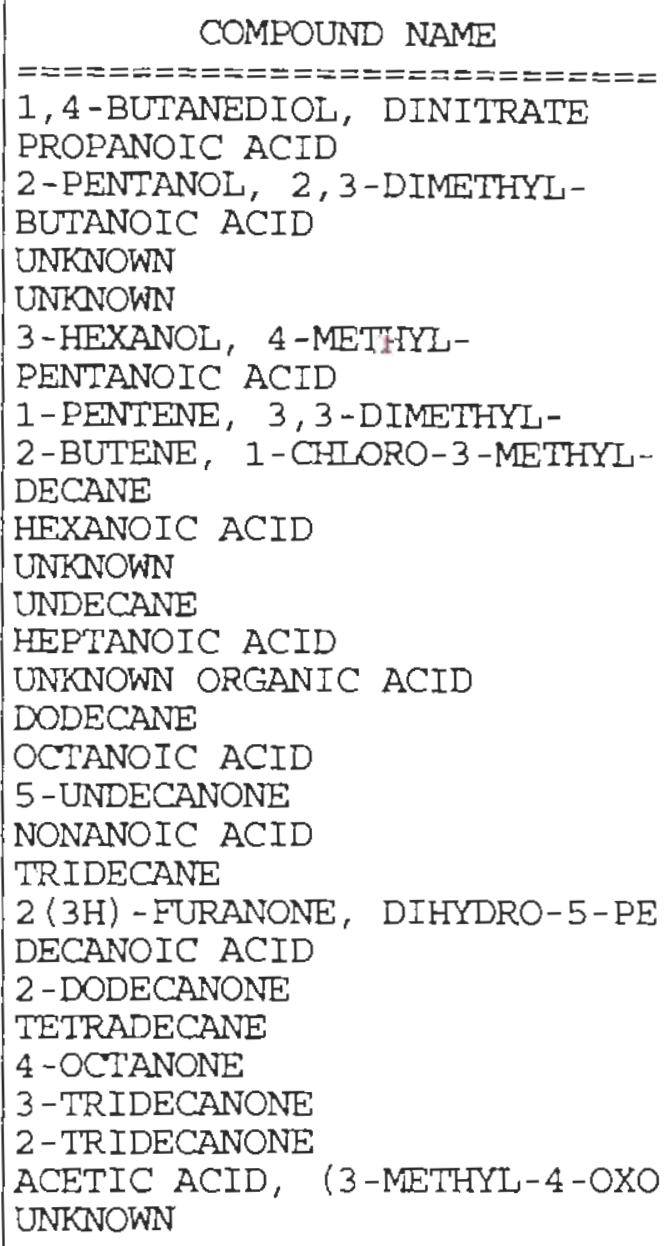 & $\begin{array}{r}R T \\
3 .===== \\
3.73 \\
4.96 \\
6.23 \\
8.23 \\
8.55 \\
9.24 \\
10.00 \\
10.44 \\
10.51 \\
11.18 \\
11.32 \\
12.44 \\
13.01 \\
13.56 \\
14.19 \\
14.53 \\
15.57 \\
15.76 \\
16.86 \\
17.19 \\
17.39 \\
18.47 \\
18.70 \\
18.95 \\
19.04 \\
20.23 \\
20.47 \\
20.57 \\
20.80 \\
22.06\end{array}$ & $\begin{array}{r}\text { EST. CONC. } \\
======== \\
1800 \\
2800 \\
3500 \\
720 \\
860 \\
5900 \\
20000 \\
9600 \\
1800 \\
850 \\
2600 \\
19000 \\
720 \\
9000 \\
11000 \\
4000 \\
13000 \\
5600 \\
450 \\
2600 \\
16000 \\
250 \\
680 \\
310 \\
4800 \\
2700 \\
350 \\
340 \\
1200 \\
790\end{array}$ & $\begin{array}{l}\quad== \\
N J \\
N J \\
N J \\
N J \\
J \\
J \\
N J \\
N J \\
N J \\
N J \\
N J \\
N J \\
J \\
N J \\
N J \\
J \\
N J \\
N J \\
N J \\
N J \\
N J \\
N J \\
N J \\
N J \\
N J \\
N J \\
N J \\
N J \\
N J \\
J\end{array}$ \\
\hline
\end{tabular}


Lab Name: PNNL,

Contract: $\mathrm{C} 1.04$

Lab Code: PNNL

Case No. :

SAS NO. :
EPA SAMPLE NO.

C104-SLS
Matrix: (soil/water) SUPERNATANT

Sample wt/vol:

$0.000(\mathrm{~g} / \mathrm{mL}) \mathrm{ML}$

Level: (low/med) LOW

\% Moisture :

decanted: $(Y / N)$

SDG No.: 000819

Lab Sample ID: 00-1.360-SLS

Lab File ID: 00081905

Date Received:

Concentrated Extract Volume: 1000 (uL)

Date Extracted:

Injection volume: (uL)

Date Analyzed: 08/19/0

GPC Cleanup: $(Y / N) \mathrm{N} \quad \mathrm{pH}$ :

Dilution Factor: 1.0

CONCENTRATION UNITS:

Number TICs found: 31

( $\mathrm{ug} / \mathrm{L}$ or $\mathrm{ug} / \mathrm{Kg}$ ) $\mathrm{ug} / \mathrm{L}$

\begin{tabular}{|c|c|c|c|c|}
\hline CAS NUMBER & COMPOUND NAME & RT & CONC. & $Q$ \\
\hline 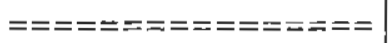 & 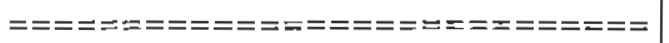 & $==\approx=====$ & $=======0==0$ & $=====$ \\
\hline I. $3457-92-9$ & 1,5-PENTANEDIOL， DINITRATE & 3.75 & 230 & NJ \\
\hline 2. $541-05-9$ & CYCLOTRISILOXANE， HEXAMETHYL & 6.43 & 8200 & NJ \\
\hline 3. $994-05-8$ & BUTANE， 2-METHOXY-2-METHYL- & 7.13 & 3800 & NJB \\
\hline 4. $1120-64-5$ & OXAZOLE $, 4,5-D I H Y D R O-2-\mathrm{METHY}$ & 7.52 & 7000 & NJ \\
\hline 5. $628-73-9$ & HEXANENITRILE & 8.29 & 140 & NJ \\
\hline 6. $109-52-4$ & PENTANOIC ACID & 9.50 & 680 & NJ \\
\hline 7. $3970-62-5$ & 3-PENTANOL, 2,2-DIMETHYL- & 9.73 & 510 & NJ \\
\hline 8. $556-67-2$ & CYCLOTETRASILOXANE, OCTAMETH & 10.85 & 3900 & NJ \\
\hline 9. $124-18-5$ & DECANE & 11.31 & 230 & NJ \\
\hline 10. $553-97-9$ & P-BENZOQUINONE，2-METHYL- & 11.75 & 400 & NJ \\
\hline 11. $142-62-1$ & HEXANOIC ACID & 11.91 & 2200 & NJ \\
\hline $12.1120-21-4$ & UNDECANE & 13.52 & 920 & NJ \\
\hline 13. $111-14-8$ & HEPTANOIC ACID & 14.07 & 7000 & NJ \\
\hline 14. & UNKNNOWN & 14.20 & 500 & $\mathrm{~J}$ \\
\hline 15. $149-57-5$ & HFXANOIC ACID, 2-ETHYL- & 14.43 & 160 & NJ \\
\hline 16. $1526-17-6$ & 2-FLUORO-6-NITROPHENOL & 14.58 & 380 & NJ \\
\hline 17. $695-06-7$ & $2(3 \mathrm{H})$-FURANONE, 5-ETHYLDIHYD & 15.15 & 170 & NJ \\
\hline 18. $112-40-3$ & DODECANE & 15.50 & 2000 & NJ \\
\hline 19. $124-07-2$ & OCIANOIC ACID & 15.92 & 9900 & NJ \\
\hline $20 \cdot 119-33-5$ & PHENOL， 4-METHYL-2-NITRO- & 16.22 & 380 & NJ \\
\hline $21.700-38-9$ & 5-METHYI - 2 -NITROPHENOL & 16.71 & 170 & NJ \\
\hline 22. $112-05-0$ & NONANOIC ACID & 17.24 & 3600 & NJ \\
\hline 23. $629-50-5$ & TRIDECANE & 17.34 & 2900 & NJ \\
\hline $394-4 I-2$ & PHFNOL， 3-FLUORO-4-NITRO- & 18.29 & 300 & $\mathrm{NJ}$ \\
\hline 25. $334-48-5$ & DECANOIC ACID & 18.81 & 3100 & NJ \\
\hline 26. $629-59-4$ & TETRADECANE & 19.01 & 820 & NJ \\
\hline $25013-16-5$ & BUTYYLATED HYDROXYANISOLE & 20.04 & 900 & NJ \\
\hline $28.79-77-6$ & 3 -BUTEN-2-ONE, $4-\{2,6,6$-TRIM & 20.12 & 270 & $\mathrm{NJ}$ \\
\hline 29. $112-37-8$ & UNDECANOIC ACID & 20.17 & 920 & NJ \\
\hline 30. $143-07-7$ & DODECANOIC ACID & 21.60 & 100 & $\mathrm{NJ}$ \\
\hline
\end{tabular}


Lab Name: PNNL

Contract: $\mathrm{C} 104$

Lab Code: PNNL

Case No.:

Matrix: (soil/water) SUPERNATANT

Sample wt/vol:

$0.000(\mathrm{~g} / \mathrm{mL}) \mathrm{ML}$

Level: (low/med) Low

응 Moisture:

decanted: $(Y / N)$

SAS NO. :
EPA SAMPLE NO.

C104-SLS

SDG No.: 000819

Lab Sample ID: 00-1360-SLS

Lab File ID: 00081905

Date Received:

Date Extracted:

Date Analyzed: 08/19/0

Dilution Factor: 1.0

Injection volume:

(uL)

1000 (UL)

pH:

GPC Cleanup: $\quad(\mathrm{Y} / \mathrm{N}\rangle \mathrm{N}$

CONCENTRATION UNITS:

Number TICs found: 31

(ug/L or $u g / \mathrm{kg}$ ) ug/L

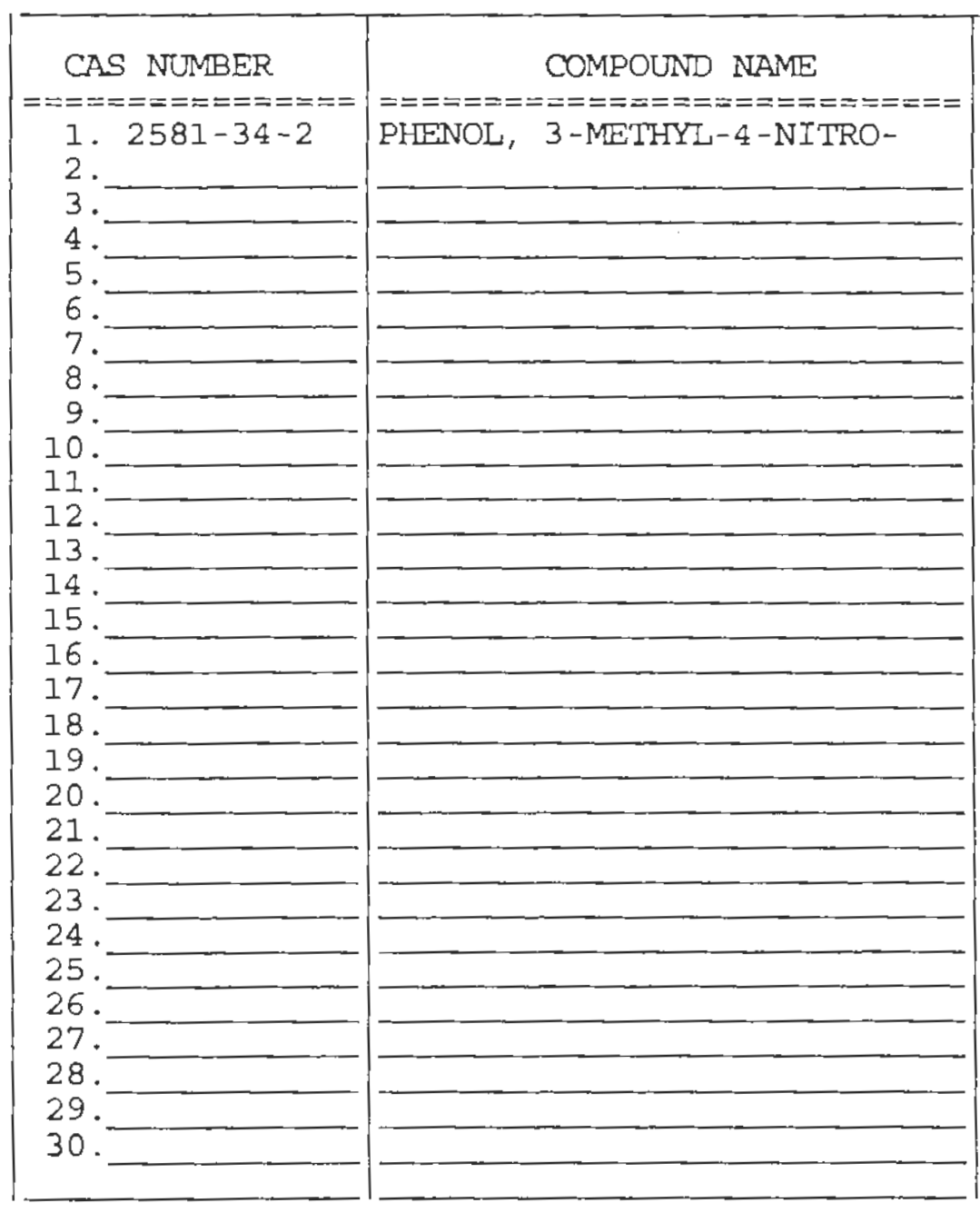

FORM I SV-TIC

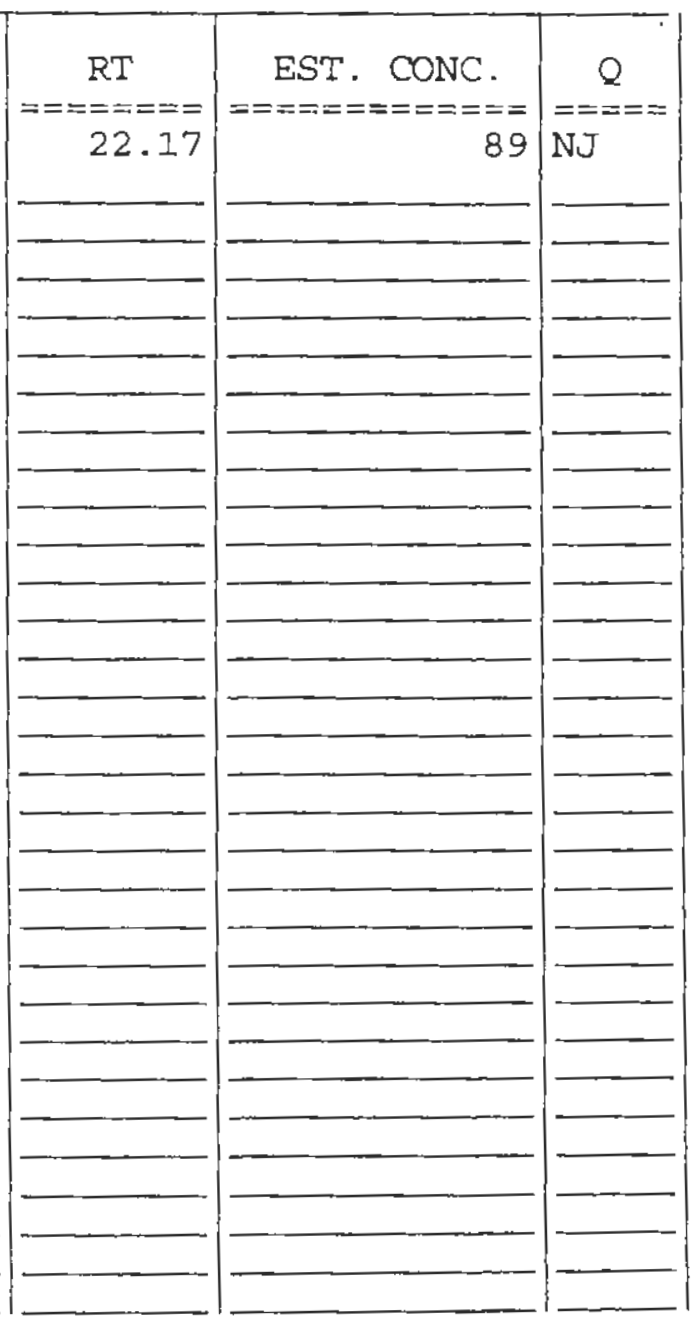

OLMO3.0 
Lab Name: PNNL

Lab code: PNNL
Contract: $\mathrm{C} 104$

SAS NO.:
C104-SSB
Matrix: (soil/water) SOLID

Sample wt/vol:

$5.0(\mathrm{~g} / \mathrm{mL}) \mathrm{G}$

Level: (low/med) LOW

\% Moisture: decanted: $(\mathrm{Y} / \mathrm{N})$

Concentrated Extract Volume: 1000 (u山)

Injection Volume: (u山)

GPC Cleanup: $\quad(Y / N) N$

$\mathrm{pH}:$
Lab Sample ID: 00-1361-SSB

Lab File ID: 00081913

Date Received:

Date Extracted:

Date Analyzed: 08/20/0

Dilution Factor: 1.0

Number TICs found: 8

CONCENTRATION UNITS:

(ug/L or $u g / \mathrm{kg}$ ) ug/ $\mathrm{kg}$

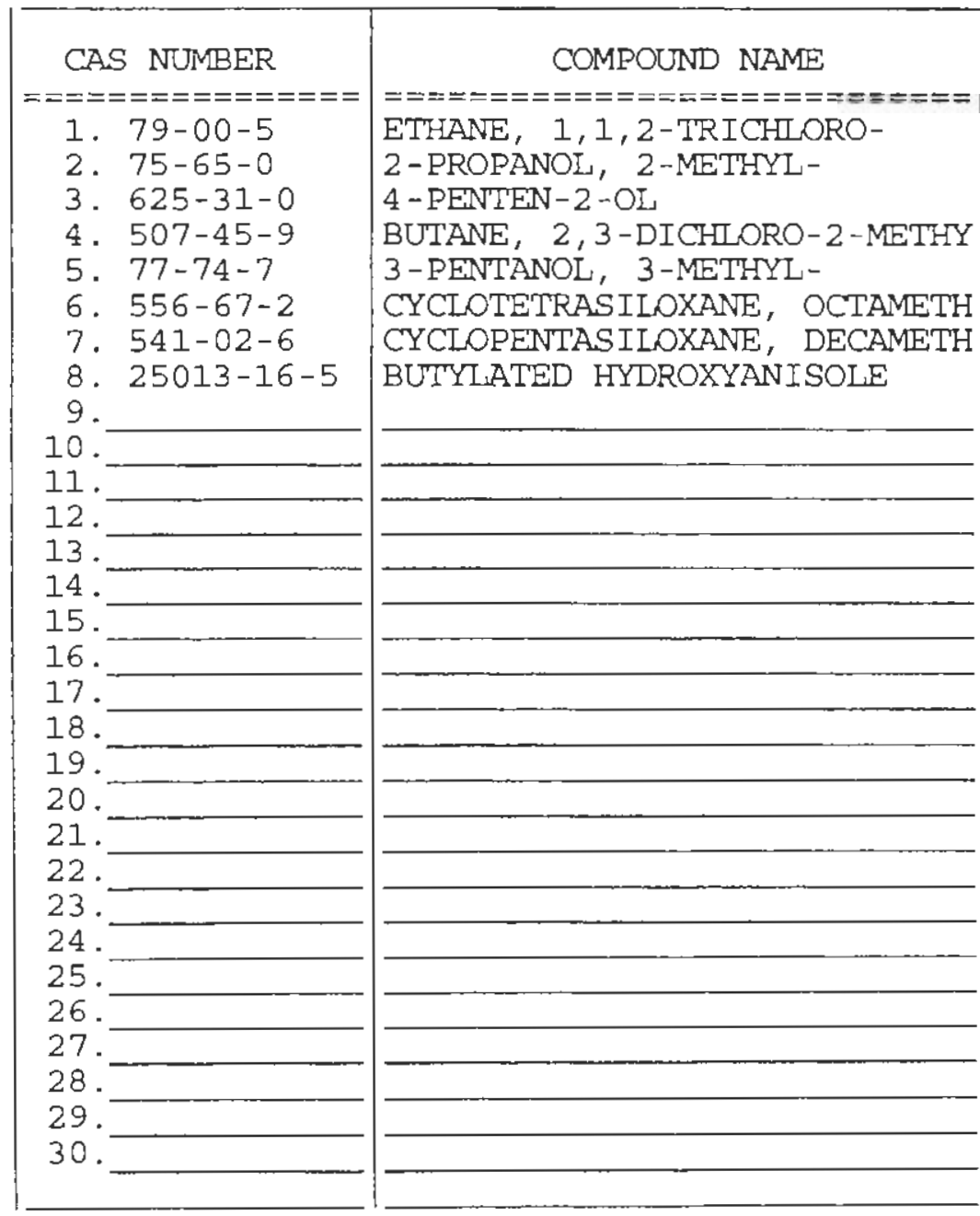

FORM I SV-TIC
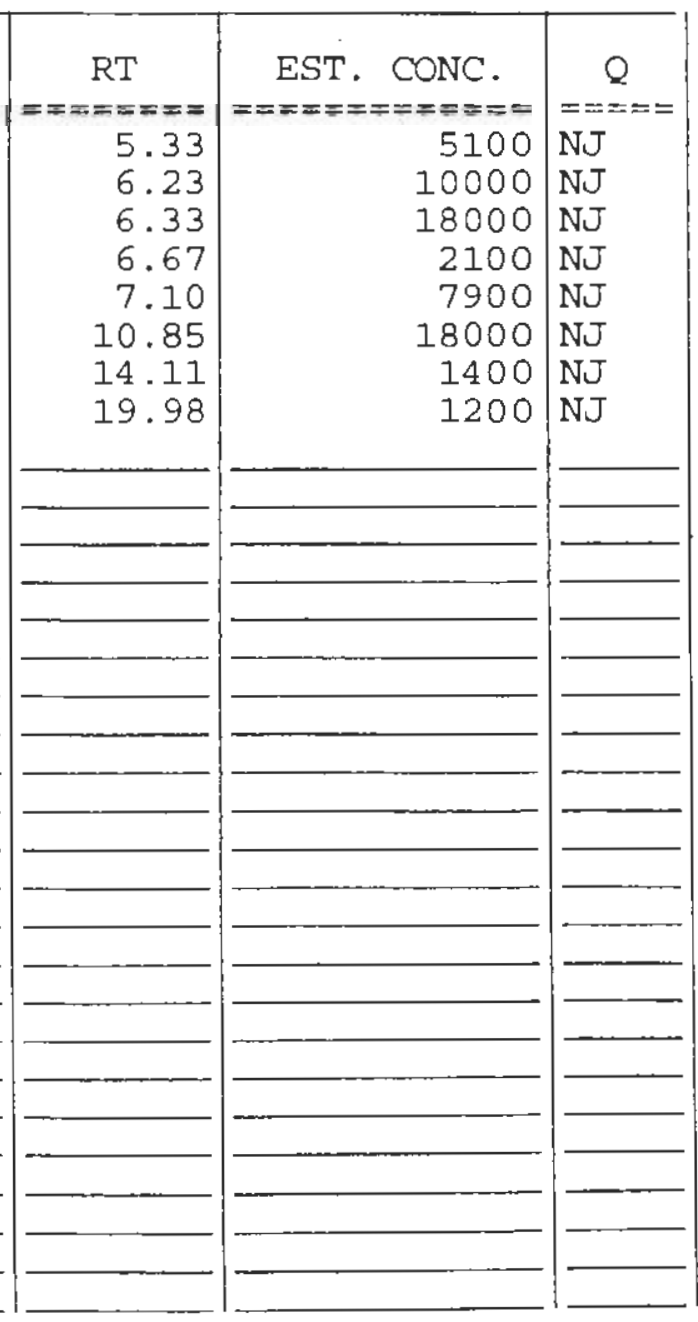
Lab Name: PNNL

Contract: CI04

Lab Code: PNNL

Case No. :

Matrix: (soil/water) SOIID

Sample wt/vol:

$4.9(\mathrm{~g} / \mathrm{m}) \mathrm{G}$

Level: (low/med) Low

: Moisture:

decanted: $(Y / N)$

SAS NO.:

Lab Sample ID: 00-1361-SSD

Lab File ID: 00081915

Date Received:

Date Extracted:

Concentrated Extract Volume: 1000 (uL)

Injection Volume: (uL)

Date Analyzed: $03 / 20 / 0$

Dilution Factor: 10.0

GPC Cleanup: $(Y / N) N \quad \mathrm{NH}$ :

Number TICs found: 14

CONCENTRATION UNITS:

$(\mathrm{ug} / \mathrm{L}$ or $\mathrm{ug} / \mathrm{Kg}) \mathrm{ug} / \mathrm{Kg}$

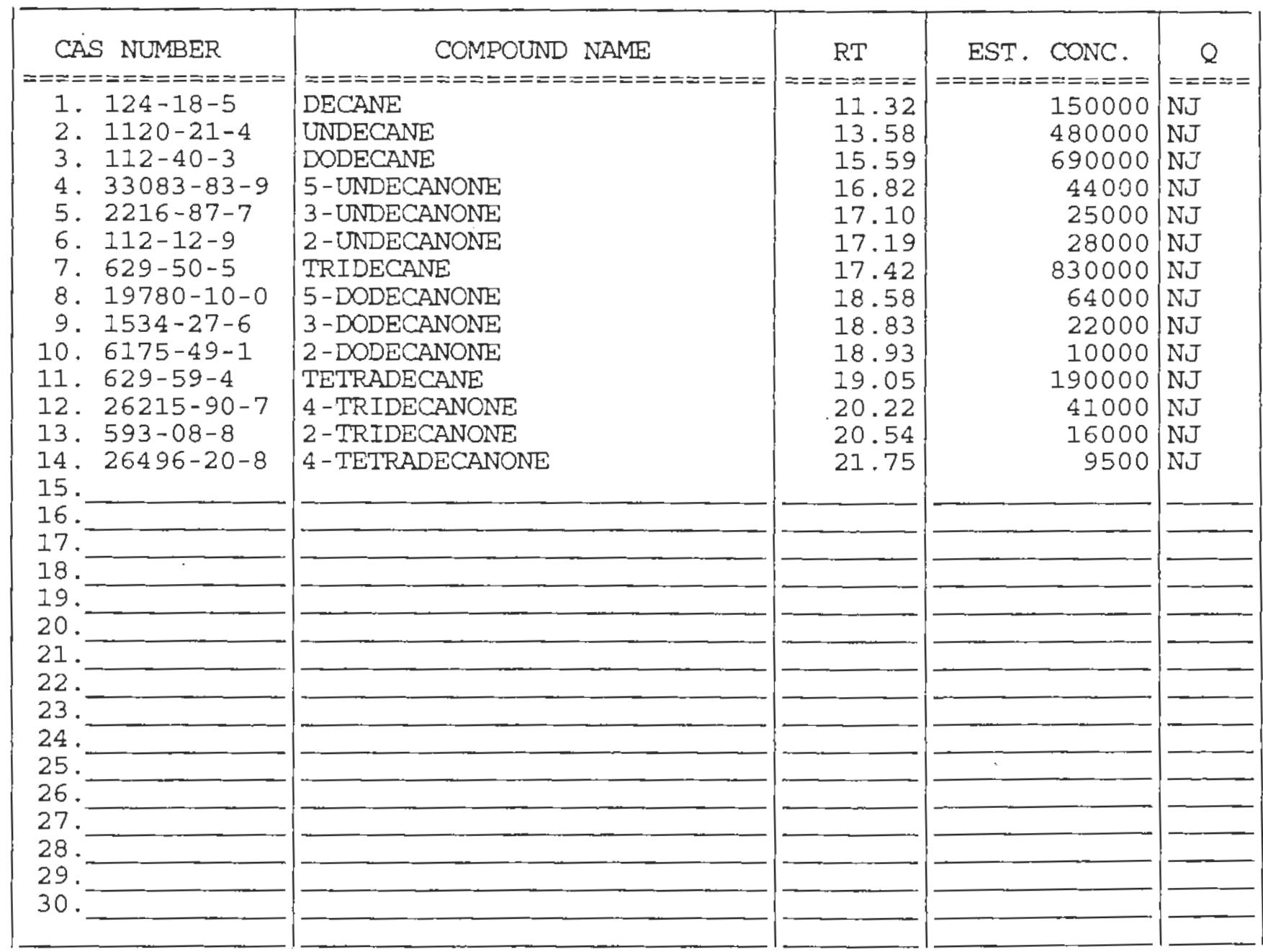


Lab Name: PNNL

Contract: $\mathrm{C} 104$

Lab Code: ENNL

SAS NO. :
EPA SAMPLE NO.

C104-SSS
Matrix: (soil/water) SOLID

Sample wt/vol:

$5.3(\mathrm{~g} / \mathrm{mL}) \quad \mathrm{G}$

Level: (low/med) LOW

$\because$ Moisture: decanted: $(\mathrm{Y} / \mathrm{N})$
SDG No.: 000819
Concentrated Extract Volume: 1000 (uL)

Injection volume: (UL)
Lab Sample ID: 00-1361-SSS

Lab File ID: 00081914

Date Received:

Date Extracted:

Date Analyzed: 08/20/0

Dilution Factor: 10.0

GPC Cleanup: $(\mathrm{Y} / \mathrm{N}) \mathrm{N} \quad \mathrm{pH}:$

Number TICs found: 16

CONCENTRATION UNITS:

(ug/L or $\mathrm{ug} / \mathrm{kg}$ ) $\mathrm{ug} / \mathrm{kg}$

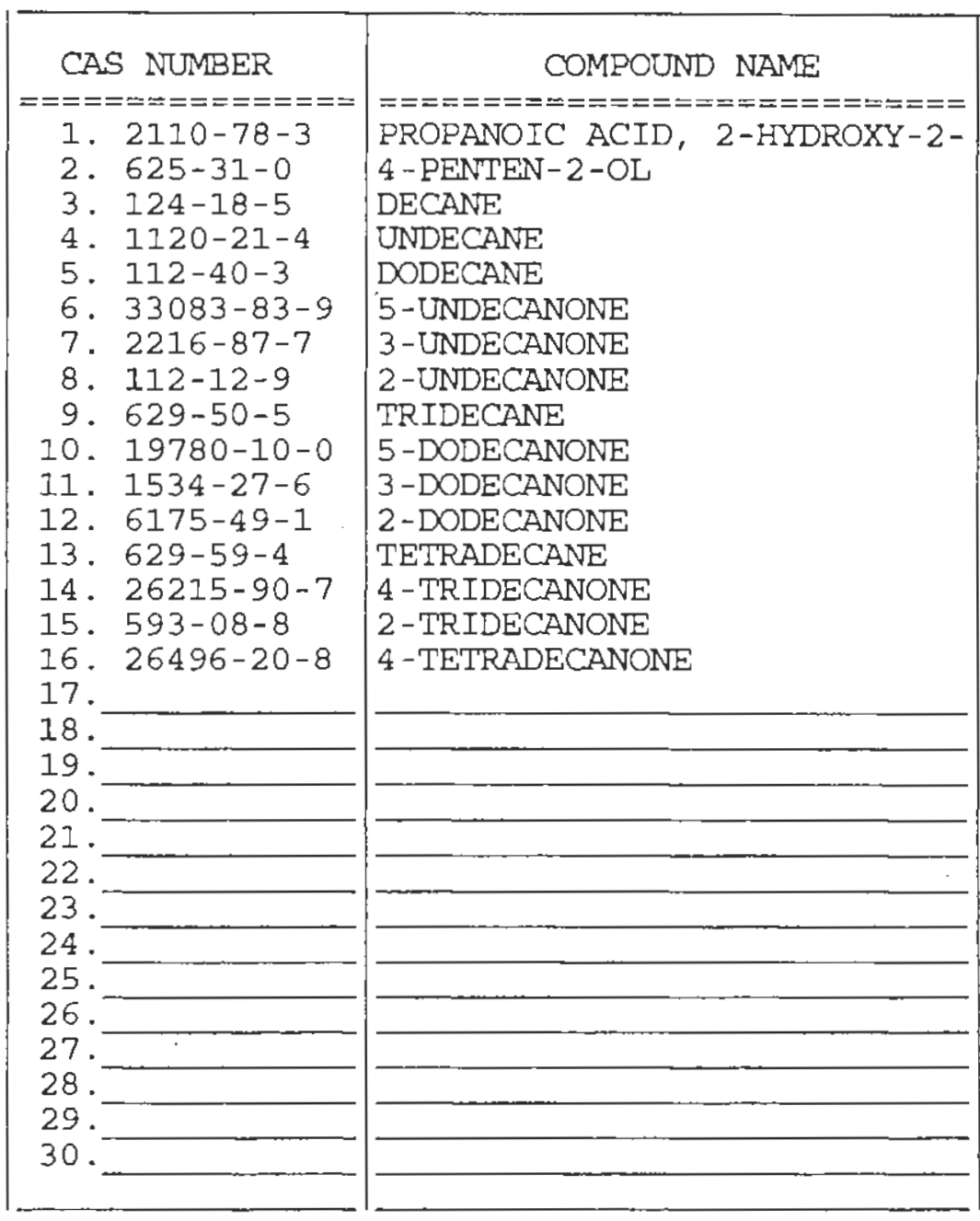

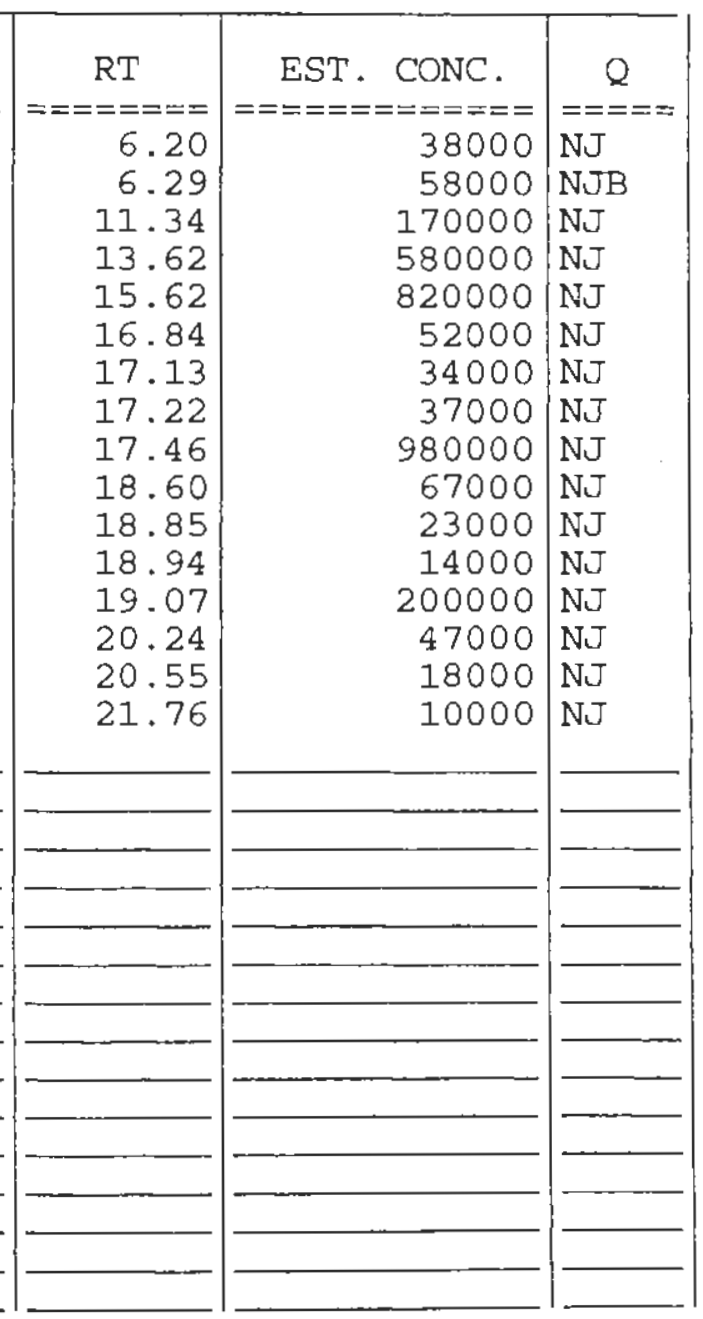


Lab Name: PNNL

Contract: $\mathrm{Cl} 04$

Lab Code: PNNL

Case No.:

Matrix: (soil/water) SOLID

Sample wt/vol:

$$
5.0(\mathrm{~g} / \mathrm{mL}) \mathrm{G}
$$

Level: (low/med) LOW

\% Moisture:

decanted: $(\mathrm{Y} / \mathrm{N})$

SAS NO. :

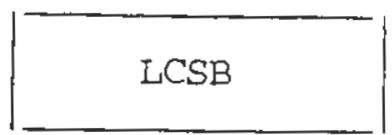

SDG No.: 000819

Concentrated Extract Volume: 1000 (UL)

Injection volume: (uL)

Lab Sample ID: LCSB

GPC Cleanup: $\quad(\mathrm{Y} / \mathrm{N}) \mathrm{N}$

$\mathrm{pH}$ :

Lab File ID: 00081918

Date Received:

Date Extracted:

Date Analyzed: 08/20/0

Dilution Factor: 1.0

CONCENTRATION UNITS:

Number TICs found: 23

(ug/L or $\mathrm{ug} / \mathrm{Kg}$ ) ug/Kg

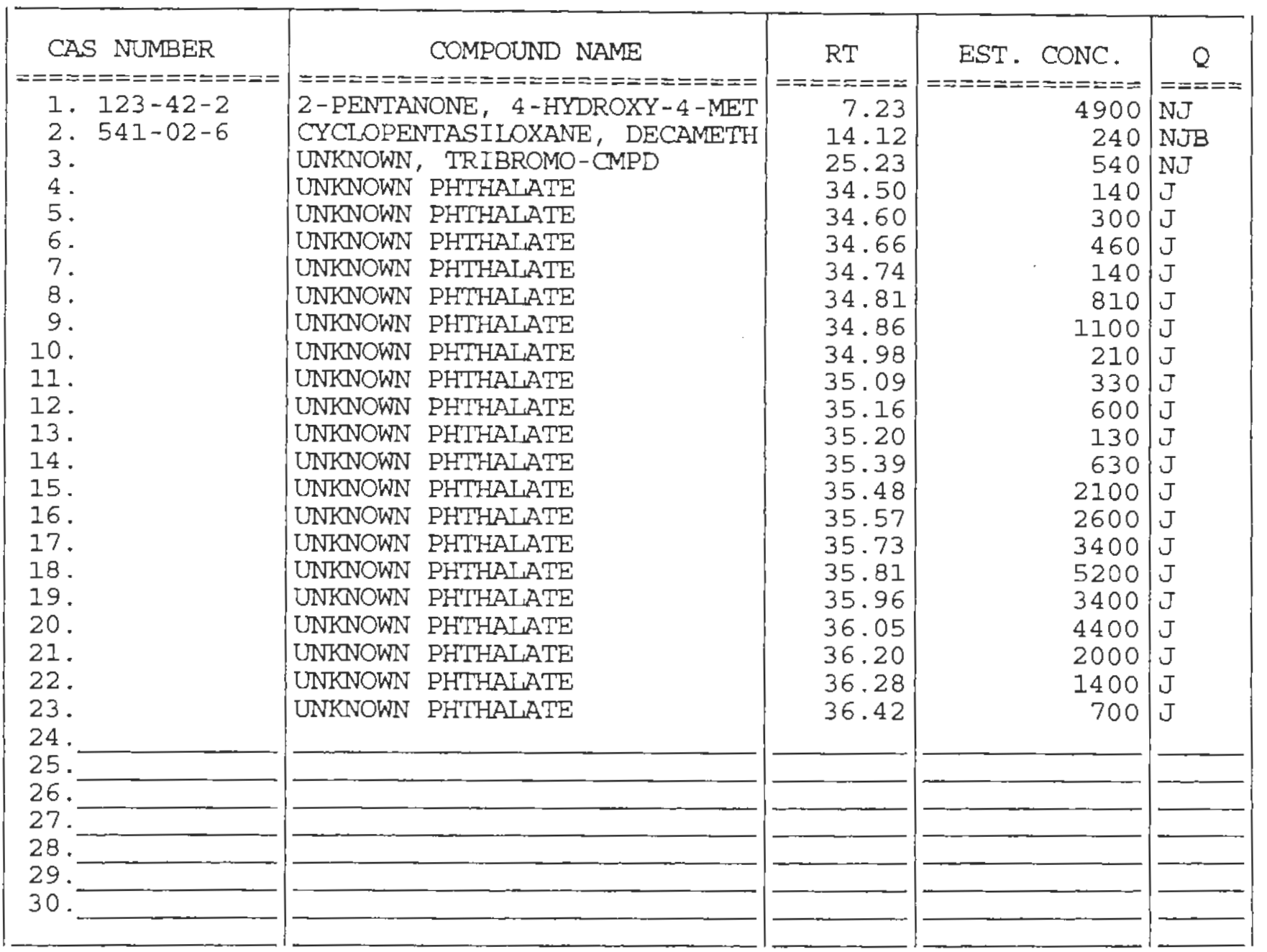


Lab Name: PNNL

Lab code: PNNL
Contract : $\mathrm{ClO4}$

Case No.:

SAS NO.:

\section{LCSMS}

SDG No.: 000819

Matrix: (soil/water) SOLID

Lab Sample ID: LCSMS

Sample wt/vol:

$5.0(\mathrm{~g} / \mathrm{mL}) \quad \mathrm{G}$

Lab File ID: 00081919

Level: (low/med) IOW

Date Received:

\% Moisture:

decanted: $(Y / N)$

Date Extracted:

Concentrated Extract Volume: 1000 (uL)

Date Analyzed: 08/20/0

Injection Volume:

(uI)

Dilution Factor: 1.0

GPC Cleanup: $\quad(\mathrm{Y} / \mathrm{N}) \mathrm{N} \quad \mathrm{pH}$ :

Number TICs found: 4

CONCENIRATION UNITS:

(ug/L or ug/Kg) ug/Kg
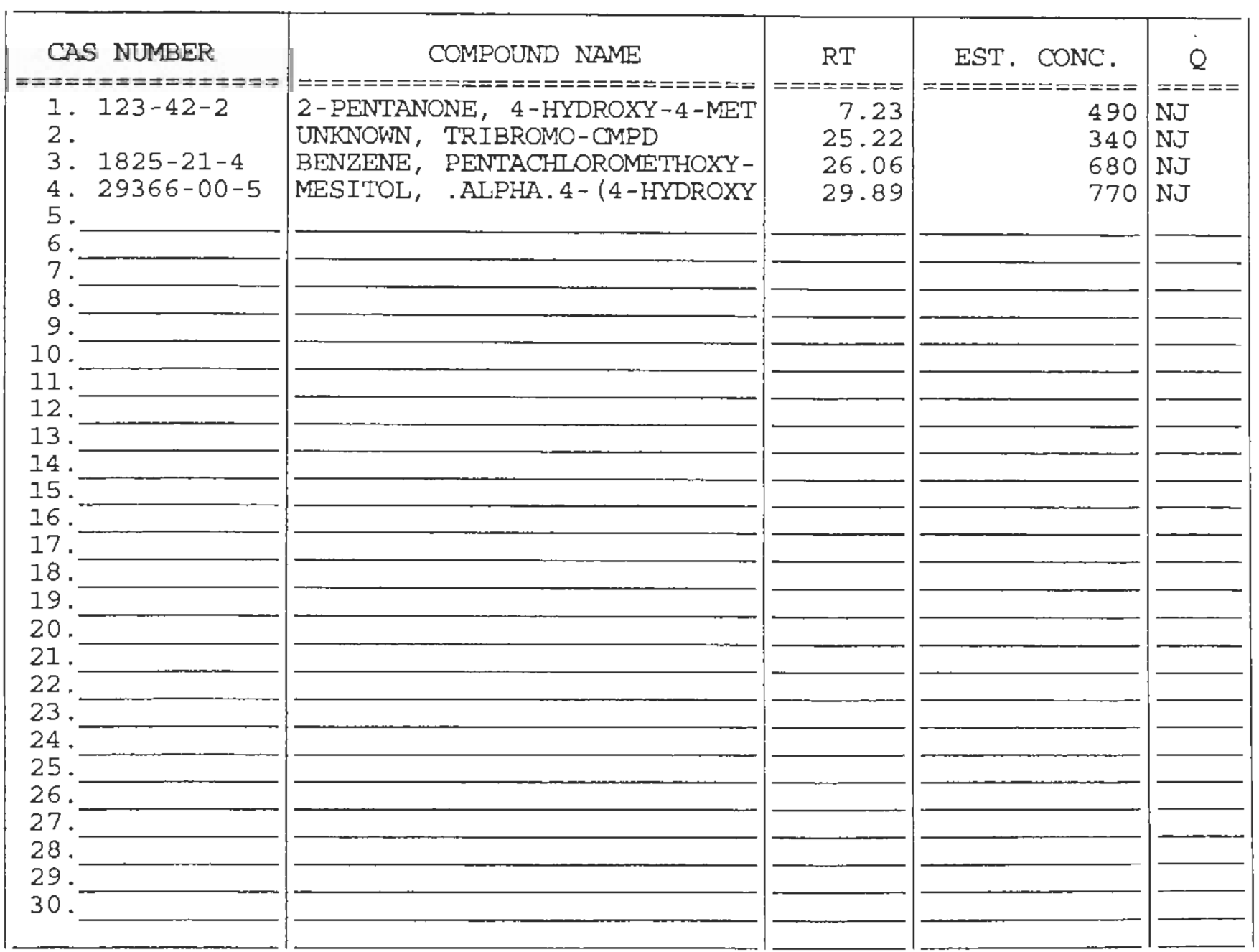
Lab Name: PNNL

Lab code: PNNL
Contract : $\mathrm{ClO} 04$

Case No.:
SAS NO.:

SDG No.: 000819

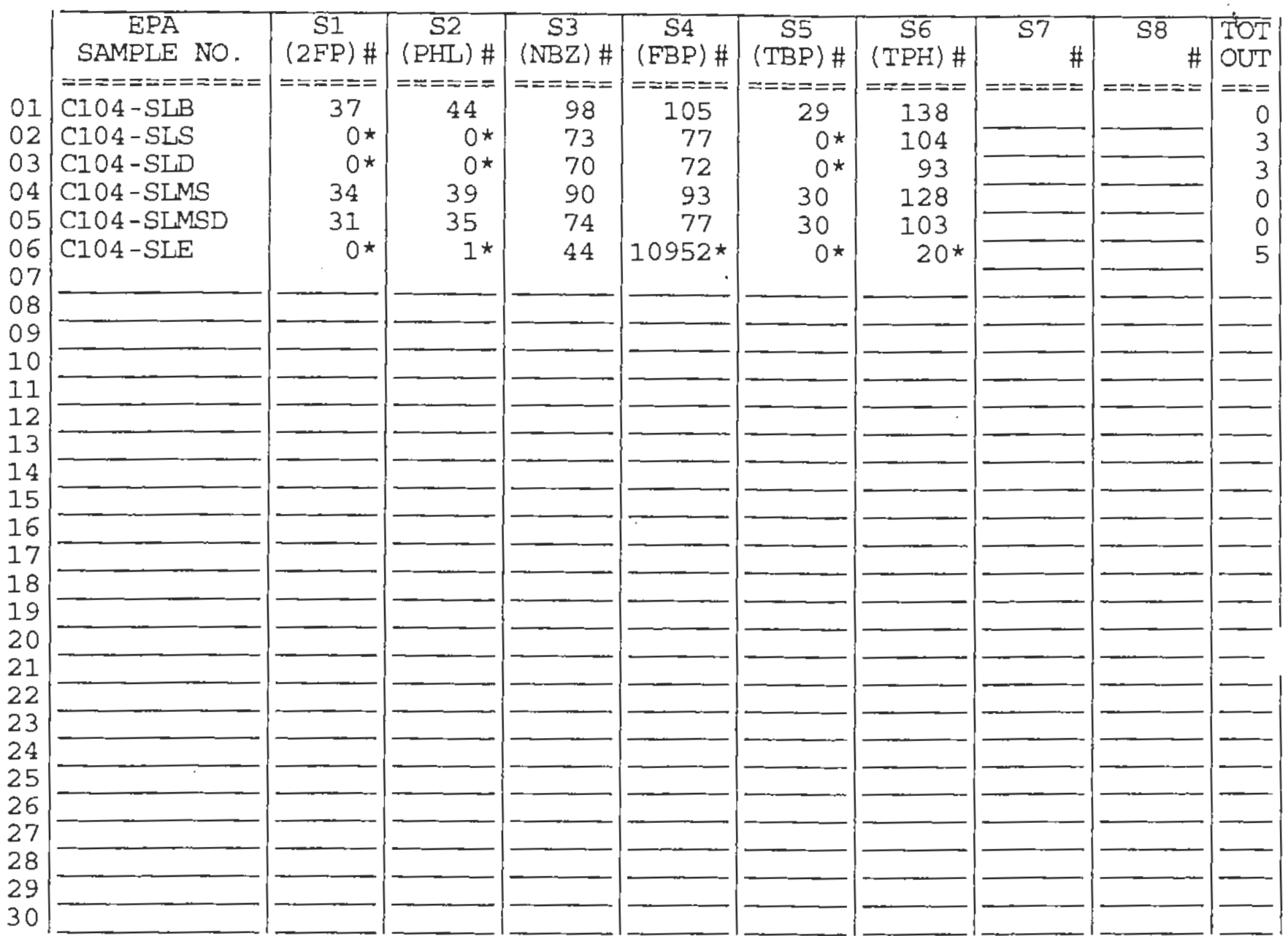

\begin{tabular}{|c|c|c|}
\hline$(2 \mathrm{FP})$ & $=2-$ Fluorophenol & $(21-110)$ \\
\hline (PHL) & $=$ Phenol-d5 & $(10-110)$ \\
\hline (NBZ) & Nitrobenzene-d5 & $(35-114)$ \\
\hline (FBP) & 2-Fluorobiphenyl & $3-116)$ \\
\hline (TBP) & $=2,4,6-$ Tribromophenol & 23) \\
\hline (TPH) & $=$ Terphenyl-d14 & $3-141)$ \\
\hline
\end{tabular}

\# Column to be used to flag recovery values

* Values outside of contract required QC limits

D Surrogate diluted out 
Lab Name: PNNL

Lab Code: PNNL

Level: (low/med)
Contract : $\mathrm{C} 104$

SAS NO. :

SDG No. : 000819

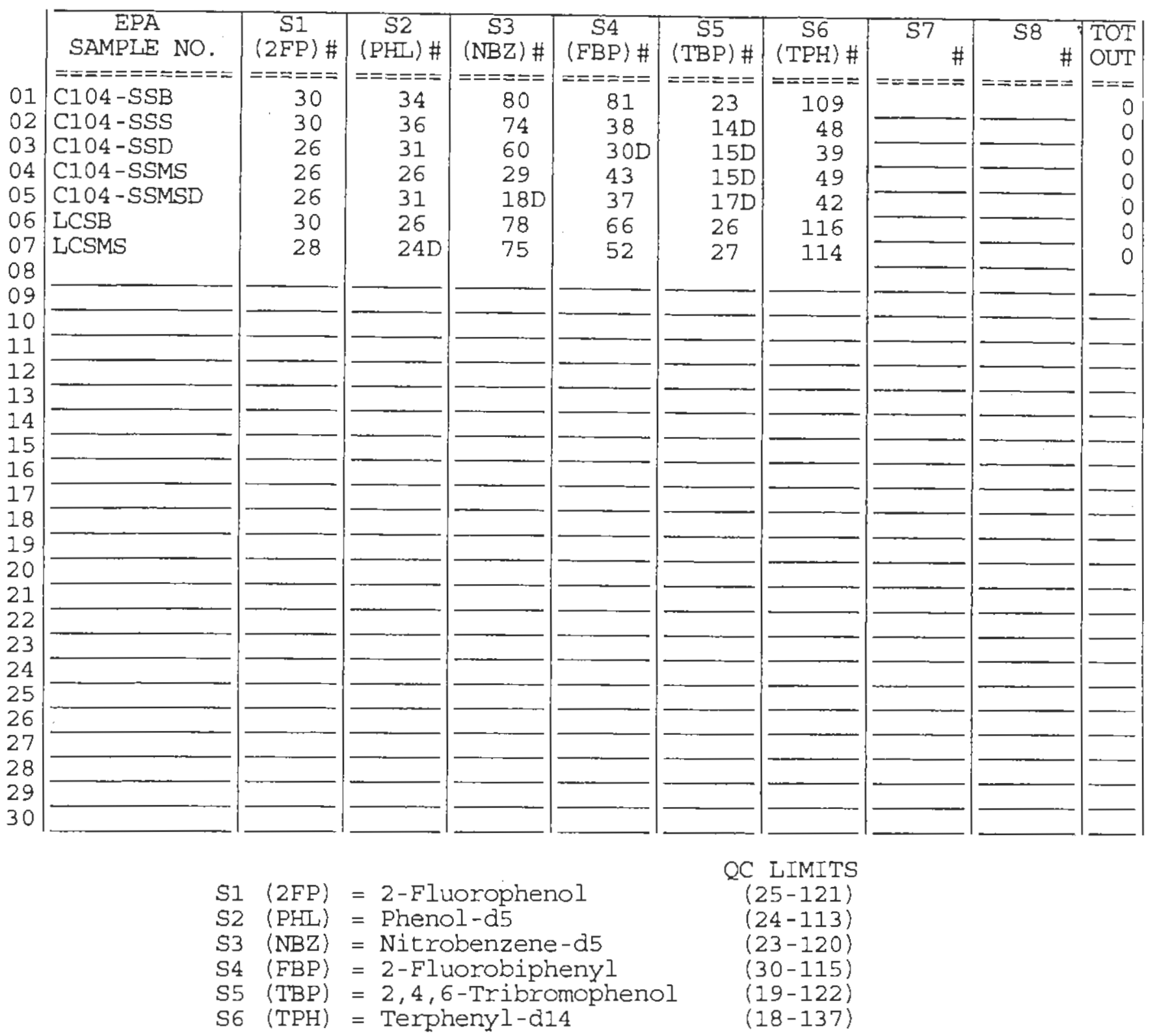

\# Column to be used to flag recovery values

* Values outside of contract required QC limits

D Surrogate diluted out 


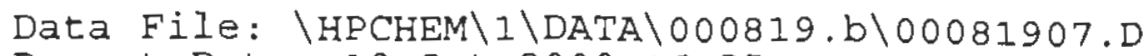

Report Date: 19-Oct-2000 16:55

Pacific Northwest National Laboratory - RPL

\section{RECOVERY REPORT}

Client Name:

Sample Matrix: LIQUID

Lab Smp Id: 00-1360-SLMS

Level: LOW

Data Type: MS DATA

Spikelist File: BNFL.spk

Sublist File: BNFL. sub

Method File: \HPCHEM II \DATA $\backslash 000819 . b \backslash S V 5972 . M$

Misc Info:

\begin{tabular}{|c|c|c|c|c|c|}
\hline SPIKE & COMPOUND & $\begin{array}{l}\text { CONC } \\
\text { ADDED } \\
\mathrm{ug} / \mathrm{L}\end{array}$ & $\begin{array}{c}\text { CONC } \\
\text { RECOVERED } \\
\mathrm{ug} / \mathrm{L}\end{array}$ & RECOVERED & LIMITS \\
\hline $\begin{array}{r}13 \\
20 \\
28 \\
51 \\
73 \\
78 \\
80 \\
102 \\
125 \\
40 \\
17 \\
3 \\
24 \\
27 \\
29 \\
49 \\
62 \\
66 \\
90 \\
92 \\
103 \\
109 \\
160\end{array}$ & 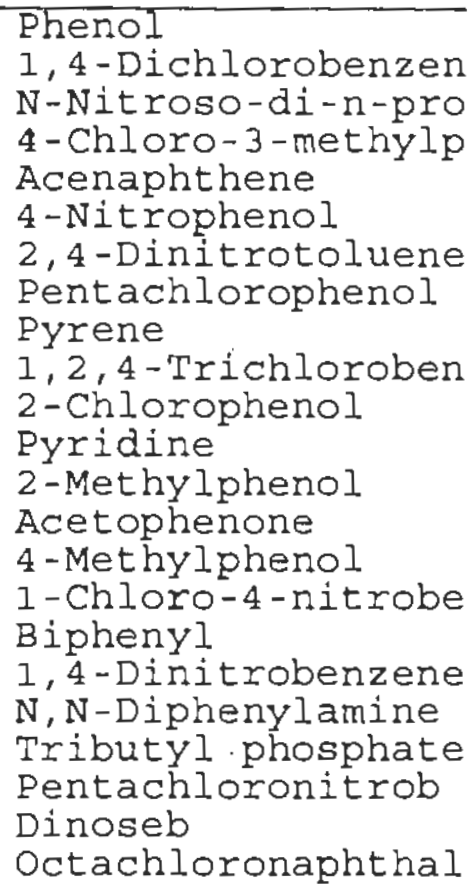 & $\begin{array}{l}4200 \\
2800 \\
2800 \\
4200 \\
2800 \\
4200 \\
2800 \\
4200 \\
2800 \\
2800 \\
4200 \\
5600 \\
5600 \\
5600 \\
11000 \\
5600 \\
5600 \\
5600 \\
5600 \\
5600 \\
5600 \\
5600 \\
5600\end{array}$ & $\begin{array}{r}1800 \\
1100 \\
2200 \\
2000 \\
2400 \\
840 \\
2600 \\
960 \\
2700 \\
1600 \\
1800 \\
5400 \\
2900 \\
5700 \\
4800 \\
4900 \\
4600 \\
3600 \\
0.0 \\
4700 \\
0.0 \\
4100 \\
94000\end{array}$ & $\begin{array}{r}43.80 \\
39.81 \\
81.27 \\
48.39 \\
85.27 \\
20.28 \\
93.97 \\
22.93 \\
97.40 \\
57.75 \\
42.72 \\
97.95 \\
52.70 \\
102.84 \\
43.06 \\
88.35 \\
83.86 \\
65.30 \\
85.40 \\
73.46 \\
1694.38 \text { * }\end{array}$ & $\begin{array}{l}12-110 \\
36-97 \\
41-116 \\
23-97 \\
46-118 \\
10-80 \\
24-96 \\
9-103 \\
26-127 \\
39-98 \\
27- \\
1-100 \\
1-150 \\
1-150 \\
1-150 \\
1-150 \\
1-150 \\
1-150 \\
1-150 \\
1-150 \\
1-150 \\
1-150 \\
1-150\end{array}$ \\
\hline
\end{tabular}

\begin{tabular}{|c|c|c|c|c|}
\hline SURROGATE COMPOUND & $\begin{array}{l}\text { CONC } \\
\text { ADDED }\end{array}$ & $\begin{array}{c}\text { CONC } \\
\text { RECOVERED }\end{array}$ & RECOVERED & LIMITS \\
\hline $\begin{array}{rll} & 7 & 2-\text { Fluorophenol } \\
& 11 \text { Phenol-d5 } \\
& 31 \text { Nitrobenzene-d5 }\end{array}$ & $\begin{array}{l}4200 \\
4200 \\
2800\end{array}$ & $\begin{array}{l}1400 \\
1600 \\
2500\end{array}$ & $\begin{array}{l}33.51 \\
39.49 \\
90.26\end{array}$ & $\begin{array}{l}21-110 \\
10-110 \\
35-114\end{array}$ \\
\hline
\end{tabular}

Client SDG: 000819

Fraction: SV

Client Smp ID: C104-SLMS

operator: GS Klinger

SampleType: $M S$

Quant TYpe: ISTD
Misc

\section{MS recovery data in lieu of CLP form $3 \mathrm{C}$}




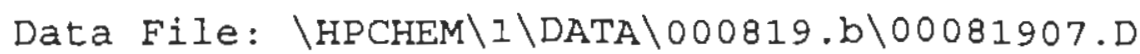

Report Date: 19-Oct-2000 16:55

\begin{tabular}{|c|c|c|c|c|}
\hline SURROGATE COMPOUND & $\begin{array}{l}\text { CONC } \\
\mathrm{ADDED} \\
\mathrm{ug} / \mathrm{L}\end{array}$ & $\begin{array}{l}\text { CONC } \\
\text { RECOVERED } \\
\mathrm{Lg} / \mathrm{L}\end{array}$ & RECOVERED & LIMITS \\
\hline $\begin{array}{lrl}\$ & 59 & 2-F \text { luorobiphenyl } \\
\$ & 93 & 2,4,6-T r i b r o m o p h e n \\
\$ & 130 & \text { Terphenyl-di4 }\end{array}$ & $\begin{array}{l}2800 \\
4200 \\
2800\end{array}$ & $\begin{array}{l}2600 \\
1200 \\
3600\end{array}$ & $\begin{array}{r}93.30 \\
29.56 \\
128.17\end{array}$ & $\begin{array}{l}4 \overline{3-116} \\
10-123 \\
33-141\end{array}$ \\
\hline
\end{tabular}


Pacific Northwest National Laboratory - RPL

\section{RECOVERY REPORT}

Client Name:

Sample Matrix: LIQUID

Lab Smp Id: 00-1360-SLMSD

Level: LOW

Data Type: MS DATA

SpikeList File: BNEL.spk

Sublist File: BNFL. sub

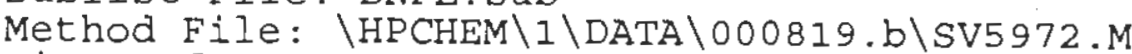

Misc Info:
Client SDG: 000819

Fraction: SV

Client Smp ID: C104-SLMSD

Operator: GS Klinger

SampleType: MSD

Quant TYpe; ISTD

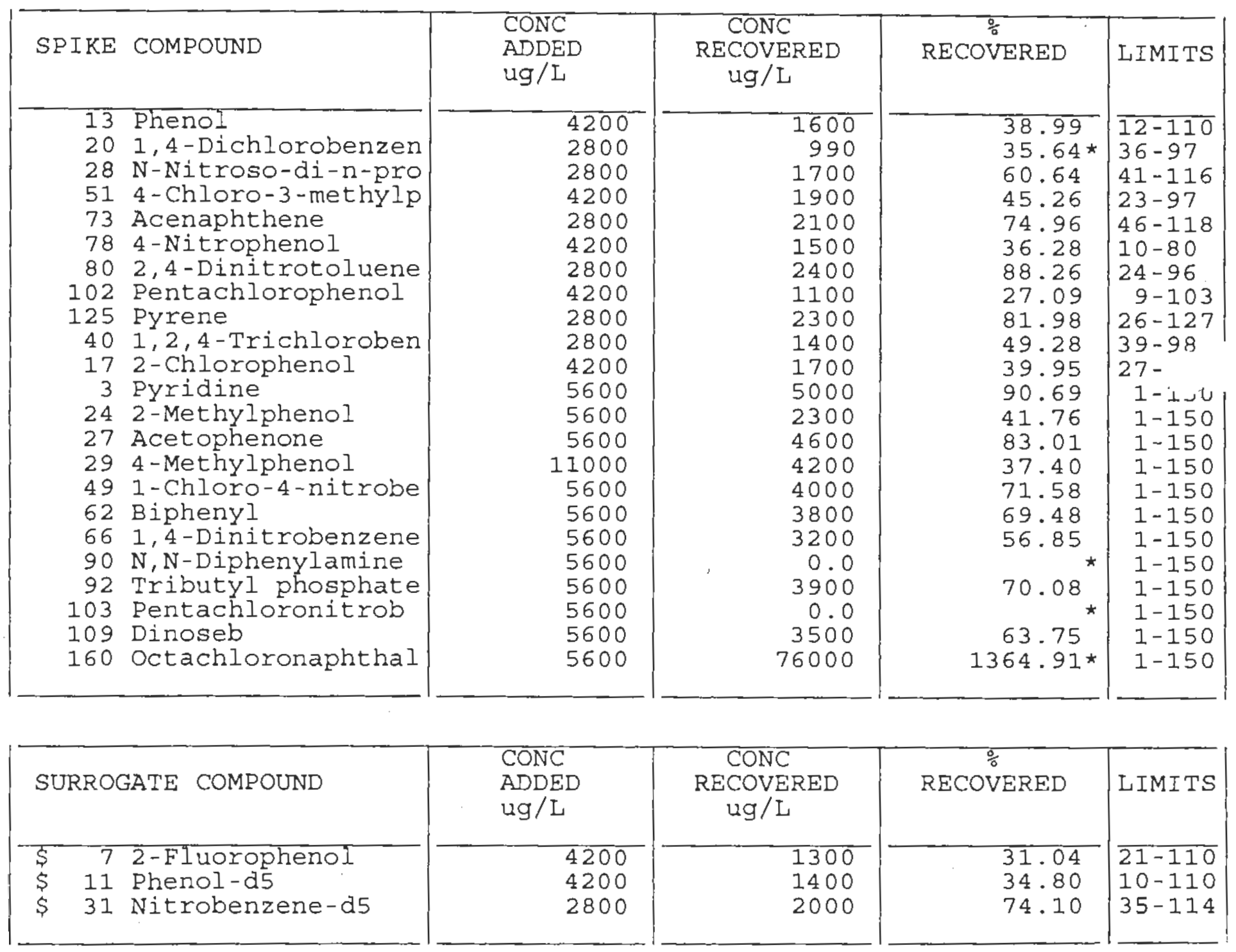

\section{MSD recovery data in lieu of CLP form 3C}




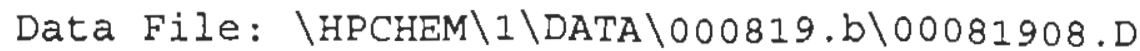

Report Date: 19-Oct-200016:56

\begin{tabular}{|c|c|c|c|c|}
\hline SURROGATE COMPOUND & $\begin{array}{l}\text { CONC } \\
\text { ADDED } \\
\mathrm{ug} / \mathrm{L}\end{array}$ & $\begin{array}{l}\text { CONC } \\
\text { RECOVERED } \\
\text { ug/L }\end{array}$ & RECOVERED & LIMITS \\
\hline $\begin{array}{lrl}\$ & 59 & 2-\text { Fluorobiphenyl } \\
\$ & 93 & 2,4,6-T r i b r o m o p h e n \\
\$ 130 & \text { Terphenyl-d14 }\end{array}$ & $\begin{array}{l}2800 \\
4200 \\
2800\end{array}$ & $\begin{array}{l}2100 \\
1200 \\
2900\end{array}$ & $\begin{array}{r}76.65 \\
30.04 \\
103.06\end{array}$ & $\begin{array}{l}43-116 \\
10-123 \\
33-141\end{array}$ \\
\hline
\end{tabular}


Pacific Northwest National Laboratory - RPL

RECOVERY REPORT

Client Name:

Sample Matrix: SOLID

Lab Smp Id: 00-1361-SSMS

Level: LOW

Data Type: MS DATA

SpikeList File: BNFL.spk

Sublist File: BNFL. sub

Method File: \HPCHEM $\backslash$ I \DATA $\backslash 000819 . \mathrm{b} \backslash S V 5972 \mathrm{~b} . \mathrm{M}$

Misc Info:
Client SDG: 000819

Fraction: SV

Client Smp ID: C104-SSMS

Operator: GS Klinger

SampleType: MS

Quant Type: ISTD

\begin{tabular}{|c|c|c|c|c|c|}
\hline SPIKE & COMPOUND & $\begin{array}{l}\text { CONC } \\
\mathrm{ADDED} \\
\mathrm{ug} / \mathrm{Kg}\end{array}$ & $\begin{array}{c}\text { CONC } \\
\text { RECOVERED } \\
\mathrm{ug} / \mathrm{Kg}\end{array}$ & RECOVERED & LIMITS \\
\hline $\begin{array}{r}13 \\
20 \\
28 \\
51 \\
73 \\
78 \\
80 \\
102 \\
125 \\
40 \\
17 \\
3 \\
24 \\
27 \\
29 \\
49 \\
62 \\
66 \\
90 \\
92 \\
103 \\
109 \\
160\end{array}$ & 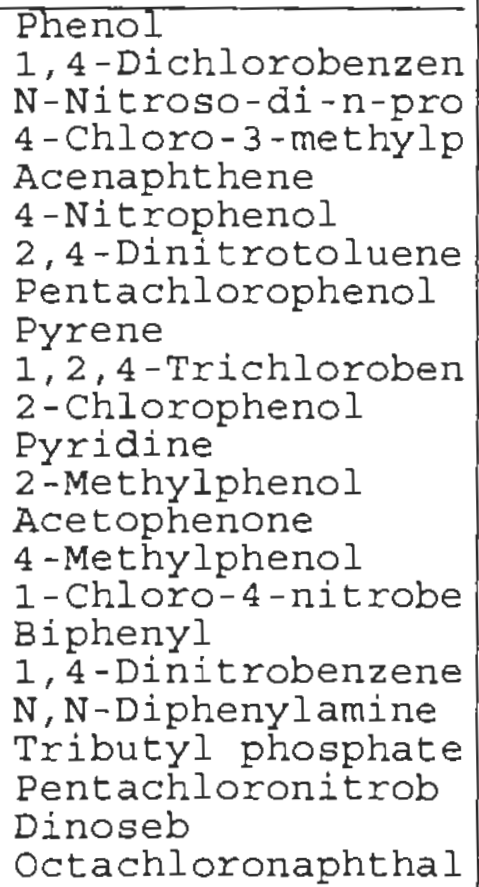 & $\begin{array}{r}14000 \\
9300 \\
9300 \\
14000 \\
9300 \\
14000 \\
9300 \\
14000 \\
9300 \\
9300 \\
14000 \\
9300 \\
9300 \\
9300 \\
18000 \\
9300 \\
9300 \\
9300 \\
9300 \\
9300 \\
9300 \\
9300 \\
9300\end{array}$ & $\begin{array}{r}7500 \\
4200 \\
6900 \\
6500 \\
6800 \\
4100 \\
8700 \\
0.0 \\
7800 \\
5800 \\
7000 \\
2700 \\
5600 \\
5000 \\
16000 \\
6900 \\
11000 \\
7100 \\
0.0 \\
92000 \\
0.0 \\
14000 \\
400000\end{array}$ & $\begin{array}{r}54.10 \\
45.79 \\
74.17 \\
47.01 \\
73.90 \\
29.19 \\
93.82 \\
84.66 \\
62.68 \\
50.48 \\
29.04 \\
60.66 \\
53.46 \\
86.55 \\
74.16 \\
122.80 \\
76.81 \\
\text { * } \\
989.65 \star \\
151.54 \star \\
4367.89 \star\end{array}$ & $\begin{array}{l}12-110 \\
36-97 \\
41-116 \\
23-97 \\
46-118 \\
10-80 \\
24-96 \\
9-103 \\
26-127 \\
39-98 \\
27- \\
1-1-10 \\
1-150 \\
1-150 \\
1-150 \\
1-150 \\
1-150 \\
1-150 \\
1-150 \\
1-150 \\
1-150 \\
1-150 \\
1-150\end{array}$ \\
\hline
\end{tabular}

\begin{tabular}{|c|c|c|c|c|}
\hline SURROGATE COMPOUND & $\begin{array}{l}\text { CONC } \\
\text { ADDED }\end{array}$ & $\begin{array}{c}\text { CONC } \\
\text { RECOVERED }\end{array}$ & RECOVERED & LIMITS \\
\hline 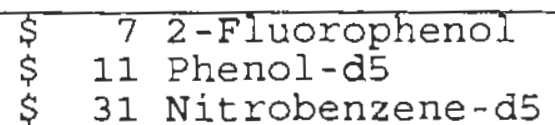 & $\begin{array}{l}28000 \\
28000 \\
18000\end{array}$ & $\begin{array}{l}7200 \\
7400 \\
5400\end{array}$ & $\begin{array}{l}25.85 \\
26.44 \\
28.87\end{array}$ & $\begin{array}{l}25-121 \\
24-113 \\
23-120\end{array}$ \\
\hline
\end{tabular}

\section{MS recovery data in lieu of CLP form 3D}


Data File: \HPCHEM\I\DATA\000819.b\00081916.D

Page 10

Report Date; 19-Oct-2000 10:13

\begin{tabular}{|c|c|c|c|c|}
\hline SURROGATE COMPOUND & $\begin{array}{l}\text { CONC } \\
\mathrm{ADDED} \\
\mathrm{ug} / \mathrm{Kg}\end{array}$ & $\begin{array}{l}\text { CONC } \\
\mathrm{RECOVERED} \\
\mathrm{ug} / \mathrm{Kg}\end{array}$ & $\begin{array}{c}\% \\
\text { RECOVERED }\end{array}$ & LIMITS \\
\hline $\begin{array}{lrl} & 59 & 2-\text { Fluorobipheny } \\
\$ & 93 & 2,4,6-T r i b r o m o p h e n \\
\$ & 130 & \text { Terphenyl-di4 }\end{array}$ & $\begin{array}{l}18000 \\
28000 \\
18000\end{array}$ & $\begin{array}{l}7900 \\
4200 \\
9100\end{array}$ & $\begin{array}{l}42.62 \\
15.24 \\
49.12\end{array}$ & $\begin{array}{l}30-115 \\
19-122 \\
18-137\end{array}$ \\
\hline
\end{tabular}




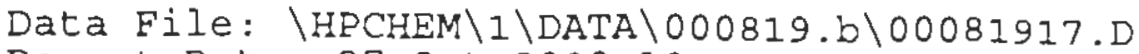

Report Date: 27-OCt-2000 10:24

Pacific Northwest National Laboratory - RPL

\section{RECOVERY REPORT}

Client Name:

Sample Matrix: SOLID

Lab Smp Id: 00-1361-SSMSD

Level: LOW

Data Type: MS DATA

SpikeList File: BNFL.spk

Sublist File: BNFL.sub

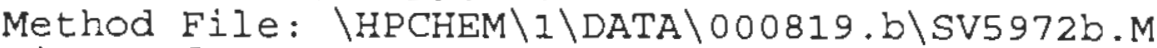

Misc Info:
Client SDG: 000819

Fraction: SV

Client Smp ID: CI04-SSMSD

Operator: GS Klinger

SampleType: MSD

Quant Type: ISTD

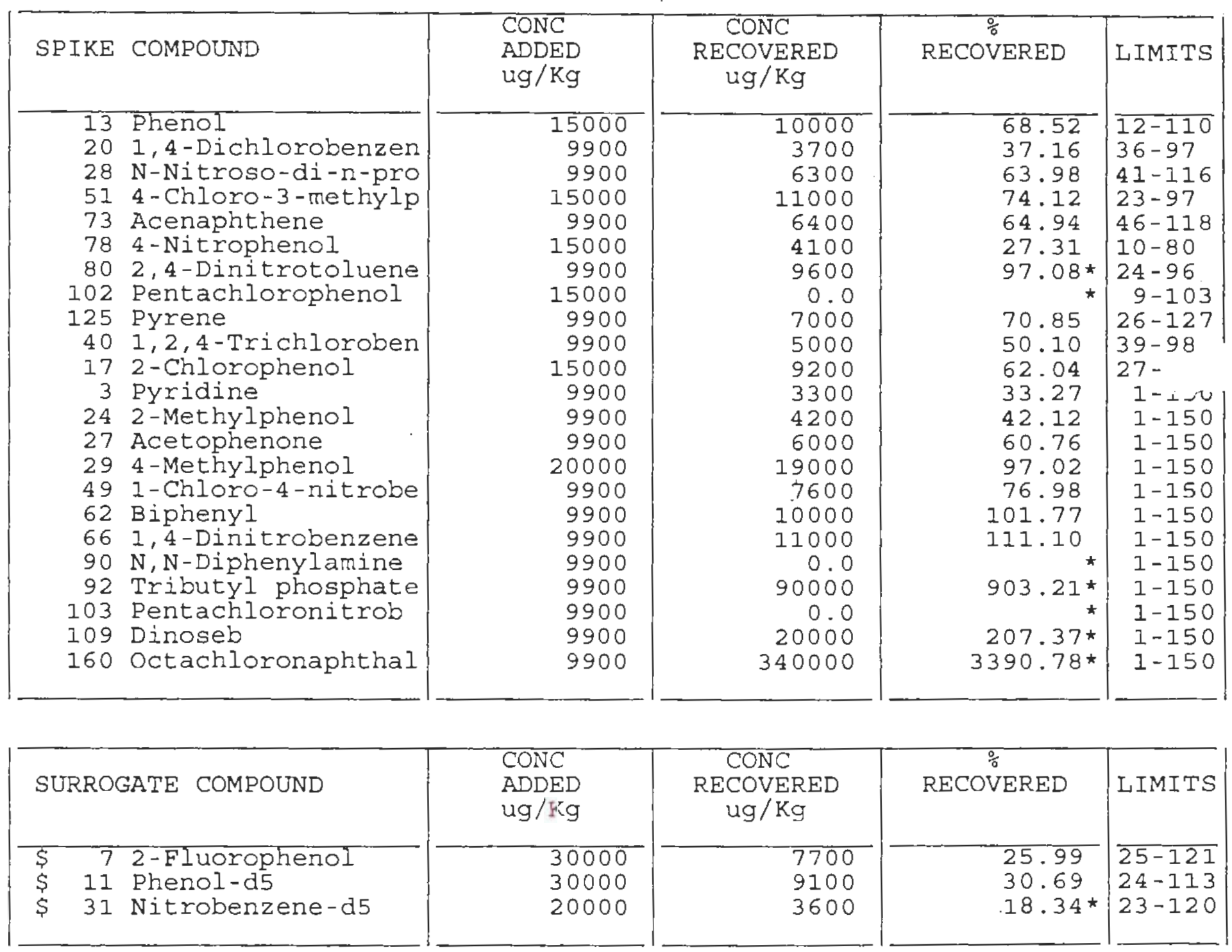




\begin{tabular}{|c|c|c|c|c|}
\hline SURROGATE COMPOUND & $\begin{array}{l}\text { CONC } \\
\mathrm{ADDED} \\
\mathrm{ug} / \mathrm{Kg}\end{array}$ & $\begin{array}{c}\text { CONC } \\
\mathrm{RECOVERED} \\
\mathrm{ug} / \mathrm{Kg}\end{array}$ & $\begin{array}{c}\frac{\circ}{6} \\
\text { RECOVERED }\end{array}$ & LIMITS \\
\hline 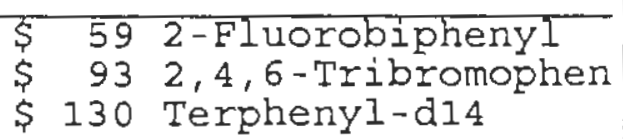 & $\begin{array}{l}20000 \\
30000 \\
20000\end{array}$ & $\begin{array}{l}7300 \\
5200 \\
8400\end{array}$ & $\begin{array}{l}36.91 \\
17.35 \\
42.44\end{array}$ & $\begin{array}{l}30-115 \\
19-122 \\
18-137\end{array}$ \\
\hline
\end{tabular}


Lab Name: PNNL Contract: $\mathrm{C} 104$

Lab code: PNNL

Case No.:

Lab File ID: 00081904

Instrument ID: HPI

Matrix: (soil/water) SUPERNATANT

Level: (low/med) LOW
EPA SAMPLE NO.

CIO4-SLB

SAS NO.:

SDG No.: 000819

Lab Sample ID: 00-1360-SLB

Date Extracted:

Date Analyzed: 08/19/0

Time Analyzed: 1738

THIS METHOD BLANK APPLIES TO THE FOLLOWING SAMPLES, MS and MSD:

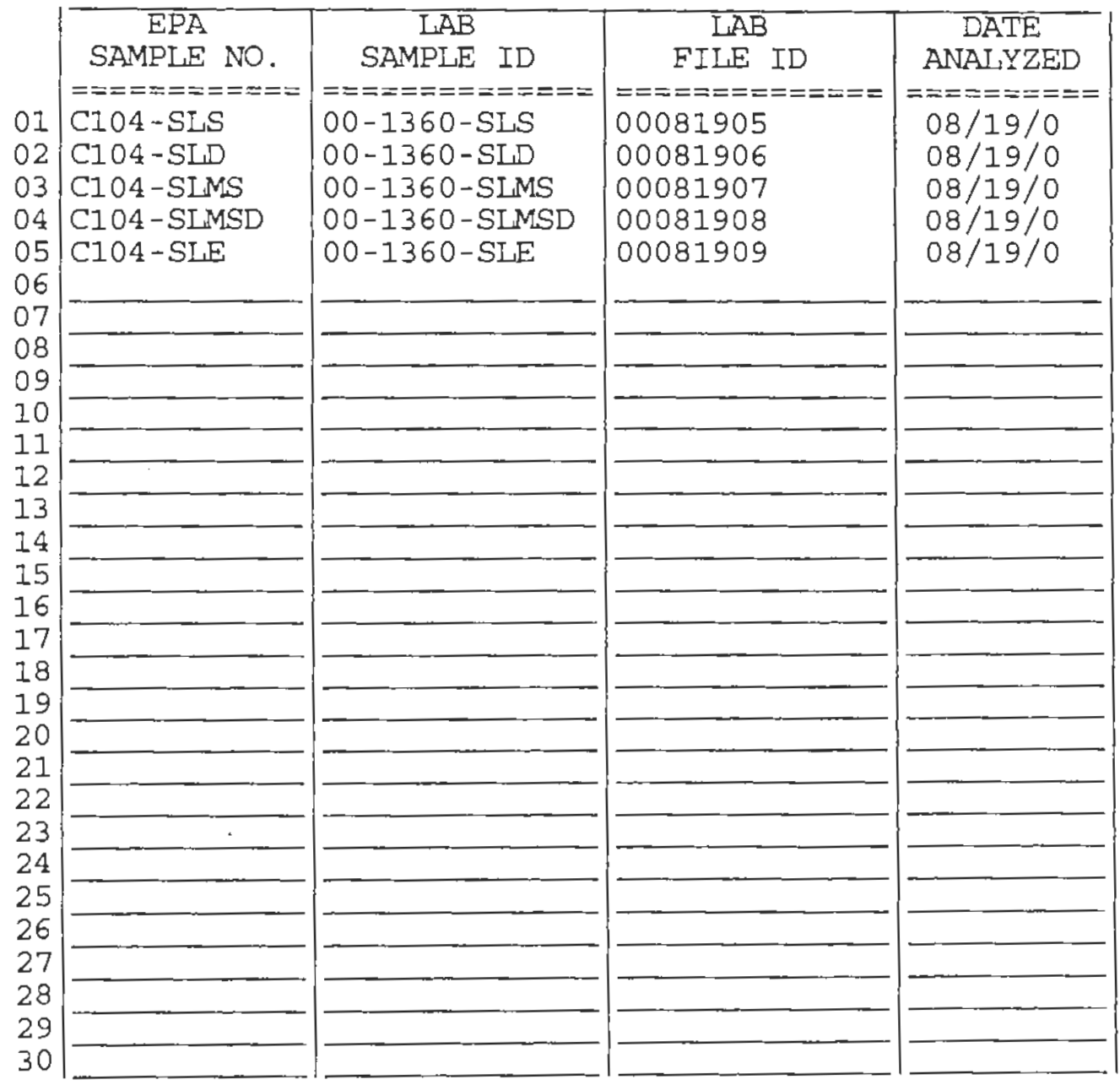

COMMENTS : 
Lab Name: PNNL

Lab Code: PNNL

Lab File ID: 00081913

Instrument ID: HPI

Matrix: (soil/water) SOLID

Level : (low/med) LOW
Contract: $\mathrm{C} 104$

Case No.:

SAS NO.:
EPA SAMPILE NO.

C104-SSB

SDG No.: 000819

Lab Sample ID: 00-1361-SSB

Date Extracted:

Date Analyzed: 08/20/0

Time Analyzed: 0220

THIS METHOD BLANK APPLIES TO THE FOLIOWING SAMPLES, MS and MSD:

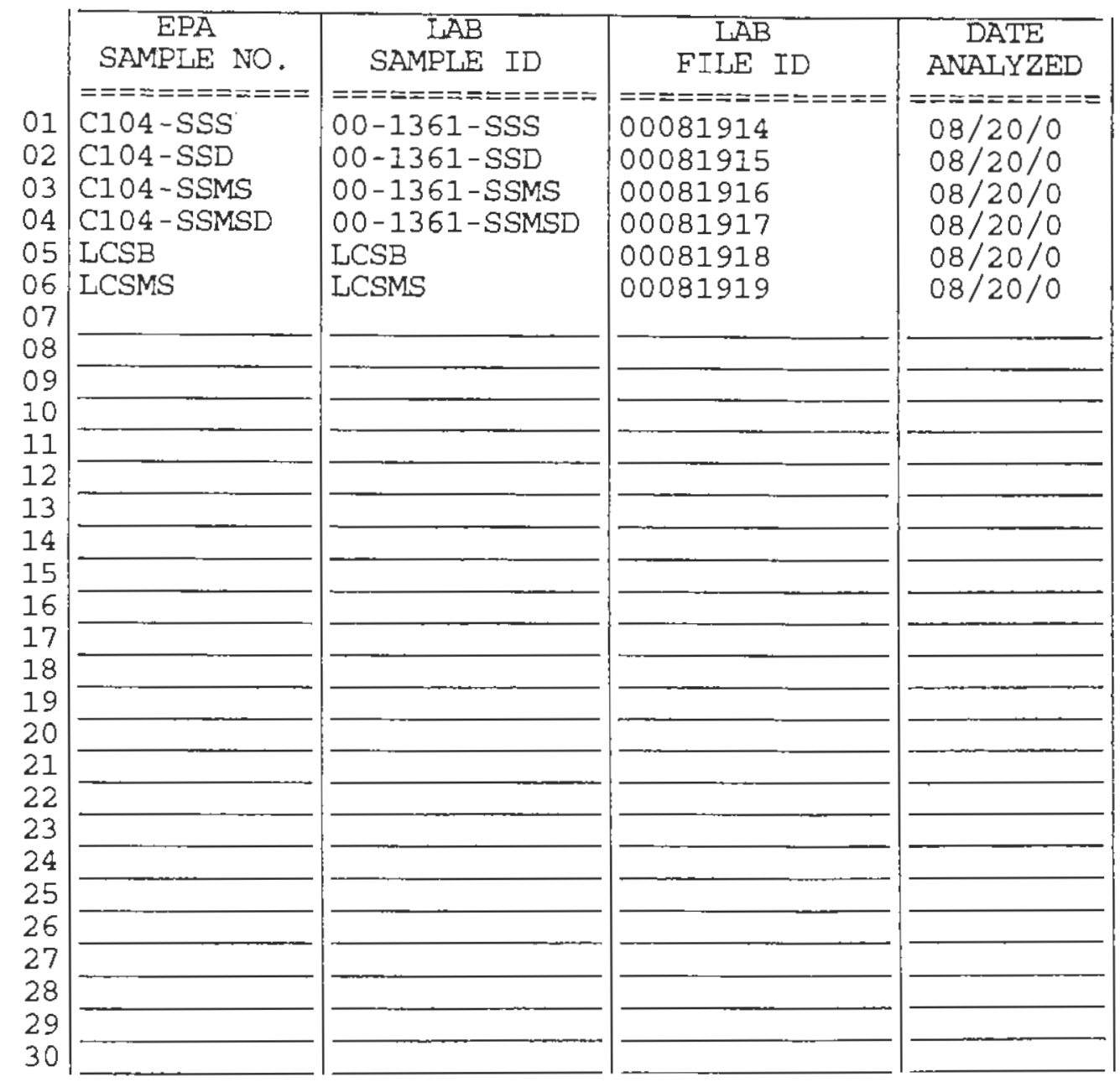

COMMENTS : 
SEMIVOLATILE ORGANIC INSTRUMENT PERFORMANCE CHECK DECAFLUOROTRIPHENYLPHOSPHINE (DFTPP)

Lab Name: PNNL

Irab code: PNNL,

Lab File ID: 00081101

Instrument ID: HPI
Contract : $\mathrm{C} 104$

SAS NO.:

SDG No : 000811

DFTPP Injection Date: 08/14/0

DFTPP Injection Time: 1642

\begin{tabular}{|c|c|c|}
\hline $\begin{array}{c}\mathrm{m} / \mathrm{e} \\
====\approx\end{array}$ & 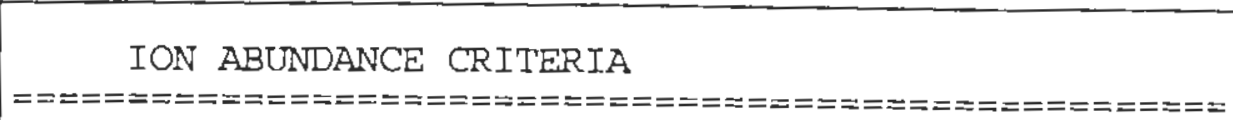 & $\begin{array}{c}\text { REIATIVE } \\
\text { ABUNDANCE } \\
=============\end{array}$ \\
\hline $5 I$ & $30.0-80.0 \%$ of mass 198 & 33.5 \\
\hline 68 & Less than $2.0 \%$ of mass $6 \overline{9}$ & $0.0 T 0.0) 1$ \\
\hline 69 & Mass 69 relative abundance & $38.7 \quad 0.1$ \\
\hline 70 & Less than $2.0 \%$ of mass 69 & $0.1 T$ \\
\hline 127 & $25.0-75.0 \%$ of mass 198 & 46.1 \\
\hline 197 & Less than $1.0 \%$ of mass 198 & 0.0 \\
\hline 198 & Base Peak, $100 \%$ relative abundance & 100.0 \\
\hline 199 & 5.0 to $9.0 \%$ of mass 198 & 6.6 \\
\hline 275 & $10.0-30.0 \%$ of mass $19 \overline{8}$ & 26.3 \\
\hline 365 & Greater than $0.75 \%$ of mass 198 & 4.57 \\
\hline 441 & Present, but less than mass $44 \overline{3}$ & 7.4 \\
\hline 442 & $40.0-110.0 \%$ of mass 198 & 52.3 \\
\hline 443 & $15.0-24.0 \%$ of mass 442 & $1 0 . 2 \longdiv { ( 1 9 . 5 ) 2 }$ \\
\hline
\end{tabular}

THIS CHECK APPLIES TO THE FOLIOWING SAMPLES, MS, MSD, BLANKS, AND STANDARDS:

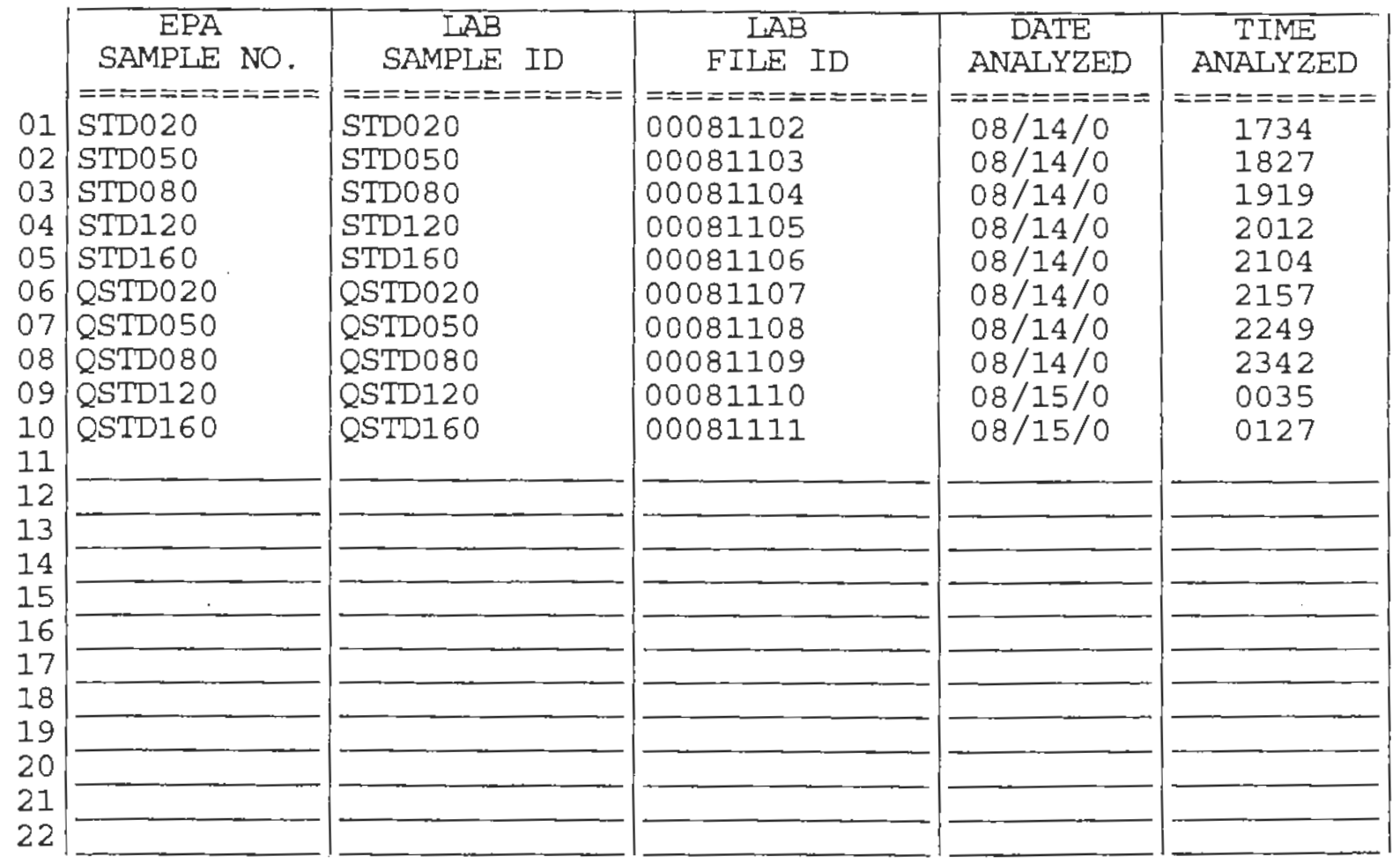

page 1 of 1 
SEMIVOLATILE ORGANIC INSTRUMENT PERFORMANCE CHECK

DECAFLUOROTRIPHENYLPHOSPHINE (DFTPP)

Lab Name: PNNL

Lab Code: PNNL

Lab File ID: 00081910

Instrument ID: HPI
Contract: $\mathrm{ClO4}$

SAS NO. :

SDG No. : 000819

\begin{tabular}{|c|c|c|}
\hline $\begin{array}{l}\mathrm{m} / \mathrm{e} \\
=====\end{array}$ & 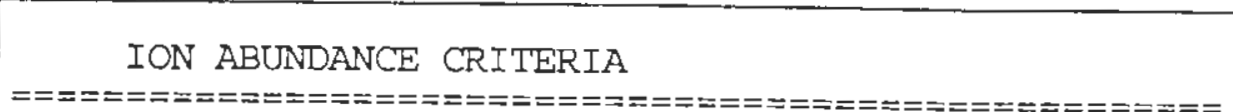 & $\begin{array}{c}\text { \% RELATIVE } \\
\text { ABUNDANCE }\end{array}$ \\
\hline 51 & $30.0-80.0 \%$ of mass 198 & $\begin{array}{l}== \pm========== \\
31.7\end{array}$ \\
\hline 68 & Less than $2.0 \%$ of mass $6 \overline{9}$ & 0.1 \\
\hline 69 & Mass 69 relative abundance & 38.0 \\
\hline 70 & Iess than $2.0 \%$ of mass $69^{-}$ & $0.270 .6) 1$ \\
\hline 127 & $25.0-75.0 \%$ of mass 198 & 44.2 \\
\hline 197 & Less than $1.0 \%$ of mass $1 \overline{98}$ & 0.0 \\
\hline 198 & Base Peak, $100 \%$ relative abundance & 100.0 \\
\hline 199 & 5.0 to $9.0 \%$ of mass 198 & 6.8 \\
\hline 275 & $10.0-30.0 \%$ of mass $19 \overline{ }$ & 28.6 \\
\hline 365 & Greater than $0.75 \%$ of mass 198 & 4.64 \\
\hline 441 & Present, but less than mass 443 & 11.07 \\
\hline 442 & $40.0-110.0 \%$ of mass 198 & $76.7-$ \\
\hline 443 & $15.0-24.0 \%$ of mass 442 & $14.4(18.8) 2$ \\
\hline
\end{tabular}

THIS CHECK APPLIES TO THE FOLLOWING SAMPLES, MS, MSD, BLANKS, AND STANDARDS:

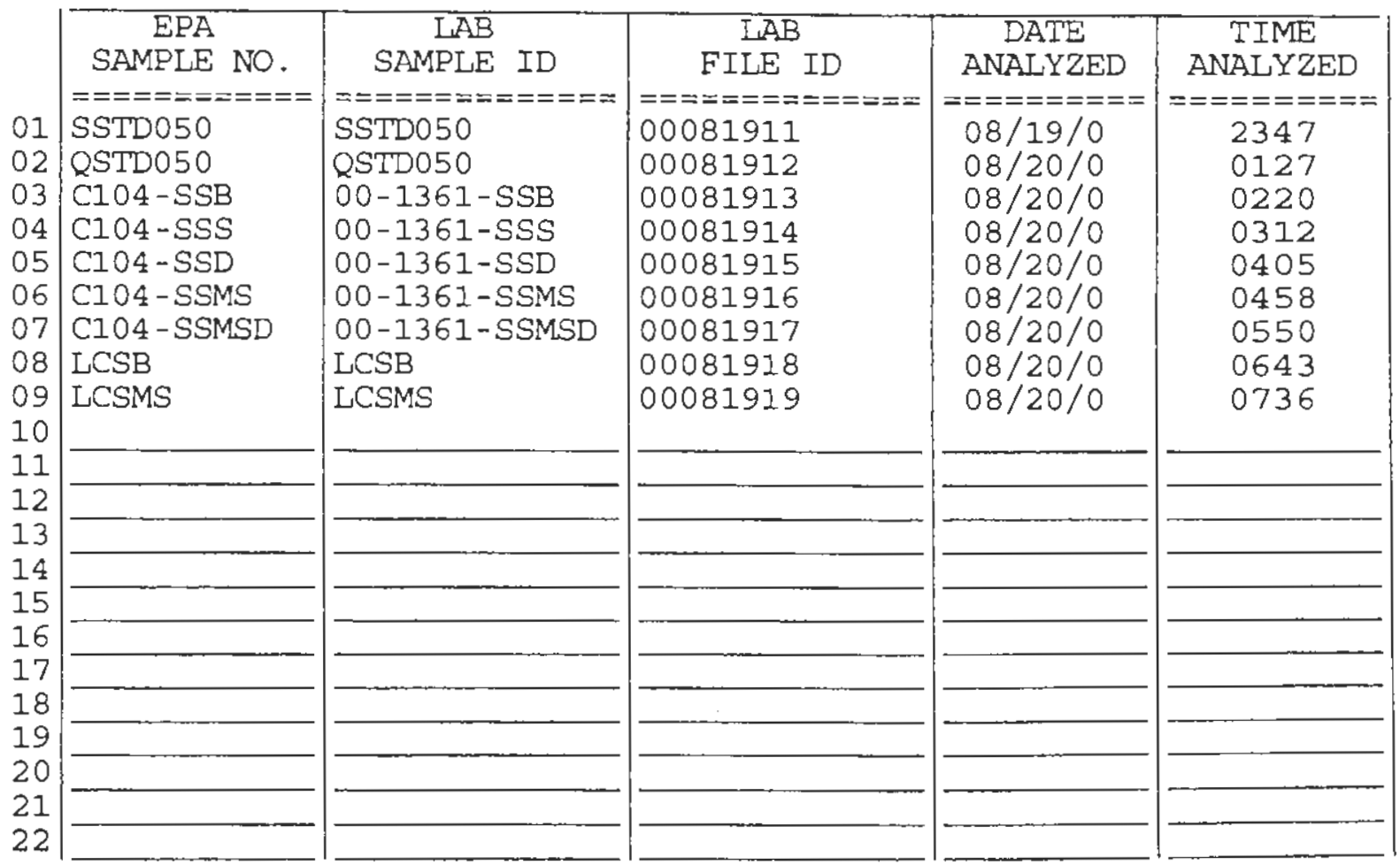

page 1 of 1 
SEMIVOLATILE ORGANIC INSTRUMENT PERFORMANCE CHECK DECAFLUOROTRIPHENYLPHOSPHINE (DETPP)

Lab Name: PNNL

Lab Code: PNNL

Lab File ID: 00081901

Instrument ID: HPI

\section{Contract : $\mathrm{C} 104$}

Case No.:

SAS NO.:
SDG No. : 000819

DFTPP Injection Date: 08/19/0

DFTPP Injection Time: 1500

\begin{tabular}{|c|c|c|}
\hline $\begin{array}{l}\mathrm{m} / \mathrm{e} \\
====\end{array}$ & 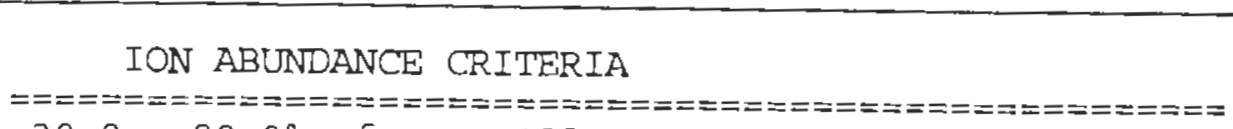 & $\begin{array}{c}\text { RELATIVE } \\
\text { ABUNDANCE } \\
=============\end{array}$ \\
\hline 51 & $30.0-80.0 \%$ of mass 198 & 34.9 \\
\hline 68 & Less than $2.0 \%$ of mass $6 \overline{9}$ & $0.070 .0) \overline{1}$ \\
\hline 69 & Mass 69 relative abundance & 40.3 \\
\hline 70 & Less than $2.0 \%$ of mass 69 & $0 . 5 \longdiv { 1 }$ \\
\hline 127 & $25.0-75.0 \%$ of mass 198 & 44.9 \\
\hline 197 & Less than $1.0 \%$ of mass $19 \overline{98}$ & 0.0 \\
\hline 198 & Base Peak, $100 \%$ relative abundance. & 100.0 \\
\hline 199 & 5.0 to $9.0 \%$ of mass 198 & 6.5 \\
\hline 275 & $10.0-30.0 \%$ of mass $19 \overline{8}$ & 28.7 \\
\hline 365 & Greater than $0.75 \%$ of mass 198 & 5.03 \\
\hline 441 & Present, but less than mass $44 \overline{3}$ & 10.9 \\
\hline 442 & $40.0-110.0 \%$ of mass 198 & 75.7 \\
\hline 443 & $15.0-24.0 \%$ of mass 442 & $14.67(19.2) 2$ \\
\hline
\end{tabular}

THIS CHECK APPLIES TO THE FOLLOWING SAMPLES, MS, MSD, BLANKS, AND STANDARDS:

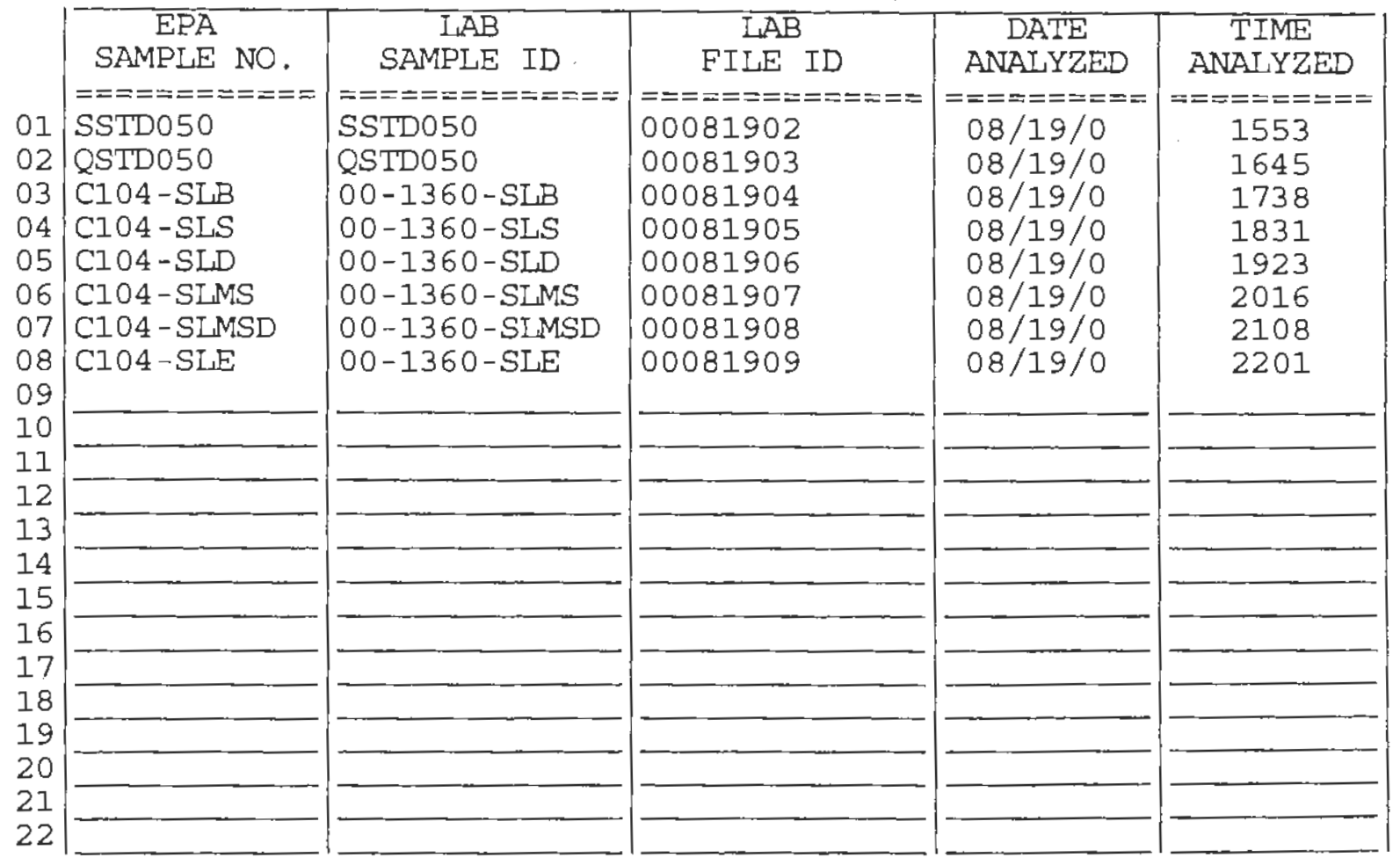

page 1 of 1 
Lab Name: PNNL

Iab Code: PNNL

Instrument ID: HP1
Contract: $\mathrm{ClO} 4$

SAS NO. :

SDG No.: 000811

$08 / 15 / 0$

0127

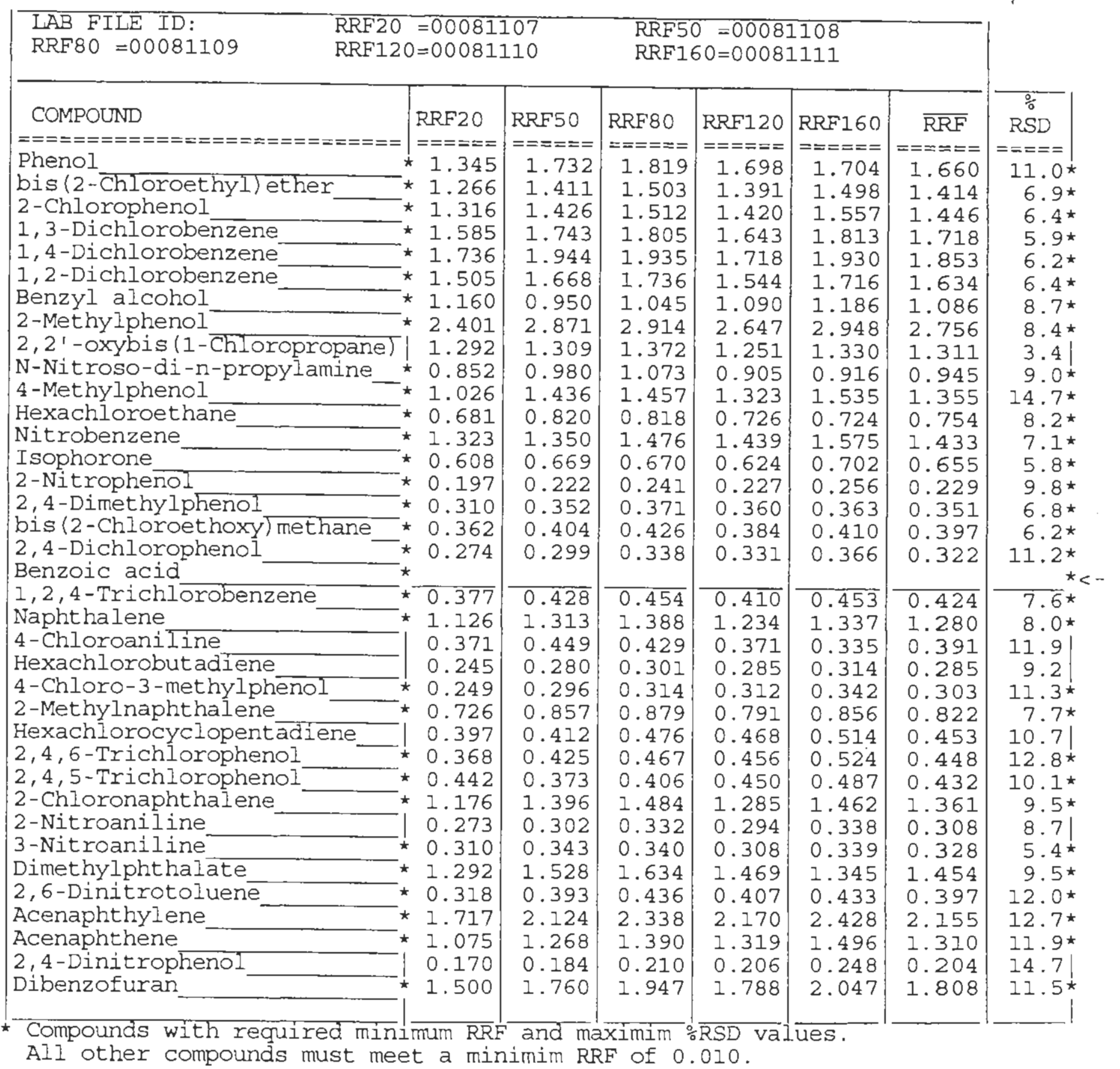

page 1 of 5 
$6 \mathrm{C}$

SEMIVOLATILE ORGANICS INITIAL CALIBRATION DATA

Lab Name: PNNL

Lab Code: PNNL

Instrument ID: HPI
Contract: $\mathrm{C} 104$

SAS NO.:

SDG No.: 000811

$08 / 15 / 0$

0127

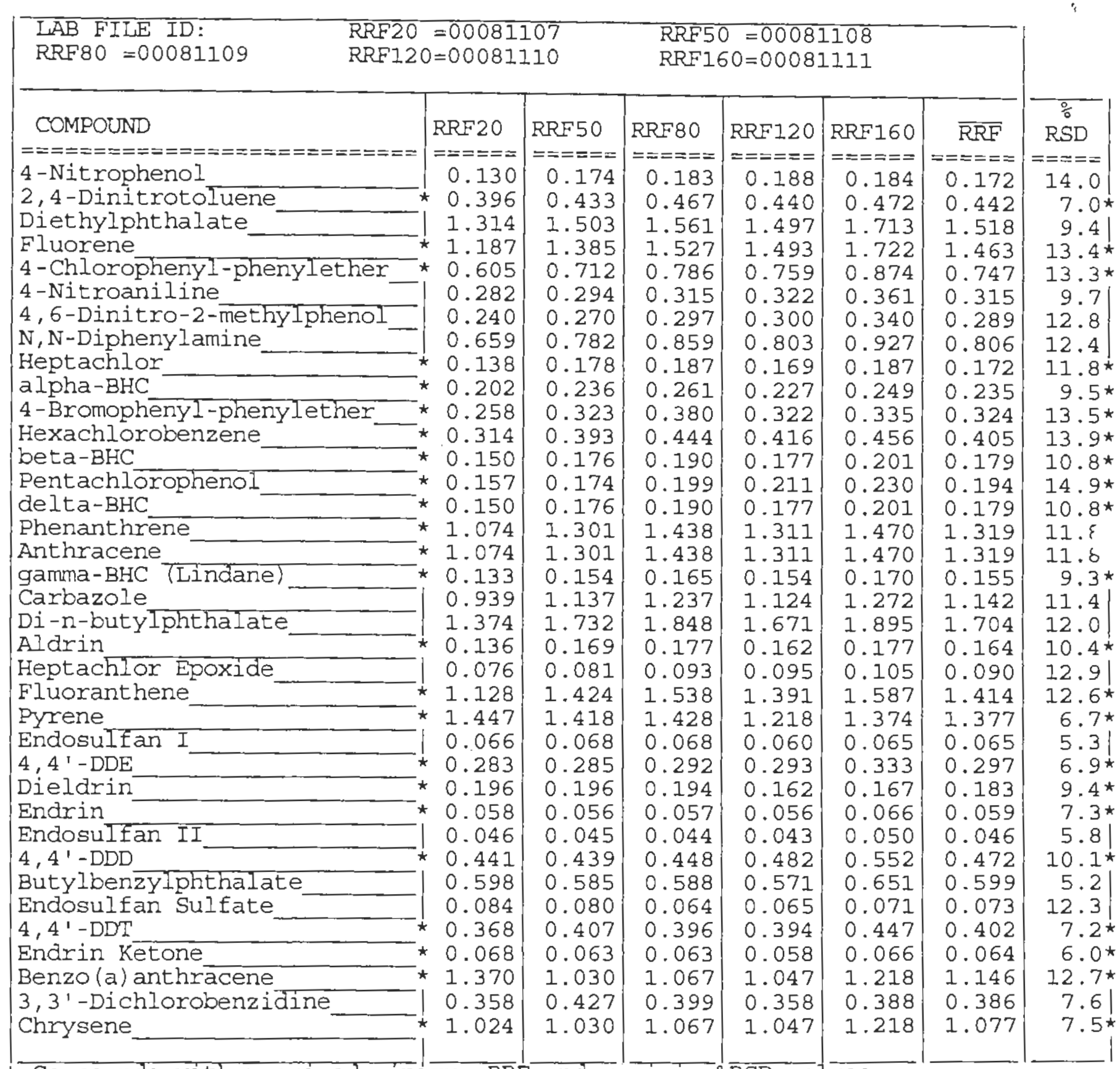

Compounds with required miñ mum RRF and maximim :

Al1 other compounds must meet a minimim RRF of 0.010 . 
Lab Name: PNNLL

Lab code: PNNL

Instrument ID: HP1
Contract: $\mathrm{C} 104$

SAS NO.:

SDG No.: 000811

$08 / 15 / 0$

0127

\begin{tabular}{|c|c|c|c|c|c|c|c|c|}
\hline $\begin{array}{l}\text { LAB FILE ID: } \\
\text { RRF80 }=00081109\end{array}$ & $\begin{array}{l}=000811 \\
0=000811\end{array}$ & & $\begin{array}{l}\text { RRF50 } \\
\text { RRF16 }\end{array}$ & $\begin{array}{l}=0008 \\
0=0008\end{array}$ & $\begin{array}{l}1108 \\
1111\end{array}$ & & & \\
\hline COMPOUND & RRF20 & RRF50 & RRF80 & RRF120 & RRE 160 & $\overline{R R F}$ & RSD & \\
\hline 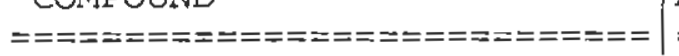 & $=====$ & $=====$ & $=====$ & $=\approx=\approx==$ & $==-==$ & $===-==$ & $\Rightarrow====$ & \\
\hline Methoxychlor & $\star 1.106$ & 1.106 & 1.092 & 0.910 & 0.930 & 1.029 & $9.7 \star$ & \\
\hline Bis (2-Ethyl hexyl)phthalate & 0.829 & 0.863 & 0.854 & 0.843 & 0.952 & 0.868 & 5.6 & \\
\hline Di-n-octylphthalate & 2.071 & 2.042 & 2.187 & 1.776 & 2.156 & 2.046 & 8.0 & \\
\hline Benzo (b) fluoranthene. & 1.872 & 1.734 & 2.062 & 1.735 & 2.175 & 1.916 & $10.3 *$ & \\
\hline Benzo $(k)$ fluoranthene & 1.653 & 1.734 & 2.062 & 1.735 & 2.175 & 1.872 & 12.4 * & \\
\hline Benzo (a) pyrene & 1.462 & 1.277 & 1.412 & 1.122 & 1.393 & 1.333 & 10.2 * & \\
\hline Indeno $(1,2,3$-cd) pyrene. & $\star 1.308$ & 1.106 & 1.454 & 1.218 & 1.421 & 1.301 & $11.0 *$ & \\
\hline Dibenz $(a, h)$ anthracene & * 1.357 & 1.174 & 1.262 & 1.078 & 1.428 & 1.260 & $11.1 *$ & \\
\hline Benzo $(g, h, i)$ perylene & 1.363 & 1.132 & 1.211 & 1.024 & 1.141 & 1.174 & $10.6^{\star}$ & \\
\hline Pyridine & 0.882 & 0.979 & 0.957 & 1.106 & 0.911 & 0.967 & 9.0 & \\
\hline Undecane & & & & & & & & \\
\hline Dodecane & & & & & & & & \\
\hline Tridecane_. & & & & & & & & - \\
\hline Tetradecañe & & & & & & & & \\
\hline Pentadecane & & & & & & & & $<-$ \\
\hline Tributyl phosphate & 1.548 & 1.776 & 1.766 & $\overline{1.739}$ & 1.555 & 1.677 & 6.9 & \\
\hline Bis (2-Ethylhexyl) phosphate & & & & & & & & \\
\hline $\begin{array}{l}\text { N-Nitrosodimethylamine } \\
\text { tetrachlorobiphenyl (peak 2) }\end{array}$ & 0.549 & 0.445 & 0.488 & 0.591 & 0.550 & 0.525 & 11.0 & $<-$ \\
\hline tetrachlorobipheny (peak 1) & & & & & & & & $<-$ \\
\hline $\begin{array}{l}\text { pentachlorobiphenyl (peak } 3)^{-}- \\
\text {pentachlorobiphenyl (peak 4) }\end{array}$ & & & & & & & & $<-$ \\
\hline & & & & & & & & $<-$ \\
\hline $\begin{array}{l}\text { pentachlorobiphenyl (peak 5) } \\
\text { pentachlorobiphenyl (peak 6) }\end{array}$ & & & & & & & & $\begin{array}{ll}<- \\
<-\end{array}$ \\
\hline $\begin{array}{l}\text { hexachlorobiphenyl (peak 7) } \\
\text { pentachlorobiphenyl (peak 8) }\end{array}$ & & & & & & & & - \\
\hline $\begin{array}{l}\text { pentachloroblpheny } 1 \text { (peak 8) - } \\
\text { hexachlorobiphenyl (peak 9) - }\end{array}$ & & & & & & & & 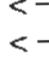 \\
\hline hexachlorobiphenyl (peak10) & & & - & & & & & \\
\hline AROCLOR 1254 & & & & & & & & \\
\hline $\begin{array}{l}\text { 2-Butoxyethanol } \\
\text { Acetophenone }\end{array}$ & & & & & & & & \\
\hline Acetophenone & $\overline{1.702}$ & 1.850 & 1.871 & 1.705 & $1.94 \overline{7}$ & 1.815 & 5.9 & \\
\hline 1-Chloro-4-nitrobenzene & 0.200 & 0.236 & 0.240 & 0.258 & 0.264 & 0.240 & 10.4 & \\
\hline Biphenyl & 2.703 & 2.880 & 2.949 & 3.003 & 2.774 & 2.862 & 4.3 & \\
\hline 1,4-Dinitrobenzene & 0.262 & 0.281 & 0.309 & 0.298 & 0.335 & 0.297 & 9.4 & \\
\hline Butylated Hydroxytoluene & 1.793 & 2.120 & 2.114 & 1.916 & 1.897 & 1.968 & 7.3 & \\
\hline Pentachloronitrobenzene & 0.141 & 0.174 & 0.188 & 0.176 & 0.194 & 0.175 & $11 \cdot 7$ & \\
\hline Dinoseb & 0.227 & 0.264 & 0.302 & 0.285 & 0.339 & 0.283 & 14.7 & \\
\hline
\end{tabular}


$6 \mathrm{C}$

\section{SEMIVOLATILE ORGANICS INITIAL CALIBRATION DATA}

Lab Name: PNNL

Lab Code: PNNL

Instrument ID: HPI
Contract: $\mathrm{C} 104$

Case No.: SAS No.:
Calibration Date(s) : 08/14/0 08/15/0

Calibration Time(s): 1734
0127

\begin{tabular}{lll}
\hline LAB FILE ID: & RRF20 $=00081107$ & RRF50 $=00081108$ \\
RRF80 $=00081109$ & RRF120 $=00081110$ & RRF160 00081111
\end{tabular}

COMPOUND

Octachloronaphthalene

N-Nitrosomethylethylamine

N-Nitrosodiethylamine

Ethyl methane sulfonate

Analine

Pentachloroethane

N-Nitrosopyrolidine

N-Nitrosopiperidine

Hexachloropropene

N-Nitrosodi-n-but -amine

Safrole

$1,2,4,5$-Tetrachlorobenzene

Isosafrole

1,4-Naphthoguinone

Pentachlorobenzene

1-Napht hylamine

$2,3,4,6$-Tetrach lorophenol

2-Naphthylamine

5-Nitro-o-toluidine

Azeobenzene

$1,3,5$-Trinitrobenzene

Diallate (cis)

Phenacetin

Diallate (trans)

4-Aminobiphenyl

Pronamine

Isodrin

Chlordane (alpha)

Benzidine

p-Dimethy laminoazobenzene

Chlorobenzilate

3,3'-Dimethylbenzidine

2-Acetylaminofluorene

3-Methylcholanthrene

2-Methylpyridine

Kepone

Chlordane (gamma)

Compounds with required minimum $\overline{R R}$ and maximim

All other compounds must meet a minimim RRF of 0.010 .

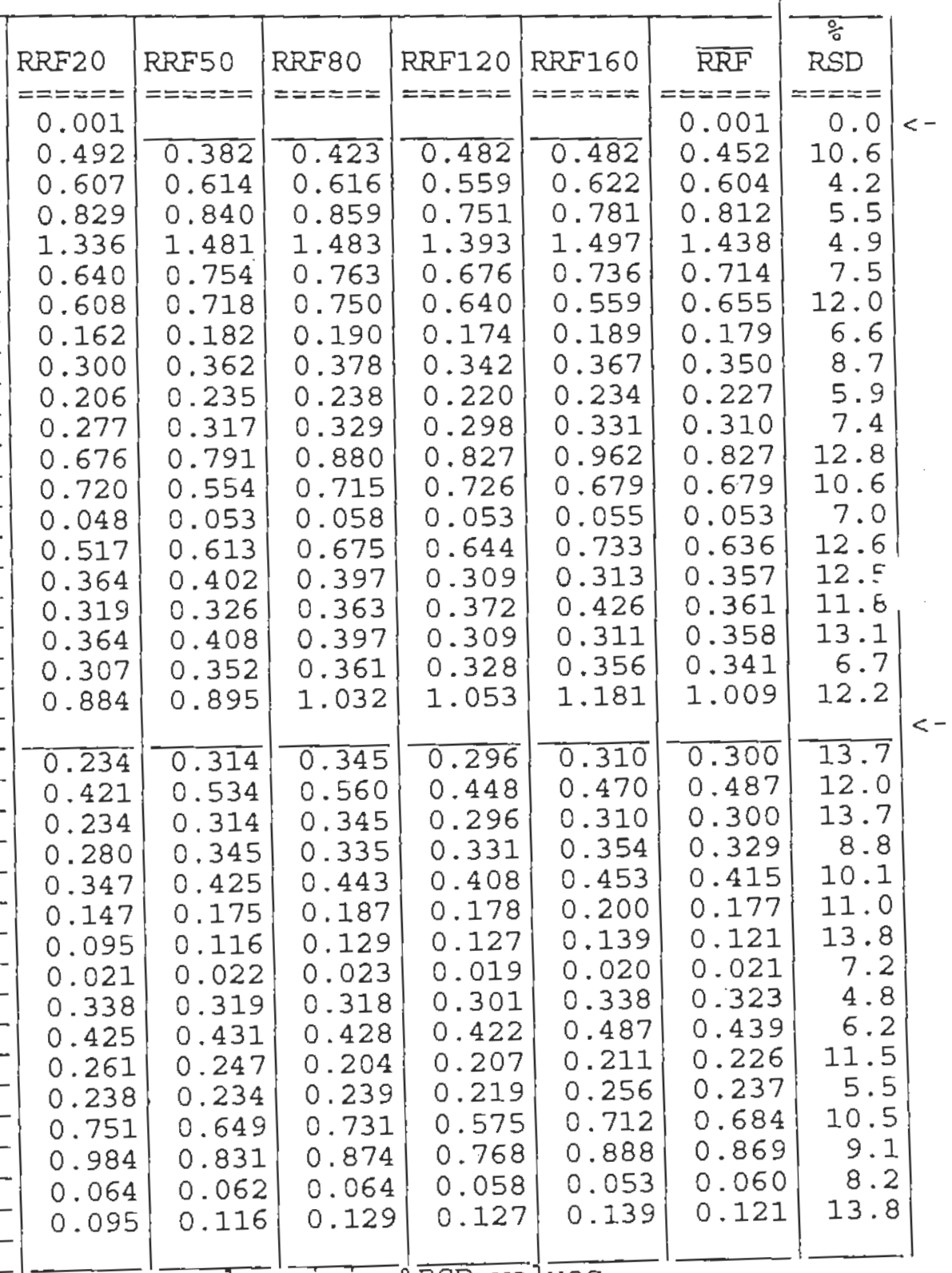

+ 


\section{SEMIVOLATILE ORGANICS INITIAL CALIBRATION DATA}

Lab Name: PNNL

Contract: $\mathrm{C} 104$

Lab Code: PNNL

Case No. :

SAS NO.:

SDG No.: 000811

Instrument ID: HP1

Calibration Date $(\mathrm{s}): 08 / 14 / 0$

$08 / 15 / 0$

Calibration Time(s): 1734

0127

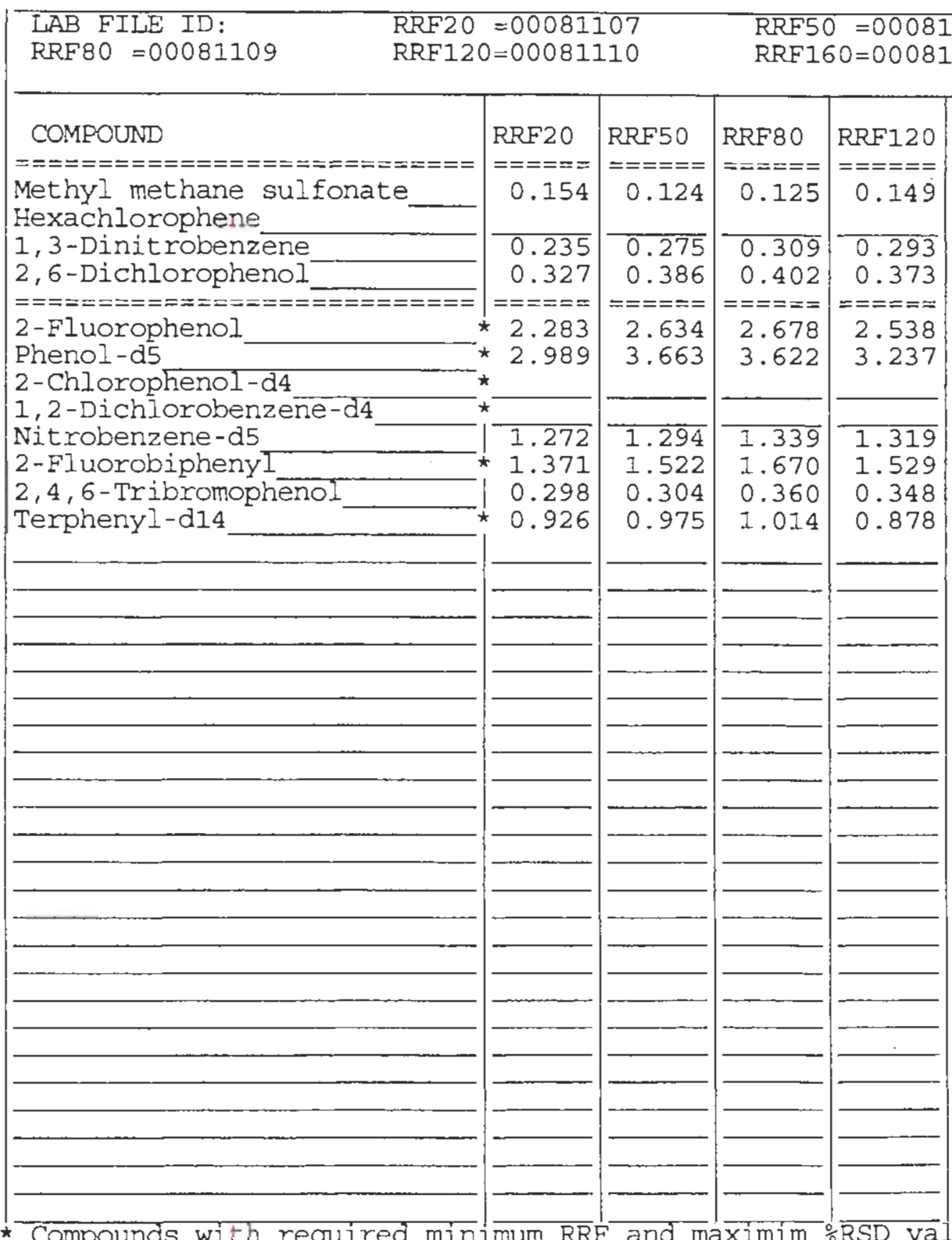

RRF50 $=00081108$
RRF160 $=00081111$

$\begin{array}{lll}\text { LAB FILE ID: } & \text { RRF20 }=00081107 & \text { RRF } 160=00081111 \\ \text { RRF80 }=00081109 & \text { RRF120 }=00081110 & \text { RR }\end{array}$

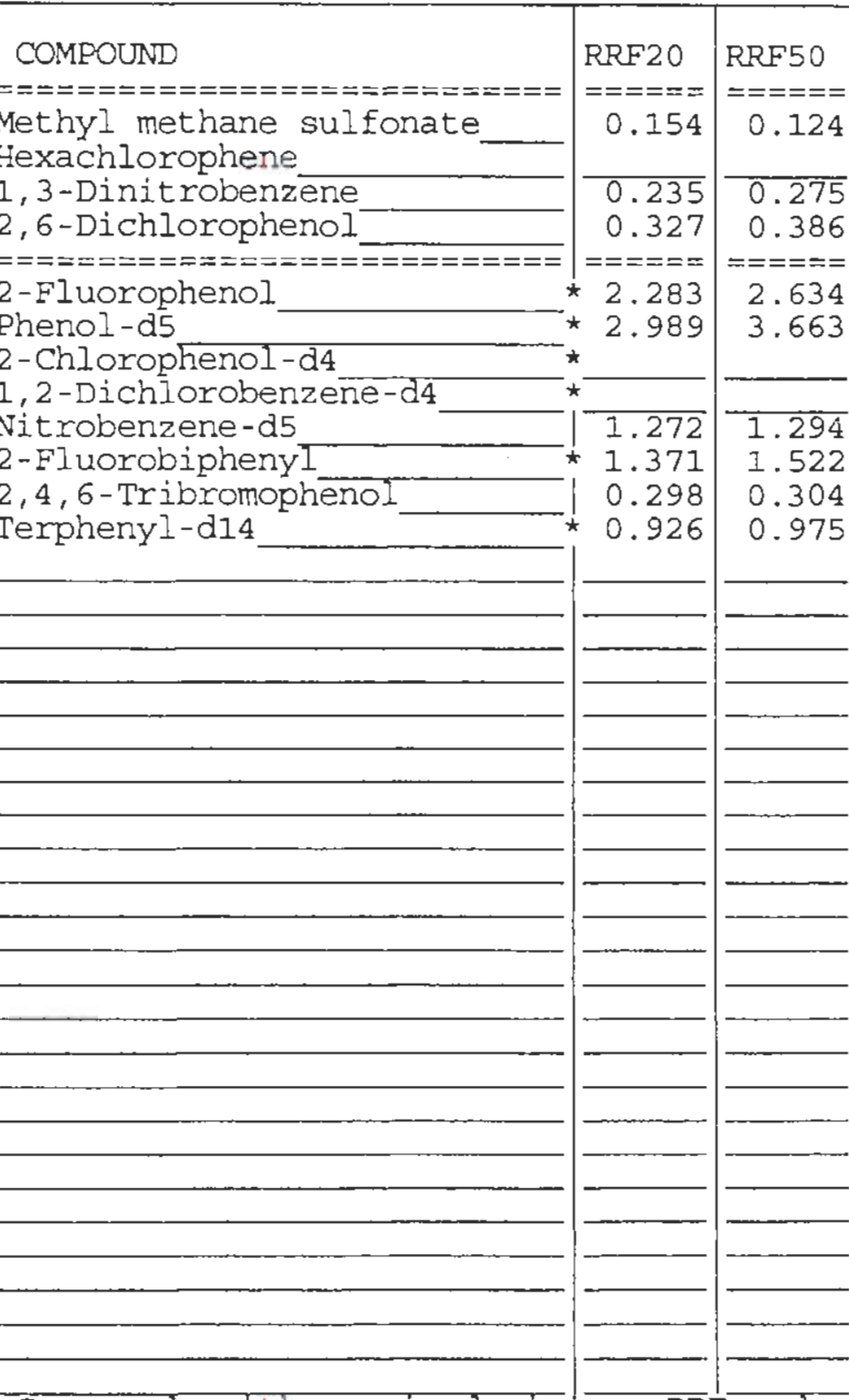

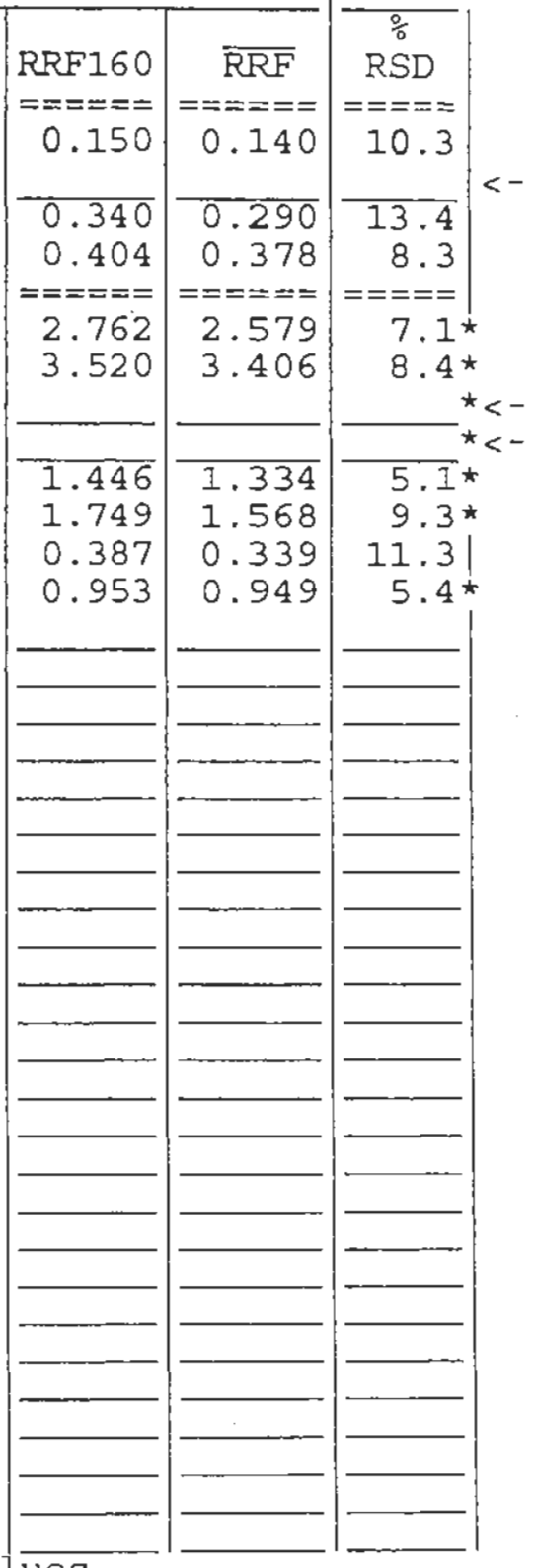

All other compounds must meet a minimim RRF of 0.010 .

page 5 of 5 
Lab Name: PNNL

Lab Code: PNNL

Instrument ID: HP1

Lab File ID: 00081902
Contract : $\mathrm{C} 104$

SAS NO.:

SDG No.: 000819

Calibration Date: 08/19/0 Time: 1553

Init. Calib. Date(s): 08/14/0 08/15/0

Init. Calib. Times: 1734

0127

\begin{tabular}{|c|c|c|c|c|c|}
\hline COMPOUND & $\overline{\mathrm{RRF}}$ & RRF 5 & $\begin{array}{l}\text { MIN } \\
\text { RRF }\end{array}$ & $\because$ & MAX \\
\hline 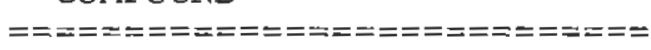 & $===\approx==$ & $== \pm== \pm$ & $=====$ & $==== \pm=$ & $==x==$ \\
\hline Methoxychlor & 1.029 & 1.084 & 0.050 & -5.3 & 40.0 \\
\hline Bis (2-Ethylhexyl)phthalate & 0.868 & 0.869 & & -0.1 & \\
\hline Di-n-octylphthalate & 2.046 & 1.827 & & 10.7 & \\
\hline Benzo (b) fluoranthene & 1.916 & 1.813 & 0.700 & 5.4 & 25.0 \\
\hline Benzo $(k)$ fluoranthene & 1.872 & 1.856 & 0.700 & 0.8 & 25.0 \\
\hline Benzo (a) pyrene & 1.333 & 1.347 & 0.700 & -1.0 & 25.0 \\
\hline Indeno $(1,2,3$-cd) pyrene & 1.301 & 1.155 & 0.500 & 11.2 & 25.0 \\
\hline Dibenz $(a, h)$ anthracene & 1.260 & 1.126 & 0.400 & 10.6 & 25.0 \\
\hline Benzo $(g, h, i)$ perylene & 1.174 & 1.048 & 0.500 & 10.7 & 25.0 \\
\hline Pyridine & 0.967 & 0.937 & & 3.1 & \\
\hline Tributyl phosphate & 1.677 & 1.489 & & 11.2 & \\
\hline N-Nitrosodimethylamine & 0.525 & 0.538 & & -2.5 & \\
\hline Acetophenone & 1.815 & 1.848 & & $-1,8$ & \\
\hline 1-Chloro-4-nitrobenzene & 0.240 & 0.184 & & 23.3 & \\
\hline Biphenyl & 2.862 & 2.300 & & 19.6 & \\
\hline 1,4-Dinitrobenzene & & 0.135 & & & \\
\hline Butylated Hydroxytoluene & 1.968 & 1.653 & & 16.0 & \\
\hline Pentachloronitrobenzene & 0.175 & 0.156 & & 10.8 & \\
\hline Dinoseb & 0.283 & 0.258 & & 8.8 & \\
\hline octachloronaphthalene & 0.001 & 0.002 & & -99.9 & \\
\hline N-Nitrosomethylethylamine & 0.452 & 0.458 & & -1.3 & \\
\hline N-Nitrosodiethylamine & 0.604 & 0.675 & & -11.8 & \\
\hline Ethyl methane sulfonate & 0.812 & 0.862 & & -6.2 & \\
\hline Analine & 1.438 & 1.539 & & -7.0 & \\
\hline Pentachloroethane & 0.714 & 0.672 & & 5.9 & \\
\hline N-Nitrosopyrolidine & 0.655 & 0.700 & & -6.9 & \\
\hline N-Nitrosopiperidine & 0.179 & 0.180 & & -0.6 & \\
\hline Hexachloropropene & 0.350 & 0.314 & & 10.3 & \\
\hline N-Nitrosodi-n-buty lamine & 0.227 & 0.238 & & -4.8 & \\
\hline Safrole & 0.310 & 0.294 & & 5.2 & \\
\hline $1,2,4,5$-Tetrachlorobenzene & 0.827 & 0.742 & & 10.3 & \\
\hline Isosafrole & 0.679 & 0.661 & & 2.6 & \\
\hline 1, 4-Naphthoquinone. & 0.053 & 0.052 & & 1.9 & \\
\hline Pentachlorobenzene & 0.636 & 0.618 & & 2.8 & \\
\hline 1-Naphthylamine & 0.357 & 0.392 & & -9.8 & \\
\hline $2,3,4,6$-Tetrachlorophenol & 0.361 & 0.334 & & 7.5 & \\
\hline
\end{tabular}

All other compounds must meet a minimum RRF of 0.010 . 
Iab Name: PNNL,

Iab Code: PNNL

Instrument ID: HPI

Iab File ID: 00081902
Contract: $\mathrm{C104}$

Case No.: $\quad$ SAS No.:
SDG No.: 000819

Calibration Date: 08/19/0 Time: 1553

Init. Calib. Date(s): 08/14/0 08/15/0

Init. Calib. Times: $1734 \quad 0127$

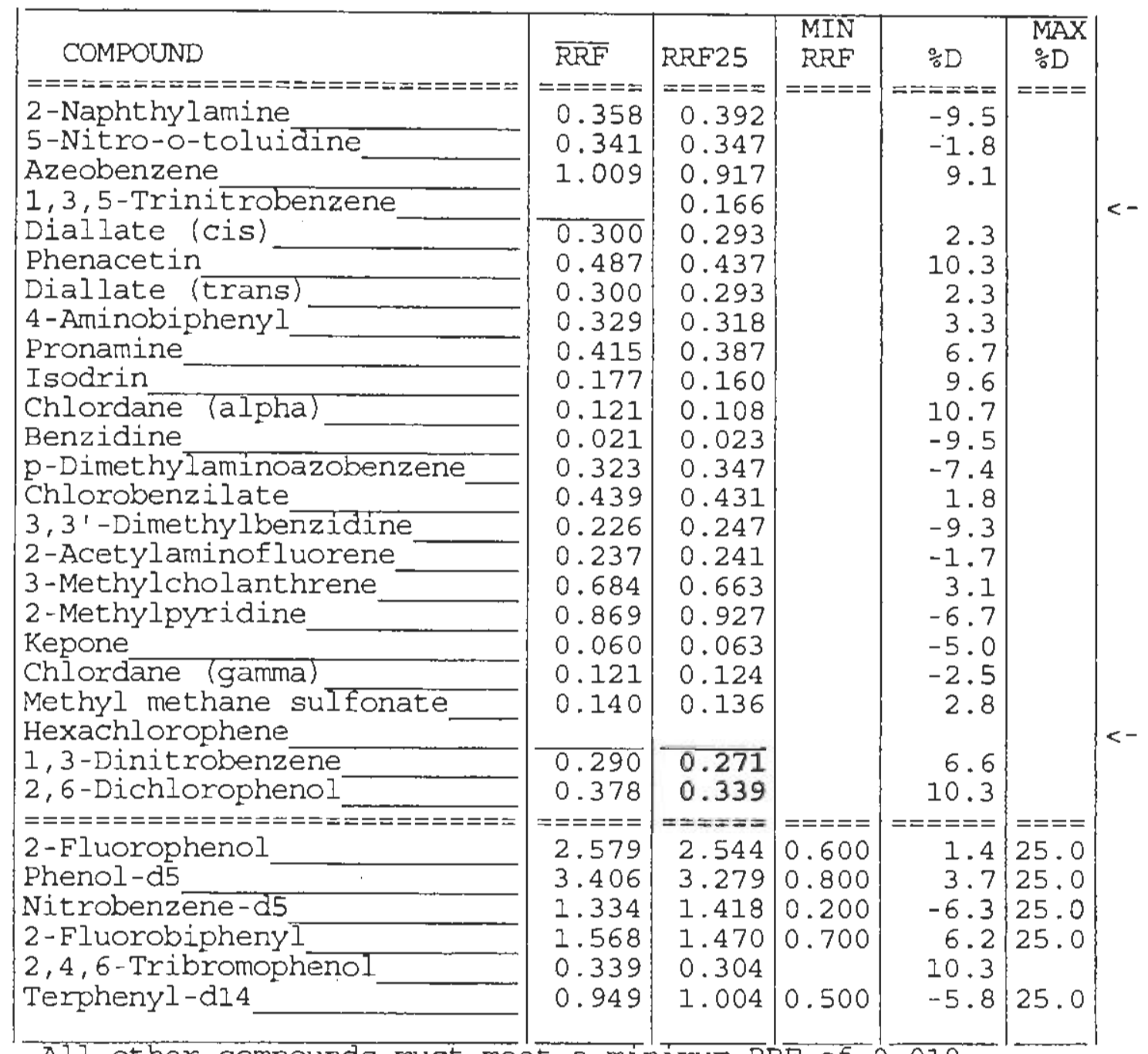

Al1 other compounds must meet a minimum RR $\bar{F}$ of $0 . \overline{010}$. 


\section{SEMIVOLATILE CONTINUING CALIBRATION GHECK}

Ialo Name: PNNL

Lab Code: PNNL

Instrument ID: HP1

Lab File ID: 00081903
Contract : $\mathrm{C104}$

Case NO.: SAS No: :

SDG No.: 000819

Calibration Date: 08/19/0 Time: 1645

Init. Calib. Date(s): 08/14/0 08/15/0

Init. Calib. Times: $1734 \quad 0127$

\begin{tabular}{|c|c|c|c|c|c|}
\hline COMPOUND & $\overline{\mathrm{R} R F}$ & RRF25 & $\begin{array}{l}\text { MIN } \\
\text { RRF }\end{array}$ & $\because D$ & $\begin{array}{l}\text { MAX } \\
\because D\end{array}$ \\
\hline 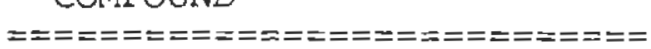 & $==== \pm=$ & $===\approx==$ & $\approx====$ & $=====$ & $====$ \\
\hline Phenol & 1.660 & 1.659 & 0.800 & 0.1 & 25.0 \\
\hline bis (2-Chloroethyl)ether & 1.414 & 1.480 & 0.700 & -4.7 & 25.0 \\
\hline 2-Chlorophe & 1.446 & 1.398 & 0.800 & 3.3 & 25.0 \\
\hline hlorobenzene & 1.718 & 1.636 & 0.600 & 4.8 & 25.0 \\
\hline hlorobenzene & 1.853 & 1.810 & 0.500 & 2.3 & 25.0 \\
\hline Toben & 1.634 & 1.580 & 0.400 & 3.3 & 25.0 \\
\hline Benzyl alcohol & 1.086 & 0.988 & 0.100 & 9.0 & 25.0 \\
\hline 2-Methylphenol & 2.756 & 2.547 & 0.700 & 7.6 & 25.0 \\
\hline -Chloropropanel & 1.311 & 1.419 & & -8.2 & \\
\hline n-propyla & 0.945 & 013 & 0.500 & -7.2 & 25.0 \\
\hline 4-Met & 1.355 & 1.268 & 0.600 & 6.4 & 25.0 \\
\hline Hexac & 0.754 & 0.736 & 0.300 & 2.4 & 25.0 \\
\hline Nit: & 1.433 & 1.464 & 0.200 & -2.2 & 25.0 \\
\hline Isol & 0.655 & 06 & 0.400 & -7.8 & 25.0 \\
\hline shenol & 0.229 & 0.222 & 0.100 & 3.0 & 25.0 \\
\hline lphenol & 0.351 & 29 & 0.200 & 6.3 & 25.0 \\
\hline pethoxy methane & 0.397 & 0.406 & 0.300 & -2.3 & 25.0 \\
\hline phenol & 0.322 & 0.293 & 0.200 & 9.0 & 25.0 \\
\hline Trichlorobenzene & 0.424 & 0.398 & 0.200 & 6.1 & 25.0 \\
\hline Napht & 1.280 & 1.220 & 0.700 & 4.7 & 25.0 \\
\hline $4-\mathrm{Ch}$ & 0.391 & 0.393 & & -0.5 & \\
\hline diene & 0.285 & 67 & & 6.3 & \\
\hline methylpheñol & 0.303 & 0.282 & 0.200 & 6.9 & 25.0 \\
\hline hthalene & 0.822 & 0.770 & 0.400 & 6.3 & 25.0 \\
\hline spentadiene & 0.453 & 433 & & 4.4 & \\
\hline lorophenol & 0.448 & 0.411 & 0.200 & 8.2 & 25.0 \\
\hline $2,4,5$-Trichlorophenol & 0.432 & 0.443 & 0.200 & -2.5 & 25.0 \\
\hline 2-Chloronaphthalene & 1.361 & $1.4 .00 \cdot 0 \cdot 0 \cdot 0$ & 0.800 & -5.7 & 25.0 \\
\hline $2-\mathrm{Nit}$ & 0.308 & 23 & & -4.9 & \\
\hline 3-Nit & 0.328 & 0.317 & 0.050 & 3.4 & 40.0 \\
\hline lylphthalate & 1.454 & 1.564 & 0.050 & -7.6 & 25.0 \\
\hline 2,6-Dinitrotoluene & 0.397 & 0.377 & 0.200 & 5.0 & 25.0 \\
\hline thetano & 2.155 & 2.014 & 1.300 & 6.5 & 25.0 \\
\hline & 1.310 & 1.250 & 0.800 & 4.6 & 25.0 \\
\hline pphenol & 0.204 & 0.200 & & 2.0 & \\
\hline Dibenzofur & 1.808 & 1.739 & 0.800 & 3.8 & 25.0 \\
\hline 4-Nitrophenol & 0.172 & 0.167 & & 2.9 & \\
\hline
\end{tabular}

All other compounds must meet a minimum RRF of 0.010 . 
$7 \mathrm{C}$

SEMIVOLATILE CONTINUING CALIBRATION CHECK

Lab Name: PNNL

Lab code: PNNL

Instrument ID: HP1

Lab File ID: 00081911
Contract: $\mathrm{C} 104$

Case No.: SAS NO.:

SDG No.: 000819

Calibration Date: 08/19/0 Time: 2347

Init. Calib. Date(s): 08/14/0 08/15/0

Init. Calib. Times: $1734 \quad 0127$

\begin{tabular}{|c|c|c|c|c|c|}
\hline COMPOUND & $\overline{\mathrm{RRF}}$ & RRF25 & $\begin{array}{l}\text { MIN } \\
\text { RRF }\end{array}$ & $\% \mathrm{D}$ & $\begin{array}{l}\text { MAXX } \\
\because D\end{array}$ \\
\hline 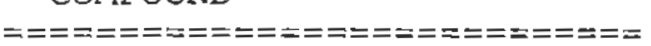 & $======$ & $=====$ & $=====$ & $======$ & $=\approx==$ \\
\hline 2,4 -Dinitrotoluene & 0.442 & 0.460 & 0.200 & -4.1 & 25.0 \\
\hline Diethylphthalate & 1.518 & 1.475 & & 2.8 & \\
\hline Fluorene & 1.463 & 1.392 & 0.900 & 4.8 & 25.0 \\
\hline 4-Chlorophenyl-phenylether & 0.747 & 0.721 & 0.400 & 3.5 & 25.0 \\
\hline 4-Nitroaniline & 0.315 & 0.301 & & 4.4 & \\
\hline 4,6 -Dinitro-2-methylphenol & 0.289 & 0.293 & & -1.4 & \\
\hline N,N-Diphenylamine & 0.806 & 0.747 & & 7.3 & \\
\hline Heptachlor & 0.172 & 0.167 & 0.050 & 2.9 & 40,0 \\
\hline alpha-BHC & 0.235 & 0.213 & 0.050 & 9.4 & 40.0 \\
\hline phenyl-phenylether & 0.324 & 0.320 & 0.100 & 1.2 & 25.0 \\
\hline Hexachlorobenz & 0.405 & 0.383 & 0.100 & 5.4 & 25.0 \\
\hline beta-BHC & 0.179 & 0.180 & 0.050 & -0.6 & 40.0 \\
\hline Pentachlorophenol & 0.194 & 0.179 & 0.050 & 7.7 & $25+0$ \\
\hline delta & 0.179 & 0.165 & 0.050 & 7.8 & 40.0 \\
\hline Phenanthrene & 1.319 & 1.262 & 0.700 & 4.3 & 25.0 \\
\hline Anthracene & 1.319 & 1.220 & 0.700 & 7.5 & 25,0 \\
\hline gamma-BHC (Lindane) & 0.155 & 0.141 & 0.050 & 9.0 & 40.0 \\
\hline Carbazole & 1.142 & 1.057 & & 7.4 & \\
\hline Di-n-buty lphthalate & 1.704 & 1.590 & & 6.7 & \\
\hline Aldrin & 0.164 & 0.156 & 0.050 & 4.9 & 40.0 \\
\hline Heptachlor Epoxide & 0.090 & 0.090 & & 0.0 & \\
\hline Fluoranthene & 1.414 & 1.301 & 0.600 & 8.0 & 25.0 \\
\hline Pyrene & 1.377 & 1.415 & 0.600 & -2.8 & 25.0 \\
\hline Endosulfan I & 0.065 & 0.066 & & -1.5 & \\
\hline $4,4^{\prime}-\mathrm{DDE}$ & 0.297 & 0.304 & 0.050 & -2.4 & 40.0 \\
\hline Dieldrin & 0.183 & 0.204 & 0.050 & -11.5 & 40.0 \\
\hline Endrin & 0.059 & 0.060 & 0.050 & -1.7 & 40.0 \\
\hline Endosulfan II & 0.046 & 0.047 & & -2.2 & \\
\hline $4,44^{\prime}-\mathrm{DDD}$ & 0.472 & 0.478 & 0.050 & -1.3 & 40.0 \\
\hline Butylbenzylphthalate & 0.599 & 0.632 & & -5.5 & \\
\hline Endosulfan Sulfate & 0.073 & 0.080 & & -9.6 & \\
\hline $4,4^{\prime}-\mathrm{DDT}$ & 0.402 & 0.399 & 0.050 & 0.7 & 40.0 \\
\hline Endrin ketone & 0.064 & 0.070 & 0.050 & -9.4 & 40.0 \\
\hline Benzo (a) anthracene & 1.146 & 1.258 & 0.800 & -9.8 & 25.0 \\
\hline $3^{3} 3^{\prime}$-Dichlorobenziálne & 0.386 & 0.434 & & -12.4 & \\
\hline Chrysene & 1.077 & 1.122 & 0.700 & -4.2 & 25.0 \\
\hline
\end{tabular}

AlI other compounds must meet a minimum RRF of 0.010 . 
$7 \mathrm{C}$

SEMIVOLATILE CONTINUING CALIBRATION CHECK

Lab Name: PNNL

Lab Code: PNNL

Instrument ID: HP1

Lab File ID: 00081911
Contract: $\mathrm{ClO} 04$

Case No.:
SAS NO.:
SDG No.: 000819

Calibration Date: 08/19/0 Time: 2347

Init. Calib. Date(s) : 08/14/0 08/15/0

Init. Calib. Times: 1734

0127

\begin{tabular}{|c|c|c|c|c|c|}
\hline COMPOUND & $\overline{R R F}$ & RRF 25 & $\begin{array}{l}\text { MIN } \\
\text { RRF }\end{array}$ & $\because 0$ & MAX \\
\hline 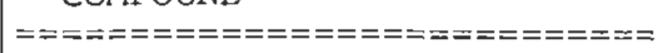 & $=====$ & $\begin{array}{l}\mathrm{RKF} 2 \mathrm{~S} \\
=====\end{array}$ & $\begin{aligned} R R H & ===\end{aligned}$ & $====$ & $==$ \\
\hline Methoxychlor & 1.029 & 0.993 & 0.050 & 3.5 & 40.0 \\
\hline Bis (2-Ethylhexyl) phthalate. & 0.868 & 0.900 & & -3.7 & \\
\hline Di-n-octyiphthalate & 2.046 & 1.915 & & 6.4 & \\
\hline Benzo (b) fluoranthene & 1.916 & 1.776 & 0.700 & 7.3 & 25.0 \\
\hline Benzo $(k)$ fluoranthene & 1.872 & 1.829 & 0.700 & 2.3 & 25.0 \\
\hline Benzo (a) pyrene & 1.333 & 1.278 & 0.700 & 4.1 & 25.0 \\
\hline Indeno $(1,2,3$-cd) pyrene & 1.301 & 1.175 & 0.500 & 9.7 & 25.0 \\
\hline Dibenz $(a, h)$ anthracene & 1.260 & 1.251 & 0.400 & 0.7 & 25.0 \\
\hline Benzo $(g, h, i)$ perylene & 1.174 & 1.063 & 0.500 & 9.4 & 25.0 \\
\hline Pyridine & 0.967 & 0.988 & & -2.2 & \\
\hline Tributyl phosphate & 1.677 & 1.888 & & -12.6 & \\
\hline N-Nitrosodimethylamine. & 0.525 & 0.528 & & -0.6 & \\
\hline Acetophenone & 1.815 & 1.873 & & -3.2 & \\
\hline 1-Chloro-4-nitrobenzene & 0.240 & 0.227 & & 5.4 & \\
\hline Biphenyl & 2.862 & 2.862 & & 0.0 & \\
\hline 1,4-Dinitrobenzene & & 0.142 & & & \\
\hline Butylated Hydroxytoluene & $1 . \overline{968}$ & 1.904 & & 3.2 & \\
\hline Pentachloronitrobenzene & 0.175 & 0.157 & & 10.3 & \\
\hline Dinoseb & 0.283 & 0.265 & & 6.4 & \\
\hline Octachloronaphthalene & 0.001 & 0.001 & & 0.0 & \\
\hline N-Nitrosomethylethylamine & 0.452 & 0.499 & & -10.4 & \\
\hline N-Nitrosodiethylamine & 0.604 & 0.627 & & -3.8 & \\
\hline Ethyl methane sulfonate & 0.812 & 0.888 & & -9.4 & \\
\hline Analine & 1.438 & 1.488 & & -3.5 & \\
\hline Pentachloroethane & 0.714 & 0.690 & & 3.4 & \\
\hline N-Nitrosopyrolidine & 0.655 & 0.730 & & -11.4 & \\
\hline N-Nitrosopiperidine & 0.179 & 0.196 & & -9.5 & \\
\hline Hexachloropropene & 0.350 & 0.312 & & 10.8 & \\
\hline N-Nitrosodi-n-but ylamine & 0.227 & 0.244 & & -7.5 & \\
\hline Safrole & 0.310 & 0.304 & & 1.9 & \\
\hline $1,2,4,5$-Tetrachlorobenzene & 0.827 & 0.795 & & 3.9 & \\
\hline Isosafrole & 0.679 & 0.642 & & 5.4 & \\
\hline 1,4-Naphthoquinone & 0.053 & 0.054 & & -1.9 & \\
\hline Pentachlorobenzene & 0.636 & 0.636 & & 0.0 & \\
\hline 1-Naphthylamine & 0.357 & 0.401 & & $-12 \cdot 3$ & \\
\hline $2,3,4,6$-Tetrachlorophenol & 0.361 & 0.343 & & 5.0 & \\
\hline
\end{tabular}


Lab Name: PNNL

Lab Code: PNNL

Instrument ID: HP1

Lab File ID: 00081911
Contract : $\mathrm{C} 104$

Case No.:
SAS NO. :
SDG No.: 000819

Calibration Date: 08/19/0 Time: 2347

Init. Calib. Date (s):08/14/0 08/15/0

Init. Calib. Times: $1734 \quad 0127$

\begin{tabular}{|c|c|c|c|c|c|}
\hline COMPOUND & $\overline{\mathrm{R}} \overline{\mathrm{R}}$ & RRF25 & $\begin{array}{l}\text { MIN } \\
\text { RRF }\end{array}$ & D & $\overline{M A X}$ \\
\hline 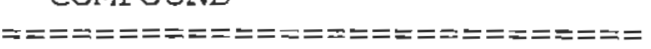 & $=====$ & $==-===$ & $=====$ & $=====$ & \\
\hline 2-Naphthylamine & 0.358 & 0.401 & & -12.0 & \\
\hline 5-Nitro-o-toluidine & 0.341 & 0.370 & & -8.5 & \\
\hline Azeobenzene & 1.009 & 0.926 & & 8.2 & \\
\hline 1,3,5-Trinitrobenzene & & 0.192 & & & \\
\hline Diallate (cis) & $0.3 \overline{00}$ & 0.290 & & 3.3 & \\
\hline Phenacetin & 0.487 & 0.449 & & 7.8 & \\
\hline Diallate (Erans) & 0.300 & 0.290 & & 3.3 & \\
\hline 4-Aminobiphenyl & 0.329 & 0.301 & & 8.5 & \\
\hline Pronamine & 0.415 & 0.389 & & 6.3 & \\
\hline Isodrin & 0.177 & 0.159 & & 10.2 & \\
\hline Chlordane (alpha) & 0.121 & 0.114 & & 5.8 & \\
\hline Benzidine & 0.021 & 0.021 & & 0.0 & \\
\hline p-Dimethylaminoazobenzene & 0.323 & 0.343 & & -6.2 & \\
\hline Chlorobenzilate & 0.439 & 0.441 & & -0.4 & \\
\hline 3,3'-Dimethylbenzidine & 0.226 & 0.205 & & 9.3 & \\
\hline 2-Acetylaminofluorene & 0.237 & 0.248 & & -4.6 & \\
\hline 3-Methyl cholanthrene & 0.684 & 0.617 & & 9.8 & \\
\hline 2-Methylpyridine & 0.869 & 0.902 & & -3.8 & \\
\hline Kepone & 0.060 & 0.059 & & 1.7 & \\
\hline Chlordane (gamma) & 0.121 & 0.134 & & -10.7 & \\
\hline Methyl methane sulfonate & 0.140 & 0.126 & & 10.0 & \\
\hline Hexachlorophene & & & & & \\
\hline 1,3-Dinitrobenzene & 0.290 & $0 . \overline{284}$ & & 2.1 & \\
\hline 2,6 -Dichlorophenol- & 0.378 & 0.342 & & 9.5 & \\
\hline 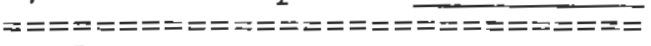 & $======$ & $=====$ & $=====$ & $=====$ & $====$ \\
\hline 2-Fluorophenol & 2.579 & 2.689 & 0.600 & -4.3 & 25.0 \\
\hline Phenol-d5 & 3.406 & 3.346 & 0.800 & 1.8 & 25.0 \\
\hline Nitrobenzene-d5 & 1.334 & 1.432 & 0.200 & -7.3 & 25.0 \\
\hline 2-Fluorobiphenyl & 1.568 & 1.562 & 0.700 & 0.4 & 25.0 \\
\hline $2,4,6$-Tribromophenol & 0.339 & 0.326 & & 3.8 & \\
\hline Terphenyl-di4 & 0.949 & 1.056 & 0.500 & -11.3 & 25.0 \\
\hline
\end{tabular}

AlI other compounds must meet a minimum RRF of $0 . \overline{010}$. 
SEMIVOLATILE CONTINUING CALIBRATION CHECK

Lab Name: PNNL

Lab Code: PNNL

Instrument ID: HPI

Lab File ID: 00081902
Contract: $\mathrm{Cl} 04$

Case No.:

SAS NO. :

SDG No.: 000819

Time: 1553

Init. Calib. Date(s): 08/14/0 08/15/0

Init. Calib. Times: $1734 \quad 0127$

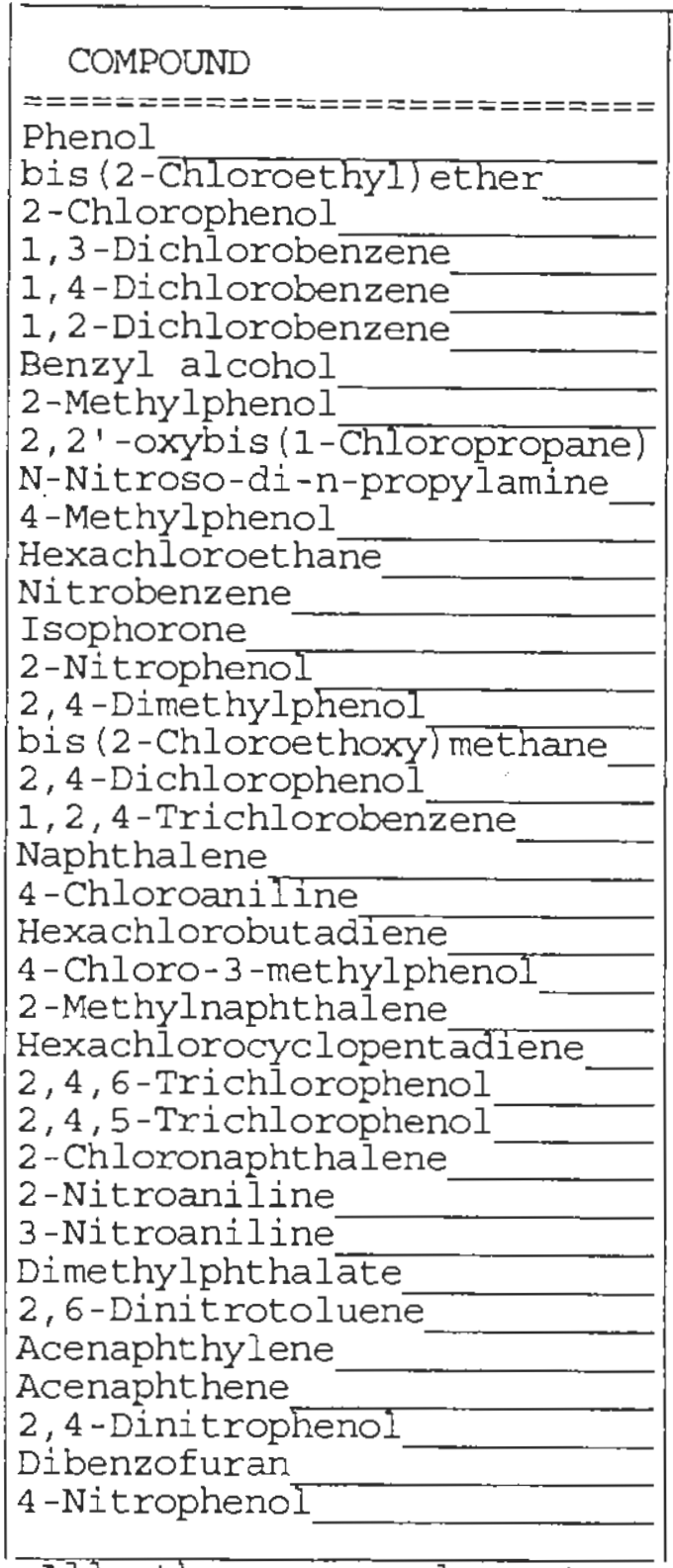

\begin{tabular}{|c|c|c|c|c|}
\hline$\overline{R R F}$ & RRF25 & $\begin{array}{l}\text { MIN } \\
\text { RRF }\end{array}$ & $\because \mathrm{D}$ & $\begin{array}{l}\text { MAX } \\
\therefore D\end{array}$ \\
\hline$====\equiv=$ & $======$ & $=====$ & $=====$ & $====$ \\
\hline 1.660 & 1.659 & 0.800 & 0.1 & 25.0 \\
\hline 1.414 & 1.480 & 0.700 & -4.7 & 25.0 \\
\hline 1.446 & 1.398 & 0.800 & 3.3 & 25.0 \\
\hline 1.718 & 1.636 & 0.600 & 4.8 & 25.0 \\
\hline 1.853 & 1.810 & 0.500 & 2.3 & 25. \\
\hline 1.634 & 1.580 & 0.400 & 3.3 & 25 . \\
\hline 1.086 & 0.988 & 0.100 & 9.0 & 25.0 \\
\hline 2.756 & 2.547 & 0.700 & 7.6 & 25.0 \\
\hline 1.311 & 1.419 & & -8.2 & \\
\hline 0.945 & 1.013 & 0.500 & -7.2 & 25.0 \\
\hline 1.355 & 1.268 & 0.600 & 6.4 & 25.0 \\
\hline 0.754 & 0.736 & 0.300 & 2.4 & 25.0 \\
\hline 1.433 & 1.464 & 0.200 & -2.2 & 25.0 \\
\hline 0.655 & 0.706 & 0.400 & -7.8 & 25.0 \\
\hline 0.229 & 0.222 & 0.100 & 3.0 & 25.0 \\
\hline 0.351 & 0.329 & 0.200 & 6.3 & 25.0 \\
\hline 0.397 & 0.406 & 0.300 & -2.3 & 25.0 \\
\hline 0.322 & 0.293 & 0.200 & 9.0 & 25.0 \\
\hline 0.424 & 0.398 & 0.200 & 6.1 & 25.0 \\
\hline 1.280 & 1.220 & 0.700 & $4+7$ & \\
\hline 0.391 & 0.393 & & -0.5 & \\
\hline 0.285 & 0.267 & & 6.3 & \\
\hline 0.303 & 0.282 & 0.200 & 6.9 & 25.0 \\
\hline 0.822 & 0.770 & 0.400 & 6.3 & \\
\hline 0.453 & 0.433 & & 4.4 & \\
\hline 0.448 & 0.411 & 0.200 & 8.2 & 25.0 \\
\hline 0.432 & 0.443 & 0.200 & -2.5 & 25.0 \\
\hline 1.361 & 1.439 & 0.800 & -5.7 & 25.8 \\
\hline 0.308 & 0.323 & & -4.9 & \\
\hline 0.328 & 0.317 & 0.050 & 3.4 & 40.0 \\
\hline 1.454 & 1.564 & 0.050 & -7.6 & 25. \\
\hline 0.397 & 0.377 & 0.200 & 5.0 & \\
\hline 2.155 & 2.014 & 1.300 & 6.5 & 25 . \\
\hline 1.310 & I. 250 & 0.800 & 4.6 & 25. \\
\hline 0.204 & 0.200 & & 2.0 & \\
\hline 1.808 & 1.739 & 0.800 & 3.8 & 25. \\
\hline 0.172 & 0.167 & & 2.9 & \\
\hline
\end{tabular}

All other compounds must meet a minimum $\bar{R} \bar{F}$ of 0.010 . 
Lab Name: PNNL,

Lab Code: PNNL

Instrument ID: HP1

Lab File ID: 00081902
Contract : 0104

SAS NO. :

SDG NO.: 000819

Time: 1553

Init. Calib. Times: $1734 \quad 0127$

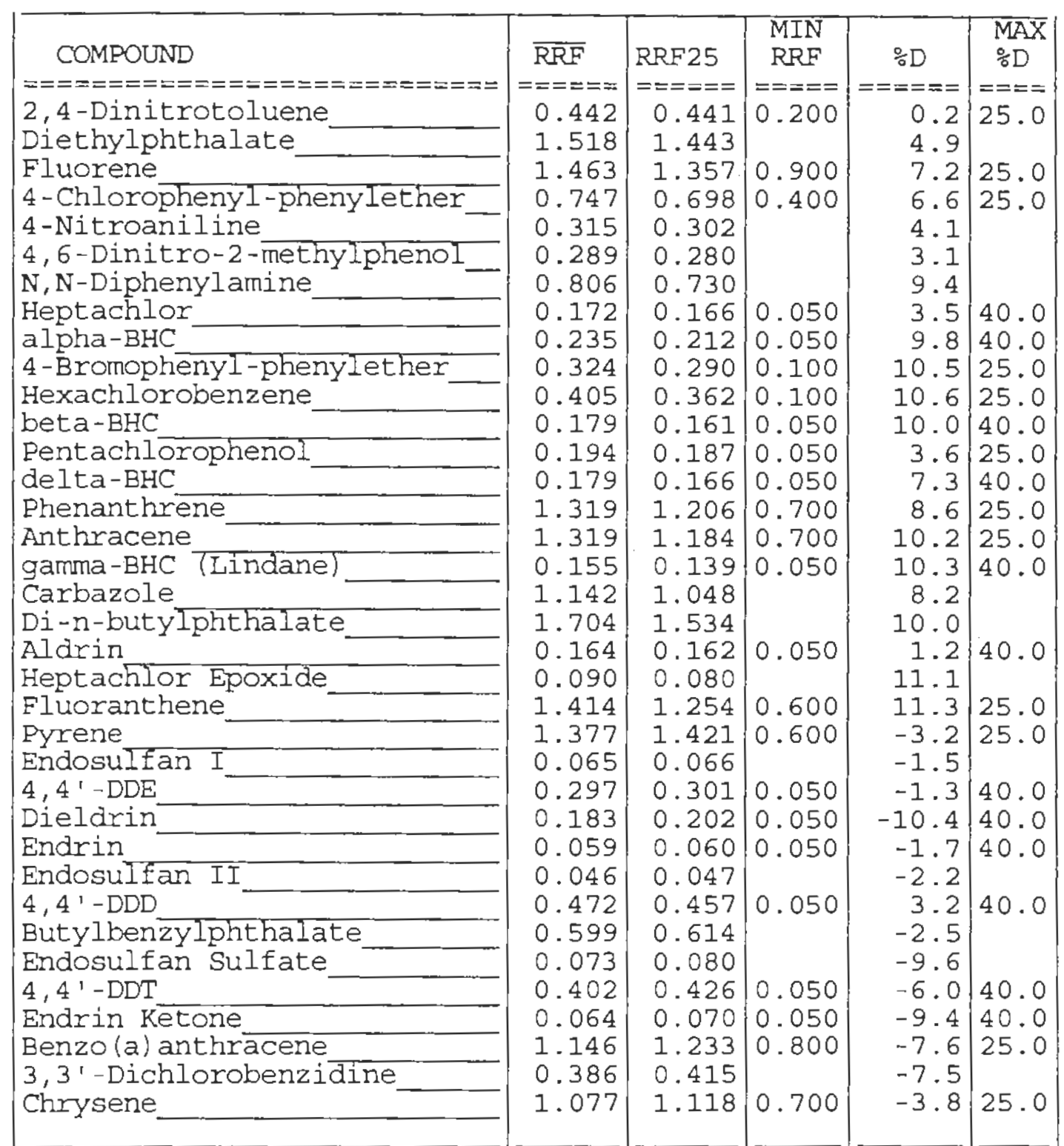

All other compounds must meet a minimum RRF of 0.010 . 
Lab Name: PNNL

Lab Code: PNNL Case No.:

Lab File ID (Standard): 00081903

Instrument ID: HP1
Contract: $\mathrm{C} 104$

SAS NO.: $\quad$ SDG NO.: 000819

Date Analyzed: 08/19/0

Time Analyzed: ' 1645

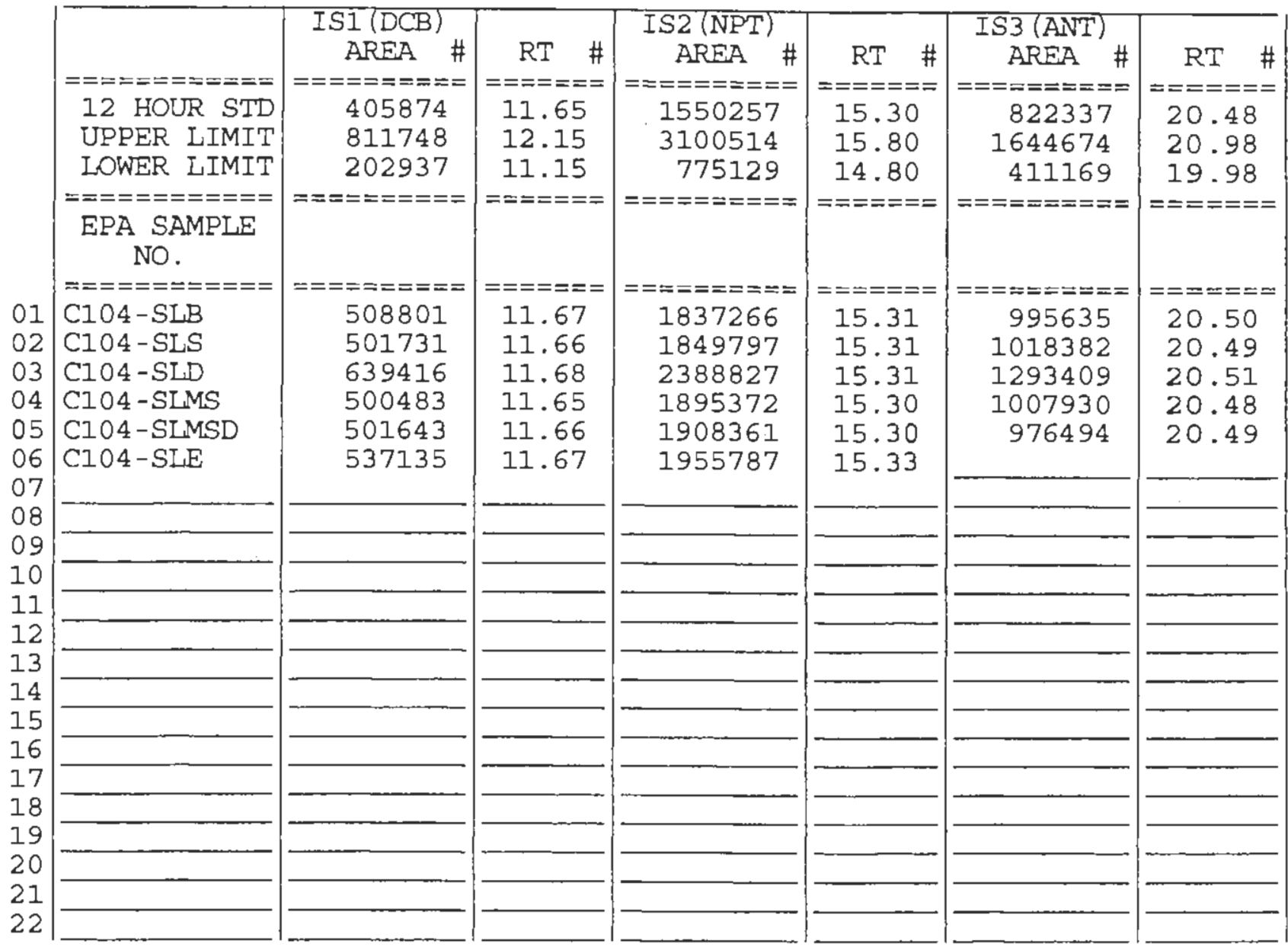

IS1 (DCB) = 1,4-Dichlorobenzene-d4

IS2 (NPT) = Naphthalene-d8

IS3 (ANT) = Acenaphthene-d10

AREA UPPER LIMIT $=+100 \%$ of internal standard area AREA LOWER LIMIT $=-50 \%$ of internal standard area RT UPPER LIMIT $=+0.50$ minutes of intemal standard RT RT LOWER LIMIT $=-0.50$ minutes of intemal standard RT

\# Column used to flag internal standard area values with an asterisk. * Values outside of QC limits. 
Lab Name: PNNL

Lab Code: PNNL Case No.:

Lab File ID (Standard): 00081903

Instrument ID: HP1
Contract: $\mathrm{ClO} 04$

SAS NO.: $\quad$ SDG No.: 000819

Date Analyzed: 08/19/0

Time Analyzed: 1645

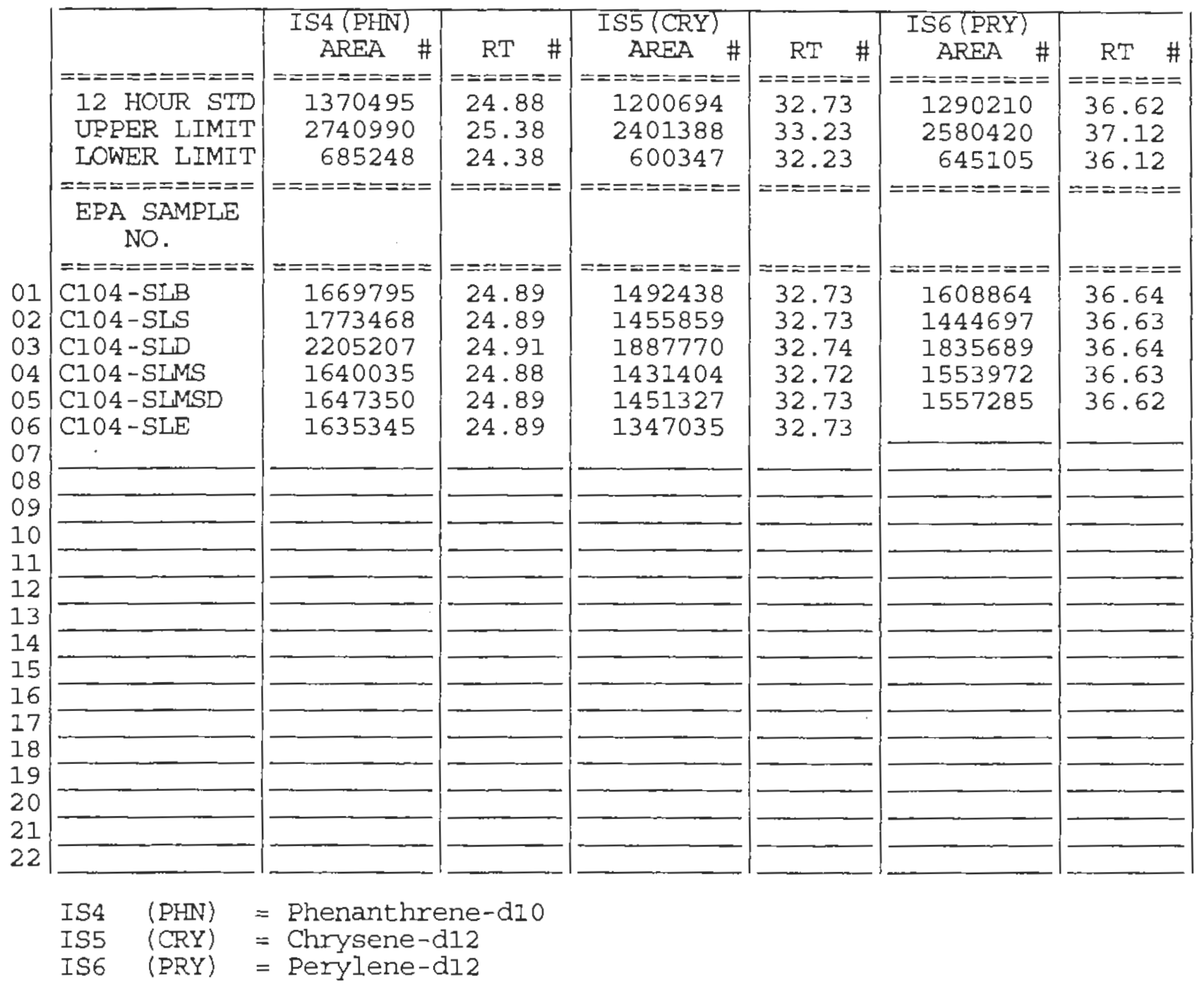

AREA UPPER LIMIT $=+100 \%$ of internal standard area AREA LOWER LIMIT $=-50 \%$ of internal standard area RT UPPER LIMIT $=+0.50$ minutes of internal standard RT RT LOWER LIMIT $=-0.50$ minutes of internal standard RT

\# Column used to flag intemal standard area values with an asterisk. * Values outside of QC limits. 
Lab Name: PNNL

Lab Code: PNNL

Case No. :

Lab File ID (Standard): 00081903

Instrument ID: HPI
Contract: C104

SAS NO.:

SDG No. : 000819

Date Analyzed: 08/19/0

Time Analyzed: 1645

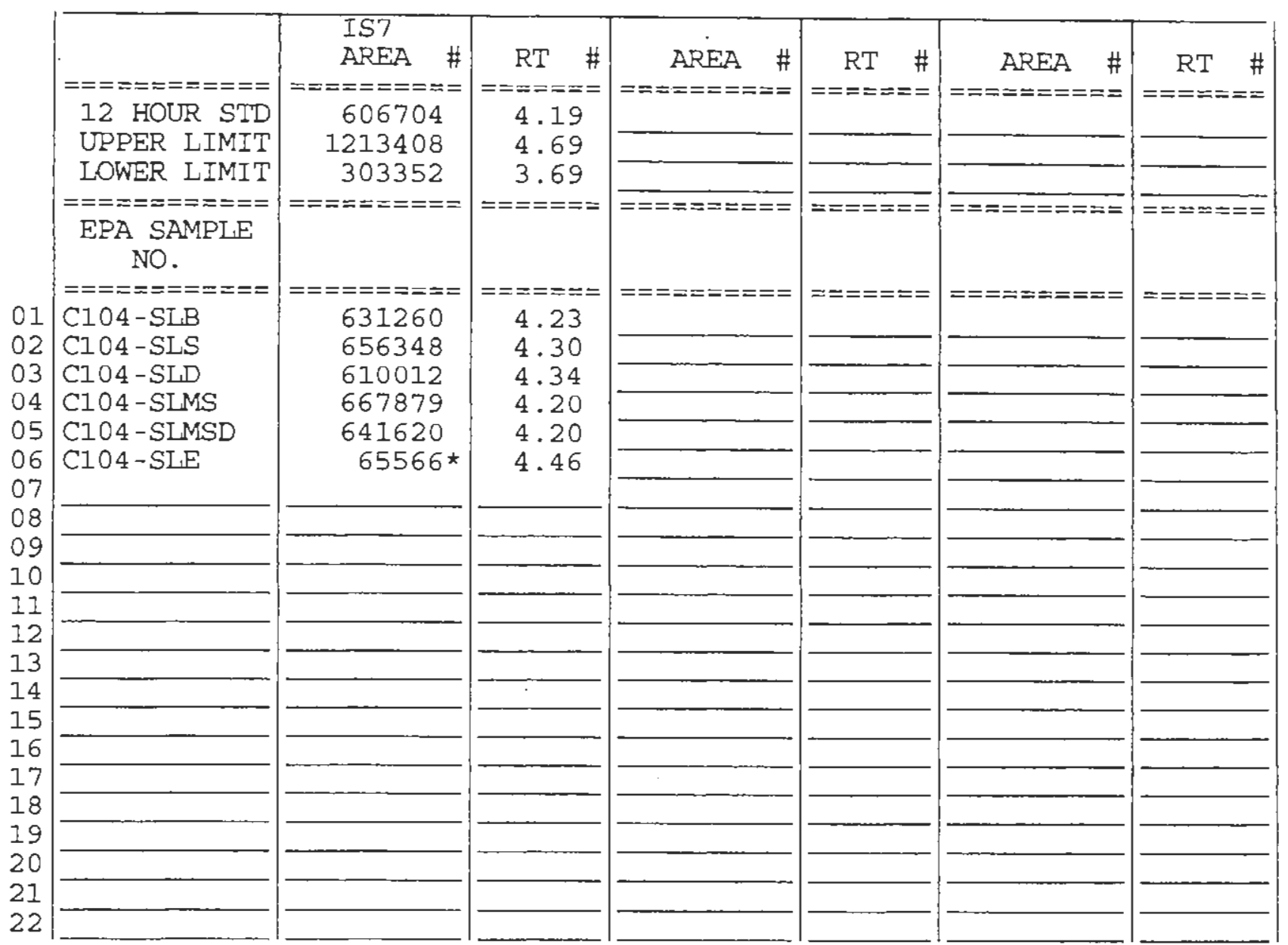

IS7

$=$ Pyridine-d5

AREA UPPER LIMIT $=+100 \%$ of internal standard area

AREA LOWER LIMIT $=-50 \%$ of internal standard area

RT UPPER LIMIT $=+0.50$ minutes of internal standard RT

RT LOWER LIMIT $=-0.50$ minutes of internal standard RT

\# Column used to flag internal standard area values with an asterisk.

* Values outside of QC limits. 
Lab Name: PNNL

Lab Code: PNNL

Case No. :

Lab File ID (Standard): 00081912

Instrument ID: HPI
Contract: $\mathrm{C} 104$

SAS NO. :

SDG No.: 000819

Date Analyzed: 08/20/0

Time Analyzed: 0127

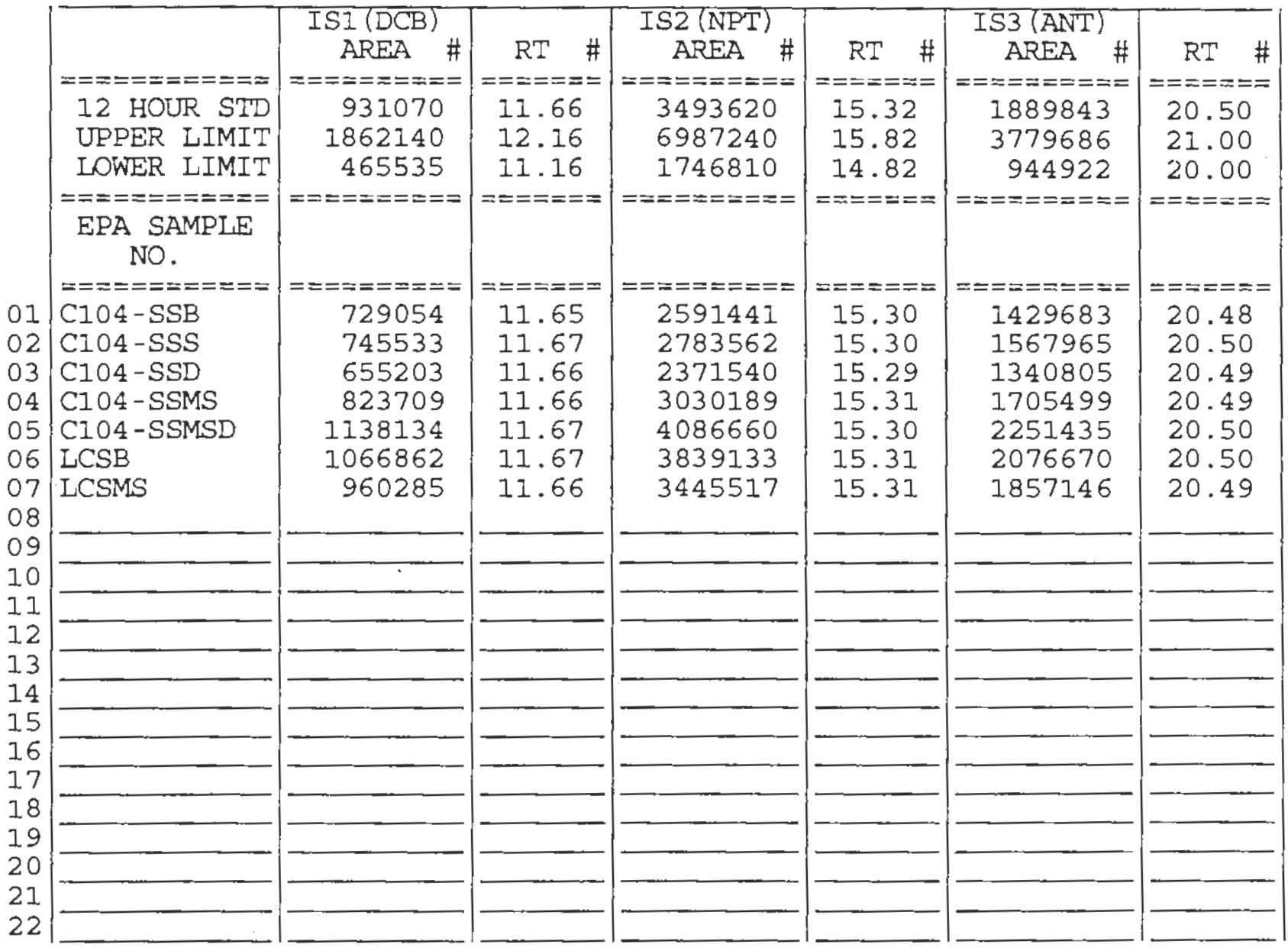

IS1 $(\mathrm{DCB})=1,4-\mathrm{Dichlorobenzene}-\mathrm{d} 4$

IS2 $(\mathrm{NPT})=$ Naphthalene-d8

IS3 (ANT) = Acenaphthene-d10

AREA UPPER LIMIT $=+100 \%$ of internal standard area AREA LOWER LIMIT $=-50 \%$ of internal standard area RT UPPER LIMIT $=+0.50$ minutes of internal standard $R T$ RT LOWER LIMIT $=-0.50$ minutes of internal standard RT

\# Column used to flag internal standard area values with an asterisk.

* Values outside of QC limits. 
Lab Name: PNNL

Lab Code: PNNL

Lab File ID (Standard) : 00081912

Instrument ID: HP1
Contract: $\mathrm{Cl} 04$

SAS NO.:

SDG No.: 000819

Date Analyzed: 08/20/0

Time Analyzed: 0127

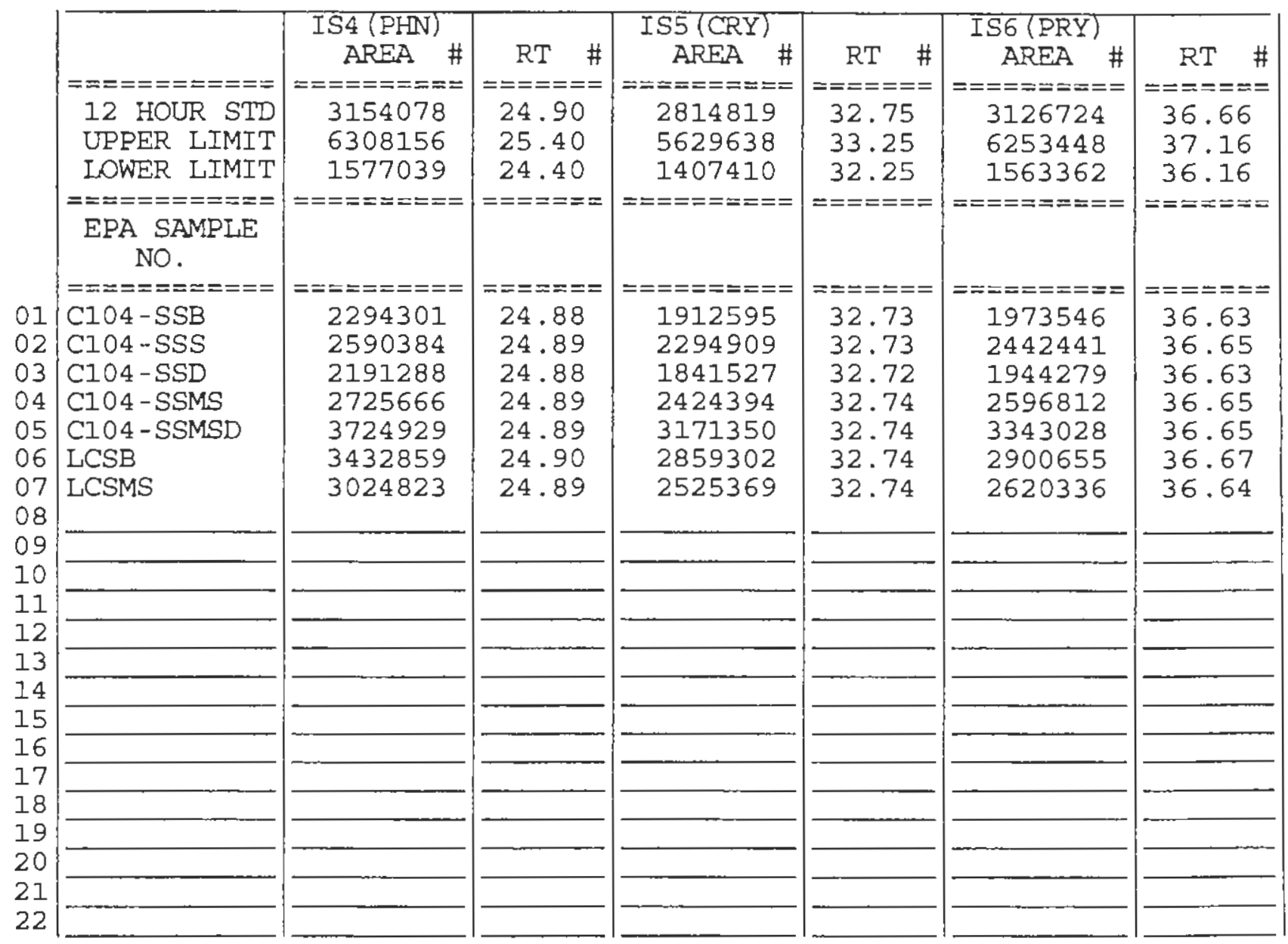

IS4 (PHN) = Phenanthrene-d10

IS5 (CRY) = Chrysene-dl2

IS6 (PRY) = Perylene-đi2

AREA UPPER LIMIT $=+100 \%$ of internal standard area AREA LOWER LIMIT $=-50 \%$ of internal standard area RT UPPER LIMIT $=+0.50$ minutes of internal standard RT RT LOWER LIMIT $=-0.50$ minutes of internal standard RT

\# Column used to flag internal standard area values with an asterisk. * Values outside of QC limits. 
Lab Name: PNNL

Lab Code: PNNL

Lab File ID (Standard): 00081912

Instrument ID: HP1
Contract: $\mathrm{ClO4}$

SAS NO.:

SDG No.: 000819

Date Analyzed: $08 / 20 / 0$

Time Analyzed: 0127

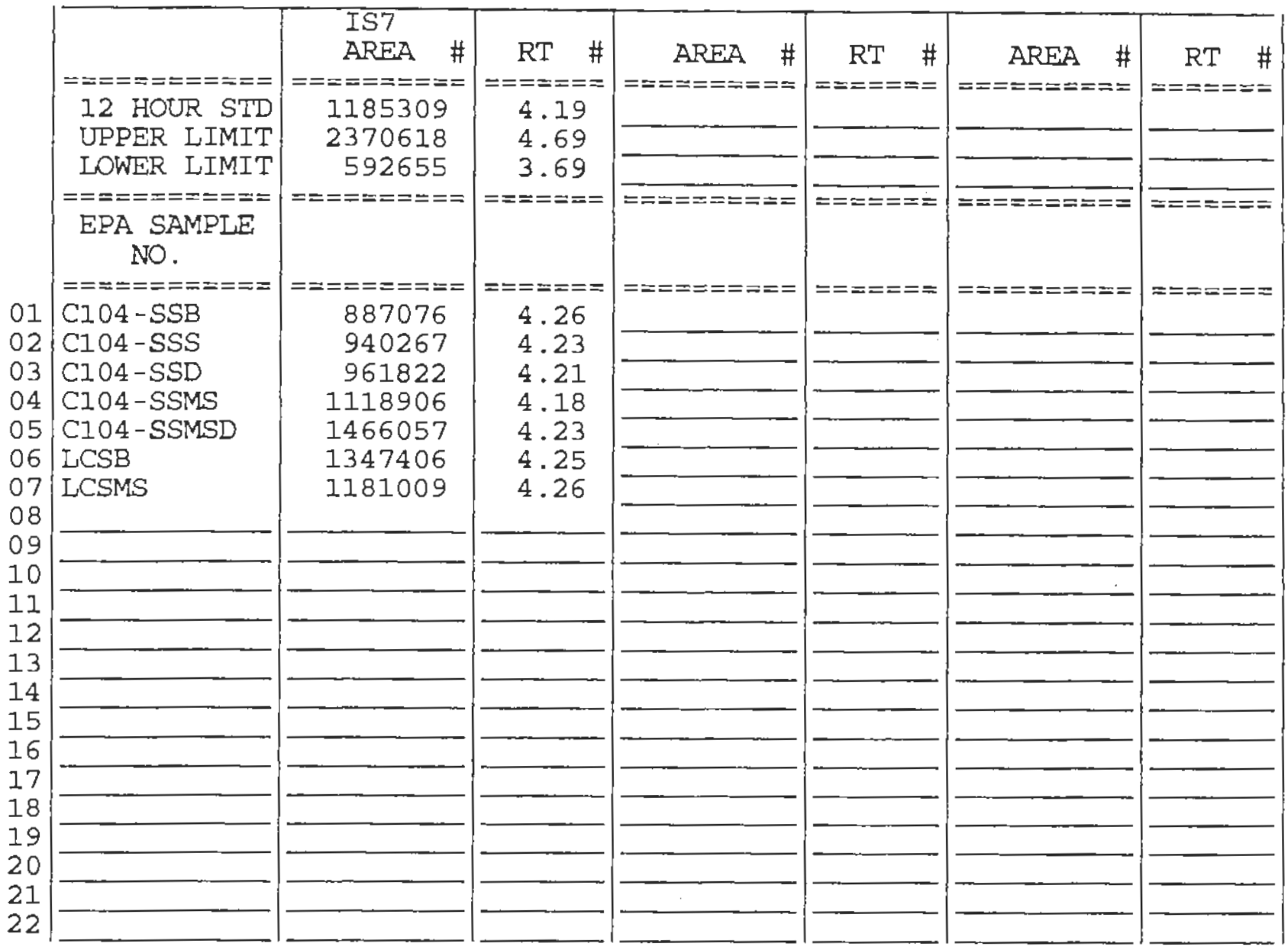

IS7

$=$ Pyridine $-\mathrm{d} 5$

AREA UPPER LIMIT $=+100 \%$ of internal standard area AREA LOWER LIMIT $=-50 \%$ of internal standard area RT UPPER LIMIT $=+0.50$ minutes of internal standard RT RT LOWER LIMIT $=-0.50$ minutes of internal standard RT

\# Column used to flag internal standard area values with an asterisk. * Values outside of QC limits. 
Appendix F: Dioxins and Furans Ion Abundance Ratios and Response Factors 
Table F.1. Ion Abundance Ratios and Response Factors for Standards

\begin{tabular}{|c|c|c|c|c|c|c|c|}
\hline Compound & $\begin{array}{l}\text { Native } \\
\text { Conc. } \\
\mu g / L\end{array}$ & $\begin{array}{l}\text { Mass } \\
\mathbf{m} / \mathbf{z}\end{array}$ & $\begin{array}{c}\text { Native } \\
\text { Ion Ratio }\end{array}$ & $\begin{array}{c}\text { Labeled } \\
\text { Ion Ratio }^{(1)}\end{array}$ & RRF & $\begin{array}{c}\text { Average } \\
\text { RRF }\end{array}$ & $\%$ RSD \\
\hline \multirow[t]{4}{*}{ HpCDD } & 2.5 & 424 & 1.06 & 1.08 & 1.08 & 0.96 & 10.2 \\
\hline & 10.0 & & 1.04 & 1.06 & 0.94 & & \\
\hline & 50.0 & & 1.05 & 1.07 & 0.96 & & \\
\hline & 200.0 & & 1.03 & 1.06 & 0.85 & & \\
\hline \multirow[t]{4}{*}{ HpCDD } & 2.5 & 426 & & & 1.11 & 0.98 & 9.8 \\
\hline & 10.0 & & & & 0.96 & & \\
\hline & 50.0 & & & & 0.97 & & \\
\hline & 200.0 & & & & 0.88 & & \\
\hline \multirow[t]{4}{*}{ HpCDF } & 2.5 & 408 & 0.95 & 1.07 & 1.06 & 0.98 & 13.1 \\
\hline & 10.0 & & 1.06 & 1.04 & 1.07 & & \\
\hline & 50.0 & & 1.07 & 1.07 & 1.06 & & \\
\hline & 200.0 & & 0.88 & 1.05 & 0.86 & & \\
\hline \multirow[t]{4}{*}{ HpCDF } & 2.5 & 410 & & & 1.19 & 1.05 & 11.8 \\
\hline & 10.0 & & & & 1.05 & & \\
\hline & 50.0 & & & & 1.05 & & \\
\hline & 200.0 & & & & 0.89 & & \\
\hline & & & & & & & \\
\hline \multirow[t]{4}{*}{ HxCDD } & 2.5 & 390 & 1.06 & 1.28 & 1.20 & 1.19 & 11.9 \\
\hline & 10.0 & & 1.31 & 1.27 & 1.32 & & \\
\hline & 50.0 & & 1.25 & 1.27 & 1.26 & & \\
\hline & 200.0 & & 1.13 & 1.27 & 0.99 & & \\
\hline \multirow[t]{4}{*}{ HxCDD } & 2.5 & 392 & & & 1.42 & 1.28 & 9.9 \\
\hline & 10.0 & & & & 1.27 & & \\
\hline & 50.0 & & & & 1.29 & & \\
\hline & 200.0 & & & & 1.15 & & \\
\hline \multirow{4}{*}{ HxCDF } & 2.5 & 374 & 1.29 & 1.24 & 1.06 & 1.16 & 123 \\
\hline & 10.0 & & 1.10 & 1.25 & 1.10 & & \\
\hline & 50.0 & & 1.27 & 1.18 & 1.11 & & \\
\hline & 200.0 & & 1.18 & 1.28 & 1.40 & & \\
\hline \multirow[t]{4}{*}{ HxCDF } & 2.5 & 376 & & & 1.20 & 1.13 & 7.7 \\
\hline & 10.0 & & & & 1.04 & & \\
\hline & 50.0 & & & & 1.06 & & \\
\hline & 200.0 & & & & 1.21 & & \\
\hline \multirow[t]{4}{*}{ OCDD } & 5.0 & 458 & 0.93 & 0.90 & 1.21 & 0.98 & 22.5 \\
\hline & 20.0 & & 0.91 & 0.92 & 0.95 & & \\
\hline & 100.0 & & 1.00 & 1.00 & 1.05 & & \\
\hline & 400.0 & & 0.98 & 0.95 & 0.69 & & \\
\hline
\end{tabular}




\begin{tabular}{|c|c|c|c|c|c|c|c|}
\hline Compound & $\begin{array}{l}\text { Native } \\
\text { Conc. } \\
\mu \mathrm{g} / \mathrm{L}\end{array}$ & $\begin{array}{l}\text { Mass } \\
\mathbf{m} / \mathbf{z}\end{array}$ & $\begin{array}{c}\text { Native } \\
\text { Ion Ratio }\end{array}$ & $\begin{array}{c}\text { Labeled } \\
\text { Ion Ratio }^{(1)}\end{array}$ & RRF & $\begin{array}{c}\text { Average } \\
\text { RRF }\end{array}$ & \%RSD \\
\hline \multirow[t]{4}{*}{ OCDD } & 5.0 & 460 & & & 1.18 & 0.97 & 22.3 \\
\hline & 20.0 & & & & 0.96 & & \\
\hline & 100.0 & & & & 1.05 & & \\
\hline & 400.0 & & & & 0.67 & & \\
\hline \multirow[t]{4}{*}{ OCDF } & 5.0 & 442 & 0.95 & 0.90 & 1.36 & 1.15 & 19.6 \\
\hline & 20.0 & & 0.92 & 0.92 & 1.20 & & \\
\hline & 100.0 & & 0.92 & 0.93 & 1.24 & & \\
\hline & 400.0 & & 0.96 & 0.95 & 0.90 & & \\
\hline \multirow{4}{*}{ OCDF } & 5.0 & 444 & & & 1.29 & 1.14 & 18.8 \\
\hline & 20.0 & & & & 1.18 & & \\
\hline & 100.0 & & & & 1.25 & & \\
\hline & 400.0 & & & & 0.83 & & \\
\hline \multirow{5}{*}{ PeCDD } & & & & & & & \\
\hline & 2.5 & 356 & 1.43 & 1.61 & 0.92 & 0.89 & 14.6 \\
\hline & 10.0 & & 1.43 & 1.55 & 0.81 & & \\
\hline & 50.0 & & 1.63 & 1.57 & 1.08 & & \\
\hline & 200.0 & & 1.39 & 1.62 & 0.74 & & \\
\hline \multirow[t]{4}{*}{ PeCDD } & 2.5 & 358 & & & 1.03 & 0.96 & 9.5 \\
\hline & 10.0 & & & & 0.88 & & \\
\hline & 50.0 & & & & 1.04 & & \\
\hline & 200.0 & & & & 0.90 & & \\
\hline \multirow{4}{*}{ PeCDF } & 25 & 340 & 138 & 167 & 113 & 102 & 217 \\
\hline & 10.0 & & 1.53 & 1.63 & 1.04 & & \\
\hline & 50.0 & & 1.58 & 1.69 & 1.11 & & \\
\hline & 200.0 & & 1.32 & 1.64 & 0.81 & & \\
\hline \multirow[t]{4}{*}{ PeCDF } & 2.5 & 342 & & & 1.40 & 1.15 & 19.5 \\
\hline & 10.0 & & & & 1.16 & & \\
\hline & 50.0 & & & & 1.19 & & \\
\hline & 200.0 & & & & 0.85 & & \\
\hline \multirow{4}{*}{ TCDD } & 0.5 & 322 & 0.83 & 0.89 & 1.06 & 1.05 & 18.6 \\
\hline & 2.0 & & 0.67 & 0.79 & 0.82 & & \\
\hline & 10.0 & & 0.70 & 0.80 & 1.02 & & \\
\hline & 40.0 & & 0.82 & 0.80 & $\begin{array}{l}1.30 \\
1.30\end{array}$ & & \\
\hline \multirow[t]{4}{*}{ TCDD } & 0.5 & 324 & & & 1.13 & 1.14 & 9.5 \\
\hline & 2.0 & & & & 1.00 & & \\
\hline & 10.0 & & & & 1.15 & & \\
\hline & 40.0 & & & & 1.26 & & \\
\hline
\end{tabular}




\begin{tabular}{|c|c|c|c|c|c|c|c|}
\hline Compound & $\begin{array}{l}\text { Native } \\
\text { Conc. } \\
\mu g / L\end{array}$ & $\begin{array}{l}\text { Mass } \\
\mathbf{m} / \mathbf{z}\end{array}$ & $\begin{array}{c}\text { Native } \\
\text { Ion Ratio }\end{array}$ & $\begin{array}{c}\text { Labeled } \\
\text { Ion Ratio }^{(1)}\end{array}$ & RRF & $\begin{array}{c}\text { Average } \\
\text { RRF }\end{array}$ & $\%$ RSD \\
\hline \multirow[t]{4}{*}{ TCDF } & 0.5 & 304 & 0.78 & 0.80 & 1.02 & 1.02 & 4.1 \\
\hline & 2.0 & & 0.78 & 0.70 & 1.07 & & \\
\hline & 10.0 & & 0.75 & 0.73 & 0.96 & & \\
\hline & 40.0 & & 0.82 & 0.82 & 1.03 & & \\
\hline \multirow[t]{4}{*}{ TCDF } & 0.5 & 306 & & & 1.04 & 0.99 & 4.9 \\
\hline & 2.0 & & & & 0.96 & & \\
\hline & 10.0 & & & & 0.94 & & \\
\hline & 40.0 & & & & 1.02 & & \\
\hline
\end{tabular}

Concentration of labeled compounds: OCDD and OCDF $=200 \mu \mathrm{g} / \mathrm{L}$, all other labeled compounds at $100 \mu \mathrm{g} / \mathrm{L}$ 
Table F.2. Ion Abundance Ratios for Supernatant Matrix Spikes

\begin{tabular}{|c|c|c|c|c|c|c|}
\hline \multirow{3}{*}{$\begin{array}{c}\begin{array}{c}\text { Tank } \\
\text { Material }\end{array} \\
\text { Sample ID } \\
\text { Ion Ratios } \\
\end{array}$} & \multicolumn{4}{|c|}{ C-104 Supernatant } & \multirow{2}{*}{\multicolumn{2}{|c|}{ LCS }} \\
\hline & \multicolumn{2}{|c|}{ 00-01360 MS } & \multicolumn{2}{|c|}{ 00-01360 MSD } & & \\
\hline & Native & Labeled & Native & Labeled & Native & Labeled \\
\hline \multicolumn{7}{|l|}{ Analyte } \\
\hline HpCDD & 1.03 & 1.08 & 1.07 & 1.03 & 1.04 & 1.08 \\
\hline HpCDF & 1.01 & 1.02 & 1.04 & 1.07 & 1.06 & 1.04 \\
\hline HxCDD & 1.07 & 1.26 & 1.21 & 1.27 & 1.27 & 1.10 \\
\hline $\mathrm{HxCDF}$ & 1.31 & 1.32 & 1.08 & 1.38 & 1.28 & 1.19 \\
\hline OCDD & 0.81 & 0.92 & 0.87 & 0.89 & 0.89 & 0.90 \\
\hline OCDF & 0.89 & 0.92 & 0.80 & 0.89 & 0.91 & 0.90 \\
\hline PeCDD & 1.56 & 1.53 & 1.53 & 1.60 & 1.55 & 1.60 \\
\hline PeCDF & 1.58 & 1.47 & 1.59 & 1.71 & 1.57 & 1.70 \\
\hline TCDD & 0.77 & 0.76 & 0.75 & 0.66 & 0.89 & 0.75 \\
\hline TCDF & 0.72 & 0.76 & 0.86 & 0.76 & 0.76 & 0.80 \\
\hline
\end{tabular}

Table F.3. Ion Abundance Ratios for Solids Matrix Spikes

\begin{tabular}{||c|c|c|c|c||}
\hline $\begin{array}{c}\text { Tank } \\
\text { Material }\end{array}$ & \multicolumn{4}{|c||}{ C-104 Wet Centrifuged Solids } \\
\hline \multicolumn{1}{|c|}{ Sample ID } & \multicolumn{2}{|c|}{ 00-01361 MS } & \multicolumn{2}{c||}{ 00-01361 MSD } \\
\hline Ion Ratios & Native & Labeled & Native & Labeled \\
\hline \hline Analyte & & & & \\
\hline HpCDD & 1.09 & 1.14 & 1.05 & 1.17 \\
\hline HpCDF & 1.08 & 0.89 & 1.06 & 0.91 \\
\hline HxCDD & 1.07 & 1.33 & 1.26 & 1.29 \\
\hline HxCDF & 1.21 & 1.28 & 1.18 & 1.29 \\
\hline OCDD & 0.79 & 0.98 & 0.92 & 1.02 \\
\hline OCDF & 0.80 & 0.98 & 0.92 & 1.02 \\
\hline PeCDD & 1.62 & 1.40 & 1.67 & 1.64 \\
\hline TCDF & 1.63 & 1.52 & 1.55 & 1.46 \\
\hline PeCDF & 0.85 & 0.82 & 0.73 & 0.71 \\
\hline TCDD & 0.78 & 0.79 & 0.81 & 0.79 \\
\hline
\end{tabular}


Table F.4. Ion Abundance Ratios for Supernatant Samples, Duplicates, and Process Blanks

\begin{tabular}{|c|c|c|c|c|c|c|}
\hline $\begin{array}{c}\text { Tank } \\
\text { Material }\end{array}$ & \multicolumn{6}{|c|}{ C-104 Supernatant } \\
\hline Sample ID & \multicolumn{2}{|c|}{ 00-01360 } & \multicolumn{2}{|c|}{ 00-01360 } & \multicolumn{2}{|c|}{ 00-01360 } \\
\hline \multirow[b]{2}{*}{ Ion Ratios } & \multicolumn{2}{|c|}{ Proc. Blk } & \multicolumn{2}{|c|}{ Sample } & \multicolumn{2}{|c|}{ Duplicate } \\
\hline & Native & Labeled & Native & Labeled & Native & Labeled \\
\hline \multicolumn{7}{|l|}{ Analvte } \\
\hline HpCDD & & 1.10 & & 1.10 & & 1.14 \\
\hline HpCDF & & 1.18 & & 1.07 & & 1.12 \\
\hline HxCDD & & 1.21 & & 1.27 & & 1.23 \\
\hline $\mathrm{HxCDF}$ & & 1.11 & & 1.42 & & 1.28 \\
\hline OCDD & & 1.00 & & 092 & & 0.91 \\
\hline OCDF & & 1.00 & & 0.92 & & 0.90 \\
\hline PeCDD & & 1.58 & & 1.58 & & 1.76 \\
\hline PeCDF & & 1.46 & & 1.33 & & 1.53 \\
\hline TCDD & & 0.84 & & 0.85 & & 0.79 \\
\hline TCDF & & 0.82 & & 0.77 & & 0.72 \\
\hline
\end{tabular}

"Blanks" = No signal or peak area detected; ion abundance ratio is zero (0) or undefined.

Table F.5. Ion Abundance Ratios for Solids Samples, Duplicates, and Process Blanks

\begin{tabular}{|c|c|c|c|c|c|c|}
\hline \multirow{4}{*}{$\begin{array}{r}\text { Tank Material } \\
\text { Sample ID }\end{array}$} & \multicolumn{6}{|c|}{ C-104 Wet Centrifuged Solids } \\
\hline & \multicolumn{2}{|c|}{ 00-01361 } & \multicolumn{2}{|c|}{$00-01361$} & \multicolumn{2}{|c|}{ 00-01361 } \\
\hline & \multicolumn{2}{|c|}{ Proc. Blank } & \multicolumn{2}{|c|}{ Sample } & \multicolumn{2}{|c|}{ Duplicate } \\
\hline & Native & Labeled & Native & Labeled & Native & Labeled \\
\hline \multicolumn{7}{|c|}{\begin{tabular}{l|l} 
Analyte & \\
\end{tabular}} \\
\hline HpCDD & & 1.06 & & 1.20 & & 1.11 \\
\hline HpCDF & & 1.00 & & 1.08 & & 1.06 \\
\hline HxCDD & & 1.33 & & 1.30 & & 1.17 \\
\hline $\mathrm{HxCDF}$ & & 1.24 & & 1.16 & & 1.27 \\
\hline OCDD & & 0.97 & & 1.02 & & 0.98 \\
\hline OCDF & & 0.97 & & 1.02 & & 0.98 \\
\hline PeCDD & & 1.57 & & 1.45 & & 1.58 \\
\hline PeCDF & & 1.43 & & $*$ & & 1.57 \\
\hline TCDD & & 0.75 & & 0.67 & & 0.82 \\
\hline TCDF & & 0.88 & & 0.82 & & 0.86 \\
\hline
\end{tabular}

"Blanks" = No signal or peak area detected; ion abundance ratio is zero (0) or undefined. 
PNNL-15042

WTP-RPT-008, Rev. 1

\section{Distribution}

No. of

Copies

\section{OFFSITE}

1 Savannah River National Laboratory

Richard Edwards

Westinghouse SA

Aiken, South Carolina 29808-0001

\begin{abstract}
No. of
Copies
\end{abstract}

ONSITE

$5 \quad$ Pacific Northwest National Laboratory

J. C. Evans K6-96

Project Office (2) P7-28

Information Release (2) K1-06

Distr. 1 